\title{
IMMIGRANT LANGUAGE MAINTENANCE AND SHIFT IN THE GUJARATI DUTCH AND SAMOAN COMMUNITIES OF WELLINGTON
}

\author{
By \\ Mary Lucy Roberts
}

A thesis

Submitted to Victoria University of Wellington

In fulfillment of the

Requirements for the degree of

Doctor of Philosophy

In Linguistics 


\begin{abstract}
This thesis makes a contribution to the study of language maintenance and shift among New Zealand ethnic minority communities; it explores reasons for different rates of shift and different outcomes in relation to language maintenance in different communities; and the results are related to wide-ranging issues of New Zealand language policy. Research was undertaken in three minority immigrant groups in Wellington. The Gujarati community in Wellington is a major part of the Indian community totalling approximately 6,000 people at the time of the research; the Samoan community consisted of approximately 16,000 people, and the Dutch of 3,000. 141 members of the Gujarati community responded to questionnaires and interviews about themselves and their children, providing information on patterns of reported language proficiency, language use and attitudes to language maintenance from a total of 327 people. 184 Dutch respondents replied to a postal questionnaire about their own and their children's language knowledge, language usage patterns and attitudes to language maintenance, providing data on 412 people. 93 Samoan respondents filled out questionnaires and responded to interviews about themselves and their 133 children. Thus information on a total of 965 New Zealanders belonging to minority immigrant communities was obtained.
\end{abstract}

The data collected on patterns of language maintenance and shift is examined in the light of a wide range of language policy issues. The history of language and identity politics, minority immigration in New Zealand, and the immigration histories of the three groups are examined in detail, and the history of language and policy formation in New Zealand is outlined and evaluated.

The research focuses on the process of immigrant language maintenance and shift in the family and immediate community, and also investigates the role of language maintenance education in these processes. Information about language use processes in childhood and adulthood is presented. The Graded Intergeneration Disruption Stages scale, proposed by Joshua Fishman is tested against the information gathered on the three communities and found to be a useful heuristic device.

The results of the research show that while processes of language maintenance and shift occur in all three communities, these processes take very different forms in each community, move at different speeds and. to date, have had very different outcomes. The reasons for the differences between the communities in these respects are examined in some detail. 
Finally, on the basis of the evidence provided by the research, language policy proposals are presented supporting the provision of government services in minority immigrant languages and indicating the advantages of state support for language maintenance education. 


\section{ACKNOWLEDGMENTS}

I would like to thank all the people who have helped me in the course of producing this thesis.

Firstly I would like to thank my thesis supervisor, Professor Janet Holmes. She introduced me to the study of linguistics and I count myself lucky to have been her student for so many years. The scholarly discourse, help and encouragement she has provided have all been invaluable.

My debt to the members of the Samoan Research Group is considerable. I would like to extend my sincere thanks and best wishes to Feaua'i Burgess, Irene Ete, Tina Manase, Faaunga Manase, Mele Nonumalo and Sera Tamaton. I would like to record my gratitude to Arthur Carter who, sadly, has passed away.

I would like to thank Miriam Tuohy of ReddFish intergalactic and Tony Sanders for their considerable assistance for everything to do with computers and computing.

Mr thanks to Mr Alf Hunkin of Victoria Lniversity and to the Wellington Indian Association Board for the help they provided. I would also like to thank all the Gujarati, Dutch and Samoan respondents who filled out questionnaires and especially the Gujarati interviewees who so generously invited me into their homes and agreed to be interviewed.

My family has provided me with support without which I would never have been able to complete this endeavour. I thank Kate, Tim, Hugh and their families and my parents, Kay and John Roberts.

Janet Macaskill has prorided me with 29 years of true friendship, she and Roger Mackey and Suzanne Foster have been unstinting in their generous support. Finnbarr, Heloise, Connor, Benny and Daniel have all played their parts as well.

I would like to dedicate this thesis to the memory of my grandparents.

Hugh Brown

Lucy Buckingham

Jim Roberts

Lucy Wallace 


\section{Table of Contents}

Introduction.

$1 \quad$ Major Issues In The Study Of Language Maintenance And Shift ........................................................

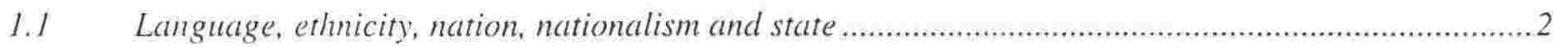

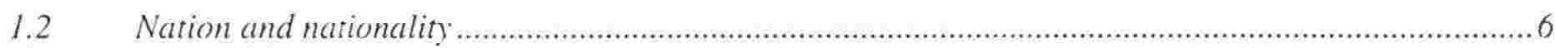

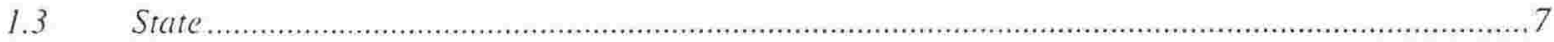

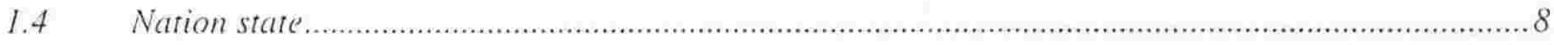

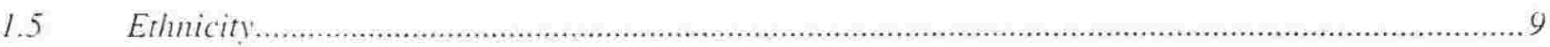

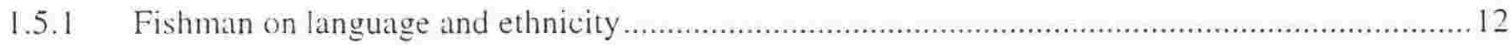

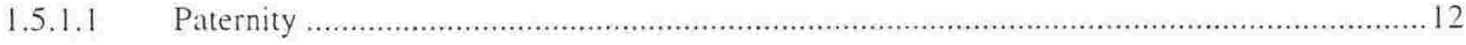

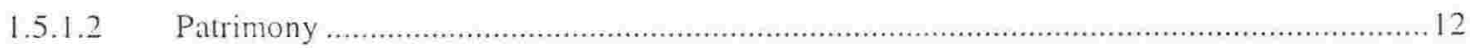

1.5.1.3 Heartland and boundary ethnicity .................................................................. 13

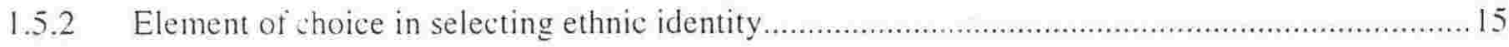

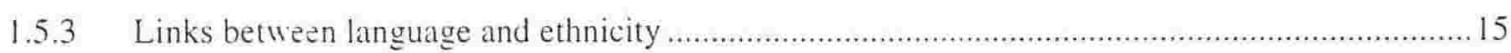

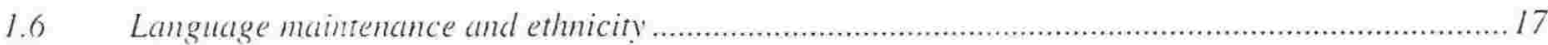

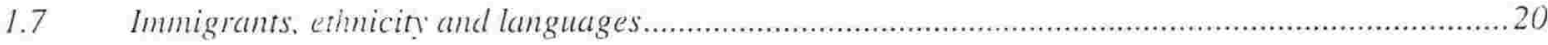

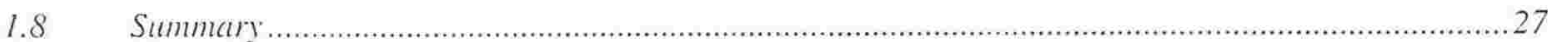

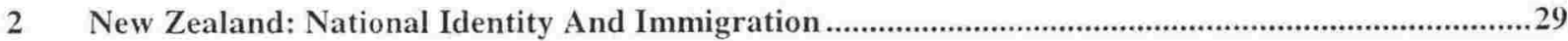

2.1 Ethnicity and national identity in New Zealand .............................................................29

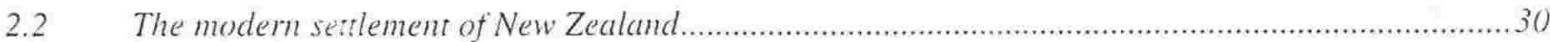

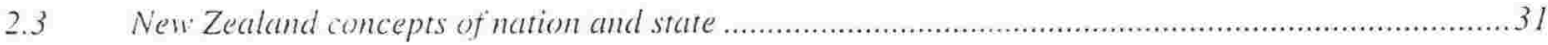

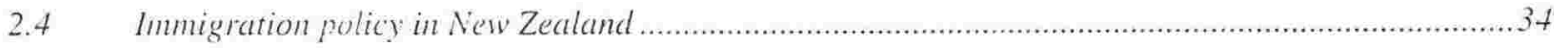

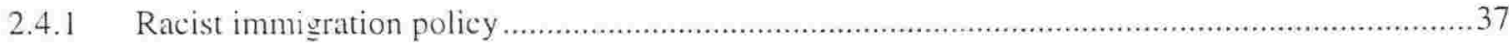

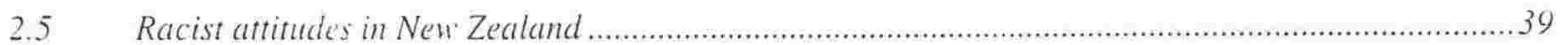

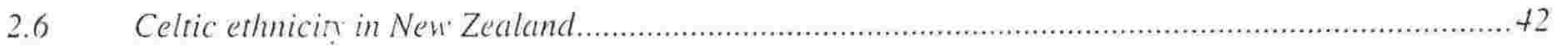

2.7 Immigration pulicy and population in New Zealand .......................................................45

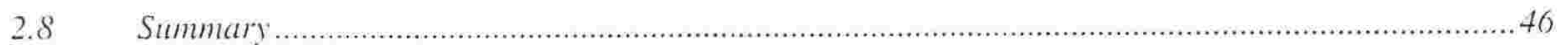

3 Immigration Background Of The Three Communities .................................................................47

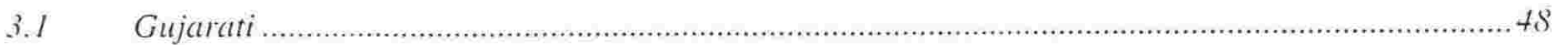


3.1.1 Language situation in Gujarat

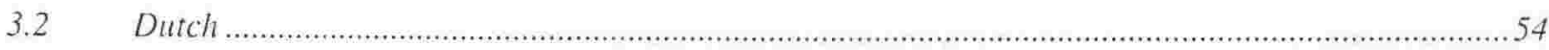

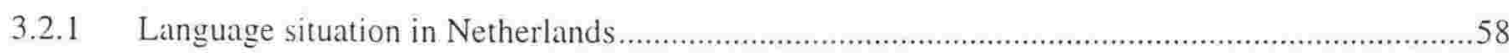

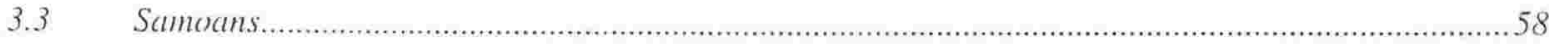

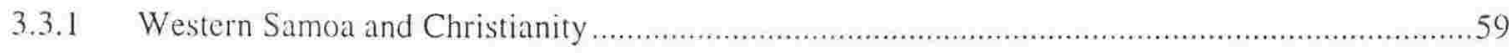

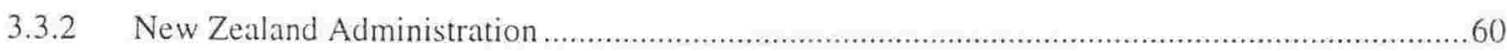

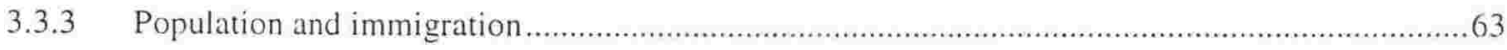

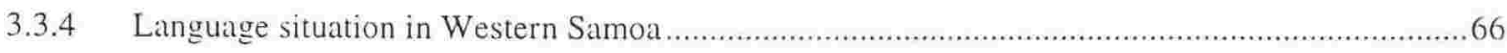

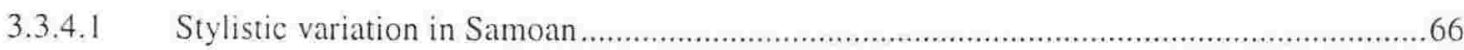

3.3.4.2 Language and education in Western Samoa ...........................................................67

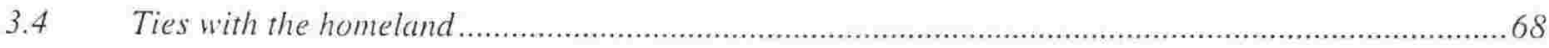

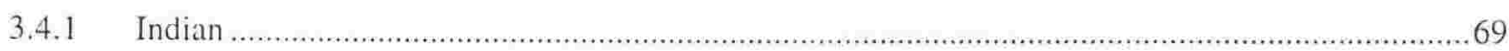

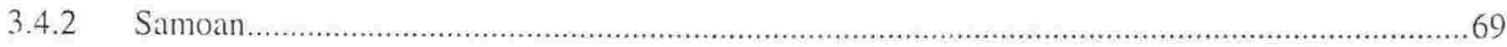

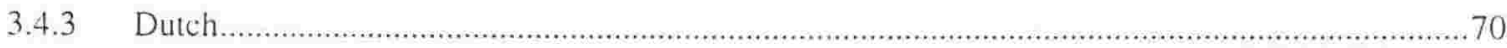

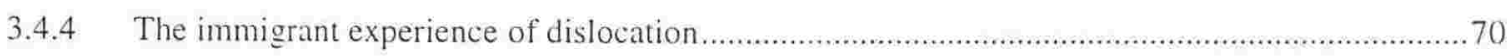

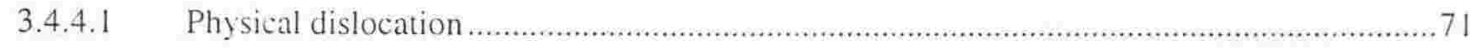

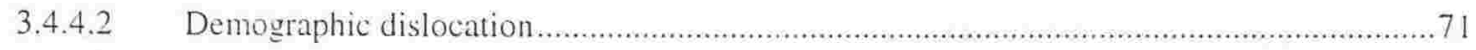

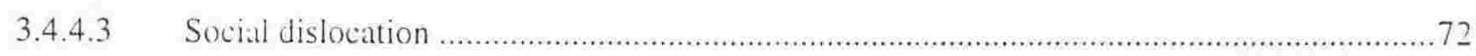

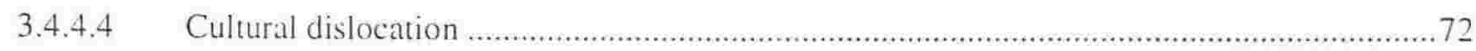

S.5 Sumary

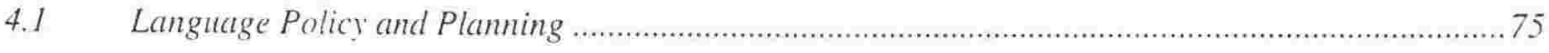

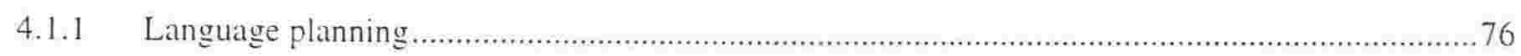

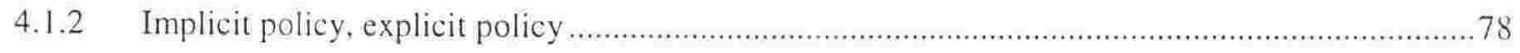

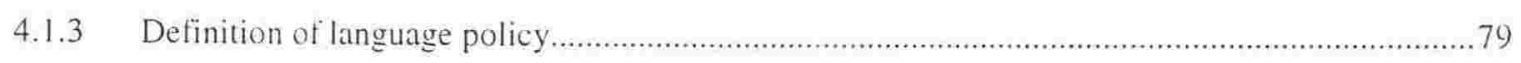

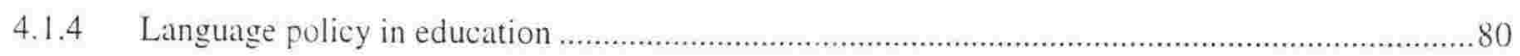

4.2 Historical background to language and language policy attitudes in New Zealand.........................8I

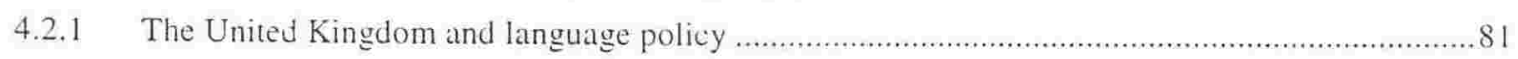

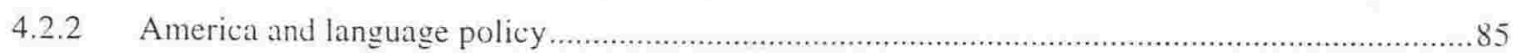

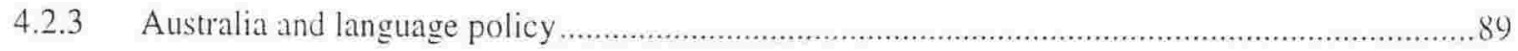

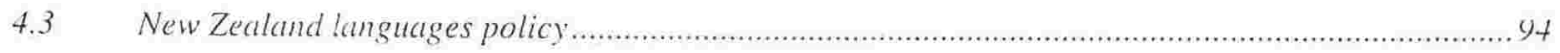

4.3.1 The Waitangi Tribunal and Te Reo Maori Claim ................................................................95

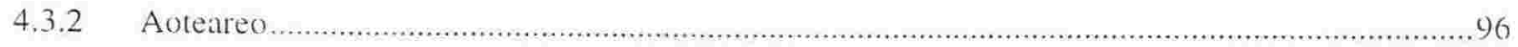

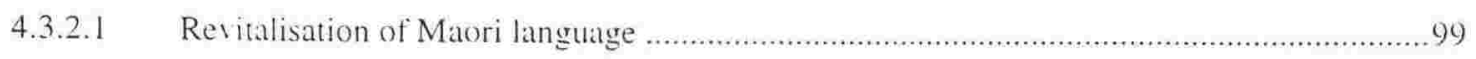

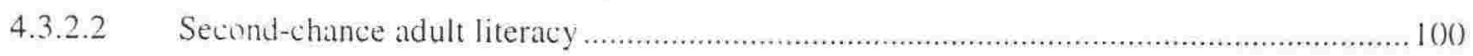

4.3.2.3 Children's ESL and fïrst language maintenance................................................... 100)

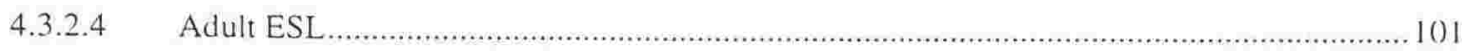




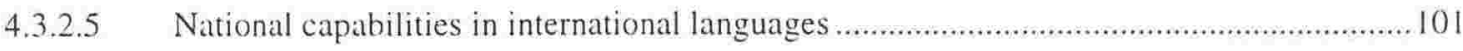

4.3.2.6 Provision of services in languages other than English ................................................ 102

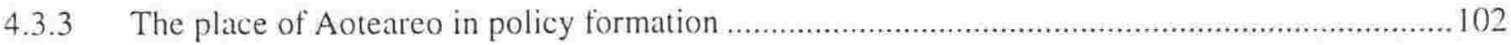

Education policy and language policy in New Zealand ....................................................... 104

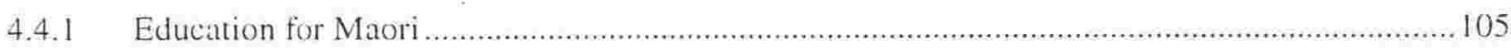

4.4.1.1 Re-emergence of Maori in the education system............................................... 107

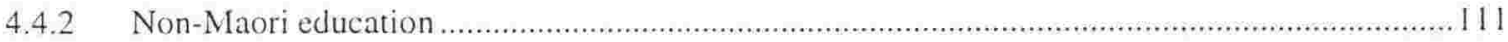

4.4.2.1 Samoan in the New Zealand educational system................................................... 114

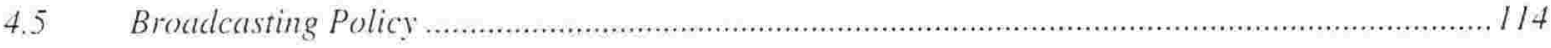

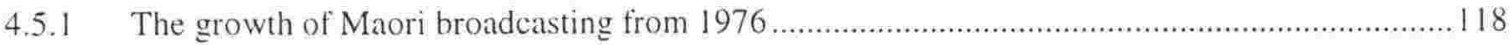

4.5.2 Royal Commission of Inquiry into Broadcasting and Related Telecommunications 1986........119

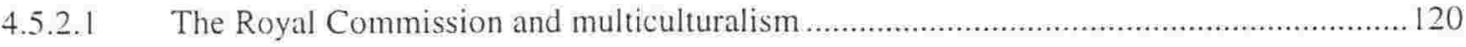

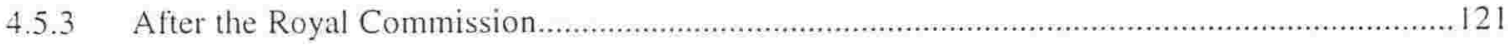

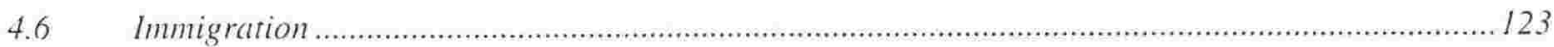

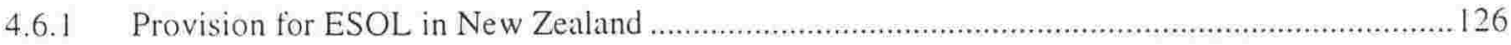

$5 \quad$ Language Maintenance And The Community .........................................................................129

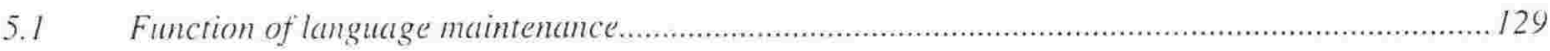

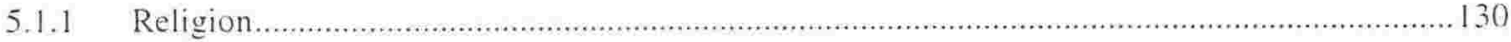

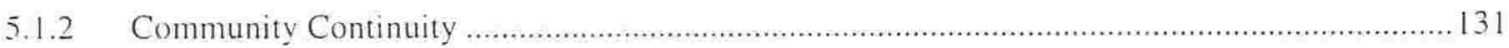

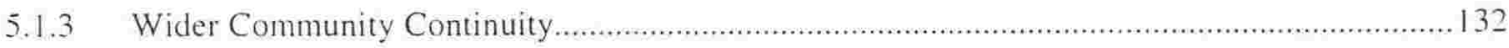

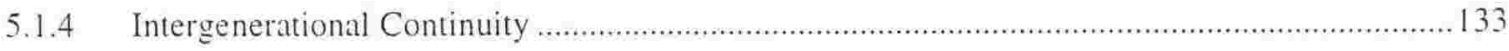

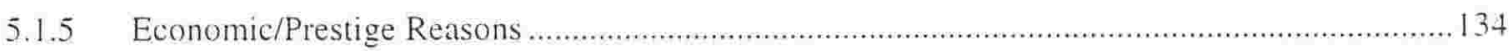

5.2 Location of language maintenance efforts or rationales within the community ..........................135

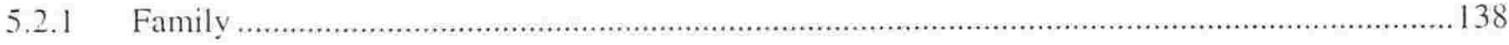

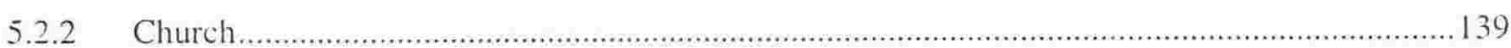

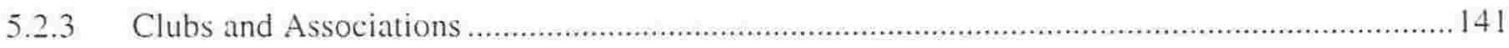

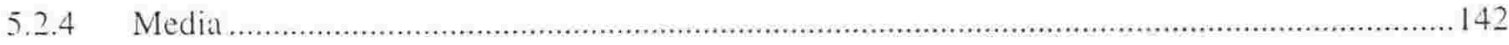

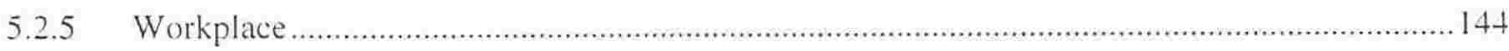

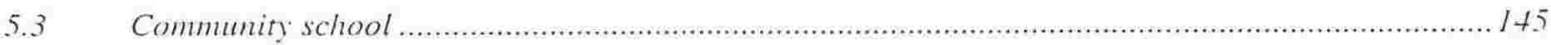

5.4 The role of mainstream education in fostering positive links between the minority and majority culture 148

5.5 Fishman's model of language maintenance and shift: an integrated interpretation.....................151

5.5.1 Definitions of terms used in the integrated model .......................................................... 15।

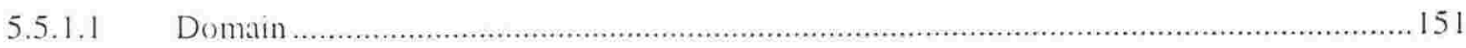

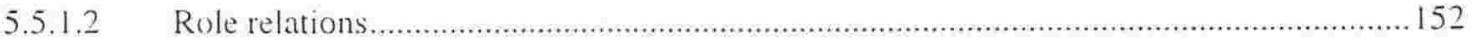

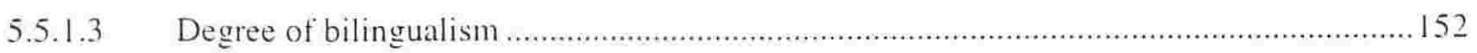

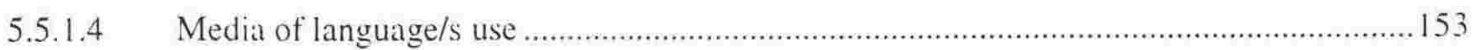


5.5.2 The integrated model

5.6 Reversing language shift.

5.6.1 GIDS in New Zealand

5.7 Research questions

6.1 Questionnaire design.....

6.2 General issues of questionnaire based research.

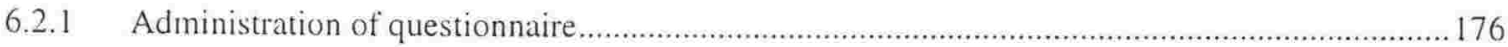

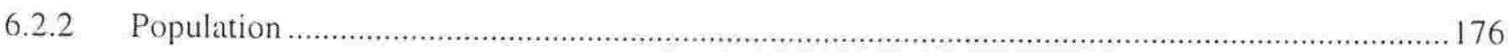

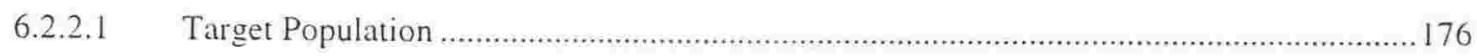

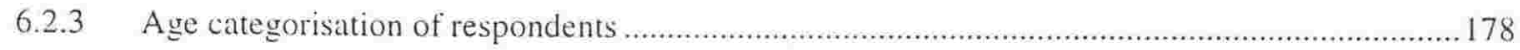

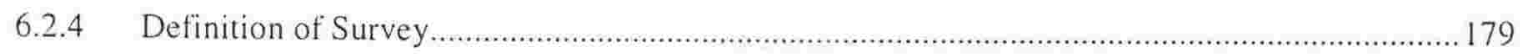

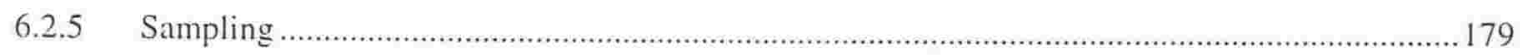

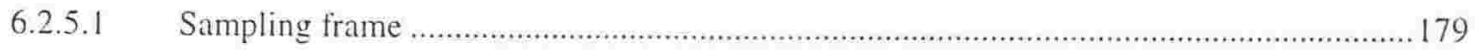

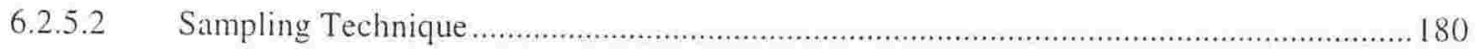

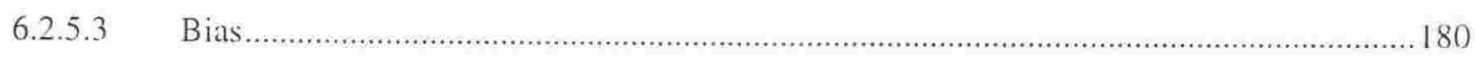

6.2.5.3.1 Bias in the sampling frame ............................................................................... 180

6.2.5.3.2 Who answers questionnaires................................................................. 181

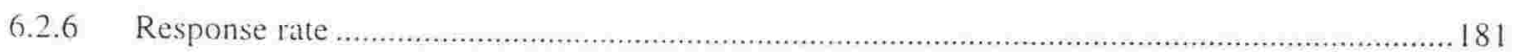

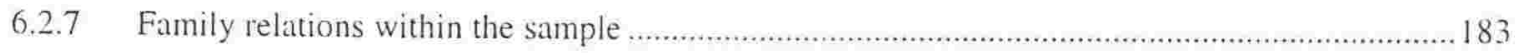

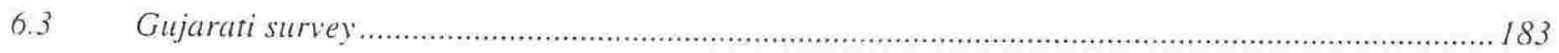

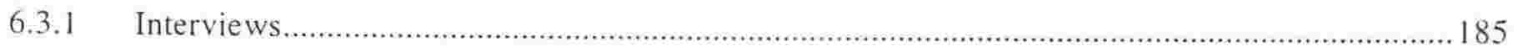

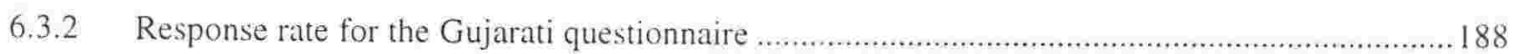

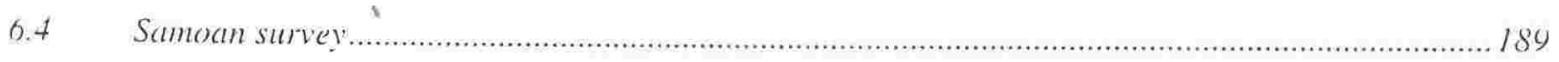

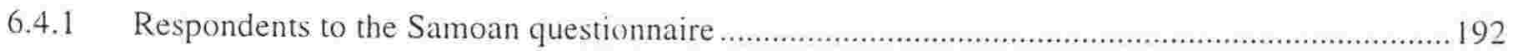

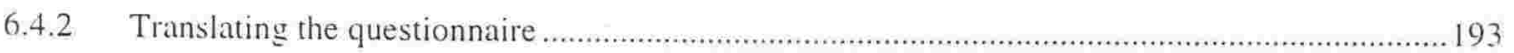

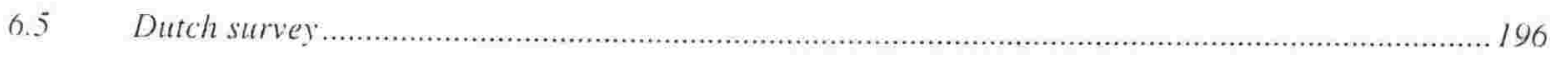

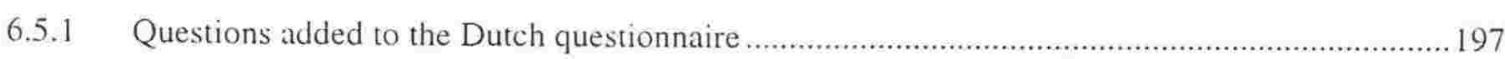

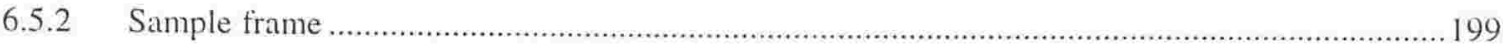

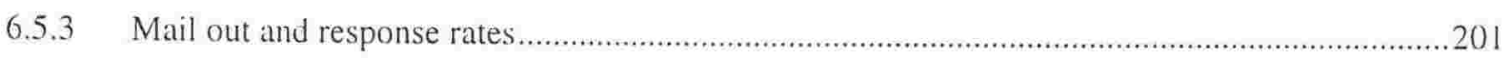

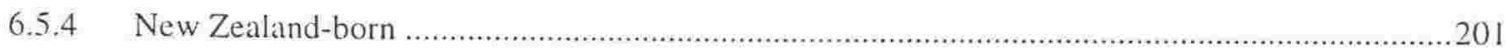

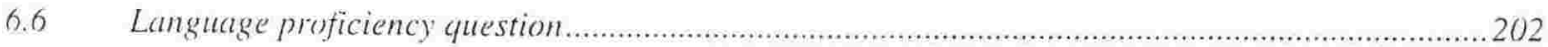

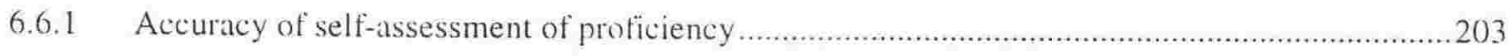

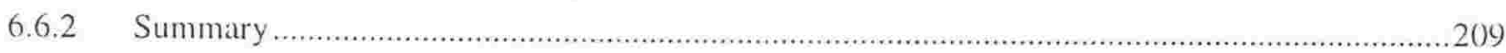

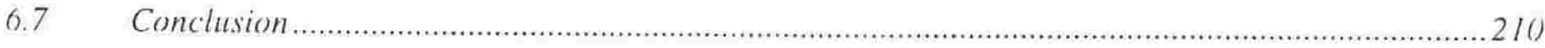


7.1 Denographic profile of Gujarati respondents.............................................................21/

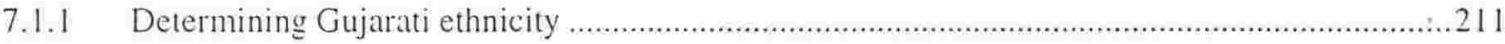

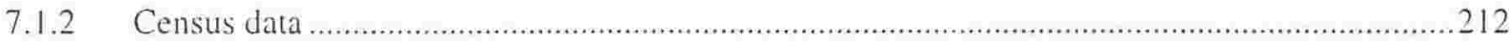

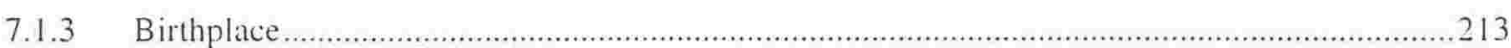

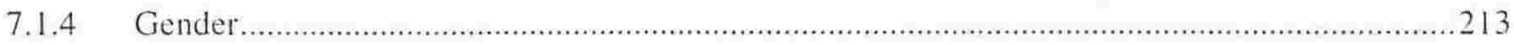

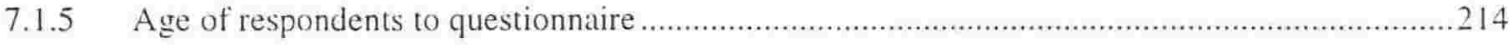

7.1.6 Marital status of respondents to questionnaire ...............................................................215

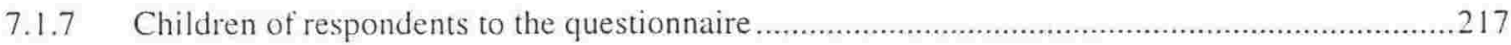

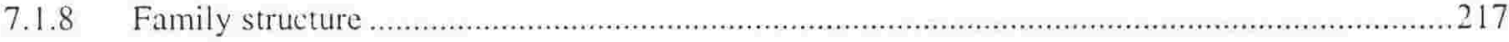

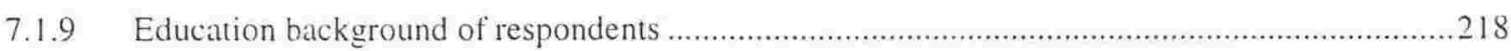

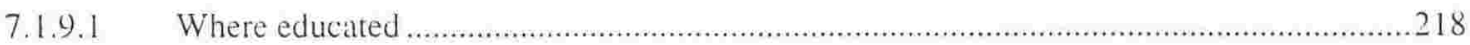

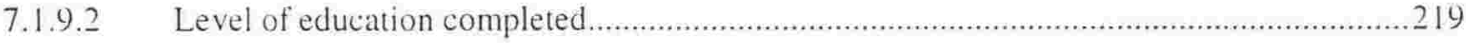

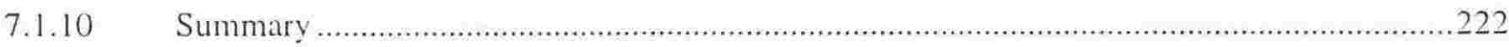

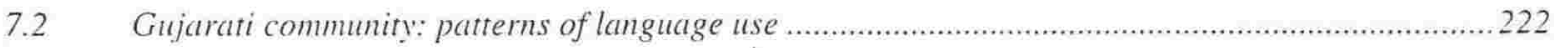

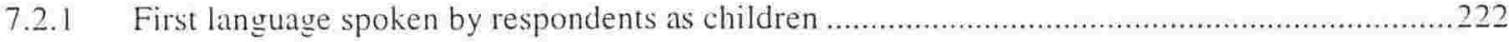

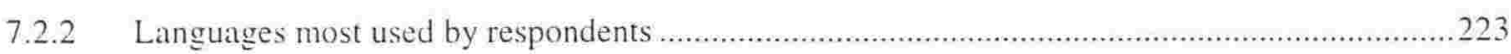

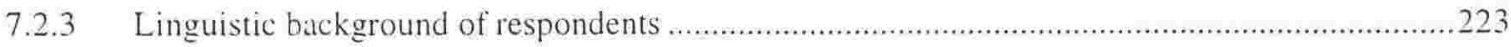

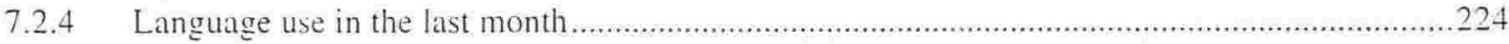

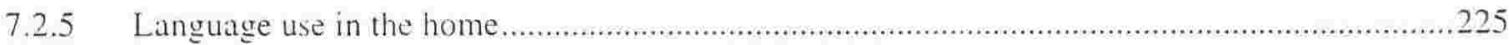

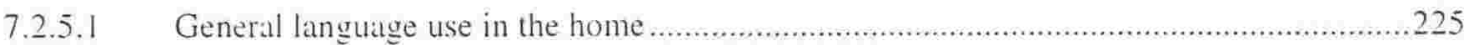

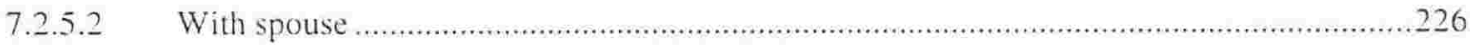

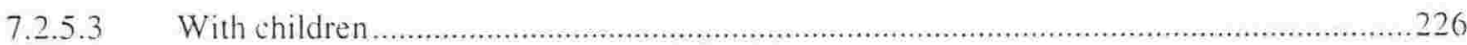

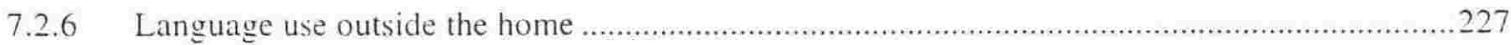

7.2.6.1 Where Gujarati was spoken outside the home ....................................................227

7.2.6.2 Gujarati speaking interlocutors; outside the home ..................................................2229

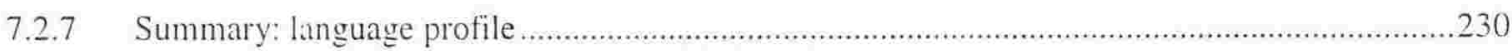

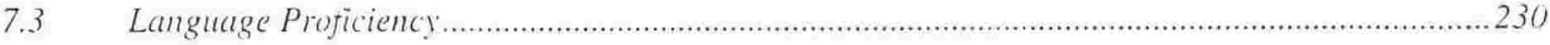

7.3.1 Self-reporting of proficiency …

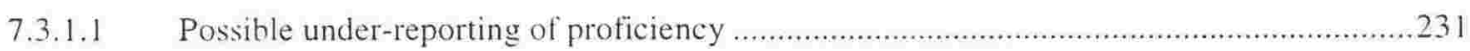

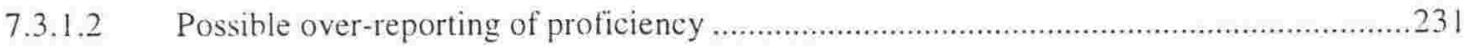

7.3.1.3 No Response to proficiency question ..................................................................232

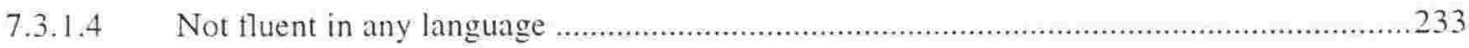

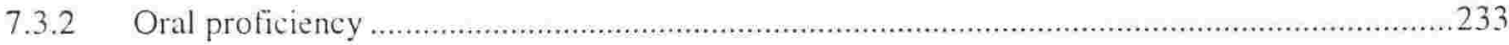

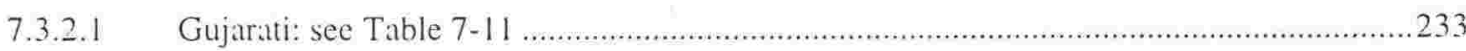

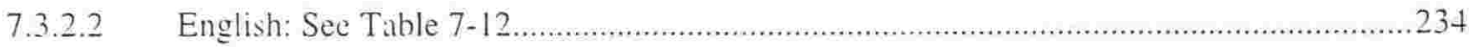

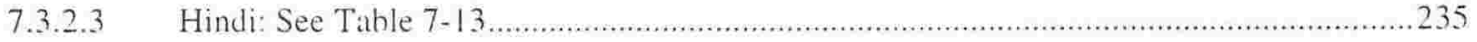

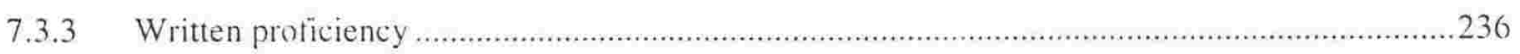

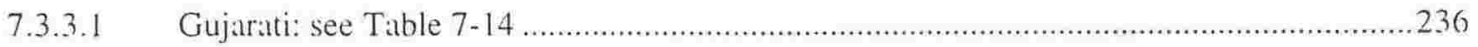


7.3.3.2 English: see Table 7-15. .236

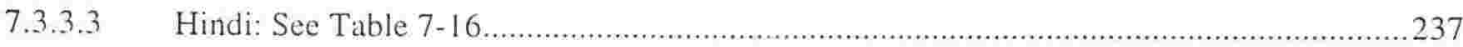

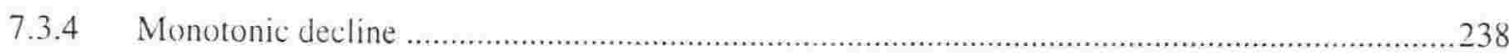

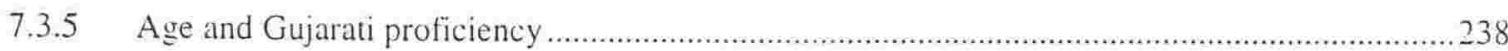

7.3.6 Gender and Language proficiency: see Table 7-17 and Table 7-18 ...................................239

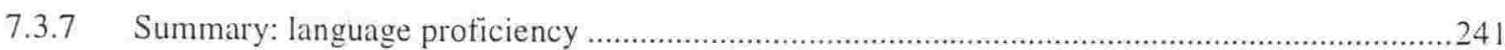

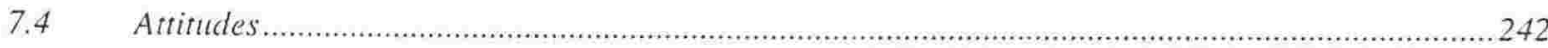

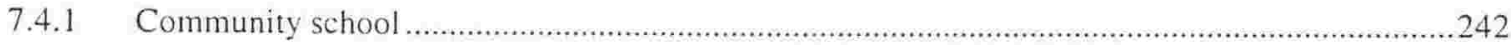

7.4.2 Gujarati and Hindi within the state school system ...........................................................242

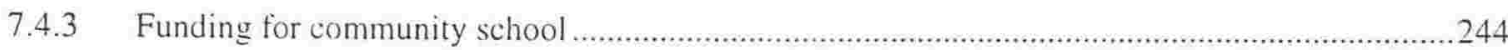

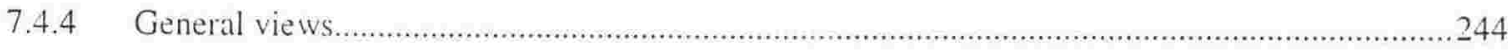

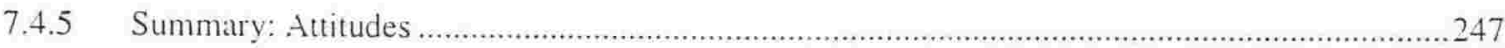

7.5 Interviewees' responses to radio, government services and state school questions .....................2.247

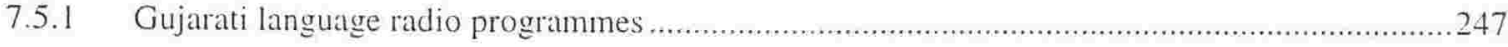

7.5.2 Gujarati language provision in government services ......................................................248

7.5.3 Interviewees' opinions of state school provision of Indian language instruction .....................252

7.5.3.1 At what level of schooling should the Indian language be taught ...............................255

7.5.3.2 How many hours a week should the language be taught ...........................................256

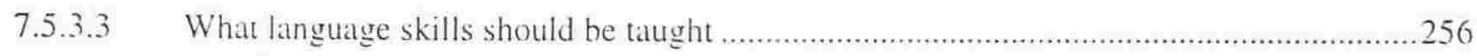

7.5.3.t Attitude to government funding of community schools and to teaching an Indian language

in state schools

7.6 Gujarati children and their use of Gujarati language.

7.6.1 Languages used by oldest and youngest Gujarati children of respondents to the questionnaire..259

7.6.2 Attendance at Gujarati language maintenance school.....................................................260

7.6.3 Interviewees and their children's Gujarati language use .............................................2. 260

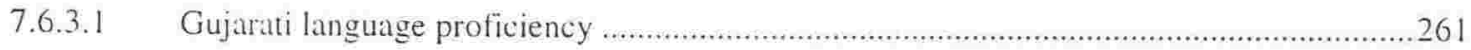

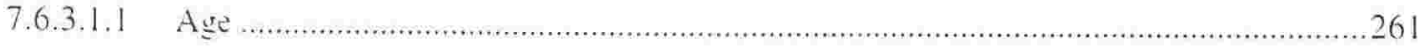

7.6.3.1.2 Position in family in relation to spoken Gujarati ...................................................2 262

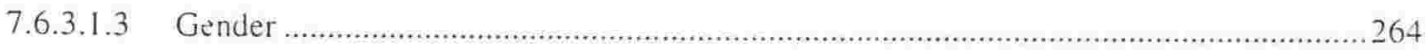

7.6.3.1.4 Fluency of parent correlated with spoken Gujarati proficiency ..............................264

7.6.3.2 Interviewees goals' for children's Gujarati language skills ..........................................2. 265

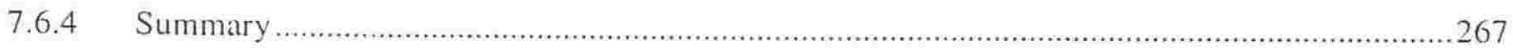

7.7 Patterns of Gujarati and Hindi use during respondents' childhood in New Zealand .....................267

7.7.1 Was Gujaratí spoken in your home in New Zealand.........................................................2.268

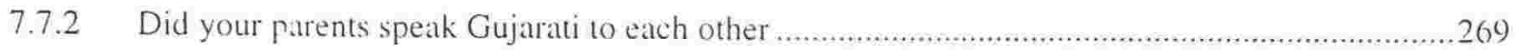

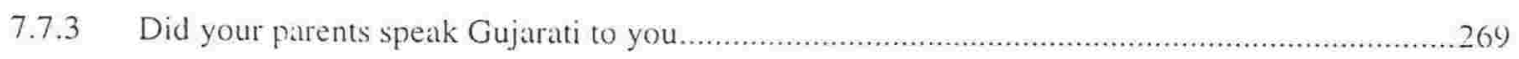

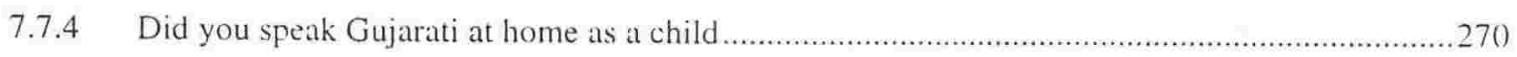

7.7.5 Did your parents speak any other Indian language to you as a child ....................................27 ।

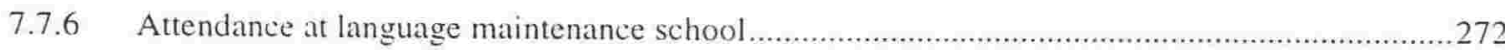




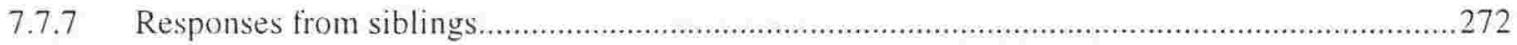

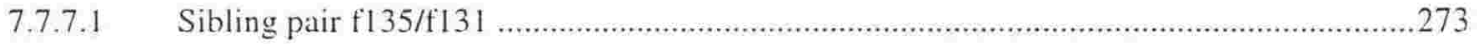

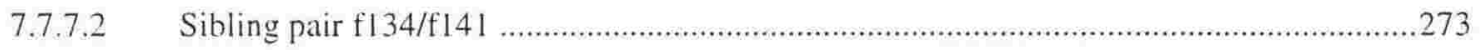

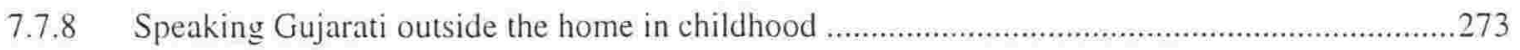

7.7.8.1 Where interviewees spoke Gujarati outside the home

7.7.8.2 Gujarati-speaking interlocutors outside the home in childhood …....................................2.

7.7.9 Gujarati language proficiency of respondents born or raised in NZ …................................277

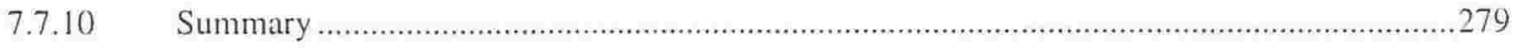

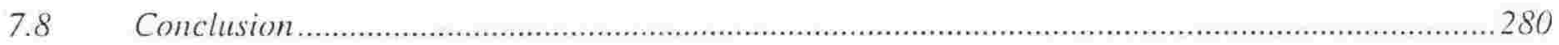

$8 \quad$ Analysis Of The Dutch Respondents' Responses To The Questionnaire..............................................281

S.I Demographic profile of Dutch respondents...................................................................28

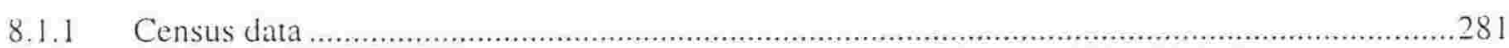

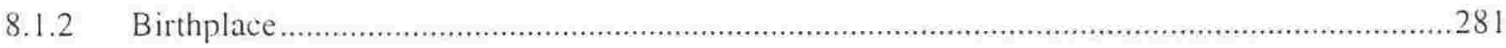

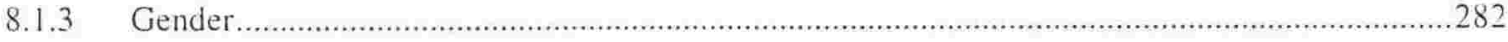

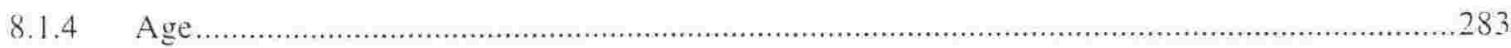

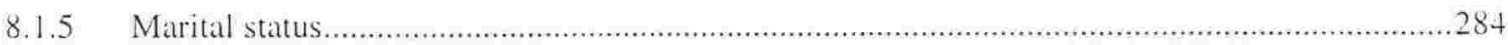

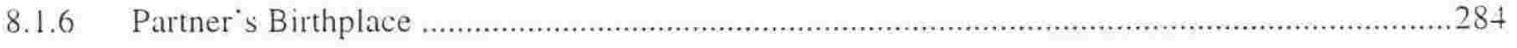

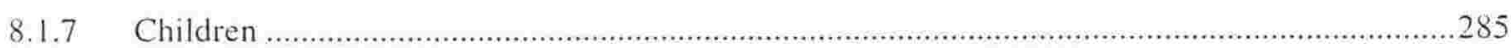

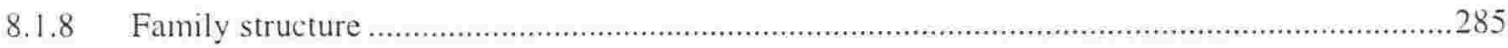

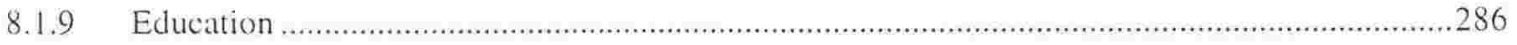

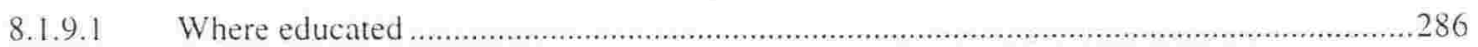

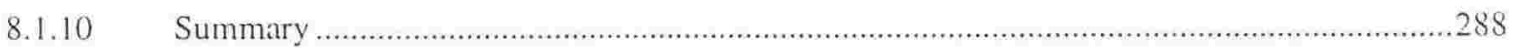

8.2 Dutch community: patterns of language use ..............................................................2. 289

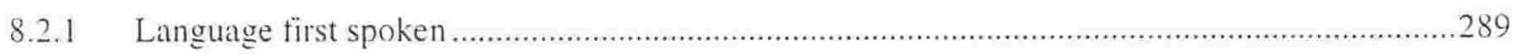

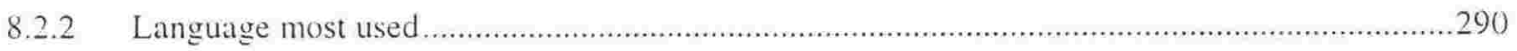

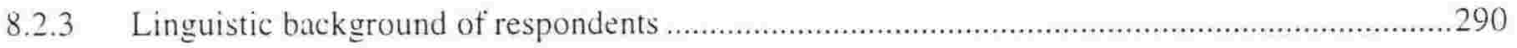

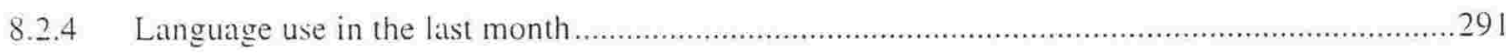

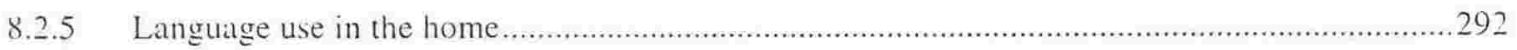

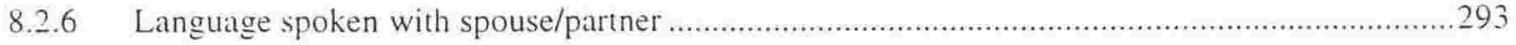

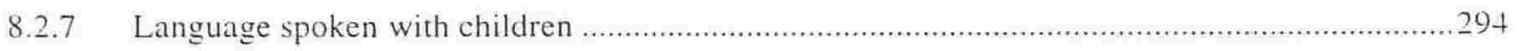

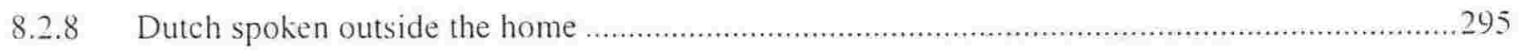

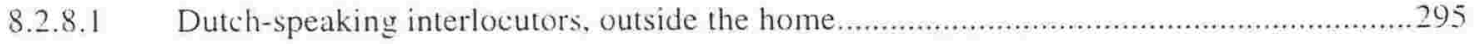

8.2.8.2 Where Dutch was spoken outside the home .............................................................296

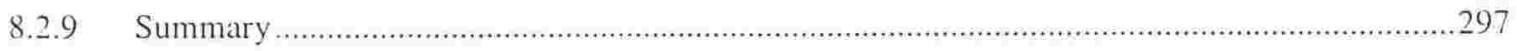

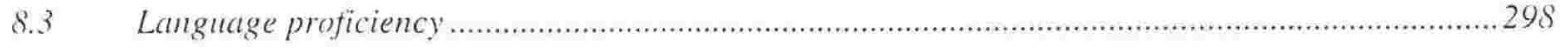

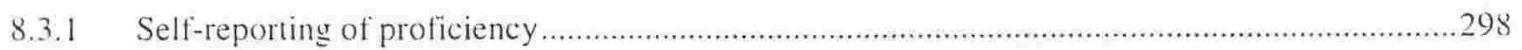

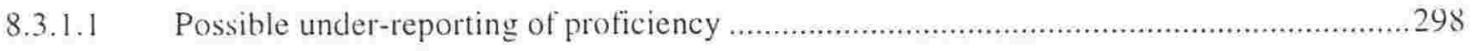

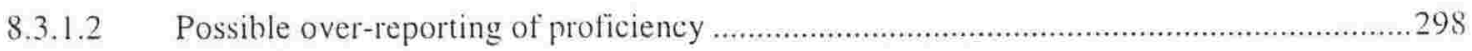


8.3.1.3 'No Response' to proficiency question.

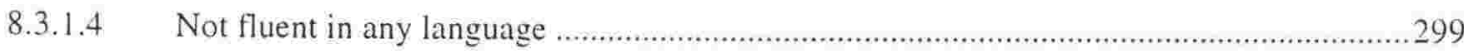

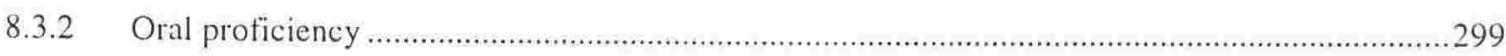

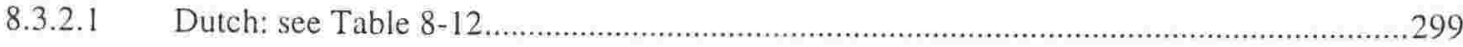

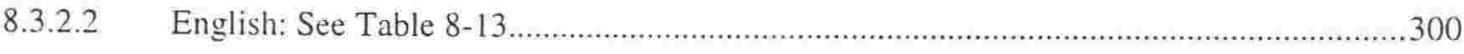

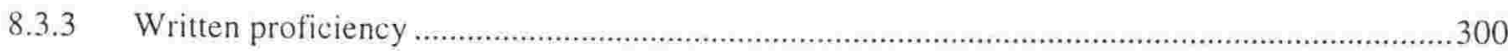

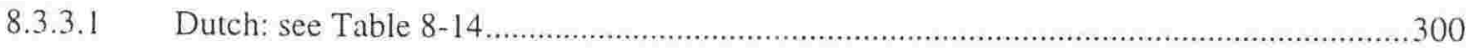

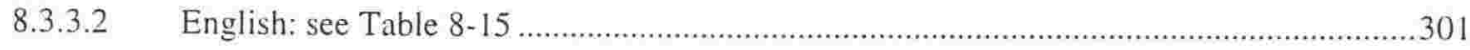

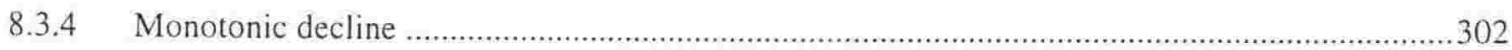

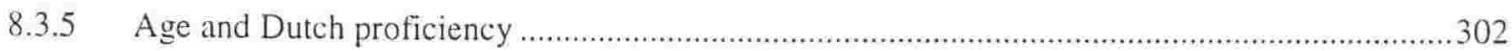

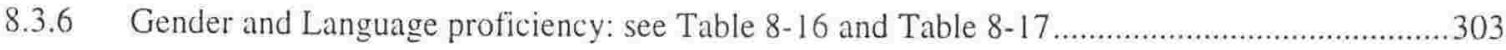

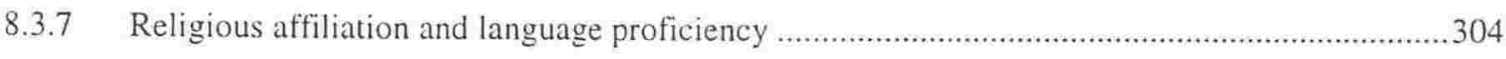

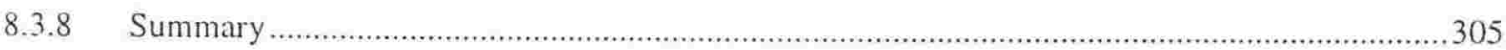

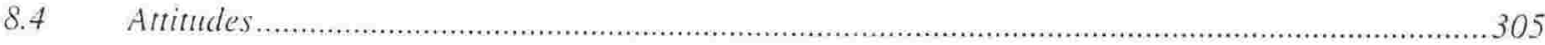

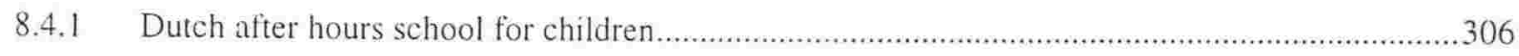

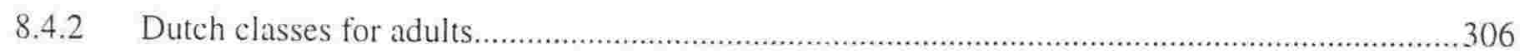

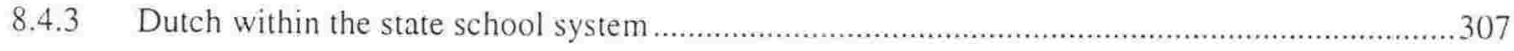

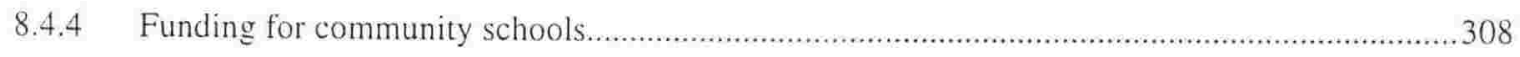

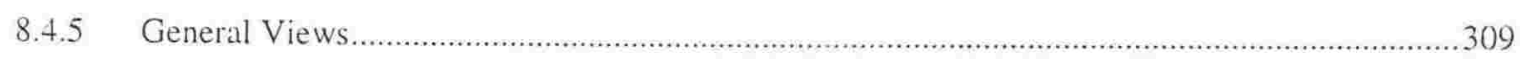

8.4.5.1 Is it important to keep Dutch as a living language in New Zealand? ..............................309

8.4.5.2 Should Dutch people see themselves as part of a Dutch/NZ community? ......................310

8.4.5.3 Should Dutch people in New Zealand see themselves simply as New Zealanders'? ...........310

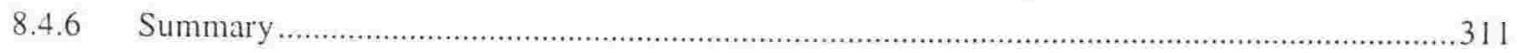

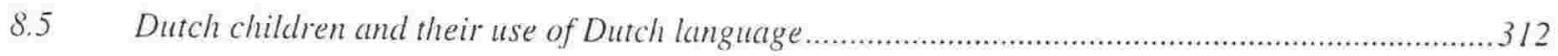

8.5.1 Languages used by oldest and youngest children of Dutch respondents to questionnaire ...........312

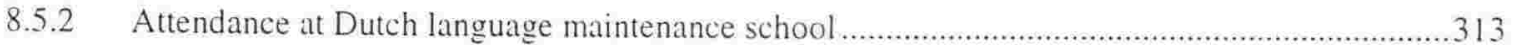

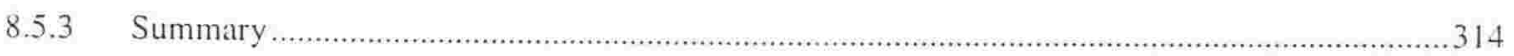

8.6 Patterns of Dutch use during respondents' childhood in New Zealand ....................................... $31+$

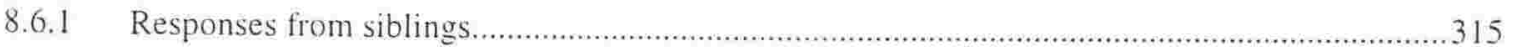

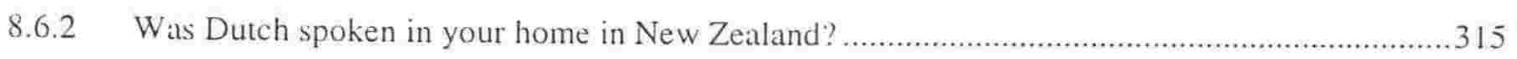

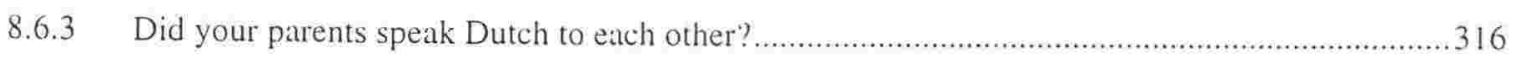

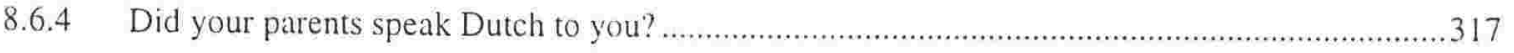

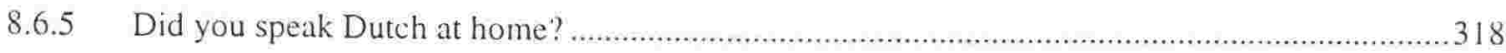

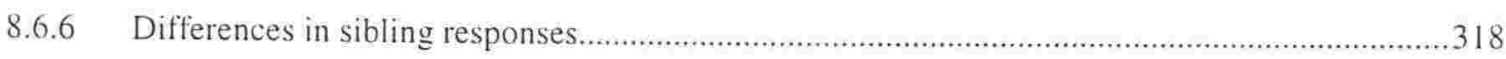

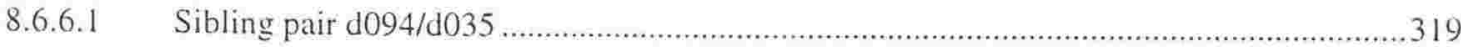

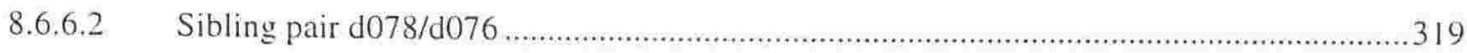

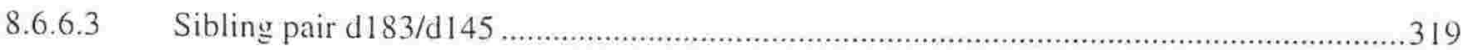

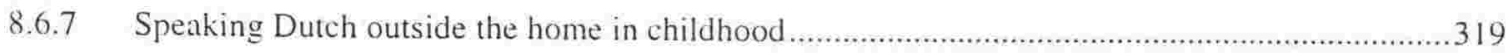

8.6.7.1 Where respondents spoke Dutch outside the home in childhood ..................................320 
8.6.7.2 Dutch-speaking interlocutors outside the home in childhood. .321

8.6.8 Dutch language proficiency of respondents born or raised in New Zealand..............................323

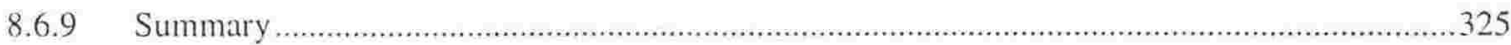

8.7 Conclusion.

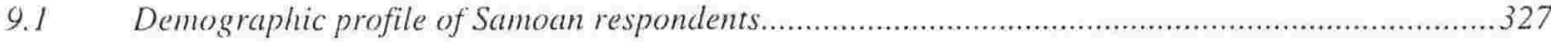

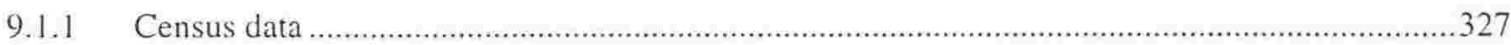

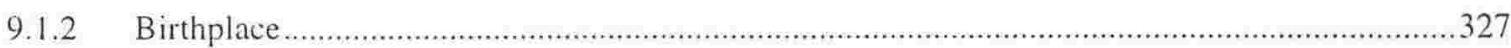

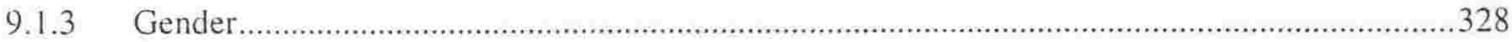

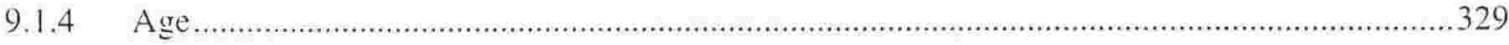

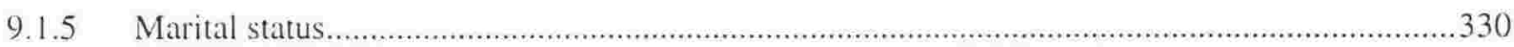

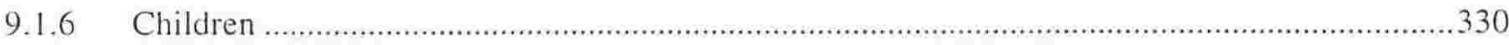

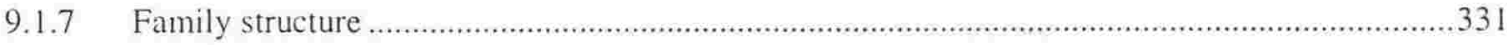

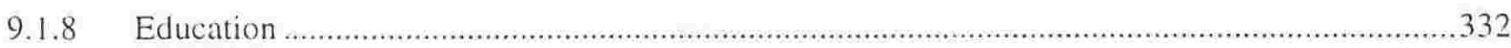

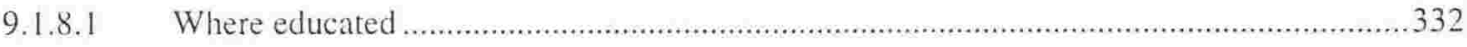

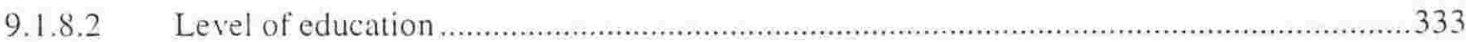

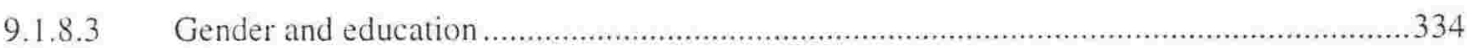

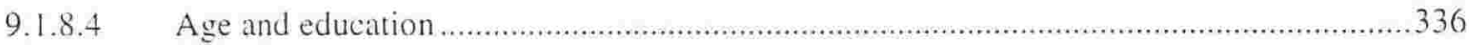

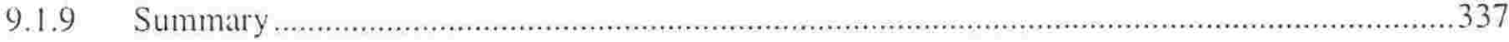

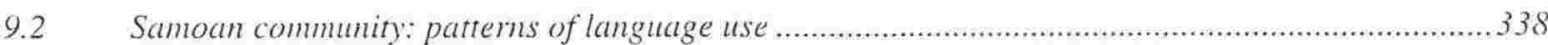

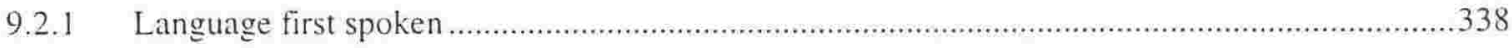

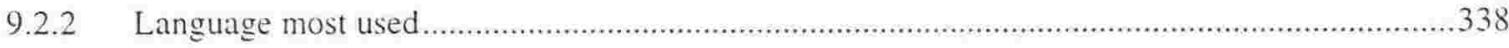

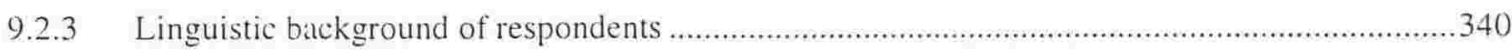

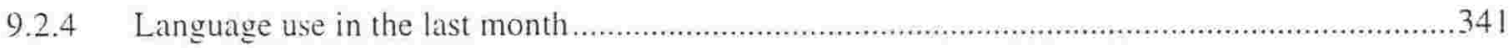

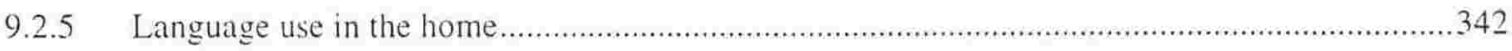

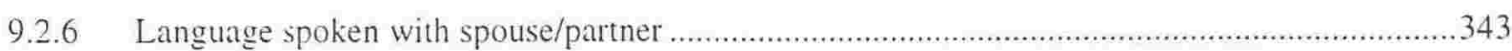

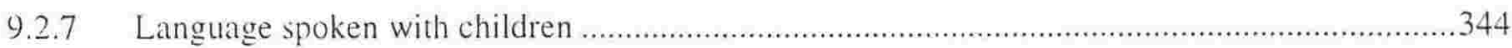

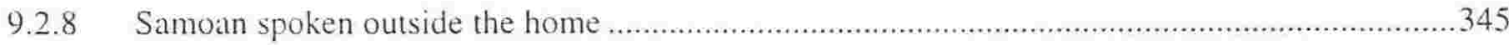

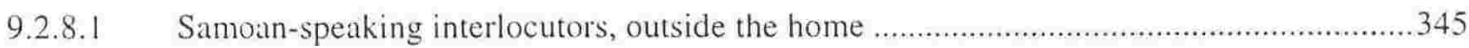

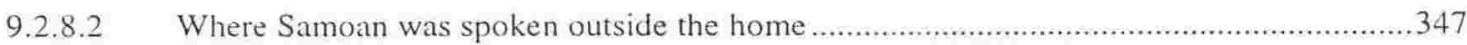

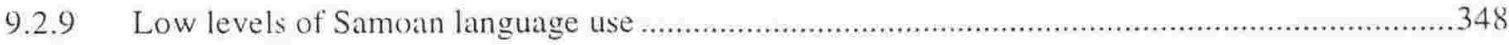

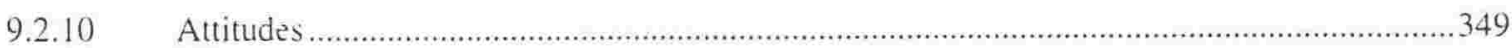

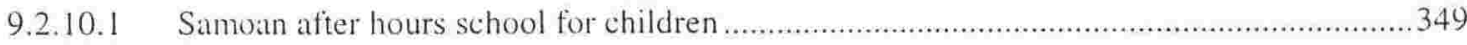

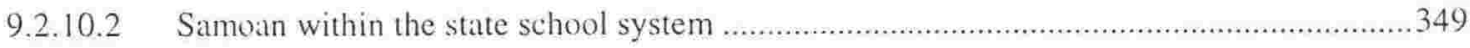

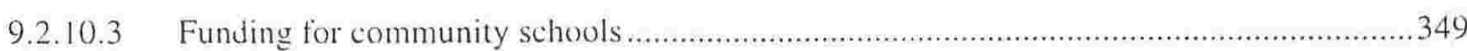

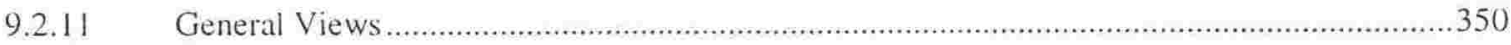

9.2.11.1 Is it important to keep Samoan as a living language in New Zealand? .........................350

9.2.11.2 Should Samoan people see themselves as part of a Siımoan/NZ community? .................350 
9.2.11.3 Should Samoan people in New Zealand see themselves simply as New Zealanders? .......350)

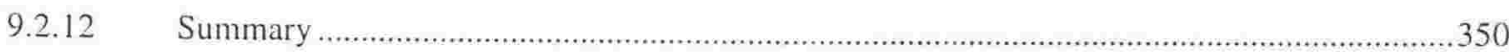

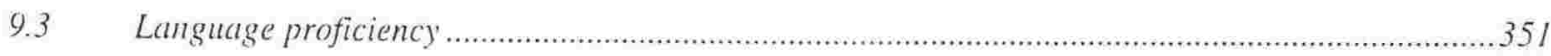

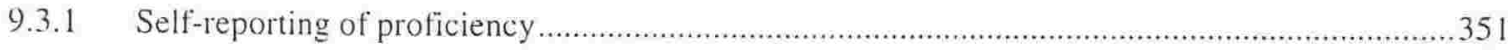

9.3.1.1 Possible under-reporting of proficiency .........................................................................

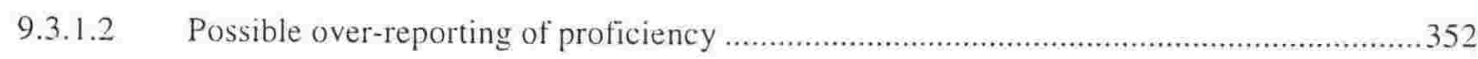

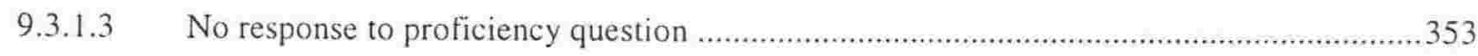

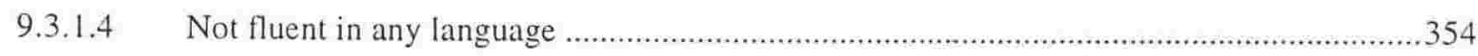

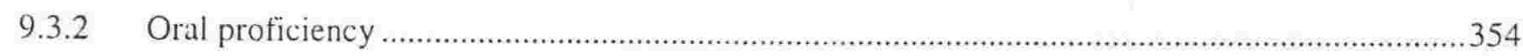

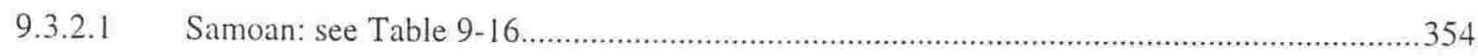

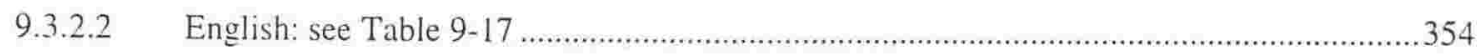

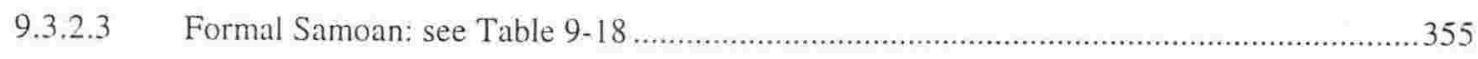

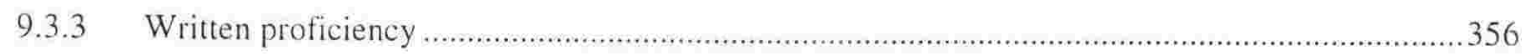

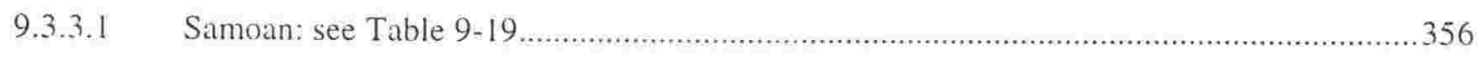

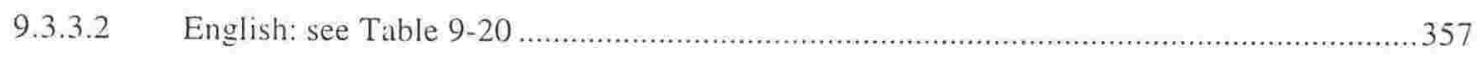

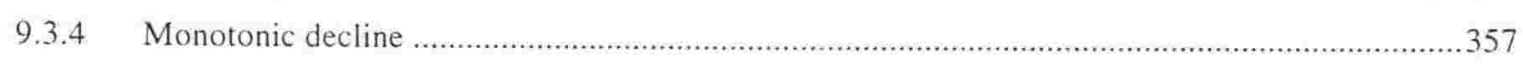

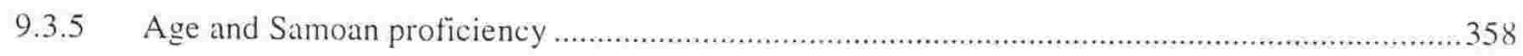

9.3.6 Gender and Language proficiency: see Table 9-21, Table 9-22, Table 9-23 .............................358

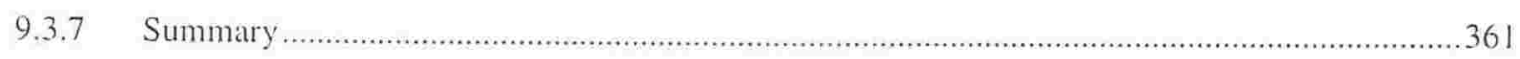

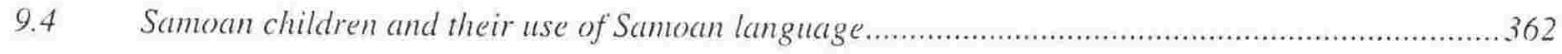

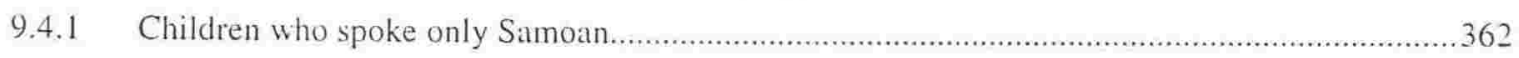

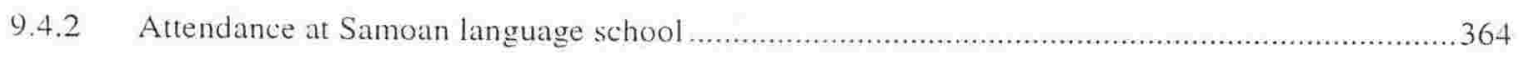

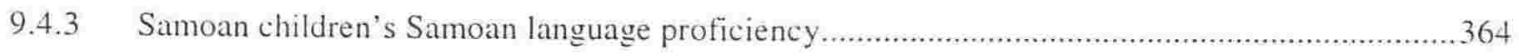

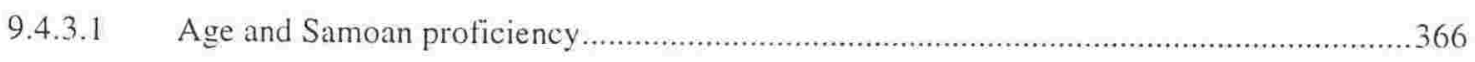

9.4.3.2 Position in the family in relation to proficiency in spoken Samoan ..................................3.366

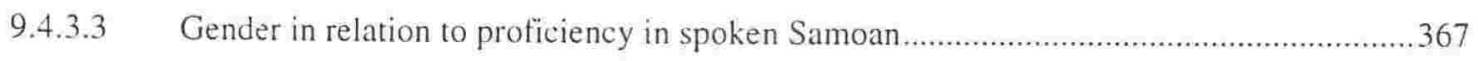

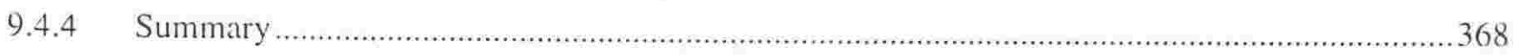

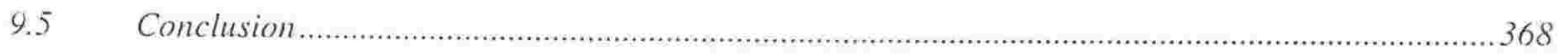

10 Comparison and Analysis: Demographic data, language use and proficiency ........................................

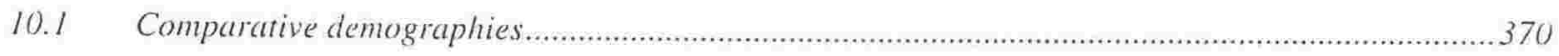

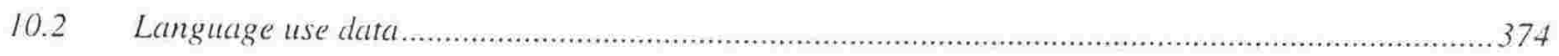

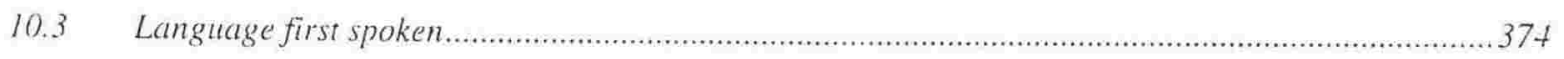

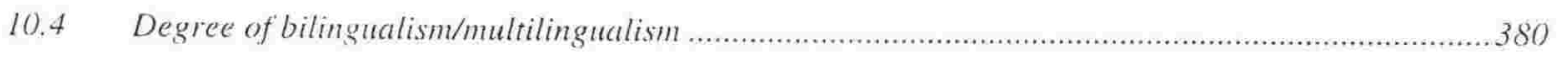

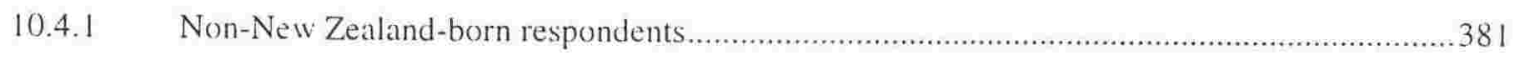

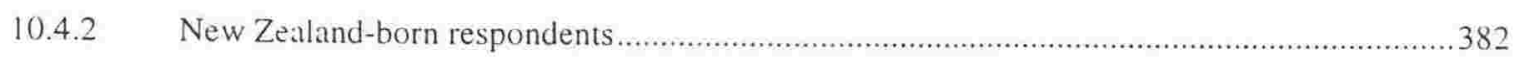

10.4.3 Correlation of multilingualism with respondents' tluency in MT ...................................383

10.4.4 Correlation of multilingual and bilingual parents with children's ability to speak the MT.....385 
10.4.5 Interaction between university education and multilingualism and its possible influence upon language maintenance . .387

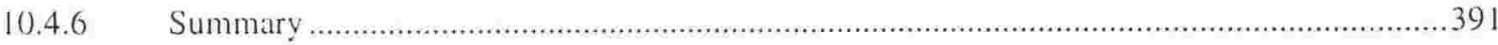

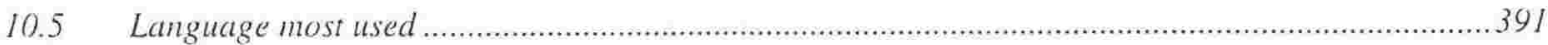

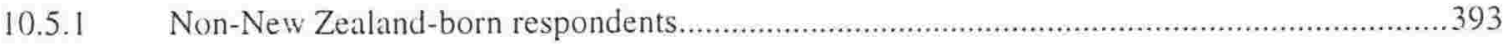

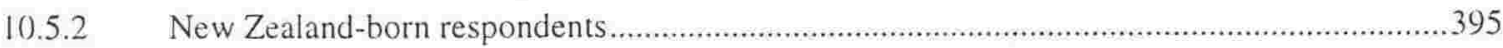

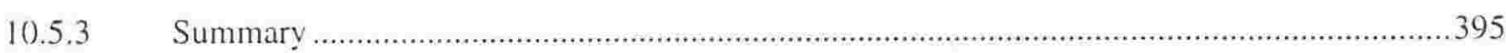

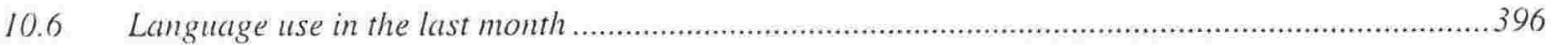

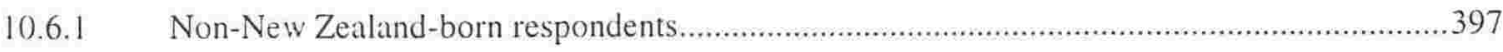

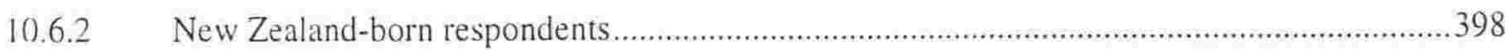

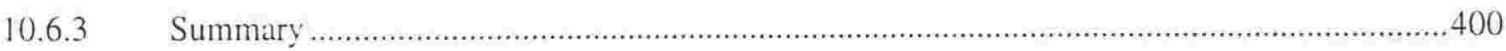

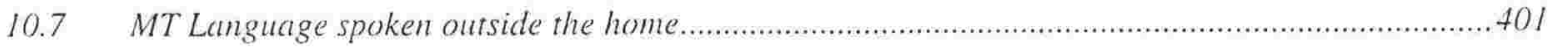

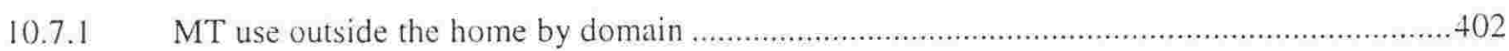

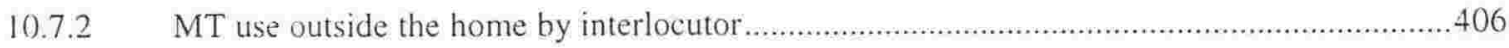

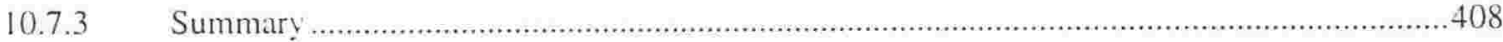

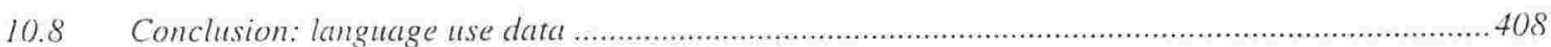

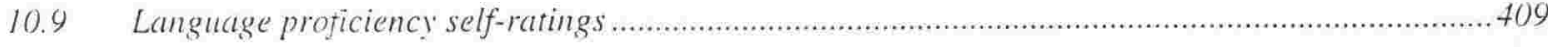

10.9.1 Oral proticiency in MT …

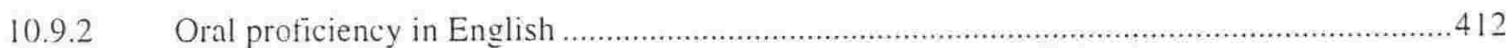

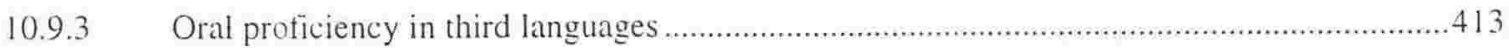

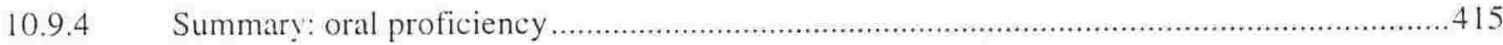

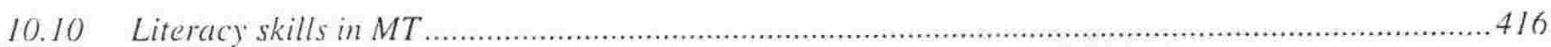

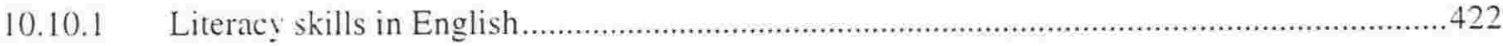

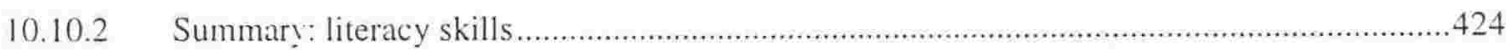

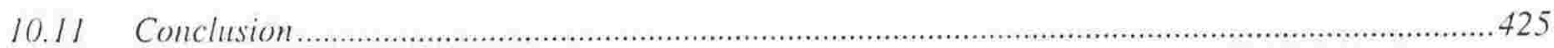

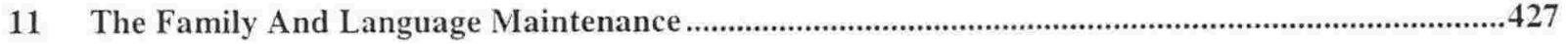

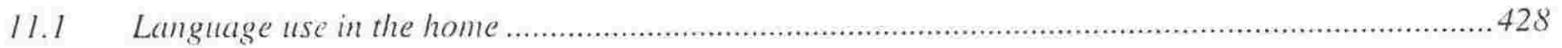

11.1.1 MT use in the home: non-New Zealand-born respondents ......................................429

11.1.2 MT language use in the home: New Zealand-born respondents ...................................431

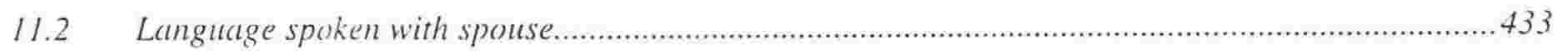

11.2.1 Language spoken with spouse. Non-New Zealand-born respondents ..............................434

11.2.2 Language used with spouse. New Zealand-born respondents ....................................435

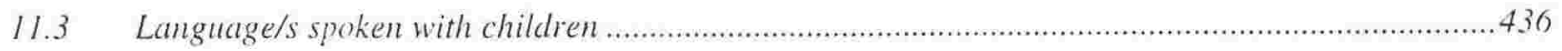

11.3.1 Language/s used with children: non-New Zealand-born respondents.............................4.437

11.3.2 Languages used with children: New Zealand-born respondents ..................................439

11.3.3 Comparison of MT use with spouse and with children .............................................441 
11.5 MT use in the family: what influences successful acquisition?.....................................................445

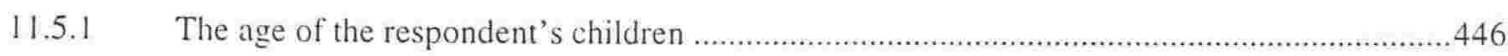

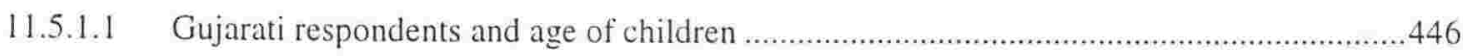

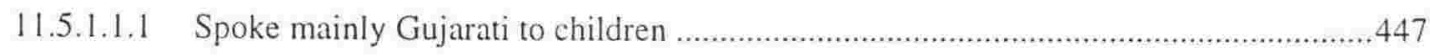

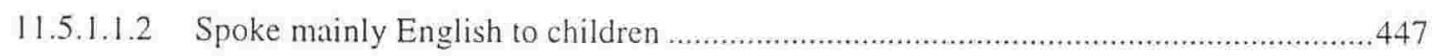

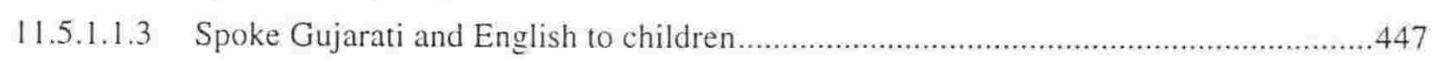

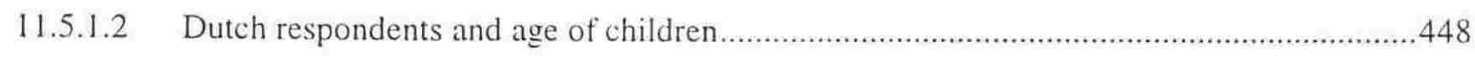

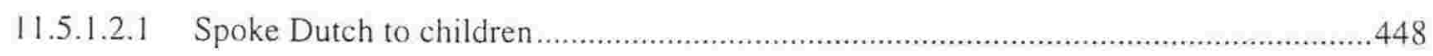

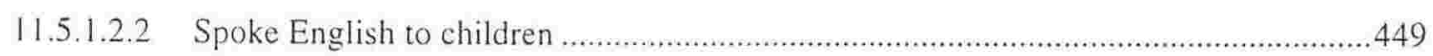

11.5.1.3 Samoan respondents and age of children...................................................................450

11.5.1.4 Summary: parental use of MT and age of children .....................................................450

11.5.2 The level of education attained by the respondent …......................................................

11.5.2.1 Gujarati respondents use of MT with children and respondent's level of education .........452

11.5.2.2 Dutch respondents use of MT with children and respondents' level of education .............453

11.5.2.3 Samoan respondents use of MT with children and respondents' level of education ..........453

11.5.2.4 Summary: level of education and use of MT with children............................................454

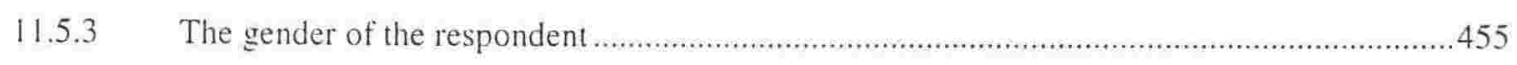

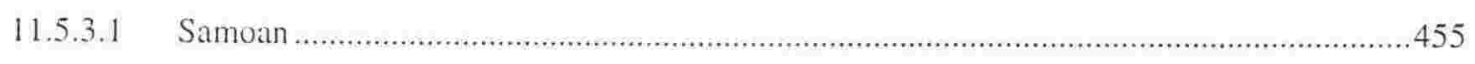

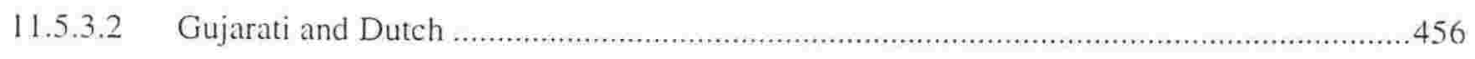

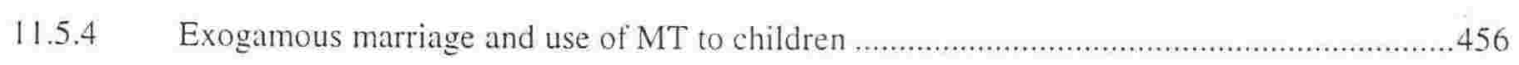

11.5.5 Parental proficiency in the MT and use of MT with children .........................................457

11.5.6 Where the respondent was born and use of MT with children ...................................459

11.5.6.1 Language spoken by Gujarati respondents with children by birthplace ..........................459

11.5.6.2 Language spoken by Dutch respondents with children by birthplace ..............................460

11.5.6.3 Language spoken by Samoan respondents with children by birthplace ..........................460

1 1.5.7 The contexts in which the respondent uses the MT outside the home ...............................460

11.5.8 Summary: factors affecting parental use of MT with children .......................................463

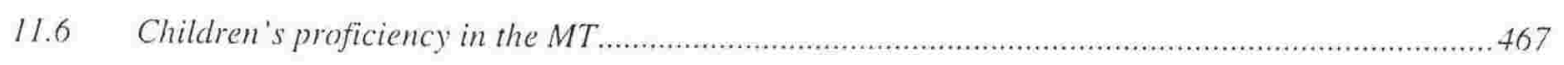

11.6.1 Language use of oldest and youngest children of respondents........................................467

11.6.2 Gujarati and Samoan children's proficiency in the MT .............................................469

11.7 Factors affecting child's proficiency in the MT ............................................................470

11.7.1 The link between MT proficiency and the range of MT interlocutors available to the child ..471

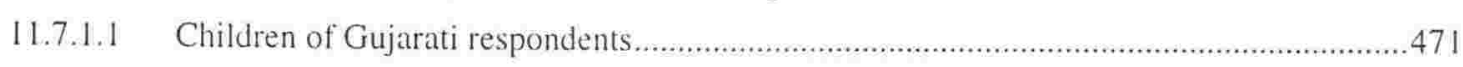

11.7.2 Dutch and Gujarati respondents: range of interlocutors in New Zealand as children ............473

11.7.2.1 Gujarati interviewees: MT interlocutors inside the home..........................................473

11.7.2.2 Gujarati interviewees: MT interlocutors outside the home ...........................................4 474

11.7.2.3 Dutch respondents : MT interlocutors inside the home ............................................474

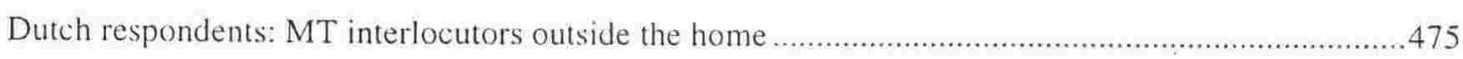




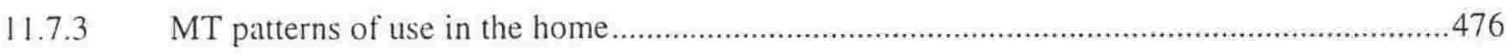

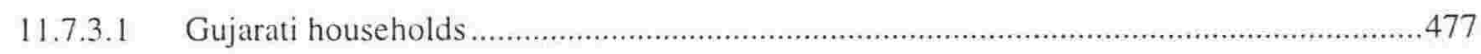

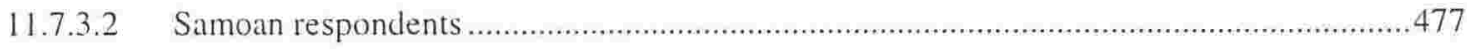

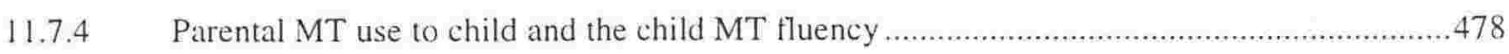

11.7.5 Childhood in New Zealand. The relationship between adult fluency in the MT and MT patterns

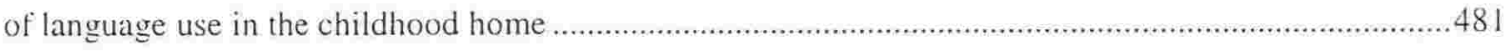

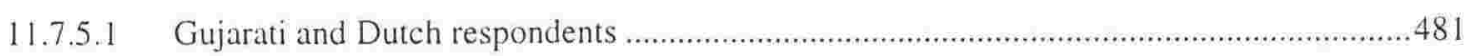

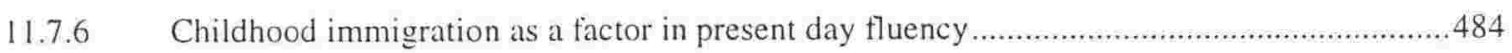

11.7.7 Attendance at language maintenance school and MT proficiency ….....................................484

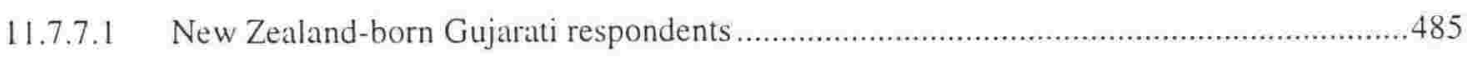

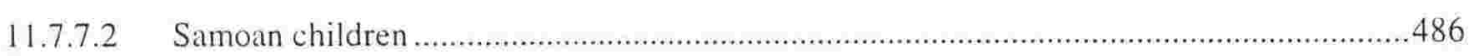

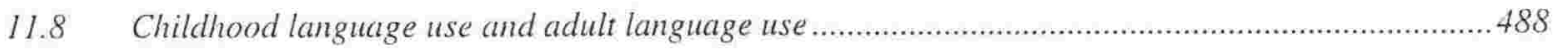

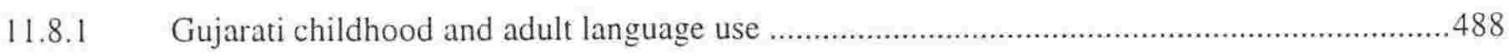

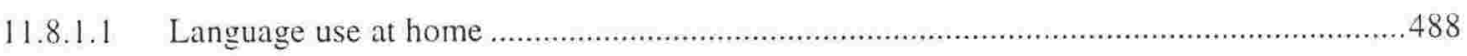

11.8.1.2 Language use outside the home

11.8.2 Dutch childhood and adult language use

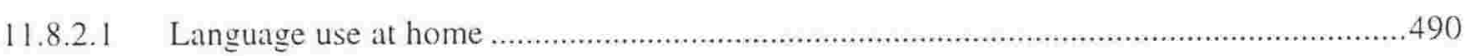

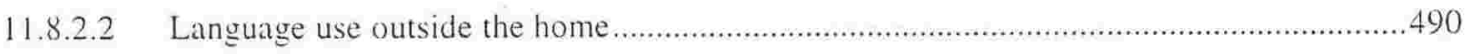

11.8.3 Summary: What influences successful MT acquisition ....................................................491

12 Language maintenance education and attitudes to language maintenance ........................................493

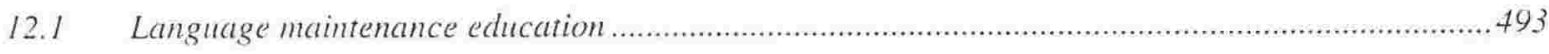

12.1.1 After hours schools for children: are they a good idea? ....................................................493

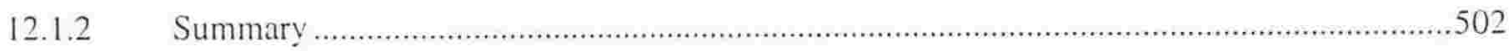

12.1.3 Should public funds go to community language maintenance schools .............................502

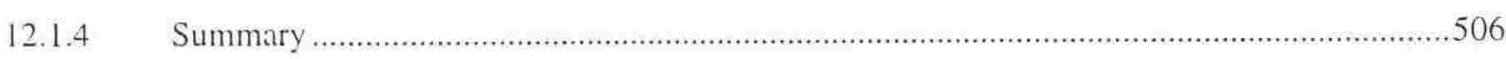

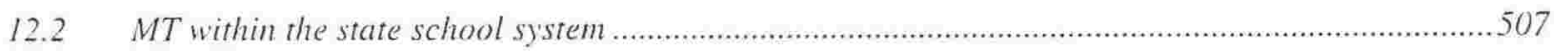

12.2.1.1 Tertiary education as a factor in attitudes to MT in the mainstream school ......................510

12.3 Summary: language maintenance education ................................................................................5I]

12.4 Should the MT be a living language in New Zealand: attitudes to language maintenance .............512

12.4.1 language attitudes and language maintenance outcomes............................................515

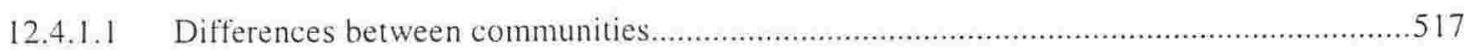

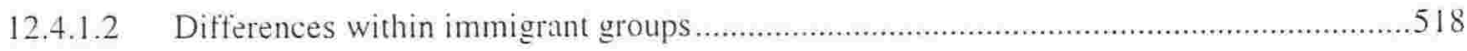

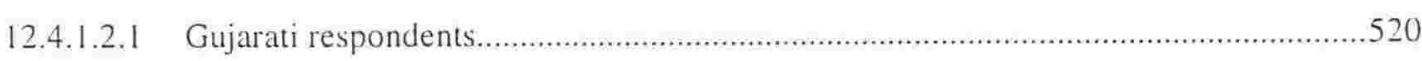

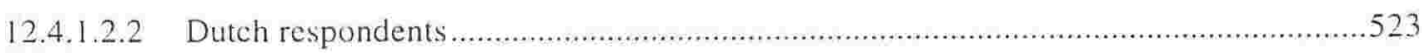

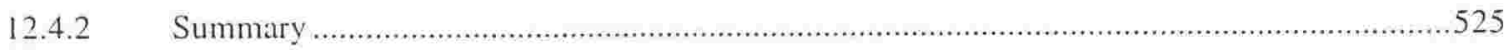

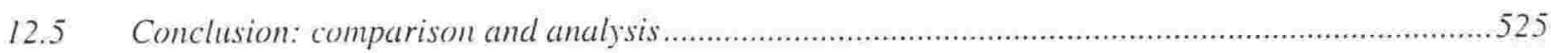


13.1 To what extent is MT language transmission occurring within the family?

13.2 How is MT language use occurring within the family? ................................................................5 530

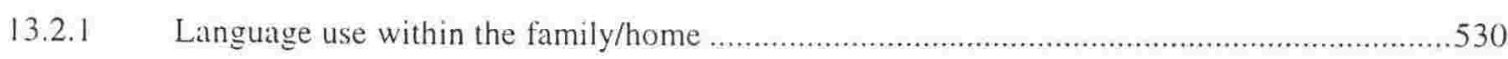

13.2.2 New Zealand born respondents: Language use in the home ............................................531

13.3 Is community MT schooling occurring and is it effective as support for the MT?.......................532

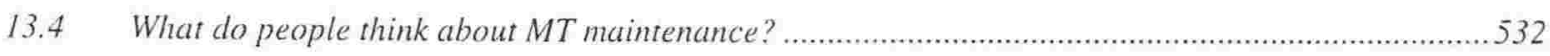

13.5 Can the GIDS usefully be applied to an analysis of immigrant language maintenance in New

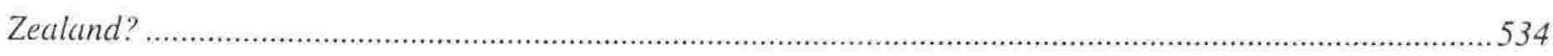

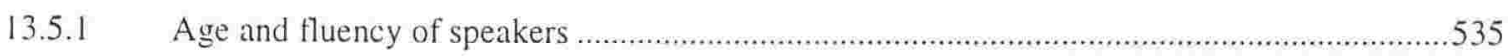

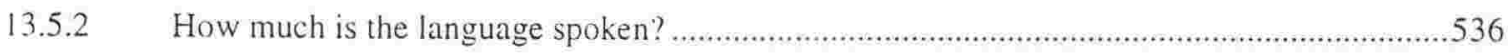

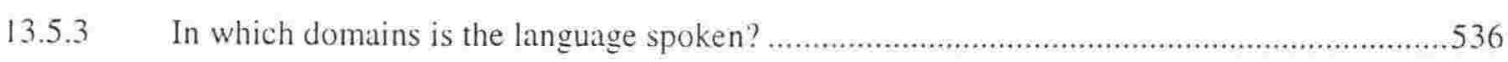

13.5.4 Interlocutors with whom community language is spoken............................................537

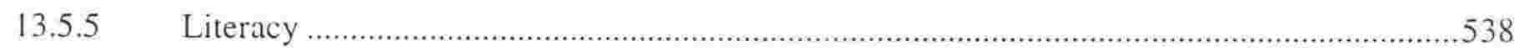

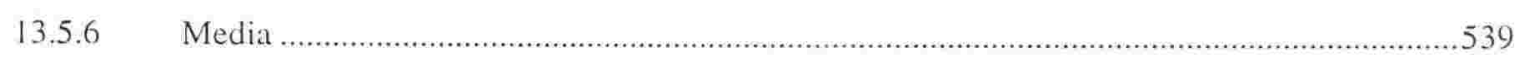

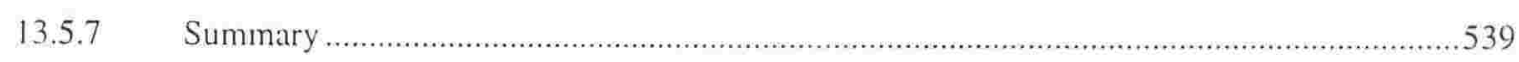

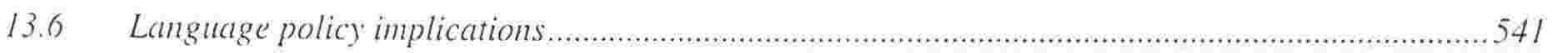

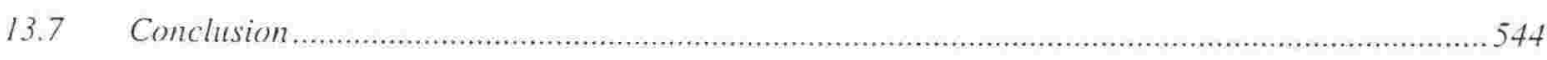

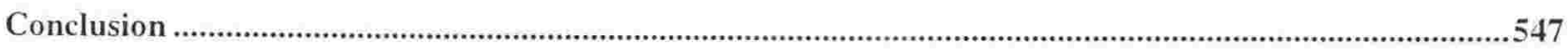

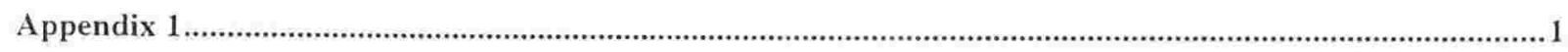

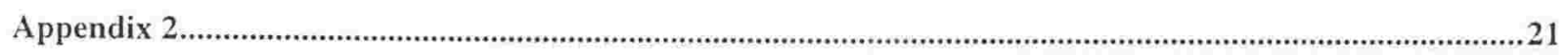

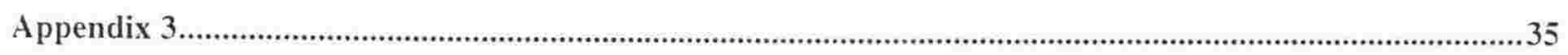

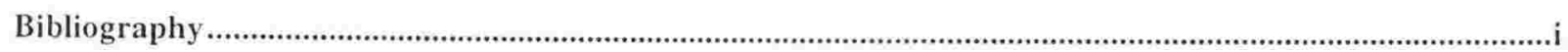




\section{Table of Tables}

Table 6-1: 1986 Census. Samoan and Indian Population figures............................................................ 177

Table 6-2: 1991 Census: Indian, Samoan \& Dutch population figures......................................................... 178

Table 7-1: Birthplace of respondents of Gujarati extraction .....................................................................213

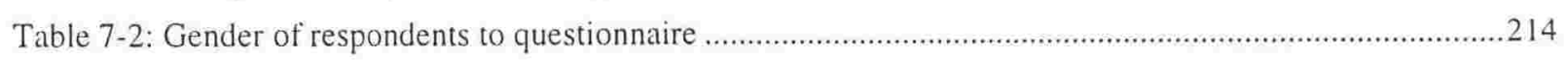

Table 7-3: Age ranges of all respondents and New Zealand-born respondents to questionnaire........................214

Table 7-4: Composition of Gujarati respondents' households ....................................................................217

Table 7-5: Countries in which the respondents were educated ……...........................................................2 18

Table 7-6: Thomson's educational level categories compared with Roberts' .................................................220

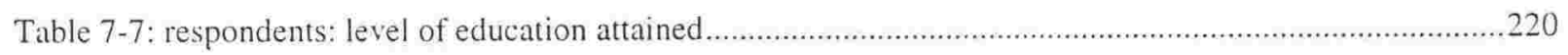

Table 7-8: Highest level of education attained by all respondents to the survey compared with level of education

attained by all Indian respondents to 1991 census (Thomson 1991:78) ..................................................221

Table 7-9: Highest level of education attained by male and female respondents to the survey compared with level of education attained by male and female Indian respondents to 1991 census (Thomson 1991:78)........221

Table 7-10: First language/s spoken. By Birthplace …….........................................................................22

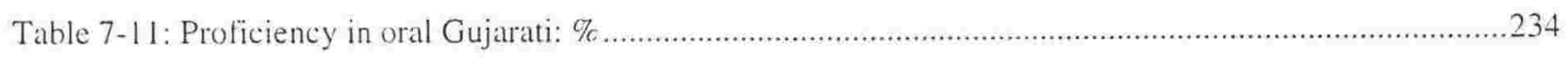

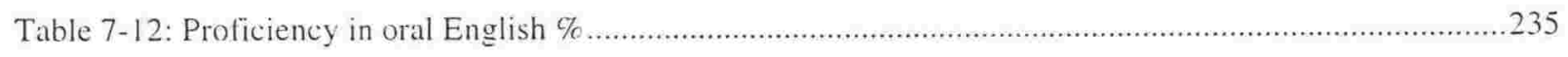

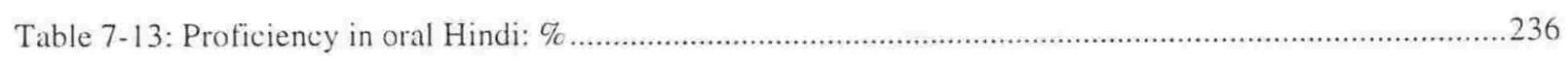

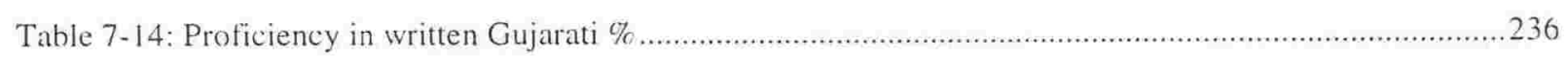

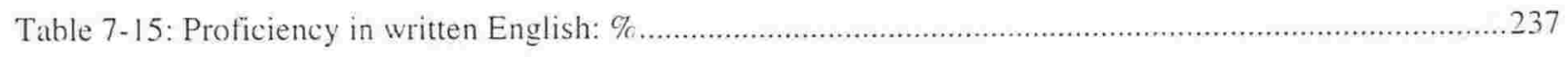

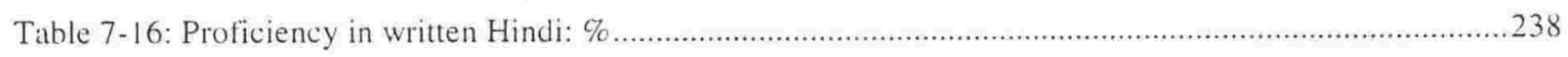

Table 7-17: Proficiency in oral Gujarati: \%: Men as a \% of all male respondents and women as a $\%$ of all female

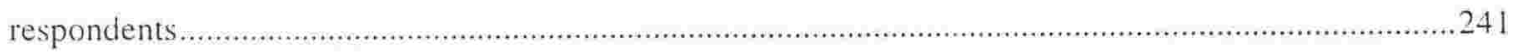

Table 7-18: Proficiency in oral English \%: Men and women as \% of each gender .....................................24

Table 7-19: Reply to question 31: should Gujarati be taught in state schools ..............................................24

Table 7-20: Reply to question 32: should Hindi be taught in state schools ...............................................243

Table 7-21: Respondents who thought Gujarati people in New Zealand be part of an Indian/NZ community and at the same time should see themselves only as New Zealanders

Table 7-22: Areas in which New Zealand-born respondents would like to see translating and interpreting facilities made available

Table 7-23: Areas in which non-New Zealand-born respondents would like to see translating and interpreting

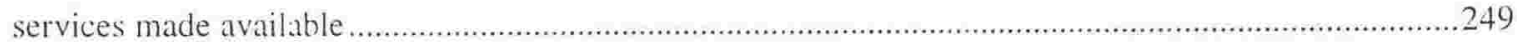

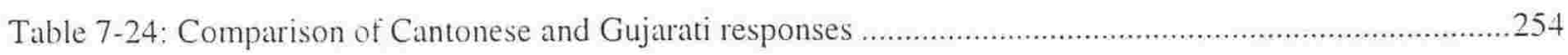

Table 7-25; Languages used by oldest and youngest Gujarati children.........................................................259

Table 7-26: Children's language proficiency as rated (mainly) by mother in \% ............................................261

Table 7-27: Language spoken in your home in New Zealand when you were a child ……...............................268

Table 7-28: How much was Gujarati spoken in your home when you were a child .........................................268 
Table 7-29: Did your parents speak Gujarati to each other when you were a child. .269

Table 7-30: Did your parents speak Gujarati to you when you were a child ....................................................2270

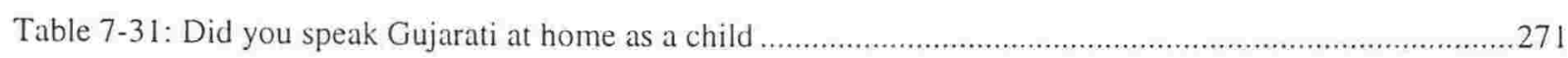

Table 7-32: Did your parents speak any other Indian language to you when you were a child .........................272

Table 7-33: Did you speak Gujarati outside the home as a child ..................................................................2. 274

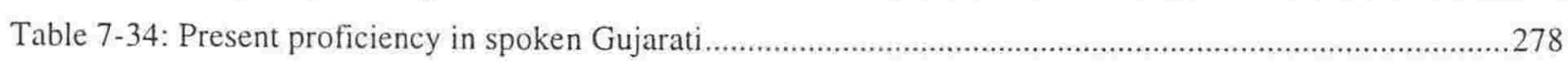

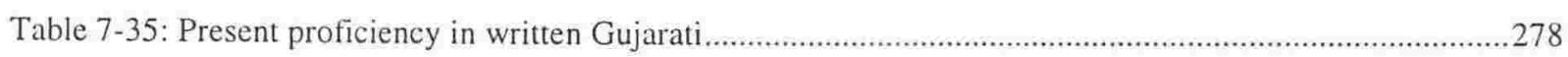

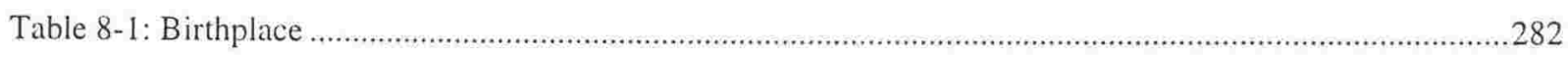

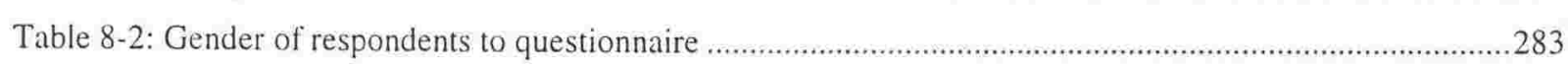

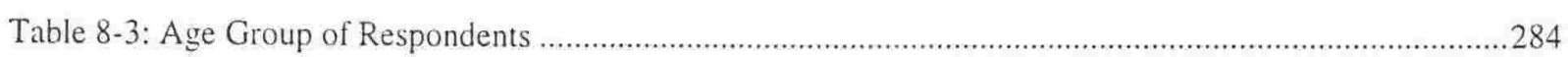

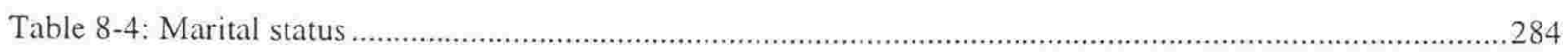

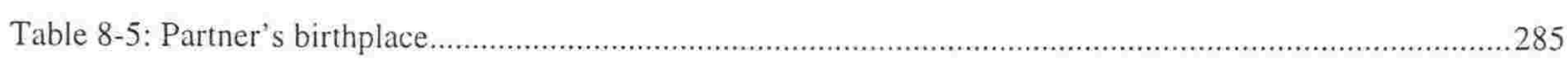

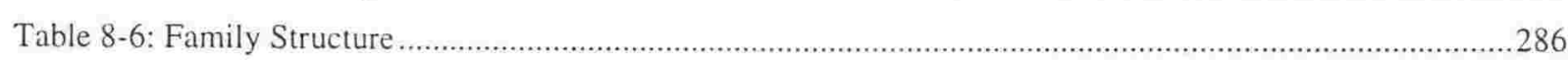

Table 8-7: Countries in which the respondents were educated .....................................................................286

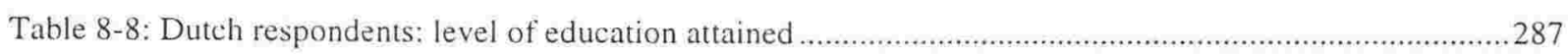

Table 8-9: Highest level of education attained by Dutch respondents to the survey compared with level of education attained by European respondents to 1991 census (Thomson 1993:78) ... 288

Table 8-10: Highest level of education attained by Dutch male and female respondents to the survey compared with level of education attained by male and female European respondents to 1991 census (Thomson 1993:78) 288

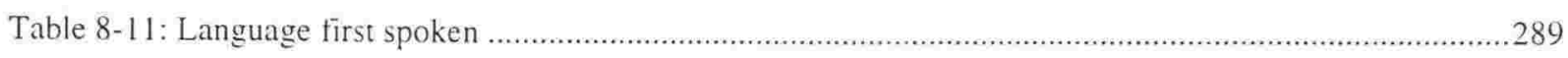

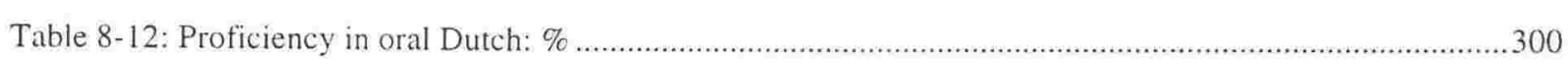

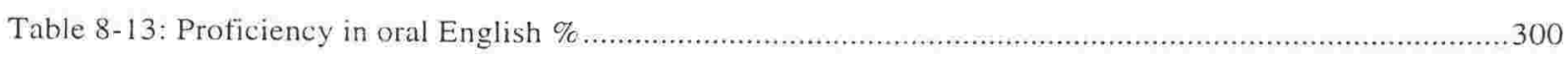

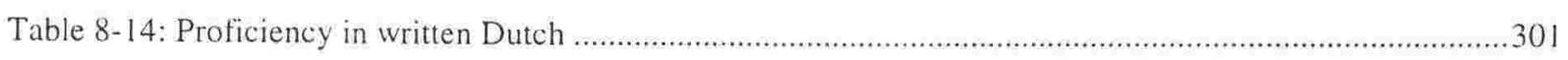

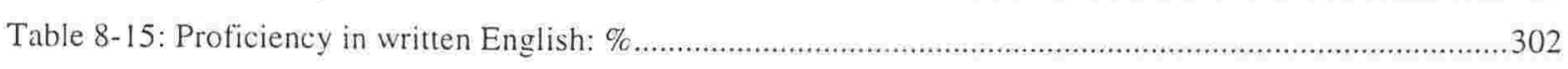

Table 8-16: Proficiency in oral English \%: Men and women as $\%$ of each gender .........................................303

Table 8-17: Proficiency in oral Dutch: \%: Men as a $\%$ of all male respondents and women as a $\%$ of all female respondents..

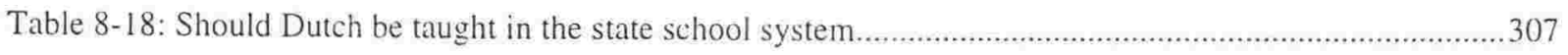

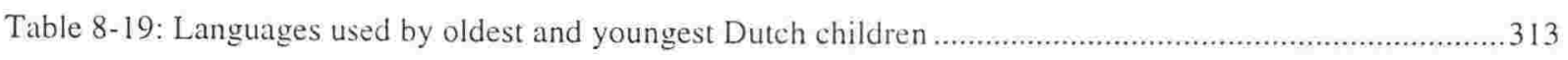

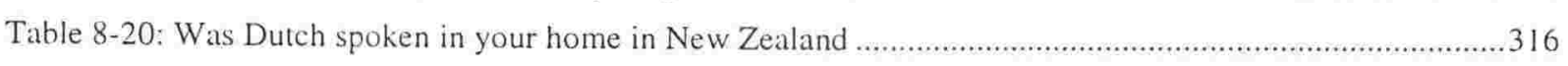

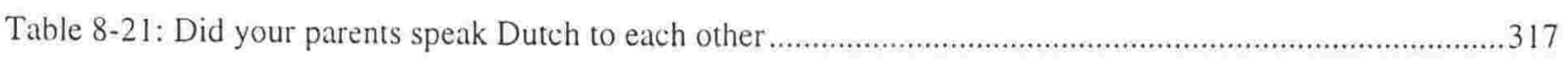

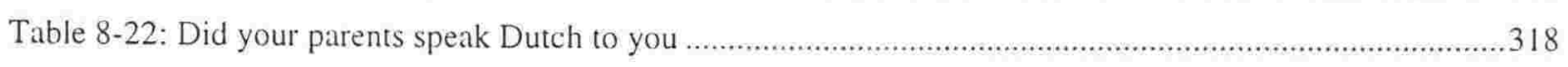

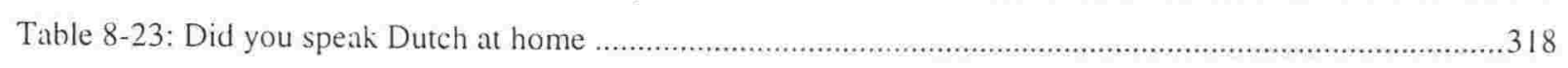

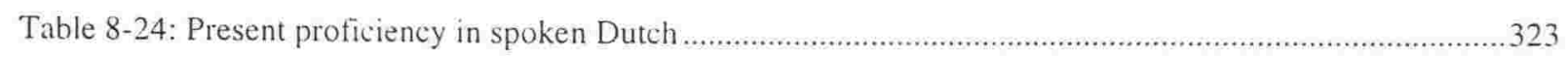

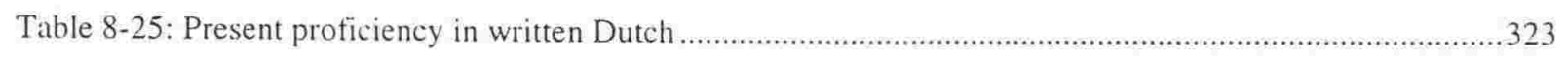

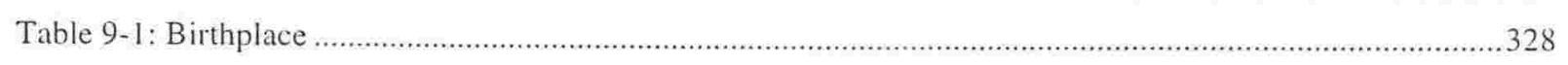

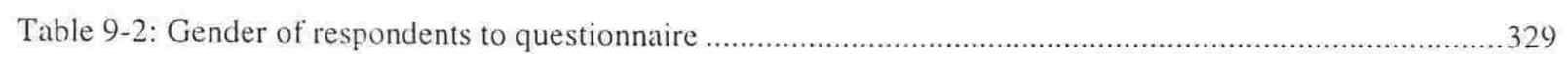

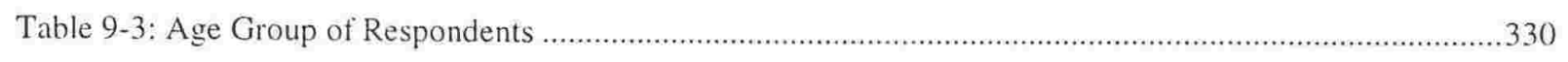

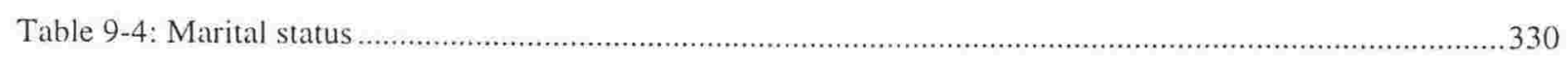


Table 9-5: Family Structure

Table 9-6: Countries in which the respondents were educated

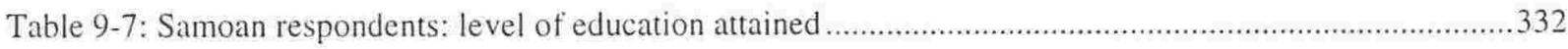

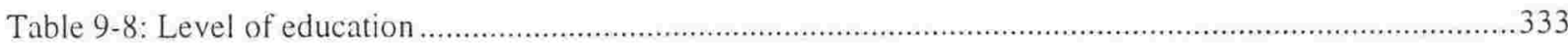

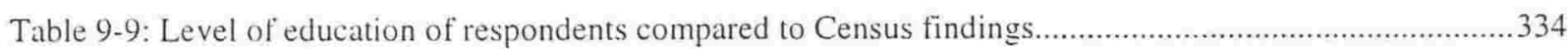

Table 9-10: Highest level of education attained by male and female respondents to the survey .......................335

Table 9-11: Highest level of education attained by male and female respondents to the survey compared to 1991

Census data.

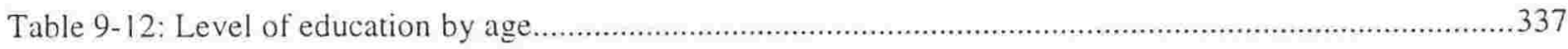

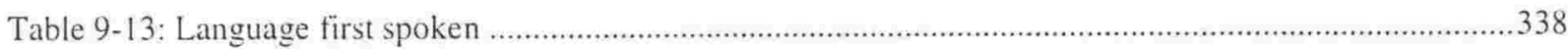

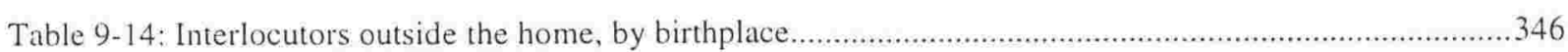

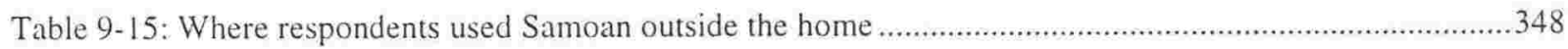

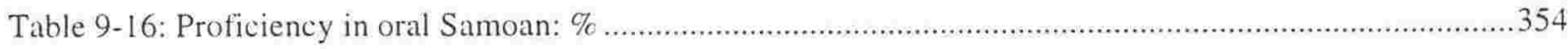

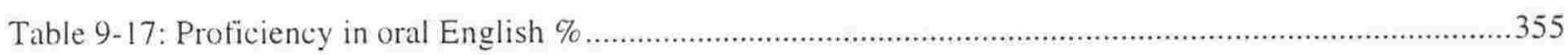

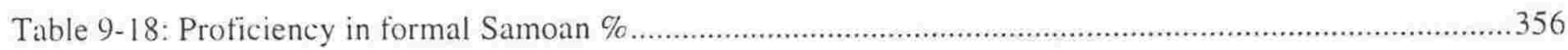

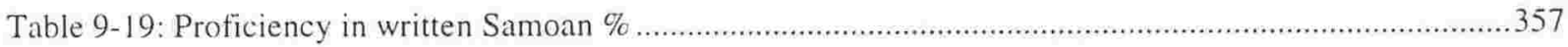

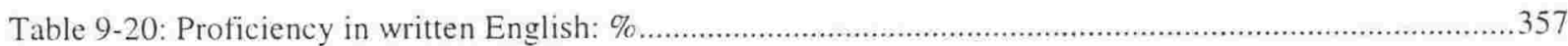

Table 9-21: Proficiency in oral Samoan: Men as a \% of all male respondents and women as a $\%$ of all female

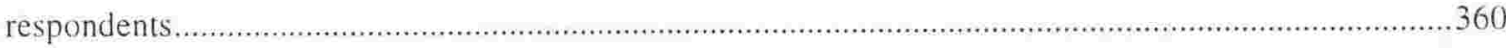

Table 9-22: Proficiency in oral English \%: Men and women as $\%$ of each gender .........................................361

Table 9-23: Proficiency in formal Samoan \%: Men and women as \% of each gender ......................................361

Table 9-24: Languages used by oldest and youngest Samoan children ...................................................363

Table 9-25: Proficiency of children's Samoan language skills as rated by parent. Shown in percentages ..........364

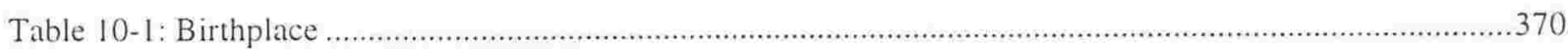

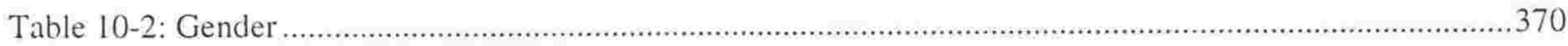

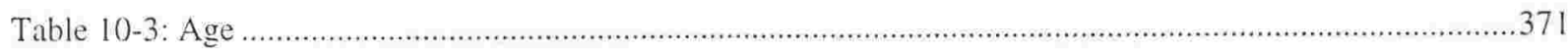

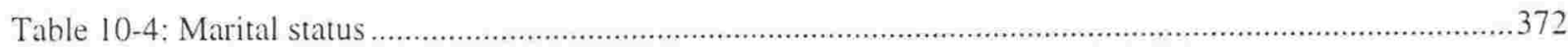

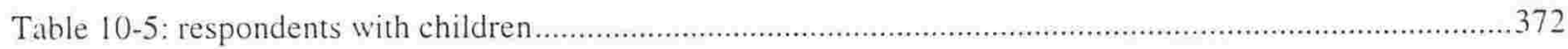

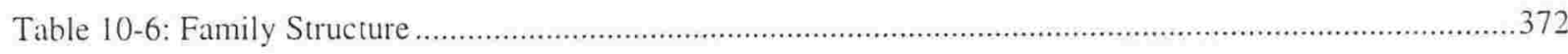

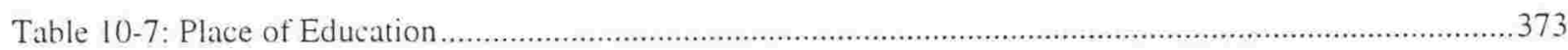

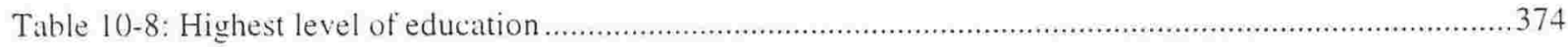

Table 10-9: Language spoke first compared to present day fluency. Percentages are of fluency rating/language spoken first

Table 10-10: Comparison of languages spoken by Indian mothers to pre-school children in Jamieson's research with language's first learnt by Gujarati respondents.....

Table 10-11: Comparison of languages spoken by Samoan mothers to pre-school children in Jamieson's research with languages first learnt by Samoan respondents.

Table 10-12: Correlation of bilingualism and multilingualism with Dutch language use and proficiency..........384

Table 10-13: Correlation of bilingualism and multilingualism with Gujarati language use and proficiency .......384

Table 10-14: Correlation of multilingual and bilingual parents with children's ability to speak Dutch.............386 
Table 10-15: Correlation of multilingual and bilingual parents with children's ability to speak Gujarati. 386

Table 10-16: Multingualism and bilingualism related to highest level of education: Dutch

Table 10-17: Multingualism and bilingualism related to highest level of education: Gujarati (percentage out of the respondents who answered the long version of the questionnaire).

Table 10-18: Children's ability to speak MT related to parent's highest level of education: Dutch respondents, non-NZ-born

Table 10-19: Children's ability to speak MT related to parent's highest level of education: Gujarati respondents, non-NZ-born

Table 10-20: Children's ability to speak MT related to parent's highest level of education: Gujarati respondents, NZ-born.

Table 10-21: Children's ability to speak MT related to parent's highest level of education: Samoan respondents, non-NZ-born

Table 10-22: Children's ability to speak MT related to parent's highest level of education: Samoan respondents,

NZ-born. 391

Table 10-23: Where respondents spoke their MT outside the home (all respondents)..... 404

Table 10-24: Where respondents spoke their MT outside the home (New Zealand-born respondents)..... 405

Table 10-25: Respondents ${ }^{*}$ MT interlocutors outside the home (non-New Zealand-born respondents) 407

Table 10-26: Respondents" MT interlocutors outside the home (New Zealand-born respondents). .408

Table 11-1: Language shift to English only in the home: 1st generation Dutch. 430

Table 11-2: Language shift to English only in the home: Adult 2nd generation Dutch reporting on use of MT in their own homes (i.e. not parent's home)

Table 11-3: Language use with pre-school children. Gujarati and Samoan respondents compared with 1980 survey

Table 1 1-4: Age range of children in families where Dutch is the main language

Table 11-5: All respondents: language use of oldest and youngest children in MT and English .....

Table 11-6: Gujarati and Samoan children: parents' rating of children's MT proficiency.....

Table 11-7: Gujarati children. Proficiency in MT related to range of interlocutors

Table 11-8: Gujarati children's MT proficiency levels correlated with MT use in the home

Table 11-9: Gujarati children's MT use correlated with language/s spoken by parents to child. Both parents interviewed.

Table 11-10: Gujarati children's MT use correlated with language/s spoken by parents to child. One parent interviewed.

Table 11-11: Was MT spoken in childhood home by fluency.

Table 11-12: Did your parents speak MT to each other by fluency..............

Table 11-13: Did your parents speak MT to you by fluency.

Table 11-14: Did you speak MT at home by fluency

Table 11-15: Gujarati interviewees use of MT at home in childhood and adulthood.... 489

Table 11-16: Dutch respondents use of MT at home: in childhood and adulthood..... 490

Table 11-17: Dutch respondents use of MT outside the home in childhood and adulthood 490

Table 12-1: Comparison with Hayden 1966: 195 
Table 12-2: respondents who thought Gujarati should be a living language in NZ

Table 12-3: respondents who thought community language schools for children were a good idea. .521

Table 12-4: respondents who thought Gujarati at mainstream schools was a good idea

Table 12-5: respondents who thought Gujarati people in NZ should see themselves as part of a Indian/NZ community.

Table 12-6: respondents who spoke mainly English with their spouse .521

Table 12-7: respondents who spoke mainly English with their children

Table 12-8: respondents who thought Dutch should be a living language in NZ

Table 12-9: respondents who thought community language schools for children were a good idea......

Table 12-10: respondents who thought Dutch at mainstream schools was a good idea

Table 12-11: respondents who thought Dutch people in NZ should see themselves as part of a Dutch/NZ community.

Table 12-12: respondents who spoke mainly English with their spouse

Table 12-13: respondents who spoke mainly English with their children

Table 13-1: Languages used at home

Table 13-2: Percentage of fluent speakers in each age group

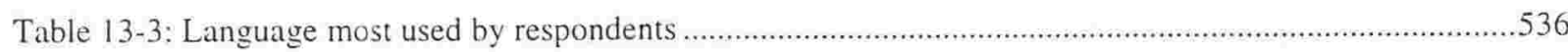

Table 13-4: Percentages of respondents using community language in a given domain ................................536

Table 13-5: Percentage of respondents speaking to interlocutors of a given age group .............................537

Table 13-6: Respondents ability to read and write community language 


\section{Table of Figures}

Figure 3-1: Indian arrivals in New Zealand: 1921-1970 ..........................................................................52

Figure 3-2: Dutch arrivals in New Zealand: from Tables By nationality intending permanent residence............57

Figure 3-3: Samoan arrivals: Men and women 1921-1970 ...................................................................65

Figure 3-4: New Zealand residents returning to NZ: Indian men and women 1921-1970 ..............................69

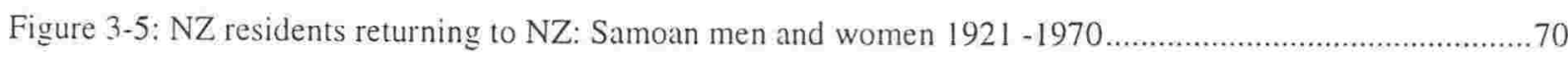

Figure 5-1: Schematic diagram of the integrated model based on Fishman's theories..................................... 158

Figure 7-1: Highest level of education attained by all respondents to the survey compared with level of education attained by all Indian respondents to 1991 Census (Thomson 1991:78) ............................................221

Figure 7-2: Most used language/s: by birthplace ..................................................................................22

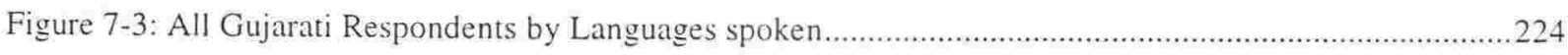

Figure 7-4: Languages spoken by respondents within the month preceding the questionnaire. Shown as

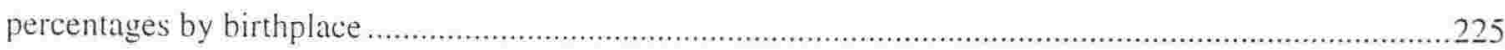

Figure 7-5 Language/s Spoken in the home by Respondents ...............................................................225

Figure 7-6: Languages that respondents spoke to their spouses. Percentages by birthplace..............................226

Figure 7-7: Languages that respondents spoke to their children. Percentages by birthplace .............................227

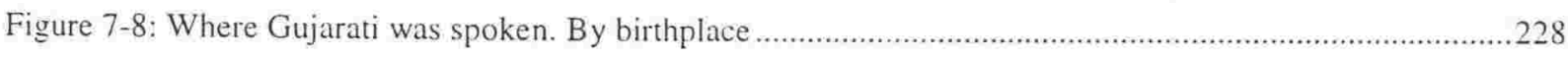

Figure 7-9: Interlocutors to whom respondents spoke Gujarati (in numbers not percentages)...........................2230

Figure 7-10: Gujarati language proficiency by age group of respondents: parallels Dutch divisions.................239

Figure 7-11: Respondent answers to 'Is it important to keep Gujarati as a living language in NZ. Percentages by

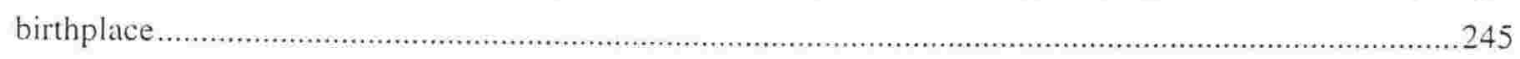

Figure 7-12: Children of Gujarati interviewees. Age and spoken Gujarati.....................................................22

Figure 7-13: Where respondents spoke Gujarati outside the childhood home in NZ …..................................22

Figure 7-14: Respondents' interlocutors outside the childhood home ............................................................276

Figure 8-1: Highest level of education attained by all Dutch respondents to the survey compared with level of education attained by 'European' respondents to 1991 census (Thomson 1993:78) ..................................28

Figure 8-2: Dutch respondents: most used languages by birthplace …...................................................290

Figure 8-3: All Dutch respondents by languages spoken..........................................................................291

Figure 8-4: Languages spoken in month preceding survey: By Birthplace ....................................................22

Figure 8-5: Languages spoken in the home by respondents ...................................................................293

Figure 8-6: Language/s spoken to spouse most of the time ............................................................................24

Figure 8-7: Language/s spoken to children most of the time .....................................................................295

Figure 8-8: Where Dutch respondents spoke Dutch outside the home ……................................................297

Figure 8-9: Dutch language proficiency by age group of respondents .........................................................303

Figure 8-10: Where respondents spoke Dutch outside the childhood home in New Zealand.............................321

Figure 8-11: Where respondents spoke Dutch outside the childhood home in New Zealand by birthplace.........321

Figure 8-12: Respondents" interlocutors outside the childhood home in NZ …..............................................323 
Figure 9-1: Highest level of education of all Samoan respondents to the survey compared to highest level of education attained by Samoan respondents to the 1991 Census (Census figures from Statistics 1995: 25)

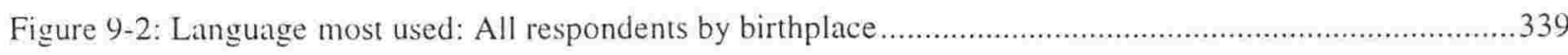

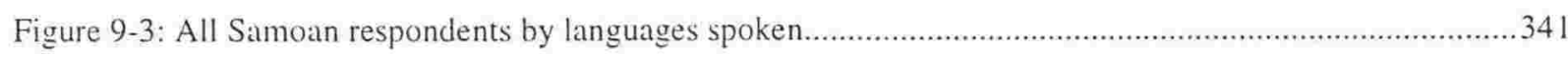

Figure 9-4: Language use in the month preceding the survey: by birthplace ..........................................342

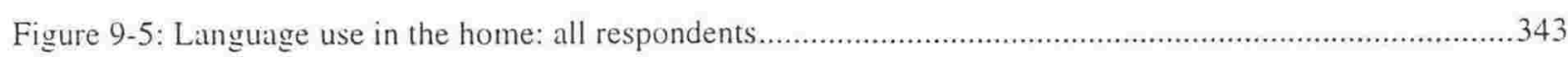

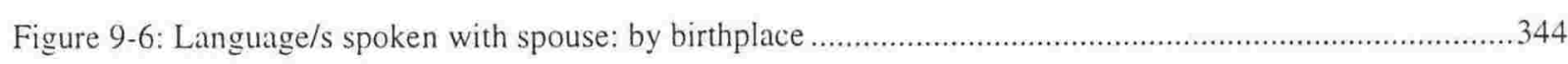

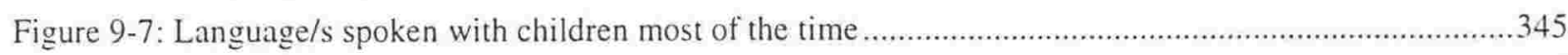

Figure 9-8: Samoan language proficiency by age group of respondents: version 2: parallels Dutch divisions ....358

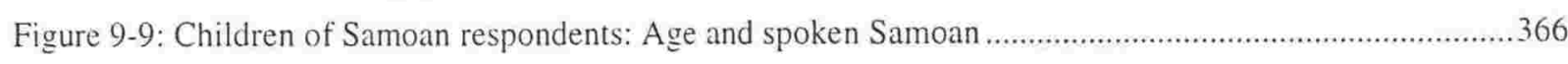

Figure 10-1: Language first spoken by respondents: All non-New Zealand-born respondents ........................375

Figure 10-2: Language first spoken by respondents: All New Zealand-born respondents ............................376

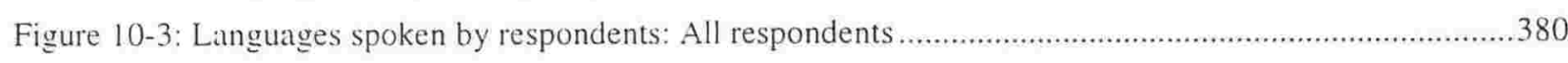

Figure 10-4: Languages spoken by respondents: All non-New Zealand-born respondents..............................38

Figure 10-5: Languages spoken by respondents: All non-New Zealand-born respondents who arrived in New

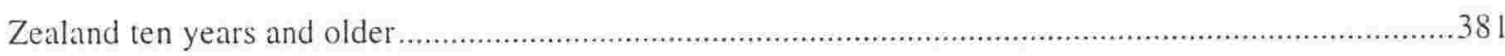

Figure 10-6: Languages spoken by respondents: All New Zealand-born respondents ..................................382

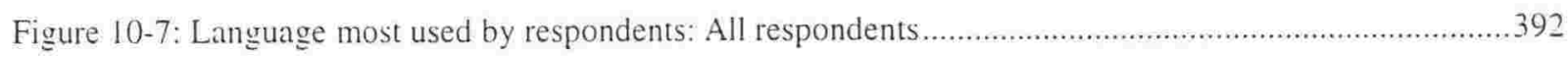

Figure 10-8: Language most used by respondents: All non-New Zealand-born respondents............................393

Figure 10-9: Language most used by respondents: All non-New Zealand-born respondents who arrived in New

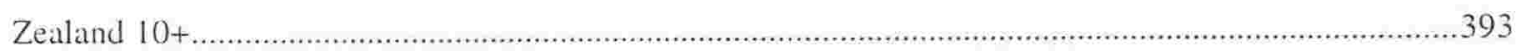

Figure 10-10: Language most used by respondents: All New Zealand-born respondents ...............................395

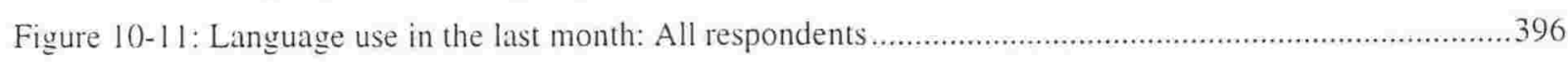

Figure 10-12: Language use in the last month: All non-NZ-born respondents............................................397

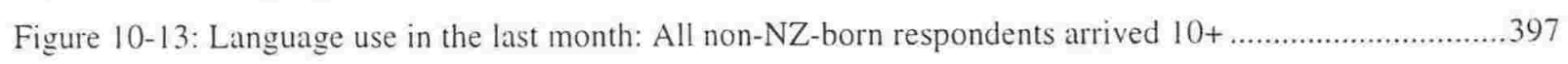

Figure 10-14: Language use in the last month: All New Zealand-born respondents .......................................398

Figure 10-15: MT Language spoken outside the home: All respondents ....................................................401

Figure 10-16: MT used outside home: All non-New Zealand-born respondents .........................................401

Figure 10-17: MT spoken outside home: All non-New Zealand-born respondents arrived in New Zealand 10+ .401

Figure 10-18: MT spoken outside home: All New Zealand-born respondents .........................................402

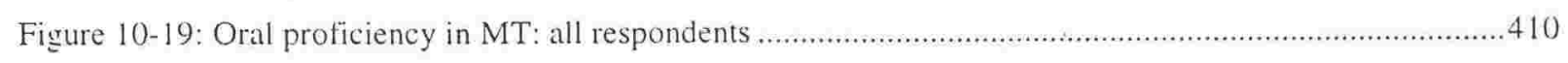

Figure 10-20: Oral proficiency in MT: all non-New Zealand-born respondents who came to New Zealand 10+

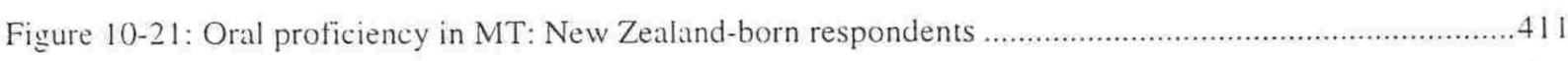

Figure 10-22; Oral proficiency in English: Non-New Zealand-born respondents ...................................... 412

Figure 10-23: Oral proficiency in English: all non-New Zealand-born respondents who arrived in New Zealand

$10+$ 
Figure 10-24: Oral proficiency in Hindi compared with Formal Samoan: all Gujarati and Samoan respondents

Figure 10-25: Oral proficiency in Hindi and Formal Samoan: New Zealand-born Gujarati and Samoan respondents.

Figure 10-26: Oral proficiency in Hindi and Formal Samoan: all non-NZ-born Gujarati and Samoan respondents

Figure 10-27: Oral proficiency in Hindi and Formal Samoan: all non-NZ-born Gujarati and Samoan respondents who arrived in New Zealand $10+$ .415

Figure 10-28: Literacy proficiency in MT: all respondents.

Figure 10-29: Literacy proficiency in MT: all non-New Zealand-born respondents who arrived in New Zealand

10 years old or older

Figure 10-30: Literacy proficiency in MT: all New Zealand-born respondents

Figure 10-31: Literacy proticiency in English: all respondents

Figure 10-32: Literacy proficiency in English: all non-New Zealand-born respondents who arrived in New

Zealand $10+$ years old

Figure 10-33: Literacy proficiency in English: all New Zealand-born respondents

Figure 11-1: Language use in the home: All respondents

Figure 11-2: Language use at home: All Non-new Zealand-born respondents.

Figure 11-3: Language use at home: All Non-new Zealand-born respondents, arrived in NZ 10+

Figure 11-4: Language use at home: All New Zealand-born respondents.

Figure 11-5: Language spoken with spouse: All respondents. 433

Figure 11-6: Language spoken with spouse: All Non-New Zealand-born respondents. 434

Figure 11-7 Language spoken with spouse: All Non-NZ-born respondents who arrived in NZ 10+ .434

Figure 11-8: Language spoken with spouse: All New Zealand-born respondents. 435

Figure 11-9: Language spoken with children: All respondents .436

Figure 11-10: Language spoken with children: All Non-New Zealand-born respondents .437

Figure 11-11: Language spoken with children: All non-New Zealand-born respondents who arrived 10+.......438

Figure 11-12: Language spoken with children: All NZ-born respondents. 439

Figure 11-13: Gujarati respondents arrived in NZ 10+: languages spoken with spouse and children. 441

Figure 11-14 Gujarati respondents born in NZ: languages spoken with spouse and children..... 441

Figure 11-15: Dutch respondents arrived in NZ 10+: languages spoken with spouse and children 442

Figure 11-16: Dutch respondents born in NZ: languages spoken with spouse and children 442

Figure 11-17: Samoan respondents arrived in NZ 10+: languages spoken with spouse and children 443

Figure 11-18: Samoan respondents born in NZ: languages spoken with spouse and children 443

Figure 11-19: Dutch respondents; limited MT use outside the home 461

Figure 11-20: Gujarati respondents; limited use of MT outside the home

Figure 11-21: Samoan respondents: limited use of MT outside the home ....................................................462

Figure 12-1: Are MT after hours schools a good idea: All respondents .......................................................494

Figure 12-2: MT after-hours schools a good idea?: All non-New Zealand-born respondents... .494 
Figure 12-3: MT after hours schools a good idea?: All non-New Zealand-born respondents arrived in New Zealand $10+$

Figure 12-4: MT after hours schools a good idea?: All New Zealand-born respondents 495

Figure 12-5: Should public funds go to community language maintenance schools: All respondents .503

Figure 12-6: Should public funds go to community language maintenance schools: All non-New Zealand-born respondents

Figure 12-7: Should public funds go to community language maintenance schools: All non-New Zealand-born respondents arrived in New Zealand $10+$

Figure 12-8: Should public funds go to community language maintenance schools: All New Zealand-born respondents

Figure 12-9: MT within state school system?: All respondents .508

Figure 12-10: MT within state school system?: All non-New Zealand-born respondents .508

Figure 12-11: MT within the state school system?: All non-New Zealand-born respondents arrived in New Zealand $10+$ .508

Figure 12-12: MT within the state school system?: All New Zealand-born respondents .511

Figure 12-13: Should the MT be a living language in New Zealand?: All respondents ..... .513

Figure 12-14: Should the MT be a living language in New Zealand?: All non-New Zealand-born respondents 514 Figure 12-15: Should the MT be a living language in New Zealand?: All non-New Zealand-born respondents arrived in New Zealand $10+$

Figure 12-16: Should the MT be a living language in New Zealand?: All New Zealand-born respondents .514 


\section{INTRODUCTION}

Over the last three decades the investigation of issues of language maintenance and shift has been dominated by Joshua A. Fishman. The publication of Language Loyalty in the United States, subtitled 'The Maintenance and Perpetuation of Non-English Mother Tongues by American Ethnic and Religious Groups', signalled the start of unprecedented investigation into this area. This was not entirely due to Fishman. He was in some respects the harbinger as well as, eventually the chronicler of, the coming 'ethnic revival'. But his research, insight and erudition have led to his pre-eminence in the field.

The table of contents for Language Loyalty in the United States, lays out some of the issues that have recurred in Fishman's work and that have left their mark on the work of almost all researchers in the field. The historical and social contexts of an inquiry into language maintenance, the ethnic group school and mother tongue maintenance, community involvement in mother tongue maintenance, the conservation of ethnic mother tongues as a neglected social resource, language maintenance in a supra-ethnic age. To these can be added the issue of language shift and language shift reversal which also came to be important parts of Fishman's work. My debt to Fishman will be obvious to any reader of this thesis.

Fishman places great emphasis on the importance of comparative work in language and maintenance shift research. This has always seemed to me to be, at the least, a useful check against assuming the group one is studying is in some way 'typical' of communities undergoing language maintenance and shift and, at the most, a research approach that can lead to worthwhile insight and understanding derived from the process of comparison. For this reason, I chose to study three different communities. The Gujarati community was chosen because they were the largest Asian community in New Zealand (after the Chinese, a community in which I had already done some research). The Dutch are the largest non-English speaking community of European descent in New Zealand and the Samoans are the largest Pacific Island community. The communities had some points in common. They were all comparatively large by the standards of minority immigrant communities in New Zealand and they all came from societies where English was important but not a first language. However, in almost all other respects, their pre-immigration backgrounds and their subsequent immigration and settlement histories in New Zealand were very different. This meant that there were some interesting points of comparison. 
In true Fishman style, the first chapter investigates the historical development of the concepts of ethnicity, the nation, nationalism, racism and the links between these concepts. In the second chapter, these concepts are sited in New Zealand and a brief history of the modern settlement is given in order to provide some background for an understanding of the immigration histories of the three immigrant communities under investigation in this thesis. Immigration policy in New Zealand and the effects of racism on that policy are also outlined. In the third chapter, the immigration histories of the three communities are presented in greater detail and it can be seen that each community has had a very different immigration history mediated through very different relationships with New Zealand.

The fourth chapter is an investigation of language policy and planning. The theoretical concepts of language policy and planning are discussed and the history of language policy in the United Kingdom, the United States of America and in Australia are all briefly discussed. All three countries have had considerable influence on the language policy debate in New Zealand. New Zealand's own attempts to develop a languages policy are discussed and then the history of language policy in education, broadcasting, and immigration is addressed. Although New Zealand has never had an explicit languages policy nonetheless, a certain amount of policy about language has been developed in those areas.

In the fifth chapter the focus narrows in to an investigation of language maintenance in the community. Fishman's theories of language maintenance and shift are investigated in more detail and his approach to reversing language shift is outlined. An integrated model of Fishman's various models of analysis of language maintenance and shift phenomena is presented and the Graded Intergenerational Dislocation Stages (GIDS) scale is introduced. The GIDS scale is a heuristic device for the analysis of language shift within a community and the data gathered during this research will be used to test the usefulness of the GIDS scale as a heuristic device.

Chapter six discusses the methodology that is underpinned by the theoretical schema outlined in the previous chapter. It is also shown that adjustments to that methodology were necessary to render it suitable in the three different communities.

Chapters seven, eight and nine present the data for each of the three communities in turn; Gujarati, Dutch and Samoan. The intention of these three chapters is to present the data with the minimum of analysis or comparison in order to avoid an unbearable amount of repetition. Some repetition is essential because very similar data are being discussed in each chapter but an 
attempt has been made to refrain from analysis and comparison until chapters ten, eleven, and twelve.

In Chapter ten the demographic, and much of the language use data from the previous three chapters are compared and analysed in the light of the integrated model that has been developed from Fishman's theories. In Chapter eleven this process of analysis is continued with particular emphasis on the family as the prime site of language maintenance and shift processes. Patterns of language use within the family are analysed and compared across the three groups and an attempt is made to isolate factors that are particularly associated with language maintenance or language shift.

In Chapter twelve, the focus is on attitudes to language, the behaviours that those attitudes engender and the consequences of attitudes and behaviours for maintenance or shift within the minority immigrant community. Attitudes to the language maintenance school are used as means of investigating both attitude and behaviour toward the mother tongue.

The final chapter sums up the answers to the research questions that were outlined in Chapter five and returns to the GIDS scale and assesses its use as a heuristic device. Based on the research that has been undertaken and that is the subject of this thesis, some recommendations for a national languages policy are made. 


\section{MAJOR ISSUES IN THE STUDY OF LANGUAGE MAINTENANCE AND SHIFT}

This thesis starts with an enquiry into issues of definition of the nation, the state, the nation state, ethnicity and the role of language as it has been perceived in defining those phenomena. It may seem strange to begin a discussion of immigrant language maintenance and shift with a discussion of the nature of the organisation of nation and state. This is, in fact, the logical starting point because the phenomenon of nineteenth and twentieth century immigration and the modern immigrant is closely tied to issues of nationality and statehood.

All modern, immigrant receiving nations have had to grapple with the concept of how immigrants become members of the body politic and social and what is the role of the immigrant in relation to the indigenous people. In the case of countries such as Canada, the USA, Australia and New Zealand where the immigrants have become a majority, the answers have been somewhat different from those propounded in Europe where the indigenous people remain a majority. The answers found to these questions in the new world however, have their genesis in the histories of the old.

RLS-efforts are often a reflection of late or reactive nationalism and modernisation, world-wide processes that are overwhelmingly characterized by dynamics that have their origins and their mainsprings in Europe (Fishman 1991: 287).

One of the themes of this thesis is that language maintenance and language shift do not take place in a social and historical vacuum. History is vitally important when looking at language maintenance and shift. It is important to look at the wider context of social and historical development and also to pursue small scale historical enquiry that shows us the minutiae that have affected one group. Thus in this thesis I have investigated both the growth of ideas that have consistently linked language with issues of group identity since the eighteenth century and I have also looked at the immigration records maintained by the New Zealand government that show us the pattern of immigrant arrivals from India, the Netherlands and Samoa.

One of the challenges of language maintenance and shift studies is to understand why language maintenance is so important to so many people and why, in the twentieth century, it is linked so strongly to issues of ethnicity and identity. Only history can provide us with the answer and this chapter is an attempt to demonstrate this fact. 


\subsection{Language, ethnicity, nation, nationalism and state}

In the first chapter of Language Loyalty in the United States, 'The Historical and Social Contexts of an Inquiry into Language Maintenance Efforts', Fishman raised an issue to which he was to return many times

'The history of organised language consciousness, language loyalty, and language maintenance on behalf of vernaculars in the Western world dates back some five centuries or more (Weisberger 1948), although its origins may be traced back much further (Jakobsen 1945)'... The history of organized language consciousness in the West is part of the history of the Renaissance, the Reformation, the growth of nationalism and the consolidation of nation-states. . (Fishman 1966:25-26).

Fishman traces our current disputes about language maintenance and shift back two thousand years to differences between what he calls the Judeo-Greek, eastern orthodox and early Islamic point of view and the Western church point of view (Fishman 1989:412, 569). The former upheld the validity of lower order bonds that could co-exist with higher order ones. The latter according to Fishman held that the falling away of lower order bonds was the natural and desirable concomitant of submitting to higher order bonds because "universality was God's will'. Thus, crudely, the former could envisage minority ethnic identities and languages co-existing with ties to a larger national order; the latter could only see such identities as temporary stages on the way to identifying completely with the majority order.

This universalising ideal reached its apotheosis in the French Revolution (see Fishman 1989: 660, Schiffman 1996: 77-94 for a brief summary of pre-revolutionary antecedents). The Abbé Gregoire (1750-1831) presented a report to the National Convention in 1794 on 'The need and the means to eradicate the patois and to universalise the use of the French language' (Grillo 1989: 23, Smith 1986:133-134, Schiffman 1996: 99). He drew, in part, on the work of Rivarol and his essay 'De l'universalite de la langue francaise' (on the universality of the French language).

Rivarol had argued that French was the supreme vehicle for the expressions of reason; 'Sure, sociale, raisonnable, ce n'est plus la langue francaise, c'est la langue humaine 1 ' (Rivarol 1930:271) ... universalising the language was ... a liberal, liberating measure. (Grillo 1989: 33. See also Smith 1986:133-134, Sciffman 1996: 98-103) for comment on the French Revolution and Abbe Gregoire).

\footnotetext{
${ }^{1}$ Certain, social, reasonable, it is not only the French language, it is the language of humanity. [my translation].
} 
The ideology of the French revolution proclaimed the concept of the state and its citizens. The diverse peoples of France who had hitherto owed allegiance to the French monarchy were to become not Breton, Rongeras or Provencal subjects of the king but French citizens of the French state. The spread of the French language was to play a role in this development. Williams discusses this theme in connection with the works of Rousseau, which he sees as influential upon the Jacobins "in their castigation and elimination of languages and cultures in their search for a single, united France (Williams 1992: 11)

The first Republic embodied the ideology of the centralised non-national state. At the same time however, the idea of the nation state was coming into being in Germany. Its ideology was expressed by Herder who published in Prussia from 1767 to 1802 (see Berlin 1976, Fishman 1989: 660 for antecedents), partly in direct contradiction to the ideology of the French Revolution.

At one important point the Herderian point of view and what we might call the Gregorian point of view converged. Herder saw language as one of the prime definitions of a people as a 'volk'. People who spoke the same language were a natural unity or polity and thus language/nation/state ought to be coterminous. This was one of the beginnings of the modern concept of the nation state. The Gregorian point of view also held that the citizens of the state should share a language, but rather than letting the language decide the nationality this point of view held that the nationality should decide the language. We see elements of both views, brought into our own era, in the address, in 1936, by Manuel L. Quezon, President of the Commonwealth of the Philippines to the First National Assembly of the Philippines.

The Constitution provides that the National Assembly take steps toward the development and adoption of a common national language based on one of the existing dialects.

This mandate of the Constitution recognizes the fact that there is no common native language spoken by the Filipino people and that it is very necessary and highly desirable that there be one.

It is needless to elucidate the proposition that a people constituting one nationality and one state should possess a language spoken and understood by all. It constitutes one of the strongest ties that bind the people and foster the unity of national ideals, aspirations and sentiments (Sibayan 1974:223).

Fishman sees Herder, in the eighteenth century, as redefining the terms of the debate and thus being the first modern commentator in this area. Herder changed the terms of the debate by emphasising the importance and worth of all languages 
A world made safe for little languages, through which people will feel deeply and think creatively, would be a better, more humane, more accepting and more innovative world for one and all (Fishman 1989:413).

Herder argued the link between language, ethnicity, nation and state, thus becoming a forerunner of von Humboldt and a guiding light of nineteenth century organic nationalism (Smith 1981: 45, Williams 1992: 14,31) but such nationalism did not have the political arena all to itself. There was always the opposing 'Western church' strain, what might be called the higher order point of view. As Fishman says, the Herderian philosophy of nation (in the sense of 'people' or 'volk') into state has, since the nineteenth century, existed in a state of tension with the state into nation view.

Because of the firm establishment of the state in Western Europe before the appearance of modern mass nationalism ... a very definite impression of the primacy of polity over nationality had come to be widely accepted by the time mass nationalism appeared as a predominantly Central Eastern and Southern European 'aberration' ... it was obvious that 'it is the state that has come first and created nationality and not vice versa' ... Western nationalism ... seemed to Western observers to be respectful of and based upon individual liberties, a loyal opposition, the balance of power etc ... the majority of Western intellectuals around the middle of the nineteenth century clearly recognised the difference between their presumably open and rational nationalism and the closed, tribal, vindictive, disruptive, and altogether wicked nationalisms then brewing among the Central, Southern, and Eastern Europeans upon which they heaped scorn and invective (Fishman 1989:130-131).

Some of the major nineteenth centuries thinkers who were opposed to this 'irrational' nationalism of the people without histories were Acton, J.S. Mill and Karl Marx himself (Smith 1981: 26) although, according to Smith part of the 'marxist legacy' was to accept and further promulgate the link between nation and language (Smith 1981: 27). There was in fact, in Western European eyes, a hierarchy of claims to nationhood. First there were the peoples with histories; essentially the old, well established single state monarchies, England, France, Spain, Portugal, Holland and Scandinavia. These were followed by the historic peoples who had valid historical claims to statehood - Italians, Germans, Poles, Hungarians and Greeks. The claims of the Eastern and Southern Slavic nations were seen as quite illegitimate and to many somewhat comic (Fishman 1989:132). Williams further makes an interesting comparison between the stereotype of 'stateless' languages and the stereotype of 'women's' language. Both stereotypes portray the languages and their speakers to be emotional, traditional, artistic etc as compared to the male and state languages which are rational, modern, scientific etc. (Williams 1992: 89). And, of course these characterisations became in their turn part of the rationale for denying power and control. The modern state of New 
Zealand was brought into being during the nineteenth century and this creation was influenced by nineteenth century ideas about nationalism and the state (see below).

The higher order point of view has also influenced Western attitudes towards ethnicity itself. In much Western thought today ethnicity is related to the despised 'organic nationalism' of the nineteenth century. It is seen as a primitive and divisive force that leads to 'balkanisation' a term that has recently been given new and horrific force. Much recent popular comment has been along the lines of Michael Ignatieff's definition of nationalism as the 'magnification of minor difference into epic hatred' (Naughton 1993:28). Fishman has patiently traced the negative connotations of the word 'ethnic' in English usage, and his article (with D.E. Fishman and R. Mayerfeld) on "Am and Goy as Designations for Ethnicity in Selected Books of the Old Testament' is well worth reading on the subject. Briefly, Fishman argues that the connotations of 'ethnic' have traditionally been negative

The predominant recurring and striking association (never an exclusive one) of goy with non-Jews leads not only to the translation of goy as ethnos in the Septuagint but also to a lingering association of ethnicity with heathendom and pagandom ... vestiges of heathen, pagan, uncouth and other pejorative semantic connotations for ethnicity have lasted to this very day, at least in popular English (Fishman 1985:36-37).

However, he goes on to argue in the same essay, there has always been a positive highsolidarity value of ethnicity. "It still retains much of its original overtones of familial togetherness, brotherly communality, emotional intimacy and relatedness' (Fishman 1985:37). And in 'The Rise and Fall of the 'Ethnic Revival' in the USA' Fishman takes the claim for a positive view of ethnicity even further

it is now not only possible to 'be American' in a variety of different ethnic ways, but sidestream ethnicity per se has also become much more modern and American. The spirit of the times is different and the vast majority of Americans reveal sidestream ethnicity-associated ways of doing, feeling and knowing within their total repertoire of social behaviors (Fishman 1989:669).

These remarks seem relevant to New Zealand as well. We too have been suspicious of ethnicity as a marker of backwardness, while appreciative of its force in binding together small scale social units. And we too are beginning, tentatively to envisage a society, often described as bi-cultural or multicultural, in which people will be able to express both their ethnicity and their New Zealandness. What is the difference between ethnicity and New Zealandness? To address this question I want to look at the difference between ethnicity, nation, nationalism and state. 


\subsection{Nation and nationality}

Nationality is defined by Fishman as

sociocultural units that have developed beyond primarily local self-concepts, concerns and integrative bonds. The term stands in contrastive juxtaposition to others such that it presupposes at least a level of sociocultural integration more elementary (i.e. simpler, smaller, more particularistic, more localistic) than the one it designates, namely ethnic group, if not also a level of sociocultural integration that is more advanced (i.e. larger, more inclusive, more complex, although still characterized to some extent to ethnicity). Although the term 'nationality' can be traced back over a century in its present use ... it first came to be 'widely applied during the first quarter of this century in connection with the well-known political problem of reconciling the sovereignty of states with the autonomy of ethnic groups (Fishman 1989:106-7).

Nation (and thus nationality) derives, ultimately from the Latin nasci 'to be born' and that 'by birth' sense has coloured its meaning to the present day. In European thought, as expressed in English, a nation was a distinct people characterised, according to the OED, by 'common descent, language or history'. Such a nation did not necessarily have to be organised into a political territorial unit but in European history such has often been the case (Smith 1986:138144). Long before there was a German state however, there was a German nation. In modern English usage the distinction between nation and state has become so blurred as to be nonfunctional in ordinary usage. Historically there is not much distinction between 'nation' and 'nationality'. Both place the stress on the people rather than the territory although both have often been used when claiming the right of a people to a territory.

\subsection{State}

State derives from Latin status and there is no sense whatever of shared origins implicit in the word. There have been many attempts to define the nature of the state

a body of persons recognised by each other as having rights, and possessing certain institutions for the maintenance of those rights (T.H. Green: Principles of Political Obligations: 443)

The state is the self-certain absolute mind which recognises no authority but its own, which acknowledges no abstract rules of good and bad, shameful and mean, cunning and deceit (Hegel: Die Absolute Regierung in System der Sittlichkeit: 32)

that society which is habitually recognised as a unit lawfully exercising force (Bosanquet quoted in Laski 1936:67-8)

The state is the Divine Idea as it exists on earth (Hegel: Philosophy of History: 41) 
All the above quotations are taken from the first chapter of Laski's The State in Theory and Practice entitled 'The Philosophic Conception of the State'. Laski himself defines the state as a territorial society possessing supreme coercive power (Laski 1936:21). These two elements seem to be the essentials in the definition of a state. There is a defined territory and within that territory there is supreme coercive power. This definition is very similar to Parson's definition of a 'societal community' or nation

The societal community presumes a relatively definable population of membership, which at this level we ordinarily call citizens for the modern case, and presumes as well that the collective organisation of reference is politically organised on a territorial basis, that is, it maintains normative order and certain political decision-making processes covering the human events which occur within a defined territorial area. Finally as a third primary criterion, at some level it is characterised by a common cultural tradition (Parsons 1975: 59).

Apart from the third criterion which, strictly speaking, has nothing to do with the definition of state I am proposing (although states often do consist of people who share a common cultural tradition), Parson's definition of 'societal community' is very close to the definition of state used here. This definition leaves room for ambiguity - all definitions of the state must leave such room. But wherever a situation that one might call a state exists and cannot readily be reconciled with these two prerequisites to statehood, then it can be seen that there is something anomalous in the situation. It may be seen from this definition that state is not dependent upon nation or nationality. In fact nation, as defined by language, and state can still be seen as being in opposition to each other as the following quotation, taken from an article concerned with the rise in nationalism following the break-up of the former Soviet Union, shows.

Just before he went into exile twenty years ago, Joseph Brodsky took up a long tradition and sent a letter to the tsar. "Dear Leonid Illich," he wrote to Brezhnev, "A language is a much more ancient and inevitable thing than a state. I belong to the Russian language. As to the state, I believe the measure of a writer's patriotism is not oaths from a high platform, but how he writes in the language of the people among whom he lives ... Although I am losing my Soviet citizenship, I do not cease to be a Russian poet. I believe that I will return. Poets always return in flesh or on paper" (Remnick 1992:44).

Here we see language and national/ethnic identity supporting each other and, together, standing in opposition to the state. 


\subsection{Nation state}

Nation state may conveniently be reserved for those cases where there has been an attempt to make the nationality coterminous with the state or where such a situation already exists. Fishman's definition of nation, is one that I would rather define as nation-state

any independent political-territorial unit which is largely or increasingly under the control of a particular nationality (Fishman 1989:108).

This definition of nation-state is also used by Smith who defines 'genuine nation-states' as monoethnic, and cites Greece, Poland and Portugal as examples (Smith 1986:150).

\subsection{Ethnicity}

Ethnicity is a term for which there appears to be no generally agreed meaning. In this section I discuss some approaches to definitions of ethnicity.

As mentioned above, 'ethnic' came into English via Greek as a translation of the Hebrew 'goy' and it retained the meaning of non-Jew while gaining also the meaning non-Christian therefore pagan or heathen. This initial meaning appears to have crossed in the nineteenth century with the meanings of a group of words, the first attested uses of which range from 1834 - 1889, where the Greek ethnos was used purely in the sense of 'nation' as the base of several words such as 'ethnography' (1834) and 'ethnology' (1842) which were intended to denote scientific branches of knowledge. In these words, all possible pejorative over or undertones of the root ethnos were to be ignored (Shorter O.E.D. 1933, revised ed. 1956). 'Ethnicity' does not appear in the OED until the 1972 supplement and the first recorded usage is 1953 (Moynihan \& Glazer 1975: introduction). De Lepervanche writing in 1980 asks

But why the new term 'ethnicity' and why is ethnic diversity celebrated today when the past was very different? (De Lepervanche 1980: 25).

The 'ethnic revival' which Fishman perceives and dates from the mid 1969s to mid 1970s (Fishman 1985: xii) led to many scholarly (and some not so scholarly) attempts to define 'ethnic'. Indeed the revival itself seems to have given the word new and common currency.

Glazer and Moynihan's Ethnicity: Theory and Experience (1975) was an early attempt, in the United States, to come to grips with concepts of ethnicity in the light of what had not yet come to be called the ethnic revival but what Glazer and Moynihan called "something new" 
(Glazer and Moynihan 1975:2). Glazer and Moynihan argue that the appearance of a new word

reflects a new reality and a new usage reflects a change in that reality. The new word is "ethnicity", and the new usage is the steady expansion of the term "ethnic group" from minority and marginal subgroups at the edges of society - groups expected to assimilate, to disappear, to continue as survivals exotic or troublesome - to major elements of society (Glazer and Moynihan 1975:5).

This new reality is not untroubling to Glazer and Moynihan's contributors and their doubts and their attempts to come to grips with the term and the concept make fascinating reading some twenty years on.

Talcott Parsons discusses ethnicity as a "primary focus of group identity" and adds that it is "an extraordinarily elusive concept and very difficult to define in any precise way" (Parsons 1975:53). He suggests different components; a biological base of relative homogeneity, religious uniformity (with the caveat that since the Reformation this has become problematical in the West), a common cultural tradition of which language is an important part (Parsons 1975:53-54). He adds that such a group has an identity rooted in 'a distinctive sense of its history', it is transgenerational and that such groups may be mutually exclusive (Parsons 1975:56-57).

Parsons also suggests that it may be possible, at least in the USA, to choose one's ethnic identity (Parsons 1975:64-65). While it is obviously not always possible to do so, it should be remembered that many ethnic boundaries and definitions of ethnicity are indeed flexible enough to allow an element of choice (see also Horowitz 1975:113-116).

Greeley and McCready do not attempt a general definition of the term 'ethnic group' but confine themselves to defining the American ethnic group

a large collectivity, based on a presumed common origin, which is, at least on occasion, part of the self-definition of a person, and which also acts as a bearer of cultural traits (Greeley and McCready 1975:210).

It is interesting to note that these authors definitely consider ethnicity to be a result of displacement

the cultural patterns of the old country existed before the ethnic group came into being. The ethnic group as self-conscious collectivity is the result of the American experience (Greeley and McCready 1975: fn p211). 
This is, or was, a quite common attitude to ethnicity and the ethnic group but it has become less common and it is certainly lacking in logic. If one looks at the authors' definition of ethnicity, it is not possible to see how it cannot accommodate Sicilians, for instance, both in Sicily and in the USA. The insistence that ethnicity or ethnic consciousness is only a result of marginalisation and is in some way quite separate from 'cultural patterns' seems to be unsatisfactory. This is discussed at greater length in connection with Fishman's comments on this issue below.

For many United States' thinkers, one of the major problems with the cluster of concepts that surround 'ethnicity' is that they seem to come into conflict with the founding principles of the United States of America as enshrined in the Constitution; the principles of the equality of individuals in the state and before the law. These doubts and concerns are thoroughly developed and explored in Glazer's Ethnic Dilemmas (1983).

Other writers have approached the topic in a variety of useful ways. Smith argues that an ethnic community must consist of

- a collective name

- a common myth of descent

- a shared history

- a distinctive shared culture

- an association with a specific territory

- a sense of solidarity (Smith 1986: 22-32)

Smith is concerned to differentiate between ethnic communities and nations and to address the question "what [is] the relationship between ethnic identities and nations " (Smith 1986: 1) and his definition functions very well to this end. Smith's definition uses six separate criteria, at least some of which are mentioned in almost all attempts to define an ethnic group. It is a thorough definition but has perhaps the drawback of being overspecified and oriented towards ethnic groups that have or had some claim to nationhood. The ethnicity of the immigrant, while not ignored (Smith 1986: 150-151), is not treated in great depth.

David Pearson, using Smith's framework, covers the issues involved in a New Zealand context in A Dream Deferred (Pearson 1990:15-19). He focusses on the sense of solidarity as an important component in ethnic identity and claims that a sense of solidarity is what distinguishes ethnic categories (such as Pacific Islander) from ethnic communities (such as Tongan). Thus it is, according to Pearson, a sense of solidarity that leads to a perception of ethnicity. 


\subsubsection{Fishman on language and ethnicity}

Here I want to summarise the arguments put forward by Fishman in 'Language and Ethnicity' (Fishman 1989:23-65). As Fishman says

There is no logical reason why ethnicity cannot be rigorously understood. However ... our problems in understanding ethnicity are not basically logical ones. (Fishman 1989: 23).

Instead Fishman suggests the problems are to do with the fact that ethnicity involves such a large number of interrelated factors and the importance of each is continually shifting. Fishman brings two useful concepts to bear in discussing the question: patrimony and paternity. ${ }^{2}$

\subsubsection{Paternity}

Fishman calls the concept of paternity the central experience of ethnicity. The concept encapsulates the idea, common to most formulations of ethnicity that you cannot, under most circumstances become a member of an ethnic group; you must be born into it.

Ethnicity is, in part, but at its core, experienced as an inherited constellation acquired from one's parents as they acquired it from theirs, and so on back further and further, ad infinitum (Fishman 1989: 25).

There are of course, what Fishman calls escape hatches and Horowitz calls 'fictions about, and exceptions to, the birth principle for most ethnic groups' (Horowitz 1975:114), but generally speaking ethnicity can only be inherited.

\subsubsection{Patrimony}

Patrimony is, as it were, the learnt part of ethnicity.

Ethnicity is not just a state of being (as paternity implies), but it is also a behavioral or implementational or enactment system (as patrimony implies) (Fishman 1989: 27-28).

Immigrants frequently try to preserve paternity by urging their sons and daughters not to 'marry out'. They try to preserve patrimony by bringing their children up in the true religion

\footnotetext{
${ }^{2}$ These terms undoubtedly focus too strongly on male inheritance. 'Patrimony' seems a particularly unfortunate choice given that it is so often the women who are seen as the active inculcators of this 'patrimony' in the new society.
} 
(Kerslake and Kerslake 1987: 145), teaching them the mother tongue (Hirsch 1975), and encouraging them to adhere to the social styles of the given ethnic group (see Patterson (1975: 329-339) for an interesting variant on this theme).

Fishman's division of ethnicity into paternity and patrimony without specifying exactly what the paternity and patrimony consist in seems to be a particularly useful, flexible approach. Sometimes matters of ethnicity will be salient, sometimes they will not, but ethnicity will always be there in a person's heritage.

\subsubsection{Heartland and boundary ethnicity}

The other question that frequently arises about ethnicity is to what extent is it a minority experience or an experience of displacement. Fishman considers this in depth at several points in his work and I have quoted at length from both an early and a later attempt to adumbrate the issues, as his comments are most enlightening. In Language Loyalty in the United States Fishman points out that

millions of immigrants to the United States remained basically unmoved by nationalistic sentiments or ideologies. Ethnicity of a traditional, particularistic, and non-ideological character ... was the general rule. The languages spoken were related to the countless acts of everyday life rather than to "causes" or ideologies. Most usually it was only after immigration that group maintenance became a conscious goal. In some instances, indeed, it was only in America that many immigrants became aware of their "groupness", i.e., of their common origin and their common past, as well as of their common current problems. Thus it was that only after immigration did language loyalty and language maintenance become aspects of consciousness for many (Fishman 1966:27),

and

For the immigrant fathers, ... ethnicity was literally an integral part of their way of life. ... It was this particular way of life that expressed an individual's ethnicity, rather than his ethnicity regulating his way of life

The point made here needs to be carefully considered if only because ethnic identification has commonly been defined as "a person's use of racial, national or religious terms to identify himself, and thereby, to relate himself to others ... Ethnic orientation, in turn, has been defined as "those features of a person's feelings and action towards others which are a function of the ethnic category by which he identifies himself" (Glazer 1958). To appreciate the difficulties posed by such definitions of ethnic identification and orientation, it suffices to recall that many peasant immigrants ... were hardly conscious of the existence of comprehensive categories by means of which they could relate themselves to others. Many a Ukrainian peasant, for example, continued until well into this century to inform census official who appeared in his village that he 
was of "indigenous" ethnic background.... he was utterly innocent of the very existence of the terms "Ukraine" or "Ukrainian" (Fishman 1966:345).

\section{In Language and Ethnicity Fishman returns to the topic}

It is often claimed that the boundary between an ethnicity collectivity [sic] 'and those that surround it is at least part of the meaning of ethnicity experience per se, that is to say, self-recognition contains within itself a recognition that there are other collectivities whose ethnicity is different ...There are others, however, who sense a stage and variety of ethnicity in which even own-group recognition ... is minimal and, therefore, a stage and variety in which consciousness of boundaries and of other ethnicity collectivities across these boundaries is also minimal. ... Certainly if the notion of ethnic identity requires heightened ethnic consciousness, then it may very well be that ethnic identity logically requires not only boundaries (contrast) but opposition across boundaries for such identity to be most fully articulated. Certainly, all would agree that ethnicity is most consciously and forcefully enacted when both contrast and opposition, boundaries and conflict, are consciously recognized.

Such consciousness is greatest and most constant among ethnicity collectivities that are small enough and weak enough to require constant alertness ... on behalf of and via their ethnicity, namely minority groups (Fishman 1989:33).

Fishman co-ordinates these two differing emphases on the nature of ethnicity by saying that there must be both heartland and boundaries to ethnicity. The Ukrainian peasant occupies the heartland; his granddaughter in Chicago sending her children to Ukrainian Saturday school is on the boundary. This seems to me to be a satisfyingly natural, yet theoretically elegant solution to the question of how conscious ethnicity has to be and solves the problems raised by definitions such as Greeley and McCready's (see above). Greeley and McCready's 'cultural patterns' should perhaps be defined as heartland or unmobilised ethnicity, whereas the 'ethnic group' they describe is a product of boundary or mobilised ethnicity. Such definitions, which allow ethnicity and the development of ethnic consciousness a place in each person's cultural and social repertoire, seem much more satisfactory than those that insist on ethnic identity as something that only some people possess. Many writers have pointed out that modern communications bring more and more cultures into contact with each other, and therefore, ethnic consciousness, if it relies upon a sense of boundary and contrast, is almost bound to increase under modern conditions (Pipes 1975:454).

\subsubsection{Element of choice in selecting ethnic identity}

It is often noted (Horowitz 1975:114, Parsons 1975:64-65, Patterson 1975:306) that individuals may, or do have an element of choice in their ethnic identity and/or that the boundaries that delimit a given ethnic group may change over time (Horowitz 1975). It is 
important to realise that the ethnic identity of a given individual, or the description of a given ethnic group does not have to, theoretically, and may not in practise be, immutable. Language may play an important part in changing definitions of ethnicity and it is noticeable that the ability to speak the mother tongue of a group may or may not be an important part of the definition of group membership (Demos 1988:60, Verivaki 1990: 106-110).

One of the strongest arguments for ethnicity as a conscious choice rather than an ascribed characteristic, is made by Oscar Patterson

[ethnicity is] that condition wherein certain members of a society, in a given social context, choose to emphasize as their most meaningful basis of primary, extrafamilial identity certain assumed cultural, national, or somatic traits (Patterson 1975: 308).

Ethnicity for Patterson is a chosen form of identity 'a conscious sense of belonging is critical' (Patterson 1975:309). Fishman's Ukrainian peasant - unconscious of his difference from others - belongs to something Patterson prefers to describe as a culture group. This seems to me to add an unnecessary layer of definition. Fishman's concept is more satisfying. Using his criteria, one is dealing with the same phenomenon in cultural, historical, linguistic and group terms whether or not there is a 'conscious sense of belonging'. With the dawn of consciousness - the phenomenon changes but not necessarily so radically that we are justified in calling it a different phenomenon.

\subsubsection{Links between language and ethnicity}

The link between language and ethnicity is often directly and unhesitatingly made. Huffines for example cites the loss of Pennsylvania German amongst members of the non-plain community (those who do not follow the traditional religious practises of this community) as evidencing a 'lack of identification with Pennsylvania German ethnicity' (Huffines: 1980:55). According to Ozolins

The literature on ethnicity and language succeeds in making problematic a relationship until recently held to be self-evident. (Ozolins 1993: 30)

and he goes on to suggest that language is used as a surrogate for ethnicity in political debate. It is true that much current writing on these issues seems to obscure rather than enlighten. It seems that some clarification can be gained by using Fishman's border and heartland metaphor. 
When ethnic consciousness is in the heartland, when it is unmobilised and rarely thought of, language choice tends to be in the same state. The link between ethnicity and language is organic, unspecified and, at a conscious level unimportant. Often indeed there is no possibility of language choice. When ethnicity moves to the border and language choice becomes not only possible but in many cases imperative, then the link between ethnicity and language tends to be strong in people's minds. As Fishman says, language has a symbolic role to play in the delimitation of the ethnic experience 'language is the recorder of paternity, the expresser of patrimony and the carrier of phenomenology' (Fishman 1989:32). Both ethnicity and language and the importance of language will vary in saliency and these saliencies will 'often co-vary [and] they may also vary independently (Fishman 1989:40).

It seems possible also that the link between ethnic identity and language could be a learnt link as well as a natural link. Herder posited a natural link

A nation's self-respect no doubt hinges on ... but it is wholly inconceivable without its own language (Herder letters XVIII 346-7)

The more a group is threatened [the more they will] preserve the distinctiveness of their own language (Herder V 141, quoted in Barnard 1969:29).

However Smith does not see the connection between language and ethnic group or nation as being universal and this would seem to diminish the strength of claims that the connection is a natural one. Smith sees the Herderian emphasis on language as the 'medium and vessel of ethnicity' as having a 'Eurocentric bias' (Smith 1986: 180)

and thus sees the emphasis of language as a criterion of a 'genuine nation' as peculiarly European. Smith's argument is however, to some extent undermined by the fact that most of the exceptions he notes to the coincidence of language and ethnic feeling are, in fact, European (Scots, Welsh and southern Jura nationalism) and one of the exceptions has proved invalid. Smith claims

In Yugoslavia, the old enmity between Orthodox Serbs and Catholic Croats is in practise, one of religious community, since language differences are very slight; for all practical purposes, Serbo-Croat represents a unified language which affords no basis for two nationalisms (Smith 1986: 27).

Since the break-up of Yugoslavia and the creation of Serbia and Croatia, we have been able to see just how wrong this statement- which seemed eminently reasonable in 1986 - is. Serbia and 
Croatia have indeed been able to use the very slight differences in their languages as part of a panoply of symbols that serve to mark their ethnic differences.

\subsection{Language maintenance and ethnicity}

Attitudes to language maintenance vary from community to community, place to place, time to time and individual to individual. Here, some of these variations are outlined.

When people today talk about the need for language maintenance one of the reasons that is almost always given is that the maintenance of a given language is necessary for a person's sense of identity, of belonging. It appears to be a largely unexamined assumption that identity and belonging are important sensations, and also that it is important to feel this sense of association with one's ancestral community. That, as Fishman would say, the individual's links with paternity and patrimony are retained.

I would like to state simply that the use and teaching of Tongan, or of any other language, rests on the foundation that is the language and heritage of that people. Language is a very personal thing which helps to programme the development of the human personality thereby moulding a cultural identity. I, for example, can identify with Tongans chiefly through the Tongan language but also through a sense of being a product of the Tongan soil (Tu'inukuafe 1987: 132).

Compare this to Barnard's summary of Herder's opinions about language and identity

A Volk, on this theory, then, is a natural division of the human race, endowed with its own language, which it must preserve as its most distinctive and sacred possession. Language is as much the embodiment of a Volk's 'soul' or character, as it is the expression of an individual's unique personality. By forsaking it, a Volk destroys its 'self' for language and the national consciousness to which it gives rise are inseparably joined (Barnard 1965: 58).

Two hundred and fifty or so years separate the two sentiments but the ideas are almost identical. Where does this assumption come from and why does it play an important role in decision making about language today.

The importance of identity, of belonging is asserted by our humanity, our common sense, our literature and traditions and more recently by the disciplines of psychology, anthropology and sociology. I am happy to take this for granted. What interests me is the assumption that the individual will be happiest and society healthiest if that sense of belonging and identity is manifested towards an ancestral community of some kind (see Isaacs (1975), Gordon (1975:92), Banks (1994: 67-79) for further discussion of this issue). There is an opposite side 
to this coin that will also be examined; that it is the state with which the individual should identify. The two ideologies can lead to widely differing interpretations of the nature of society, they are both influential in New Zealand (and elsewhere) today and they have common roots in eighteenth century Europe and the development of the nation state.

The antecedents of nationalism go back a long way, but in its modern form the ideology of nationalism began to take shape in the eighteenth century

Of particular importance in this connection is the eighteenth-century flowering of secular intellectuals who pioneered the 'historicist' revolution. It was the educators who supplied the ideals which not only revived' but also transformed ethnic ties and sentiments throughout Europe into a movement for national unity and statehood (Smith 1981: 134)

The ideology of nationalism was hammered out in the nineteenth and twentieth centuries. The battle is not yet over nonetheless, the modern idea of the nation-state has a strong influence on the international regulation of world affairs. Nationalist calls for nation states can still be heard around the world. This is essentially a modern phenomenon, the seeds sown in the nineteenth century are still springing to life (see Kandiah (1986:186) for a Sri Lankan example).

For Herder language, community, culture and nation were closely entwined. Language both enables people to think and shapes the way they think. People who speak the same language will have thought processes or patterns in common, they will have a culture in common. They will thus, because of language form a community of like-minded individuals and from this community the nation will emerge.

Conceivably, because Herder's political ideas were so heavily overlaid by 'culture', they proved particularly influential in the propagation of nationalist claims, at any rate in Europe, where it was music to the ears of nationalists to be told that existing states were mere phantoms while ethnic cultures were the true expression, if not the embodiment of political reality ... For [European nationalists] it was Herder who unequivocally gave utmost prominence to the oneness of state and nationality. And it was to him ... they turned for the moral justification of their political claims, even if they had little taste or understanding for his anti-centralist, anti-bureaucratic, anti-authoritarian beliefs. (Barnard 1988: 306)

Herder's philosophy of ethnic identity relied heavily on language as a marker of identity and this line of thinking did not begin with Herder. It has been characterised by Schiavoni as

A long and illustrious philosophical tradition, from Vico to Merlean-Ponty and beyond [which] has established the inseparability and the quasi-identity of language and culture (1991: 40) 
and Crowley (1996: 63) argues that Swift can be seen as a forerunner of Herder and quotes Harris, writing in 1751

'we shall be led to observe how Nations, like single men, have their peculiar Ideas; how these peculiar Ideas become THE GENIUS OF THEIR LANGUAGE' (Crowley 1996: 67 , emphasis in the original).

It was Herder however who particularly influenced the thinking of his contemporaries and those who came immediately after him and his writing has been very influential from the end of the eighteenth century to the present day. Herder, Fichte, Novalis and Schleiermacher (Kamenka 1976: 10-11) were the prophets of ethnic, linguistic nationalism. The same connections are still being made today. For instance Pandharipande points out that there are three options available to tribal societies in modern India: assimilation with, co-existence with, or isolation from mainstream Indian life. According to him, there is a direct link between degree of assimilation and degree of shift away from tribal languages. As he says, this

paradigm (of assimilation, co-existence, and isolation) makes a strong assumption; namely that there exists an invariable correlation between maintenance of culture and maintenance of language (Pandharipande 1992: 260).

In the nineteenth century this ideology was to be the driving force behind the unification and creation of Germany and Italy. After WWI it was to provide some of the moral basis for the division of Europe under the provisions of the Treaty of Versailles (Sharp 1991: 130-158). And, as many have pointed out, it was to give a cloak of patchy ideological legitimacy to Nazism; the concept "of the man who shares your language, your history and your national aspirations" (Kamenka 1976: 10-11).

The philosophy that unites language, thought, identity and community in a manner that led to Herder calling heimweh the 'noblest emotion of them all' was first put to political use to bolster the claims of communities that wished to become nation states. The age that saw the growth of the nation-state was also the age that saw one of the greatest migrations of all time; the movement of African, Asian and European peoples to the New World to what were to become new states (Glazer and Moynihan 1975:13). In some of the states of the New World the philosophy of linguistic nationalism was to be transmuted into linguistic ethnicism.

In Canada, the USA South and Central America, Australia and New Zealand the issues of language, identity and culture were to take forms very different from those they had taken in 
Europe. In New Zealand by the beginning of this century, the majority culture was English speaking and our national as well as, for many, our individual identity was also English speaking with a very heavy bias toward Britain.

\subsection{Immigrants, ethnicity and languages}

The twentieth century is the age of the immigrant and the immigrant had no ready place in the original European formulas of linguistic/ethnic nationalism. Mikes, for example, compares the European with the USA case and suggests that because immigrants acquired their minority status through an act of 'free will' they understandably express weaker attitudes to language maintenance than autocthonous minorities. Ohannessian makes exactly the same point about immigrants to the USA in comparison with American Indians (Mikes 1986:154, Ohannessian 1972: 15). When things turn sour it is all too easy to turn on the immigrant minorities and seek to expel them from the national polity. This is the unpleasant side of linguistic/ethnic nationalism; the side that at its mildest says 'Turks, Greeks, Samoans etc are O.K. back where they belong but why do they have to come here' the 'I'm not a racist but ...' argument.

Intermixture with other nationalities, therefore, is to be avoided. The situation most congenial to the preservation of the natural order of things is analogous to the growth of a plant rooted in the soil. If all nationalities remained where they were originally 'planted', one could look upon the world as a garden of diverse national plants, each flowering according to its own nature and development (Barnard 1965: 58).

The immigrant majorities of the New World are however in a logically weaker position than the indigenous majorities of Europe when it comes to this kind of argument. We cannot simply say that everyone should stay at home and then all problems would be solved for where then should we be? America had a particular need for immigrants and thus a particular need for a philosophy of immigration. That philosophy used to be summed up by the cliché of the 'melting pot'.

this line of reasoning assumed that the ethnic communities and their traditions would gradually disappear into the melting pot ... Such arguments were, of course, closely akin to the assumptions of 'modernisation' theory with its unilinear scheme of development towards a fixed target of the secular, industrial nation-state and the modern, participant society (Smith 1981: 152-3).

It was a policy diametrically opposed to that of ethnic nationalism. The pattern was state into nation, polity in people. After WWII the philosophy of the melting pot gradually changed into that of the 'salad bowl'. This metaphor summed up a world view that envisaged a process of 
state into nation but in this nation the ethnic origins of the citizens would not melt away. The ideology summed up in the cliché of the salad bowl has its genesis in ethnic nationalism although, in America and New Zealand the claims made by minority immigrant groups are, by and large, not nationalist ones (Fishman 1989: 667). These changes in attitude to immigrants and culture are directly linked to changes in attitude to non-host country languages by Hofman and Cais

The national ideal of a cultural 'melting pot' in countries with a constant influx of immigrants went hand in hand with stressing a shift toward the common language of the new country. Accordingly, a change from the 'melting pot' ideal to that of 'cultural diversity' would imply a shift toward favouring of MTM [mother tongue maintenance] among members of minority groups (Hofman and Cais 1984:147).

The only major difference between ethnic nationalism and ethnicism is that the first is linked to claims of independent statehood and thus territory, the second is not. Apart from that their claims tend to be similar. Paulston defines ethnic nationalism as being crucially and necessarily linked to territory. Without territorial claims immigrants claims are closer to what Paulston calls 'ethnic movement' and what I am calling 'ethnicism' (Paulston 1987:38,41).

In New Zealand today there are examples of both ethnic nationalism and ethnicism. Claims of ethnic nationalism are asserted by those Maori who want to see Maori Sovereignty in New Zealand. Claims of ethnicism are asserted by those who do not wish to change the basic political structure of New Zealand, but who wish to see policies formulated for particular ethnic groups.

Both claims rest, at least in part, on the Herderian concept that language and culture create a discrete, identifiable community that has differing needs from other communities. Language has become the standard under which such communities advance. The concept has of course undergone something of a sea change for immigrant groups. Maori claims are fair and square in the Herderian tradition, but Samoan or Chinese claims within New Zealand have to broaden their ideological base. The concept of the right or need of immigrants to preserve their languages in a new country comes from several sources. The three most important are the Herderian ideologies already discussed, the modern democratic ideology of equality and fairness and the concept (linked to that of equality) of taking special care for the weaker members of society. This attitude is splendidly summed up by the Victorian writer and thinker Lord Acton 
[Civilization] depends on preserving, at infinite cost, which is infinite loss, the crippled child and the victim of accident, the idiot and the madman, the pauper and the culprit, the old and the infirm, curable and incurable. This growing dominion of disinterested motive, this liberality towards the weak in social life, corresponds to that respect for the minority, in political life, which is the essence of freedom (cited in Kohn 1962: 45).

This is a classic statement of the liberal argument that says society is only as strong as its weakest member, is only as just as the justice accorded to its weakest member and is only as equal as the equality enjoyed by its weakest member.

These three ideas then unite to form the charter for the immigrants' right to maintain ancestral language and culture in the new country. We can hear them given expression by Senator Paul Yuzyk

The third element ethnic groups now numbering approximately five million persons, are co-builders of the West and other parts of Canada, along with the British and French Canadians and are just as permanent a part of the Canadian scene ... As co-founders they should be co-partners who would be guaranteed the right to perpetuate their mother tongues and cultures (Porter 1975: 283).

or by Reynoldo Macias

It is not a question of loyalty or of rights solely, but of justice and quality of life (Macias quoted in Marshall 1986:55).

There have always been strong arguments against the desirability of ethnic identification and also against allowing immigrants in a new country to identify with their 'old' culture and these arguments are strongly made by Porter

Ethnic differences may be linked to class differences leading to 'ethnic stratification' (Porter 1975:289)

Ethnicity is atavistic as a 'salient organising principle of social life' (293)

An emphasis on ethnicity threatens social mobility and opportunity (p294) because ethnic groups have limited resources and cannot at one and the same time adequately reinforce ethnic identity and 'prepare its members for achievement in the larger society of which it is a part' (p295)

If ethnicity is used as an organising principle of society it undercuts the principle of universalistic rights of the individual citizen and this is undesirable (p.298)

Ethnicity is, to some extent, based on endogamy and this may lead to new forms of discrimination based on culture rather than race (see also Glazer 1983 for arguments about group and particularistic claims versus the individual citizen and universalistic claims) 
Porter sums up his argument against acknowledging the claims of ethnicity by saying that 'the saliency of ethnic differences is a retreat from the liberal notions of the unity of mankind' (Porter (1975:303). See also Marshall (1986: 31-38) for arguments against maintenance of minority immigrant languages in the USA on grounds of divisiveness).

The ideology of equality has been very important in the twentieth century although it has taken many strange forms. In New Zealand, equality has been widely perceived as a mixture of equality of opportunity, combined with what might be termed basic equality of provision (see Beeby 1992, Renwick 1998: 67-89 for description and discussion of these ideas, particularly as they affected education in New Zealand from the 1930s onward). If access to ancestral language and culture is defined as a social good that improves the quality of life for the individual then an ideology of equality of opportunity and basic provision allows immigrant groups to make claims on the state for help in continuing, gaining or improving such access. Corson expresses this view when, in a discussion of social justice in language in education policy, he says that assimilative policies are unjust

since the minimal language rights of individuals are not guaranteed (Corson 1993:78).

Working against the concept of immigrant languages having any right or need to be maintained is that strand of immigration thinking that says 'we came here to forget all that' and the ideology of the non-ethnic state. Corson commenting on this ideology as it affected language in education from 1919 - 1960 says

Responding to robust narratives of racism and in order to remove the threat to social cohesion and national solidarity that widespread linguistic diversity was deemed to represent, efforts were made almost everywhere through schooling to replace minority languages with the dominant language or languages (Corson 1993:82).

The concept of community/language identity, the concept of identity based on shared ancestral roots did not initially lend itself to use by the immigrant. The immigrant had, after all, abandoned such claims by leaving home. Once the immigrant was established however as part of a migrant community in the new country then the migrant community could if it wished make strong claims for the importance of ancestral ties. In New Zealand these claims could be bolstered by reference to the fact that the majority community was also an immigrant community and by claims to equality and fairness that asserted that if Maori cultural maintenance was important then by the same token so was cultural maintenance of any other 
group. (Although most politically active claimants have been careful to grant primacy to Maori).

The idea that everyone needs access to the culture of their ancestors and that in a just society that will include immigrant members of the society and their descendants, has been a powerful idea fuelling the ethnic revival noted by Fishman et al (1985).

The link between Herder and the various ethnically based ideologies of today has already been noted. We can trace a line of descent from the thinking of Herder to the present day. Herder's philosophy had a profound effect on the Romantic movement, influential throughout Europe and has strongly influenced modern anthropology, including Boas, and the sociolinguistics of Sapir and Whorf (Grillo 1989:64). An example of how Herder's philosophy of the importance of language in defining group identity spread from one influential thinker to another can be traced in the following way. Herder believed in the importance of all languages. Fichte, who was deeply concerned with German nationalism was greatly influenced by Herder

The separation of Prussians from the rest of the Germans is purely artificial ... The separation of the Germans from the other European nations is based on nature. Through a common language and through German national characteristics which unite Germans, they are separated from others' (Fichte, Patriotic dialogues \{1806-7\} quoted in Grillo 1989:65).

Fichte's writing in turn, was influential in the intellectual development of Thomas Davies

"the inspirational figure of [Young Ireland] until his early death in 1845" (Hutchison 1987:

97), who urged

To lose our native tongue, and learn that of an alien, is the worst badge of conquest - it is the chain on the soul' (Thomas Davis, quoted in Grillo (1989:91)).

Crowley also notes the influence of Fichte on Davis showing how the following quotation from Davis, is an echo of Fichte

To impose another language on such a people is to send their history adrift among the accidents of translation - "tis to tear their identity from all places - "tis to substitute arbitrary signs for picturesque and suggestive names - "tis to cut off the entail of feelings and separate the people from their forefathers by a deep gulf (Davis 1914 quoted in Crowley 1996: 128) 
Note the claim that language and identity are inextricably linked and the assumption that identity must be linked to heritage of place, genealogy and language. Immigrants in the twentieth century were to abandon the claim to identity marked by place but they were to use the same rhetoric about language and genealogy.

Crowley points out that Irish nationalists saw their political struggle as very similar to that of other European national movements

Were the slave nations of the earth banded together, they would scatter their gaolers as the avalanche breaks the bulwarks on which its snows, if disunited, would have stormed in vain ... let not us only rejoice, but let all who, like us are provincials fighting for nationality - let not only Ireland, but Poland, Italy and Hungary, be glad at the progress which the foreign policy of Ireland is making .... We are battling for Ireland; if we conquer, 'twill be for mankind (The Nation 1842-5: I, 377. Quoted in Crowley 1996: 126).

and goes on to say that

what we find in the discourse of Irish cultural nationalism is many extremely close links between it and its European forebear [sic]. (Crowley 1996: 127)

Hutchison traces these links in his book The Dynamics of Cultural Nationalism: The Gaelic Revival and the Creation of the Irish National State

In Ireland, as elsewhere in western Europe this doctrine was propounded from the 1740 s by humanist intellectuals in touch with an emerging international culture of secular literati, among whom was developing a growing fascination with the diverse roots of world civilization. Contact with this culture has regularly had galvanizing effect on young Irish intellectuals. Indeed, all three cultural revivals [in Ireland] were inspired by a spirit of competition with or emulation of the achievements of the scholars of Britain, France and Germany in using Irish materials to show the Celts as one of the formative peoples of European culture (Hutchison 1987: 197).

Thus Herder's philosophy arrives in the twentieth century ready to the hand, not only of indigenous peoples but also of immigrant minorities (see also Jayasuriya 1989:43 for comments on the influence of this tradition in Australia). In the case of many of the immigrant minorities, it has been reassuringly safe from any overtones of political or territorial independence and this has no doubt helped this form of the ideology find acceptance. 


\subsection{Summary}

This chapter has examined the increasing importance of language as a marker of identity since the eighteenth century. In nineteenth century Europe a clear link between nationality and language was established, generally accepted by many, and elaborated to include the concept of language as a factor in personal and group identity. The mass immigration movements of the last 200 years and the colonial regimes of the European powers have spread this concept, in its European form, over the world. In the late twentieth century it has become both a truism and a motivating force for indigenous and immigrant people aligning language with issues of group identity, social and political equity and justice. 


\section{NEW ZEALAND: NATIONAL IDENTITY AND IMMIGRATION}

How were these issues of language, national identity, immigration and ethnic identity played out in New Zealand? This chapter outlines their place in the modern settlement of New Zealand $^{3}$ and examines how New Zealand was settled in the nineteenth and twentieth centuries, how concepts of nation and state developed here, how immigration policy was formulated and how racism helped shape that policy. There is also some comment on how the racist belief systems developed in the nineteenth century, and still influential today, affected Anglo-Celtic Pakeha views of Maori as opposed to non-North-European immigrants. Finally there is a brief discussion of Celtic ethnicity in New Zealand. The Celtic peoples of the United Kingdom had in the preceding centuries been subject to many of the same techniques of cultural and linguistic assimilation as were to be practised in New Zealand. It is interesting to consider the role that the Celtic section of the Anglo-Celtic majority of modern New Zealand had to play in creating a society with such a strong assimilationist imperative.

\subsection{Ethnicity and national identity in New Zealand}

Anglo-Celtic Pakeha New Zealanders would seem, in one way, to occupy the ethnic heartland described by Fishman and this colours their attitudes to issues of ethnicity. Such New Zealanders might be able to identify with the ethnic affiliation 'Pakeha' (although equally they might choose not to). But it would be difficult for them to say in what particulars their ethnic identity consisted. What is it that makes an Anglo-Celtic Pakeha New Zealander different from an Anglo-Celtic Australian, Canadian, American or indeed Briton? At the level of ethnicity it is, I suggest, very difficult to answer that question. Fishman suggests that "[i]n more modern life, ethnicity retreats into a corner of social experience under the impact of international influences' (Fishman 1989:6) (although see Pipes (1975) quoted above for a contrasting opinion as to the relationship between modernity and ethnic consciousness) and New Zealand is a modern entity of which this statement is particularly true. Ethnicity for most Pakeha New Zealanders is not phenomenologically perceived as such and as Fishman says '[a]bove all, ethnicity is phenomenological' (Fishman 1989:6). Therefore to New Zealanders of Anglo-Celtic origin our national identity is in some ways more special, 'more unique' than

\footnotetext{
${ }^{3}$ When I refer to New Zealand in this context, I am talking of the entity that came into being with the signing of the Treaty of Waitangi. In this sense there was no New Zealand prior to 1840 .
} 
our ethnic identity. We share our ethnic identity with a large part of a currently dominant world culture, but we share our history with no-one.

\subsection{The modern settlement of New Zealand}

New Zealand's modern settlement was undertaken by Great Britain - a modern state in which a number of separate ethnic groups had been subsumed throughout the course of history. At the time of the settlement of New Zealand the self- and other-perceived ethnic groups of Great Britain were the Scots, the Irish, the Welsh and the English. As is well known the English were dominant and had with some degree of success (far from complete) achieved a cultural and social as well as political hegemony over the other three groups.

In 1840 New Zealand was not in any way a modern state. The Maori were the dominant population and their political and social organisation was primarily familial and tribal. By 1851 New Zealand had the political instruments of self-government and by 1876, the political institutions of statehood. As Pearson says, by the 1870 s,

increasing numbers of Pakeha and a lesser but not insignificant number of Maori were beginning to conceive of themselves as an independent new nation, and this idea was backed up by the knowledge that the state now controlled a territorially demarcated area - named New Zealand (Pearson 1990: 67).

Within 36 years land inhabited by Maori people organised in tribal groups had become a state with recognised boundaries, where the majority of the people were of British extraction and were organised in a fully developed modern state.

In a sense the trauma was not as great as it might seem. The majority of the population was made up of immigrants and their descendants. With the immigrant had come their social and political institutions. It was not only people who immigrated to New Zealand but with them all the fruits of the long European struggle to define a state, a nation, a national identity and to deliver power to a wider population base than that represented by a monarchy or aristocracy. For the Maori, the trauma was great and Maori society bears that and other scars to this day. But the ideas the settlers brought with them in 1840 , today still colour the rhetoric of the Maori ethnic revival. 


\subsection{New Zealand concepts of nation and state}

Nineteenth and twentieth century New Zealanders were influenced by Acton and Mill but they were also, less directly influenced by Herder, Fichte and von Humboldt whose ideas of organic nationalism were known to English thinkers as part of the German romantic movement. New Zealand was formed as a colony that would become a state, that would one day become a nation but it was assumed that the task would be much easier if there was an element of nation to state in the process. If the majority of the population were 'British Race' or at least northern European then nation/statehood would be easier to achieve. When Vogel began his drive to acquire more immigrants for New Zealand it was clearly understood that British immigrants were the most desirable followed by Germans and Scandinavians in that order. Germans were seen as 'most like us'. This attitude lasted well into the twentieth century.

\section{Do we want Scandinavian immigrants?}

The answer is simple. If we want alien immigrants at all, then it is Scandinavians, the least alien of aliens, that we want in preference to any others (Lochore 1951:19).

chain migration tends to build up alien communities in New Zealand. That should not be allowed. We cannot import the minority problems of Europe. If we admit European aliens, it is on the tacit understanding (and an explicit understanding would be preferable) that they are prepared to make such concessions in language and customs as are necessary if they are to blend in with our predominantly British community. If they are unwilling to make that sacrifice, let them go elsewhere (Lochore 1951:25).

Do we want Italian immigrants?

We want them probably only in small numbers and for special purposes. It takes three generation to make Italians into New Zealanders, and common sense requires us to give preference to North Europeans who have more in common with ourselves and find their place more quickly in our community (Lochore 1951:34).

Dalmatia has provided us with our finest type of South European settler. He is a born pioneer; his turbulent and intractable nature is but a sign of firm character, his many faults are but the growing-pains of a new citizenry. We do not wish to anglicize him: it will do us no harm if some day Croatian is spoken as commonly as Maori in the Northland. But he must also learn to speak English, and to speak it as we New Zealanders do because English is the dominant language of our society. And Croatian lingual and cultural aspirations must remain as unpolitical as are the Welsh language and the crwth in western Britain (Lochore 1951:49).

Lochore's was a liberal point of view as may be seen from the final quotation about Dalmatians. It is not the point of view of a racist redneck, indeed it was written by a senior civil servant, but by today's standards of reference the terms of the discussion have become 
unacceptable, although many private individuals undoubtedly still subscribe to the general ideas expressed by Lochore. One of the main assumptions of Lochore's book is that immigrants should aim to become 'like us' as quickly as possible.

I have quoted extensively from the work because it gives an authentic flavour of New Zealand attitudes before there were any ideas of bicultural or multicultural societies. The aim of immigration authorities should be to seek out immigrants who would be as much like 'us' as possible. The aim of immigrants should be to teach their children to be as much like New Zealanders as possible and the aim of New Zealanders should be to help and encourage immigrants to assimilate as rapidly as possible. There is no thought that New Zealand society might wish to change to accommodate the immigrants, nor any suggestion that the immigrants would, inevitably, contribute their influence to the direction of change in New Zealand. Borrie (a New Zealander settled in Australia) writing about Australian attitudes to 'New Australians' in 1953 points out that for Australians, assimilation

has meant the shedding by migrants of all those traits of language, habits and customs which have been considered to be un-Australian (Borrie 1953:176)

Mackay, writing 40 years later, makes the same point

Australians' attitudes towards immigration, even when benign, have generally been egocentric and one-sided .... The typical Australian view is that migrants have, by definition, committed themselves to a process of adaptation and that it is they who should be making the primary effort to adjust .... In effect, the traditional Australian attitude towards migrants is that they should become as invisible as possible as quickly as possible. Assimilation has, in effect, meant homogenisation (Mackay 1993:157).

Lochore's book was published in 1951. By the late fifties and sixties, according to Beaglehole, these attitudes had begun to change:

knowing another language at school, though still rather strange and lacking a stamp of validity, was no longer something to be ashamed of. The younger respondents in this study [of the children of refugees from Europe] were more likely to consider being multilingual almost a positive attribute ... a changing New Zealand environment brought about by successive waves of immigrants contributed to the new attitudes. (Beaglehole 1990: 99)

Borrie also, in 1953, pointed out that

where the migrants constitute any substantial minority, the assimilation process never operates in one direction only. It must, even if imperceptibly, cause changes in the attitudes and culture of the majority (Borrie 1953:175) 
Gordon (1975:106) makes a distinction between racist, assimilationist, liberal pluralist (characterised by an absence of legal recognition of ethnic differences and the prohibition of the use of ethnic criteria) and corporate pluralist (characterised by formal recognition of ethnic differences and quotas for ethnic groups) societies. Gordon points out that these types may co-exist in a given society and, using his schema, we might say that New Zealand has shifted from being a racist/assimilationist society to a liberal pluralist/corporate pluralist society with strong traces of assimilationism still present in it.

New Zealand was founded as a colony of Great Britain. Full independence was not achieved until the New Zealand Parliament passed the Statute of Westminster Adoption Act in 1947, but New Zealand has been basically self-governing, certainly in internal matters, from 1876. From the beginning of New Zealand's existence in 1840 it was foreseen that New Zealand should consist of two peoples: Maori indigenes and British settlers, although the frequently expressed official hope was that the two would become one people "He iwi tahi tatou", Lieutenant-Governor Hobson's words to the Maori chiefs at the signing of the Treaty of Waitangi. The Treaty of Waitangi had promised to confer the rights of British subjects on Maori inhabitants of New Zealand (Orange 1987: 174,201) and in this sense the Pakeha and Maori were to be one. As Orange says of the 1934 celebrations of the signing of the Treaty :

[Governor-General] 'Bledisloe's first prayer [that God 'grant that the sacred compact then made in these waters may be faithfully and honourably kept for all time to come'] became the accepted expression of national commitment to the Waitangi ideal for some fifty years, it sustaining the notion that a sacred compact had been forged in 1840 , and nurturing the concept of one people formed of two races. (Orange 1987:235) ${ }^{4}$

New Zealand began with a Treaty to unite two races into one people. The British drafters of the Treaty acted firmly in the British tradition of polity first then nationality. What was to become of the other races within this scheme. According to Pearson New Zealand followed the pattern described by Baker

'The subsequent influx of other groups, white and non-white, often precipitated intergroup conflict, and that contributed to the intensification of discriminatory policies against other group(s) by the dominant Anglo-[Celtic] group.' Historically, the white

\footnotetext{
${ }^{4}$ There was another way in which the one people was seen as coming into being. "The Hunn Report of 1960 crystallised Maori fears by assuming the ultimate demise of any separate Maori identity in New Zealand ... it was more than likely that intermarriage would create one people - and that people would be all Pakeha, some more brown than others (Orange 197:242-243).
} 
majority have pursued primarily exclusionist policies towards non-indigenous, non-white groups. (Pearson 1990:31)

\subsection{Immigration policy in New Zealand}

New Zealand has only sporadically had a policy of encouraging immigration. After the New Zealand Constitution Act of 1852 immigrants were actively sought by the Provinces, each Provincial government establishing its own agency in Great Britain and 'the possibility of obtaining non-British stock was not seriously considered' (Borrie 1991:14). Once there is official involvement in immigration we begin to see the formation of ideas that were to colour and still colour New Zealand attitudes to immigration. The influx of gold-miners seemed about to weaken the Scottish nature of Otago so 'the council ... suggested to the government the imposition of an immigration tax of 5/- per head on European, and 10/- per head on Chinese and Maori immigrants [sic]' (Borrie 1991: 15).

In 1863 a scheme to bring German settlers to Taranaki was proposed despite, Borrie says, the government's 'obvious pride, even at that date, in the purity of the colony's racial composition' (Borrie 1991: 24). Borrie sees the various schemes of the 1860 s and 1870s to bring in Germans and Scandinavians or indeed Europeans in general as liberal when compared with "that suspicion against [all foreigners] which was to dominate migration policies after the eighties' (Borrie 1991: 26).

During the wars of the 1860 s immigration schemes died down but after that period Sir Julius Vogel took up the task of encouraging immigration. He was, in this area, as in others, a visionary and it was under his guidance that New Zealand entered into its most active phase of immigration sponsorship prior to the post WWII period. The Immigration and Public Works Act was passed in 1870 with the intention of encouraging large scale, planned immigration from Europe ${ }^{5}$. Inviting non-European immigration was first suggested in 1872 , when a shortage of railway labourers caused the government to consider introducing 'asiatic' labour. There had, of course, been Chinese immigration to the goldfields prior to this period but this was the first (and only - until the 1980s) suggestion that such immigrants should be encouraged. The central government put the question to the provincial governments with interesting results. Auckland and Wellington, feeling the pinch of a labour shortage, agreed to

\footnotetext{
${ }^{5}$ It is perhaps worth mentioning here that in legislation passed in 1867 those categorically barred from entry into New Zealand were criminal rather than foreign. The mistrust of foreigners was to come later.
} 
the idea. Taranaki and Hawkes Bay were not enthusiastic. The Southern colonies were all opposed and Borrie makes the point that Otago and Canterbury 'with their particularly Scottish and English affinities' were the most strongly opposed (Borrie 1991: 57-8).

After the Liberal government representing working class interests, came to power in 1891, planned, sponsored immigration, seen as threatening New Zealand workers' jobs, ceased. The government's interest in immigration was confined to restricting entry to New Zealand, particularly the entry of Chinese, and immigration as a tool of national development was abandoned.

In the first decades of the twentieth century, immigration became bound up with the imperial ideal'

There was a growing desire that emigration [from Britain] should be undertaken with one idea, namely the distribution of the British peoples throughout the Empire to develop resources for the benefit of the whole (Borrie 1991: 153).

After WWI immigration was an unimportant issue in New Zealand. Troubled economic times meant immigrants were not encouraged. To the extent that people still wished to come here, New Zealand policy was to put British immigrants first. This led to justified resentment in the 1930s when New Zealand could have taken more refugees from Nazi Germany (Beaglehole 1988: 5, 8-11).

After World War Two government attitudes changed again. There was a 'manpower' shortage. Large-scale sponsored immigration schemes were implemented for the first time since the 1870s (McKinnon 1996:6). Included in this policy was the scheme that brought many Dutch immigrants to New Zealand (see section 3.2). However, the stress was still firmly upon British immigration as the following passage, in all its smugness, illustrates

We are, however, also alive to the fact that complete homogeneity is neither possible or desirable. Nor are we so small minded as to dislike talent in other people. We therefore welcome a number of other [non-British] migrants (New Zealand Labour and Employment gazette 1954:47).

There were various changes in the laws relating to citizenship and immigration in the years following WWII, most notably perhaps, in 1952, Chinese people resident in New Zealand became, once again eligible for naturalisation as they had not been since 1908 (McKinnon 1996: 27,41). 
Pacific Island immigration, which had been virtually non-existent before 1950, also increased considerably in the post WWII years. In the 1950s and 1960s, the demand for labour was such that little attention was paid to the 'legal niceties of permanent entry' (Pearson 1990: 120). This situation changed suddenly in the 1970s with the change in New Zealand's economic fortunes. The relationship of Pacific Island nations to New Zealand and the status of their citizens in New Zealand depended on whether or not there was a former or continuing colonial relationship. In the case of Western Samoa, there has been, since independence, an annual immigration quota (see section 3.3.3 for further discussion).

There were however no major changes in general attitudes, administrative action or government policy until the 1970s and even those were more muted in their effects than had, perhaps, been intended. Controls on immigration from Britain and Ireland were introduced for the first time in 1974, and in 1977 a new citizenship law was introduced that reduced the privileged position of British and Irish immigrants (privileged in comparison with immigrants from other places) in New Zealand society (McKinnon 1996: 43). As McKinnon points out however, for a variety of reasons, the effect of these changes was not great and there were no dramatic changes to the role of immigration in New Zealand until the 1987 Immigration Act. The Act was foreshadowed by a White Paper in 1986, which set out the explicitly non-racist basis of the new policy

the selection of new immigrants will be based on the criteria of personal merit without discrimination on grounds of race, national or ethnic origin, colour, sex or marital status, religion or ethical belief (cited in McKinnon 1996: 46).

The 1987 Act was followed by legislation in 1991 which introduced the points system for entry into New Zealand, whereby an applicant's suitability for entry is calculated according to their score on a set of criteria made public by the government (McKinnon 1996: 47). These two pieces of legislation form the basis of New Zealand's current immigration policy. They are as described above, explicitly non-racist in their formulation and for the first time in New Zealand' history immigration from Asia has been relatively easy. The consequent flow of immigrants from Asia to New Zealand has had political effects that appear to have been unwelcome to the government and in 1995 immigration policy relating to language was introduced for the first time since before WWI in New Zealand. The new policy was seen by many as a return to the bad old days of an immigration policy based on race, and is discussed in greater detail in Chapter 4. 


\subsubsection{Racist immigration policy}

The policies outlined above helped to create a monocultural and egalitarian New Zealand. A country which was almost monomaniacally obsessed with the concept of itself as a British outpost. New Zealand was British and as such had no room for cultural or linguistic diversity.

New Zealand in the nineteenth and early twentieth centuries was a small, parochial, and insular society. Cultural homogeneity was one of the hallmarks of settler society (Pearson 1990: 97).

As Pearson points out at various times New Zealanders protested against the immigration of Germans, Scandinavians, Italians, Greeks, French, Lebanese, Sikhs, Gujaratis, Punjabis, Dalmatians ('the Chinese of the North'!), the Irish, the Cantonese and even 'homies' - that is new immigrants from Britain (Pearson 1990: 95-6).

Most of this protest had a semi 'rational' base. It tended to occur in times of economic hardship and was fuelled by fear of the competition that the immigrants were thought to provide. (Marshall (1986:13) comments on the same linkage in the USA and Borrie comments on the phenomenon in Australia, (Borrie 1953:178)). It is worth noting for two reasons. Firstly, it contributed to the stifling monoculturalism of New Zealand because the protest in the early part of this century led to the Immigration Restriction Amendment Act of 1920 which remained the cornerstone of New Zealand's immigration policy until 1964 (Henderson 1998: 146), and as such was used to exclude non-European immigrants (and indeed some European immigrants). Secondly, there was a distinction made between types of immigration - a racist distinction - as 'Chinese immigration was regarded as a substantially greater evil because it involved the migration of a race that differed fundamentally in kind from the European' (Warburton 1982, quoted in Pearson 1990: 97)

The flurry of anti-Chinese legislation set before parliament in the late 1870 s and early 1880 s was designed not only to protect the economic and moral standards of the society but also to enhance the independence of the state. ...

Seddon's views reflected a general feeling among the Lower House in parliament that New Zealand should be able to dictate its own policy regarding the size and composition of its future populace'. (Pearson 1990: 98-9)

Thus the process of creating the concept of a nation contributed directly to the creation of a rigidly monocultural society that had very limited means at its disposal for dealing with manifestations of cultures other than its own. 
The fact that New Zealand always (even if sometimes only provisionally - 'the dying race' acknowledgment) has acknowledged the existence of two peoples and cultures in New Zealand, seems to have had no effect on this hysterical monoculturalism. In 1906, 260 Chinese entered New Zealand, 127 left the country. That year saw a net gain in the New Zealand Chinese population of 133. In the same year 39,000, mainly British, immigrants came into New Zealand - yet fears were raised as to the large numbers of Chinese immigrants (Pearson 1990: 83). In view of these circumstances 'hysteria' seems the only word to describe New Zealanders' attitudes to non-British immigration.

New Zealand would also have liked to exclude or discourage Indian immigrants in the same manner as Chinese, but was under constant pressure from the British government to allow free Indian immigration because Indians were subjects of the British Empire (McKinnon 1996: 27). Although the Indians never faced the overtly discriminatory legislation that hindered Chinese immigrants to New Zealand, nonetheless they too found entry to New Zealand more difficult once the Immigration Restriction Amendment Act of 1920 was passed.

New Zealand was not alone in implementing racist legislation and policies that affected immigrant intake. Canada and Australia trod a very similar path. Canada's first discriminating immigration legislation was passed in 1910 and in 1918 Canada prohibited entry to immigrants who travelled to Canada on more than one vessel. This legislation was passed in order to stop Indians immigrating to Canada - it was not possible to get from India to Canada on one ship. There are two interesting points about it; one that Canadians wished to stop Indians from entering the country, two, that they considered that it was not politic simply to say so - thus producing an ostentatiously ludicrous piece of legislation. It was not until 1967 that race and ethnicity were eliminated as criteria for the selection of immigrants to Canada (see Bhatnagar 1981:73-5) At about the same time (1966) Australia relaxed the White Australia policy.

In Australia's multi-cultural society of the 1980s both state and federal legislation outlaws [sic] race and gender discrimination ... In the move towards federation of the colonies, accomplished in 1901, racist practices against Aboriginals, Asian and Melanesian immigrants, legitimated by 'scientific' notions of biological difference helped weld the 'white' nation. Only in the 1970s was the 'white' Australia policy finally abandoned, together with the abandonment of a policy which had enjoined immigrants and Aboriginals to assimilate to Anglo conformity. (de Lepervanche: 1989:36)

Borrie's 1953 comments on the White Australia Policy are an interesting presentation of liberal Australian views of that time 
Most Australians would argue that this policy has not a racial bias, but is designed to exclude those who would undercut basic economic standards in this country ... there can be little doubt that, quite apart from this economic basis, there has been an element of opposition to non-white peoples which has had a racial content. But as the immigration policy has effectively excluded non-white settlers, Australians have not had to clarify attitudes towards these ... They have tended to congratulate themselves upon the fact that this policy has enabled Australia to develop a homogeneous population which is British in origin and which in turn has created a social structure based upon a colonial adaptation of the traditional institutions of the British Isles. In support of this argument they point to the fundamentally British character of Australia's political, religious and social institutions (Borrie 1953:176)

New Zealand however was more thoroughgoing than either Canada or Australia. This was partly because New Zealand did not have the same need for immigrants; there was less territory to be filled and partly because New Zealand was always more dependent on Britain.

The economic link that was established with the development of refrigeration tied New Zealand to Britain's apron strings much more securely than Canada or Australia.

\subsection{Racist attitudes in New Zealand}

New Zealand came to a realisation of itself as a nation at a time when social darwinism had a particularly strong hold on the common imagination (Jones 1980: 106, 147, 148, 157, 158). It was axiomatic that races were ordered in a hierarchy and that the white race was at the top. 'The purity of the race' was a topic much discussed and it was generally considered important to guard that purity

In discussions about the national type, on one topic there was unanimity: it was to be white.. . Ignoring Maoris, it was assumed that New Zealanders would be of European, mainly British. descent, though with an admixture of Maori 'blood', that is genes (Sinclair 1986: 91).

Sharp points out that at the Paris peace negotiations in 1919 the Japanese (who had been on the allied side) hoped to get a clause on racial equality written into the Covenant of the League of Nations. However

It proved impossible to discover a form of words which would satisfy [the Japanese] and yet not alarm the Australians, New Zealanders, British Columbians and Californians who feared unlimited Japanese immigration [Lord Robert Cecil, the British representative] was faced with the embarrassing task of opposing a principle of obvious justice. (Sharp 1991: 61)

The link between philology and theories of race was very close in the nineteenth century (Graff 1987: 67-77). 
Possibly the Anglo-Saxon blood is more potent than that of other races; but it is to be remembered that the Anglo-Saxon language is the simplest, the most perfectly and simply symbolic that the world has ever seen; and that by means of it the Anglo-Saxon saves his vitality for conquest instead of wasting it under the Juggernaut of a cumbrous mechanism for conveyance of thought.

(McGee quoted in Williams 1992: 30)

These were the words, at the end of the century, of William McGee the first president of the American Anthropological Association. The subordinated as well as the conqueror could believe in such racial/linguistic myths. Crowley quotes Davis asking was it right for

the fiery, delicate-organed Celt to abandon his beautiful tongue, docile and spirited as an Arab, 'sweet as music, strong as the wave' - is it befitting for him to abandon this wild liquid speech for the mongrel of a hundred breeds called English, which, powerful though it be, creaks and bangs about the Celt who tries to use it? (Davis 1914: 98, quoted in Crowley 1996: 128)

And the subordinated as well as the victors of history relied on science to back their claims (rooted in the Herderian tradition).

That idiom is the counterpart of racial idiosyncrasy, long believed as a matter of intuition, is now being elucidated with scientific certainty. The most rudimentary idioms of speech are found to indicate the psychological angle from which the racial mind confronts the universe .... Irish idiom is the logic of Irish psychology, while an Irish sentence, apart from its explicit meaning, commits the speaker, by its grammar and order, to an Irish theory of life. (Trench 1912: 26, quoted in Crowley 1996: 133)

Arguments in New Zealand about the position of the Maori in the racial hierarchy were philologically based and a such may be seen as fair and square in the nineteenth century mainstream of thought that connected issues of race, language and nationality.

With such a wealth of affinity in the words and roots, such similarity in the original range of sounds and in the sound-laws between Polynesian and primeval Aryan, it is difficult to resist the conclusion that the Polynesians came from Europe many thousands of years ago (Brown 1920, quoted in Sorrenson 1979: 23)

The Chinese and Indians fared badly in the hierarchy of races but the Maori, in general, did not. Tregear's statement that in New Zealand

it is certain that the difference between the Colonel and the Maori chief is hardly skindeep. Brave men looking over crossed weapons and loving women cooing to their babies find their kin all round the world. Very close is this kinship between the restless sea-rover from the Northern isles and his darker brother of the Southern seas (Tregear 1904:7) 
represents the fairly general (though not ubiquitous) point of view that Maori were a 'superior' race. Indeed the Maori were not only superior they were, like the Briton, Aryan according to many early writers

the highly-civilised Britain [sic] and the Maori, just emerging from barbarism, are one in origin; that in fraternising with the Maori the European undergoes no degradation; in intermarrying with the race he does no violence to the claims of consanguinity. It is thought that when this is thoroughly well known there will arise a more cordial feeling between the peoples inhabiting the colony, both equally the subjects of one King. (Thompson 1905-6 quoted in Sorrenson 1979: 29)

According to Sorrenson the founding of modern New Zealand coincided with a period at which 'racist prejudices were beginning to surge forward' (Sorrenson 1979:73) and he asks why the Maori were exempted from this prejudice by many New Zealanders. Sorrenson's answer is, in effect one of national necessity.

Nations are based on historical myths and New Zealand by the late nineteenth century was in the process of inventing hers. There was room for a heroic Maori past, starting in India or the Caucasus, blossoming in the discoveries of Kupe ... The myth survived with the Maori to bolster pride in Anglo-Maori achievement. (Sorrenson 1979: 84)

Today the idea of a hierarchy of races is seen as repulsive nonsense; moreover it was nonsense that was expressed in exceedingly offensive terms. The fight to exclude races perceived as degenerate and demoralising from New Zealand's shores was not a pretty one. Indians and Chinese particularly were characterised as immoral, unclean and inferior. These attitudes must have affected the attitudes of the newly arrived immigrants to New Zealand but it is worth pointing out that the general tone of public comment on immigration issues was of a nature that has happily become unimaginable. In the 1870s it was possible for The Otago Daily Times to refer to 33 workhouse girls from Cork as 'certified scum' (McGill 1990: 150). This was the same prejudice that led one British commentator to write

The careless, squalid, unaspiring Irishman, fed on potatoes living in a pig-stye, doting on a superstition, multiplies like rabbits or ephemera; the frugal, foreseeing self-respecting Scot passes his best years in struggle and celibacy (quoted in Jones 1980:102).

Another commentator, the Regius Professor of History at Oxford, travelling in America, commented that America would be perfect if only each Irishman would shoot a Negro and be hung for it (James Belich. Macmillan Brown Lecture 16/11/94). It was not only 'coloured races' that bore the brunt of a pernicious habit of thought. 


\subsection{Celtic ethnicity in New Zealand}

The Scots and Irish immigrants to New Zealand occupy an interesting place in all this. Both groups were officially welcome although as the Otago Daily Times quotation shows, certain groups were looked down upon by some New Zealanders. The Scots and the Irish while, in 1840, part of the political economy of Great Britain, were not fully part of that social and cultural economy and the Irish (or most of them) subsequently freed themselves from the political ties that then linked them to England. The Scots and the Irish then may be said to have had ethnic consciousness and that consciousness was to some extent entwined with a linguistic consciousness. How important is it in the New Zealand context that many of the settlers were from Scotland and from Ireland?

The official and general view was undoubtedly that New Zealand was British and this implied a single culture

The statistician must be right: modern New Zealand is virtually 100 per cent British. Yet she plainly carries on in a modest way the fine tradition of Britain herself: she can absorb and make her own different strains and cultures and can think of minorities with pride rather than hostility. (Wood 1958: 54)

However, Michael King's testimony from a childhood of the 1940's suggests that the subgroups within the designation British may not always have seen things in quite the same light as the officials and the dominant English British.

We were New Zealanders, but Irish New Zealanders. Although statistics may have lumped us among the almost ninety percent of the population descended from the European migration to New Zealand, we did not feel like members of a majority. Nor did we feel like part of a wider group and culture that had displaced an indigenous people ... we ... saw no Maori at this time, we had no concept of race; simply of Irish and Scots versus the rest. (King 1988: 34)

The Scots and Irish who emigrated to New Zealand left their homelands with an ethnic consciousness that was partly defined in terms of their difference from the English. Many were unconcerned at blending into the generally 'English' nature of New Zealand society but there were also immigrants who were determined to identify with Scotland or Ireland (or even Wales) only.

There were real Hebredeans in the 1940's, families who ate porridge for tea, and (it is said) at least one community whose mother tongue was Gaelic. Again there are parts of New Zealand where every second man, though he may never have left his birthplace marks himself as Irish long before his name is revealed to be O'Regan or O'Malley ... 
and a modern schoolgirl, asked to name an eminent man of letters, could think of no one but a poet who wrote in Welsh for the people of Wales. (Wood 1958: 53-4)

In the thirteen years from 1851, New Zealand's European population increased more than fivefold from 26,707 in 1851 to 171,009 in 1864 . These people, like most of New Zealand's immigrants came in hope of escaping poverty but they had social and political ambitions as well as economic ones.

Among them were naturally men and women tinged by the radical ideas which were fermenting in Europe in the middle of last century. The fundamental thing, however, was not social theory but the common-sense impatience of the ordinary man ... In New Zealand the government was to be the instrument by which men could conquer nature and remedy the injustices of human society. (Wood 1958: 45)

John A. Lee brings together the strands of Celtic escape from oppression and the more general hope of a more equal, more just and wealthier life.

The early pioneers were an adventurous and free-spirited people, ... many of whom had been driven from Ireland and Scotland by exacting landlordism, and in New Zealand they found themselves free from enslaving political tradition. Here was a new world where opportunity, though exacting, offered prospects to capacity and industry. (Lee 1938: 15) 
limitation - they were glad to cast it off'. For many Irish 'the only good thing in Ireland was the road out'. King, talking of his Scottish grandmother says 'to her the past was something to defeat and transcend ... She was unsentimental about Scotland ... 'We came here to forget all that' (King 1988: 22). New Zealand saw its destiny to be a Britain of the South Seas: economic, geographic and demographic factors conspired to make this dream achievable. De Lepervanche makes a similar point about Australia when she says

In the nineteenth century the Catholic Irish working class component of the population contributed substantially to the development of the Australian Labour [sic] movement, while the colonial establishments remained attached to all things British and Protestant. But, despite their 'ethnic' disadvantages, Irish catholics were never excluded from Australian society as much as Aboriginals and Asian immigrants were. (de Lepervanche 1989:47)

and Borrie echoes these sentiments in Australia and New Zealand when he writes in 1953

We need not worry overmuch about the British [as opposed to non-British] immigrants. They may not be quite like Australians, nor for that matter like one another. Irishman are not Scotsmen, and neither are Englishmen, and none of them are "dinkum Aussies" when they first reach our shores. But there is sufficient similarity amongst them all in regard to language, religion, and political and social institutions for English, Scots and Australians, and even Irish (emphasis added) to be able to intermingle without too much friction (Borrie 1953:173)

\subsection{Immigration policy and population in New Zealand}

The fact that New Zealanders, on the whole believed in a hierarchy of races, made New Zealand a racist nation that wished to keep non-white races out. New Zealand could afford to do so for longer than other countries (Canada, Australia) that had much the same aim and so today is noticeably more monocultural than those countries.

What did New Zealand want from its immigrants? Essentially New Zealanders saw themselves as members of an egalitarian society where everyone had a chance to make good. But this chance to make good could only be extended to those who would be full members of the society. The business of nation building was seen as a co-operative venture that, because it relied on social consensus, could only be undertaken by a band of like minded 'brothers'. The

\footnotetext{
${ }^{6}$ For those who came to political consciousness through Marxism, religion came to be seen as a drag on progress and a means of cheating the working class. Once the link to the Catholic religion was broken, a lot of the ties to a sense of Irish community were weakened.
} 
Chinese and the Indians (and at various times the Dalmatians, the Scandinavians, the Irish etc) were seen as so essentially different that they could not fulfil their part of the bargain. They could not become one of that band and consequently had to be kept out of the country. As late as the 1970s the Department of Labour was citing the Chinese inability to assimilate as a reason for not letting them into the country.

'In 1970 the Department of Labour stated quite openly that restrictions to Asian immigration were based on 'perceived problems of assimilation', thus repeating, although in less inflammatory language, the sentiments of their late nineteenth century predecessors" (Pearson 1990: 155)

The greater and more obvious the differences between the immigrant and the average New Zealander, the longer and more difficult the period of assimilation and [the] greater the tendency of immigrants to hive off into little colonies which become self sufficient and resistant to the process of assimilation. This tendency is present not only in groups of non-European origin, but also in people from some European countries whose social and cultural heritage differ widely from ours. (Department of Labour, 1970:3. Quoted in Trlin 1986:2)

It was a narrow view of national identity that feared difference.

This fear undoubtedly helped to shape the immigrant communities of New Zealand. Because of this fear the numbers of Indians and Chinese were kept smaller than they would otherwise have been (Trlin 1986:2) - this in itself has affected the nature of those communities. It also caused community members to be particularly careful of the manner in which they reacted with the larger community. Careful not to dress differently, not to be heard speaking their own language, not to advertise their presence.

Equally, this fear led to the large numbers of Dutch people in New Zealand. The Dutch were ready to emigrate and they were seen as, and indeed were, white, European and Christian. They were like us, they could keep their half of the bargain. If we gave them a chance they could become New Zealanders in a way that Chinese and Indians (or indeed Italians and 'Dalmatians') could not. In the words of the post-WWII Dominion Population Committee

... we think it is important to comment that, if it is proposed to encourage immigration of other European types, they should be of such character as will, within a relatively short space of time, become completely assimilated within the New Zealand population and have a distinctly New Zealand point of view ... We therefore feel that if any positive steps are taken to encourage immigrants other than from Great Britain they should be found in northern European countries. (Cited in McKinnon 1996: 37-38) 


\subsection{Summary}

This chapter has shown that New Zealand was strongly affected by the racist doctrines that developed in the nineteenth century, that these doctrines shaped New Zealand's immigration policy for over 100 years, and they have left their mark on New Zealand today. This has been the background against which Gujarati, Dutch and Samoan settlement in New Zealand occurred. Each of these groups has been affected by the general New Zealand attitude to issues of identity, language, race and nationality. 


\section{IMMIGRATION BACKGROUND OF THE THREE COMMUNITIES}

In order to understand how processes of language maintenance and shift occur within a given community, it is necessary to have some idea of the social forces that formed the community. In the case of immigrants these forces include the nature of the immigration process itself. This chapter provides some information about those social and, indeed, linguistic forces.

In the previous chapter, New Zealand's development as a nation since 1840 was outlined and particular attention was paid to the concepts of nation-building and national identity that informed that development. Modern New Zealand was created by a process of immigration, and immigration issues have formed, and still form, part of the debate about national development and identity. In the past, immigration policy in New Zealand focussed both on recruiting from Britain and Ireland and limiting the intake of people from elsewhere. Why did the immigrants from 'elsewhere' want to come to New Zealand and how did they manage to be part of the limited intake not from Britain and Ireland? This chapter explores these issues.

The social and historical background in the home countries of the immigrants is briefly outlined. The colonial links between New Zealand and Samoa are discussed in slightly more detail because of their importance in the relationship between the two countries; there probably would not be such a large Samoan community in New Zealand if it were not for the colonial history shared by Samoans and New Zealanders. The language background of the immigrant groups is also briefly sketched and the difference between 'formal' and 'everyday' Samoan discussed. The immigration flows of the three communities are also examined as they show, very clearly, that each community was formed over a differing period of time, in differing ways (e.g. initially male immigration heavily outweighed female immigration for the Gujaratis but the discrepancy was not so marked for the Dutch or Samoans).

The immigration figures given in the following section are all drawn from the Census and Statistics publications over the years 1921 to $1970^{7}$. Throughout that 49 year period the method of collection varied, as did the categories under which information was collected and

\footnotetext{
${ }^{7} 1921 \quad$ figures in Statistical Report on the Population of New Zealand

1922-1932 figures in Statistical Report on the External Migration of the Dominion of New Zealand

1933 - 1969/70 figures in Statistical Report on Population and Buildings
} 
grouped. For instance the classification "Hindu" was changed to "Indian" in 1924, the classification Race Alien Arrivals and Departures by Race and Country changed to Arrivals and Departures of Persons other than Europeans by Race and Country in 1932, and data on Samoans was, sporadically, not gathered separately and has to be extrapolated from general data on Polynesians. There is also a gap in the figures during the WWII years 1941/42 to 1944/45 (inclusive). The changes of classification have not all been noted as it would be tedious in the extreme for the reader and not necessary for present purposes. The information both for Arrivals and for New Zealand Residents Returning for the Indian and Samoan figures comes from the 'race aliens' or 'persons other than European' tables but because the Dutch were not included in these categories, the figures for Dutch arrivals in New Zealand are taken from the tables External Migration: Nationalities of New Immigrants Intending Permanent Residence. The classification Arrivals and Departures of Persons other than Europeans by Race and Country ceased to be used in 1970/71 and thus the figures stop at that point. Luckily, as far as this research is concerned, they cover the period when most of the subjects of the research would have immigrated to New Zealand.

\subsection{Gujarati}

Gujarat is a large province on the Northwest coast of India in the bulge above Bombay. The basic social unit in Gujarat is the extended patrilineal family, the kutumb. Moving up the hierarchy of organisation from the kutumb are the jati or sub-caste, the village, the language group. One's family and one's jati have the greatest influence on a person's life.

Caste transcends linguistic and local boundaries but sub-castes are usually constituted within those boundaries. The four castes are
1. Brahman priests, men of learning
2. Kshatriya rulers and warriors
3. Vaishya traders, merchants, farmers and artisans
4. Shudra servants, workers on the land

Each caste is endogamous. In addition to the four castes there is a fifth group the untouchables.

There are many different jati however and according to Kasanji they are usually locally defined within a given linguistic dialect. 
In the coastal areas of Gujarat trading overseas has been a way of life for many centuries. It was generally expected that a man would trade overseas before marrying and settling down. Thus the concept of trading or working overseas and then returning to your country was a well established one by the end of the nineteenth century when Gujaratis began coming to New Zealand.

Gujarati immigration to New Zealand, however, took place at a time when the old economic patterns were changing in Gujarat. The port of Surat silted up which meant that trade shifted to Bombay and along with it significant portions of industry and commerce. Also, the British cotton goods industry was destroying the traditional fabric trade of Gujarat. In 1896 and in 1902-11 there was Bubonic plague and famine, accompanied from 1900-11 by drought. Despite disease and disaster the population continued to grow, largely because of improved medical services. These factors produced the pressures on resources which led to a greatly increased exodus of men.

The pattern of migration to New Zealand and elsewhere was one of chain migration of men who saw themselves as sojourners earning money to send home to improve family life at home. They expected eventually to return home to settle and many of them did so. Most of the men who came to New Zealand were from the Vaishya caste. Many of them did return home to marry and settle, and by the 1920s their sons were coming to New Zealand to perpetuate the pattern.

The men tended to live together, partly to save money, partly to keep each other company in a strange land, partly no doubt to produce something that bore some relationship to the extended family they were used to at home and partly to avoid problems with religious and dietary observance. In Wellington Indians rented houses in Tory, Taranaki and Vivian Streets and by the 1930s had moved into Adelaide Road as well.

It was hard for the immigrants to get work. They lacked skills and there was considerable prejudice against hiring Indians; employers who did so were often faced with strike threats. the jobs they got were all very low status ones; scrub cutters, road builders, labourers, porters, dishwashers, kitchen hands, assistant cooks, fruit and vegetable hawkers, ragmen, bottlemen. Most of these were jobs where they could either work on their own or where they could form an all Indian gang and contract for the job. In some cases they would form a single caste gang 
for scrub cutting or road building. World War II saw many Indians able to participate more fully in the labour market - they were manpowered into a wide variety of jobs ${ }^{8}$.

The link with Gujarat continues to this day. Strong family ties in New Zealand and India and running between the two countries have made linguistic and cultural maintenance a necessity for most individuals and for the community as a whole.

The number of Indians entering New Zealand does not rise above 100 a year until 1909 when 157 Indians (35 of whom were women) entered the country. Most Indian immigrants to New Zealand were from Gujarat (Pearson 1990:85) with a small number coming from Punjab. At the same time that Gujarati emigration was increasing, some of the other destinations for Gujarati migrant workers were closing their doors. Australia, South Africa, Canada and the United States all introduced restrictive legislation at this time (Pearson 1990:86). New Zealand already had restrictive legislation, the 1899 Immigration Restriction Act which required those not of British or Irish parentage to take an 'educational test' (Ip 1990:178), but presumably this was less of a barrier than was found in other potential host countries. From 1909 until 1920 there appears to be (apart from the years 1915-1917 inclusive) a small but steady rise in the numbers of Indians entering New Zealand but the passage of the Immigration Restriction Amendment Act in 1920, sees a sudden drop the following year from 225 in 1920 to 71 in 1921. Until 1938/39 numbers remained below 100 per annum rising to 149 in that year and apart from the immediate post-war years 1945-47 never falling below 100 again. In 1948/49 Indian arrival in New Zealand ex-India hit a high (for the period under consideration) of 368 people, about a quarter of whom were women. The percentage of female arrivals was to rise to a high of $53.51 \%$ in $1957 / 58$. When looking at the proportions of male to female in the Indian population resident in New Zealand, women do not rise above $36 \%$ until 1951. By 1971 they made up $43 \%$ of the Indian population of New Zealand (Pearson 1990:87, see Kasanji 1982: 70-71 for a discussion of the reasons for increased female migration in the 1950s).

The Gujarati community is the longest established of the three communities under consideration and this means that the processes of settlement, including language maintenance and shift, are at a different stage in the Gujarati community than in the more recently arrived

\footnotetext{
${ }^{8}$ Most of the above draws heavily on Kasanji 1982.
} 
Dutch and Samoan communities. When discussing and comparing the three communities, the Gujarati community's greater length of time in New Zealand is viewed as a factor with explanatory power. It does, in my opinion, have such power, but it must always be remembered that although the Gujarati community is considerably longer established than the Dutch and Samoan communities, it was, for many years, essentially a male sojourner community. As a community with equal numbers of men and women, it is about as old as the Dutch community. This means that there are comparatively few New Zealand Gujarati who are third or fourth generation New Zealand-born - even if their fathers and grandfathers both earned their livings in New Zealand. Nonetheless, the age of the Gujarati community in New Zealand and the fact that there have been some Indian families here throughout that time, have had their effect. The Gujarati community has had time to develop immigrant community strategies for language and cultural maintenance and new immigrants have been able to access these strategies when they arrived. One very obvious example of such a strategy is the Gujarati language maintenance school established in the late 1940 s and still running today. 
荘

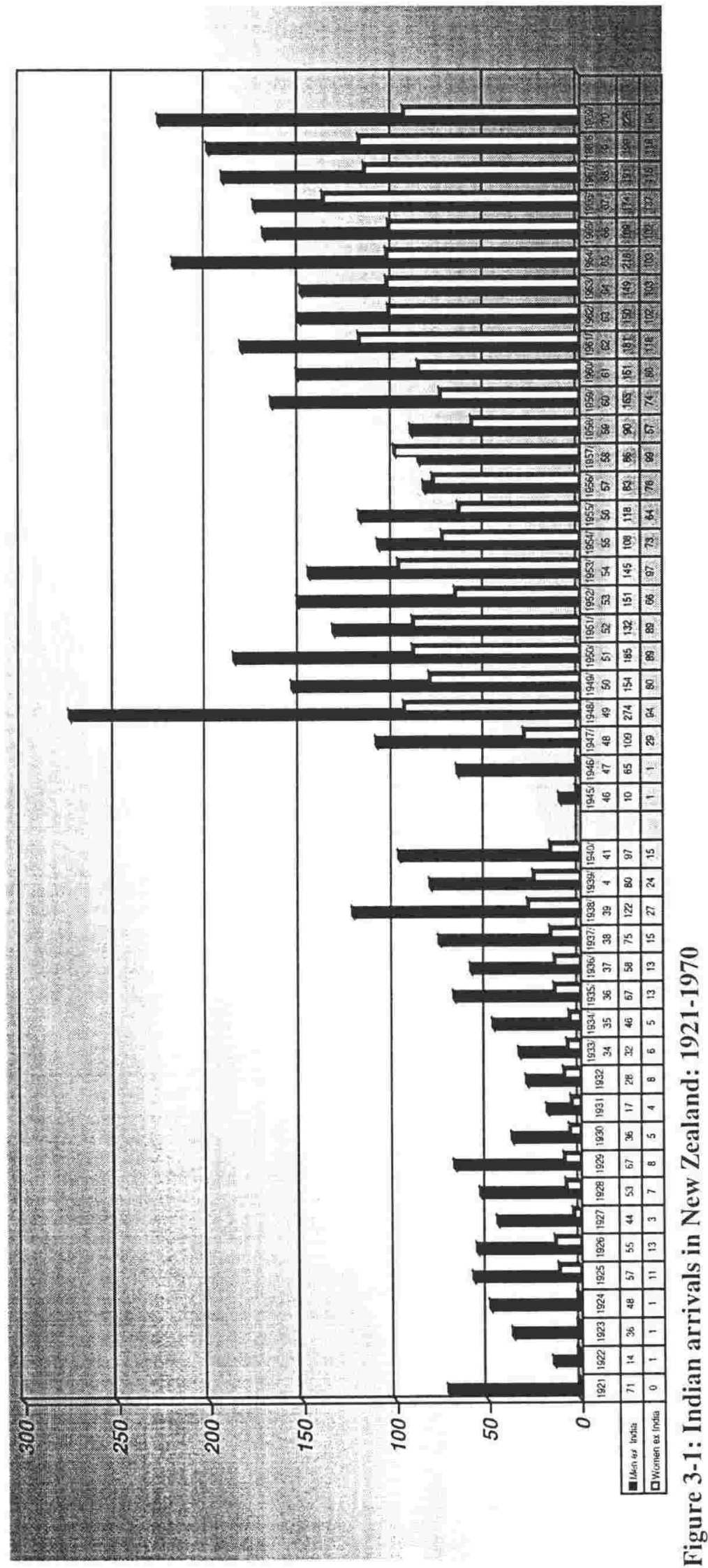




\subsubsection{Language situation in Gujarat}

Gujarati is an Indo-Aryan language closely related to Hindi. Standard Gujarati is the 'educated speech of Ahmadabad, the former state capital' and there are three main regional dialects; Charotari, Surati and Kathiwari (Raeside 1994, vol 3: 1512).

India of course, is a great multicultural, multilingual nation, and the Indian immigrants to New Zealand bring that heritage with them. After Independence in India, some of the provinces of India were reorganised on linguistic lines. In 1960 Gujarat was one of the provinces created in this process (Brass 1990:147) when the former Bombay province was divided into the present provinces of Gujarat and Maharashtra. This move was apparently more strongly favoured by the Marathi speakers of what was to become Maharashtra than by the Gujarati speakers of what was to become Gujarat "where for a time it was felt that the loss of Bombay city was too high a price to pay for a separate Gujarati -speaking state" (Brass 1990:151).

In some provinces of India, the official provincial language comes into competition with large minority mother tongue languages (for instance Bengali in Assam (Brass 1990:165)) but in Gujarat $90 \%$ of the population speak Gujarati or Hindi, which are the official languages of Gujarat (Brass 1990:153). There are approximately 33 million speakers of Gujarati in India, not all of them in Gujarat, Gujarati is also spoken elsewhere in India, mainly by about 8 million speakers in Bombay and of course it is spoken in the major overseas populations in South and East Africa, Canada, USA and the United Kingdom as well as New Zealand (Raeside 1994, vol. 3: 1512)

After Independence, the Constituent assembly of India decided to phase in Hindi over a 15 year period as the only official language of India. This included an attempt to introduce Hindi as a language of schooling in areas where it was not spoken. This move was comparatively successful in Gujarat and Maharashtra, but not very successful elsewhere (Brass 1990:142).

English has considerable official status in India. It is an associate official language (with Hindi) of national government and administration and also has official status in many of the states. Bilingualism in English is high and it is estimated that $26 \%$ of the bilinguals in India have English as their second language (Annamalai 1994, vol. 3: 1652) English has considerable prestige in India and 'serves as a model and source for the modernization of Indian languages' (Asher 1994, vol. 3: 1653) 


\subsection{Dutch}

The Dutch are the only group under consideration whose presence in New Zealand was actively sought by the New Zealand government. After World War II New Zealand suffered from a shortage of labour and in that period New Zealand's immigration policy was shaped primarily by a perceived need for labour. The Dominion Population Committee was appointed in 1945 to consider New Zealand's population policy. This Committee supported immigration from the British Isles that would meet New Zealand's labour needs, and free passage was given to various suitable categories of British citizen. However, as the labour shortage continued in New Zealand's post-war boom, it was clear that Britain alone could not provide enough immigrants to meet New Zealand's labour needs. A bilateral agreement was negotiated between New Zealand and the Netherlands in 1951 allowing up to 1000 Dutch migrants a year whose occupations were not on the Occupational Priority List (OPL) (Trlin 1986: 6) and in 1951-52 Dutch emigration to New Zealand rose to 3747 from 1188 in 195051. Dutch immigration to New Zealand had started to rise prior to the bilateral agreement. In 1945/46 there were 20 Dutch immigrants intending PR - the largest number since records began (for this particular category: Arrivals by Nationality intending PR). By 1948/49 numbers had risen over the hundred mark to 147, next year they were at 291 and in the following year, as we have already said, at 1188 .

During this period the proportion of male/female migrants varied somewhat. The proportion of females fell to a low of $21 \%$ in $1949 / 50$, rising to a high of $51 \%$ in $1956 / 57$ (its highest mark in the post-war period was actually $55 \%$ in 1945/46 - 11 out of 20 immigrants). Most years (1945-1970) the percentage of females never fell below $45 \%$.

Dutch immigration continued fairly steadily throughout the 1950s, dropped somewhat in the sixties and has maintained at a rate of several hundreds a year since then. Between 1950 and 1968 25,000 Dutch immigrants arrived in New Zealand from Indonesia and the Netherlands, 6,000 of them as subsidised immigrants (Pearson 1990:114).

New Zealand encouraged Dutch immigration because of the need to expand the labour force rapidly. There were not enough immigrants arriving from Britain and the Dutch were seen as culturally and racially acceptable. They would 'fit in', they would 'assimilate'. Why did Dutch people want to come to New Zealand? 
There was relatively little emigration from the Netherlands until after World War II. Although Holland had been a great naval power (as who should realise better than the inhabitants of Nieuw Zeeland) and despite the existence of considerable overseas possessions, most noticeably The Dutch East Indies (Indonesia), the Dutch had not been great emigrants in the same way as the British. In 1946, 500 people emigrated from the Netherlands. Six years later at the height of the outflow in $1952,48,600$ people left the Netherlands.

The causes of this were varied. According to Vervoort, there was no strong economic basis for the sudden increase in Dutch emigration, rather the reasons were primarily social. If you were a twenty year old in The Netherlands in 1950, you had been born into the depression, then, just as that was lifting, you had been plunged into war and your country had undergone invasion and occupation by an enemy army, and you and your compatriots had come close to outright starvation. The post war reconstruction of Europe was only just beginning to show any dividends at all and the Netherlands was generally perceived as being desperately overpopulated. Between 1899 and 1945 the population of the Netherlands almost doubled, from 5.1 million to 10 million - this in a country not much bigger than Otago Province. The shooting war was over but the cold war had begun and you and many like you thought there would soon be another war on European territory - not surprisingly life in the 'old country' did not seem so good. Many young people made the decision to leave.

There were other factors as well. The 'loss' of Indonesia had a demoralising effect as well as depriving The Netherlands of considerable income and the terrible floods of 1952 put pressure on the agrarian population. Another factor which is mentioned by Vervoort and which has also been mentioned to me in informal conversations is the socially liberalising effect of the contact with the allied soldiers particularly the Canadians (who were the first allied troops to enter Holland in any numbers). The soldiers were seen as liberators, as heroes, but more than that they introduced young Dutch people to a 'new world' way of seeing that seemed to show up the 'old world' as hidebound and lacking in opportunity.

Post war emigration was unique; it arose quickly from within Dutch society; it was influenced by a feeling of social disquiet, mass fear of over population, a perception of economic difficulties and a clash of traditional religious values. As quickly as it rose it waned, its explanation cannot be found in purely economic or social theory; rather emigration was the result of a complex of [several factors], set in the timeframe of post-war Netherlands (Vervoort 1983:44). 
Most of the Dutch who emigrated to New Zealand were young and most of the men were labourers or skilled workers (Schouten 1992: 145-155). Dutch immigrants faced relatively little prejudice in New Zealand and that has made their experience of settling in New Zealand significantly different from that of the Asian or Polynesian immigrants. Both Asian and Polynesian immigrants have tended to use their culture as a shield against an often unwelcoming and hostile society. For the Dutch, their language and culture have not had to play this defensive role. Partly because of this the Dutch language has not had a very high profile for Dutch New Zealanders "...I have never actually pushed them to learn the language with the idea of preserving the language, I don't really believe in it really" (Dutch immigrant, father of 3 teenage children, quoted in Vervoort 1983:78). There is no desire to cast off or deny their Dutch heritage and there is a widespread assumption that children will go to Holland on a visit.

"It may be handy for them when they grow up, knowing things about it, especially when we are not around anymore, because it is in their blood, somewhere they want to know things about Holland, so I think it is important that they know all about how the Dutch are living and who their relations are". Mrs van Dijk added, "the children will learn also, by going to Holland" (Parents of three teenage children quoted in Vervoort 1983:78). 


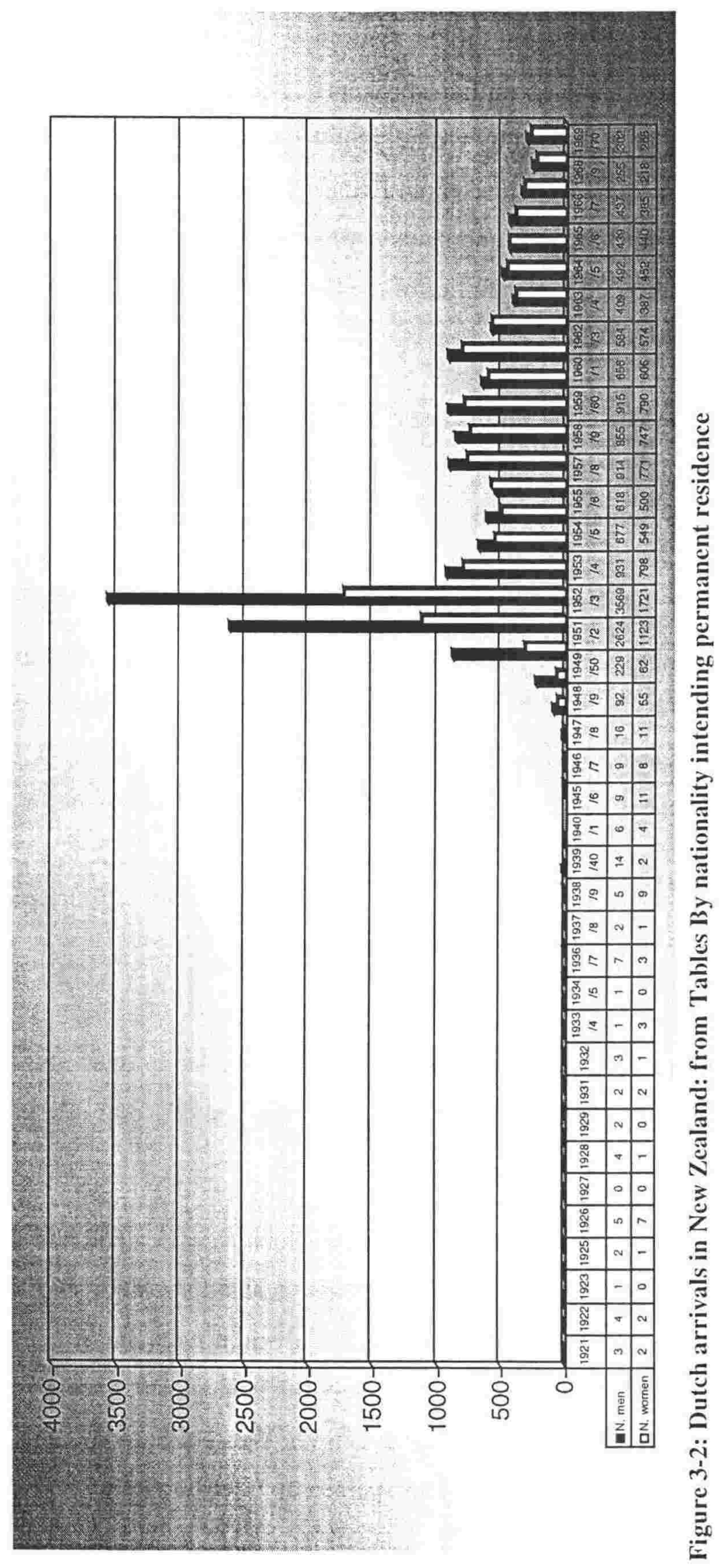




\subsubsection{Language situation in Netherlands}

Dutch is of course the only one of the languages under consideration which is closely related to English. Along with English and Frisian it belongs to the Low German branch of West Germanic languages. There are approximately 15 million speakers of Dutch in the Netherlands where it is the main language, spoken by virtually all the population and about another 6 million speakers in Belgium and a few speakers in France. In addition to speakers in Europe there is also some Dutch still used in the Netherlands Antilles and Suriname and Dutch is still spoken in the Dutch immigrant communities of the USA, Canada and Australia (Simpson 1994, vol. 2: 1072-1073).

The Netherlands, unlike India and Samoa has never been subject to an English speaking power, nonetheless, the modern dominance of English as a language of wider communication (LWC) is particularly marked in The Netherlands and

The main foreign language taught at secondary schools is English. In addition French and German are widely offered .... The medium of instruction at university level is Dutch. It is, however, common practice to teach language related subjects for language degrees in the target language (Verhoeven 1994, vol. 5: 2779).

In Friesland, Frisian is recognised as an official language as well as Dutch. It is spoken as a first or second language by approximately 400,000 people (two thirds of the total population of Friesland) (Verhoeven 1994, vol. 5: 2779).

\subsection{Samoans}

Western Samoa is made up of the two large islands of Upolo and Savai' $i$, the smaller islands of Manono and Apolina, and several even smaller islands of the coast of the larger ones. Its land area is about 1,130 square miles. American Samoa lies to the South-east of Upolo, about 50 miles away. (Davidson 1967: 10)

Of the three areas under consideration, Samoa is the only one with which New Zealand has had a direct colonial relationship (one could perhaps argue that New Zealand's relationship with India was to some extent mediated by the fact of British colonialism in India, but it certainly was not a direct colonial relationship). New Zealand does not have glorious record of administration in the Pacific Islands. New Zealand's stewardship of Western Samoa seems to have been characterised by relatively benign neglect interspersed by brief flurries of 
activity. Liu characterises New Zealand policy in Western Samoa as a "lack of policy" (Liu 1991: 81). Prime Minister Peter Fraser's instructions to Beeby in 1945 sum it up accurately

New Zealand has been shockingly neglectful of its Pacific Island dependencies ... I want you ... to give special attention to Western Samoa because it's a trusteeship territory.... tell me how long you think it will take to fit them educationally to run their own country (Beeby 1992: 211).

Because of the colonial relationship between New Zealand and Samoa that intertwines the history of the two countries, this section on Samoa will be a little more detailed than the historical sections on Gujarat and the Netherlands.

\subsubsection{Western Samoa and Christianity}

Most observers of modern Samoan society both in Samoa and in New Zealand comment on the deeply held Christian faith of most Samoans; '[t]oday Samoans pride themselves on being among the most devout Christians in the world." (O'Meara 1990: 15), '[i]n New Zealand, Samoans are holding fast to their language, to their belief in God, to their practises, and to their customs and traditions.' (Ngan-Woo, no date: 9), '[Christian religion] in Western Samoa remains one of the major formations producing identity' (Liu 1991: 224)

Christianity arrived in Samoa in 1828 brought by Tongan Methodist missionaries, two years later John Williams headed a mission from the London Missionary Society (L.M.S.)

(O’Meara 1990: 44),

To the people as a whole, the church's opposition to war, private violence and brutal forms of punishment brought a promise of personal security greater than they had previously known. Within ten or fifteen years of Williams's first visit, the great majority of Samoans had become nominal Christians. [Matai tended to instruct all the people under their control to convert]. The authority of the pastor over his congregation, and of the matai over his household, remained central to the Samoan concept of religion (Davidson 1967: 34- 37)

The missionaries also brought literacy with them

When the Samoans encountered writing for the first time in the early 1830 s, they flocked to the houses of the teachers John Williams had brought from eastern Polynesia "to learn this mysterious art, many of them coming eight to ten times each day, to be taught their letters." By 1842 there were in the Samoan Islands, in addition to 11 missionaries, some 224 native teachers, most of them Samoan, and such was the eagerness for instruction that paper for writing had become a principal medium for exchange ... (Freeman 1983: 156) 
In the 1870s there was an increase of European demand for land in Samoa and a war that lasted from April 1869 to May 1873 encouraged Samoans to sell their land. However as the extent of the land sales was realised the Samoans were horrified and shocked

Even before the war Samoan leaders had been anxious to restrict land sales. Now they developed a repugnance to alienation that took such deep root that today - ninety years later - the inalienability of Samoan land is regarded as a corner-stone of custom (Davidson 1967: 46)

\subsubsection{New Zealand Administration}

Western Samoa came under New Zealand administration in 1914. Western Samoa had been administered by Germany since February 1900 when Germany declared a protectorate over all of Samoa west of 171 degrees longitude. "[O]ver all, the period of German rule was the most progressive, economically, that the country has experienced." (Davidson 1967: 78). At the outbreak of World War I, New Zealand occupied the territory in the name of Great Britain. Western Samoa was to remain under New Zealand jurisdiction until independence in 1962.

On 7 November 1918 the ship Talune, known to be carrying passengers with pneumonic influenza, was allowed to berth at Apia without quarantine being imposed. Twenty-two percent of the population of Western Samoa died in the consequent epidemic. The effect on all aspects of Samoan life was catastrophic (Meleisea 1987:121)

The New Zealand government ... felt bound both to examine the causes of the disaster and to take account of the Samoan reaction. It appointed a commission of inquiry, which visited Samoa in the middle of 1919. By its fair-mindedness and its thoroughness, the commission did much to restore New Zealand's reputation. But it was, on the whole, an appalling story that it brought to light (Davidson 1967: 95).

In 1919, when it became obvious that there was going to be a delay in issuing the mandate, New Zealand passed legislation to enable it to initiate civil administration. Davidson claims that the debate that preceded the passage of the legislation shows that the 'major part of the New Zealand parliament entered upon its responsibilities towards Samoa in a frame of mind that was naive, ill-informed and out-dated' (Davidson 1967: 99). In 1920, Samoa formally became a mandated territory of the League of Nations, administered by New Zealand. 
In 1923 Brigadier-General George Spafford Richardson became Administrator - amongst other things he arranged that the proceedings of the Fono of Faipule (a consultative body) should be published in Samoan (Davidson 1967: 105).

The most notorious incident in the period of New Zealand's administration of Western Samoa was that of the Mau. In 1926 leaders in the Samoan and local European communities formed an organisation called O Le Mau. The aim of the organisation was to "procure by lawful means the alteration of the laws or constitution of the Territory wherever these were "prejudicial to the welfare and interests of the people"' (Barrington 1968: 35). The then Administrator of Western Samoa Brigadier-General George Spafford Richardson had the Mau proclaimed a seditious organisation and refused to deal with it in any way. At the same time he placed restrictions upon the movement of several prominent Samoans and repealed a number of matai titles. The Mau then proceeded to petition the League of Nations to grant self-government to Samoa or to transfer the mandate from New Zealand to Great Britain. Neither of these were actions were taken and New Zealand was left to deal ineptly with the growing discontent in Samoa. Members of the Mau began a campaign of passive resistance against the Administration; withholding taxes, withdrawing children from government schools, refusing to register births and deaths and refusing to acknowledge the authority of officials appointed by the administration. Eventually two cruisers were sent from New Zealand to Western Samoa and armed sailors arrested four hundred Mau members. Hundreds more presented themselves, asking to be arrested, in a fresh wave of civil disobedience with which the administration was incapable of dealing. In 1928 Richardson was replaced by Colonel Stephen Allen but he was unable to resolve the conflict between the Mau and New Zealand administration. On the 28th December 1929 (Black Sunday as it came to be known) a Mau procession took place in Apia. Police attempted to arrest a leading member of the movement and in the fracas that followed 11 Samoans, including the tama'aiga ${ }^{9}$ Tupua Tamasese Lealofi III, and one European constable were killed. Allen's reaction was to send for marines and a cruiser. Tamasese died a martyr's death

My blood has been spilt for Samoa. I am proud to give it. Do not dream of avenging it, as it was spilt in maintaining the peace. If I die, peace must be maintained at any price (Davidson 1967: 138)

\footnotetext{
'Tama'aiga are the 'sons of the family'. They have a semi-royal status in Samoan society.
} 
Allen was succeeded by Brigadier-General Herbert Hart in 1931 and during his term of office tensions slowly eased although the bitterness created is not forgotten to this day. When the Labour Party came to power in New Zealand in 1935, it was generally seen as a propitious event by the Mau and, according to Meleisea, Labour's regime, which included repealing anti-Mau legislation was generally welcomed in Samoa (Meleisea 1987: 149-152).

WWII both deflected New Zealand's attention (such as it had been) from Samoa and led to social and economic changes, largely caused by the money pumped briefly into the economy by the U.S. soldiers who were stationed in Samoa (Davidson 1967: 157, Meleisea 1987: 153).

Constitutionally, Samoa was still in 1946 almost as far from self-government as it had been [at the time of the $\mathrm{Mau}$ ] ten years earlier. But, in some significant respects, the situation had changed. A new generation of Samoan leaders had emerged that was better equipped to take an active part in the work of government when the opportunity should arise. These younger men did not possess a more adequate formal education than their predecessors, since New Zealand policy had nothing towards providing them with it. ... But they possess a confidence ... in arguing questions of politics and economics with European administrators. (Davidson 1967: 159).

On 13 December 1946 the General Assembly of the United Nations approved the trusteeship agreement for Western Samoa. This was followed by a United Nations mission to Samoa in 1947 that recommended a definite framework be provided that would outline the steps to be taken to achieve independence for Western Samoa. In 1947 the New Zealand parliament passed the Samoan Amendment Act which established the Legislative Assembly (Davidson 1967: 164-187, Meleisea 1987: 147-150). The Assembly consisted of 11 Samoan members, 5 European members and 6 official members. It could make law but could be vetoed by the High Commissioner appointed by New Zealand (Meleisea and Schoffel 1987: 149).

All proceedings of the assembly were conducted in Samoan and English.

As a matter of propriety, the Fatua and the Samoan members always spoke in their own language [would sometimes struggle to find appropriate Samoan expression of 'English' concept] only once during my period of membership - when Tofa Tomasi [used] 'economic stabilization' - did a Samoan member use English in debate. The European members .. spoke wholly in English (Davidson 1967: 216).

In 1962 a United Nations supervised plebiscite was held in which $79 \%$ of the voting population voted their assent to the proposed constitution and to Samoa becoming an independent nation. General elections were held the same year and in 1962 Western Samoa became independent. Perhaps the most unusual feature of the Samoan constitution to Western democratic eyes was that the suffrage was largely restricted to matai (chiefs) (Meleisea and 
Meleisea-Schoffel 1987: 155-157). Thirty years later, universal suffrage was introduced to Samoa (Liu 1991:31).

Samoan culture was extremely complex, and it had proved peculiarly resistant to the generally disintegrating effects of contact with the West; but the Samoans seemed to have relied at one time on one institution and at another time on another in their efforts to maintain their cultural autonomy and self respect. Europeans seem never to have been accorded even the outward marks of deference so characteristic of the colonial situation; but the Samoans had accepted - or absorbed - many elements of European culture, and individual Europeans and part-Europeans had played leading roles in their political life. (Davidson 1967: 6)

\subsubsection{Population and immigration}

Samoan arrival in New Zealand does not go over the 100 per annum mark until 1945/46 when 158 people arrived, 81 of whom were female, and 77 male. We can see immediately that this is a different type of migration process from the male sojourner migration of the Gujaratis. Initially many of the Samoans coming to New Zealand were coming for education, some of them on New Zealand government scholarships, but soon their ranks were swelled by those who wanted to work in New Zealand.

By the early 1960s when Samoa became independent and Samoan emigration to New Zealand started to increase, the population of Samoa had grown enormously. In 1945 there was a population of 68,197 , by 1961 it had grown to 114,427 people, a $68 \%$ increase in 16 years. $50.2 \%$ of the population was under the age of 14 . Most people ( $81 \%$ ) lived in the coastal villages of Upolo and Savai’i where population densities grew rapidly from 114 to 192 person per square mile in Upolo and from 27 to 46 in Savai'i between 1945 and 1961.

(Davidson 1967:). This was obviously one factor in the flow of immigrants to New Zealand. Another was the New Zealand desire for more workers. In the 1960s this desire was so strong that labour recruiters were paid a bounty for the workers they recruited. (De Bres and Campbell 1976, quoted in Pulotu-Endemann \& Spoonley 1992: 85). The outflow of immigrants was and is of concern to Samoans (Meleisea and Meleisea-Schoffel 1987: 161) as it has a strong effect on Samoan society.

Perhaps the most difficult change, the one that causes the most heartache and regret today, is the break-up of families. A generation ago families were still united; in good times and in bad. The village had not yet lost many of its most promising young people. Today migration is often expected and in many cases desired - yet it is also feared. Parents become separated from their children, friends are lost, and brothers and sisters scatter as they disappear into waiting airplanes. (O'Meara 1991: 70) 
Liu points out that immigration has also operated as a sort of a 'safety valve' for Western Samoa (Liu 1991: 72, ftnt 9).

Other important social trends noted by Meleisea and Meleisea-Schoffel are the increasingly high aspirations for education, the growth of contact with international organisations, the development of tourism, environmental problems and improved communications infrastructure. They also point out the increasing dependence on foreign aid and remittances from New Zealand (Meleisea and Meleisea-Schoffel 1987: 162-168).

As with the Dutch and in contrast with the Indians, not only were no special legal and policy barriers placed in the way of Samoan immigration, but, on the contrary, after Samoan independence a Treaty of Friendship was signed (in 1962) between the two countries and Samoa was given a special quota for immigrants who would be allowed into New Zealand in addition to those who qualify under normal immigration policy (Trlin 1986:6). The quota still operates today (New Zealand Immigration Service 1996: 25). The number fluctuated between 1100 and 1650 in the 1960s and 1970s (Pulotu-Endemann \& Spoonley 1992: 85). Samoan immigration to New Zealand was marked not only by equal male/female immigration but also by whole family migration (Pulotu-Endemann \& Spoonley 1992: 86). 


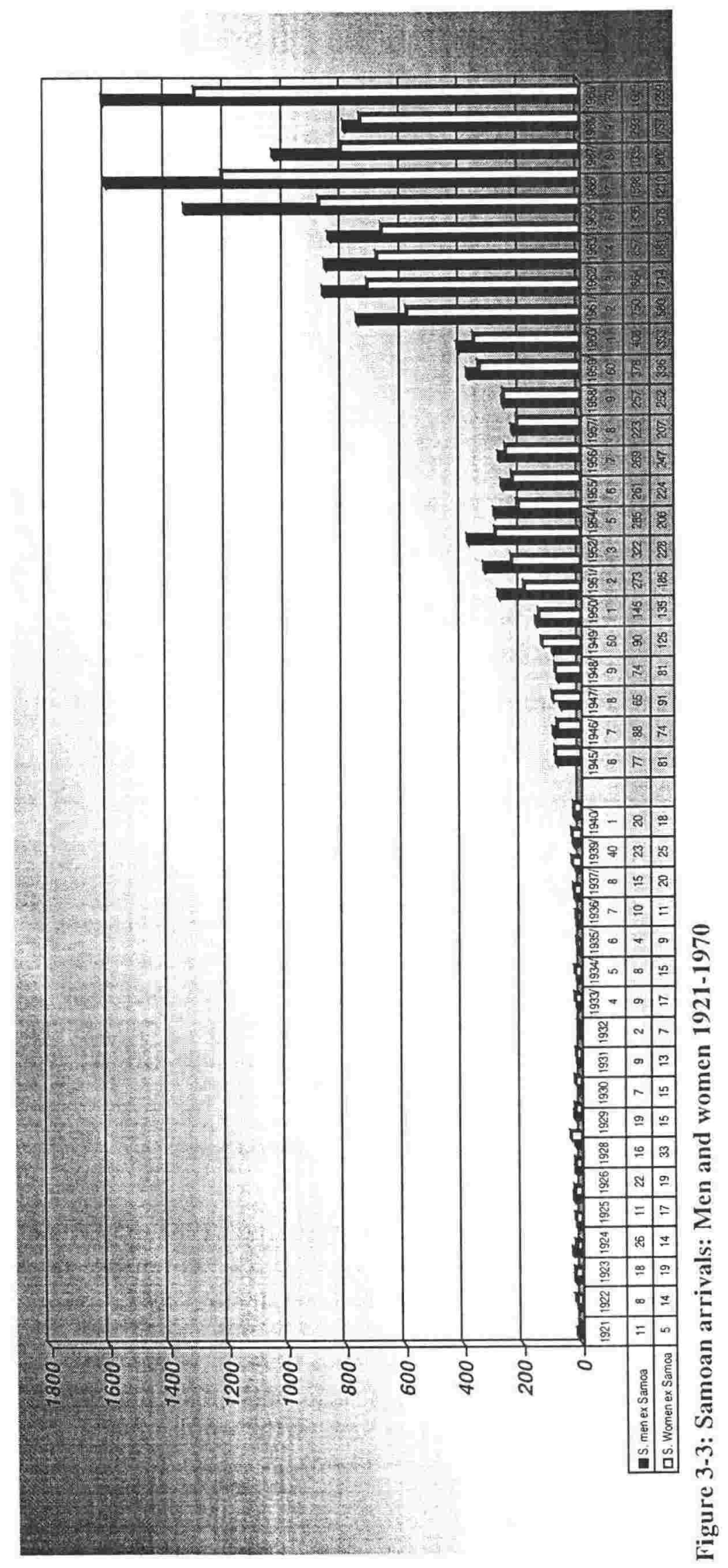




\subsubsection{Language situation in Western Samoa}

Samoan is a member of the Polynesian sub-branch of the Oceanic branch of the Austronesian family. It is closely related to East Futuuan, Niuaf'ouan, Pukapukan, Tokelauan and Tuvaluan (Mosel and Hovdhaugen 1992: 4). Samoan is spoken in Western Samoa, in American Samoa and of course in Samoan immigrant communities in New Zealand, Australia and the USA.

There is very little geographical variation in Samoan although Mosel and Hovdhaugen note some differences between the Samoan spoken in Western Samoa and that spoken in American Samoa (Mosel and Hovdhaugen 1992: 8) and have chosen to base their grammar on the Samoan of Western Samoa.

\subsubsection{Stylistic variation in Samoan}

The major variation in Samoan is the sociolinguistic variation of the tautala lelei (translated as 'good speech' (Duranti 1994: 44-46) or 'literary language' (Mosel and Hovdhaugen 1992: 8)) and tautala leaga (translated as 'bad speech' (Duranti 1994: 44-46) or 'colloquial language' (Mosel and Hovdhaugen 1992: 8)). In addition to this is "the difference in vocabulary between a basic general level of words and several layers of a limited number of polite words ('upu fa'aaloalo)" (Mosel and Hovdhaugen 1992: 8). The differences and interactions between these varieties are described by different writers in different ways. Mosel and Hovdhaugen say

Many Samoans have very strong feelings concerning the difference between tautala lelei and tautala leaga. Tautala leaga is regarded as vulgar even by persons who practically never use the other variant of Samoan, while tautala lele $i$ is considered "the hallmark of good education and good breeding" (Milner 1966:xv). Young people in general seem to have a more relaxed attitude towards the two variants. (Mosel and Hovdhaugen 1992: 9)

Duranti however characterises the role of the two varieties somewhat differently

Contrary to what was stated by several authors in the past (see Cook 1988, 55; Milner 1966, xv-xvi), good speech is not the "formal pronunciation," at least not in any of the usual meanings of the term "formal" (cf. Irvine 1979), and bad speech is not "colloquial pronunciation" either. With the exception of a few words and phrases, the great majority of fono [meeting of the village matai. Duranti 1994:28] discourse recorded ... was in bad speech. When asked about it, participants told me that they felt bad speech was the appropriate style for speaking in a fono. In the words of an old orator, "in a fono, bad speech is good." (Duranti 1994:44-45) 
There is a considerable amount of code-switching between varieties

The use of different forms of speech can switch within conversations or even in individual sentences, varying with the context and person(s) addressed. ... In addition to these two forms, the oratorical (high) form of speech also exists, used when reciting faalupega, during fono and other formal occasions. The use of different forms of speech can establish or recognize status ... express displeasure (using "bad" speech), or vary with occasion (lotu are almost always in "good" speech). The different forms of language also represent knowledge and power, so that mistakes in speaking, particularly in oratory, can prove costly to the user, and usually in all cases result in embarrassment. The ability to speak all forms can vary to a wide range ...

The ability and desire to use the different forms of Samoan also varies with class, ethnicity, and gender. Aspirations to politics usually require gaining extensive knowledge of the high language, but for many people this knowledge may not be relevant, so that many overseas-educated Samoans may not be able to use or understand much of this language. (Liu 1991: 86)

The tautala lele $i$ is "the basis of the written language and the language of education" (Mosel and Hovdhaugen 1992: 9) thus if Samoan respondents to the questionnaire said that they could read and write Samoan, they had, at least to some extent, mastery of the tautala lelei. The formal or high language of oratory includes the 'upu fa' aaloalo as well as the mastery of what Duranti calls 'ceremonial expertise' (Duranti 1994:36) in such areas as the fa'alupega (ceremonial address) (Duranti 1994: 32). This oratorical or high language is restricted in domain, function and user as can be seen by the reaction of some Samoans when, in the 1960s, Samoan educators developed a Samoan language and customs course for use in Samoan schools

[They] came under heavy criticism initially both for recording the oratorical language and for making freely available to students what had hitherto been considered the property of certain chiefly groups. (Benton 1981:91)

In the questionnaire, this level of Samoan was translated as 'formal Samoan' in English and was referred to as gagana Samoa fa'aaloalo in Samoan.

\subsubsection{Language and education in Western Samoa}

Both under the New Zealand administration and as an independent nation, the education system in Samoa has operated in both Samoan and English, with Samoan tending to be used in the lower more universal levels of education and English becoming more and more widespread in the higher and more elite levels of education (Benton 1981:85-92). There is universal literacy in Samoan and has been for some generations (Benton 1981: 91) but 
There remains a suspicion that education in Samoan is in some way second class, and that there is a resistance on the part of educators to the use of Samoan as a medium of instruction beyond the elementary school level. (Benton 1981: 90)

Liu puts this even more strongly

The missionaries constructed a hierarchy of language within the discourses of colonialism, where English marked closeness to the missionaries and by extension their God. The hierarchy of languages, which grew with the introduction of indentured labour (Chinese, Solomon Islander) and German colonization, reproduces itself in the education system, so that English, taught not as a second language (ESL), but as the primary language, is the dominant language for instruction in all subjects, with the exception of Samoan language. The hierarchy of schools and class follows the hierarchy of languages, so that almost all instruction in Samoa College is in English, as is both public and private speech of most of the upper classes, whereas in schools of lower status teachers use more and more Samoan, as the English speaking, reading and writing ability of students declines. (Liu: 1991: 151)

If Liu's analysis is correct and ability in English, in a Samoan context, marked and to some extent still marks a Samoan's closeness to God then it is ironic that in a New Zealand context it is the Samoan language that has become a marker of closeness to God and strength of faith. In the immigrant context the bundle of attributes that go together to mark being true to fa'aSamoa and a Samoan identity include, for many, Samoan language and, worship at a Christian (Samoan) congregationn.

\subsection{Ties with the homeland}

The next set of graphs shows numbers of New Zealand Residents returning to New Zealand after travel overseas. There are figures for the Indians and Samoans, but none for the Dutch this is because the table from which these figures were drawn concerns itself only with 'Persons Other than European'. The tables of course, do not indicate where the New Zealand Residents were returning from. That is, they may well have been to Timbuktu, rather than 'home', but they do add weight to considerable community testimony, that many people, especially men did travel between New Zealand and home, sometimes on a regular basis. That the Chinese and Indian communities were known for their visits 'home' from an early stage in their immigration histories is illustrated by the following quotation

The tendency for Chinese residents of New Zealand to pay periodic visits to their native land is well known. . . . This tendency is also noticeable in the case of Hindus . . (Statistical Report on the Population of New Zealand 1921: vi) 


\subsubsection{Indian}

The figures for Indian New Zealand residents returning show a fairly straightforward picture. The relatively sharp fall for $1939 / 40$ presumably reflects the start of W.W.II. After the war we see a fairly steady rise. The one major peak for the years 1947-1949 presumably reflects people who were caught in India by the war, and/or who did not like the look of independence and partition. After this we see a fairly steady rise in numbers. Note the comparatively dramatic growth in the number of women, but overall numbers remain low reflecting the small size of the Indian community in New Zealand at the time. In 1966 the Indian population of New Zealand was $6843,37 \%$ of whom were female (Pearson 1990:87).

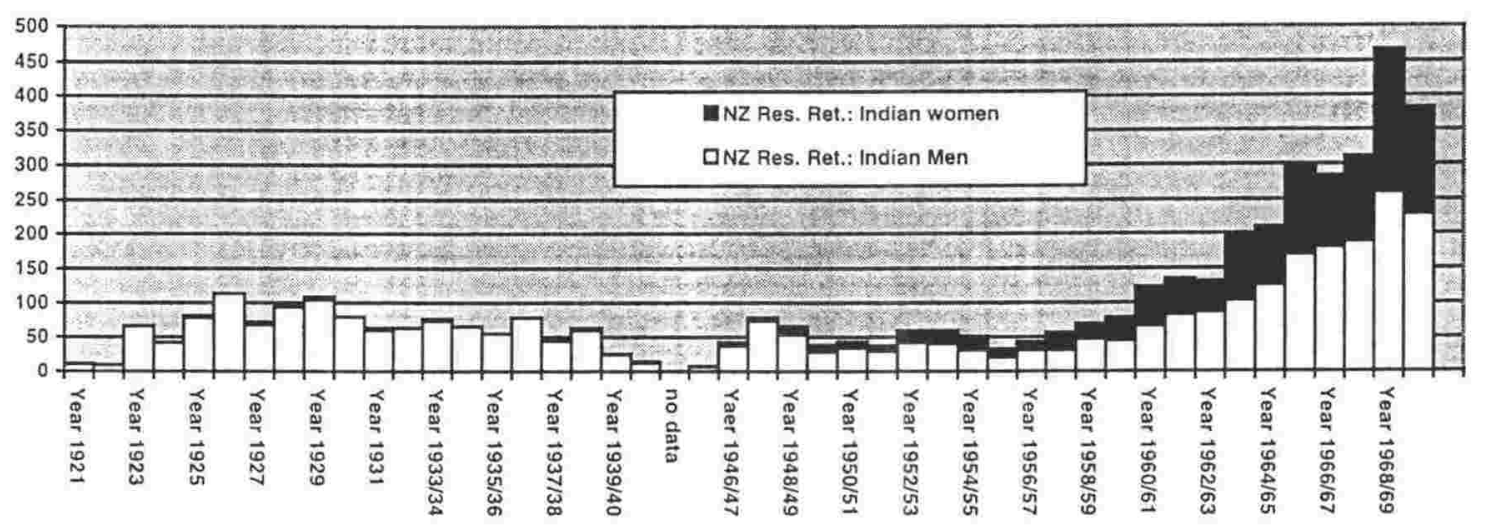

Figure 3-4: New Zealand residents returning to NZ: Indian men and women 1921-1970

\subsubsection{Samoan}

The Samoan figures are the most straightforward to interpret, showing a steady rise in Samoan New Zealand residents returning. This presumably reflects the concurrent rise in the Samoan population of New Zealand and is some indication of the numbers of Samoan people returning to Samoa for a visit and then coming back to New Zealand. 


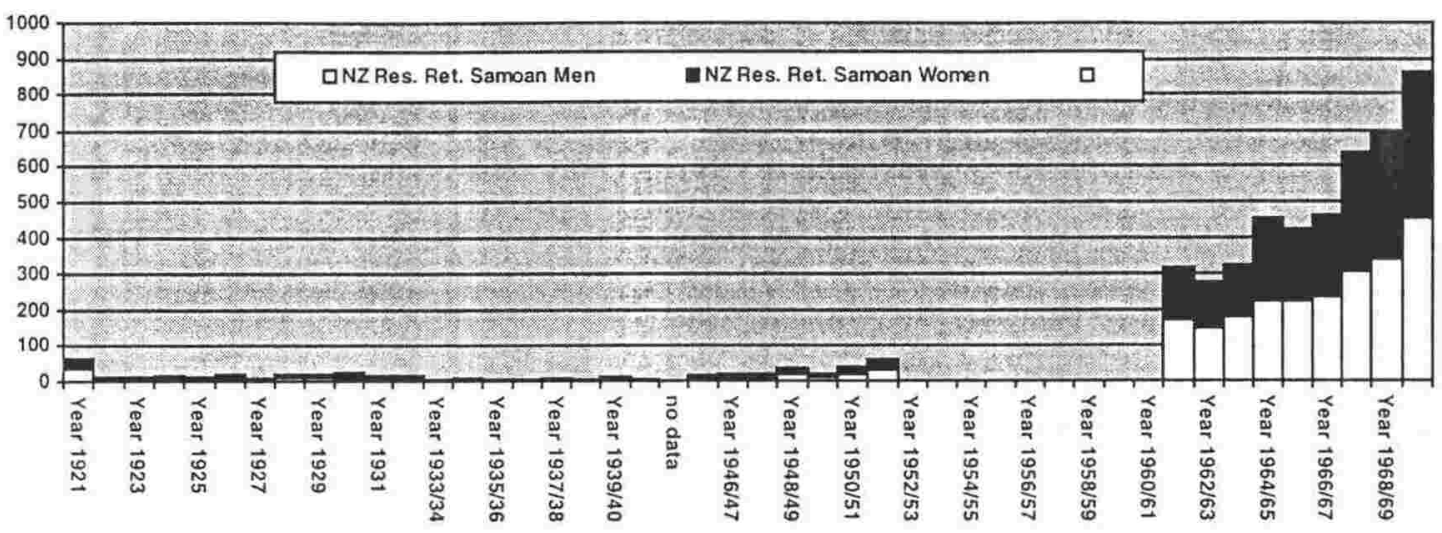

Figure 3-5: NZ residents returning to NZ: Samoan men and women $1921-1970$

\subsubsection{Dutch}

As noted above, there are no comparable figures for the Dutch residents of New Zealand. However, most (90\%) of the respondents to the questionnaire had been from New Zealand to the Netherlands for a visit. It seems that the Dutch too, have a fairly high rate of visits 'home'.

All three groups under consideration have in common a pattern of return visits home. It should be borne in mind that the function of these visits can vary widely from time, to time, place to place, culture to culture and individual to individual but they must all surely involve some renewal of both linguistic and cultural ties, as well as, in many cases, familial ones.

\subsubsection{The immigrant experience of dislocation}

Fishman points out that ' $[\mathrm{t}]$ the where and why of language shift are necessarily intimately related' and goes on to talk about the why in terms of various kinds of dislocation Fishman 1991:55-67).

Immigration is one of the major causes of language shift. When speakers of language A move to country where language B is dominant then, in all likelihood, the process of shifting from language $\mathrm{A}$ to language $\mathrm{B}$ will begin. This in turn is likely to produce a move to language maintenance so immigration is both a factor in language shift and in language maintenance. Fishman, in discussing the process of reversing language shift, says that one must have a 'framework' for the investigation of language shift, undertake 'data-gathering' so that components of the process are known, and investigate the 'causes'. Amongst the causes will 
be found physical, demographic, social and cultural dislocation. Immigration produces all these forms of dislocation. Below they are considered in turn.

\subsubsection{Physical dislocation}

The physical dislocation is, perhaps, the most striking aspect of the immigrant situation. All the immigrant groups considered here are a long way from their homelands. Before the days of comparatively cheap air travel, the time and expenses taken to travel between New Zealand and the homeland was considerable. Nonetheless, both the Gujaratis and the Samoans were likely to assume that they would return home some day. The immigration process for the early immigrants in both groups was sojourner migration and a return home, at least for a visit, was quite likely, despite the expense and the time involved. The Dutch on the other hand, thought they were coming for ever, many of them thought they would never see the Netherlands again. In fact, most of them have returned home for visits, but in the 1950 s the jumbo jets of the 1970s could not be foreseen. These different attitudes to the physical dislocation involved in immigration had their effect on attitudes to assimilation and to language and cultural maintenance in the new country.

\subsubsection{Demographic dislocation}

The demographic dislocation caused by immigration nearly always manifests itself in the incomplete representation of ages in the new immigrant community. This was the case for all three communities under investigation, most of the immigrants in the initial period of immigration were fairly young. This means that when the first children are born in the new community, there are often no grandparents for them to interact with and to provide another layer of MT interlocutors and teachers.

Demographic dislocation may also manifest itself in the imbalance of gender in the new community. This was not the case for the Dutch and Samoan immigrants, there were fairly equal numbers of men and women even in the very early days of immigration. For the Gujaratis, of course, there were initially very few women and this meant that language and cultural maintenance for the new generation was initially of concern to only a few families in New Zealand. Thus, although the Gujarati immigrant community has been established in New Zealand for at least 50 years longer than the Dutch and Samoan communities, it did not have 
to concern itself, as a community, with questions of language and culture maintenance for the New Zealand born members of the community until the 1940s.

\subsubsection{Social dislocation}

One form of social dislocation that often affects immigrant communities is the dislocation that occurs when only one section of society immigrates. This was certainly the case with the Gujarati and Dutch communities. The Gujarati immigrants were drawn from the villages around Nausari and they tended to have farming or small tradesmen backgrounds. They were all from the lowest caste group, no Brahmins or Kshatrias seem to have immigrated. Amongst the Dutch from the Netherlands, a similar social profile was evident. Immigrants tended to have a farming background and/or to be trained in a trade. The Dutch who came, in effect as refugees, from the former Dutch East Indies tended to come from a different background. They were more likely to have a university education and more likely to have earned their living in an office.

In the case of the Samoan immigrant community the social dislocation was not so marked, immigrants were more likely to be drawn from a wider range of Samoan society but even so, Samoan families who settled in areas where there were not many Samoans would be subject to a similar socially dislocating experience.

The restricted range of social backgrounds in an immigrant community has an effect on language maintenance as well. The natural range of language that a child might hear when growing up in the homeland is not available. The language and culture of the homeland may seen unsophisticated to the New Zealand-born child who does not have access to the full range of language and culture that would be available to them at home.

\subsubsection{Cultural dislocation}

Cultural dislocation can be extreme in the new country. For the Gujarati immigrants to New Zealand the dislocation was perhaps at the furthest extremity of the scale, when compared to the other two groups. Religious observance, dietary observance, festivals, schooling, marriage practices, even the writing systems were completely different. A vast new cultural apparatus needed to be mastered, at least to the point of being understood, even if not practised, in order for the immigrant to function efficiently in the new society. 
The Samoan immigrants were coming to a country and a society very different from the one they had left but there were some points in common. In the first place the New Zealand bureaucracy was a constant in both societies. Christianity was the dominant religion in both countries, there were no difference of dietary laws, the schools were not the same but they had been created by the same Department of Education and the upper reaches of the Samoan education system were intended to channel student into the New Zealand system. The writing systems were the same. For all that the differences were great and publications such as Understanding Samoans (Vocational Guidance Council 1987) were written to explain the difference both to Samoans and to Palagi. The Samoan communities in New Zealand were eventually, in the bigger cities, large enough to recreate much of their cultural structure, especially that surrounding the church, in New Zealand. An obvious example of such a process which has had an effect on language maintenance is the establishment of Samoan language Pastor Schools and Sunday schools.

The Dutch also suffered cultural dislocation but compared to the Samoans and the Gujaratis they dislocation was not as great. They too shared religion and writing system, they came from an industrialised society unlike the Gujaratis and the Samoans. The Netherlands was in fact more heavily industrialised than New Zealand. The education systems were different, but formed within the same north European, democratic, Judeo-Christian cultural framework. The Netherlands had been chosen as a source country because it was thought that Dutch people would be 'like us' and to a large extent that was true. The Dutch did, nonetheless, suffer culture shock in New Zealand.To say that the Dutch were not as culturally distant from New Zealand society of the 1950s and 1960s as the Gujaratis and Samoans is not to say that they were particularly close.

That cultural dislocation inevitably has its effect on language and culture maintenance. At the most basic level, because the artefacts of its own culture no longer surround the community, it can not longer pass the knowledge of them on in a completely unselfconscious manner to the next generation. It may simply not be possible to access parts of the culture that could be easily accessed at home. For instance, because no Brahmins immigrated to New Zealand, it was not possible for Gujaratis in New Zealand to carry out many of the religious ceremonies (such as those connected with marriage) that they would participate in at home. Language is situated in culture and the more complete the homeland cultural structure can be in the new country the more support is provided for the MT. Most immigrant communities attempt a compromise. They realise it is not possible to import all their cultural structures into the new 
country, they may not even wish to do so, but they try to establish some cultural framework in the new country. How extensive this framework is depends on the community.

\subsection{Summary}

The Gujarati, Dutch and Samoan immigrants all arrived in New Zealand at different times, in different ways and were received with different attitudes by the New Zealand government as represented by its legislators and officials, and by the New Zealand society as represented by the individuals, neighbourhoods and neighbourhood institutions (such as schools) with which they found themselves in contact.

The Gujarati have the longest and most fragmented immigration history of the three groups and were received with the most explicitly racist attitudes. The Dutch have the most compact immigration history (although there has been a steady trickle of Dutch immigrants since the 1950s) and were received with the greatest degree of official approbation and, indeed, encouragement. They are also the group that has been most enthusiastic about assimilating into the general New Zealand society, and the group which, of the three, seems to have had the least trouble in doing so. The Samoans, the most recently arrived, are, as it were, positioned between the other two. New Zealand has a special immigration agreement with Samoa and technically, the Samoan immigrants have always been welcome here. The warmth of that welcome however, has fluctuated somewhat over the last 40 years. McKinnon comments that to New Zealanders, Pacific Islanders were not 'foreigners' or 'race aliens' but rather 'a different kind of Maori' ${ }^{10}(1996: 40)$. This seems to have meant that while Samoans, like the Gujaratis, came up against racist attitudes and structures in New Zealand society, the racism was of a different kind, not embodied in official policy and not denying, in toto, their right to be here. These varying settlement processes and the differing valencies of the role of racism in each community's experience, have affected their relationships with the wider New Zealand society today.

\footnotetext{
${ }^{10} \mathrm{He}$ also points out that this is definitely not how Samoan people in New Zealand see themselves.
} 


\section{LANGUAGE POLICY}

The term and the concept of Language Policy would appear to be modern although policies about language are thousands of years old (Fishman 1989:265, 271, Wardhaugh 1987:9). In fact, the term language policy does not appear to have been widely used in linguistics literature until the last ten years or so. As Corson says

Language policies are now receiving world-wide attention because of the great population shifts that occurred over the last two or three generations. These shifts highlight language issues that were formerly unnoticed, even in those countries where there were always significant language minorities. . . . Stacy Churchill (1986) sees major changes occurring everywhere in national attitudes to minorities. He sees the most potent factor in this move to the recent development of an international climate of opinion favouring the more open and tolerant treatment of minorities. (Corson 1993:73)

It is this development that has brought the topic of language policy within the scope of a study of minority immigrant language maintenance and shift. There is not a great deal of language policy pertaining to minority immigrant languages in New Zealand but in the last decade, small interest groups have begun to lobby both for more state assistance for minority immigrant languages and also, more generally, for an over-arching language policy in New Zealand. Much of this effort has been inspired by the development of a national languages policy in Australia. This chapter first discusses language policy and planning in general and the history of language policy in the UK, USA and Australia. This provides necessary background for the understanding of how such issues have developed in New Zealand. The discussion then moves to language policy in education, broadcasting and immigration in New Zealand and to the national languages policy discussion document Aoteareo. To the extent that there has been explicit policy about language in New Zealand, it has often been about Maori language. Although this is not strictly of concern to minority immigrant language groups in New Zealand, nonetheless it provides the context in which such fragmentary and ad hoc policy as does exist about minority immigrant languages has been made. It also provides the context in which the lobby for a national languages policy in New Zealand had developed.

\subsection{Language Policy and Planning}

It is not altogether self-evident of what language policy should or does consist. Broadly speaking language policy is any policy decision that affects language in some way. Narrowly speaking language policy is a policy decision taken within the framework of a languages' 
policy with the conscious intent of affecting the language behaviour of the people accessible to the policy makers' control. Language policy decisions in the broad sense have been taken for centuries and have had a great effect on our attitudes towards language issues. Some of these decisions have been specifically about language and some have not but what separates them from the narrow definition of language policy is that they have not taken place within an explicit language policy framework. Language policy decisions in the narrow sense are comparatively more recent.

\subsubsection{Language planning}

Where language policy is discussed, language planning is often mentioned and it is not always easy to know what the difference is between these two concepts and how writers on the subject perceive that difference. According to Kaplan, language planning came into existence after the Second World War and 'lent itself to a conceptualization of nation as a monolingual entity' (Kaplan 1990:3-4). Karam suggests that Haugen was the first to use the term language planning in 1959 and notes that he introduced it in the course of describing the Norwegian attempt 'to achieve a language expressive of nationalistic individuality' (Karam 1974:104-105). Rubin claims that the term 'language planning' was barely known at the time of the Language Planning Conference in Honolulu in 1969 (Rubin 1983:329). It was however well enough known by that time for Kloss to have made his well-known distinction between corpus planning and status planning. Kloss identifies language corpus planning with codification and language status planning with policy (Kloss 1969:81-3, cited in Karam 1974:104-5).

Language planning, specifically status planning for those who follow Kloss's distinction, has often been considered in conjunction with language policy, but there is no generally agreed hierarchy whereby one subsumes the other.

In the introduction to Advances in Language Planning (Fishman 1974a) Fishman talks about planning and policy without making a clear distinction between the two. Articles about policy appear in the book, which seems to suggest that policy and planning are one and the same or else that planning includes policy. Fishman notes that Haugen listed policy formulation as part of language planning, and says that the policy stage or dimension of language planning is the most frequently observed 'aspect of language planning' (Fishman 1974b: 16-17). Tauli notes 
Language planning is the methodical activity of regulating and improving existing languages or creating new common regional, national or international languages. Often the use of the term 'language planning' includes governmental linguistic policy in the widest sense (cf. Belgium or India) or it is used only in this meaning. But it is more expedient to employ the traditional term language policy for the latter meaning. (Tauli 1974: 56)

Kaplan says that

language policy [is] the inevitable outcome of language planning, whether formally stated or merely implicit in the actions of agencies of government. (Kaplan 1990:8)

According to Cobarrubias status planning

is basically done by politicians, statesmen, or a policy making body ... [and] decisions conform to ideologies of the power elite or respond to conflicting ideologies ... [of] the power elite and ... other constituent groups (Cobarrubias 1983:62)

This seems yet again to suggest that status planning and language policy are one and the same thing. Cobarrubias made the above statement in the context of a discussion about postcolonial choice of official language in African countries and this brings up two points worthy of notice when considering the terms 'status planning' and 'language policy'. Much of the earlier writing about status planning or language policy is concerned with the question of official language/s in post-colonial societies eg. the Philippines, India and Africa. Whitely for instance, writing about language policies in independent African states, discusses the 'implicit or explicit choices on the official medium of communication' (Whitely 1974:187). There seems also to be a fairly widespread assumption that status planning or language policy is something that applies only to 'new' states such as the post-colonial states making official language choices or perhaps to slightly less new states that have a particular language question they need to address. Wurm for example writes about Australian language policy solely in terms of policy about Aboriginal languages (Wurm 1974). Rubin, writing in 1983, makes this point when she says that ten years ago language planning was the concern of 'new' nations but that now

many seemingly monolingual, developed and older nations and regions have begun to reconsider the status of minority or nonofficial languages and in many cases made efforts to change the status and allocation of use of these languages (Rubin 1983:330).

Adams and Brink pick up on a similar point when they note that

In becoming a champion of language planning in the 1960s, Fishman had two major intellectual obstacles to overcome: the consensus view that language planning - at least, 
as a means of maintaining minority languages - could not be done ... and the widely held opinion that such planning should not be done (Adams \& Brink 1991:10).

That is, in the 1960 s, language planning was seen as having a comparatively narrow sphere. It was limited to those ex-colonial countries where the discontinuities of their histories had given people the opportunity to 'make it new'. By the 1990s language planning has extended its sphere, at least for many people. Even those nations that might once have seen their continuity, both social and political, as an indicator and guarantee of the success of their policies or lack thereof, have had to acknowledge that there are minorities in their midst whose needs are not met by the assumption that the majority language will serve in all cases. The interest in language policy in New Zealand over the last ten to fifteen years is part of that world-wide process, undoubtedly given added impetus by the Maori community's insistence on the importance of the Maori language for the survival of the Maori people as a people.

\subsubsection{Implicit policy, explicit policy}

Most writers on the topic of language policy recognise that as Lo Bianco says

The absence of explicit policy on language issues does not mean that policies on language do not exist. Rather such policies are implied in related actions which the society takes (Lo Bianco 1990:).

Implicit policy has been the Anglo Saxon tradition, inherited from Britain by the U.S.A., Australia and New Zealand. Schiffman characterises it as part of 'linguistic culture' and Gessinger calls it structural language policy (Schiffman 1996: 14). The language policy traditions of these countries are discussed below. Australia is discussed however largely in the light of its definitive break with British tradition. The creation of a language policy for the whole of Australian society; not just for the minorities, not just for education, not simply to establish an official language, but rather to gather in, to consider and to plan for all aspects of language use in Australia:

this whole process [of drafting a policy] consisted of converting the best principles which have underpinned language planning in the past into explicit statements of desired objectives and into the establishment of programs to take these towards realisation. To do this involved describing the context for language policy at the national level and the factors which shape it (Lo Bianco 1990:59, my emphasis) 


\subsubsection{Definition of language policy}

It is impossible to define 'policy' in a way that will take into account all the uses of the word, in both everyday and specialised contexts. Here I offer a definition, or rather a consideration of the word and the concepts it signifies.

There are at least two types of policy that can be distinguished.

a. lower level, specific policy that states a specific goal for an organisation. For instance a hospital might have as policy that all people who require it, should be provided with properly qualified interpreters.

b. higher level policy that will usually be fairly general (but may be detailed on certain points). Such a policy sets broad goals for an organisation, usually one that governs a territorial unit and has power to make and enforce laws or regulations in that territory. Generally the setting of goals also involves the description of how it is intended that these goals should be achieved. At this point policy and planning become entwined. If a clear division of the nature of policy and planning is insisted on then we may say that policy consists of the setting of goals and planning consists working out how to achieve these goals but, in fact, any attempt clearly to separate the two fails to provide any theoretical insight into how the process works and it certainly does not accurately describe the ways in which the two terms are used.

A National Policy then will

a. set goals

b. describe how these goals will be attained

c. (allocate funding)

d. describe a system for evaluating how well the goals are being attained

e. describe a system for allowing evaluation to feed back into performance and, possibly into definition of goals

Goals, Performance, (Funding), Evaluation, Feedback. These are the elements of a good National Policy, whether for language or some other area. 


\subsubsection{Language policy in education}

Language policy in education is mentioned separately because so many policy makers concentrate language issues in the area of education administration. This happened in New Zealand when the Ministry of Education became the site for the work that was done on the language policy discussion document Aoteareo. Language policy is, or should be, more than language in education policy but, in most countries, education is one of the main sites of action and concern about language on a national level. Language in education policy therefore deserves a special mention. Corson, following Churchill outlines six stages of language policy in education

Stage 1 (Learning Deficit): sees minority groups as simply lacking the majority language. The typical policy response is to provide supplementary teaching in the majority tongue (e.g. ESL) with a rapid transition expected to use of the majority language.

Stage 2 (Socially-Linked Learning Deficit): sees a minority group's deficit as being linked to family status. An additional policy response is to provide special measures to help minority peoples to adjust to the majority society, such as aids, tutors, psychologists, social workers, career advisers etc. in concert with majority language teaching.

Stage 3 (Learning Deficit from Social/Cultural Differences): sees a minority group's deficit linked to disparities in esteem between the group's culture and the majority culture. Additional policy responses are to include multicultural teaching programmes for all children in order to sensitize teachers and others to minority needs, and to revise textbooks and teaching practises to eliminate racial stereotyping.

Stage 4 (Learning Deficit from Mother Tongue Deprivation): sees the premature loss of the minority tongue as inhibiting transition to learning the majority tongue because of cognitive and affective deprivations. An additional policy response is to provide some transitional study of minority languages in schools, perhaps as a very early or occasional medium of instruction.

Stage 5 (Private Use of Language Maintenance): sees the minority group's language threatened with extinction if it is not supported. The policy response is to provide the minority language as a medium of instruction, mainly in the early years of schooling.

Stage 6 (Language Equality): sees the minority and majority languages as having equal rights in society, with special support available for the less viable languages. Policy responses include recognising a minority language as an official language, providing separate educational institutions for language groups, offering opportunities for all children to learn both languages, and extending further support beyond educational systems. (Corson 1993:74-75)

Corson himself thinks that New Zealand has begun to move towards stage 5 as far as the Maori population is concerned (Corson 1993: 75). Stage 5 has both positive and negative 
aspects; the language is severely threatened but, at the same time, serious measures are in place to assist the speakers of the language in the fight for its survival.

\subsection{Historical background to language and language policy attitudes in New Zealand}

The English attitude to minority languages and language policy was transmitted to the countries that were once English colonies; the United States, Australia and New Zealand all share in that inheritance. Canada is in a somewhat different position because the existence of Quebec always forced a formal acknowledgment of bilingualism from the federal government. In practice the attitudes of many Anglo-Canadians were little different from those held in the aforementioned countries (Maldoff 1986). The attitudes may be summarised as indifference ranging to hostility to minority languages, a strong appreciation of English for its usefulness as a language of wider communication and an administrative and legislative history that took very little formal cognisance of language issues and thus tended not to form explicit language policy.

\subsubsection{The United Kingdom and language policy}

Until recently, New Zealand attitudes to issues of language and language policy have been similar to traditional British/English attitudes on these matters and the legislative, administrative and social actions of New Zealanders have had their roots in British/English legislative, administrative and social history. In order to understand this aspect of New Zealand history it is necessary to have some understanding of British history. Heath and Mandabach make the same point about the link between the U.S.A. and Britain (Heath and Mandabach 1983:88-92).

Britain as a political entity came into being over a period of centuries. The process may be seen as beginning with the Norman Conquest. At this time the languages of Britain were Norman French, English, Scottish Gaelic, Irish Gaelic, Welsh, Cornish and Manx. The largest territorial extent of Britain was reached in 1801 when Wales, Scotland and the whole of Ireland were part of the polity. Since the creation of the Irish Free State in 1922, the United Kingdom has consisted of England, Wales, Scotland and Northern Ireland.

Britain has thus always consisted of several different language groups but the steady drive has been towards the creation of a single language polity and that language has, of course, been 
English. This steady drive has been expressed both legally and formally and also socially and informally. Henry III's English Proclamation in 1258 may be seen perhaps as a combination of the two. It

railed against monoglot French speakers but achieved nothing in terms of giving English an improved status. (Heath and Mandabach 1983:89)

The first legal expressions of a preference for English were enacted over a century later and established English rather than French (at that time the language of the nobility and polite society) as the appropriate language of the courts in 1362

that all pleas which shall be pleaded in [the King's] courts whatsoever, before any of his justices whatsoever, or in his other places, or before any of his other ministers whatsoever, or in the courts or places of any lords whatsoever within the realm, shall be pleaded, shewed, defended, answered, debated and judged in the English tongue, and that they be entered and enroled in Latin (trans. in Baugh 1957:178 from Grillo 1989:47)

Heath and Mandabach suggest that by 1500 in all areas of life

Except for higher education and the law, English had achieved recognition as the norm ... English had gained a secure status. (Heath and Mandabach 1983:89)

Grillo largely agrees with Heath and Mandabach stating that English gained dominance over French as the language of the state between 1400 and 1600 and that

Since then there has been a largely unspoken assumption of its pre-eminence, at least on the part of the English, and the case for English as the dominant language of the British Isles has rarely had to be made - by the English. The case against English ... had to be argued, was argued, certainly from the eighteenth century onwards as speakers of what, by then, were the subordinate languages of Wales, Scotland and Ireland were caught up in the fervour of Romanticism. (Grillo 1989:47)

The process by which the languages of Wales, Scotland and Ireland became subordinate showed the same mixture of legislated policy and unlegislated but steady social and institutional pressure.

In fourteenth century Ireland, concern over the assimilation into Gaelic culture of the Anglo-Norman nobility led to an order in 1360 that 'anyone of the English race shall forfeit English liberty, if after the next feast of St. John the Baptist he shall speak Irish with other Englishmen' (cited in Hyde 1967: 609), and in 1366 by the Statutes of Kilkenny, Englishmen using Irish were threatened with forfeiture of their lands. (Grillo 1989: 84).

According to Grillo these measures were ineffectual and one of the first effective pieces of legislation was an Act of Henry VIII which said 
every person or persons, the King's true subjects, inhabiting this land of Ireland, of what estate condition or degree he or they be, or shall be, to the uttermost of the power, cunning and knowledge shall use and speak commonly the English tongue and language (cited in O Murchu 1970:40, Grillo 1989:85).

This legislation did not ban the use of Gaelic but played a significant part in establishing English in Ireland. There were later (1610) enactments in Scotland which were intended to 'abolish and remove' the Gaelic tongue in Scotland as one of the 'cheif and principall causis of the continewance of barbaritie and incivilite amongis the inhabitantis of the Ilis and Heylandis' (Grillo 1989:85). English was established as the language of the law and the state in Wales by the Act of Union of England and Wales 1536

And also that fromhensforth no psonne or psonnes that use the Welsshe speche or langage shall have or enjoy any maner office or fees within the realme of Englond Wales or other the Kinges dominions, upon peyn of forfaiting the same office or fees onles he or they use and exercise the speche or langage of Englishe (The Act of Union of England and Wales 1536, 27 Henry VIII, Ch. 26, Clause XVII cited in Grillo 1989:84)

These were clearly all legislative acts of language policy. For all that, the English tradition has not been one of maintaining a clear and explicit policy concerned with language, although Thompson et al (1996: 99) point out that policy has always been 'more explicit and definable in Wales'. Comparing England and France Grillo comments on 'the greater explicit ideological salience accorded language in France as compared with Britain'. But he goes on to say that this is evident 'more in what is said than what is done' (Grillo 1989:21). This is brought out again by Grillo when he says

Apart from brief moments during the Anglo-Norman period ... language has not figured conspicuously in the articulation of British or English identity within the British Isles. During the last hundred years the prevailing view of the nature of the British nation-state may be characterised as the 'unionist' perspective. (Grillo 1989:44)

It is interesting to note the comments of at least one authority on the effects produced by different language policies. Since the proclamation of the Irish Free State in 1922 (the Republic of Ireland was created in 1948), Irish governments have been able to implement programmes strongly supportive of the Irish language. It is sometimes suggested that these programmes have been largely a waste of time and resources (see Smolicz 1979:50) but Dorian suggests we look at this in a somewhat different light. She points to the difference between Ireland and the Highlands of Scotland where there has never been a territory-wide, government backed movement in support of Gaelic and says 
But when one considers the cultural climate overall, there have surely been substantial gains. The contrast with Scotland is instructive. Highlanders usually know next to nothing about their ethnic heritage .. Highland schoolchildren are fortunate if they are even given history texts which represent so much as the Scottish viewpoint, never mind the Celtic viewpoint, on British history from time to time ...Ireland, by contrast, produces mountains of scholarship on its Celtic past at every possible level of accessibility ... Schoolchildren have copious materials to acquaint them with their ancestral culture (Dorian 1987:65 see also Fishman 1991: 143)

In British history major language policy decisions were those that led to English becoming the language of the church and courts and gradually the language of all society and literature.

There were also the policy decisions taken to ban the use of Irish in Ireland and the legislation that led to universal education and consequently a generally literate population. All of these decisions were language policy decisions in the broad sense.

England, as the dominant partner in the British Isles confederation, has followed the Western European trend that Fishman identifies as Western and Christian, and has been particularly unwelcoming to minority languages within the British Isles. The continued use of Scots Gaelic, Irish Gaelic and Welsh, even when they were not banned, was generally condemned and the schools were seen as a prime place for the replacement of these languages with English. England today does not have an official languages policy although there are many languages, indigenous and exotic, spoken in modern Britain. According to Corson, ancestral languages are relatively well provided for but new settler community languages receive minimal recognition. He characterises treatment of new settler language users as being at Stage 1 on his language in education schema (Corson 1993:76) and Thompson et al, writing three years later, do not see much change (1996: 116).

\subsubsection{America and language policy}

The U.S.A. fits neatly into this "British" pattern. Neither country has had a strong explicit policy of monolingualism although, as Hymes says in the American context

It is not that extermination of [linguistic] diversity has not had its advocates and successes. (Hymes 1981: introduction)

But equally,

Americans do not have a language ideology which identifies nation and language. (Heath and Ferguson 1981:3) 
One of the most effective techniques of this Anglo tradition has been to ignore other languages. Hymes, writing in 1981 points out that although the U.S.A. has had universities for 200 years there was still not one chair devoted to Native American languages (Hymes 1981: introduction). It is interesting to contrast this with the Spanish approach in Peru where the first chair of Quechua was founded in 1551 although it was not filled until 20 years later (Cerron-Palomino 1989:20).

\section{Adams and Brink comment that}

Fishman would very much like to see developed [in the USA] the kind of language policy that exists in Australia. However, he argues that given the present English-only mentality, it ". . .would be not only premature but dangerously self-defeating to engage, at any now-foreseeable date, in the requisite discussion out of which such a policy might ultimately flow". (Adams \& Brink 1991:22)

The practice of American language policy has to be seen against the background of federal legislation that affects both state and federal institutions as they deal with language issues.

According to Marshall (1986:11) the founding fathers deliberately chose not make any mention of language in the constitution for a variety of reasons, not least of which was that the right to speak the language of one's choice was regarded as a fundamental liberty. Subsequently the 14th Amendment has been regarded as the guarantee of language rights in the United States. The 14th amendment, passed in 1868 is one of the three great abolitionist amendments of the Civil War period. The first Section reads
All persons born or naturalised in the United States, and subject to the jurisdiction thereof, are citizens of the United States and of the State wherein they reside. No State shall make or enforce any law which shall abridge the privileges or immunities of citizens of the United States; nor shall any State deprive any person of life, liberty, or property, without due process of law; nor deny to any person within its jurisdiction the equal protection of the laws

The 14th Amendment was first invoked in language rights issues in 1923 in a Supreme Court ruling that a state could not require private schools to use English as a medium of instruction (Marshall 1986:15) and has subsequently been used by the Supreme Court to overturn 'all the low-court rulings upholding the restriction of the use of foreign languages' (Heath and Mandabach 1983:97). The effect of this amendment on speakers of languages other than English can be seen in decisions such as Lau v. Nichols (1974) where the U.S. Supreme Court decided that for non-mother tongue speakers of English "learning English and getting an 
equitable education were not the same thing and that due process was denied when the latter was not forthcoming" (Fishman 1989: 406)

During the 19th century with widespread immigration from many parts of Europe and especially Germany, there was a plethora of languages in daily use in the United States. German was particularly widely used. .It was possible for children to attend German language schools, many newspapers were published in German and there was a wide-ranging cultural and business life carried on in German (Ricento 1996: 126,Sciffman 1996: 235). However the United States' entry into WWI

sounded the death knell of the great bilingual German-American public schools of the Midwest (Landry 1986:135-136)

Most commentators on immigrants and immigrant languages in the U.S.A. agree that after a period of comparative unconcern and open-mindedness on the topic of non-English immigrants to the United States there was a change of attitude amongst both the general public and their elected representatives. However, there is not much agreement as to the dates of the changes in the climate of opinion. The suggested periods range from the 1840 s to the 1950s. There is some general agreement that the 1920 s were a particularly xenophobic period (Heath 1981:17, Heath and Mandabach 1983:98 Landry 1986:135-136, Marshall 1986:1214,53, Schiffman 1996: 238).

The 1920s in the United States were an uneasy time. There was widespread concern about the process of nationhood and from the 1920s to the 1960s the general climate of opinion was that immigrants should assimilate as quickly as possible. The metaphor of the melting pot was widely used and approved and legislation against the use of languages other than English began to be enacted. The 1920 s also saw the introduction of the 'national origins' quota system in force from 1929 to 1965 . The quota system was based on the national origins of the United States population in 1920. Thus if persons of German origin made up $16 \%$ of the population in 1920 then the quota for German immigrants should be $16 \%$ of the overall annual immigration quota (Price 1985:46). There is something Canute-like in this desire to stem the changes that were taking place in American society. Interestingly, 1920 also saw the passage of the Immigration Restriction Amendment Act in New Zealand which 'legislatively entrenched' racism in New Zealand (McKinnon 1996: 32). 
The Nationality Act of 1906 was the first naturalisation law to demand that an alien seeking nationalisation should speak English (Heath 1981:15). The Nationality Act of 1940 codified the requirement and the 1950 Amendments to the Act added literacy requirements on the grounds that "reading the Constitution in its original language somehow assured a seriousness of purpose and dedication that was demanded by the oath of citizenship" (Marshall 1986:17)

The first piece of legislation in this century that positively encourages diversity of language use is the Civil Rights Act of 1964. "The federal Courts interpretation of this law is that it is a specific mandate for bilingual education" (Marshall 1986:17). This led to the Bilingual Education Act 1974, which formally guarantees children's right to an education in a language that they can understand. The intention of this act is not that the school should assist children to maintain their home language but rather that their education should be transitionally bilingual. The framers of the Act apparently envisaged that transitional bilingual education was a necessary step toward monolingual education in English.

Since that time there has been an increasing provision for bilinguals in the United States. Education and the electoral process are perhaps the two most obvious areas where the state makes bilingual provision. Private enterprise provides a range of non-English services including non-English media.

This change has not occurred completely unnoticed or unopposed. The most formalised opposition to bilingual or non-English provision in the US has come from Senators Hayakawa and Huddleston and Representative Shumway, all of whom have, at various times, introduced an English Language Amendment (ELA) to the Constitution. These amendments, introduced between 1982 and 1985 have all been unsuccessful.

Although attempts to alter the Constitution have failed, there is considerable support for the aims of those who introduced the unsuccessful amendments. Senator Hayakawa started an organisation, US English, to promote the cause of English as the official language of the US in 1983, with a membership of 300. By the next year US English had 35,000 members.

Fishman considers movements to make English either the 'official' or 'only' language of the United States or of any of the individual States in an essay he entitles 'Bias and antiintellectualism: the frenzied fiction of 'English Only' (Fishman 1989: 639-654). He considers English Official/English Only legislation together and shows that Illinois, Hawaii, Tennessee, Indiana, Kentucky, Nevada, Virginia, Georgia, California, Arkansas, Mississippi and North 
Dakota (total 12) have passed English Official laws (it is worth noting that such laws do not necessarily exclude other languages; Hawaiian is also an official language of Hawaii). Marshall (1986 40-53) points out some of the difficulties faced by any English Language Amendment, describing how states as diverse as New Mexico, Hawaii and Maine all have special reasons to guard their bilingual status.

It is clear that although the United States has never framed an explicit, official Language Policy as such and although English has had a huge historical advantage in the US, nonetheless America's legislators, administrators and teachers have had consistently to frame language policy as the need has arisen over the years. In California at least, this has produced what Marshall describes as "legally sanctioned multilingualism" (Marshall 1986:54). Recently, in California, there has been something of a backlash against what is seen by some as unnecessary multilingualism and Proposition 227 "English as Required Language of Instruction" has been introduced. The Proposition was voted on in mid-1998 and passed, but it remains to be seen what effect it will have. The intention of the Proposition is clear from its title. Its two main clauses state that it

Requires California public schools to teach LEP (limited English Proficiency) students in special classes that are taught nearly all in English. This would eliminate "bilingual" classes in most cases.

Shortens the time most LEP students would stay in special classes. The initiative states that: (1) LEP students should move from special classes to regular classes when they have acquired a good working knowledge of English and (2) these special classes should not normally last longer than one year. This would eliminate most programmes that provide special classes to LEP students over several years.

(www.lao.ca.gov/laohome.html, 01/05/98)

Regarding language in education policy, Corson characterises the U.S.A. as being at Stage 1 or 2 'in practise' although, as he points out, the Bilingual Education Act puts the U.S.A. officially at Stage 4. However

the responses of many schools and school systems themselves seem to be at a much lower stage. (Corson 1993:76)

Proposition 227, which has been controversial, shows that there is as yet relatively little public consensus on language issues (especially perhaps language in education issues) in the USA and it seems unlikely that there will be any major, national policy developments in the near future. 


\subsubsection{Australia and language policy}

Australia as Fesl (1991:56) points out, has been a multilingual and multicultural national for all of its human history. After Aboriginal - European contact this state of affairs of course continued. In addition to the multiplicity of Aboriginal languages, a range of European and Asian languages established themselves more or less precariously (see Borrie 1953:177, Wallace-Crabbe 1991: 3, Kipp, Clyne and Pauwels 1995: 1, Herriman 1996: 37-41).

Until the post World War II period Australia's attitudes to language policy reflected those of England. There was very little explicit language policy and such as there was, focused on creating a monolingual Australia (Lo Bianco 1990:52). As Lo Bianco says

Australian language planning has been, insofar as broad generalisations are possible, firmly within the implicit and often unconscious categories of the continuum of socially directed actions on language. This has been punctuated by occasional deliberate intervention, usually for negative purposes representative of particular political positions and cultural values. (Lo Bianco 1990:53)

Although before the First World War there were a variety of non-Aboriginal languages other than English used for a wide range of purposes, English was the dominant language. As in America the period during which hostility to speakers of languages other than English was strongest was the period between the two world wars (Lo Bianco 1987:9, Ozolins 1993: Chapter 1). It was during the interwar period that legislation was introduced to "severely restrict entry of Southern Europeans to Australia ... [and] Mussolini ... could be regaled in Australia as 'prescient, peremptory and plucky', as 'a second Alexander', for stopping Italians 'being dumped upon Australian Territory'" (Shergold 1985:63).

After World War II the Australian government introduced a new immigration policy which encouraged European immigration from sources other than the United Kingdom and Ireland. According to Lo Bianco, initially no language provisions of any kind were made for these new immigrants although the official policies were those of linguistic assimilation (Lo Bianco 1987:9, 1990:55). De Lepervanche states that

Postwar immigration to Australia was initially accompanied by the publicly sanctioned policy of assimilation to Anglo conformity, in force until the early 1970s ... As late as 1968 the Minister for Immigration was quoted as saying "we must have a single culture". (de Lepervanche 1989:39).

Ozolins (1993:10) agrees that policies were assimilationist, but notes that 'fear of national groups and social divisiveness' caused policy makers to institute English classes from the 
beginning of the period of post WWII mass migration. The first 'experiment of intensive English language teaching in Australia' was at the Bonegilla reception camp in 1947 (Ozolins 1993:71). In 1971 with the Immigration (Education) Act the Commonwealth

assumed the responsibility for English instruction as a consequence of its constitutional responsibility for recruiting immigrants (Lo Bianco 1990:55)

When eventually the Migrant Education Service was founded in order to provide English tuition to migrants, this was still within the policy context of eventual assimilation. It is only recently that Australian policy makers have begun to view immigrant language maintenance rather than immigrant language shift as a possible policy end.

Most commentators agree that since the 1970 s there has been a change in official and, to some extent, popular attitudes to the 'ethnic' populations of Australia and there have also been changes in official policies affecting Aboriginal and Torres Strait Islanders (see Ozolins 1993 for a history of attitude changes and also a detailed account of the policy build up to the 1987 National Policy on Languages). De Lepervanche for example, suggests that

after Labor came to power in 1973 ... multi-culturalism became government policy. Behind this acceptance of cultural variety there was, first, the settlement of more nonBritish than ever before in Australian history. Second, many of these newcomers had begun to demand a voice in social affairs, had the vote and were critical of assimilation policy. Third, a number of Australians shared these sentiments and were increasingly critical of some problems immigrant assimilation entailed ... By the mid-1970s public response had apparently undergone a complete metamorphosis: the new emphasis was on cultural diversity. Newcomers were invited to celebrate their ethnicity and the rhetoric of assimilation was formally abandoned (de Lepervanche 1989:39) .

This forms a strong contrast to Smolicz's description of general attitudes to the immediate post WWII arrival of immigrants

Anglo-Australians were at first rather startled to discover such 'cultural strangers' in their midst - and their reactions were frequently negative (Smolicz 1979:10).

These attitudinal changes as far as they affect language are embodied in Lo Bianco's 1987 National Policy on Languages. This work was commissioned by the Minister for Education in a Labour Administration in response to a 1984 recommendation from the Senate Standing Committee on Education and the Arts. In 1982 the Senate had addressed to the Committee a reference on "Development and Implementation of a Co-ordinated Language Policy for Australia". The Senate Committee 'assembled a large amount of data and considered in detail a wide range of relevant issues. The Committee's first recommendation was: 
Language policies should be developed and co-ordinated at the national level on the basis of four guiding principles, namely:

- competence in English

- maintenance and development of languages other than English

- provision of services in languages other than English

- opportunities for learning second languages

National Policy on Languages was produced as a policy document in response to that recommendation and as Lo Bianco says in his covering letter to the minister he "attempted to devise a principled way of reconciling interests and priorities perceived to be national and the interests and priorities of the community generally'. The National Policy in Languages was preceded by the development in all state and territory administrations of language education policies (Clyne 1991a).

The report on the National Policy on Languages begins with this rationale

it is necessary that broad statements with clear principles be enunciated so that the language problems which face the country as a whole can be tackled at the various relevant levels by the appropriate authorities (Lo Bianco 1987:189)

and a statement of principle

These principles are that the nature of language as dynamic and arbitrary needs to be acknowledged, as does the need to enhance levels of competence and standardization to achieve better communication. The different languages spoken in Australia are recognised. Other principles relate to the need for a balanced, comprehensive and just approach to language issues (Lo Bianco 1987: 189)

The problems to be addressed are:

- the overcoming of injustices, disadvantages and discrimination related to language

- the enrichment of cultural and intellectual life in Australia

- the integration of language teaching/learning with Australia's external (economic and political) needs and priorities

- the provision of clear expectations to the community about language in general and about language in education in particular

- support for the component groups of Australian society (ethnic communities, the deaf and Aboriginal groups), for whom language issues are very important, with recognition and encouragement, and guidance in attempts to link technology and language use and learning (Lo Bianco 1987: 189)

These were the main areas to be addressed by a national languages policy. The policy that was developed dealt with the status of languages, the teaching and learning of languages, language 
services and the proposed Advisory Council on Australia's Language Policy (Lo Bianco 1987: 192).

In the area of teaching and learning, the policy stressed the importance of reasonable levels of English competence for all Australians and highlighted issues of ESL teaching for adult Australians and the need for adult literacy programmes. The policy stressed the importance of Aboriginal and Torres Strait Islander languages and proposed a support programme for those languages with an educational focus (Lo Bianco 1987: 195). The concept that all Australians should have a language other than English was proposed and it was foreseen that for many Australians this would involve the language maintenance of a community mother tongue. Specific proposals for teacher development were also made. Corson sees Australia as being at several stages in his schema, with treatment of users of Aboriginal languages and some community languages being at Stage 4 or Stage 5, while other community language users languish at Stage 3.

In the area of language services, proposals were made regarding interpreting and translating services (these 'ought to be regarded as an aspect of service provision in Australia rather than a welfarist programme for the disadvantaged' (Lo Bianco 1987: 200\}), and also regarding the media and 'modern technology'. Language testing was another language service area which needed to be addressed.

The Advisory Council on Australia's Language Policy was proposed as 'the structure for ensuring that the diverse elements of language considered in this policy are co-ordinated and integrated' (Lo Bianco 1987: 202).

As part of the policy development exercise the various Ministers responsible for education in the States and Territories of the Australian Federation were asked to contribute views on issues of language policy that fell within their jurisdiction. They were asked 'not to focus exclusively on schooling nor exclusively on minorities' (Lo Bianco 1987: 204). These statements were included in the report and were presumably an exercise both in consciousness raising and consensus development.

The Australian National Languages Policy was an innovation in the English speaking world. It was a clear, explicit and principled investigation into language issues at several levels. It considered language in an educational context as was customary, but also addressed language issues on a broader social front and it proposed specific policy moves that were intended to 
have an effect on both language use and social interaction. One of the distinguishing features of the context in which Lo Bianco produced the report was a groundswell of popular demand for federal level action on language issues. This was something new in Australia. It was a break with the British tradition in which language issues were not articulated at a national level by legislation based on principled consideration arising out of popular concerns. It was also a break with the attitudes of the past which had led Smolicz to say

The majority group obviously did not wish to perpetuate the cultural diversity which had come fortuitously to flourish among them. (Smolicz 1979:12)

New Zealand shares a British heritage with Australia and, like Australia, has had to come to terms with the realisation that it is no longer an outpost of Britain in the South Seas. New Zealand, like Australia, is no longer British and the Australian concept of a national policy on languages has proved influential in New Zealand. That influence has perhaps been rather weakened in this decade as the Australian National Policy on Languages was replaced in 1991 with the Australian Language and Literacy Policy (ALLP). The ALLP saw a shift in emphasis from concerns of social justice and pluralism to concerns of trade and vocational training (Kipp, Clyne, and Pauwels 1995: 6, Herriman 1996: 54, 56). The change in emphasis within language policy at a national level in Australia has made Australia's policy less of a rallying point for those in New Zealand who were inspired by the NPL. They were mainly drawn from the minority immigrant language groups and TESOL educators and tended to be more in sympathy with the Lo Bianco report than with the ALLP. Nonetheless, Australia, with its far greater emphasis both on language policy and minority immigrant languages tends to be seen as an exemplar by many informed people in New Zealand minority immigrant communities.

\subsection{New Zealand languages policy}

New Zealand has not had a history of explicit, principled language policy making and implementation, but language policy decisions have been made from the time of contact between Maori and European. New Zealand administrators have also been involved in language policy decisions in the Pacific Island territories that have been administered by New Zealand, and in the case of Samoa there has been a continuum of language and education policy decisions affecting language and education for Samoans resident in Samoa and New Zealand. 
The Waitangi Tribunal has been an important force in the formation of policy about Maori language in New Zealand. The legislation that has most explicitly dealt with language to date has been the Maori Language Act 1987 which grew out of the recommendations of the Waitangi Tribunal. This Act established the Maori language as an official language of New Zealand and legislated for its use in certain areas and under certain conditions. This is the first example of language status planning in New Zealand and its introduction and successful passage were a sign that the old 'English' attitudes of not being explicit about language issues and deprecating minority languages were being successfully questioned. The expansion of Kohanga Reo and the establishment of Kura Kaupapa Maori have also been major language policy decisions that can trace their roots in part to the findings of the Waitangi Tribunal.

\subsubsection{The Waitangi Tribunal and Te Reo Maori Claim}

The Waitangi Tribunal was established in 1975 under a Labour government to investigate grievances of the Maori people that could, potentially, be addressed under the provisions of the Treaty of Waitangi (1840). Initially the impact of the Tribunal was somewhat muted as it could only investigate matters that had arisen since 1975. In 1985 a different Labour administration passed a new law which allowed all grievances back to 1840 to be investigated and a major national attempt at reparation was underway. (http://io.knowledgebasket.co.nz/waitangi/ . The Waitangi Tribunal Reports Database).

The Waitangi Tribunal is important to language policy in New Zealand because its findings in the area of Maori language have been most influential.

In 1985 a claim was lodged

by Huirangi Waikerepuru and Nga Kaiwhakapumau i te Reo (Inc) asking that the Maori language receive official recognition. It was proposed that the language be official for all purposes enabling its use as of right in Parliament, the Courts, Government. Departments, local authorities and public bodies. Over seventy recommendations were sought to achieve that purpose, concentrating in particular on broadcasting, education, health and the Public Service. (http://www.knowledgebasket.co.nz/topic4/waitr_db/text/wai011/doc005.html)

The Tribunal recommendations, published in 1986 went further than simply finding that the Marori language should be an official language of New Zealand. The Tribunal recommended that 
1. people should be able to use Maori in all Courts of Law and in any dealings with Government Departments, local authorities and other public bodies

2. that a supervising body be established by statute to supervise and foster the use of the Maori language

3. that there be an enquiry into the education of Maori children and that policies be instituted to ensure that all children who wished to learn Maori be able to do so 'in circumstances most beneficial to them and with financial support from the State' (Waitangi Tribunal: para 10.3)

4. that the Crown has an obligation under the Treaty of Waitangi to recognise and protect the Maori language and that the Minister of Broadcasting has an obligation in this respect

5. that the State Services Commission should make bilingualism in English and Maori a prerequisite for some positions in the public service

(see Waitangi Tribunal 1986: Section 10)

On the basis of the 1986 findings of the Waitangi Tribunal, New Zealand can be said to have a very clear policy in the area of Maori language, even if it has no clear and overarching policy in other areas of language.

\subsubsection{Aoteareo}

Most New Zealand policy that has explicitly mentioned language has been in the area of education, immigration and broadcasting, and these are examined in more detail below. In this section the history of New Zealand's one attempt (to date) at establishing an overarching language policy is examined, The inspiration came directly from the Australian process outlined above, but in New Zealand it has not lead to the same conclusion. New Zealand at the time of writing has no national language policy.

Despite the increasing importance of language issues in New Zealand, fuelled mainly by the rising prominence of Maori language issues, there had been no attempt to consider what the nature of a general, comprehensive and explicit language policy for New Zealand might be until Aoteareo: Speaking for Ourselves (Waite 1992a \& b) was published in 1992. 
In 1988 the First TESOL and Community Languages Conference was held in Wellington. One of the speakers was Jo Lo Bianco who had designed the Australian National languages Policy and was in the process of helping to implement it. His visit provided the impetus for the formation of an action group whose purpose was to persuade the government to formulate a National Languages Policy. This purpose was successful at the end of 1990 when the Labour Minister of Education approved the appointment of someone to research and write a policy document and, after Labour's defeat in the general elections the National Minister of Education decided to continue with the plan.

The Ministry of Education was given the responsibility of implementing the decision. There was some concern that by locating the National Languages Policy Project within the Ministry there would be too much emphasis given to education issues and not enough given to other language issues but on balance it was considered that the Ministry of Education was the most natural site ${ }^{\text {. }}$. Jeffrey Waite was appointed as the National Language Policy Project Manager and had funding for a year to research and present his report. Jo Lo Bianco was involved in the planning stages and his advice was helpful and influential in the form that the research and the eventual report took. Amongst other things, Lo Bianco emphasised the importance of a coalition of interest groups to form a lobby for the implementation of a languages policy. He considered that this had been a vital step in the process of achieving Australia's languages policy.

Waite decided on a process of extensive community consultation in tandem with considerable consultation with other government ministries and departments. He set up an interdepartmental committee consisting of all the government bodies which could be held to have an interest in the area of language policy and four meetings were held throughout 1991 . Waite also convened three forums for non-governmental organisations held in Auckland, Christchurch and Wellington ${ }^{12}$. In addition Dr Waite consulted with a large number of individuals and groups. There was also a Ministerial Advisory Group. The formation of the

\footnotetext{
"Robert Kaplan (Convenor of the Ministerial Advisory Group) commented that the ideal situation is to have a cabinet minister with responsibility for a language policy portfolio as in the Philippines and Israel (R Kaplan personal communication).

${ }^{12}$ Lists of those who made up the interdepartmental committee and who attended the NGO forums can be found in Aoteareo (1992).
} 
National Language Policy discussion document was handicapped throughout by the lack of information available on language issues. As Mikes says

Polemics may go on and the attitudes toward racial, ethnic, and linguistic prejudices may change from time to time, but a real contribution to any solution of language problems must be based on valid sociolinguistic research (Mikes 1986:156)

Marshall makes the same point (Marshall 1986:70) and Lo Bianco's National Policy on Languages was preceded by two and a half years 'ambitious' information gathering by the Senate Standing Committee on Education and the Arts (Ozolins 1988:120). The consultation process undertaken by Waite went some way towards remedying the dire lack of information on patterns of language use in New Zealand but even so the information obtained could only be partial and anecdotal.

The biggest difference between New Zealand's National Language Policy and that of Australia is the relative weighting of indigenous languages as opposed to immigrant languages. In both Australia and New Zealand the majority language is the immigrant language of English, but in New Zealand the other, minority immigrant languages are not regarded as particularly important. In Australia, on the other hand, some of the larger minority immigrant languages such as Italian and Greek have a very high profile indeed. This difference in emphasis clearly reflects the difference in demographic composition of the two countries. The Maori population of New Zealand is, proportionately, considerably larger than the Aboriginal population of Australia. It may have other components as well including the relatively stronger position of Maori in the New Zealand polity. As Corson says of the Maori in New Zealand 'their vigorous presence as a cultural force has never been in doubt' (Corson 1993:74) and the multiplicity of Aboriginal languages, 150 in use today (Kipp, Clyne and Pauwels 1995: 1) as compared to one Maori language (albeit with considerable regional variation).

One of the main functions of the policy document was to arrange the language issues discussed in order of priority, an 'invidious task' as Waite says, but one that he clearly saw as an essential part of the job. He stresses that all the areas outlined 'are considered to have a high priority' but

It is essential ... to determine a ranking upon which decisions can be made about the distribution of limited resources to the language areas that are discussed in detail in the following chapter (Waite 1992a:18) 
The areas identified in Aoteareo, in order of priority, from most important to least important are:

- revitalisation of Maori language

- second-chance adult literacy

- children's ESL and first language maintenance

- adult ESL

- national capabilities in international languages

- provision of services in languages other than English (Waite 1992 a:18-22)

As Waite is at pains to point out such a list is very hard to compile and it will inevitably fail to satisfy everyone. Language is an area where people's passions run high and people tend to think that the area in which they are involved is necessarily the most important and the most deserving, what Lo Bianco calls "the interest-laden bases of language advocacy" (Lo Bianco 1990:67). Waite's list is to some extent based on order of urgency, which is one of the reasons that the revitalisation of Maori language heads the list (there are very few fluent speakers of Maori under 35 \{Waite 1992b: 31 \} - a worrying statistic for any language. Cf. Lo Bianco \{1990:57-59\} for similar comments on Aboriginal languages in Australia).

Although Waite notes that many of the National Education Goals set by the Government are basic to the report and that 'a sound education system is at the heart of a sound languages policy' (Waite 1992a: 12), he does not consider English language education for school children in any great detail. It is assumed, with reason, that this aspect has been given sufficient attention elsewhere.

The body of the report is devoted to a discussion of the language areas that have been singled out as integral to a national languages policy, and to an explanation of the priority ranking that Waite has assigned to them.

\subsubsection{Revitalisation of Maori language}

This is seen as most important for three main reasons.

(a) The Maori people are the tangata whenua and Maori is recognised as a taonga within the meaning of Article 2 of the Treaty Waitangi. This gives the language both moral and legal claim to support.

(b) The Maori language is in danger of ceasing to be used on a day-to day basis and ceasing to be the mother tongue of many of the Maori people. 
(c) If Maori dies out in New Zealand, it dies out in the world and New Zealand and the world lose a part of their linguistic heritage.

These three reasons, acting together, form the rationale for putting revitalisation of Maori at the head of the list. There is some discussion of who is responsible for action in this area and 'the ineluctable conclusion ... is that a major responsibility for the revitalisation of the language lies with those people who currently speak Maori as their first language' (Waite 1992b:31). However, Waite is also firmly of the opinion that, in addition, formal, national, institutional support is needed.

\subsubsection{Second-chance adult literacy}

This appears to have been ranked second because of the desire to stress the importance of English in a New Zealand languages policy and because being illiterate in English in New Zealand is seen as such a major handicap to the individual

In a technology-oriented democracy such as New Zealand, the inability to deal with the written word is an obstacle to achievement in personal, vocational and community life. It is essential therefore that all New Zealanders ... be able to achieve a level of literacy that allows them to pursue their own goals. Literacy is placed near the top of the scale, because it is considered an essential element of a basic education for all. (Waite 1992a: 19)

It is suggested that English language illiteracy is an expense to the nation as well as to the individual and that possibly all adults should have a right to state-funded literacy (and numeracy, problem solving and communication skills) training if they need it.

\subsubsection{Children's ESL and first language maintenance}

Children's ESL is seen as important because of the overwhelming importance of English in New Zealand public life. As at 1 July 1991 there were 23,539 children in primary and secondary school for whom English was a second language and who needed some assistance with English skills (Waite 1992b: 26). Because access to English as a primary step in full participation in New Zealand society is seen as one of the major tenets of the policy, these children obviously need to be provided with the necessary assistance to enable them to function adequately in English.

The maintenance of the children's first languages is not neglected however. A strong case is made that it is 'vital' that a deficit analysis of these children's language situation should not 
be made; that the richness of their linguistic heritage should be recognised, that first language maintenance contributes to general educational achievement and must be seen as the other side of the ESL coin and that the 'problem', if any, lies with the educational system, not with the bilingual child. (Waite 1992b: 26). It is also noted that the proportion of non-English speaking immigrants to New Zealand is likely to grow rather than diminish in the foreseeable future.

\subsubsection{Adult ESL}

The reasons for stressing adult ESL are essentially the same as those for stressing adult literacy and child ESL. The cost to society and the individual at the individual's not being able to participate fully in New Zealand society. Waite points out that, apart from a ESL provision for refugees, the government does not do much in the way of ESL provision for new settlers (Waite 1992b: 28) and suggests that Study Right provisions should be made available to ESOL students to enable them to take advantage of a range of formal and informal programmes that could be instituted (some of which already exist at polytechnics). Waite suggests that programmes should deal with cultural as well as linguistic matters, that special attention needs to be paid to the situation of mothers at home with children who may not find it easy to get to any kind of classes, and that not all adults who need ESL instruction are recent arrivals in New Zealand. My own research in the Gujarati community bears out both of the latter points quite strongly. Immigrant Indian women are often unlikely to be in a position to acquire English with any ease and there are many older Gujarati women immigrants whose English skills are very limited, despite their having lived in New Zealand for many years. This is partly because traditional village Gujarati thinking does not see a place for women to play the kind of active role in the wider society that would necessitate the learning of English.

\subsubsection{National capabilities in international languages}

This has its place in the policy discussion mainly because of the possible economic benefits that would flow to New Zealand if we were to have a greater number of speakers bi-lingual in English and an international language. It is also acknowledged that there is considerable personal enrichment to be obtained by the individual in mastering another language and that this may be a strong personal reason for wishing to master an international language. A two tier structure is proposed 
- Tier I International Languages (in alphabetical order): Chinese (Standard Chinese), French, German, Japanese, Spanish

- Tier II International Languages (in alphabetical order): Arabic, Indonesian (Bahasa Indonesia), Italian, Korean, Russian (Waite 1992b: 72)

\subsubsection{Provision of services in languages other than English}

This receives a lower ranking than ESL teaching because provision of services in languages other than English (and Maori) is seen as a short term solution for the individual whereas learning English is seen as the long term solution. It is assumed that

With adequate programmes for the teaching of English to adults, new settlers can be expected to achieve a level of ability in English that will allow them to pursue the goals they have set for themselves, including gaining access to public information and services in English. (Waite 1992a: 22)

It is pointed out however that for some members of the Deaf community provision of services in New Zealand Sign Language may be a permanent necessity. It should also be pointed out that some immigrants, because of a combination of circumstances, are unlikely ever to achieve the level of ability that might be seen as desirable. For these people too, provision of services will be permanent.

\subsubsection{The place of Aoteareo in policy formation}

In 1995-6 Nick Shackleford undertook a study of the fate of Aoteareo as part of his research for a M.A. thesis. He found general agreement that Aoteareo had been a useful document that shed light on the issue of how New Zealand could best proceed in the area of language policy. Various Ministry of Education staff made comments to Shackleford about the usefulness and the impact of Aoteareo

"Aoteareo had a profound influence on the subsequent development of the Ministry of Education languages policies, including the language and languages statements in the New Zealand Curriculum Framework."

"[Aoteareo was] influential in guiding the development of Ministry policy in such matters as second language learning, the identification of priority languages for development, te reo initiatives, and English as a Second Language. As far as I know it continues to be used as a primary reference for policy developments relevant to learning languages."

"[Aoteareo is] a helpful reference point for the Ministry's work and it has certainly influenced many of the decisions that have been made. It has influenced the selection of 
languages for new development work and it's proving to be a very helpful reference point although it doesn't have official status as a language policy document."13

(All quotes from Shackleford 1996: 105)

Despite the generally high regard in which Aoteareo was held, it did not become the basis of a New Zealand National Languages Policy. Although the Minister of Education initially agreed that Aoteareo should become the basis of at least the Ministry of Education's language education policy development work (Shackleford 1996: 102) by May 1993 the New Zealand Languages Policy Project had been 'formally abandoned' (Shackleford 1996: 104) and had been replaced by a series of separate policy initiatives

The reasons for the abandonment on the New Zealand Languages Policy Project are covered in some detail by Shackleford and his summary of the status of Aoteareo as a policy document is quoted below ${ }^{14}$.

.... although the contents of Aoteareo received a high level of support through submissions, there was little support for an interdepartmental initiative under the Ministry of Education. The Ministry felt that there was no clear mandate for a comprehensive languages policy and replaced the National Languages Policy Project on its workplan in May 1993 with two discrete policy developments, ESOL and Asia 2000. At the insistence of the Minister, second language learning was added to the list of policy developments.

The National Languages Policy Project was established to develop a comprehensive languages policy for New Zealand. Because of the project design, a lack of interdepartmental commitment to the project and financial and political considerations, the attempt to develop a comprehensive languages policy failed. However, Aoteareo has been influential in selected areas of policy development and has been regarded by the Ministry of Education as a key resource and as an important reference point for the development of curriculum statements, the New Zealand Curriculum Framework and the selection of languages for new development work. (Shackleford 1996: 106)

Hoffman (1998: 210) comments that political events overtook Aoteareo. At the very time it was being written, government administration was being restructured to make it impervious to the kind of interest group influence or 'capture' that Lo Bianco had, in practice recommended,

\footnotetext{
1.3 This range of opinions. garnered by Shackleford in a series of interviews and letters. is similar to opinions expressed to me in more informal conversations with those connected with issues of language policy and education, along with a considerable admiration for Jeffrey Waite's achievement in producing this report.

${ }^{14}$ The interested reader is well advised to consult Shackleford's work.
} 
and that Waite, implicitly saw as necessary for the full implementation of a National Languages Policy in New Zealand.

In default of an explicit languages policy in New Zealand, what kind of non-explicit policy has been implemented? As noted above, the three main areas of policy concerning language in New Zealand have been education, broadcasting and immigration, and these are discussed below.

\subsection{Education policy and language policy in New Zealand}

One of the main areas in which language policy was framed de facto in New Zealand was in the area of education. In order to understand the decisions that were from time to time taken about language in education, it is necessary to have some understanding of the education framework within which those language decisions were made.

In colonial and post-colonial New Zealand there were always two streams of education policy: education for the Maori population and education for the rest. In the early years of post-Treaty settlement, education for the Maori was the main official concern; education for the settler population was not an official priority (see Cumming \& Cumming 1978: 22). And until the 1970s, immigrants, wherever they came from, seem to have fallen into the category of 'the rest'.

The Native Schools Act 1867 assumed that the purpose of educating Maori was to educate them in the English language and European ways. This remained a given of the New Zealand educational system until the time when the Maori language had ceased to be spoken as a first language by the majority of young Maori.

The education of the Maori, once regarded as the Europeanising of his language, thought and habits, is now being considered realistically. His native culture, his natural abilities, and his possible vocational future must all be considered: his education involves help in the Maori community, stress on manual, technical, health and domestic training and encouragement towards secondary and higher education (Murdoch 1946: 20).

This statement, although it has a thoroughly patronising ring to it today, represented a considerable advance at the time in attitudes towards education of Maori. The legislative and curriculum decisions that were made about the teaching of languages in schools were also examples of language policy. As far as non-English speaking immigrants were concerned, there was an unspoken but general assumption that language shift and cultural assimilation 
were the only desired and desirable ends for non-English speaking immigrants. Despite this assumption there was little formal English language education provided for adult immigrants and it was not until 1987 that the Mangere Centre for Refugees was established and able to provide a minimum of ESL instruction for immigrants who were also refugees.

\subsubsection{Education for Maori}

There were mission schools for Maori already established (Beaglehole 1970: 21-25) but the first government ordinance pertaining to Maori education was promulgated in 1847, An Ordinance For Promoting the Education of Youth in the Colony of New Zealand. The Ordinance declared that English rather than Maori (which had been used in the mission schools up to that time) should be the language of instruction (Openshaw et al 1992: 29). From 1847 to the Native Schools Act in 1867 there were a variety of government initiatives to provide schools for Maori children. In all cases instruction in English was an important part of the education envisaged. In the debates preceding the passing of the 1867 Act, several MPs spoke on the importance of English acquisition for the "civilisation of the remnants of a noble race' as one of them put it (Openshaw et al 1993:40). The emphasis on English acquisition by Maori students was strongly supported by Maori MPs (Openshaw et al 1993: 42).

By 1874 there were 64 native schools with 1,487 children in attendance (Cumming \& Cumming 1978: 65-66). Commenting on the system that came into being as a result of the 1867 Act and 1871 amendment Pearson points out

This system ... was supported by the Maori MPs and many Maori parents. At a time when the Maori language seemed unthreatened and when the inevitability of Pakeha dominance was apparent, the desire to aid adaptation by acquiring the English language and knowledge of Pakeha institutions was often uppermost in many Maori minds (Pearson 1990: 56. See also Beaglehole 1970: 30).

The teaching of English to Maori children, often accompanied by a school imposed ban on the speaking of English in the school grounds, has its origins here. The banning of English (never an official policy (Openshaw et al 1993: 64), came to be bitterly resented by a later generation of Maori looking back on their education and many came to see it as an entirely Pakeha imposition although others acknowledged it had its origins in Maori perceptions and attitudes 
also $^{15}$. In reference to a famous statement by Apirana Ngata; "What is the most important thing for the Maori to learn ....", Pihama quotes Maaka Jones as saying

At school we were forbidden to speak Maori. You got the cane or the strap. All native schools, all around. There was no chance. Looking back it's appalling. But Apirana (Ngata) had something there really; we had to learn how to speak English (Pihama no date: 5).

In 1877 the Education Act was passed providing for a nationwide system of free secular and more-or-less compulsory (it was left to the discretion of the individual local education boards) education for non-Maori children. Nothing in the 1877 Act was binding on Maori but Maori parents were at liberty to send their children to public schools should they so desire. At those schools the children were of course instructed in English. By 1894 under the School Attendance Act both Maori and non-Maori children had to attend some school for a given amount of time a week between the ages of 7 to 13. The recognised goal of the education system for Maori children was to increase their assimilation into Pakeha New Zealand life and for this the mastery of English was crucial.

J H Pope and W W Bird [both at one time inspectors of native schools] believed that the Maori, for his own material good, had to be assimilated into British-style society; therefore his education had to be similar to that of the European in the State public schools. The Maori themselves encouraged the establishment of native schools and the shrewdest of them - including Apirana Ngata - realised the practical value of a knowledge of English (Cumming \& Cumming 1978: 260). (See also Openshaw et al 1993: 46-49).

\subsubsection{Re-emergence of Maori in the education system}

The emphasis upon assimilation began, slowly, to change in the 1920s and 1930s (Benton 1996: 66). In the 1930s, a new policy framework was created for Maori education.

At the theoretical level, the new policy was based on three articles of faith; that the happiness and welfare of people was dependant on the strength and stability of their own social institutions, including a 'healthy pride in race', history and achievements; that the role of education in regenerating and integrating the Maori into New Zealand society should be limited to assisting them to acquire the worthwhile elements of both cultures; and that the Maori were no different from any other race in their power and capacity to adapt to changing conditions (Openshaw et al 1993: 61).

\footnotetext{
15 One of the earliest references to banning Maori at school appears to be a 1877 petition by Wi Te Hakiro and 336 others asking, amongst other things, 'that not a word of Maori be allowed to be spoken in any school' (Barrington 1966: 3).
} 
It was still the case however that one of the main functions of the Native primary schools was to teach English and there was to be no Maori language curriculum (Openshaw et al 1993: 6164).

There was no stated aim to abolish Maori but the fact that it was often banned on the school premises made Maori children feel that it had a second rate status in the Pakeha world. In the 1940s, attitudes began to shift slightly. In 1943 Smyth's Te Reo Māori - A Guide to the Study of the Māori Language was published, a harbinger of the renewed Pakeha interest in what was now beginning to be a language under threat. This was followed by A T Ngata's Complete Manual of Māori Grammar (1948) (Cumming \& Cumming 1978: 287-8.).

In the 1950s we see signs of what was to become a major controversy in the New Zealand education system and within New Zealand generally - Maori demands for greater prominence for the Maori language, te reo Mäori - both within the education system and in wider society. In 1955 E G Schwimmer, editor of Ao Hou said

it was pointless for the Maoris to keep making unconvincing demands about their language when they discourage their children doing homework, when they refused to allow their children some quiet time at home for study, and when they did nothing to encourage the habit of reading (Cumming \& Cumming 1978: 301 ).

Also in 1955, for the first time a group of Maori representatives was asked to contribute at national level to discussions on Maori. A National Advisory Committee on Maori Education was set up as a result of their deliberations and policy for the future was developed. This included an increasing emphasis on Maori culture in both Maori and non-Maori board schools and also the gradual phasing out of the Maori schools (they ceased to be 'native' schools in 1946). As Beeby said,

I took some pleasure, on my travels overseas, in boasting that, while minorities in America and elsewhere were fighting for the integration of their schools, I was one of the few educational administrators in the world committed to giving sympathetic consideration to a native people opposing integration. But I knew it was a lost cause. (Beeby 1992:208).

In August 1961 the New Zealand Council for Educational Research organised a conference on Maori education. The conference outlined areas that it considered of particular importance including those of language and communication. In the following years the Council published a variety of works concerned with Maori education and language (Cumming \& Cumming 1978: 340). 
In 1969 the reconstituted National Advisory Committee on Maori education was asked to report to the Minister of Education on priorities in Maori education.

The Committee realised that the lack of progress of Maori children in learning English was 'a major cause of concern', and it called, too, for a thorough teaching of English to Maori and other Polynesian pupils throughout primary and secondary schools. The Board of Trustees appointed under the Maori Education Foundation Act of 1961 had also devoted much of its energy to pre-school education which had for one of its objects the improvement of the young Maori's command of English. At the same time pressure groups were demanding that 'Maori studies' and the Maori language should be taught in the schools (Cumming \& Cumming 1978: 342).

In 1971 the government made funds available for two research projects on the education of Maori and Pacific Island children. Both of these were to have implications for de facto educational language policy in New Zealand. The NZCER was given money to research the linguistic abilities of Maori pupils and the Department of Maori and Island Affairs was to administer a research project to investigate a wide range of 'educational and social problems facing' Pacific Islanders and Maori (Cumming \& Cumming 1978: 340). Also in 1971 the Department of Maori and Island affairs noted that New Zealand pre-schools programmes (mainly play centres and kindergartens) failed to provide for the needs of Maori and Pacific Island children (Cumming \& Cumming 1978: 341).

Two main themes emerge. The stress on English language acquisition, not only for Maori but for Pacific Islanders too, and the acknowledgment of the growing pressure for a place for Maori language and taha Maori within the education system. The move to teach Maori in the general New Zealand education system had slowly been gaining ground. According to evidence given at the Waitangi Tribunal in 1986, the Department of Education has, since 1955 , been aware that

... an understanding of Maori language and culture was necessary not only to develop the full personal development of Maori children but also to assist the pakeha to fully appreciate the history, achievements and character of Maori society (Waitangi Tribunal 1997: 35).

In the mid-1950s about a thousand people had studied Maori through the Correspondence school and in Maori district high schools and denominational colleges. By the early 1970s the numbers had grown to 2400 and Maori was being taught at about 30 New Zealand secondary schools (Cumming \& Cumming 1978: 343). It was realised in the 1970s that there was going to be a problem with a shortage of Maori language teachers and Cumming and Cumming in their 1978 book say that it is from the pupils of these 30 schools that 
the Government will look to future teachers instead of resorting to the expedient of using unqualified Maori teachers (Cumming \& Cumming 1978: 343).

It would be pleasant to report that their prophecy had come true, but in fact the provision of an adequate number of qualified Maori language teachers is as problematic as ever - undoubtedly in part because of a boom in Maori language learning that was unforeseen in 1978.

By 1974, 94 secondary schools were teaching Maori and it was being studied by 9,111 pupils of Maori descent and 3,535 pupils of non-Maori descent. In this year a few more active steps were taken to promote the learning of Maori within the New Zealand school system. Advisers in Maori education were appointed as were itinerant teachers of Maori (Waitangi Tribunal 1997: 35). Ten years later in 1984 there were 14,950 Maori pupils and 5,399 non-Maori pupils taking Maori at 179 schools (Waitangi Tribunal 1997: 35).

The 1980s also saw the beginning of the Kohanga Reo movement which, although begun outside the framework of government policy, has subsequently become an important part of government policy in the area of Maori language. The movement began, according to the Waitangi Tribunal, as the result of a statement made in 1982 by the then Secretary of the Maori Affairs Department, Mr Kara Puketapu.

He said publicly that it was up to Maori parents to preserve the language. The seed that he planted fell on fertile soil and in Waiwhetu in the Hutt Valley the first group of parents gathered together to give their infants an understanding of Maori (Waitangi Tribunal 1997: 12).

The Kohanga Reo Movement provides pre-school education in a Maori language immersion environment. It sprang up very rapidly at 'flax roots' level and from one kohanga reo in 1982, the number had grown to 416 in 1986 attended by over 6000 children (Waitangi Tribunal 1997: 12). It was quickly realised that Kohanga Reo were not enough. While it was entirely satisfactory that so many children were being introduced to the Maori language at such a young age and that so many seemed to be doing so well, it was entirely unsatisfactory that they left the kohanga to attend mainstream, English-medium primary schools where, it was justifiably feared, their Maori language skills would receive little support (Openshaw et al 1993: 79). In response to this unsatisfactory state of affairs, the first kura kaupapa Maori was established on Hoani Waititi Marae in Auckland in 1984 (Ministry of Education Website 1997). 
By 1989 twelve kura kaupapa Maori had been established by communities, 'mostly without state support' and by 1990 the state had begun to fund them on the same basis as other state schools (Ministry of Education Website 1997). In 1990 there were seven state-funded kura kaupapa Maori and by 1995 there were 38 such schools with an enrolment of 2,590 (Ministry of Education Website 1997). In addition to the kohanga reo and kura kaupapa Maori there are also schools which offer Maori medium education within a school that also teaches in English and Maori language continues to be taught as a language subject at primary and secondary level, there are also Taha Maori classes in which children 'learn Maori songs, greetings and simple words, without taking te reo Maori as a separate subject' (Ministry of Education Website 1997).

The history of Maori language in education policy is important in the history of language policy in New Zealand because it is one of the few areas where we can trace changes in explicit policy about language over a long period of time. The education of Maori children is one of the first areas in which a New Zealand administration made policy decisions about language; in this case the necessity of teaching Maori children English. All subsequent policy dealing with non-English speaking children was, unthinkingly and unhesitatingly, albeit in an 'ad hoc' manner (Benton 1996: 66) modelled on that initial decision until very recently. The change in Maori attitudes to the use of Maori language in the state school system seems to have been one of the factors in influencing the very slight changes to policy about other nonEnglish MTs in the classroom and the slightly greater changes of attitude to such languages on the part of teachers (see Kennedy \& Dewar, 1997). One of the early direct links drawn between the experience of Maori children and immigrant children can be seen in the early 1970s. In 1972 New Zealand policy makers began to deal with aspects of language and education policy for Pacific Islanders in New Zealand and a Pacific Island Education Foundation Act was passed. Pickering, when moving its introduction said

We are reaching the stage where a significant proportion of Pacific Islands school children have little knowledge of the home language and where the English used by their parents is inadequate

The National government wanted to take prophylactic measures to ensure that there was not 'a repetition of what has happened to Maori children' (Cumming \& Cumming 1978: 343). Admittedly they were concerned with low educational achievement not MT language loss, but it is an example of how parallels between Maori and immigrant were perceived by policy makers at the time. Assessing the situation now, it seems that Maori have perhaps gained 
most in the area of MT language (although it must be remembered that they also lost the most). Corson makes the point that vis-à-vis Maori New Zealand has

begun to move towards the enrichment Stage 5 and perhaps ultimately to Stage 6 , at least in relation to its Maori minority. However in relation to its very large Pacific Island and other smaller minorities it is still located at Stage 1, Stage 2 or Stage 3. (Corson 1993:75-76).

\subsubsection{Non-Maori education}

Non-Maori education in New Zealand was initially entirely a matter of the individual initiative of missionaries and school teachers who might care to offer instruction in return, in most cases, for a fee. It was not until 1852 and the passage of the Constitution Act that the Provinces assumed some responsibility for education in their region. And it was not until the Education Act of 1877 that the central government assumed responsibility for the education of the majority of the children of New Zealand (Cumming \& Cumming 1978).

One of the interesting changes that has taken place in New Zealand education (as part of an international trend) is the shift from a foreign languages oriented education system to one where languages (other than English) have been comparatively unimportant (Benton 1996: $69,72)$. The reasons for this are many, and extend well beyond the present discussion, nonetheless, the gradual decline in the emphasis in languages other than English in the New Zealand school curriculum does overlap in a curious way with the topic of immigrant language maintenance and shift. Possibly we are now witnessing a shift back to a greater emphasis on languages in schools and now the emphasis is not only on the traditional, statusbestowing languages of ancient and modern Europe but on Maori, other Polynesian languages and the languages of Asia (Benton 1996: 69, 75-76). In the Crown Colony, the Provincial and the initial National stages of development of a New Zealand education system it was assumed that the majority of children would not complete more than a primary education. It was equally assumed that a small proportion of children, mainly, but not exclusively, Pakeha boys, would go on to secondary or even tertiary education. Language issues at primary level extended no further than the proper teaching of English (itself a vast subject, and one on which New Zealand inspectors tended to be querulous). At secondary and tertiary level the teaching of languages other than English became very important. The secondary and tertiary education systems that were introduced into New Zealand at this time were systems that placed a very high value on the importance of language learning. The British settlers of New Zealand brought with them the Greek and Latin higher education of their homeland (Benton 
1996: 68). To be a properly educated man (I used the term advisedly) one had to have a nodding acquaintance of Greek and at least a good reading knowledge of Latin. This, at any rate, was the theory. By today's standards, the emphasis on languages was phenomenal. The 1878 O'Rorke Commissioners made the following suggestions for two secondary school curricula for boys. For the classical side they suggested the school week consist of

- 8 hours Latin

- 5 hours Greek

- 5 hours Mathematics

- 5 hours English

- 2 hours French or German

- 2 hours drawing

That is, a boy on the classical side would spend 15 of his 27 hours a week studying a language other than English. If English is included then 20 of his 27 hours are spent in language study. A boy on the modern side would spend less time on languages but still 9 of his 27 hours would be spent studying a language other than English and if the five hours of English are included more than half his school hours are spent on language study.

It is not to be wondered at that in New Zealand during the 1880 s there was some controversy on whether secondary schools should be part of the national system and be maintained out of public funds. The 'man in the street' was not convinced that, to prepare for the business of life, a boy needed to study modern languages, other than English, and the ancient classics for from nine to fifteen hours out of 27 each school week. (Cumming \& Cumming 1978: 117).

There was indeed a constant tension as the twentieth century advanced and as secondary school education became more general, between those who advocated 'a good general education' - which usually included at least one foreign language and those who were opposed to education that was too academic - one of the usual criteria for this judgement being that too many foreign languages were taught. It was not always the case though, as Cumming and Cumming suggest, that it was the 'man on the street' who was opposed to the academic education. Many men (and women) on the street recognised very clearly that acquisition of languages, especially French and Latin, meant status and they were most concerned that their children should have access to that status and upward mobility (Beeby 1992: 210).

According to Cumming and Cumming New Zealand education suddenly fell into the 'Slough of Despond' in 1926 (Cumming \& Cumming 1978: 232). If this was indeed so, it is safe to say that with the Labour Party victory of 1935 and Peter Fraser's appointment as Minister of 
Education, New Zealand education began to crawl out of the Slough, although the Depression was to deliver a few more body blows (See Cumming \& Cumming 1978: 249).

In 1937 came the New Education Fellowship Conference, which had a major effect on the thinking of New Zealand educationalists. The direction in which opinions had been trending can be seen from the comments of the Secondary School's Association in 1936 when they condemned

a curriculum which neglected the creative, artistic and physical sides of life; it was bound by external examinations; false valuations were placed on foreign languages and mathematics etc. (Cumming \& Cumming 1978: 263).

In 1938, Dr. Beeby was appointed as Director of the Department of Education under Peter Fraser and began to implement, and in part, create, a range of new policies in New Zealand education (Beeby: 1992). A major change in the direction of secondary education occurred with the report of the Thomas Committee in the early 1940s. The recommendations of which were incorporated in regulations in 1945. The Thomas Committee was, at least in part, trying to design a suitable curriculum for secondary schools that for the first time in New Zealand history were envisaged as providing for all children under the age of 15 . A core curriculum was proposed and it contained no foreign languages at all (Cumming \& Cumming 1978: 280).

The history of mainstream or non-Maori education in New Zealand is then, in part, a history of a move away from the overwhelming importance of languages other than English in education. This move incorporated, for a time, an explicit denigration of 'foreign' languages. The foreign languages that minority immigrant children brought with them were unlikely to be valued in such a climate and, in fact, they were, usually, not valued.

in Europe in those days when I came out we were always fascinated by people that spoke another language. You'd listen [unclear] hey! German or English or French and then quite often you wanted to converse with them y'know to see how good you were type of thing. But here it was another bloody foreigner if they hear another language $y$ 'know then all hackles go up and um people feel as though they're being talked about (Paul Veltman MSC 5409 MSC 5410. See also Beaglehole 1990: 99).

It seems unlikely that Latin and Greek will regain their importance and the changed geopolitical environment means that French and German are no longer the most important modern languages for a New Zealander to acquire but there is, once again, a greater emphasis on languages in the New Zealand education system (Benton 1996: 95). 


\subsubsection{Samoan in the New Zealand educational system}

In section 4.4.1.1 the first shoots of interest in Pacific Island languages on the part of the New Zealand educational bureaucracy were noted. Thanks largely to the unremitting efforts of the Samoan community these were to bear fruit. Pre-school a'oga amata were began to be established in 1985 and the first tertiary level course started at Victoria University in 1989. By 1996 Victoria University, Auckland University and Whitirea Polytechnic all offered at least some courses in Samoan (Masina 1996: 24-25). A mixture of primary and secondary schools offered Samoan courses of varying types but the system, such as it was, was patchy and uncoordinated (Masina 1996: 92-93). The publication of the draft 'Samoan Language Curriculum Statement' had a beneficial effect

The statement can be used to implement programmes from the early childhood level, through to the end of secondary school.

The importance and success of this development can not be over-stated. Primary schools and colleges have been the slowest sectors to react to the growing trend of Samoan language recovery (Masina 1996: 25)

It has in general been the pre-schools where the greatest effect has been felt.

On the national level, pre-school education shows greatest recognition of the place of heritage languages of one subset of the non-English speaking population, those from other parts of Polynesia. In 1993, 177 Polynesian language nests, catering for 3,877 children, were receiving government funding (Benton 1996: 88-89)

\subsection{Broadcasting Policy}

Broadcasting policy and explicit language policy overlap mainly in the area of Maori language broadcasting. The various broadcasting institutions have long had in-house policies about English and Maori pronunciation and usage and these policies have undoubtedly been influential, however they operate well below the level of national policy on which we are focussing and will not be mentioned in much detail here.

Broadcasting has long been seen as having an important social and political role to play in New Zealand and in the last 20 years this role has increasingly included Maori language broadcasting. As an adjunct to this, there has been some increased emphasis on minority immigrant language programming.

New Zealand appears to have the slightly dubious honour of being the first country in the world to have introduced legislation to control the new technology of the wireless. In 
September 1903 the New Zealand Wireless Telegraphy Act was passed in Parliament and broadcasting was, in effect, banned (Day 1994: 13). You could say, that the New Zealand government was taking care to start as it meant to go on. Between 1906 and 1920 various other pieces of legislation were passed to ensure adequate control of the new technology, and it was not until 1921 that the ban was lifted and broadcasting began in New Zealand, at Otago University (Day 1994: 16-39). 1923 the Radio Telegraph Regulations for Amateur, Experimental, and Broadcasting Stations were presented (Day: 1994: 49). These Regulations controlled various technical aspects of broadcasting and they were also used to control the content there was a ban on 'material of a seditious, profane, obscene, libellous, or offensive nature', a ban on controversial content, an emphasis on the importance of religious broadcasts on Sundays, a prohibition of advertising and a requirement that stations repeat their call signals at regular intervals.

The general policy attitude that was to shape broadcasting in New Zealand was clear. Radio was to be educative and informative and to play no overt part in controversy or, heaven forbid, politics. It was also to be tightly regulated (Day 1994: 51 ).

In 1925, the government signed a contract with the newly-formed Radio Broadcasting Company, which then proceeded to establish the first national broadcasting system in New Zealand (Day 1994: 63-66). The RBC had a basic and conservative policy on the use of language in broadcasting, it acknowledged 'the importance of correct English diction' and that 'broadcasting should be a powerful medium in speech training'. The RBC also provided some encouragement for the "correct" use of te reo Maori. In fact, the RBC had some of its biggest successes with Maori programming. The RBC also presented programmes that aimed at improving people's pronunciation of Maori and covered such matters as the meaning of Maori placenames and phrases (Day 1994: 124).

In 1932 publicly owned broadcasting was established in New Zealand under the Broadcasting Act of 1931. Under the new Act, the New Zealand Broadcasting Board was established and state control of the national broadcasting system was assumed. The NZBB was meant to be politically independent of the government (Day 1994: 148-9). British broadcasting was explicitly the model according to the postmaster general 'We propose to follow very similar lines to those adopted by Britain.' (Day 1994: 148). Under the Broadcasting Amendment Act 1934-35, the ban on controversy was removed. 
State ownership of broadcasting in New Zealand became virtually absolute after the first Labour government came to power in 1935. Labour politicians had long been suspicious of the press, considering that it favoured conservative parties and policies (Day 1994: 213, Gustafson 1986: 169-170, Carter 1993: 203, Wood 1958: 89). This attitude on the part of the Labour Party, led to the Broadcasting Act of 1936. The NZBB was abolished and a new government department, the National Broadcasting Service was established. The privately owned stations were not closed down, they were bought out and placed under the control of Colin Scrimgeour as controller of commercial broadcasting stations ${ }^{16}$. Professor James Shelley an Englishman and professor of education at Canterbury University College became the Director of broadcasting (Day 1994: 220, Carter 1993: 204). A charismatic and influential figure, he was 'clearly in the Reithian mould' (Day 1994: 220).

Shelley supported attempts to find new ways to think about New Zealand life, but he never entertained a doubt about the dominion's umbilicus to a nourishing Home. At Broadcasting he insisted on the English language being spoken with an English accent. 'Not necessarily that of Harrow or Oxford', Alan Mulgan recalled, 'but the real thing with no affectation or provincialisms.' (Carter 1993: 274).

This insistence was backed by practical assistance to the announcers, to help them achieve the desired model of pronunciation. Arnold Wall, the recently retired professor of English at Canterbury University College, was contracted to analyse the speech of the announcers and to help them improve their pronunciation (Day 1994: 246).

Shelley does not appear to have had any strong opinions about either Maori personnel or Maori language in New Zealand broadcasting. Scrimgeour however did consider the question of both people and language. He instituted a policy that each of the commercial stations was to employ at least one Maori announcer and he encouraged the employment of other Maori staff. Scrimgeour also opposed the idea that it was acceptable to anglicise the pronunciation of Maori words (Day 1994: 242-3). According to Day

[Scrimgeour] was not the first to have specific Maori programmes, but he was the first broadcaster in authority who thought beyond the immediate topic of programming and considered a policy in terms of long-term benefits to the Maori (Day 1994: 243).

Scrimgeour and Wall were of one mind in this area. Wall comments

\footnotetext{
${ }^{16}$ Which position he held until dismissed, essentially for political reasons in 1943, by the Labour administration (Day 1994: 277).
} 
We are indeed fortunate in having at nearly all the main broadcasting stations in New Zealand announcers who realize their responsibilities in this respect, have made a close study of the Maori language, received assistance from natives, and pronounce all Maori names and words in the correct manner. The correct pronunciation of Maori names should be carefully taught to children in schools, by both duty and precept (Wall 1938: 14).

Despite Shelley's apparent lack of interest in Maori issues, Maori were not totally ignored on the non-commercial stations. The Maori news began in 1942 and in the 1950s local and national programming in Maori was begun (Day 1994: 315). The amount of programming was slight however and, according to Day, the strong emphasis by policy-makers was on radio as an instrument of national cohesion rather than as a tool for allowing differing groups within New Zealand society to express their individuality (Day 1994: 315). This general indifference to the position of Maori language in New Zealand broadcasting was eventually to undergo a dramatic change.

During the 1960s the structure of radio in New Zealand remained essentially unaltered but from 1960 onwards, it was operating in a rapidly changing environment; television broadcasting had begun in New Zealand in 1960. Throughout the 1960s pressure on the government grew to allow the licensing of private radio stations and in 1970 it was once again possible to set up a legal private radio station in New Zealand (Yeabsley et al 1994: 22).

\subsubsection{The growth of Maori broadcasting from 1976}

In some ways, $1976 \mathrm{can}$ be seen as a watershed year for language and culture policy in broadcasting in New Zealand. In 1976, the National government passed the Broadcasting Act which created the Broadcasting Corporation of New Zealand (BCNZ) and set up the Broadcasting Tribunal with wide-ranging powers (Yeabsley et al 1994: 22). The Broadcasting Act also required the BCNZ 'to reflect and develop New Zealand's identity and culture' (Royal Commission 1986: 295). In 1978 the Board of the BCNZ presumably partly, at least, in response to their statuary obligation enjoined on them by the 1976 Act, "developed a policy on Maori broadcasting, relating especially to television, which dealt with staff recruitment and bi-lingualism in television and programme changes which were to be taken as a result of this' (Royal Commission 1986: 295-6). This seems to be the first time that Maori language and Maori oriented programming rose to the level of Corporation policy rather than being dealt with as a series of more or less ad hoc decisions, albeit sometimes taken at a senior level. In the same year, Te Reo Aotearoa was established by Radio New Zealand in order to 'provide 
news and information of special interest to Maori and Pacific Island listeners' (Royal Commission 1986: 300).

Thus by the late 1970s Maori broadcasting was beginning to have a higher profile in both television and radio. Throughout the 1980s the pace of change in broadcasting in New Zealand increased. In 1986 (under a Labour government) a Royal Commission on Broadcasting and Related Telecommunications was established and the Waitangi Tribunal reported on the Te Reo Maori claim. In 1988 amongst other developments, there was a Broadcasting Policy Review, the BCNZ Restructuring Act was passed and the newly created state owned enterprises (SOEs) came into being, in 1989 the Broadcasting Act was passed and TV3 (New Zealand's third television channel) began broadcasting (Yeabsley et al 1994:

22). Many of these developments were to have important consequences for Maori broadcasting.

The Waitangi Tribunal findings on the Te Reo Claim in the area of broadcasting were also important for the development of Maori broadcasting. The Tribunal Report was reluctant to make any very specific recommendations, partly because the Royal Commission was considering the same issues, but it was extremely clear in its main finding that the Maori language was protected under the Treaty of Waitangi.

7.2.3 We have quickly come to the conclusion that we must avoid trespassing into areas that are properly the primary concern of both the [Broadcasting] Tribunal and the Royal Commission. We are quite clear in our view that Article II of the Treaty guarantees protection to the Maori language as we have said, and we are also quite clear in our view that the predominance of English in the media has had an adverse effect upon it. We might very easily further conclude that we should make recommendations of a positive kind as to how this harm could be reduced or eliminated but to do so we would necessarily be discussing what part radio and television stations should be required to play in achieving that result. For example, it might be said as the claimants urged us to recommend, that particular radio stations ought to be converted entirely to Maori language transmissions, or that one or other of the television channels ought to broadcast a minimum number of hours each day or each week devoted solely to Maori language and cultural interests (Waitangi Tribunal 1986).

\subsubsection{Royal Commission of Inquiry into Broadcasting and Related Telecommunications 1986}

At much the same time as the Waitangi Tribunal was considering these issues, the Royal Commission was, under its Term of Reference 6 , considering "the reflection in broadcasting 
of the multicultural nature of New Zealand society" with special reference to Maori (Royal Commission 1986: 293). The Commission asked BCNZ representatives how the Corporation had been fulfilling its obligation to 'reflect and develop New Zealand's identity and culture'

The Corporation told us that it encourages its producers, programme makers and executives to attend hui to gain a wider understanding and appreciation of the needs and expectations of the Maori community. Correct pronunciation of the Maori language is required of all on-air staff in both services and training is provided in this. ... The Chairman of the Corporation admitted to us that television had been a late starter in the process of identifying means of providing Maori programme content ... [he said much had changed] ... and contended that the leopard had not so much changes its spots but that there was, in fact, a new leopard (Royal Commission 1986: 295).

There may well have been a new leopard in terms of awareness of and attitude towards Maori language but, to stretch the metaphor a point, one would have to note that the new leopard was yet a cub. Allan Martin (a former Director-General of Television New Zealand at the time he gave evidence) said that Television New Zealand reflected Maori culture in two ways

through its general programming as a mass medium, and in special language and other programmes. Its production departments deal with Maori subjects as part of normal programming. Maori attitudes and activities have been reflected where appropriate, both socially and historically, through drama, special interest programmes, entertainment, documentaries, news, current affairs and children's programmes [he noted that Koha and Te Karere, both Maori language programmes, had started in 1980 and 1983 respectively] .... Nevertheless Mr Martin admitted that Television New Zealand's Maori programming in both English and Maori constituted at best two hours per week over both channels and he acknowledged that this was not sufficient (Royal Commission 1986:297).

The Director-General of Radio New Zealand was equally circumspect in his claims for that institution

The Director-General of Radio New Zealand assured us that public radio had "always been conscious of its statutory obligations towards the Maori and Pacific Island segment of its listeners - although it may not have fulfilled their needs to the extent and in the way that some contemporary thinking now demands" (Royal Commission 1986:299).

The Royal Commission made 15 recommendations in respect of the Maori language and broadcasting; amongst other things it supported the Waitangi Tribunal's recommendation that a Maori Language Commission should be established 'with the right, inter alia, to advise the Minister of Broadcasting' (Royal Commission 1986: 312) and the general tendency of the 
recommendations was to suggest that more effort and more haste were required to improve the quality and quantity of Maori broadcasting.

\subsubsection{The Royal Commission and multiculturalism}

The Royal Commission was also required to consider the 'place of multiculturalism in radio and television, not only in respect of those sections of our community which come from the Pacific Island nations, but also those whose cultural backgrounds lie in Continental European and Asian countries' (Royal Commission 1986: 313). The Royal Commission stressed that

we believe the logical progression to multi-culturalism on television and radio is through bi-culturalism and recognition of the rights of the tangata whenua. Indeed the majority of submissions made to us by and on behalf of representatives of non-Maori minority groups stressed that they would not wish to see their interests met at the expense of the Maori people (Royal Commission 1986: 313-4).

The authors of the Report give no reason for their belief that there is a logical progression from biculturalism to multiculturalism in radio and television in New Zealand and it is not obvious what the grounds for this belief might have been. Some clue is given by their statement that representatives of non-Maori minority groups would not want to benefit at the expense of Maori. The implication that can be drawn from this is that the use of the word 'expense' is not metaphorical and that the Commission saw the progression largely in terms of financing and resourcing. Once biculturalism was firmly established then it would be time to devote some resources to multiculturalism; the fact that meeting the interests of non-Maori minorities is seen as being, potentially at least, at the expense of Maori seems to suggest that this is the nature of the progression that the Commission envisaged. It is hard to see in what other ways multicultural broadcasting could have been at the expense of Maori broadcasting.

This is not to say that issues of multicultural broadcasting were completely ignored. Most of the section in which this issue is considered concerns Pacific Island cultures. The brief consideration which is given to non-Maori, non-Pacific Island cultures identifies 'narrowcasting' as most appropriate for their needs and goes on to say that 'it is radio which is better suited to 'narrowcasting' in this respect' (Royal Commission 1986: 319). The Royal Commission seems to be of the view that Radio Access, a Radio New Zealand outlet in Wellington was adequate for the needs of such minority groups. Radio Access was launched in April 1981 and according to the Commission it 'provides a forum for individuals and community groups to produce and present their own programmes.' The programme presenters 
did not have to pay for air time, nor were they paid for their contributions. In 1986, Radio Access broadcast for 120 hours a month using frequencies that were used at other times for broadcasting Parliament (Royal Commission 1986: 340). By 1997, Radio Access was broadcasting for 336 hours a month and was used by over 130 groups and individuals broadcasting in more than 20 languages $^{17}$ (see below section 5.2.4 and 5.6.1) for further comment on the role of radio in language maintenance). Radio Access frequencies are also used for Samoan Capital Radio Siufofoga o le Laumua (Wilson 1994: 123) which broadcasts in Wellington. There are also Samoan language radio stations in Christchurch and Auckland (Wilson 1994: 123-125).

\subsubsection{After the Royal Commission}

The Broadcasting Act 1989 established the Broadcasting Commission, known as New Zealand On Air. New Zealand On Air is funded through the Public Broadcasting Fee (as New Zealanders are constantly reminded by television and radio advertisements) and has the following functions

- to reflect and develop New Zealand identity and culture (including the promotion of Maori language and culture);

- to maintain, where the Commission considers that it is appropriate, extend television and radio coverage to New Zealand communities that would not otherwise receive a commercially viable signal [sic];

- to ensure that a range of programmes is available to provide for the interests of women, children, disabled people and other minorities (including ethnic minorities); and

- to encourage the establishment and operation of archives of programmes. (Ministry of Commerce, Communications Division Website 1996).

New Zealand On Air is essentially a funding agency and achieves these goals through disbursing funds for 'broadcasting, production of programmes and archiving of programmes' . New Zealand On Air provides partial funding for the Community Access Radio Stations including Wellington Access Radio (Wilson 1994: 116) and funding for two Samoan language radio stations (Wilson 1994: 123). The Broadcasting Amendment Act 1993 established Te Reo Whakapuaki Irirangi (known as Te Mangai Paho) to act as a Maori broadcasting funding agency. Te Mangai Paho receives a percentage of the Public

\footnotetext{
${ }^{17}$ Information supplied by Radio Access PO Box 9073, Wellington.
} 
Broadcasting Fee and also receives some money direct from the Crown (Ministry of Commerce, Communications Division Website 1996).

The Waitangi Tribunal Report on the Te Reo claim and the Report of the Royal Commission on Broadcasting, both in 1986, seem to mark a watershed in issues of Maori broadcasting. From that time on, although Maori individuals and organisations may have felt dissatisfied with the progress made by Maori broadcasting and by the response of various governments of the day to Maori needs and claims nonetheless, from 1986 Maori issues in broadcasting have been to the forefront of government policy making on language and culture issues in broadcasting. ${ }^{18}$

This new salience of Maori issues in broadcasting saw its first legislative embodiment in the Radiocommunications Act 1989. Under the Act special provision was made for noncommercial broadcasters and both radio and television frequencies were reserved for noncommercial broadcasters. By 1996 there were over twenty iwi (local or tribal Maori) radio stations and one Pacific Island radio station broadcasting on reserved frequencies ${ }^{19}$ (Ministry of Commerce, Communications Division Website 1996).

Broadcasting in New Zealand has, from its inception, been under tight government control. For the first 50 years, although Maori language and Maori issues were always acknowledged, the main purpose of this tightly controlled government broadcasting system was to present a united, homogenous, almost monocultural New Zealand. Since the 1970s, this purpose has begun slowly to change. As with education, the most explicit and most far-reaching changes have been focused on Maori but there has been recognition of the minority immigrant diversity of New Zealand as well. As Mfodwo points out

much of the media practice ... reflects the hesitancies and uncertainties of commercial and governmental [media] "gate-keepers" caught in a dilemma [as to how to react to] a swirling world of diversity and difference... The contention is that the current spectrum of ethnic identities in New Zealand cannot be assimilated into the various forms of subordinated Anglo-centric identity that have hitherto been the dominant modes of diversity management in New Zealand. There are currently too many non-

\footnotetext{
${ }^{18}$ So much so that when I went to the Ministry of Commerce library to do some research in this area and told the librarian that I was interested in broadcasting policy, all the material I was handed was about Maori broadcasting policy.

${ }^{19}$ In addition access radio continued to have non-commercial frequencies made available to it.
} 
European "others" in New Zealand who cannot be made over into some manageable version of Englishness. It is argued that possible ways forward lie in a New Zealand version of the imaginative and highly successful integrative approaches to multicultural media in Australia and other countries of diverse population. Such a version must understand the affinities and shared needs of New Zealand's diverse sectors including, most importantly, the convergence of mass media interest between Maori and the new migrants (Mfodwo 1998: 100).

Broadcast media can certainly be a means both for presenting possibilities to a mass audience as to how we imagine our society and culture and also a means for subsections of that society and culture to focus on issues (such as language maintenance) that are important to them. In section 5.6.1 this aspect is considered as part of a discussion of Fishman's GIDS scale and the process of reversing language shift.

\subsection{Immigration}

Immigration in general is discussed in some detail in an earlier chapter but this is one area where policy about language has occasionally manifested itself and as such, it should be mentioned in this chapter. It has already been noted that the racist nature of much of New Zealand's immigration policy kept minority immigrant communities small and thus had a strong effect on language and culture maintenance in those communities. This was however a subsidiary effect as it were, of the larger intention which was simply to reduce the numbers of people in New Zealand whom the framers of the legislation considered to be inferior. What immigration policy and legislation has dealt directly with issues of language?

Essentially, there are two periods when New Zealand's immigration policy has concerned itself directly with language. The first period is that of the end of the nineteenth century and beginning of the twentieth when, before the passage of the Immigration Restriction Amendment Act of 1920, immigration issues were still in the forefront of public debate and legislators were trying to devise ways to keep out non-European immigrants, particularly Indians and Chinese. In 1899 the Immigration Restriction Act provided for a language test for non-British people wishing to enter New Zealand to be administered at an official's discretion. A non-British ('British' here includes Irish) person could be refused permission to land in New Zealand if they could not write out their application to land in New Zealand in a European language of the official's choice (McKinnon 1996: 27-28). This Act was not directed at a particular race and appears to have been devised as a means of keeping out Indian immigrants as well as Chinese. The Act was obviously regarded as inadequate, at least as far as the Chinese were concerned and in 1907 the Chinese Immigrants Amendment Act 
'made provision for Chinese to pass an English language reading test' (McKinnon 1996: 27). This Act, which was not formally repealed until 1944 (although its operation had fallen into abeyance by that time) (Henderson 1998: 146), seems to have been the last piece of immigration legislation aimed specifically at language until the 1990s and, given the history of language legislation in an immigration policy context, it is perhaps not surprising that the recent policy has been seen as racist.

The immigration policy changes enacted in the Immigration Act of 1987 allowed, for the first time in New Zealand's history for the immigration of large numbers of non-English speaking immigrants. English language assessment had been a part of post-WWII immigration policy, but the relatively limited number of NESB immigrants had meant that such assessment was not an important feature of the policy. The 1986 Review of Immigration Policy signalled the changes that were to occur

... in future all applicants for occupational entry, and their families, must be personally interviewed [to assess their English fluency] (Cited in Henderson 1998: 147).

Present immigration policy states very clearly that immigrants to New Zealand should be able to speak English as well and as quickly as possible

English is a key to successful settlement. Immigration is more successful for the immigrants, the community they live in, and the whole country if the new resident has a modest command of English. This applies not only to the principal applicant but to the whole family unit. Lack of English can be costly for everyone (New Zealand Immigration Service 1995: 10).

In order to make sure immigrants to New Zealand achieve this goal not only does the principal applicant for immigration under the General Skills or Business Investor categories have to meet the standard demonstrated by passing the General Module of the International English Language Testing System (IELTS Level 4, the level was originally set at 5) but all non-principal applicants over the age of 16 who do not meet that standard but who wish to enter the country will have to pay a bond of $\$ 20,000$ (refundable partially or in whole depending on their progress in English).

The new policy [introduced in October 1995] recognises the cost lack of language skills can impose on New Zealand. The $\$ 20,000$ fee acts as an incentive for a person to rapidly acquire basic English language skills (New Zealand Immigration Service 1995: 10). 
Undoubtedly, when it was introduced, some commentators saw it as an essentially racist move designed to weed out Asian applicants. The Evening Post (Wellington's evening newspaper) editorial (July 25, 1995) commented on this aspect of the policy at some length

While the Minister claims the language policy is not racist ... You cannot claim to be non-racist simply by saying you are not; deeds are as telling as words ... the Maxwell [Minister for Immigration] language regime disadvantages migrants from Korea, China, Taiwan and Indonesia who tend not to use English ... It does not reflect well on racial policies New Zealand is said to cherish, at least in public. ${ }^{20}$

The official emphasis on the importance of English language acquisition in New Zealand can scarcely be overstated and, by and large, immigrants to New Zealand agree with the importance of English language acquisition (Smith 1994: 135, Shameen 1995: 269, Henderson 1998: 143-144). Walker and Stapleton, who conducted research on immigrants in the Manawatu, found that $94 \%$ of respondents of varying ethnicity had studied English before coming to New Zealand and $85 \%$ would like to improve their English through more study (Walker and Stapleton 1998: 226). All the Gujarati interviewees in this research wanted their children to 'have a good command of English' and, as Kennedy and Dewar point out, for some immigrant parents, the importance of English easily overshadows that of the MT

not all NESB parents or students with to maintain their first language as they feel that they should devote their energies to perfecting English in order to maximise their opportunities for success in New Zealand society and in the workforce (Kennedy and Dewar 1997: 247).

\subsubsection{Provision for ESOL in New Zealand}

With such a strong emphasis on the importance of English for immigrants to New Zealand we would expect to see an equally strong emphasis on the importance of adequate provision of English language teaching services for immigrants. In fact, this is far from being the case, a point also made by Benton (1996: 93). This is partly because the present immigration policy stresses the importance of pre-arrival acquisition of an adequate level of English and partly because, the issue seems to have gone into limbo. In fact, this is one area where the need for some sort of overarching or co-ordinating languages policy can be clearly seen. It has already been noted that this was an area that Waite singled out as one of the six high priority areas for language policy in New Zealand (Waite 1992b: 28). There is a link here between education and

\footnotetext{
${ }^{20}$ A policy initiative announced by the Minister in October 1998 stated that this policy was to be abandoned.
} 
immigration policy that that the current system cannot easily address and does not, in fact, address very well.

Proficiency in English is deemed to provide the key to successful resettlement, yet the non-English speaking background immigrant is provided with little or no information as to which courses would best suit his/her learning needs. Choice, that hallowed tenet of educational provision in the nineties, is scarcely and issue for an ill-informed newlyarrived purchaser of English courses. Nor have market forces given rise to a plethora of specialist providers of English language courses. Those who most desperately need to learn English cannot afford the high costs of non-government subsidised private provision (Altinkaya 1998: 180-181).

Altinkaya summarises the options available to adult immigrants who wish to acquire or improve their English language skills (1998: 181-182)

- subsidised places at polytechnics (with long waiting lists)

- (usually) unsubsidised ESOL university course

- subsidised (to varying extents) adult Community Education ESOL programmes

- fully-funded ESOL places (very limited in number) at polytechnics and private providers funded through Education and Training Support Agency (ETSA)

- fully-funded ESOL places (very limited in number) at polytechnics and private providers funded through New Zealand Employment Service

- a range of ESOL courses, of a limited nature, from local providers purchased by New Zealand Employment Service in conjunction with Income Support ${ }^{21}$

- ESOL courses offered by the Correspondence School

- private language schools, unsubsidised and with fees of several hundred dollars a week

- private individuals charging, on average, thirty dollars an hour

- full-time secondary school places (for a few adults only)

- local church and community groups offering non-formal ESOL assistance

- $\quad$ subsidised ESOL Home Tutor Service ${ }^{22}$

There appears to be a wide range of choice but, as Altinkaya points out, this choice is severely constrained by cost, knowledge of what is available and the quality of what is available. The low priority accorded to ESOL provision by the government, despite frequent utterances in this area as to the importance of English (Bradford 1998: 22) is attested to by the fact that ESOL provision is not accorded priority funding (as are other language areas) by the government (Altinkaya

1998: 182).

${ }^{21}$ As I write, these two agencies are being combined into one.

22 To this list should be added the ESOL classes, fully funded by the Ministry of Education, run for refugees and disadvantaged migrants in Wellington by the Multicultural Centre for Learning and Support Services (MCLaSS). 
In sum, the history of immigration and language policies in New Zealand is not one of which to be proud. We seem, almost to have come full circle from using English language requirements as a de facto form of immigration barrier to exclude Asian immigrants, through a clearly-stated though perhaps less clearly acted-upon principle of excluding race as a factor in immigration policy and back to language as a de facto barrier once again. In addition, the provision we make for enabling immigrants to achieve, in New Zealand, what both the immigrants and the wider society recognise as vitally important, adequate mastery of English, is uncoordinated, expensive and, often of poor quality. Perhaps the last word on immigration and policy should be left to the Minister of Immigration

The last point: What does all this mean for policy? We must see all of our policies as interlocking. Immigration policy in New Zealand has not really been part of the major mosaic of policy, hasn't been given a very high status in terms of cabinet deliberations. It certainly matters in terms of being able to influence the way, in which decisions are made in government. We have to keep reminding ourselves that it is people that matter in all of this (Bradford 1998: 23, emphasis in original). 


\section{LANGUAGE MAINTENANCE AND THE COMMUNITY}

So far wider questions of language maintenance and shift have been under consideration; issues such as the links between language and identity and the sociophilosophical constructs which have been predicated on the existence of those links. Issues of national identity and the history of minority immigration to New Zealand have been discussed, as well as the specific immigration histories of the three communities under investigation. A brief outline of the nature of language policy at national level and some of the specific instances of nation policymaking about language in New Zealand have also been given.

This section focuses on more specific issues of language maintenance and shift, examining the process at a local and community level rather than at a theoretical and national, or even international, level. What are some of the reasons for immigrant language maintenance? Where, within an immigrant community, is language maintenance situated? And can language shift be reversed? This last question is, of course, asked in response to Fishman's concept of Reversing Language Shift (RLS). Both RLS and Fishman's GIDS scale will be discussed.

\subsection{Function of language maintenance}

Language maintenance is not an end in itself for immigrant communities. Rather language maintenance is worked for because it is perceived as having functional benefits for the community. These functional benefits cover a wide range and are usually perceived in terms of allowing members of the immigrant community born in the host country to participate in community or family life. In the first stages of a community's existence in the host country it may not occur to members that it is possible to participate fully in community or family life unless one uses the immigrant language. If it does seem possible, it may well appear to be highly undesirable

The Samoan language ... is basic to fa'aSamoa (Samoan way of life). To the Samoans, fa'aSamoa is their unique lifestyle. It unites them and gives them their identity. Most Samoans choose to keep their language and live their culture in New Zealand. For them, this is the true life. It maintains their ties with their homeland and gives them roots in their adopted country (Kerslake and Kerslake 1987: 144)

These are very common attitudes in immigrant groups at an early stage of settlement in the host country. Punetha et al describing Hindu, Muslim and Sikh Indian immigrants in England say that 
They attempt to maintain their cultural values and transmit them to succeeding generation ... they consider language as a vehicle for cultural and value maintenance (Punetha et al 1987:230).

Sometimes this group of attitudes remains substantially unchanged. Sometimes they undergo radical change leading to the phenomenon Fishman describes as 'being Xmen via Yish' (Fishman 1991: 16).

The phenomenon of 'Xmen via Yish' occurs when members of the community decide that speaking the traditional community language is no longer a prerequisite for membership of the community. Thus for example, one can be a good member of the Maori community in New Zealand without speaking Maori. It is possible, in many community members' eyes (though not all) to be an authentic member of the Maori community via the medium of English. As Laksiri says

the sense of 'ethnicity', or belonging to an ethnic group, and one's cultural identity may not necessarily be associated with language. In unravelling the dynamics of the language/culture relationship we need to consider carefully how the concepts of 'culture' and 'ethnicity' have been understood when used in public policy (Laksiri 1989:43).

(See also Kouzmin (1988: 55-56) for further comment on disjunctions between linguistic and cultural loyalties.) Allowing, then for the fact that the connection between language and cultural identity is not straightforward, we can also note that it is frequently made by many ethnic groups in various ways. Some of the most commonly perceived functional benefits of speaking the traditional language are in the areas outlined below.

\subsubsection{Religion}

It may be considered necessary to maintain the language in order to maintain the true religion (Schiffman 1996: 59-62). The Jewish diaspora maintenance of Hebrew/Aramaic as a religious language relying mainly on writing and classroom learning for its transmission is a good example. Religion may also lead to a tradition of oral language maintenance as with the maintenance of German amongst the Old Order Amish and the Mennonites in America (Huffines 1980, Buchheit 1988, Dow 1988) or the maintenance of Greek in the United States (Demos 1988), Australia (Smolicz 1985: 26) and New Zealand (Verivaki 1991: 92).

Religion can however be neutral or even hostile to language maintenance efforts. In the case of the Cantonese Chinese in New Zealand most of whom, if they are institutionally religious, affiliate with a Christian church, the church provides a meeting place where they can speak 
Cantonese with other community members but there is no traditional link between Cantonese and their Christian faith. Indeed in most cases they only became Christians after moving to New Zealand. According to Fishman the Roman Catholic Church in the United States was 'most active' in 'de-ethnicizing parishes and Anglyfying church activities' (Fishman 1966: 398).

The church may also abandon language maintenance in order to maintain adherents. According to Clyne this was the position in which the Templars found themselves in Australia where by the late 1970 s ' they had to choose between religious and language maintenance' and chose the former (Clyne 198:75).

\subsubsection{Community Continuity}

Community continuity is the extent to which the immigrant community functions and is perceived as functioning as a community in the new country.

Community continuity promotes language maintenance by creating and/or maintaining a community where the language may be used and language maintenance is perceived as necessary for community continuity so that the generation born in the new country can communicate with their elders.

Community continuity may be and often is closely linked to religious continuity. In America, the ultra Orthodox communities maintain strong community continuity and strong community boundaries in order to maintain religious continuity. Yiddish therefore remains the language of everyday life for ultra-Orthodox Americans even although it has no sacred or liturgical function - such functions being reserved for Hebrew/Aramaic (Fishman 1991). ${ }^{23}$

Garner, commenting on the difference between the prospects for the Russian and Swedish language in Melbourne highlights the role that community continuity plays in language maintenance. He points out that Swedish suffers from a lack of a multigenerational Australian

\footnotetext{
${ }^{23}$ It should be noted that a primary function of Pennsylvania German language maintenance in Old Order groups and Yiddish language maintenance in Orthodox groups appears to be maintaining the apartness of the group identity necessary, in community eyes in order for the group to carry out its religious observance. In this way language maintenance fultils both communal and religious maintenance functions at one and the same time, as, for the community, each is a necessary condition of the other.
} 
community, it is a language with "no local Australian roots (Garner 1988: 48). Russian on the other hand, is in a very different position;

despite the relatively small size of the community ... the sociological and psychological environments are conducive to its continued existence for some considerable time ... The community has a three-generational structure, with extensive, strong social networks within it ... the parents' and children's generations ... continue to show a marked orientation toward the community and they hold its culture and language in high regard. The three main churches ... all have a noticeable influence on the maintenance and even the propagation of the Russian language (Garner 1988: 48).

However religion is not an essential component of community continuity. The Newark Ukrainians described by Hayden in Language Loyalty in the United States saw their national language as 'inseparably related to their national heritage' (Fishman et al 1966:197) although for many of them that national heritage may not be perceived in religious terms.

\subsubsection{Wider Community Continuity}

Community continuity may extend beyond the immigrant community to include the community in the country of origin. Both the San Antonio and New York Hispanics discussed by Hayden made 'frequent visits to their respective home countries [and were] visited in turn, by relatives from the homeland' (Fishman et al 1966:190-91). In New Zealand both the Samoan and the Gujarati communities have exhibited this wider community continuity to a considerable degree and one of the functions of language maintenance within some of the New Zealand immigrant communities is to enable members of the community to be able to function as members of the wider community. The Dutch community also seems to have developed a strong tradition of a 'trip back' to Holland for New Zealanders born of Dutch parents. This has not led to a general community emphasis on Dutch language maintenance for New Zealand born children ${ }^{24}$ - although it does appear to have encouraged many New Zealand born Dutch in their late teens and early twenties, preparing for that New Zealand rite de passage 'the big O.E.' to learn a little Dutch.

For some groups however return to and interaction with the home or wider community is not a factor. Political refugees may be cut off from contact with their homeland or poverty and distance may make effective interaction impossible. The traditional source New Zealand

\footnotetext{
${ }^{2+}$ Most of their contemporaries in the Netherlands are, after all, competent English speakers.
} 
Chinese for example found themselves in a situation similar to that of political refugees when their access to the wider community was cut off in 1949. The kind of coming and going between New Zealand and China that had characterised Chinese community life in New Zealand ceased, and the New Zealand Chinese community was thrown largely upon its own cultural and linguistic resources.

\subsubsection{Intergenerational Continuity}

Sometimes language maintenance may be perceived more narrowly as fulfilling a subfunction of community continuity - intergenerational continuity. That is, the expressed reason for language maintenance may be to enable children to talk with their elders, most usually their grandparents. Garner mentions this as being an important reason for language maintenance for both Russian and Swedish parents (see Garner 1988: 42,47) and it also frequently mentioned by Gujarati and Samoan respondents as major reason for language maintenance.

Beaglehole mentions some of the negative consequences of a lack of intergenerational linguistic continuity.

The parents' authority, already undermined by the upheavals of emigration, was probably further impaired by language problems ... The relationship between parents and children was further eroded when the children refused to speak German, Czech, Hungarian or Polish or to admit that they understood these languages. ... However, a more lasting and therefor more serious problem, was the lack of a shared terminology for deeper and more personal discussions (Beaglehole 1990: 102-103).

Unlike the other reasons for language maintenance which could continue to exist indefinitely, this rationale for language maintenance has a limited duration, as once the first host countryborn generation become grandparents they will be able to talk to their grandchildren in the host country language. Unless bolstered by other reasons for language maintenance this motivation will not lead to long term language maintenance. However, as Clyne comments, 'family cohesion' is a reason for the relatively high rates of language maintenance in the Italian community in Australia. This might seem to contradict the notion that a desire for intergenerational continuity can only have comparatively short term effects on language maintenance. Clyne suggests (1988: 71) that family cohesion is a cultural core value for Italians and that they need a language (other than English, in Australia) to express this core value. This leads to high language maintenance rates in a group that does not value language maintenance, in itself, all that highly. It seems possible that intergenerational continuity and 
family cohesion, while obviously related, are not necessarily the same thing and that a desire to express family cohesion might lead to more positive language maintenance results over the long term than the desire that your children be able to speak to your parents.

\subsubsection{Economic/Prestige Reasons}

I have classed these two together because they are linked by not being directly related to the community and also because they appear to be comparatively weak and uncommon reasons for community language maintenance. There are some possible examples however. Glazer suggests that in the USA 'French, Spanish and German, have been stronger than the more recently introduced languages of the period of mass immigration' (Fishman et al 1966:362) because they carried greater prestige as the languages of 'the makers of history' in a given area. Hayden comments that

Attitudes and activities connected with mother tongue maintenance may well be unrelated to interest in the maintenance of ethnic communities and cultures. This is perhaps particularly true in the case of highly prestigeful or popular languages such as Spanish or French. It is not unusual to view facility in Spanish or French as being highly desirable, whether in respect to ethnics or non-ethnics. Accordingly, knowledge and even use of these two languages may be fostered because of their utility and/or prestige in American society (Fishman et al 1966:196).

Hofman and Cais suggest that foreign born Israeli children of American, British and West European origin favour mother tongue maintenance more than Soviet block children because of the 'usefulness or prestige of the mother tongue in question' (Hofman and Cais 1984:151). Paulston notes another -nonimmigrant - example when she says that in Catalonia white-collar jobs are 'increasingly restricted to those fluent in Catalan' (Shabad \& Gunter, quoted in Paulston 1987:52). Linking language and employment is thus one factor in the strength of mother tongue maintenance in Catalonia. None of the three communities under discussion here seems to have been influenced by such considerations.

\subsection{Location of language maintenance efforts or rationales within the community}

Language maintenance may take place in all areas of individual and community life or it may be limited in scope. Generally speaking its areas of operation will diminish over time but there are many exceptions to this. Below, some of these domains are examined as though each one existed discrete from the others. This is merely an analytical device and it must be borne 
in mind that all these domains interact with each other, often in a combination of the available languages.

An examination of language maintenance and shift studies in New Zealand suggests three generalisations: the first, that languages tend to be fairly well-maintained in the first New Zealand-born generation, the second that there is considerable variation as to what happens in the second New Zealand-born generation and the third, that the attitude of the immigrant community affects the outcome for MT language maintenance for that second and subsequent New Zealand-born generations.

Swift language shift is found according to Stoffel amongst the Dalmatian community in Northland. Stoffel found that it was rare for third generation Dalmatians to speak or understand Serbo-Croatian (1982: 134) ${ }^{25}$. However, there is no consensus about attitudes to language maintenance in the Yugoslav/Dalmatian community. Stoffel's opinion is that they have not been very interested in language maintenance (Stoffel 1982: 137) whereas Trlin found that 'preservation of the mother tongue was widely and loudly urged' (Trlin 1979: 208). According to Jakich (1987: 118), third and fourth generation New Zealanders of Yugoslav descent find the language 'totally alien'. Folmer's (1992) research into three generations of a Dutch family in New Zealand shows, amongst other things, that not all Dutch immigrants came to New Zealand determined to abandon their language and culture. The first generation in her study 'wanted to maintain the Dutch language and culture' (1992: 15) and they had been largely successful at handing it on to the second generation but, despite this success, language shift to English had been very marked in some of the third generation (1992: 11). These findings for a single family were not dissimilar to the findings of the current research into 184 respondents. Johri (1998: 267) also found that the Dutch were not maintaining their MT as well as, for example, the Samoan respondents in her study.

Verivaki's study of language maintenance and shift in the Greek community in Wellington found that

With each succeeding generation, there is less Greek language proficiency and use, although attitudes towards the Greek language remain very favourable (1991: 71).

\footnotetext{
${ }^{25}$ Dalmatian and Serbo-Croatian are the terms used by Stoffel. Trlin (1979) however, prefers 'Yugoslav'.
} 
The Cantonese community values language and culture maintenance and Chinese immigrants have been generally successful in handing on Cantonese to the first generation born in New Zealand (Roberts 1990). That generation, in turn, has been keen to see their children speak some Cantonese but the respondents in the (1990) study were achieving varying degrees of success in reaching that goal. Nonetheless there were certainly some families in which second, and in some cases, third New Zealand-born generations were learning Cantonese as well as English.

Amongst some of the more recently arrived communities that have been studied, researchers report high levels of positive orientation to language and culture maintenance. 'Aipolo and Holmes concluded that the short term maintenance of Tongan in New Zealand was likely but that more 'formal community language initiatives' would be needed to foster long term language maintenance ('Aipolo and Holmes 1990: 518). Smith (1994: 138) found the Lao community placed a high value on language and culture maintenance, as did the Indo-Fijian community investigated by Shameem (1995). Shameem found that teenagers supported FijiHindi maintenance in New Zealand even more strongly than their mothers, although their mothers would have liked them to use more Fiji-Hindi than in fact they did (Shameem 1995: 277).

One of the groups most consistently reported to have a positive orientation to language and culture maintenance in New Zealand is the Samoan. Fairburn-Dunlop found that Samoan parents tended to have consciously created structures in place (such as rules about using Samoan at home) to help MT maintenance in New Zealand (1984: 104). Fairburn-Dunlop also emphasises the important role played by the Church in Samoan language maintenance in New Zealand (1984: 108). Fairburn - Dunlop found a very high rate of MT language transmission but acknowledged that the second generation (the first to be born in New Zealand) were all young, living at home, and under the influence of their parents (184:112) and that their future language use patterns, when none of these factors applied, were unpredictable. Johri, 14 years later came to similar conclusions. She found that her Samoan respondents were aware of the phenomenon of language shift, wished to slow it and put mechanisms in place to do so (a'oga amata, Pastor schools etc (Johri 1998: 271)). She concluded that the Samoan respondents in her study were maintaining their MT comparatively well. This study has also found that language transmission to the first New Zealand-born generation has been relatively successful and that, in turn, that generation is now, in many cases, succeeding in transmitting at least some MT skills to the second New Zealand-born generation. 
One of the newest groups of immigrants in New Zealand is the Koreans. Youn and Starks found a very dramatic rate of shift to English amongst Korean children in New Zealand and predict a decline in Korean proficiency in the second generation of Koreans in New Zealand (Youn and Starks forthcoming). However, Johri found that the Korean respondents in her study 'exhibited comparatively little language shift' and that Korean children were encouraged to speak Korean (1998: 267-269).

The Dutch, and possibly the Dalmatians, have not, in general, placed a high value on language maintenance in New Zealand. The Tongans, Indo-Fijians, Lao, Greek, Cantonese and Samoan all do overtly value language maintenance in New Zealand. In the case of the first three communities it is too early in their immigration histories to know if that value will be translated in language maintenance. The last three communities in the list have all, succeeded to at least a modest level of language maintenance in the first New Zealand-born generation. Whether this will be enough to produce a second New Zealand-born generation who are bilingual in MT and English remains to be seen. A recent small scale study of two German families in New Zealand emphasises that if language maintenance is to succeed then it is important to maintain both family and wider social networks in which the MT can be used (Walker 1996: 39-45). How do New Zealand immigrant families pursue language maintenance in the sites that were singled out above as being potentially important in this activity?

\subsubsection{Family}

Without families there is no language maintenance, indeed there is no need for language maintenance. Although immigrant communities, usually of working men, may exist without families for a short time such communities are, by their nature short lived.

Families are the basis of immigrant communities and they are also the most important site of language transmission (and indeed of socialisation generally). Without language transmission in the family, maintenance of a given language as a living oral phenomenon is extremely unlikely. As Fishman says in connection with Reversing Language Shift (RLS - discussed below),

The family is an unexpendable bulwark of RLS. The family has a natural boundary that serves as a bulwark against outside pressures, customs and influences. Its association with intimacy and privacy gives it both a psychological and a sociological 
strength that makes it peculiarly resistant to outside competition and substitution (Fishman 1991:94).

The first generation immigrant family has generally been a site of MT use in New Zealand, often in combination with some English use ('Aipolo 1989: 73, 76, Folmer 1992: 9, Johri 1998: 269, Kerslake \& Kerslake 1987: 144, Roberts 1990: 99, Shameem 1995: 245-247, Smith 1994: 91, 101, Trlin 1979: 208, Tiwari 1980: 36, Verivaki 1990: 123) but there are some communities in which extensive language shift has occurred even in this generation (Cogle van Schie 1987: 156, Vervoort 1983: 77). In the second generation (first New Zealand-born) there is considerable variation. The communities that 'Aipolo, Youn and Starks, Smith, and Shameem studied (and the Korean community studied by Johri) have not been here long enough for a New Zealand-born generation to be raising children as yet. Some communities, such as the Dalmatians (Jakich (1987: 119), Stoffel 1982: 137) and Dutch (Cogle van Schie (1987: 157), this study), shifted very rapidly within the family domain others have maintained the family as a shift resistant domain for longer. The first New Zealand-born generation of Greek households often used and uses some Greek (Verivaki: 1990: 124). The first generation of New Zealand-born Gujaratis (Patel 1987: 152, this study) and Samoans (Fairburn Dunlop, Macpherson 1984: 115, 117 (but see also 121-122), this study) are also likely to use at least some MT within the home.

The importance of the home as primary site of language maintenance is recognised by many immigrant families. A survey of respondents of Portuguese origin in California found that these respondents ranked the family as the most important factor in linguistic and cultural maintenance (Renz 1987: 342), and Ukrainian mothers interviewed in Toronto recognised the family as the most important place for mother tongue language maintenance. However they also thought that a wider framework for language maintenance was necessary (ChumakHorbatsch 1987:112) and as Fishman also points out 'intergenerational mother tongue transmission and language maintenance are not one and the same' (Fishman 1991:113). Although languages ideally should be transmitted within the family, they need to be maintained outside the family as well. What are the main channels of language maintenance outside the family?

\subsubsection{Church}

The Church has already been mentioned. As well as providing a rationale for the maintenance of sacred or liturgical languages, which may or may not also be vernaculars the church also 
provides a meeting place for a community. For many immigrant communities their religion and the ethnic identity are closely linked. It may well be the case that only or mainly people of their ethnic background attend a particular church. Thus church (or, more widely, religious institution) going and the socialising associated with it provide a regular and frequent occasion on which the language may be spoken (Fishman 1985 251-268, Kouzmin 1988:61-2, Garner 1988: 44).

For some New Zealand immigrant communities, their religious institutions have been important sites of MT maintenance. The Samoans (Fairburn Dunlop, Kerslake \& Kerslake 1987: 145, Macpherson 1984: 115, 116 (but see also p. 123), this study) and the Greeks (Verivaki: 1990: 141-142) have perhaps been the most obvious cases. In both of these communities, religion plays an important role in organising and regulating social relationships. Both communities maintain their own churches in New Zealand, separate from pre-existing Christian Churches in New Zealand. The Samoan community maintains a range of Christian denomination churches and the Greek community maintains the Greek Orthodox Christian Church.

Amongst Pacific Island communities in New Zealand in general, the association between Christian religion and the MT is often strong (see 'Aipolo 1989: 99-100, 'Aipolo and Holmes 1990: 510, Macpherson 1984: 115, Spolsky 1988: 15) and many of the Samoan respondents to the questionnaire made comments such as

'[the language is important for] the spiritual side - all teaching in Samoan language e.g. reading the Bible, Hymn' (RI030, female, age 51-55).

Not all members of the communities attend church, nor do they all attend their community churches, but for those who do, the Church provides a regular opportunity for the use of the MT. In 1988 Spolsky estimated that $70-80 \%$ of Samoans in New Zealand were active church members. Some communities do not have a community-based religious organisation available to them. For instance, although many of the Lao respondents in Smith's study attended the Buddhist temple, the monks at the temple were European and so was part of the congregation. The Lao respondents spoke Lao to other Lao at the temple but English to everyone else. Thus the temple itself was not particularly a site of language maintenance for the Lao except to the extent that it provided another meeting space for them (Smith 1994: 103). 
Amongst Indo-Fijian teenagers in Wellington, who had spent at least part of their lives in Fiji, a language other than English was preferred for most religious activity although English was used by some of them for some formulaic prayers. Fiji Hindi was used for personal prayer and they tended to use Shudh Hindi with their clergy (Shameem 1995: 246). Religion was thus proving a site of language maintenance for these respondents.

Even amongst communities such as the Dutch, where the majority of people did not attend a community church, and where the authorities actively discouraged the establishment of a community church there were a small handful who chose to establish such a church.

The idea was not to make a Dutch congregation - a Dutch church - that was deliberate policy - and I think that X for example, ... had a great wisdom on that point thinking of America, United States of America, the union of the states was not so strong because in many cases the churches became the centres in which old nationalities were continued - Swedish, German, Dutch perhaps French too, I'm not sure. And New Zealand wanted to have immigrants that would integrate completely and not remain apart - no apartheid - so we were not supposed to start anywhere a Dutch congregation.

(Male immigrant to New Zealand arrived in 1955. Anton Everts. New Zealand/ Netherlands Foundation. Interviewer Kees Snoek. Interviewed 16/11/1992).

While many of the Dutch Protestant immigrants to New Zealand did join the Presbyterian Church, a small group, dissatisfied with what they took as doctrinal laxity on the part of the Presbyterians, formed the Reformed Church congregation. The strong commitment to assimilation was not abandoned. English language services, as well as Dutch, were held from the first. Nonetheless, although the Reformed Church played no active role in language maintenance (by such activities as setting up schools), it did, at least in the early years, provide a place where people could use Dutch on a regular basis (Schouten 1992: 162-166).

Religious institutions can also be important for language maintenance because of the role they play in organising formal language maintenance classes. The Chinese Anglican Mission has performed this role for many years in Wellington, many Samoan Churches organise formal language lessons, and the Assyrian Church organises Assyrian language maintenance classes in Wellington.

\subsubsection{Clubs and Associations}

'Clubs' may range from Language Clubs set up specifically to foster the immigrant language to Sports Clubs set up by the younger members of the community specifically to provide a 
setting where the immigrant culture and language are not so important and where those born in the host country can meet on a basis that disregards some of the old shibboleths. Generally speaking, clubs contribute to language and culture maintenance by providing a setting where people of the same culture and language can meet together. To what extent they concentrate on language per se depends upon the nature of the club. Apart from clubs there may well be Associations, that is some kind of grouping that covers all the community members.

The role of clubs and associations appears to be under-investigated in New Zealand studies of language maintenance and shift. This might be a fruitful course of study for future researchers. Kerslake and Kerslake (1987) mention the role of Youth Clubs in supporting Samoan language and culture maintenance, but they make it clear that these are Church organised clubs and as such they should perhaps be placed in the sphere of religious institutions. Associations undoubtedly play a role in language maintenance for some New Zealand immigrant communities. The Wellington Indian Association (Tiwari 1980: 42-49) and the Wellington Chinese Association have both been responsible for organising language maintenance classes, and they also undoubtedly provide a venue where the MT is spoken, but there has been little systematic investigation of their role in this area so far. The Dutch immigrants founded Dutch clubs and associations and these seem to have provided a venue for Dutch language use (Schouten 1992: 170-181), but the Dutch Associations have not, until very recently, been involved in formal language maintenance activities for Dutch children. This has begun to change however, and in 1995 the Friendly Society, a Dutch community organisation, founded a one-day a week after-school-hours Dutch language maintenance school in Wellington (information from Mrs Maria van der Meel, personal communication). Thus the three groups investigated in this study now all have language maintenance classes formally organised by community organisations/associations (the Gujarati and Dutch communities) or by the Church (the Samoan community). It should also be pointed out that there is no very clear cut division between the secular and religious organisations. Within the Samoan community the Church is a primary organising structure and so it tends to take on activities that might be handled by a secular structure in another community. The Wellington Indian Association not only runs Gujarati language maintenance classes but it is also home to a Hindu temple and is the main place of worship outside the home for most religiously oriented Gujarati families in Wellington (Tiwari 1980: 44-46). The Dutch language maintenance classes however, have no religious association. 


\subsubsection{Media}

It is not uncommon for immigrant groups to publish or broadcast on a regular basis in their language (Fishman 1985: Ch.9, Ch.10, Renz 1987, Resnick 1988:93). They may also have access to videos made in their country of origin in either their language or in a second language widely used in their country. Hindi language videos are very popular amongst the Gujarati speaking population in Wellington for example - as are Hong Kong productions for the Cantonese speaking Chinese. These various media are much enjoyed by speakers dominant in the immigrant language and they help provide a traditional language ambience and a sense of community, both valuable ends, but it is doubtful to what extent they contribute to language maintenance for those born in the host country. They provide a limited opportunity for improving listening and reading skills but by their nature do not provide much opportunity for interaction. It is possible that they may prompt interaction in a particular language.

Fishman notes that the broadcast media do not provide much opportunity for interaction or, as he puts it, 'we are dealing with an undemanding medium'. However he goes on to make the sound point that the undemanding nature of these media may help account for their success and also that they make the language available to listeners whether they are literate or not, this being especially important for the second generation. Fishman seems to have a higher opinion of the ethnic periodical press saying that

the struggle to preserve community creates and strengthens the community (Fishman 1985271 ).

Foreign language media have not played a major role in language maintenance in New Zealand in the past. This has been a product of New Zealand's historical suspicion of foreign languages and of the small size of the immigrant communities. Immigrant communities whose numbers in any one place might be only a few hundred or, at most, a few thousand could not usually provide the circulation to support a regular journal of any kind. The Dutch community, one of the largest minority immigrant communities in New Zealand, has supported the English language publication Windmill Post (Schouten 1992: 178). The lack of local reading material in the MT has certainly affected attitudes to the maintenance of the written language in some communities. The Cantonese Chinese community in Wellington clearly viewed the lack of available reading material, and the fact that there was no reason to read Chinese in New Zealand as a reason for not concentrating on Chinese language literacy 
skills for their New Zealand-born children (Roberts 1990: 139). Verivaki (1990: 152-153) noted that the paucity of written material in Greek (apart from personal letters) was one of the reasons that maintaining Greek literacy was not seen as important by some Greeks. Recently there have been some changes. The most obvious is that there are now several Chinese language newspapers available in New Zealand.

Radio Access was probably the first media outlet to provide regular MT material for a wide range of minority immigrant (see section 4.5.2.1). Gujarati and Dutch language broadcasts are available on Radio Access. Samoan listeners in Wellington can listen to Samoan Capital Radio Siufofoga o le Laumua, funded by New Zealand On Air and broadcasting during the day on the same frequency as Access Radio. Samoan broadcasting started in Wellington in 1989 and has been on the Wellington Access Radio frequency since 1991. The station broadcasts in Samoan most of the time and appears to appeal to a large section of the Wellington Samoan community (Wilson 1994: 123-124).

Members of the Indo-Fijian community often have access to Hindi language newspapers from Fiji (Shanti Narayan, personal communication) but the only Indian newspaper regularly available in New Zealand at the time of Shameem's research was an English language publication (1995: 221). There are Hindi language broadcasts on Radio Access, but the teenagers in Shameem's study (1995: 221), like the New Zealand-born Gujarati respondents in this study (section 7.5.1) did not listen to it very much. For both the Indo-Fijians and the Gujaratis, Bollywood was the most important source of spoken Indian language other than personal communication. Bollywood (a name for the Indian film industry, based in Mumbai/Bombay) produces a flood of, mainly Hindi language, videos and these are popular both in the Fiji Hindi speaking community (Shameem 1995: 221) and the Gujarati community. Many of the Gujarat-born respondents speak and understand some Hindi (see section 7.3.2.3), so the language of the videos is not a problem for them and even amongst the New Zealand-born whose Hindi skills are weak to non-existent, the films appear to be enjoyed. The Gujarati respondents were not specifically asked about the movies they watched, but the interviewees often mentioned the fact that they enjoyed watching Indian movies on video. One Gujarati interviewee commented to me that the only time his mother spoke Hindi in the home was during or immediately after watching a Hindi language video. 


\subsubsection{Workplace}

For some immigrants the workplace is a possible site of traditional language use. In New Zealand this normally occurs in low paying manual work jobs which do not require a high level of English competence or in family owned and operated businesses.

the kind of work people did affected their opportunities to use Tongan to fellow workers 'on the job'. Working as a cleaner, kitchen hand or labourer provided greater opportunities to use Tongan than an office job or a service job such as shop assistant. In low-status jobs Tongans were generally working with other Tongans rather than interacting with the English-speaking majority group ('Aipolo and Holmes 1990:512).

The Indian and Chinese immigrants to New Zealand have often run owner operated retail businesses and these too have provided a largely immigrant language workplace. Unlike the Tongan example given above they have also often provided an environment for the children of the family. When the children are very young, they are often looked after by someone who is working in the shop and as they get older, they too start to work in the shop. It is the aim of most immigrants however to get out of the low paying job, or out of the retail business with its killing hours of work and many immigrants are successful in ensuring that their children will not have to work in such environments. The workplace then, in a New Zealand setting, is unlikely to provide for language maintenance for the New Zealand born except in the case of the second generation whose parents own and operate their business. There are exceptions to this. Some people work in professions where clients may come to them specifically because the professional and the client share a language other than English. I have come across doctors, accountants and travel agents where this is the case. In the case of the Samoan population there are also the language maintenance institutions such as a'oga amata which provide a Samoan speaking workplace for their staff.

\subsection{Community school}

In Language Loyalty in the United States, written before the 'ethnic revival' Fishman describes the ethnic school as a new element in most immigrants' ethnic repertoire. Prior to coming to the United States there had been no such things as ethnic schools in the largely illiterate peasant communities from which the nineteenth century immigrants to America came.

Schools as, well as other formal ethnic institutions, became necessary because the complete ethnic pattern no longer functioned and automatic acculturation of the young via exposure to the daily activities of the family could no longer be counted upon to 
ensure ethnic continuity. But the ethnic group school taught about ethnicity, whereas ethnicity consists of living ethnically. In the school, ethnicity became self-conscious (Fishman 1966:93).

Fishman and Nahirny (1966) paint a fairly gloomy picture of almost inevitable drift away from ethnic language competence and a considerable lack of interest, not to say hostility on the part of the parents who send their children to the ethnic group schools '[o]nce again, parental attitudes (indifference and hostility) are considered [by mother tongue teachers] to be the primary source of negative pupil attitudes' ${ }^{26}$ (Fishman 1966:119).

Fishman and Nahirny discuss three types of ethnic group schools; the All Day School, the Weekday Afternoon School and the Weekend School. Neither of the first two has ever been common in New Zealand. The All Day Schools to which they refer are largely parochial schools and the only group in New Zealand that felt strongly enough to set up its own comprehensive alternative education system in New Zealand has been the Catholic Church. In general, in New Zealand not only the Catholic hierarchy but also the Catholic commonality have been predominantly English speaking. While the Catholic school system in New Zealand was source of religious and, to some extent, Irish cultural, maintenance it has never been a source of language maintenance. The Weekday Afternoon School has existed at certain times and places in New Zealand but has never been very common. The most common ethnic group school in New Zealand has always been the Weekend School.

Fishman and Nahirny rate the Weekday Afternoon School as the most effective in terms of cultural and linguistic maintenance. They see the All Day Schools as having largely abdicated their responsibilities in this area and about the Weekend Schools they say

By comparison [with the Weekend Afternoon School], the Weekend School is far less frequently under religious auspices, far less frequently employs trained mother tongue teachers, and far more often involves foreign born or second generation teachers, parents, and pupils. With their fewer hours of instruction and their more frequent foreign born personnel the Weekend Schools are intermediate in language maintenance emphasis (Fishman 1966:96).

${ }^{26}$ It may seem strange that parents sending their children to an ethnic group school would have negative attitudes language maintenance but Fishman and Nahirny included parochial schools in their count and parents who were sending their children to a given school for largely religious reasons might not necessarily have any strong desire to see the mother tongue maintained. It should also be borne in mind that this research dates from the early 1960 s. 
Features of the Weekend School identified by Fishman and Nahirny are that it is likely to have a high $(68 \%)$ ratio of students from the appropriate ethnic background and $15 \%$ of the schools reported a majority of their students as being foreign born. Weekend Schools also have the highest proportion of foreign born contributors and activists. It is worth noting here that Fishman and Nahirny observe that all contributors are male and that major activists are usually male. As they say

This is of interest to us in view of the common assumption that religio-ethnic concerns have been predominantly delegated (or relegated) to females after the early postimmigration period (Fishman 1966:102) $)^{27}$

Fishman and Nahirny see the All Day School as having trod a path leading away from ethnic identification. They see the Weekend School as being least advanced along that path but ultimately under pressure to make the same journey. As a general comment on the aims and achievements of the ethnic group schools the authors suggest that

language maintenance efforts attain limited and narrowly linguistic goals at best, and that the broader culture maintenance and intergenerational continuity goals frequently advanced as the ultimate justifications for language maintenance are rarely attained (Fishman 1966: 107).

Even among schools that do offer mother tongue instruction, language mastery remains only one of a number of ultimate goals. Among these group maintenance is usually far more fundamental than language maintenance (Fishman 1966:109).

It is interesting, in the light of Fishman and Nahirny's comments about the differing achievements of ethnic group schools, to consider Ozolins' comments about the 1983 investigation of such schools by the Commonwealth Schools Commission in Australia. The Commission came to the conclusion that

after-hours ethnic schools 'are not regarded by the Commission as the major provider of second language learning opportunities for Australian children. the role is most properly one for the day school' (Australia, Commonwealth Schools Commission 1983: 34) In terms of resources, curriculum development and standards of teaching, only the day

\footnotetext{
${ }^{27}$ It is worth pointing out that in New Zealand the funding for language maintenance schools has usually come from men (in their position as head of household) and in the early days of Chinese and Indian immigration it seems to have been mainly men who started and taught in the language maintenance schools. There has always been a tendency however to leave the teaching of the youngest children to women, and today the pre-school efforts of the Samoan, Indian and Chinese communities have all been initiated by women and staffed by women. This has sometimes meant that the women have had to be quite assertive in order to get what they have perceived as desirable for their children from what, in many cases, is still a male dominated system.
} 
school system could adequately cope with teaching community languages as second languages (Ozolins 1993: 189).

These kind of conclusions need to be regarded with a wary eye (as Ozolins, indeed, regards them). It is paradoxical that the mainstreaming of second languages may result in the marginalising of those second languages ${ }^{28}$. And Ozolins goes on to comment that this report 'seems to mark the beginning of a shift against the positive attitudes towards ethnic schools expressed [by government agencies] in the late 1970s and early 1980s' (Ozolins 1993: 189).

As was mentioned above, the most common kind of language maintenance school in New Zealand has been the weekend school. Such schools are typically run by volunteers and have volunteer teachers. The community effort required to keep them operating is enormous and their existence can depend on the hard work and initiative of a handful of dedicated people. For this reason, weekend language maintenance schools tend to come and go, but some communities, particularly committed to language maintenance, have managed to maintain language maintenance schools over a period of several decades. The Cantonese, Gujarati, Greek and Samoan communities all fall into this category (Roberts 1997: 76-78, Tiwari 1980: 47). At present in Wellington, all of these communities operate language maintenance schools as do the Hindi, Tamil, Sinhalese, Mandarin, Assyrian, Dutch and Khmer communities. It is not possible to provide a comprehensive list as the situation is in constant flux and there is no central register of any kind for such schools.

\subsection{The role of mainstream education in fostering positive links between the minority and majority culture}

Most of the language maintenance initiatives that have been discussed in this chapter so far are initiatives that are taken by the community with little, if any, input from the wider society. Why might the wider society wish to become involved in minority language maintenance? It is important that the host society is seen to support language maintenance in order that the minority group can see that its needs and interests can be met without the members of that group having to become totally assimilated into the host society culture. Tomic, for instance, claims that revitalisation of Macedonian in Australia has raised the status of the Macedonian community both in the eyes of other ethnic communities and the government (1992: 391). 
An example of a language and education programme with the aim of fostering the language and culture of the newly arrived immigrants and of sharing it with the host country population, was the Dade County programme set up in Florida in 1963. The programme catered for the children of the newly arrived Cuban immigrants and for the children of the established English-speaking Americans. Tuition occurred in both English and Spanish as the medium of education for both groups. The programme was widely regarded as successful for both groups of students (it has obvious similarities with Lambert's immersion classes in St Lambert in Montreal, but his classes were not for an immigrant group and a host country group). However, the programme was discontinued in 1975 when it was ruled that Federal funds would only be disbursed to programmes that focussed purely on complete transition to English (Romaine 1995: 248-250). A similar type of programme aimed at both minority and majority group children was instituted in Redwood, California (Appel and Muysken 1987:64). In Australia such programmes have been shown to be beneficial to the children who participate in them and to increase their confidence as MT speakers and hence as bilinguals. Imberger found that children attending German language maintenance classes in the mainstream education system in Australia used more German at home and had a more positive orientation to German than previously (Imberger 1986: 122). Typical comments from parents and grandparents were

"She's not so embarrassed to speak German any more" (English-speaking mother) ...

"I would never really have considered speaking German at home with him before the program. It brings me close to him and German is now something special between him and his father" (German-speaking grandmother) ...

"He is no longer ashamed of speaking German or being different to the others as he was in the other school which had no German program" (German-speaking mother) (Imberger 1986: 123).

In a discussion of a short-term experimental programme designed to assess the effects of supporting MT languages within the context of mainstream educational programmes, Laurie Makin argues that there are many advantages to providing such support. The project provided MT support to bilingual children in preschool and early schooling (year one) in Australia. There appeared to be a number of academic and social benefits for all the children involved.

\footnotetext{
${ }^{28}$ See Ozolins 1993: 190-192 for a more general discussion of the problems of mainstreaming in the Australian context.
} 
The project raised the profile of bilingual children, especially for monolingual teachers and for monolingual children. It appeared to give the bilingual children higher status in the eyes of others and themselves. ....

Teachers reported that children seemed more interested, more self-confident and more outgoing when they were able to use their home language within the mainstream settings. Interestingly, the interest in using languages other than English was not limited to children whose home language was used in the project. Some children speaking other languages, who had hitherto been unwilling to use those languages, began to volunteer words and phrases in them, appearing to see the project as a general validation of themselves, their identities, their families, their experiences.

Parents reported that their children were more interested in talking about activities at school and more willing to use the home language at home. ...

Learning was also facilitated. Small group work in which children who shared the same language were supported by adults or older children fluent in that language offered children the opportunity to work at an appropriate linguistic and conceptual level ... One school reported higher than expected results in the school-wide end-ofterm mathematics test by bilingual children involved in the Project.

(Makin 1992: 78-79).

No doubt there have been others but such programmes have, world-wide, been all too infrequent as Romaine is at pains to point out in her chapter on bilingualism and education (Romaine 1995).

Is there any evidence that encouraging the immigrant group to maintain linguistic and cultural practices and encouraging the host society to learn about them leads to a greater degree of social cohesion? Appel and Muysken document an experimental programme in the Netherlands where the children of Turkish and Moroccan immigrant workers were taught in Dutch and in their MT over a period of three years and their academic and social performance was compared with that of children from similar background who were in regular Dutch school programmes (where they got a minimal amount of teaching in their MT as a subject). It was found that not only did the children in the experimental group do better in their academic subjects than those in the control group but that

Children from the Comparison Group exhibited more problems of aggressive behaviour, apathy, isolation, strong fear of failure or exaggerated nationalism than children from the experimental bilingual school. Also more children from the Comparison Group seemed to develop a growing feeling of resistance towards the dominant (Dutch) school culture (Appel and Muysken 1987: 68).

Wong Fillmore also argues that accommodating linguistically and culturally to children in the classroom produces students who have been 'freed ... to learn' and thus has educational and 
social benefits but she argues that it must be done with great thought and care. She cites the Hawaiian Kamehameha Early Education Programme as an example of a programme which has accommodated culturally to its students and

enabled Hawaiian children to move from among the lowest achieving groups in the country to a place at or slightly above national norms in all measures of academic achievement (Wong Fillmore 1989: 118).

Masina has reviewed the available literature pertaining to Samaon educational achievement in New Zealand and states

From this small collection of literature, there appears to be general feeling [sic] of support for the inclusion of Samoan culture and language into schools to assist in enhancing the achievement levels of Samoan students (Masina 1996: 39)

There appear to be real benefits in providing mainstream school support for language maintenance, but the form this provision takes needs to be carefully considered.

\subsection{Fishman's model of language maintenance and shift: an integrated interpretation}

This research is based on Fishman's theories of language maintenance, language shift, language shift reversal, language and ethnicity and on Fishman's theories of what needs to be investigated in order to come to some conclusion about language maintenance and shift within a given community. Below is an attempt to adumbrate a theory of methodology for investigating language maintenance and shift, based on Fishman's writings since 1966. This interpretation does not present a single model offered in a particular work by Fishman.

Fishman's work displays considerable unity over a long working career, although obviously there have been shifts in emphasis throughout that time. The theoretical underpinnings of this thesis come from a synthesis of Fishman's work and this is what is outlined below.

In Reversing Language Shift, Fishman states that analysis of the following are needed to assess language shift

a) a framework for specifying the social location of language shift

b) language shift data

c) the causes of language shift (Fishman 1991: 45)

In an earlier work (1971), Fishman posited three major subdivisions of the study of language maintenance and shift

d) habitual language use at more than one point in time or space 
e) antecedent, concurrent and/or consequent social and cultural processes and their relationship to stability or change in habitual language use

f) behaviour towards language including directed language maintenance or language shift efforts (Fishman 1971: 301, 337)

Here, I attempt to combine the two typologies into an integrated model. The three factors from the 1971 work, essentially all become subdivisions of the 'framework' suggested by the 1991 work, although there are obvious links between (e) and (c).

\subsubsection{Definitions of terms used in the integrated model}

\subsubsection{Domain}

A key ingredient of the investigation of habitual language use is the idea of domain. The concept of domain was introduced into sociolinguistics by Fishman and it has proved, as he hoped, both 'fruitful' and 'manageable' (Fishman 1971: 304). In Language Loyalty he defined it as

A sociocultural construct abstracted from topics of communication, relationships and interactions between communicators and locales of communication in accord with the institutions of a society and the spheres of activity of a culture in such a way that individual behavior and social patterns can be distinguished from each other and yet related to each other (Fishman 1966: 430).

The concept of domain enables a tripartite focus that helps to ensure that no one aspect of the trio of locale/interlocutor/topic is overlooked - or, at least, that is the ideal, in practise some aspects are almost always given more weight than others, depending on the design of the study as Fishman notes (1966: 430).

Locale/institution (e.g. home, school, work, church etc), interlocutors (family members, coworkers, boss, priest etc), and topic (family matters, work matters, politics, religious topics etc) have remained the three recognised components of domain and these have been investigated in the foregoing sections.

\subsubsection{Role relations}

Fishman points out that the contexts of the 'role relationships' in which an individual interacts with others are perhaps more important than individual preferences for one language or another (Fishman 1966: 430-431). For example, a woman whose control of MT is not strong might choose always to speak the non-MT language with her husband but may choose to 
speak MT to her baby because that is the language she deems appropriate in her role as mother.

\subsubsection{Degree of bilingualism}

Fishman packed many aspects of bilingualism in language maintenance and shift situations into the simple phrase 'degree of bilingualism'. The concept touched upon concepts of codeswitching, L1 and L2 interference, frequencies of use in different settings (1971: 302), media of language use, the concept of domain itself, and the concepts of co-ordinate and compound bilingualism (1971: 304). Fishman's main point was that no one measure sufficed to assess the degree of bilingualism (1971: 302-303). In fact, reading Fishman's summary it seems so many measures were needed that perhaps the concept of degree of bilingualism needed to be radically re-thought before it could be useful. In this thesis it refers primarily to the extent to which languages $\mathrm{A}$ and $\mathrm{B}$ are used in given domains by speakers (and also, if applicable, brings languages $\mathrm{C}, \mathrm{D}$ and $\mathrm{E}$ into consideration).

\subsubsection{Media of language/s use}

This simply points to the fact that processes of language maintenance and language shift usually occur at different rates in the language skill areas of writing, reading, speaking and listening (Fishman 1971: 43). In his later work Fishman also points out that there may well be an implicational scale formed in the order, understanding, speaking, reading and writing, whereby those who have command of the earlier skills also command the later ones. As he says, there is no implicationality in the other direction and he suggests that

Observers should, therefore, be encourages to report separately the command of skills vis-à-vis each medium and their reports should be checked for monotonic decline ... since this provides a minor check on informant accuracy (Fishman 1991: 44).

\subsubsection{Competence and Performance}

These are, of course, two very well-known terms in sociolinguistics. Fishman tends to use them in a rather broad and non-specific sense. Competence is defined as 'being able to' use a language (whether listening, speaking, reading or writing, needs to be defined according to the specific situation) and performance is 'actually doing so' (Fishman 1991: 44). This thesis makes no attempt to define the terms more narrowly as Fishman's relatively broad definitions 
seem to work well in language maintenance and shift description and analysis. In addition to 'competence', the term 'proficiency' is also used in this thesis.

The framework is perhaps, ironically, the most amorphous of the three components because, if perfectly constructed, it would be nothing less than a complete and detailed description of the minority society in all its complexity. Inevitably, the framework has to be reduced to simpler elements for the purposes of research and analysis

\subsubsection{The integrated model}

\section{Framework: the social location of language shift}

1. (a) Habitual language use at more than one point in time or space

This category takes into account the following factors

- domain (institution/locale, interlocutor, topic)

- role relations

- degree of bilingualism

- media of language/s use

- competence

- performance

- in order to establish the path of language shift all the foregoing factors must be measured over time (Fishman 1971: 337, 1991:43-44)

1. (b) Antecedent, concurrent and/or consequent social and cultural processes and their relationship to stability or change in habitual language use

This category and the following category contain factors that help to explain why and how language shift occurs. As Fishman noted 'the major common characteristic' of the processes in this category is 'that they are primarily outside of language per se' (1971: 310). In 1971 (p.337) Fishman said that no 'conceptual systematization of these processes is currently available' and this is still the case. Perhaps no adequate systematisation is altogether possible because it would be so vast. Giles and his colleagues have tackled part of the challenge and Fishman himself in later works has tackled the same question.

In Reversing Language Shift Fishman asks 'why does language shift occur' and his answer is framed in terms of dislocation. He discusses demographic, physical, social and cultural dislocation as central to the experience of language maintenance and shift. In Chapter 3 some of the various dislocations attendent upon immigration were discussed. Although they were not investigated in the questionnaire-based part of this research, nonetheless they are 
recognised as having explanatory power as part of the answer to the question 'why does language shift (or maintenance) occur?'.

Many of these dislocations can be further probed by bringing information about habitual patterns of language use into conjunction with demographic information about the group under investigation. Some basic demographic information was gathered in the questionnaire and was used in order to make such comparisons

- age of the respondent,

- birthplace of the respondent,

- age at which they came to New Zealand (if not New Zealand-born),

- level of education,

- whether they are exogamously or endogamously married

All of this information can help map the disjunctures than have occurred in the life of the individual and their community in the context of the immigrant experience. At the same time, one must beware of viewing the immigrant and settlement process too negatively. Although Fishman frames his theory almost entirely in terms of 'dislocation', this is not perhaps how a New Zealand-born woman of Dutch parentage, happily married to an New Zealand-born man of British/Scots/Maori heritage, speaking English to her children and sending them to the whanau unit at the local school, might characterise her life choices.

The work of Giles and his colleagues does not touch on all the areas of study that could be included under this heading but it does take up some areas that Fishman described (1971: 312) under the heading 'A Few Questionable Generalisations". Issues such as group loyalty (Fishman 1971: 312, Giles and Johnson 1987), demographic factors (Fishman 1971:315, Giles et al 1985: 254) and status and prestige (Fishman 1971:321, Giles \& Byrne 1982: 21-22, Giles et al 1985: 254) have all been much better investigated since 1971 thanks to Giles and colleagues.

\section{1 (b) Behaviour towards language including directed language maintenance or language shift efforts (Fishman 1971: 301, 337)}

Fishman notes that this could well be considered at subtopic of (b) but maintains that it is of such importance that it needs to be singled out as the third main subdivision of language maintenance and shift as a field of enquiry (1971: 330 - 331). He also acknowledges that the category 'cognitive behaviours' 'flits' between the two categories of attitudinal affective behaviours and overt behavioural implementation (Fishman 1971: 333)

- attitudinal affective behaviours 
- overt behavioural implementation (such as establishing language maintenance schools)

- cognitive behaviours (language consciousness and knowledge)

\section{Data gathering}

Involves counting individuals and assessing language attitudes, competence and performance.

When counting individuals care must be taken with definitional issues. Descriptors such as age, occupation and education must be arrived at in a manner that is useful but does not force preconceived notions onto the data (Fishman 1991: 46).

It is difficult to collect reliable 'bias-free' data on these two factors because of 'the inherent covertness of much of the attitudinal and competence data' (Fishman 1991: 49)

On the other hand performance or language use is 'somewhat easier to evaluate' (Fishman 1991: 49).

The response categories used in language surveys are most commonly left undefined, i.e. they are presented as intuitively understandable and interpretable "relative frequency clusters'. Fortunately, our dependence on such categories is not entirely and article of faith. It has been demonstrated many times ... that ... the responses on selfreport Likert-type instruments are significantly related to independently attained daily behavioral records of a more precise type (Fishman 1991: 52)

\section{Causes}

Under this rubric go

- physical and demographic dislocation

- social dislocation

- cultural dislocation (Fishman 1991: 57)

This area overlaps with $1(\mathrm{~b})$ and 1 (c) which are both descriptive and explanatory. The dislocations identified by Fishman do, to a limited extent, operate as descriptions of the processes of language maintenance and shift but they are more important as part of the explanation of why language maintenance and shift occur. These dislocations were not, in the main, addressed through the questionnaire. They have been discussed in Chapter 3.

Once the framework is established, the data-gathering complete and the causes investigated to the best of the researchers ability then it is possible to look at recommendations for action.

For one of the things that Fishman never loses sight of in his studies of language maintenance 
and shift is that the communities that are being studied are almost always crying out for action.

No outline of Fishman's theories of language maintenance and shift would be complete without a mention of three more phenomena; history, ethnicity and the importance of boundary maintenance. The last factor is at least implicit in the mention above of domain and interlocutor because Fishman has always been quick to point out the benefits for language maintenance in maintaining boundaries between one domain associated with language $\mathrm{A}$ and the other domain associated with language B (Fishman 1971: 304-305).

Fishman has always believed in the importance of an understanding of the historical forces at play in the whole field of language maintenance and language shift. None of our attitudes to language maintenance and language shift exists in an ahistorical vacuum and this is stressed by Fishman (1966: 26, 1968: 3, 1971: 299, 1989: 5-175). The importance accorded by Fishman to the concept of ethnicity and its role in the study of language maintenance and shift, is demonstrated by the fact that many of his writings on or related to language maintenance and shift were collected in Language and Ethnicity in Minority Sociolinguistic Perspective in 1989.

The final point in this outline is to mention the importance of comparative work

The comparative method is quite central to inquiry in this topic area [by using comparative methodology] it should become possible to more meaningfully apportion the variance in language maintenance or language shift outcome (Fishman 1971: 327$330)$.

This research has, of course taken the above comment to heart and the research was designed, from the beginning to adhere to a comparative methodology.

The model can be illustrated by the following figure. In the discussion above, and in Figure 5-1 below, I have followed the order: social location of language shift - data-gathering causes used by Fishman in Reversing Language Shift (1991: 40-65) but it should be pointed out that there does not appear to be anything immutable about this sequence. There is no particular reason why one should precede the other and in fact, in this thesis, I have discussed the various dislocations that help cause language shift and language maintenance in immigrant communities in section 3.4.4 above. These causes are also discussed again in Chapters 11 and 12 when the model is used as an analytic device for ordering the information that has been amassed about the three immigrant communities. 


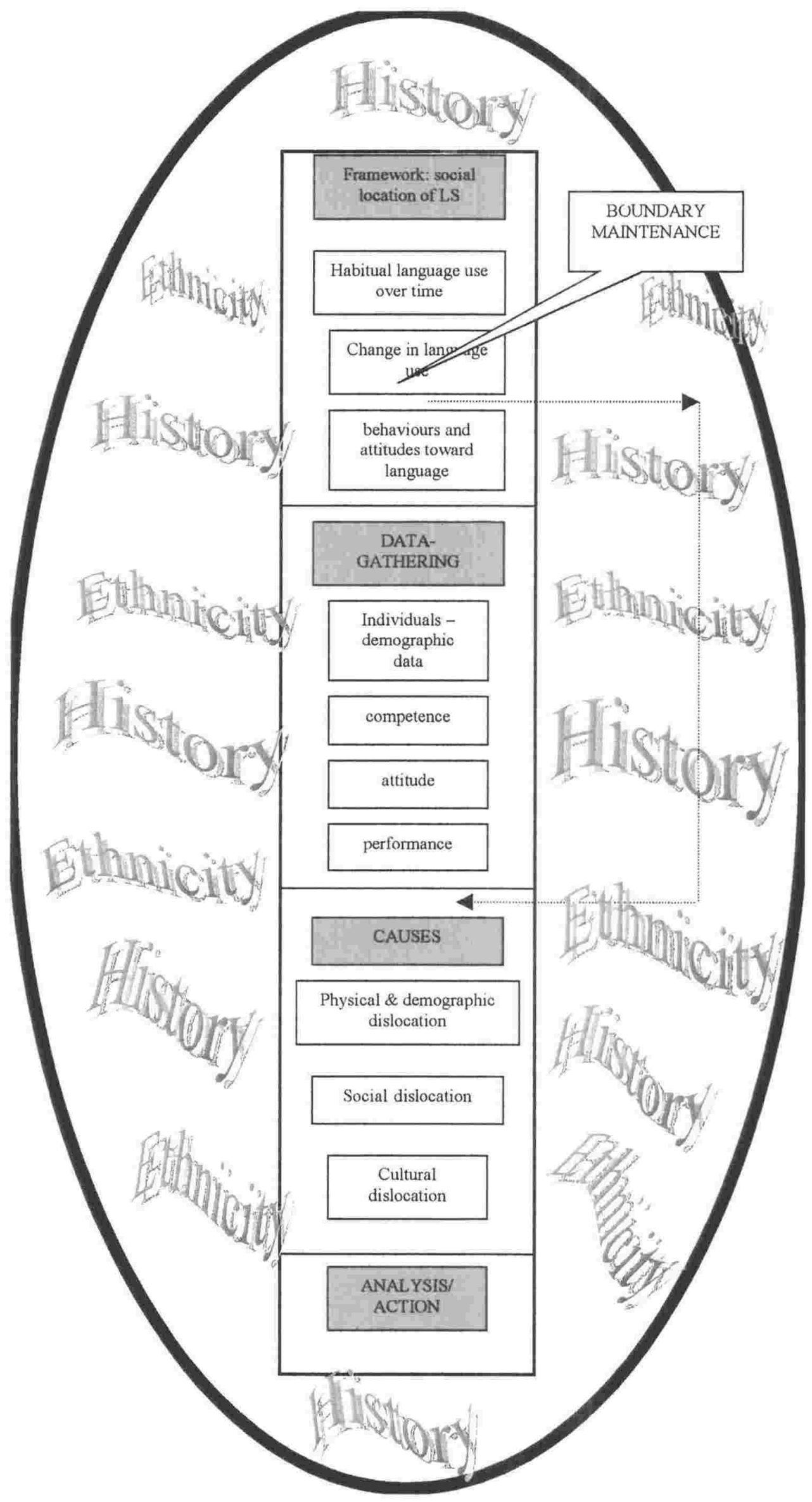

Figure 5-1: Schematic diagram of the integrated model based on Fishman's theories 


\subsection{Reversing language shift}

Joshua Fishman has devoted a whole book to this controversial subject. In Reversing Language Shift he regrets influencing professional enquiry against stories of language maintenance success and 'near success'. He says 'the entire positive side of the ledger is far less represented in the intellectual economy of the macro-sociological enterprise than it could and should be' (Fishman 1991:xi). Reversing Language Shift is the 'payment ... of a long regretted debt'.

Fishman sees language maintenance as part of the process of RLS. As noted above he makes the point that intergenerational transmission and language maintenance are both necessary for RLS. We may also comment at this point that where intergenerational transmission and language maintenance are perfectly achieved there is presumably no need for RLS. However it is usually the case that when people start discussing language maintenance for a given community they are talking about a process that Fishman would designate as RLS. It is hard to imagine a case where concern about language maintenance was raised without some degree of language attrition having already taken place.

As Fishman says, "views about the desirability of RLS are, in essence, views as to the relationship between language and culture. It is very hard to tell the truth about the relationship between language and culture' (Fishman 1991:15). It is hard to tell the truth because one's own experience and attitudes colour one's perception and also because the 'truth' in this connection is so big, so various and so faceted. The size, variety and many faces of the truth about language and culture mean that one should eschew dogmatism as much as possible and especially that one should be willing to admit the phenomena that Fishman labels Xmen via Yish, where X stands for the minority culture and $Y$ for the majority. Being an Xman via Yish will be different from being an Xman via Xish but it will still be valid. Fishman acknowledges this but obviously perceives language as such a major support to Xman identity that once it goes the whole structure becomes precarious 'most cultures reveal the 'domino principle' in operation and when any of their major props, such as language, are lost, most other props are seriously weakened and are far more likely to be altered and lost as well' (Fishman 1991:17). Therefore

A call for RLS must ... be seen and explained as a call for cultural reconstruction and for greater cultural-self-regulation. If this is not understood then RLS-efforts must, inevitably fail, as all ethnocultural planning that lacks a central and crucial integrative component must fail (Fishman 1991:17) 
The book is subtitled Theoretical and Empirical Foundations of Assistance to Threatened Languages and Fishman lays these foundations by means of an eight point typology. The GIDS (Graded Intergenerational Disruption Stages) scale is summarised below.

\section{Stage 8}

most vestigial users of Xish are socially isolated old folks and Xish needs to be reassembled from their mouths and memories and taught to demographically unconcentrated adults

\section{Stage 7}

most of the users of Xish are a socially integrated and ethnolinguistically active population but they are beyond child-bearing age

\section{Stage 6}

the attainment of intergenerational informal oralcy and its demographic concentration and institutional reinforcement

\section{Stage 5}

Xish literacy in the home, school and community, but without taking on extracommunal reinforcement of such literacy

\section{Stage 4}

Xish in lower education that meets the requirements of compulsory education laws

\section{Stage 3}

use of Xish in the lower work sphere (outside the Xish neighborhood/community) involving interaction between Xmen and Ymen

\section{Stage 2}

Xish in lower governmental services and mass media but not in higher spheres of either

\section{Stage 1}

some use of Xish in higher level educational, occupational and media efforts (but without the additional safety provided by political independence) (Fishman 1991:88109)

According to Fishman there is a 'continental divide' between stage 4 and 5 . The temptation for activists is to concentrate on stages $1-4$ because that is where the glamour and power may be seen to reside and where large symbolic gains - in the media for instance - may be made. But as Fishman is at pains to stress over and over again, if the gains are not made and 
consolidated in the family and neighbourhood community then all the television hours and all the university papers in the world cannot save a language. Not all language activists would agree with this of course. Fishman's attitudes are expressed in this comment on the foreign language media in Australia

All in all, a great deal of attention and a sizeable amount of funding is currently being lavished on non-print media utilizing immigrant-based languages with very meager (if any) evidence of positive RLS consequences being derived therefrom. The positive social climate and public acceptability of ethnic community languages to which television and radio contribute is 'something', of course, but that 'something' is, in itself, not effective RLS, precisely because it is not intergenerationally linked from the point of view of mother tongue transmission (Fishman 1991:271).

However some communities consider this kind of activity to be of great importance

Community groups consider that these broadcasts give languages status within the community. It was claimed for example that the radio had been a key factor in the linguistic cultural resurgence within the Maltese community in Melbourne in recent years, leading to the establishment of an annual Cultural Festival, a resurgence in vernacular writing and the establishment of three Maltese ethnic schools in the past three years (Australian Institute of Multicultural Affairs 1980:18 quoted in Ozolins 1988:125).

Portuguese respondents in California regarded broadcasting as second only to the family in its importance for linguistic and cultural maintenance (Renz 1987:32). Renz found this a surprising result and suggests six possible reasons

- radio links a somewhat dispersed community and acts as a community bulletin board

- it serves as a symbol of community pride

- it introduces role models into the community

- it enables people to improve their Portuguese

- it is perceived as a vehicle of information/entertainment

- it is also perceived as a vehicle of language maintenance

\subsubsection{GIDS in New Zealand}

Most of Fishman's examples in Reversing Language Shift are drawn from indigenous, not immigrant, communities but in the chapter on Australia he explicitly includes immigrant communities in his RLS schema. The GIDS is designed as a "quasi-implicational scale, i.e. higher (more disrupted) scores imply all or nearly all of the lesser degrees of disruption as well" (Fishman 1991:87). It can perhaps be argued that it functions less well as an implicational scale for immigrant languages than for indigenous languages. Many immigrant groups can look to a homeland where their MT, as the indigenous language is automatically 
used for all functions. Such a language, no matter how threatened in the host country, is clearly in a very different position from an indigenous language at stage 8 or 7 . It is worth noting however that it is the languages that are in very different respective positions. Functionally, the communities that speak or once spoke those languages may be in very similar conditions. Can we apply the GIDS to New Zealand immigrant communities and use it to analyse the relative conditions of the three groups under investigation here?

New Zealand's minority immigrant communities would seem to range from stage 7 ('Yugoslav' see Jakich 1987:118-124) to stage 5 (Samoan). None of New Zealand's minority immigrant languages really fit stage 8 because apart from Tokelauan (which does not in other ways fit the stage 8 profile) no New Zealand minority immigrant language is in threat of dying out in the world. It is possible that some minority immigrant languages might wish to move into stage 4 - Samoan and Mandarin Chinese are cases that spring to mind and, of course these two languages are also taught at university level in New Zealand as is Italian (a minority immigrant language with a very small population base) thus to some extent qualifying for stage 1. I can think of no example of stage 3 in New Zealand and there are limited examples of stage 2 - the provision of interpreting services in hospitals, courts, for sitting driving licence tests etc, but these services are provided on a fairly ad hoc basis.

Gujarati could well be described as being at stage 5 although the fairly high level of community literacy is a result more of education in India rather than in New Zealand. Samoan could also be described as being at stage 5 with considerable community effort to maintain the literacy base in New Zealand. As Fishman says

Stage 5 presents the risk of timidity vis-à-vis the outside Yish world of affairs and, therefore, a tendency to remain within the safe and comfortable world 'inside Xishness', thereby resigning Xish and Xishness to a parochialism that cannot satisfy more than a small number of self isolates (Fishman 1991:110).

Fishman's typology is useful because it provides an analytic framework that can be applied to any language maintenance and shift situation and enable us to make a meaningful comparison. When looking at one community undergoing processes of language maintenance and shift or even when looking at several such communities, it is all too easy to come to the conclusion that there is a kind of inevitability to the nature of the particular process that is being observed. The GIDS scale is not an entirely objective scale but it is based on the wide ranging experience of a specialist in the area of language maintenance and shift; it is not entirely subjectively derived from the investigation of just one or two groups. Even more 
pertinent for the purposes of this research, it was not devised from reference to the groups under consideration. For these reasons it can be assumed to provide a reasonably neutral and objective point of reference for the communities reported on here. The three communities under investigation will be viewed as individual phenomena, as related only to one another and as related on the GIDS. The intention of using these three viewpoints is to enrich our understanding of the communities involved and also to further our understanding of the processes of language maintenance and shift in general. Using the GIDS framework should also make it easier to think about where each community might advance from here. Implicit in the GIDS, and made explicit in Fishman's commentary, is a ranking of priorities that would be useful for any language activist to contemplate and this will be taken up in Chapter 13 .

\subsection{Research questions}

The questions that will provide the focus of this research draw heavily upon the investigative framework developed over many years by Fishman and his colleagues. The emphasis is upon language maintenance and language shift as sociological processes that can be examined by investigating the social (and especially the familial) context in which they occur. This is not to deny that there are other fruitful means of exploring language maintenance and shift phenomena. One of the most well known, which itself often draws on Fishman's research and is sympathetic to it, is the work on ethnolinguistic vitality and identity carried out by Giles and his various colleagues. Giles considers many of the points also considered by Fishman, and discussed in the foregoing pages. Issues such as the nature of an ethnic group (Giles and Coupland 1991: 106), and the link between language and ethnicity (Giles and Johnson 1987, Giles and Coupland 1991: 94-126). There are also some obvious links between Fishman's GIDS scale and the concept of ethnolinguistic vitality put forward by Giles and his colleagues in a range of papers. Both approaches stress demographic and institutional support factors, although the ethnolinguistic vitality approach probably places somewhat more emphasis on status variables (Giles et al 1981:146).

The two systems of analysis do not seem to be incompatible (although that would be a very interesting research point in itself) but they would appear to require a very large and accommodating framework if they were to be investigated as being part of the same general approach. This work is already very large because of the comparative approach used in investigating three different immigrant groups. In order to keep the inquiry manageable, it seemed more appropriate to use one model of enquiry without in any way suggesting that 
other approaches suffered from any deficiency. What then, are the questions that arise, when viewing immigrant language maintenance and shift form the sociological perspective of Fishman and his colleagues? Chapters 1,2 and 4 addressed the wider social and historical issues that, in Fishman's model, form the vital background to language maintenance and shift research. Chapter 3 focussed on specifically immigration related causes of language shift and explored the dislocations of the immigrant experience. The following chapters take up the questionnaire-based language use research that was carried out. Below, are listed the main questions that informed the design of this research. The first four questions focus on the family and the immigrant community, the fifth considers one of Fishman's most formally and succinctly structured theories, the GIDS scale, and the sixth and last question asks how the research and theory can contribute to policy formation in New Zealand.

\section{To what extent is MT language transmission occurring within the family?}

This question fits into the model under: habitual language use - domain, role relations and performance.

Given that transmission within the family is such an important element of language maintenance and that the cessation of transmission is an almost certain sign of language shift, one of the goals of this research is simply to measure to what extent family members are using the MT within the family home.

\section{How is MT language use occurring within the family?}

This questions fits into the model under: habitual language use - role relations and performance.

If the MT is being used within the family home then it is important to know who is speaking it and to whom. This research was not designed to undertake a microanalysis of MT use but has asked more global questions, focusing on the respondent and asking who their MT and English interlocutors within the family are. Some of the Dutch and Gujarati respondents were also asked about MT use during their childhood, within their family homes in New Zealand. This provides evidence across two generations of family MT use (or not, as the case may be).

\section{Is community MT schooling occurring and is it effective as support for the MT?}

This questions fits into the model under: behaviour towards language - overt behavioural implementation.

This question is approached both by asking respondents about the present day situation and the choices they have made about MT language maintenance education for their children and also by asking some of the respondents (the Dutch and Gujarati) about their childhood 
experiences. In order to judge the effectiveness of community language maintenance schooling, attendance at such schools is correlated with MT proficiency.

\section{What do people think about MT maintenance?}

This questions fits into the model under: behaviour towards language - attitudinal affective behaviours and cognitive behaviours.

This question draws on the research about the role of language in the creation and maintenance of a personal and community sense of identity. To what extent do respondents think that language maintenance is important and why do they choose to attempt to maintain the MT or, conversely, decide not to do so.

Can the GIDS usefully be applied to an analysis of immigrant language maintenance in New Zealand?

Because the three communities have such different immigration and language maintenance histories and because, as mentioned above, none of them was considered in the creation of the GIDS, they can be used to test the usefulness of the GIDS as an analytical tool.

\section{What are the language policy implications of the findings of this research.}

This will draw upon the wealth of information about language and identity, language and immigration, language policy to date in New Zealand and the material gathered about the three language communities in the course of this research. Considering all of this information, what are the policy implications for minority immigrant languages in New Zealand. 


\section{METHODOLOGY}

This section will first outline the research methodology as originally envisaged and will then discuss the modifications that were made as the research developed. I have followed the example of researchers such as McEntegart and Le Page and Alison Jones in my approach to discussing the methodology of this research. McEntegart and Le Page in "An appraisal of the techniques used in the Sociolinguistic Survey of Multilingual Communities" went to some trouble to "report the outcome of that appraisal, reporting defects and failures as fully as space permits for the benefit of further research in sociolinguistics' (McEntegart \& Le Page 1982 p.105). Alison Jones, talking about difficulties encountered during her research in schools in New Zealand, wrote

My difficulties did not lead me to believe I was a 'bad' researcher with few techniques of rapport. Rather they intensified my suspicion that social scientists usually write selective reports which tell only half the story; they do not provide information about their 'unsuccessful' interviews, rejections by the people they are studying, misunderstandings and so on. Most research reports avoid accounts of false starts, mistakes and problems of doing the fieldwork, and usually present only their rich and relevant material (Jones 1991: 27).

In this chapter, I hope to provide some idea of the false starts, mistakes and problems I encountered. I also hope that it will be useful to have an account of the ways in which a researcher's plans are always subject, and must be creatively responsive, to external pressures that affect the design and indeed the emphasis of the research.

First, some issues of questionnaire design; the sample population, the nature of surveys, sampling technique, response rate and family relationships within the sample are discussed. Following this, each of the three surveys is described and finally there is a general discussion of the issue of self-rating of language skills proficiency.

\subsection{Questionnaire design}

Having established a model of enquiry into language maintenance and shift based on Fishman's theories, the model was then used as a basis for designing the questionnaire that 
was to be the primary research instrument ${ }^{29}$. In order to demonstrate the manner in which the model, created from Fishman's theory and practice of language maintenance and shift research, was used as the basis for the design of the questionnaire, the questions will be discussed using the model as a guideline (see section 5.5.2). As change over time is an important part of plotting patterns of maintenance and shift the manner in which this has been addressed is noted separately in each section. As mentioned in section 5.5.2 - there are three methods of ascertaining change over time; conducting a longitudinal study, asking respondents about their language use then and their language use now, and comparing (at least) two different age cohorts at the same time. The two most common ways of establishing language change over time are to ask respondents about their language use past and present and to compare age cohorts at one point in time. Both of these approaches were used in this research. The following schema notes when respondents were asked about their language use as children and when they were asked about their children's present day language use. Age cohort information that was gathered from the respondents and that could be used to compare one age cohort with another on any point where it seemed relevant is not noted for each question.

Because of the different immigration histories of the four groups, the final version of each questionnaire differed to some extent from the others (see Appendices).

All the questionnaires were designed to elicit information about

- respondent's childhood language use

- respondent's present language use

- respondent's children's present language use

- respondent's attitudes to language maintenance and language maintenance education for their children.

- respondents' and respondents' children's levels of language competence in and usage of first, second, and in the case of the Gujarati population, third languages.

For the Gujarati interviews two experimental sections were added. All respondents were asked several questions about government support for a variety of language services and those respondents who had immigrated to New Zealand were asked what steps they had taken to

The questionnaire was very similar to one, designed using the same premises, used for research into the Cantonese community in Wellington (Roberts 1990). All the questionnaires used the same framework in order to be able to make comparisons between the different immigrant groups investigated. 
improve their English ${ }^{30}$. The questionnaire was piloted on a group of Gujarati parents who attended a parent teacher meeting at the Wellington Indian Association school.

The Samoan version of the questionnaire was translated into Samoan and then back translated into English by Sera Tamatoa. This process is dealt with in section 6.4.2. Although the Samoan version was not separately piloted, the clarity of wording of the questions was thoroughly checked in the process of translation.

The Dutch questionnaire was, again, not independently piloted although some changes were made to wording and some new questions were added (see section 6.5.1). It was discussed with Maria Stubbe, who made some useful suggestions and questions 15 and 16 were added at her suggestion (see Appendix 2).

\section{Framework for specifying the social location of language maintenance and shift}

\section{Domain}

\section{Institution/locale}

A basic division was established between language use in the home and language use outside the home. This division was based on Fishman's dictum that 'the home is the unexpendable bulwark of language maintenance'. Respondents were asked

- what languages they used within the home (q. 5)

- what languages they used outside the home (q. 11)

The locations outside the home were further categorised as

- social gatherings, work, and religious gatherings (q. 13)

- and as community language school (q.s 15 - 20).

\section{Change over time}

An important feature of the model is the attempt to capture change in language use over time. This was done by asking respondents about their patterns of language use in the past and by asking them about their children's language use. In order to capture the variation in institutional language use over time respondents were asked

\footnotetext{
${ }^{30}$ Once the design of the Gujarati version of the questionnaire was complete, it was checked by Janet Holmes, Jenny Ne:ile and John Read.
} 
- whether their children attended community language school (q. 29)

- about the language/s spoken in their childhood home $\left({ }^{31} \mathrm{cq} .4,5\right)$

- whether they spoke Gujarat within the home as children (cq. 9)

- whether they spoke it outside the home as children (cq. 11).

\section{Interlocutors}

The second component of domain is the interlocutors. Respondents were asked

- who the potential interlocutors within their household were (q. 6)

- what languages were used with which family members (q. 7 - 10)

- they were asked with whom the MT was used outside the household (q. 12)

\section{Change over time}

\section{Respondents were asked}

- what language/s were spoken in their childhood homes (cq. 4, 5)

- if their parents had spoken Gujarati or any other Indian language to them as children (cq. 7,8)

- to whom they had spoken Gujarati ${ }^{32}$ within their childhood homes (cq. 10)

- with whom they had spoken Gujarati outside the childhood home (cq. 11a)

\section{Topic}

In the foregoing chapter it was noted that the tripartite division of domain is not always followed. 'Topic' is an important but rather amorphous category that is difficult to define in a clear cut manner. In the case of research such as this, heavily reliant upon self-report data, it was decided that it would be confusing rather than clarifying to add topic to the list of variable enquired into.

\section{Role relations}

Respondents were asked about the language/s that they used in the context of different role relations

- child to parent (q. 7,8)

- $\quad$ spouse to spouse (q. 9)

- parent to child (q. 10)

- older to younger (within and outside the family) (q. 7, 8, 10, 12)

\footnotetext{
${ }^{31}$ The question numbers refer to the Gujarati questionnaire unless specified, 'q' stands for 'question in the main questionnaire' and 'cq' stands for 'question that was asked in the interviews with Gujarati interviewees (or in some cases asked in the Dutch questionnaire)'

${ }^{32}$ Respondents were actually asked about Gujarati, Hindi and any other Indian language/s but as most of them only talked about Gujarati, the other language mentioned in the questionnaire are, in the interests of simplicity, not listed here.
} 
- younger to older (within and outside the family) (q. 7, 8, 10, 12)

- religious leader/congregation member (q. 12)

- new immigrant/established immigrant or NZ-born (q. 12)

\section{Change over time}

Respondents were asked a similar set of questions about role relationships and language use in their childhood

- child to parent (cq. 9, 10)

- parent to child (cq. 7)

- older to younger (within and outside the family) (cq. 10, 11a)

- younger to older (within and outside the family) (cq. 10, 11a)

- new immigrant/established immigrant or NZ-born (cq. 11a)

\section{Degree of bilingualism (or multilingualism)}

Respondents were asked

- what languages they spoke (q. 1)

- what language they spoke first (q. 2)

- which language they used most now (q. 3)

- the 'amount' of any given language spoken with specific interlocutors (. 7, 8, 9, 10)

\section{Change over time}

Questions 1,2 and 3 listed above contain their own implications about change over a lifetime. In addition, children's questionnaire q.s $4-13$ provide data about childhood language use that can be compared with the data in questions $5-13$ in the adult questionnaire to give a picture of the degree of bilingual usage and change over time in that usage.

\section{Media of language use and Competence}

Respondents were asked about their abilities in written language and oral language for the MT, English (and Hindi and Formal Samoan for the Gujaratis and Samoans respectively) in q.s 21 and 22. They were also asked if anyone had taught them to read and write the MT as children (q. 14). Because the questionnaire was intended to be used as a self-report questionnaire by many of the respondents an attempt was made to keep it comparatively simple. For this reason, respondents were not asked to report separately on each skill area (speaking, comprehension, reading, and writing) in both oral and written media. This meant that Fishman's recommendation of checking for monotonic decline across each skill area could not be followed. However, monotonic decline form between oral and written skills could be, and was, checked.

\section{Change over time}


Respondents were asked to rate their children's abilities in MT written language and oral language cq. 38 - 41)

\section{Performance}

Respondents were asked

- which language they used most (q. 3)

- which language/s they had used in the last month (q. 4)

- which language/s they spoke at home (q. 5)

- which language/s they spoke with family members (q.s $7-10)$

- whether they spoke MT outside the home (q. 11)

- to whom and where they spoke MT outside the home (q.s 12, 13)

\section{Change over time}

Respondents/interviewees were asked

- what languages their oldest and youngest children used (q.s 27, 28)

- where and with whom do their children speak the MT (cq. 26, 27

- if they spoke MT at home in childhood and, if so, with whom (cq. 9, 10)

- if they spoke MT outside the home in childhood and, if so, with whom (cq. 11, 12)

\section{Social and cultural processes and their relationship to stability and change in language use.}

These factors were examined largely through the demographic data that was collected and also through the questions about education. Data such as age, sex, birthplace and age of arrival in New Zealand provide information that helps to locate the respondent in a particular social and cultural network. Respondents were asked

- $\operatorname{sex}(\mathrm{q} .37)$

- age (q. 38)

- birthplace of respondent and respondent's parents (q.39, 41, 42)

- age of immigration (q. 40)

- exogamous/endogamous marriage (Dutch q. 60 )

- level of education completed (q.s 48,49 )

\section{Behaviours and attitudes toward language}

This section is divided into three. The first sub-section concerns itself with attitudinal and affective behaviours, the second with overt behavioural implementation, such as teaching children the MT and the third with cognitive behaviours. As Fishman notes (see section 5.5.2), it is difficult to make a clear cut distinction between these three areas but the questions in the area can, arguably, be divided in the following manner.

\section{Attitudinal, affective}


Respondents were asked a range of questions intended to reflect their attitude to the MT and language maintenance in New Zealand.

- what was their opinion of the MT maintenance school (q. 23)

- why did their children attend the MT school (q.s 29, 30)

- should children be able to study the MT (and/or Hindi in the case of the Gujarati respondents ) at a mainstream school (q. 31, 32)

- should MT schools receive some government funding assistance (q. 33)

- is it important to keep Gujarati as a living language in New Zealand (q. 34)

- should people of their community see themselves as members of that community or should they see themselves only as New Zealanders (q.s 35, 36)

- why did parents want their children to have Gujarati language competence (cq. 29)

- were they happy with the level of competence children had attained (cq. 28)

\section{Overt behavioural implementation}

- did their children attend the MT school

\section{change over time}

- did anyone teach respondent, as a child, to read and write MT (q. 14)

- did respondent attend language maintenance class (q. 15)

- what kind of language maintenance class (q. 16)

- how long did respondent attend class for, how many hours each week and how regular was attendance (q.s $17-20$ )

\section{Cognitive behaviours}

- will speaking Gujarati affect children's school study (cq. 30)

- is it important that interviewees' children have a good command of English (cq. 31)

- would interviewee like their children to master languages other than MT and English (cq. 32)

- does interviewee want child to speak an Indian language when they grow up and which one/s (cq. 33, 34)

- is it important that the child has a good command of English (cq. 31)

- can interviewee teach child at home (cq. 36)

- is it important that children be literate in an Indian language (cq. 37)

- if respondent replied positively to mainstream provision of Indian language, what form should that provision take (cq. 35)

- are there any radio stations broadcasting in Gujarati or Hindi (cq. 18)

\section{Data-gathering}

\section{Demographic data: information on individuals}

Respondents were asked

- their age within a five year age-range (q. 38)

- their sex (q. 37) 
- how many children they had (q. 24)

- the age of their oldest and youngest children (q.s 25, 26)

- interviewees (Samoan and Gujarati) were asked the ages of all their children (unnumbered)

- their occupation (q. 43)

- their marital status (q. 44)

- their spouse's occupation (q.45)

- their educational level (q. 49)

It was assumed that one of the important factors in the processes of language maintenance and shift in an immigrant community would be the nature of the immigrant experience itself. Was the respondent an immigrant to New Zealand? Had they arrived as an adult or a child? Were they an immigrant from the homeland of the MT (Gujarat, the Netherlands, Samoa) or had they arrived from some intervening location? Were they born in New Zealand to immigrant parents, or New Zealand-born parent/s? All of these questions are, in a way, questions about where the individual respondent can be placed in relation to the dislocations and disjunctures of immigration. The-questions about birthplace therefore, were intended to enable this relationship to be established. Respondents were asked

- were they born in New Zealand, the homeland, elsewhere (q. 39, cq. 1)

- their age when they came to New Zealand (if not New Zealand-born) (q. 40 cq. 13)

- their father's birthplace, their mother's birthplace (q.s 41, 42, cq. 2, 3)

As a classifying device the respondents were separated into New Zealand-born and non-New Zealand-born. Within the non-New Zealand-born, the Gujarati respondents were divided into Gujarat-born and other-born (Africa, Fiji or elsewhere in India). The Dutch were divided into Netherlands-born (which in fact, included one person born elsewhere in Europe), Dutch East Indies (D.E.I.)- born. The Samoans were all regarded as either New Zealand-born or non-New Zealand-born (although there were two respondents born elsewhere in the Pacific, there were too few of them to single out as a group). The Gujarati respondents as a whole and the Dutch respondents as a whole, were sometimes referred to as being of 'Gujarati extraction' or 'Dutch extraction'.

There is one other terminological issue that needs to be considered here. Fishman points out that the researcher must be careful not to 'force preconceived notions onto the data' (1991: 46). One of the 'notions' that is used in this research is the notion of a Gujarati, Dutch or Samoan 'community'. To what extent are we justified in talking of such communities and to what extent can it be known that the individuals who responded to the questionnaires were members of one or other of the communities? The much contested notion of speech 
community (see Fasold 1990: 41-42, Milroy 1987: 75-76)) has been by-passed in this case. Membership of the community has been based on an individual's birthplace or on an individual's parents' birthplace. As long as the individual was born in the homeland or had a parent who was born in the homeland, they are assumed to be a member of the community. To what extent is it justifiable to talk about the Gujarati, Dutch or Samoan communities in New Zealand? The Gujarati community is united by bonds of family (there has been extensive chain migration from villages around Nausari), has a social focus provided by the Wellington Indian Association and its complex in Kemp St, Kilbirnie which provides a venue for language maintenance classes, religious study and worship, events such as weddings, festivals and social occasions generally, and overall, appears to be a fairly small, fairly cohesive group. Although individuals may participate to varying degrees in the community life, they would be unlikely to be completely removed from it. The same may be said of the Samoan community. Community life is likely to be centred around one or other of the Samoan churches and although, as with the Gujarati community, an individual person or a family may decide to isolate themselves to some extent from the community (Macpherson, 1984, describes such families) nonetheless, the community exists. The picture is less clear cut in the case of the Dutch respondents. There are definitely many Dutch people in New Zealand who do not see themselves as part of a Dutch community. However, there are some Dutch social organisations, a Dutch church, a Dutch old people's home (in Auckland, Schouten 1992: 180) and although a greater percentage of Dutch immigrants may choose not to participate in 'community' activities and although they may have richer, denser and more social ties in the wider New Zealand community than in the Dutch immigrant community, nonetheless there is a sense of that community existing. The Dutch have not completely vanished into general Pakeha society - yet - and the term "Dutch community' will be used in this thesis with the caveat that, as a community it is less dense and less likely to attract all potential community members than the other immigrant communities under consideration here. Some indication of the respondents' attitudes to the concept of their belonging to an ethnic/language 'community' can be given by their responses to the questions 35 and 36

- $90.3 \%$ of all Samoan respondents thought Samoans in New Zealand should see themselves as part of a Samoan/New Zealand community

- $95.7 \%$ of all Gujarati respondents think Indians in New Zealand should see themselves as part of an Indian/New Zealand community

- $61.4 \%$ of all Dutch respondent thought Dutch people should see themselves as part of a Dutch/New Zealand community 


\section{Causes}

As was noted in the previous chapter there is an inevitable overlap between section I(b) and l(c) of the model and section (3) which addresses itself to the causes of language maintenance and shift from the point of view of the minority group experience of dislocation. The major dislocations of the immigrant experience were discussed in Chapter 3. The only major immigrant dislocation that was addressed in the questionnaire was the question of birthplace, already noted above.

\subsection{General issues of questionnaire based research}

\subsubsection{Administration of questionnaire}

In order to get as much information as possible it was decided to use a postal questionnaire in conjunction with face-to-face interviews. The postal questionnaire would enable me to approach more people than would have been possible to interview, and the interviews would allow questions of a depth and complexity that would not be possible to ask in a postal questionnaire. I also hoped to be able to use the information obtained in the postal questionnaire as a basis on which to frame some questions for the face to face interviews. There are several aspects to the use of questionnaires and these are dealt with in the following section.

\subsubsection{Population}

\subsubsection{Target Population}

Before beginning research of this kind the target population must be determined. Kalton talks in terms of a target population and a survey population. The target population is the "ideal one required to meet the survey objectives' (Kalton 1983:6) which is modified to the survey population - the population that it is practicable to survey. The target population for this research could be seen as the entire Gujarati, Samoan and Dutch communities of Wellington. In the initial planning stages of the research the survey population was envisaged as a certain proportion of the people who belonged to the Wellington Indian Association and the Samoan Churches. In the case of the Dutch, it always seemed unlikely that any organisational framework existed that could be used as a sampling frame for the research. Because the research was descriptive in orientation the question of what proportion of the population was needed to give a representative sample did not arise. Ideally all the Gujarati, Samoan and Dutch immigrants in New Zealand would have been surveyed. Lack of resources made this impossible. The survey had to be 
confined to the Wellington area where contacts could be relatively easily established and the survey administered.

The next issue was to define the Wellington area. The 1986 census gives the following figures for people of Samoan and Indian (not just Gujarati) descent living in the Wellington Region, but does not provide any breakdown for people of Dutch descent.

Table 6-1: 1986 Census. Samoan and Indian Population figures

\begin{tabular}{|l|c|r|}
\hline & Samoan & Indian \\
\hline Porirua & 4,257 & 243 \\
Lower Hutt & 2,601 & 690 \\
Wellington City Zone & 3,327 & 2,097 \\
Wellington Local Govt. Region & 10,368 & 3,150 \\
Total New Zealand & 60,202 & 12,126 \\
\hline
\end{tabular}

(Figures from 1986 Census of Population and Dwellings, Series C, Report 6: Birthplaces and Ethnic Origin. Unpublished. Tables 22 \& 24)

It was obvious that, while most of the Indian population lived in the Wellington City and Lower Hutt area, there was a sizeable body of Samoans living in Porirua in addition to the other two areas. However, because the church lists that I hoped to use for the Samoan population, were only applicable for that part of the population that lived in Wellington City, the Samoan questionnaire mailout would be confined to Wellington City and, in the interests of uniformity, so would the Gujarati questionnaires. For the face-to-face interviews, where the respondents would be selected on different grounds, people in Lower Hutt would also be interviewed. The Samoan population in Porirua was excluded because there was no equivalent Indian population and one of the subsidiary aims of the survey was to be able to compare the different immigrant groups surveyed. Thus it was necessary that they came from roughly the same geographical areas.

Following this reasoning, the target population became the Gujaratis and Samoans living in the Wellington City Area. The ideal survey would have produced results that were statistically valid 
By the time the Dutch questionnaire was organised, the figures from the 1991 Census were available and in the 1991 Census there was a breakdown of people of Dutch descent. The 1991 figures are

Table 6-2: 1991 Census: Indian, Samoan \& Dutch population figures

\begin{tabular}{|l|r|r|c|}
\hline \multicolumn{1}{|c|}{} & Indian & Samoan & Dutch \\
\hline Wellington Local Authority Region & 6,024 & 16,275 & 3,047 \\
Total NZ & 26,979 & 68,565 & 19,591 \\
\hline
\end{tabular}

(Samoan figures from New Zealand Census 1991, Pacific Islands Population and Dwellings: Table 2. Indian and Dutch figures from Thomson 1993:95)

The experience gained in organising the Gujarati and Samoan questionnaires could be applied at the planning stage of the Dutch questionnaire. This affected the manner in which the target population for the Dutch was determined and is discussed in section 6.5.2.

\subsubsection{Age categorisation of respondents}

Respondents were asked to indicate their age by ticking boxes that represented 5 year age bands, 20-25, 26-30 etc, up to 60, at which point they simply indicated that they were $60+$. The cut off point of 60 was chosen mainly because it was obvious that not many respondents would be over that age. The respondents in that age group were conflated in to a $60+$ plus group rather than having to deal with very small groups in the 60 and over category. Respondents younger than 20 were not expected (although one Samoan respondent is under 20.

Respondents were also asked to indicate the age at which they arrived in New Zealand. In response to this question they were asked to tick boxes that represented 10 year age bands. It was not clear what would be relevant age groupings for this question. The 10 year groupings were chosen because it was assumed that those respondents who arrived in the first 10 years of their life were in a different position from those who arrived later in life. This assumption is given weight by Stock's 1970s research reported by Clyne, which showed that in a sample of German speaking migrants in Australia, those who arrived at the age of seven or eight sounded completely 'Australian' to native born Australians but those who arrived at the age of 10 were less likely to be perceived as completely native like. Twelve years of age seemed to be the 'absolute age limit' for being able to produce a native like Australian English (Clyne 1986: 12) (see section 11.7 .6 for further discussion). 


\subsubsection{Definition of Survey}

At this point some comment should be made about the use of the word 'survey'. Cooper in his 1980 article "Sociolinguistic Surveys: The State of the Art" says

The distinction between survey and other types of research ... is based on the obtained results' generalizability to a target population (Cooper 1980:114).

Thus sociolinguistic research which produces results that are not generalizable to a target population is not, by this definition, survey research. As Martin-Jones (1991) acknowledges it is often very difficult to obtain any reliable degree of generalizability when dealing with a minority group. Martin-Jones, writing about the Linguistic Minorities Project 'Adult Language Use Survey' (ALUS), says that it was not possible to 'assess the representativeness of the ALUS findings in a strict statistical sense' but that it did provide 'the basis for a number of general descriptive statements about the extent of bilingualism and minority language use among those actually surveyed" (Martin-Jones 1991:45). The research that was undertaken into the Samoan, Dutch and Gujarati communities in Wellington was not survey research by Cooper's definition, but it fulfilled descriptive goals similar to those set by the designers of ALUS where the emphasis was on 'dimensions of language use' (Martin-Jones 1991:46). Woods, Fletcher and Hughes agree with Martin-Jones about the difficulties of establishing a sampling frame, saying

In practise, however, it is frequently impossible [in linguistic research] to draw up an acceptable sampling frame (Woods, Fletcher and Hughes 1986:54)

The word 'survey' will (with acknowledgement of the caveats noted above) be used from time to time in reporting on this research.

\subsubsection{Sampling}

\subsubsection{Sampling frame}

In order to send out a postal questionnaire a list of names and addresses is needed. This is the researcher's sampling frame. There was no way of getting a comprehensive list of names and addresses of all people of Gujarati, Dutch and Samoan background in the Wellington area. However it was considered possible to get a list of those people who belonged to the Wellington Indian Association and those people who belonged to some of the major Wellington Samoan churches. From the beginning it was clear that there was no frame of this kind available for the Dutch community. 


\subsubsection{Sampling Technique}

The sampling technique used was that of non-probability sampling. In a probability sample 'each element has a known nonzero chance of being included in the sample' (Kalton 1983:8). Without knowing who all the members of the Gujarati, Dutch and Samoan communities in Wellington were, it was not possible to conduct a survey where each one of those members had a known chance of being included in the sample. Non-probability sampling is what Kalton calls 'haphazard, convenience or accidental sampling'. The examples he gives of this kind of sampling are

- volunteer subjects

- patients of a given doctor

- children in a particular school

- interviews conducted on a street corner

- respondents to a pull out questionnaire included in a magazine

- persons calling in response to a television request for opinions (Kalton 1983:90)

\subsubsection{Bias}

Bias is that which compromises a statistically valid result for that target population. In a statistical sense there is no reason to consider respondent bias in the construction of this research. As the research is not in any case generalizable, statistical bias is not in question. It is interesting however to consider as best one may what kind of bias might be present in the research

\subsection{Bias in the sampling frame}

The first biasing factor, already mentioned, is that it was not possible to get an adequate sampling frame for the populations under consideration. The sampling frames that I hoped to use (people belonging to the Association or Churches) could be presumed to bias the sample towards those who felt it was, to some degree or another, important to maintain links with the immigrant community. In the case of the Gujarati survey, where the Association list was, in the event, used as a frame, this bias presumably exists. In the case of the Samoan community, where the Church membership lists were not, in the event, used, this particular bias presumably does not exist. However, there were some questionnaires that were filled out by women attending a course in early childhood education; these women hoped to teach at Samoan language nests and it can be assumed that they too were self-selecting as strongly supportive of maintaining community links. 


\subsection{Who answers questionnaires}

The next biasing factor was "who answers or does not answer postal questionnaires?" There are many studies on non-response bias and a wide variety of biases have been indicated, but the only one that seems generally applicable is that which correlates higher education with response (Leong 1980:4,18). Even there, for a contrary view, see Barnett (1950), Maas (1955) and Bachrack (1967) (cited in Leong 1980:4). Apart from the education correlation, the other factor that seems to affect questionnaire response is whether the person who receives the questionnaire thinks that the subject is interesting, and whether or not they think they can make a useful reply (Oppenheim 1992: 105). Thus it is likely that the respondents to the Gujarati and Dutch questionnaires tended to be better educated and more interested in questions of language and cultural maintenance than the Wellington Gujarati or Dutch population as a whole. Because the Samoan respondents were not obtained by postal questionnaire it is harder to suggest (apart from the trainee teachers who filled out the questionnaire) what inherent bias they might have.

\subsubsection{Response rate}

It is generally recognised that one of the disadvantages of a mail-out questionnaire is the low response rate

The main disadvantages of the postal questionnaire are:

(a) generally low response rates, and consequent biases... (Oppenheim 1992: 102).

The main problem with mail surveys is that of getting an adequate response rate ... response rates reported for many mail surveys have been very much lower than those for interview surveys (Moser \& Kalton 1972:262)

Following Kviz in Brennan (1987: 2-4), the completion rate, rather than the response rate, was calculated in the following way.

Completion rate $=\frac{\text { No. of completed interviews }}{\text { Sample size }}$

Completion rate rather than response rate was chosen because of its simplicity and because of the difficulty and unreliability of calculation the number of eligible sample members when dealing with such comparatively small surveys. 


$\begin{array}{lll}\text { Returns } & \text { Ineligible } & =\mathrm{A} \\ & \text { Gone No address } & =\mathrm{B} \\ & \text { Refusals } & =\mathrm{C} \\ & \text { Useable } & =\mathrm{D} \\ \text { Non-returns } & & =\mathrm{E}\end{array}$

The response rate is calculated by adding $\mathrm{D}$ and $\mathrm{A}$ and dividing them by the total mailout.

Using this method the overall response rate for the Gujarati questionnaire is $36.2 \%$ and for the Dutch questionnaire $80.6 \%$ (for a more detailed discussion see sections 6.3.2 and 6.5.3). The Samoan questionnaire was not delivered by mail-out so the question of response rate does not arise.

How do these two very different response rates compare to postal questionnaire response rates in general? Estimates of the rate of response that may be expected to a postal questionnaire vary widely. Moser and Kalton (1972: 262) suggest a range of 10 - 90\%. Lyon (1991:168) in a postal questionnaire study of parental language use in Wales reports that $45 \%$ of questionnaires sent out were returned and Alasdair Roberts (1991:254) reports a 61\% response rate to a questionnaire on parental attitudes to Gaelic-medium education in the Western Isles of Scotland. Roberts also comments that this response rate is almost double that of a 'much broader survey of attitudes to Gaelic and education' carried out by Fraser.

Lyon's and Roberts's studies were also investigations into issues connected with language maintenance and thus seem a reasonable comparison with this present study. In the light of their returns, the response rate of the Dutch sample may be seen to be very high. Possibly this indicates that, as a group, the Dutch had strong opinions about the issues raised in the questionnaire. The high response rate may also reflect the friend-of-a-friend technique that was used to get in touch with each respondent.

The response rate of the Gujarati sample seems rather low (though comparable with Fraser's study mentioned by Roberts) and this may have been influenced by several factors. Undoubtedly some questionnaires went to non-existent people and some more went to no longer valid addresses. Some questionnaires probably went to people who could not read them. The fact that several questionnaires were filled out by the English speaking child of an elderly Gujarati respondent suggests that some unknown number were probably received by people who could either not read them, or were not capable of answering them in English. It also seems possible that there would be some resistance within the Gujarati community to 
answering busybody questionnaires from an outsider. People who had agreed to be interviewed were usually interested in the process of my research and often asked what kind of response I was getting to the mail-out. When I told them it was running at about $33.3 \%$ they were always surprised and impressed that it was so high. They themselves seemed to conceptualise their community as being resistant to investigation by outsiders and were pleasantly surprised to find that it did not appear to be quite as resistant as they had assumed. All in all, it seems possible to say that (allowing for non-existent people, a fairly high rate of 'gone no address' and a number of recipients who were unable to read and/or answer a questionnaire in English) the response rate to the Gujarati questionnaire is very probably higher than $36.2 \%$ by some unknown amount.

\subsubsection{Family relations within the sample}

When interviewing the Gujarati interviewees, I became aware from occasional chance remarks that, in some cases, I was being handed on from one member of a family to another member. That is, I was interviewing someone's sister, brother, parent, child, aunt or uncle. No-one told me that one of the names they had suggested was that of a relative. This became clear too late into the Gujarati interviews to make any systematic record of who was related to whom, although I noted relationships when I became aware of them. In the case of the Samoan questionnaire, researchers were asked to note any relationships between respondents of which they were aware. In the case of the Dutch respondents, they were asked in the questionnaire if they were related to the person who had provided their name as a possible contact (see Appendix 2).

\subsection{Gujarati survey}

The Gujarati survey, unlike the Samoan survey, ran closely to the original plan. The Wellington Indian Association Committee kindly agreed to let me use their telephone book as my sampling frame. The telephone book was for the year 1988 and was a reasonably complete list of the Gujarati families in Wellington. Up to and including 1988 the policy of the Indian Association was to include the names of all known Gujarati families in the phone book. So inclusive was this policy that some non-Indians were included because their names 
sounded Indian ${ }^{33}$. After 1988 the policy changed and the Wellington Indian Association only included in the phone book those who made contributions to the development of the new community centre in Kilbirnie.

Before I completed the questionnaire design I visited the Wellington Indian Association. After observing the five classes, I talked to most of the teachers and discussed some of their concerns about Gujarati language maintenance for children in Wellington. A week or so after this visit I attended a parent-teacher meeting at the Association where I asked parents to help me pilot the questionnaire. Visiting the school gave me useful additional background for the interviews that I later did with interviewees. Most of them had gone to the school, were sending, had sent or intended to send children to the school, and, in one case, one respondent had been involved in setting up the school. That I had taken the trouble to visit the school was considered a point in my favour.

Using the list of names in the phone book, 102 twelve page questionnaires were sent out, followed by 102 four page questionnaires. I was interested, amongst other things to see if the shorter questionnaire would have a higher response rate but, as detailed below that was not the case. Once it was clear that the shorter version of the questionnaire did not attract a higher response rate, another 100 long questionnaires were sent out. There was a covering letter attached to each questionnaire explaining what I was doing and how I had come by the addressee's name and address. At the end of the questionnaire a space was provided for people to write any further comments. Respondents were also asked for their name and address and for the names and addresses of any other Gujarati speakers whom they knew were willing to be interviewed. A stamped self addressed envelope was included with the questionnaire. I also gave my phone number in case people wanted to contact me. A few people did ring, mainly to check my bona fides.

Because most of the Indian Association entries were for male heads of households, half the questionnaires were addressed to Mrs X rather than $\mathrm{Mr}$ X. Obviously some of these women did not exist, but even so Mr X sometimes answered - explaining that there was no Mrs but

\footnotetext{
${ }^{33}$ I discovered this because I sent a questionnaire to one of these non-Indian entries and he rang to tell me that he was not Indian. It might seem strange that he did not simply throw the questionnaire away but he was motivated to ring me partly out of a desire to be helpful, partly to explain about not being able to get his name out of the Association phonebook, partly to check if I was on the level, and partly to offer me the name of an Indian friend of his, who would be prepared to answer the questionnaire.
} 
that he was prepared to answer. There was also at least one answer from a daughter replying to a questionnaire sent to her deceased father. In general I was pleasantly surprised at the trouble that people went to answer the questionnaire - not only the examples mentioned above, but also cases where people whose English did not enable them to answer the questionnaire asked children to help them fill it out. I would not have expected responses from these groups of people and it was encouraging that they had taken the trouble to answer the questionnaire.

\subsubsection{Interviews}

The Gujarati interviews enabled me to ask a variety of questions not included in the mail-out questionnaire in order to avoid making it too long and complicated. In the case of respondents who had originally answered the short version of the questionnaire it also provided an opportunity to ask them the rest of the questions from the long version. There were 27 supplementary questions that interviewees were asked (see Appendix 1). All interviewees were asked every question but I did not adhere rigidly to the form or order of the questions, so not every interviewee was asked the questions in exactly the same way or the same order. People with children were asked another 14 questions about each of their children. The first seven questions concerned the child's abilities in speaking Gujarati, Hindi and English and asked for their sex, age and educational level. The next seven questions asked about where and with whom the child spoke Gujarati (and Hindi if it was relevant) and I then asked whether the respondent was happy with the child's competence in Gujarati, why the respondent wanted the child to be able to speak Gujarati and what the respondent thought the effect of speaking Gujarati would be on the child's school study. Respondents were also asked if it was important to them that their child had a good command of English and whether they had any desire to see their children master languages other than Gujarati and English.

The first five general supplementary questions were about the provision of services in Gujarati and/or Hindi. Questions 7 - 9 were added at the suggestion of the first interviewee and concerned the caste and religion of the respondent and the respondent's spouse (if there was one). In practice, this was usually the last section of the interview. Questions 10 to 12 were about the birthplace of the respondent's parents, and questions 13 - 22 were about the respondent's language use as a child. Questions 23 - 27 only applied to those born out of New Zealand and were about their age of arrival in New Zealand, what country they had come to 
New Zealand from, their level of English when they arrived in New Zealand and the steps they had taken to improve it.

The government services' questions were added at the suggestion of Jeffrey Waite who was, at the time the questionnaire was designed, conducting the National Languages Policy development exercise. He suggested the results of such questions would be interesting to those working in language policy areas. The 'improving English' questions were added partly because I was interested to discover what people had done for themselves in this area, and partly to get some indication as to whether there was any correlation between respondent's attitudes to their own language learning and their children's language learning ${ }^{34}$.

Most of the interviews were set up by a letter to people who had indicated their willingness to be interviewed at the end of the questionnaire form. The letter was followed by a phone call to arrange a suitable time. Generally I asked if I could also interview the respondent's spouse, and about two thirds of the time succeeded in doing so. The usual reason for not interviewing the spouse was logistical, and unless the arrangement could be made fairly easily I did not pursue the matter. In some cases however, I left a questionnaire form with the interviewee for the spouse to fill out.

Most interviews took place in people's homes but in a few cases it was easier to interview a person at work. When interviewing both a wife and husband I tried to interview them separately as this is generally less confusing for the interviewer. I used a small tape-recorder and asked people if they had any objection to being recorded. Most people had no objection, but some people asked for the tape recorder to be turned off while they talked about a particular topic - usually a topic that focused on community rather than personal or family matters. The answers were recorded on the questionnaire form as the respondent was talking. In most cases I also went over the postal questionnaire form in order to check the answers. In some cases there were internal contradictions that needed sorting out and in a few cases the level of English of the respondent had led to comprehension problems on both sides.

The interviews were conducted in English, which was unproblematic in all but a few cases. There was only one interviewee whose English competence was such that I had grave doubts

\footnotetext{
${ }^{34}$ In the event, these questions are not discussed in this thesis. They will be considered in an article for 'Many Voices'
} 
whether we had understood each other. There were another two where I was aware that there was a language barrier and where I had to rephrase some questions several times in order to be reasonably sure that there was mutual, accurate comprehension.

Interviews usually lasted at least 45 minutes and in some cases lasted much longer if the respondent was particularly informative. Everyone offered refreshments and I drank lots of delicious tea spiced with Gujarati tea masala. In some homes I had a chance to talk informally with the children who were present, and who were sometimes asked to confirm certain points of information or to translate the occasional word. I was also given photographs and videos of trips to Gujarat to look at. All of this helped fill out my understanding of the community.

In the course of conducting the Gujarati interviews the truth of McEntegart's and Le Page's observations was borne out

If one were to learn from the experience of our survey, it would be

(a) to standardize interview settings

(b) to standardize a list of topics and keep one's sample of constant length on comparable topics constraining the respondent's time on each as far as possible, or alternatively, transcribing the whole of the interview

(c) to standardize the interviewer's lead up to each topic

Anybody who has done fieldwork where any degree of intimacy is to be established with respondents so that information of value may be gathered will recognize that the above ideals militate strongly against those of achieving a relaxed intimacy. It may well be therefore that one has to choose between statistically comparable but dehumanized 'answers' and linguistically and socially informative conversations (such as have been used in Tabouret-Keller 1980 and Le Page 1980a). A high level of statistical sophistication seems to militate against anything except rather superficial observations" (McEntegart \& Le Page in Romaine 1982: 115)

McEntegart and Le Page were interested in gathering data on specific linguistic features but their strictures seem to hold true when one is gathering attitudinal and language use data also. The more one tries to keep interview structures constant, the more formal and artificial the interview situation and the more uncomfortable both interviewer and interviewee will be.

Most interviews were arranged as a result of interviewees having answered a mail-out questionnaire. Eventually, however, it was decided that to build up the number of New 
Zealand-born respondents and the number of interviewees, New Zealand-born Indians would have to be sought out. Fourteen friend-of-friend interviews were conducted, nine with New Zealand-born Indians, bringing the number of New Zealand-born respondents to 35.

\subsubsection{Response rate for the Gujarati questionnaire}

The Gujarati questionnaire was sent out in three waves. The first wave was the long version of the questionnaire. The second wave was a short version sent out to see if being faced with fewer pages would lead more people to reply - this version got the lowest response rate. Moser and Kalton (1972: 263-4) suggest that the effect of length of questionnaire on response rate is unclear and hard to disentangle from the subject matter of the questionnaire and this certainly seemed to be the case with the Gujarati questionnaires. It might appear that a shorter questionnaire is less time-consuming to fill out, and therefore would always be more likely to obtain respondents. It seems possible that in the case of the Gujarati questionnaire those people who were interested in filling it out were interested in the issues raised by the questionnaire questions. The shorter version, therefore, had less substance to engage a potential respondent's interest. Whether or not this is the reason, it was certainly the case that using a short version questionnaire did not increase the response rate. For the third wave of questionnaires the long version was used. The response rates for the three waves are presented below, with an overall response rate for the total $304^{35}$ questionnaires that were sent out.

${ }^{35}$ It was intended to send out 100 questionnaires in each wave, but 102 inadvertently were sent out in the first two waves 


\section{Questionnaire 1: long version}

$\begin{array}{lll}\text { Returns } & \text { Ineligible } & =2 \\ & \text { Gone No address } & =5 \\ & \text { Refusals } & =1 \\ & \text { Useable } & =38 \\ \text { Non-returns } & & =56 \\ \text { Total } & & =102\end{array}$

Response Rate $=39.2 \%$

\section{Questionnaire 2: short version}

$\begin{array}{lll}\text { Returns } & \text { Ineligible } & =1 \\ & \text { Gone No address } & =5 \\ & \text { Refusals } & =1 \\ & \text { Useable } & =30 \\ \text { Non-returns } & & =65 \\ \text { Total } & & =102\end{array}$

Response Rate $=30.4 \%$

Questionnaire 3: long version

$\begin{array}{lll}\text { Returns } & \text { Ineligible } & =4 \\ & \text { Gone No address } & =3 \\ & \text { Refusals } & =0 \\ & \text { Useable } & =35 \\ \text { Non-returns } & & =58 \\ \text { Total } & & =100\end{array}$

Response Rate $=39 \%$

Overall response rate for 304 postal questionnaires $=36.2 \%$

In addition to the 304 questionnaires sent out in the postal survey, approximately 30 questionnaires were handed out at a meeting of the Wellington Indian Association School parent teacher group; of those, 16 were returned.

It must be remembered that some of the questionnaires were sent to non-existent people. This means the real response rate is somewhat higher than that given above but how much higher is unknown.

\subsection{Samoan survey}

The approach to the Samoan survey changed radically over time. I wished to do research in the Samoan community because it is the largest Pacific Island minority in New Zealand. However, it is also a community with which I had no connections. I started by following the methodology used by 'Anahina 'Aipolo in her survey of Tongans living in Wellington ('Aipolo and Holmes 1990:503) and wrote letters to the pastors of various Samoan Churches in Wellington explaining what I was doing and asking if I could use parishioner lists as a 
basis for my research. I felt increasingly uneasy about this method of approach. Unlike 'Aipolo, I was not a member of the community concerned and I could see no good reason why, from the churches' point of view, I should be given parishioner lists. The more I thought about it the less adequate I felt to conduct all the interviews. It was obvious that with such a comparatively recently arrived immigrant group it would be most unrepresentative to interview only those members of the community whose English was fluent.

Because the Gujarati community is much longer established, I was less concerned (though not completely unconcerned) about the distorting effect of doing all the interviews in English. In the case of the Dutch community I did not intend to do any interviews and I also expected to find a high level of English competence. This expectation was largely borne out. With the Samoan community I was also on an instinctive level more worried about my status as a palagi. With the Gujarati and Dutch communities I felt, rightly or wrongly, that my being an outsider would not lead to questions within the community as to the propriety of an outsider undertaking research within the community. With the Samoan community I felt that such questions would be raised, and that I would be in no position to answer them.

I received no replies from the various pastors to whom I wrote and this, along with my growing doubts led me to abandon this line of approach, even though it also meant abandoning all opportunity of establishing any kind of readily definable sampling frame. I decided that I had first to establish some legitimate entrée into the community, with which I had no links at all, and that having done so, I would take matters from there. I started off on my home ground and went to talk to the head of Samoan Studies at Victoria, Mr Alf Hunkin. I explained to him what I was hoping to do and he suggested to me the names of two women whom he thought would be willing to help. I wrote to both women and, as I subsequently discovered, they discussed the matter and decide to help me. Mrs Fereni Ete was too busy to become directly involved but gave her blessing to the project, a far from negligible contribution. Mrs Feaua'i Burgess agreed to work with me on the project. Her involvement in early childhood education for Samoan children and her work in the Early Childhood Unit at the Wellington College of Education meant that she had a natural interest in the project and considerable expertise to bring to bear.

Feaul'i and I discussed the project and gradually a new methodology began to take shape. We decided to work with a group of Samoan people who would conduct the interviews. Feaua'i undertook to approach a variety of people who would provide representation of men, women, 
younger people, older people and Samoan and New Zealand born. Feaua'i also felt strongly that it was important to have representatives of the different Wellington Samoan communities and to interview people from all those communities. That meant having someone each from Wainuiomata, Porirua, and Wellington Central. This conflicted with my original idea of interviewing people only from Wellington City and Lower Hutt but we felt that it was worth abandoning that plan to get a wider representation of respondents.

At the first meeting of what came to be called the Samoan Research Group we discussed the outline of what I hoped to do, how the members of the Group would be able to help me and what we might jointly be able to do. The question of my being a palagi was raised at this point. This was a question which Feaua'i had already had to address in her own mind and she had discussed the matter with several people. She had come to the conclusion that it was better to have a palagi doing the research than no-one at all. She put this view to the Research Group and I also pointed out that research is not finite. The fact that I was doing this research did not preclude anyone else from doing research in the same area. Indeed, I hope that my research will provide a base for comparison. Another concern was that I might draw and publish conclusions with which members of the Group did not agree. I said that because of the academic nature of this piece of research I would have to be free to state my conclusions as I saw them, but I gave a guarantee that if the Group were unhappy with any of conclusions, I was prepared to include a statement of their views that would stand along with mine. Alladina and Edwards in a list of problems facing those who "[describe] speech communities other than their own' say

There are political considerations, too. For as long as writers choose to work on and be recognized as experts on a community other than their own, they are effectively setting themselves up in competition with members of minority communities for extremely limited research funding; they may also inadvertently engage in academic paternalism in which the hidden message is 'We understand your situation much better than you do yourselves.' (Alladina \& Edwards 1991)

I felt that my guarantee to state differing conclusions avoided the second danger, and, as far as the first danger is concerned, I can only say that the funding I received for this research was personal to me in the form of a scholarship and my decision to use some of this funding for doing research within the Wellington Samoan community did not deprive any member of that community of research funds. 


\subsubsection{Respondents to the Samoan questionnaire}

In the end the respondents to the Samoan questionnaire were selected by four of the Samoan Research group. The four interviewers used a variety of methods to obtain respondents to the questionnaire. Initially they approached friends and acquaintances, sometimes interviewing them and sometimes leaving a copy of the questionnaire for the respondent to fill out later. One interviewer who was involved in teaching Samoan women gave the questionnaire to groups of her students to fill out. The first batch of questionnaires to be returned to me was very heavily biased towards female respondents who were also teachers. Out of 39 completed questionnaires, only five had been filled out by men. After this I asked researchers to concentrate on finding male respondents, and when the next 18 questionnaires came in the proportion of male to female was 23/43. At this point I met with the three members of the original group who were still interested in being actively involved in the project and asked them to target respondents who fell into specified age/gender categories (see Appendix 3) in order to balance the number of men and women and the age-ranges in the survey. Another 20 questionnaires were filled out and the number of male respondents rose to 41. Apart from the students, most respondents were friends, acquaintances or friends of friends of the interviewers. Interviewees could nominate the language of the questionnaire and the language of the interview. All the interviewers were fluent in English and Samoan. The respondents to the Samoan questionnaire were the only respondents who were approached and/or interviewed by in-group members. Tixier y Vigil and Elasser in their 1978 study of the effects of the ethnicity of the interviewer on subjects' responses found that ethnicity did, in fact, have an effect. Interviewers from same minority group as the subjects and interviewers from the majority group both elicited fuller and franker discussions than each other - but on differing topics (Tixier y Vigil and Elasser 1978). The fact that Samoan respondents were approached by in-group members and the other respondents were approached by and out-group member may have had an effect on the responses that were elicited, but it is not possible to know exactly what that effect might have been.

The final concern was whether the questionnaire should be translated into Samoan. The Group felt very strongly that it should be translated. There were two main reasons for this; one was the pragmatic reason that when conducting an interview in Samoan it was easier to have the questionnaire in Samoan, the other, perhaps more important reason, was symbolic. It was felt that the project would be seen to be serious only if the questionnaire was in Samoan. 
Therefore the first thing that we had to do was to translate the questionnaire. This was a long, time-consuming task.

\subsubsection{Translating the questionnaire}

A group of varying size from six to eight people met about five times to work on translating the questionnaire. Everyone apart from me was a bilingual Samoan/English speaker and there were usually slightly more women than men in the group. Several people had a New Zealand university education, and several people were working in areas that brought them into frequent contact with formal, written New Zealand English. There were two main areas of debate. One was the general question of the degree of formality of Samoan that should be used. The problem was to strike a balance between gagana Samoa fa'aaoga i aso uma or colloquial Samoan and gagana Samoa fa'aaloala, formal Samoan. Some people felt that it was disrespectful to use language that was too colloquial whereas others found particular phrases too offputtingly formal to be used in conversation with another person. When my opinion was asked for I tended to stress that the written questionnaire was to be used as a guideline or framework for the questions that were to be asked, and thus the language should be closer to conversational Samoan. Nonetheless each turn of phrase had to be hammered out on its merits. In the questions about birthplace the options of 'Niu Sila = New Zealand ', 'Samoa' and 'o se isi atunuu = elsewhere' were offered. It subsequently occurred to me that 'Samoa' did not specify 'Western Samoa' although in a New Zealand context this is almost always understood. Most of the Samoan population in New Zealand is of Western Samoan origin (Pearson 1990: 121, Krishnan et al 1994: 16-17).

The other main area of debate concerned concepts that were hard to translate into Samoan. The most noticeable were 'flatmate', 'community', 'children', 'sex', 'older relatives' and 'living with a partner'.

\section{'flatmate'}

The social category does not exist in Samoa and where in New Zealand Samoan people are flatmates, they are likely to use the English word. In the end the term tagata o loo mautotogi was used.

$\begin{array}{lll}\text { Tagata } & \text { oloo } & \text { mautotogi } \\ \text { PEOPLE } & \text { VERBAL PARTICLE } & \text { TO BE A TENANT/PAY RENT }\end{array}$




\section{'community'}

The difficulties with this word were fascinating. 'Flatmates' do not exist in Samoa, therefore there is no word with which to describe them - this is obvious and unproblematic, even to the most unsophisticated observer. But communities exist everywhere - to be human is to live in a community. Of course communities exist in Samoa but the mainstream New Zealand concept of community is construed very differently from the Samoan concept of community. In New Zealand we can have a community in the abstract. Communities for us can be flexible, mutating concepts and social groupings and we can redefine our membership of them almost at will. Some memberships are immutable, but not many. In Samoa communities are concrete, hard to consider in the abstract and the Samoan tendency is not to talk of 'communities' - indeed it is difficult to do so - but rather to use the word for the particular community under discussion at any given time.

There were two contexts in which 'community' was used in the questionnaire: 'community schools' and 'Samoan/New Zealand community'. After much discussion and after back translation of the questionnaire had revealed the translations initially decided on were problematic, the terms were given as

\begin{tabular}{|c|c|c|c|}
\hline community school & $\begin{array}{l}a^{\prime} \operatorname{og} a \\
\text { SCHOOL }\end{array}$ & & $\begin{array}{l}u^{\prime} u \\
\text { MUNITY }\end{array}$ \\
\hline \multirow[t]{2}{*}{ Samoan/New Zealand community } & Tagata & "Samoa & Niu Sila" \\
\hline & PEOPLE & SAMOA & NEW ZEALAND \\
\hline
\end{tabular}

\section{'children'}

Caused a problem where, in the context of the questionnaire, 'your own birth children' was meant. The word tamaiti, although it translates as 'children', sometimes (depending on context) failed to convey this sense and so the term o lau fanau was used instead. Another problem was caused by the fact that the usual Samoan word for children actually means 'boys'. There was considerable debate as to whether this was inappropriately sexist in a New Zealand, academic context, or whether to use anything else would be inappropriately un-Samoan.
$o$
lau
fanau
PARTICLE
YOUR
OFFSPRING

\section{'older relatives' or 'younger relatives'}

The terms originally used translated simply as younger or older people. It was difficult to capture the fact of them being relatives in a natural turn of phrase. Eventually, after back translation showed isi aiga and aiga talavou to be unsatisfactory, the phrases tagata matutua o lou aiga and tupulaga talavou were used.
isi
aiga
OTHER
FAMILY
aiga
talavou
FAMILY
NEW/YOUNG




$\begin{array}{lllll}\text { tagata } & \text { matutua } & \text { o } & \text { lou } & \text { aiga } \\ \text { PEOPLE } & \text { MATURE } & \text { PARTICLE } & \text { YOUR } & \text { FAMILY } \\ & & & & \\ \text { tupulaga } & \text { talavou } & & & \\ \text { GENERATION } & \text { NEW } & & \end{array}$

'sex'

This caused a problem at question 37 which in the English reads

SEX

Male

Female

The question cannot be asked this way in Samoan and the formulation

Iutaga

KIND/SORT/PEOPLE/TRIBE/SEX

tane

MAN

fafine

WOMAN

was used.

\section{'living with a partner'}

There is no polite way to express this concept in Samoan. New Zealand English has standard polite bureaucratese terms of which 'living with a partner' is one, but social change in Samoan society has not led to the need for such terms. This question probably caused more problems than all the others. The question was translated as ua fai sou to 'alua fa'caipoipo, po'o e nofo fa' apouliuli and I stressed that if you knew that the person to whom you were talking was married then you simply needed to say something along the lines of 'you're married, aren't you', and that no mention of partners needed to be made at all.

$\begin{array}{llllll}\text { Ua } & \text { fai } & \text { sou } & \text { to'alua } & \text { fa'aipoipo, po'o } & e \\ \text { PARTICLE } & \text { DO YOU } & \text { SPOUSE } & \text { MARRY } & \text { INTEROGATIVE } & \text { PARTICLE } \\ \text { nofo } & \text { fa'apouliuli } & & & & \\ \text { LIVE } & \text { IRREGULAR } & & & \end{array}$

Once the initial translation process was completed, the questionnaire was back-translated into English by Sera Tamatoa. This process checked the accuracy of the translation and also how generally comprehensible the Samoan translation of the questionnaire was. Translating the questionnaire, though time-consuming, seems to have been appreciated by the respondents, as 70 out of 93 questionnaires were answered in Samoan. Translating the questionnaire also gave the interviewers an opportunity to analyse the questions in some depth and thus to develop their understanding of the questionnaire before administering it. 


\subsection{Dutch survey}

The Dutch survey was begun when the Gujarati survey was nearing completion and the Samoan survey was well underway. This meant that the experience of these two exercises was available to draw on in planning the Dutch survey. It is a commonplace of interview-based research that

interviews are expensive and time-consuming to conduct and to process, there are always risks of interviewer bias, and interviews are usually too expensive to reach a widely dispersed sample (Oppenheim 1992:102).

Interviewing respondents for the Gujarati survey was certainly exceedingly time-consuming, so it was decided to, if possible, limit the Dutch survey to a postal questionnaire. If response quality to the initial questionnaires seemed high (essentially if the number of contradictory responses and non-responses was low) follow-up interviews would not be conducted. With this in mind, the questionnaire was expanded somewhat to get answers to questions that, in the Gujarati survey, had been asked in interviews and that, for the sake of simplicity and brevity, the Samoan respondents had not been asked.

In the end the quality of responses to the Dutch questionnaire was very high, and no interviews were done. Interviews may appear to provide advantages that the postal questionnaire lacks, and intuitively the researcher feels that the face-to-face interview has a dimension of clarity and authenticity that the postal response cannot provide. However the situation is not as clear cut as it may seem

Survey questions may be asked in face-to-face interviews, telephone interviews, or selfadministered questionnaires. These forms differ along two dimensions: their degree of impersonality and the cognitive demands they place on the respondent.

Regarding the degree of impersonality, self-administered questionnaires provide more anonymity than face-to-face interviews - with telephone interviews somewhere inbetween. The more anonymous methods are likely to encourage fuller reports in response to threatening and sensitive questions.... With regard to the cognitive demands placed on the respondent, things are more complex. On the one hand, self-administered questionnaires allow respondents to use as much time to answer a questions as they may wish. On the other hand, an interviewer who could provide clarification and encouragement is not available. Depending on the nature of the question, these factors may offset one another, resulting in the finding that "contrary to the common belief favoring face-to-face interviews, there is no clearly superior method that yields better results for all types of questions"' (Bradburn, 1983, p. 294; see also Sudman \& Bradburn, 1974; Dillman, 1978).

Telephone interviews, on the other hand, are likely to place a higher burden on respondents than either face-to-face interviews or self-administered questionnaires. (Hippler \& Schwarz 1987: 116) 


\subsubsection{Questions added to the Dutch questionnaire}

The following questions were added to the first version of the Dutch questionnaire and were all retained for the second version.

11. If you speak mainly English to your children, do you try to speak some Dutch to them as well?

This question was added because it was expected that many Dutch parents would speak mainly English to their children and the question would reveal if the respondents spoke any Dutch to their children.

15. Have you been from NZ to the Netherlands for a visit?

16. Have your children been to visit the Netherlands

These two questions were added at the suggestion of Maria Stubbe who thought that return visits to the Netherlands might turn out to correlate with Dutch language proficiency.

Questions 17 - 31 which were not included in the Gujarati questionnaire but were included in the Gujarati interview schedule, were included in the Dutch questionnaire. All these questions were concerned with Dutch language use in childhood in New Zealand (see Appendix 2).

The questions about mother-tongue language schools for children in New Zealand had to be changed slightly because there were no such schools operating in Wellington for the Dutch community, whereas the Gujarati and Samoan communities both have such schools. In addition to this change of wording, another question was added

44. What do you think about the idea of classes aimed at NZ born Dutch adults who wanted to learn some Dutch or improve their present level of Dutch.

This question was added mainly because a Dutch language course had started up at Auckland University and was apparently proving very popular with New Zealanders of Dutch descent. I was interested therefore to get some general opinion on such courses. As the questionnaires were returned, I discovered that, at various times, adult evening classes in Dutch had also been available in Wellington. 
56. What was the religion of the household in which you grew up?

This question was added because people from both Catholic and Protestant areas of the Netherlands had emigrated to New Zealand and it seemed possible that religious affiliation might have had some impact on language maintenance.

\section{Where was your spouse/partner born?}

This was a question that I greatly regretted not having asked in the Gujarati and Samoan questionnaires. To some extent, the important information was contained in the question about the languages spoken by spouse, but it became more and more obvious as analysis of the first two questionnaires proceeded that it was a handicap not to know where a respondent's spouse had been born.

The second version of the Dutch questionnaire was much the same as the first version, but incorporated a change to a set of questions that had been used in all the questionnaires with the Cantonese, Gujaratis and Samoans, and which had never been entirely satisfactory. It was not until the Dutch questionnaire was being rewritten, however, that I found an appropriate way of rewording the set

The set was made up of questions three and four

3. What language do you use most?

4. Apart from the language that you use most, have you used any other language/s in the last month?

$\square \quad$ No

$\square \quad$ Yes - please specify the language/s you have used

It was clear this set of questions was potentially confusing for people who were filling out the questionnaire on their own because, in answering question four they tended to refer back not only to question three but also to question one 'what language/s do you speak?'. Thus, if a respondent had said that they spoke Samoan and English in question one, then said that they spoke Samoan most of the time in response to question three, then they were likely to reply 'no' to question four, which strictly speaking should have been interpreted as 'no, I have spoken no language other than Samoan in the last month'. In fact where internal evidence from other answers to the questionnaire seemed to make it likely that English had been spoken (especially if respondents said that they spoke English at home or with family 
members) then 'English' was entered as an answer to the question. This technique was used in both the Gujarati and Samoan questionnaires. Its deficiencies were obvious but I was unable to think of a satisfactory alternative. Eventually one occurred to me and it was first used in the fourteenth questionnaire of the Dutch mailout. It proved to be much more satisfactory and was used in all the subsequent Dutch questionnaires. Questions three and four now read

3. a. Have you spoken English in the last month?

b. Have you spoken Dutch in the last month?

c. Have you spoken any other language in the last month? (Please specify)

4. Which language do you use most?

\subsubsection{Sample frame}

It is very difficult to determine the number of Dutch people and people of Dutch descent in New Zealand. The census allows the option 'NZ European' and, not unreasonably, many Dutch people and people of Dutch descent appear to take this option. The 1991 Census recorded 3,047 Dutch people in the Wellington Local Authority Region (Thomson 1993:95), but it seems unlikely that this represents more than a fraction of the total Dutch and Dutchdescended population

In the case of European ethnic groups (such as Dutch, Greek, Polish, Yugoslavian and Italian), the New Zealand born generations fitted the category 'New Zealand European'. If they did not identify with the ethnicity of their parent or parents, and only ticked this box, such persons would disappear from our analysis. This appears to have affected the size and age structure of the European ethnic groups. Our data tends to give the impression of an ageing population, even although the older generation may have had many descendants (Thomson 1993:8).

The Dutch, as a group in New Zealand are not affiliated, in large numbers, with any particular Church and/or associations. There are some Dutch social organisations, but they do not have large memberships that are representative of Dutch in Wellington. With no very clear idea of the numbers of people involved, and with no organisation that could reasonably be used as a sampling frame, it was decided to use friend of a friend methodology to contact potential respondents.

Lesley Milroy in her classic description of friend of a friend methodology in Belfast describes a situation where in order to gain entree in a community it is necessary to have some connection with a member of the community 
The important functions of naming a 'friend' in these communities, [are] first to guarantee good faith, but also as a means of becoming rapidly enmeshed in the rights and obligations relationships of the network (Milroy 1987:54).

It was decided to use a variation of friend of a friend methodology as a way of making contact by post rather than in person. This method was primarily chosen as way of accessing names and addresses that there seemed to be no other way of acquiring, but I hoped that as well as providing possible contacts, it would also, at least to some extent, have the function of guaranteeing my good faith. I offered to become 'enmeshed in rights and obligations' by running a seminar on the results of my research for those who were interested in attending. Although friend of a friend methodology may not have been necessary to gain entree, it did enable me to write a covering letter in which I could put forward what Oppenheim calls 'sponsorship'. Oppenheim suggests that sponsorship, linking the researcher with some person or body expected to influence the recipient of the request to accede to the request is one of the factors in increasing response rate in postal questionnaires (Oppenheim 1992: 104).

I wrote to two Dutch people who were friends of friends (and interviewed a third covering the same ground as with the two whom I wrote to), enclosing a copy of the questionnaire and a covering letter explaining what I was doing. At the end of the questionnaire was a section where I asked them to write down the names and addresses of friends or acquaintances of theirs who might be interested in answering the questionnaire. I specified that I was interested in people living in the Wellington region who were born in the Netherlands or born in Indonesia or New Zealand with a Dutch-speaking parent or parents. I gave respondents to the questionnaire the option of being anonymous, but stipulated that if they gave me names of other possible respondents I needed their name also so that I could tell the people to whom I was writing who had given me their name. In the initial mail-outs, I simply asked for other possible respondents' names and addresses but I soon realised that I had to ask for titles as well otherwise I would be given names in the following kind of format

\section{A.B. Respondent \\ 12 Somewhere Rd \\ Wellington}

This meant that I had to write to A.B. Respondent rather than to Ms, Mrs or Mr Respondent. This seemed to my mind to be a rather impersonal method of approach, and I was keen to avoid it. Although many studies have found that personalisation does not produce a significant increase in response rate (Moser \& Kalton 1972: 265, Wright 1986:8-12), Wright found that in a New Zealand context 
Personalisation of address and salutation is significantly better than the alternative of impersonal address and salutation (Wright 1986:7).

After I started requesting respondents to provide titles they usually did so, and this particular problem was solved.

\subsubsection{Mail out and response rates}

The Dutch mail-out could not be done in one or a few big waves because I had to wait for questionnaire returns from respondents in order to get names of people to whom I could send more questionnaires. In practise this meant that I tended to wait until I had about ten names and would then send off another batch of questionnaires. All in all 230 questionnaires were sent out in addition to the initial three. The response rate is calculated on all 233 questionnaires and is as follows

$\begin{array}{lll}\text { Returns } & \text { Ineligible } & =4 \\ & \text { Gone No address } & =0 \\ & \text { Refusals } & =2 \\ \text { Usable } & =184 \\ \text { Non-returns } & & =43 \\ \text { Total } & & =233\end{array}$

Response Rate $=80.6 \%$

Because of the friend-of-friend networking there were no 'gone no address' returns. The four 'ineligible' were all non-Dutch spouses of Dutch people. A married couple to whom I had sent questionnaires sent me a note wishing me well with my research but saying (without explanation) that they were unable to assist me.

\subsubsection{New Zealand-born}

After approximately 110 questionnaires had been sent out, I became concerned at the comparatively low number of New Zealand born respondents. The section at the end of the questionnaire where I asked people to give me names and addresses of those who might be willing to answer the questionnaire was changed. It was specified that I was looking for "people who were born in New Zealand with a Dutch speaking parent or parents and who now live in the Wellington region'. With the responses to this request, I was able to send out 48 questionnaires, all of which were going to New Zealand-born respondents according to the informants who had provided the names (as it turned out one went to a respondent born in Indonesia, one went to someone born in the Netherlands and two went to non-Dutch 
respondents). A first it seemed possible that one of the reasons that there were comparatively few New Zealand-born answering the questionnaires was because the New Zealand-born would be less likely to choose to respond. However this does not seem to be the case as the response rate for the 48 questionnaires sent to New Zealand-born respondents is very similar to the response rate for the group as a whole.

$\begin{array}{lll}\text { Returns } & \text { Ineligible } & =4=\text { the non-NZB who replied } \\ & \text { Gone No address } & =0 \\ & \text { Refusals } & =0 \\ & \text { Usable } & =35 \\ \text { Non-returns } & & =9 \\ \text { Total } & & =48\end{array}$

Response Rate $=81.25 \%$

Thus the overall response-rate for New Zealand-born Dutch people was about the same as for the Dutch mail-out population as a whole.

\subsection{Language proficiency question}

All three sets of respondents were asked essentially the same type of language proficiency question (see Appendices 1-3 for format). The questionnaires were based on the questions that had been used in the research on the Cantonese community in Wellington (Roberts 1990) but were altered in order to make them both simpler and shorter for the purposes of a postal questionnaire. Respondents were asked whether they considered themselves 'fluent', 'fairly fluent', 'not very fluent', 'not able to speak but able to understand', and 'not able to speak or understand'.

The Gujarati respondents were asked these questions about Gujarati, English and Hindi. Hindi was included because it was known that many of the respondents who had grown up and been educated in India would have acquired Hindi. The questions were intended to discover not only how likely non-New Zealand-born respondents were to speak Hindi but also to find out if any of the New Zealand-born respondents had continued to use Hindi.

The Samoan respondents were asked about English, everyday Samoan and Formal Samoan. The command of both types of Samoan can be considered to be an indicator of maintenance of a full range of Samoan sociolinguistic skills.

The Dutch were asked to assess their proficiency in English and Dutch. Many of the Dutch and Indonesia-born respondents were multilingual and this was an expected result, but it was 
not possible to predict which languages would be most likely to be spoken other than Dutch and English. Nor were there any other languages or varieties which were as socially important to the Dutch as Hindi to Indians or Formal Samoan to Samoans.

\subsubsection{Accuracy of self-assessment of proficiency}

The question of respondents' levels of proficiency in the three languages that they were asked about, presents several interesting questions. There is the question of the usefulness of selfreport data as a means of assessing proficiency in a language. This in turn, leads to a variety of questions; some of which are considered below.

- Firstly, how accurately does an individual assess their proficiency in a language. To what extent are assessments coloured by over-confidence, lack of confidence or sheer poor judgement?

- Secondly, how closely do the researcher's and subjects' standards converge? Do they have the same concept of 'fluent' or 'limited proficiency' for example.

- Thirdly, what can be done to improve this convergence?

- Fourthly, can self-assessment of fluency be used as an independent variable?

How accurate are subjects' self assessments of linguistic proficiency? There is considerable difference of opinion in the literature as to the accuracy of self-assessment. Most of the research has been done in the area of language teaching and this adds an irrelevant dimension for the purposes of this research. The respondents to this survey were not in a classroom language learning situation and were therefore not in the position of receiving formal assessment from a teacher. The respondents had no sense of themselves as performing well or badly in academic terms, no sense of any class-room ranking or of being 'good at' or bad at' Gujarati or Samoan or Dutch or English as a subject. Presumably they had instead a sense of how comfortable they felt when speaking those languages, how wide a range of situations they felt they could cope with in a given language, and perhaps a sense of how other community members regarded them as potential interlocutors in the MT or in English.

Peirce, Swain and Hart (1993) in their study of teenage French immersion students in Canada found that

In general, there are weak correlations between the two respective measures of selfassessment and the objective measures of proficiency (Peirce, Swain and Hart 1993: 33).

However such studies of second language learners do not really seem directly relevant to studies of community language maintenance. As Peirce, Swain and Hart themselves point out 
the vast majority of French immersion students have little access to French or francophones outside the classroom ... For this reason, many French immersion students do not have an authentic native speaker peer standard by which to compare their proficiency in French ... in the month prior to the self-report, only approximately a third of the students had watched French TV or listened to French language radio (Peirce, Swain and Hart 1993: 35).

In communities such as the Gujarati and Samoan communities in Wellington with high levels of native speaker use of the MT, there is no shortage of 'native speaker peer standard' with which the respondents could compare their Gujarati or Samoan. Although there is no Gujarati or Samoan TV, there is a Samoan language radio station and there are Access Radio broadcasts in Gujarati and Hindi (not targeted specifically at the Gujarati community) and Dutch. The same holds true for English. Most respondents are in a situation where they hear plenty of native speaker English and also watch English Ianguage TV and listen to English language radio. The only languages where there is a shortage of contact with "native speaker peer standard' are Hindi (where most of the Hindi that people get a chance to hear comes from Hindi language video) and Dutch. Due to the lower use of Dutch within the home, and due to the more fragmented nature of the Dutch community, it seems likely that some New Zealand-born respondents might in fact have very little access to a 'native speaker peer standard'.

Other studies which have been more positive in their findings about self-assessment by second-language learners are those by LeBlanc and Painchaud (1985) and by Bachman and Palmer (1989). LeBlanc and Painchaud studied students entering the University of Ottawa and learning either English or French as a second language. They were interested in selfassessment as a method of placement and concluded that

Although the results are not of the highest level, the correlation of .53 between the two total scores [for self-assessment and proficiency tests], which is in keeping with the .50 result deemed acceptable by Oskarsson (1978), shows that students can assess their own knowledge of the second language to some extent (LeBlanc \& Painchaud 1985: 679).

Even more tellingly perhaps, they discovered that student placements in courses carried out on the basis of self assessments necessitated fewer course changes than placements in previous years determined as a result of proficiency tests (LeBlanc and Painchaud 1985:685).

Bachman and Palmer concluded 
The results of this study indicate that self-ratings can be reliable and valid measures of communicative language abilities. The obtained reliabilities are much higher than had been expected, and all the self-rating measures in this study had strong loadings on a general factor (Bachman \& Palmer 1989: 22)

Both LeBlanc and Painchaud, and Bachman and Palmer were using a much more detailed and specific assessment instrument than was used in this survey. (They had more time and space available and were not conducting a postal questionnaire). As was mentioned above, they were studying subjects who were formal learners of a second language. Their subjects were very different from the subjects of this study who in most cases were being asked to assess proficiency in a language acquired as a first language or in a language the study of which may have begun at school in the homeland, but had been informally continued or where acquisition had been completely informal subsequent to migration. Non-New Zealand-born respondents from all three groups might have had some formal English language instruction at educational institutes in their countries of origin and some of them might have attended formal courses of instruction once they had arrived in New Zealand but, as far as is known, none of them were attending English language courses at the time of the survey.

Two points stand out. One is that these two studies found self-assessment of language ability to correspond positively to objective assessment of proficiency; the other is that selfassessment seems to provide particularly good assessment of communicative or practical proficiency.

Shameen, in her study of language shift in the first generation Wellington Indo-Fijian community, compared fairly detailed and specific self-reports of Fiji Hindi with performance tests and concluded that

On the whole the self-reports showed a high positive correlation with the performance data. This provided evidence of the validity of the self report scales (Shameen 1995: 192).

Hakuta and D'Andrea also came to a positive conclusion about the use of self-assessment. They studied Spanish language maintenance and loss among Mexican high-school students in Northern California. They

believed in the possibility that self-reported language proficiency may not be entirely accurate. Thus, a comparison was planned between self-reported language proficiency and actual measured language proficiency (Hakuta and D'Andrea 1992:73) 
This proved a somewhat more useful study for the purposes of the present research because the students, like the respondents in this survey, were in a bilingual, language maintenance situation. However they were all still at school and, perhaps more importantly, were all 'enrolled in courses of either Spanish as a Foreign Language (SFL) or Spanish for Spanishspeakers' (Hakuta \& D'Andrea 1992:74) so that they were still in a situation of getting formal, teacher-provided assessment of their Spanish proficiency. What Hakuta and D'Andrea found was that

self-rated proficiency in Spanish and English was correlated with actual proficiency measurements, but not very highly. ... For Spanish, maintenance and subtractive orientations contribute to the prediction of self-reported proficiency in expected directions, i.e. with maintenance orientation leading to higher self-reported proficiency than the actual measurement would predict, and the subtractive orientation working in the opposite direction. ... it might even be said that self-reported language ability is as much a measure of language attitude as it is of language proficiency (Hakuta \& D'Andrea 1992:90-91).

Hakuta and D'Andrea make the telling point that self-reported proficiency ratings cannot be taken as an independent variable in relation to measures of attitude

attitudinal orientation contaminates self-reported proficiency (at least as globally measured in this study) to a substantial degree. Indeed, in the case of Spanish, the magnitude of the predictive power of the maintenance orientation threatened to match the magnitude of measured Spanish proficiency, such that a self-reported measure of proficiency would be almost as good a measure of attitude as it would be of language proficiency (Hakuta \& D'Andrea 1992:95).

Albert Bandura points out that misjudgement of abilities can be efficacious:

optimistic self-appraisals of capability that are not unduly disparate from what is possible can be advantageous, whereas veridical judgements can be self-limiting. When people err in their self-appraisal they tend to overestimate their capabilities, which is a benefit rather than a cognitive failing to be eradicated. If self-efficacy beliefs always reflected only what people can do routinely, they would rarely fail but they would not mount the extra effort needed to surpass their ordinary performances (Bandura 1990:343)

This suggests that even if people do overestimate their proficiency in a language, this overestimation is not only associated with a more positive view of the language, but it also may assist the individual in attaining a greater proficiency in the language.

Bandura also makes the point that 'judgement of competence is, by definition, a social construction.' (Bandura 1990:324). He is particularly concerned with the social regulation of professional competence but it seems to me that this comment applies equally strongly to 
language proficiency. This seems to be well-illustrated by the case described by Nancy

Dorian where a fluent semi-speaker and her fluent Gaelic speaking friend only realised as a result of Dorian's test that the semi-speaker was not, in fact, a fluent speaker (Romaine 1982:30). Socially, the semi-speaker operates as a fluent speaker in the estimation of herself and her interlocutors. Williams points out in connection with Dorian's research that

There is a shift from defining the speech community in terms of distinctive linguistic features to a definition based on behaviour in context (Williams 1992: 73)

Thus people may operate efficiently within the community as speakers of a language because they can behave appropriately in context. They themselves might not be aware that they are what Dorian would call semi-speakers.

This may be related to the observation that

It is unrealistic to expect omnibus tests to predict with much accuracy how people will function in different domains under diverse circumstances. Indeed, in comparative studies, domain-linked measures of personal capability typically predict changes in functioning better than do general measures (Bandura 1990:330).

Peirce, Swain and Hart came to the same conclusion in relation to language self-assessment

there were higher correlations between the 'specific tasks' benchmark and measures of tested proficiency than there were for the more global 'francophone peer' benchmark and measures of tested proficiency. This suggest that the more specific and focused a self-assessment instrument is, the greater the likelihood that there be higher correlations with objective measures of proficiency (Peirce, Swain \& Hart 1993:39).

Respondents to this survey were not asked to respond to a measure as global as the 'francophone peer' bench mark ${ }^{36}$ but neither were they asked questions as specific as those used for the 'specific tasks' benchmark ${ }^{37}$. A balance was attempted between the desire to be specific and the fear that such a scale might be confusing and unwieldy within the context of a postal questionnaire. There was also the problem of generating relevant cross-group specific tasks.

\footnotetext{
36 ."My French is: about the same, somewhat worse, much worse, than a person your age whose first language is French" (Peirce, Swain \& Hart 1993:28).

${ }^{37}$ E.g. 'You can listen to and understand a French radio show: not at all - with much difficulty - with some difficulty - with little difficulty - without any difficulty".
} 
Janssen-van Dieten (1989:38) also throws doubt on the efficacy of global self-assessments. Her study is of interest because she was looking at adult learners of Dutch assessing their Dutch language competence. Once again however, these subjects were in a formal learning situation and, as in the case of the Canadian study, the subjects were being tested on a second language not a MT that was being maintained. Their position is roughly comparable to the position of adult Gujarati, Samoan and Dutch respondents assessing their English competence. Janssen-van Dieten also makes the interesting comment that

no clear relationship could be found between [length of] attendance on language courses and correct estimation [of language skills] suggests that attending language courses did not provide subjects with a better insight into evaluation criteria (Janssenvan Dieten 1989:44).

If this is generally true (it was not the main focus of Janssen-van Dieten's study and can only be regarded as an interesting indication of a possibility), it suggests at least, that the fact that respondents to this survey were not in formal language learning situation, did not make them any the less reliable as estimators compared to the subjects in the studies (all in formal learning contexts) that have been mentioned.

Fishman, in a discussion of these questions, comes to the conclusion that broad categories for self-report ratings can, in the absence of the time and resources that we would have in a perfect world, be reasonably reliable.

Fortunately, our dependence on such categories is not entirely an article of faith. It has been demonstrated many times, and even in connection with sociolinguistic data on LS concerns, that where there is no overpowering reason for dissimulation .... the responses on self-report Likert-type instruments are significantly related to independently obtained daily behavioral records of a more precise type (Fishman 1991: 52).

\subsubsection{Summary}

Looking at the available evidence, a few conclusions can be drawn. In terms of answering the four questions that were asked at the beginning of this discussion.

- The first and the second question are answered by the same point. Accuracy of response and convergence of researchers' and subjects' standards may be increased by making the questions more specific. The more specific they are, the more likely that researcher and subject will have the same understanding of the aspect of proficiency that is being measured.

- This is really the answer to the third question as well. Make the questions more specific - this will improve convergence. 
- In answer to the fourth question, it would appear that self-assessment of fluency cannot be used as a variable that is independent of attitude towards the language that is being assessed.

More generally

- Self-assessment of language ability provides a generally accurate indication of ability, but not a measure that would correspond exactly with a proficiency test.

- Language maintenance self-assessments are probably different from second language self-assessments, but it is not currently possible to say how. The same may be true of self-assessments by those who have learned a language formally compared to those who have learned it informally.

- Self-assessment of proficiency and general attitude to the language seem to be related.

- The more specific a self-assessment schedule is, the more accurate it is likely to be.

It is hard to be sure that the proficiency that is being self-assessed and the proficiency that is being tested are the same thing. The more global a self-assessment is, the truer the foregoing statement is. Shameem comments on the same phenomenon when she says

To be valid, a test must demonstrate that it is measuring what it is purporting to measure; to be reliable it must show stability over time and across raters. One of the greatest tensions in language performance assessment is the one between validity and reliability. The closer one gets to replicating reality and eliciting real-life type language use, the more unreliable the data may become with the absence of structural constraints and the lack of consistency from one test-taker to another (Shameem 1995: 102)

For the purposes of this survey, it seems that the respondents' self-assessment of proficiency should be regarded as providing reasonably useful information on their actual language abilities but perhaps as having an even greater bearing on their confidence in speaking the language. Taft and Cahill made a similar finding when investigating immigrant Lebanese children in Australia and went on to say that it seemed that 'some degree of confidence in ability to speak the language is more influential in its use than is actual ability' (Taft and Cahill 1989: 140)

\subsection{Conclusion}

Doing questionnaire based research in three completely different communities was a challenging and exciting process. This chapter has outlined how the integrated model developed from Fishman's theories was used as a framework upon which to develop a questionnaire. We have seen how the basic framework of the research design was modified for each community, taking 
account of differing backgrounds and requirements. The questionnaire had to be translated for the Samoan research, expanded for the Dutch research and a series of face-to-face interviews conducted for the research in the Gujarati community. Self-assessment of proficiency was requested of respondents in all three communities and the potential difficulties inherent in this process are also discussed. 


\section{ANALYSIS OF THE GUJARATI RESPONDENTS' RESPONSES TO THE QUESTIONNAIRE}

In the next six chapters, the findings of the questionnaire-based research into the three communities are presented. Chapters 7,8 and 9 present the data gathered from the Gujarati, Dutch and Samoan communities respectively. There is very little analysis or comparison in these chapters. The intention has been to present the material as clearly as possible without much interpretation. As each chapter is dealing with essentially the same phenomena, mediated through different experiences, the necessary amount of repetition would be extremely tedious if each chapter were to expatiate upon the same points.

Analysis, comparison and interpretation are presented in Chapters 10, 11 and 12. In these chapters, the three groups are compared with each other and with other groups in which language maintenance and shift have occurred or are occurring. These three chapters use as their guideline, the model presented in Chapter 5 and based on Fishman's theories of language maintenance and shift.

\subsection{Demographic profile of Gujarati respondents}

The Gujarati survey consisted of data obtained from 147 adults, 141 of whom were of Gujarati extraction. Information was also obtained from Gujarati extraction respondents as to aspects of their children's language use. Thus information on a total of 327 people of Gujarati extraction was gathered.

\subsubsection{Determining Gujarati ethnicity}

The Gujarati questionnaires were posted to the Wellington Indian Association membership and consequently some of them went to non-Gujarati respondents. Some method had to be established therefore to determine whether a given respondent was of Gujarati ethnicity or not. The survey respondents discussed here were either born in Gujarat or are the sons and daughters or, in some cases, the grandsons and granddaughters of Gujarat-born parents or grandparents. In most cases, whether or not someone was of Gujarati extraction was determined simply by examining where that person, or the parents of that person, had been born. If the person, or one or both parent/s was born in Gujarat, then that person was considered to be of Gujarati extraction. In the 12 cases where the person under consideration 
and both parents had been born outside Gujarat (or where parents' birthplace information was not available because the short questionnaire was used, or there was no response or unclear response) then the languages spoken by the person were considered. If one of those languages was Gujarati, then that person was considered to be of Gujarati extraction. Six respondents were classed as Gujarati in this way ${ }^{38}$.

The data was collected using three questionnaires (see Chapter 6). The different questionnaires contained a core of identical questions but each questionnaire had a number of additional questions and for this reason the total number of respondents varies depending on the set of answers that is being discussed.

\subsubsection{Census data}

There are no Census figures for the Gujarati population of New Zealand; therefore all comparisons of questionnaire data must be with the Indian population as a whole, rather than with the Gujarati population in particular.

As of the 1991 Census, the Indian population numbered 30,609. This makes the Indian population one of the largest ethnic minority populations in New Zealand. The Indian population makes up $0.91 \%$ of the population of New Zealand (Thomson 1993:15) ${ }^{39}$. By far the majority of the Indian population lives in Auckland (almost 60\%) but the second largest population cluster is in the Wellington region where almost $20 \%$ of the Indian population of New Zealand lives (Thomson 1993:104). In the 1991 Census there were 6024 people of Indian ethnicity in the Wellington region (Thomson 1993:94). This research is therefore based on data from $2.4 \%$ of the Wellington regional Indian population - the respondents therefore represent more than $2.4 \%$ of the Gujarati population.

\footnotetext{
${ }^{38}$ Five of the six respondents who were born outside Gujarat, whose parents were born outside Gujarat (or whose birthplaces were unknown) and who did not speak Gujarati, were. in addition to being speakers of Hindi and English, speakers of Indian languages other than Hindi (Tamil, Kannada, Panjabi and Urdu) as well. All of these facts led to classing them as non-Gujarati respondents. Obviously there is some room for error in this method of calculating ethnic affiliation but overall it seems adequate as a rough measure. It was applied to only $8 \%$ of all 147 respondents.
}

${ }^{39}$ In comparison the Indian community in South Africa makes up $3.3 \%$ of the total population (Desai 1994:1) 


\subsubsection{Birthplace}

Most of the Gujarati respondents were born in Gujarat

Table 7-1: Birthplace of respondents of Gujarati extraction

\begin{tabular}{|l|l|l|}
\hline Birthplace & No. & $\%$ \\
\hline Born in Gujarat & 94 & $66 \%$ \\
Born in New Zealand & 35 & $25 \%$ \\
Born in India: ex Gujarat & 2 & $1.5 \%$ \\
Born in Fiji & 3 & $2 \%$ \\
Born in Tanzania & 2 & $1.5 \%$ \\
Born in South Africa & 1 & $1 \%$ \\
Born in Uganda & 1 & $1 \%$ \\
No response & 3 & $2 \%$ \\
N= & 141 & $100 \%$ \\
\hline
\end{tabular}

\subsubsection{Gender}

Overall, more men than women replied to questionnaire ${ }^{40}$.

- 80 men (57\% of respondents) and

- 61 women (43\% of respondents) answered the questionnaire.

This corresponds roughly to the proportion of men and women in the Indian population of New Zealand as a whole at the time of the 1991 Census (Thomson 1993:24).

- $53 \%$ of the Indian population was male

- $47 \%$ was female

It is noteworthy that amongst the New Zealand-born respondents to the questionnaire, the proportions of women to men were quite different.

- $21(60 \%)$ of the 35 of New Zealand-born respondents were female,

- $14(40 \%)$ of New Zealand-born respondents were male.

In comparison, if we look at the respondents who were born in Gujarat the preponderance of male respondents is, of course, greater.

- $61(65 \%)$ of the 94 Gujarat-born respondents were men

- $33(35 \%)$ were women.

\footnotetext{
${ }^{40}$ See methodology chapter 6 for discussion of gender of recipients of questionnaire.
} 
Table 7-2: Gender of respondents to questionnaire

\begin{tabular}{|l|l|c|c|}
\hline & Total & Born in Gujarat & Born in New Zealand \\
\hline Male & $57 \%$ & $65 \%$ & $40 \%$ \\
Female & $43 \%$ & $35 \%$ & $60 \%$ \\
$\mathrm{~N}=$ & $141^{41}$ & 94 & 35 \\
\hline
\end{tabular}

We can only speculate as to why this difference exists. Two factors may be relevant. First, amongst the Gujarat-born population more women than men are likely to be illiterate in English and thus unable to answer an English language questionnaire. Secondly, amongst the New Zealand-born population, issues involving language and culture maintenance (especially those that touch upon children's education) are more likely to be seen as the responsibility of women. This, certainly, has been informally confirmed by comments made to me by New Zealand Indian and New Zealand Chinese parents, to the effect that decisions in these areas are left to the mother of the children.

\subsubsection{Age of respondents to questionnaire}

Table 7-3: Age ranges of all respondents and New Zealand-born respondents to questionnaire

\begin{tabular}{|l|rr|rr|}
\hline Age ranges & \multicolumn{2}{|c|}{ All Gujarati Respondents } & \multicolumn{2}{|c|}{ NZ-born Respondents } \\
\hline $26-30$ & 7 & $5 \%$ & 1 & $3 \%$ \\
$31-35$ & 18 & $13 \%$ & 11 & $31 \%$ \\
$36-40$ & 27 & $19 \%$ & 14 & $40 \%$ \\
$41-45$ & 32 & $23 \%$ & 5 & $14 \%$ \\
$46-50$ & 20 & $14 \%$ & 2 & $6 \%$ \\
$51-55$ & 13 & $9 \%$ & 2 & $6 \%$ \\
$56-60$ & 5 & $4 \%$ & - & \\
$60+$ & 17 & $12 \%$ & - & \\
No response & 2 & $1 \%$ & - & \\
N= & 141 & & 35 & \\
\hline
\end{tabular}

There was a good spread across the child-rearing age groups. It is unclear why there is such a disproportionate number of responses from respondents over 60. It may be that, as a group, they have more time to indulge in activities such as answering questionnaires that turn up in the post; they may be a greater proportion of the membership of the Wellington Indian Association; they may be more concerned, in general, with issues of language and culture maintenance. The range of respondents' ages does not, of course, reflect the age range in the

\footnotetext{
${ }^{41}$ The totals for NZ-born and Gujarat-born, do not add up to 141. The Indian-, Fijian- and African-born respondents have not been included in the analysis.
} 
New Zealand Indian population as a whole. The questionnaire was not directed at children, and because of the heavy emphasis on questions about partners and children, it seems possible that respondents to some extent self-selected as married with children, and this means that there are relatively few respondents in the young adult age groups. The use of the Wellington Indian Association phone-book may also have had an effect; younger adults seem less likely to be members in their own right, and more likely to be still included in parental membership. Thus, they were less likely to receive a questionnaire in the mailout.

\subsubsection{Marital status of respondents to questionnaire}

From the data gathered by questionnaire, there are two ways of ascertaining respondents' marital status. They produce very slightly varying answers. We can examine answers to the question 'Are you married or living with a partner?' which appeared in the long questionnaire, or to the question 'What language do you speak with your spouse/partner most of the time?', which appeared in both the long and short questionnaires. The respondents to the short questionnaire were not specifically asked whether they were married.

One hundred and fifteen respondents of Gujarati extraction were asked whether they were married.

- $102(89 \%)$ were married

- 2 respondents were not married (both New Zealand born)

- 2 were separated (one New Zealand born)

- 7 respondents were widows and

- 1 was a widower.

Twenty-nine of the 32 New Zealand-born respondents who answered the long version of the questionnaire were married $(91 \%)$. As mentioned above, one was separated and two were unmarried.

Although only 115 of the 141 respondents were directly asked whether they were married, all the respondents were asked what languages they spoke with their spouse or partner. If we look at responses to this question we see 124 respondents listed the language/s they spoke with their spouse/partner. Of the five respondents who entered 'no response' to this question, three answered that they were married and two that they were widows, to the question about marriage. Thus it seems reasonable to suggest that 127 of the 141 respondents ( $90 \%$ ) were married. 
Turning to the responses given by New Zealand-born respondents to this question, we discover that only three answered that the question was 'not applicable', the remaining 32 respondents answered the question. Thus we can assume that $91 \%$ of the New Zealand-born respondents were married.

In summary, if the responses to the question about marriage in the long questionnaire are used, it can be said that

- $89 \%$ of all respondents were married

- $91 \%$ of New Zealand-born respondents were married.

Using the responses to the question about language/s spoken with spouse/partner it can be inferred that

- $90 \%$ of all respondents were married

- $91 \%$ of New Zealand-born respondents were married.

The two sets of responses are consistent with each other, suggesting that we can be confident that each is a fairly accurate measure and that the great majority of respondents were married. As has been discussed, the nature of the questionnaire and the mailout encouraged responses from married respondents with children. Amongst the 141 respondents were 30 respondents ( 15 couples) who were married to another respondent.

The other question to be discussed under the heading of marriage is the ethnicity of the respondent's spouse. Respondents were asked what language/s their spouse could speak. If Gujarati was one of those languages then it was assumed that the partner was of Gujarati ethnicity. Because this question was not asked in the short questionnaire, there is data from 115 respondents. One hundred and two respondents out of 115 were married; 99 (97\%) were married to a Gujarati speaker ${ }^{42}$. The 33 interviewees were specifically asked the ethnicity of their spouse (or, if the spouse was present his/her ethnicity was noted by me). Thirty-two interviewees were married, 31 of them to an Gujarati spouse.

42 In fact three respondents answered this question even though their spouses were deceased. This gives a total of 105 'married' responses 102 of which indicated that their spouse spoke Gujarati. 


\subsubsection{Children of respondents to the questionnaire}

Most respondents did have children. Out of 141 respondents of Gujarati extraction

- $133(94 \%)$ had children ${ }^{43}$

- $8(6 \%)$ did not have any children.

Of the New Zealand-born respondents

- 32 out of $35(91 \%)$ of the respondents had children.

It is interesting to note, that although there are sometimes marked differences between the responses of the New Zealand-born respondents and those of the sample as whole (e.g. proportion of male and female respondents), in the two areas of marriage and children, the situation of the New Zealand-born respondents is virtually identical to that of the sample as a whole. This may, of course, be due simply to the subject matter of the questionnaire.

\subsubsection{Family structure}

The structure of a respondent's household was determined from the answer/s to the question 'Who are other members of your household?'. This question was not asked in the short questionnaire. Taking into account the couples who answered the questionnaire there were 115 respondents living in 100 households. Fifty-two households were made up of a nuclear family with spouses and child/ren. Another 19 households consisted of spouse and children and others (usually other family members). Ten households consisted of the respondent their children and other family members but no spouse.

Table 7-4: Composition of Gujarati respondents' households

\begin{tabular}{|l|l|}
\hline Members of Respondent's Household & No. of households \\
\hline Spouse, children & 52 \\
Spouse, children, others (mainly relatives) & 19 \\
Children, family member/s & 10 \\
Spouse only & 5 \\
Children only & 5 \\
Spouse and/or family members & 4 \\
No response & 3 \\
Live alone & 2 \\
N= & 100 \\
\hline
\end{tabular}

4.3 Two respondents gave NR to the question about how many children they had, but listed the languages they spoke with their children at q. 10. They were counted as having children and are included in the total of 133 respondents with children. 
A tiny majority of respondents were living in two-generation nuclear families. Slightly over a quarter $(28 \%)$ were living with their children in some kind of extended family where there were generally three generations living in the household ${ }^{44}$. The remaining $20 \%$ lived in households of varying compositions.

\subsubsection{Education background of respondents}

\subsubsection{Where educated}

Table 7-5: Countries in which the respondents were educated

\begin{tabular}{|lll|}
\hline No. & $\%$ & Place of Education \\
\hline 38 & $33 \%$ & educated entirely in India \\
40 & $35 \%$ & educated entirely in New Zealand \\
8 & $7 \%$ & received tertiary education in New Zealand after education in India \\
10 & $9 \%$ & continued their education in New Zealand from 12+ (inclusive of 12) \\
5 & $4 \%$ & continued their education New Zealand at 12- \\
2 & $1.5 \%$ & educated entirely outside New Zealand or India (Fiji, Tanzania) \\
3 & $3 \%$ & educated in India and elsewhere (Tanzania, Uganda, East Africa) \\
1 & $1 \%$ & educated in Fiji, New Zealand \\
5 & $4 \%$ & unclear \\
2 & $1.5 \%$ & educated mainly in NZ but attended school in India on family visits \\
1 & $1 \%$ & Never attended school \\
TOTAL 115 & & \\
\hline
\end{tabular}

About one third of the respondents were educated entirely in India, slightly more than a third were educated entirely in New Zealand. Of the remaining third, a handful were educated outside New Zealand and India, or in India or New Zealand and another country. Twenty per cent were educated in both India and New Zealand, in most cases starting their education in India and entering the New Zealand education system at primary (4\%), secondary (9\%) or tertiary (7\%) level. Two respondents specifically noted that although they had been educated almost completely in New Zealand, they had attended school in Gujarati while the family had been making a visit to India. There may be other respondents of whom this is also true but who did not enter it on the questionnaire for fear of confusing the issue. Certainly amongst the

\footnotetext{
${ }^{44}$ Among the ten households that were recorded as consisting of respondent, respondent's children and family members are five where the respondent answered the question (Q.6) "who are the other members of your household?' by ticking father, mother, children. It is not possible to know whether the respondents intended to indicate that their households consisted of themselves, their parents and their children, or whether the respondents intended to indicate that their households were consisted of a nuclear family made up of mother father and children.
} 
interviewees, there were several who mentioned that their children had attended school in Gujarat while on family visits. This has obviously been a strand in the process of Gujarati language maintenance in New Zealand. One mother whom I interviewed, pointed out that not only had her daughter had a chance to attend school in Gujarat whilst on a visit, thus strengthening her Gujarati, but that she had taken photographs and written letters to be published in her school magazine in New Zealand, thus broadening her New Zealand classmates' knowledge of the Gujarati community.

\subsubsection{Level of education completed}

University education was taken as the highest level of education. Respondents who recorded both (for example) teacher training and university education were treated as though the university qualification was their highest qualification. Thus more than one respondent completed teacher training, but only one respondent completed teacher training and did not complete university. She is the only respondent to show up in the table below as having done teacher training. If (as many respondents did) a respondent entered that they had completed both polytechnic and an apprenticeship, the apprenticeship has been taken as the highest qualification.

These figures are compared with those in Ethnic Groups in New Zealand: A Statistical Profile (Thomson: 1993). The categories employed by Thomson are slightly different from those used here. For purposes of comparison Thomson's categories have been collapsed as follows 
Table 7-6: Thomson's educational level categories compared with Roberts'

\begin{tabular}{|l|l|}
\hline Thomson & Roberts \\
\hline $\begin{array}{l}\text { Postgraduate } \\
\text { Undergraduate }\end{array}$ & Completed university \\
Technician & \\
Teacher/Nurse & \\
Trade C & Other tertiary \\
Other tertiary & \\
Higher School & \\
UE or Sixth & \\
School C & Completed secondary education
\end{tabular}

(Thomson 1993:78)

Table 7-7: respondents: level of education attained

\begin{tabular}{|rlll|}
\hline No. & Level of education & subtotal & total \\
\hline 38 & completed university education & & $=33 \%$ \\
43 & completed secondary education & & $=37 \%$ \\
15 & completed polytechnic & $=13 \%$ & \\
6 & completed apprenticeship & $=5 \%$ & \\
1 & completed teacher training & $=1 \%$ & \\
1 & completed library school & $=1 \%$ & \\
Other tertiary & & \\
6 & completed primary & $=5 \%$ & \\
1 & Never attended school & $=1 \%$ & \\
No Qualifications & $=$ & $4 \%$ \\
4 & Unclear/No response & & \\
115 & GRAND TOTAL & & \\
\end{tabular}

${ }^{4.5}$ It should be noted that respondents were not asked what secondary qualifications they had gained; merely what level of education they had completed. It is possible of course that a respondent who had not gained any secondary qualifications could regard themselves as having 'completed' secondary school. Thus there may be 
Table 7-8: Highest level of education attained by all respondents to the survey compared with level of education attained by all Indian respondents to 1991 census (Thomson 1991:78)

\begin{tabular}{|l|c|c|}
\hline & Gujarati Respondents & Indian Respondents to 1991 Census \\
\hline completed uni education & $33 \%$ & $16.5 \%$ \\
completed secondary education & $37 \%$ & $34.5 \%$ \\
Other tertiary & $20 \%$ & $25 \%$ \\
No Qualifications & $6 \%$ & $20.5 \%$ \\
Unclear/No response & $4 \%$ & $2.5 \% 46$ \\
\hline
\end{tabular}

Table 7-9: Highest level of education attained by male and female respondents to the survey compared with level of education attained by male and female Indian respondents to 1991 census (Thomson 1991:78)

\begin{tabular}{|l|c|c|c|c|}
\hline Level of Education & $\begin{array}{c}\text { Gujarati Men } \\
\%\end{array}$ & $\begin{array}{c}\text { Indian Men } \\
\%\end{array}$ & $\begin{array}{c}\text { Gujarati Women } \\
\%\end{array}$ & $\begin{array}{c}\text { Indian Women } \\
\%\end{array}$ \\
\hline University & 43.4 & 20 & 22 & 13 \\
Secondary & 28.3 & 32 & 45 & 37 \\
Other Tertiary & 20 & 27 & 20 & 23 \\
Primary & 3.3 & 17 & 11 & 24 \\
NR/Unclear & 5 & $3^{47}$ & 2 & $2^{48}$ \\
\hline
\end{tabular}

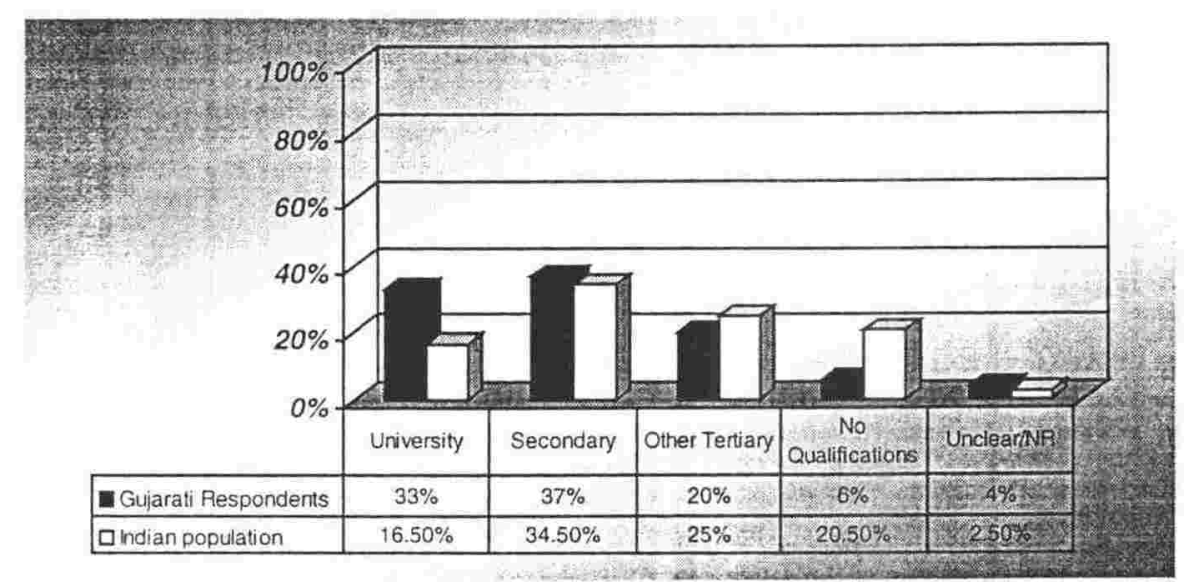

Figure 7-1: Highest level of education attained by all respondents to the survey compared with level of education attained by all Indian respondents to 1991 Census (Thomson 1991:78)

some respondents in this category who, would, in Thomson's classification be included in the category of 'no qualifications.

\footnotetext{
${ }^{46}$ Total $=99$ ('Still at school' not included)

${ }^{47}$ Total $=99$ ('Still at school' not included)

${ }^{48}$ Total $=99$ ('Still at school' not included)
} 
The striking difference between the survey respondents and the Census respondents is the greater proportion of university educated respondents in the survey and the concomitantly smaller proportion of survey respondents with no qualifications. This fits in with the previously noted observation that people with a higher level of education are more likely to respond to postal questionnaires (Leong 1980:4,18). It should be noted that the proportions of those with a secondary education or an 'other tertiary' qualification are roughly similar in both groups.

\subsubsection{Summary}

The bulk of the Gujarati population surveyed was Gujarat-born. A quarter of them were born in New Zealand and the remainder in a variety of other places. Slightly more men than women responded to the questionnaire and most respondents were between 31 and 60 years of age. Almost all the respondents were married to a Gujarati-speaking spouse and there are 15 couples amongst the respondents. A majority of the respondents have children and a small majority live in a two generation nuclear family. A third of the respondents were educated entirely in India, just over a third entirely in New Zealand and the remainder were educated in more than one country. On average, the Gujarati respondents have a higher level of education than the Indian population in New Zealand. A third have completed a university education.

\subsection{Gujarati community: patterns of language use}

This section gives an overview of the patterns of language use in the community. The Gujarati community in Wellington values the Gujarati language and certain aspects of Indian culture highly. Because of continued chain migration from the Nausari area and because of the very common practice of New Zealand-born Gujarati people being married to Gujarat-born partners there has been a high rate of linguistic continuity. Not only have MT Gujarati speakers continued to enter the community but they have also been scattered about among the English dominant speakers rather than forming new arrivals' enclaves of their own.

\subsubsection{First language spoken by respondents as children}

The strong place of Gujarati in the community is clear. One hundred and twenty-two of the respondents spoke Gujarati as a first language; another seven indicated that Gujarati and Hindi or Gujarati and English were their concurrent first languages. Only 11 respondents spoke English first. Even when we look at the 35 New Zealand-born respondents we still find that 24 of them spoke Gujarati first. 
Table 7-10: First language/s spoken. By Birthplace

\begin{tabular}{|c|c|c|c|c|c|}
\hline Birthplace & Spoke Guj 1st & Spoke Eng 1st & Spoke Guj/Eng 1st & Spoke Guj/Hind 1st & N= \\
\hline Gujarat & 87 & 2 & 1 & 3 & 94 \\
NZ & 24 & 9 & 2 & 0 & 35 \\
Other & 11 & 0 & 1 & 0 & $12^{49}$ \\
Total Guj Resp & 123 & 11 & 4 & 3 & $141^{50}$ \\
\hline
\end{tabular}

\subsubsection{Languages most used by respondents}

Turning to respondents' current day-to-day usage, the picture alters somewhat. A small majority of people use English most in their daily lives, but there is still a large number of people who use Gujarati most (see Figure 7-2). Some people considered that they used the two languages equally and their usage is recorded under 'both'. It can be seen, however, that the New Zealand-born respondents use comparatively little Gujarati. None of the New Zealand-born respondents used Gujarati more than English and only five of the 35 considered that they used the two languages equally.

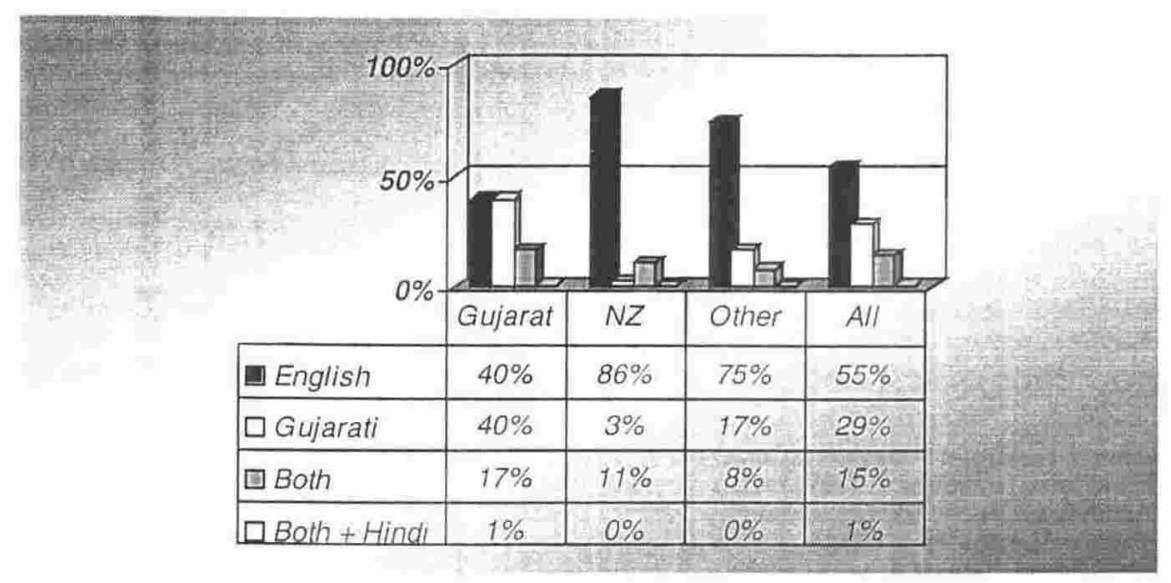

Figure 7-2: Most used language/s: by birthplace

\subsubsection{Linguistic background of respondents}

One of the noticeable features of this community is that it is not a bilingual community but a multilingual one [see Figure 7-3]. Almost half the respondents are trilingual and a handful are quadrilingual. For most people their third language is Hindi. 


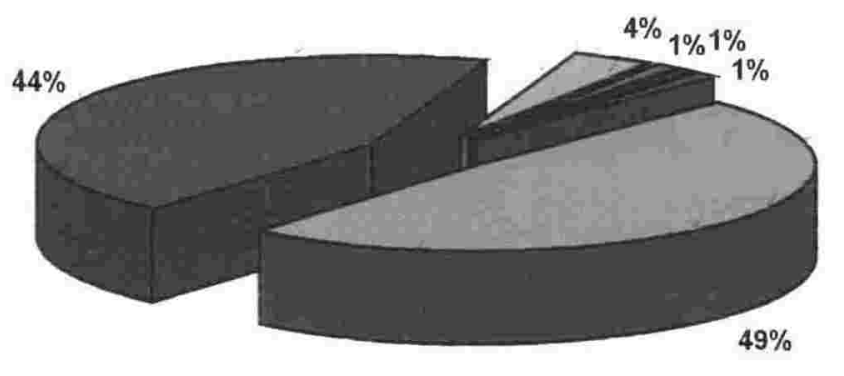

Figure 7-3: All Gujarati Respondents by Languages spoken

The Indian born respondents are more likely to be multilingual than the New Zealand-born, as they are more likely to speak Hindi $(57 \%)$ but this is not an absolute correlation, $17 \%$ of the New Zealand-born respondents speak Hindi, although none is very fluent. Altogether 20\% of the New Zealand-born respondents spoke three or more languages.

\subsubsection{Language use in the last month}

Respondents were also asked not only which languages they spoke, but also which languages they had actually used in the last month prior to filling out the questionnaire or being interviewed. On the basis of these patterns of language use, the community still appears as multilingual. Only a tiny proportion of respondents were monolingual in their language usage.

- $7.8 \%$ (11 out of 141 ) respondents declared themselves to have used only one language in the last month. All these respondents were born in Gujarat.

- Three of them (two men, one woman; age range 31 - 45) reported that they had spoken only English in the last month.

- The eight who reported that they had spoken only Gujarati were mainly from an older age group. Six of them (three men, three women) were over 60 . The other two men were in the age range 41-45.

A substantial majority had spoken two languages in the preceding month and some had used three.

- 129 respondents (91.4\% of all respondents) had spoken Gujarati and English in the month before filling out the questionnaire.

- 113 (80.1\% of all respondents) had spoken only in those two languages and

- $11.3 \%$ (of all respondents) had spoken at least three languages in the last month. In most cases the other language was Hindi but in one case the third language was Maori and in another the respondent had used Gujarati, English, Hindi and Sanscrit in the last month. 


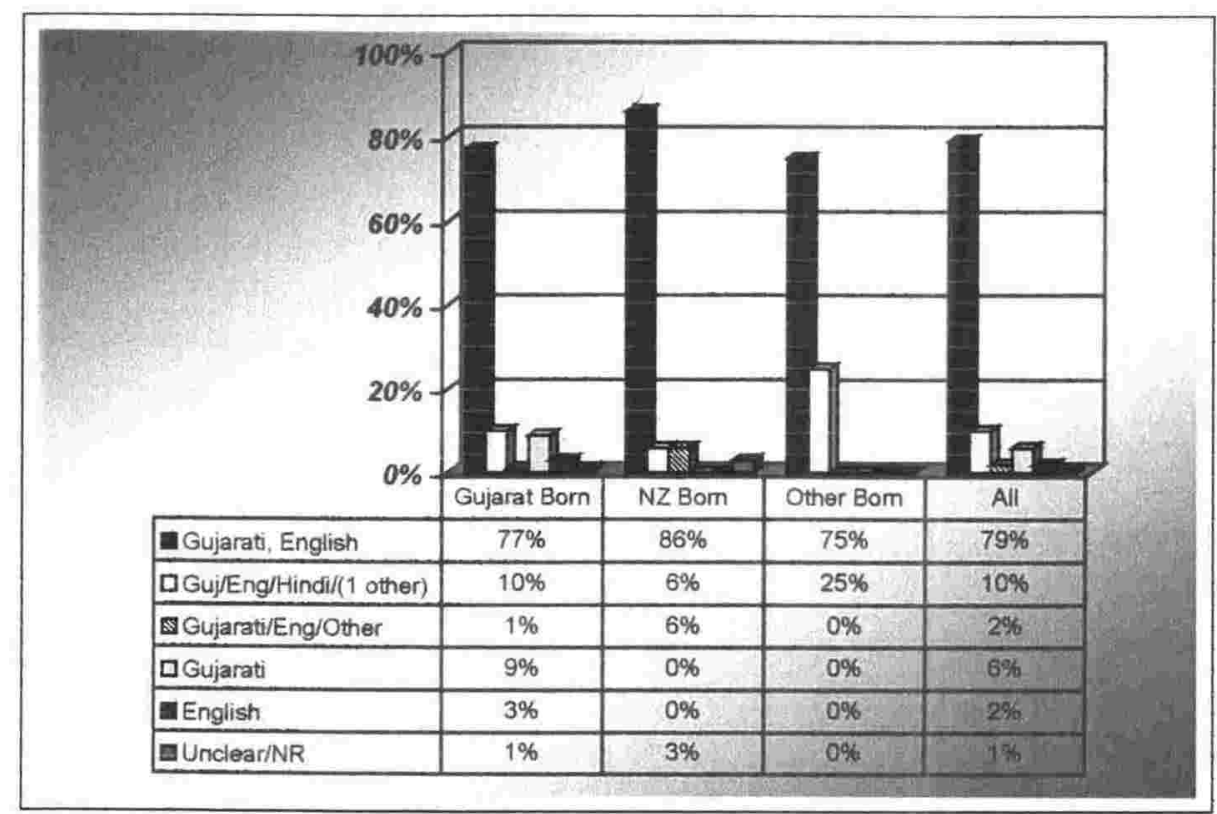

Figure 7-4: Languages spoken by respondents within the month preceding the questionnaire. Shown as percentages by birthplace

\subsubsection{Language use in the home}

\subsubsection{General language use in the home}

Most people (65.9\%) indicated that they used both Gujarati and English at home (see Figure 7-5). This did not necessarily mean that a respondent was using both languages to all interlocutors. A respondent might, for instance, speak mainly Gujarati with her husband and mainly English with her children. Respondents were asked which language they spoke 'MOST of the time' to their spouse and children (see Appendix 1).

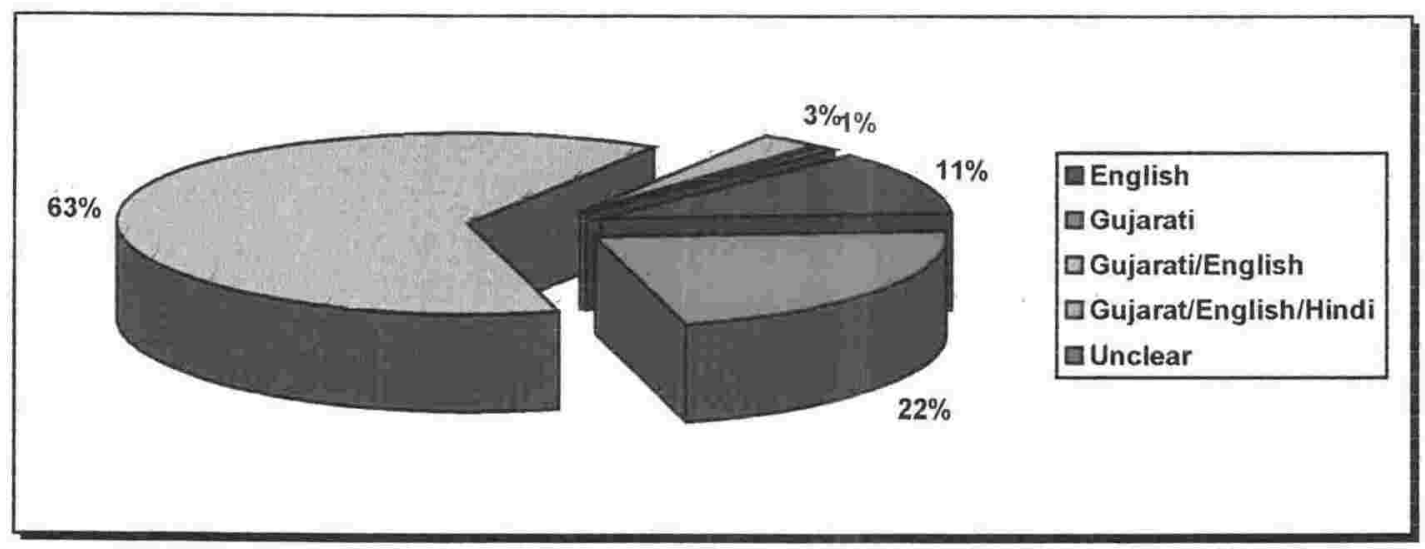

Figure 7-5 Language/s Spoken in the home by Respondents 


\subsubsection{With spouse}

Most respondents spoke Gujarati most of the time with their spouse.

- $48 \%$ (of the 129 respondents who were living with a spouse) considered that, most of the time, they spoke Gujarati to their spouse.

- $33.3 \%$ responded that English was the language they used most with their spouse

- $13.9 \%$, a small minority, considered that they spoke a fairly even mixture of the two languages

There was older one respondent who spoke Gujarati, Hindi and English at home to his spouse.

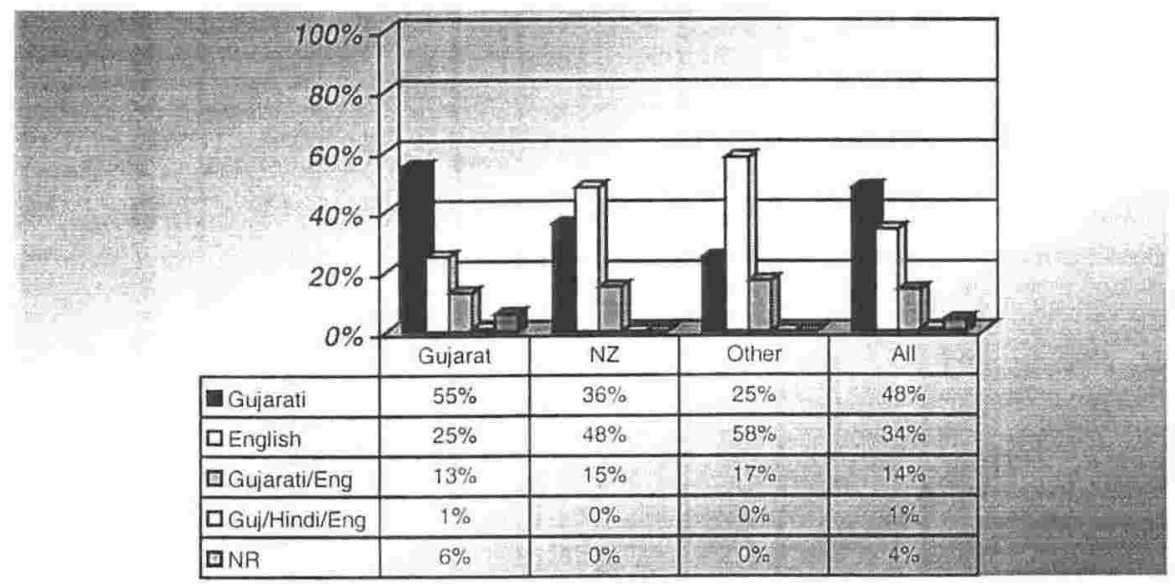

Figure 7-6: Languages that respondents spoke to their spouses. Percentages by birthplace

\subsubsection{With children}

With the children the situation was, to some extent, reversed.

- the single largest group of respondents (42.1\%) used English most of the time with their children

- a large minority (28.6\%) used mainly Gujarati

- a substantial minority of respondents answered that they used both languages fairly equally with their children, considerably more than had chosen that answer for the question regarding language used with their spouse $(27.1 \%$ compared to 13.9\%. See Figure 7-6 and Figure 7-7) 


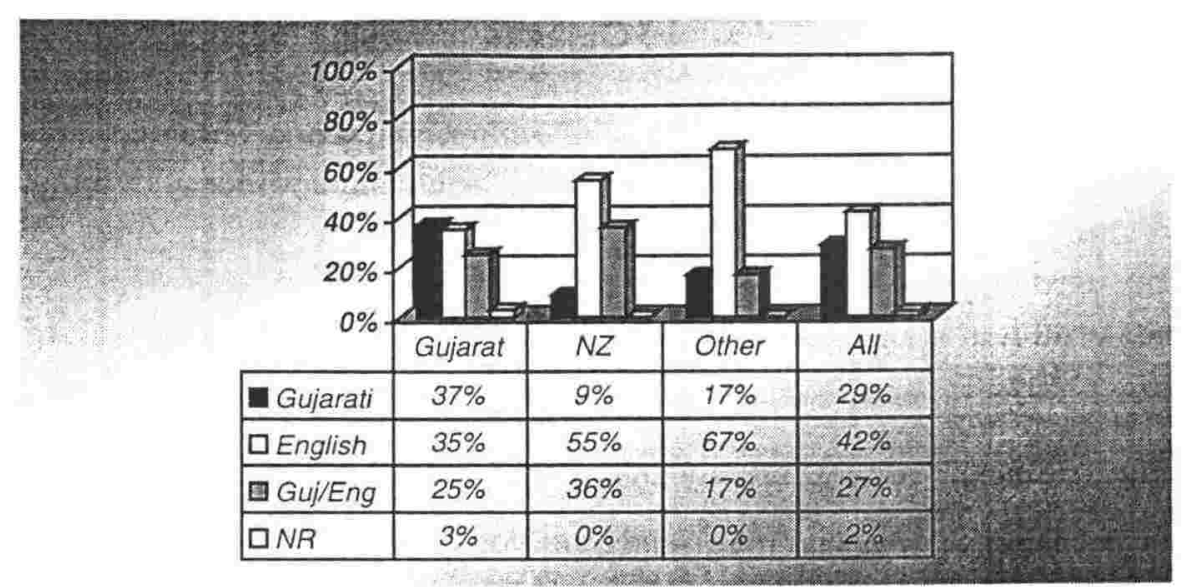

Figure 7-7: Languages that respondents spoke to their children. Percentages by birthplace

Overall the answers tend to show that the home is a major site of Gujarati use but that English is steadily encroaching. If we look at the New Zealand-born respondents we can see that English usage in the home is steadily increasing in the homes of the New Zealand-born members of the community [Figure 7-6 and Figure 7-7] and it seems likely that such a pattern will continue.

\subsubsection{Language use outside the home}

Most respondents still have occasion to speak Gujarati outside their home but for many people Gujarati is only used in situations where all or most of the participants or onlookers are Indian. Respondents were asked to indicate if they spoke Gujarati at social gatherings, at work or at Gita class. Gita class was established in Wellington in 1926 (Kasanji 1982: 54-55). It is not like 'church' in the Christian understanding of the word but readings of religious texts are conducted by members of the class. According to Kasanji (1982: 83), most Hindu religious worship in Wellington actually takes place at home. Certainly many of the homes I visited contained small shrines set up in the main room and one, at least, had a small room dedicated as a place of worship.

\subsubsection{Where Gujarati was spoken outside the home}

- $136(96.5 \%)$ respondents stated that they spoke Gujarati outside the home.

- 4 respondents ${ }^{51}$ said that they did not use Gujarati outside the home (all born in Gujarat and all used Gujarati at home)

- $53(37.6 \%)$ of respondents used Gujarati only at Indian social gatherings.

\footnotetext{
${ }^{51}$ One respondent did not reply to this question.
} 
- Only one respondent replied that s/he spoke Gujarati 'anywhere' outside the home (another wrote 'when I see them')

- 10 respondents ticked all three categories 'social gatherings, work, Gita class'.

One of this group also used Gujarati in teaching raja yoga and another added that she also used Gujarati on the sports-field and at fund-raisers.

- 29 respondents used Gujarati only at social gatherings and at Gita class

- 14 respondents used it at social gatherings and at work, with four of them adding other occasions to the list

The remaining respondents to this question generally noted that they used Gujarati at social gatherings and at one other occasion; sports, visiting friends, raj yoga, bajans were all mentioned in this context. There was an 'other (please specify)' category for this question and it is worth mentioning that the single largest category specifically written in by respondents was that of 'visiting' - just visiting on its own or visiting friends relatives or parents. Thirteen respondents $(9.2 \%)$ added 'visiting' as an occasion on which they spoke Gujarati.

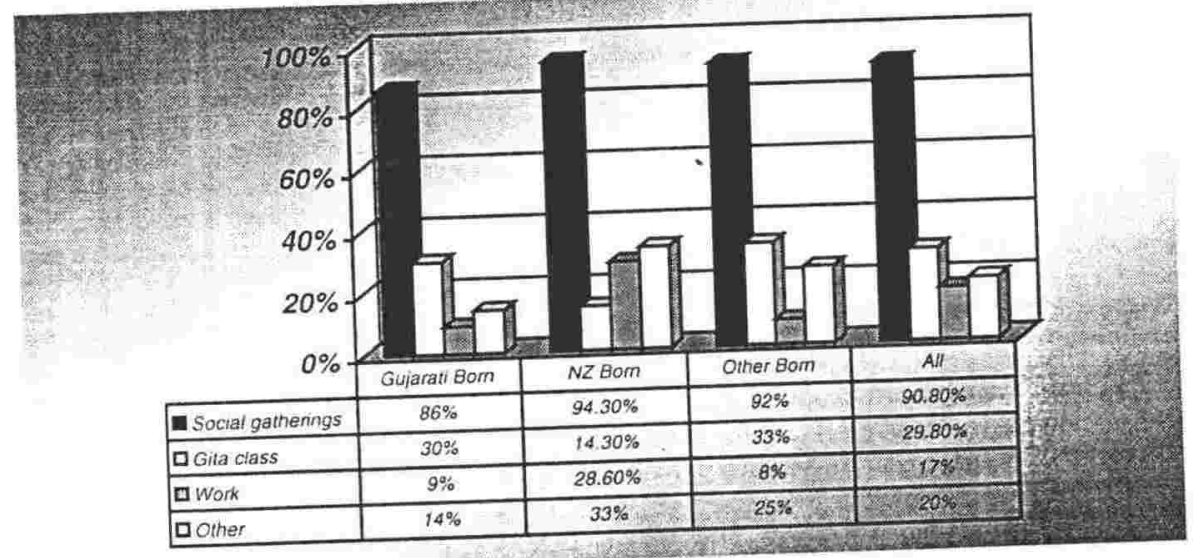

Figure 7-8: Where Gujarati was spoken. By birthplace

It is interesting to note that it is the New Zealand-born respondents who say they are most likely to use Gujarati at work. Their jobs were:

- administration manager

- medical receptionist

- managing director

- self-employed manager

- teacher

- baker \& landowner \& printer

- legal executive

- bank officer (2)

- semi-retired

The teacher had taught Gujarati classes at the primary school where she worked. It seems likely that the bank officers, medical receptionist and legal executive might sometimes be called upon 
to speak Gujarati with a Gujarati client. The same may well be true of the self-employed manager, and the baker-landowner-printer might well work with Gujarati speakers. The reason for comparatively fewer Gujarati-born respondents speaking Gujarati at work may, of course, be that more of them were retired.

It is also noticeable that Gita class was a comparatively important site of Gujarati use for the Gujarati-born and Other-born respondents (35\% and 33\% respectively) but less important for the New Zealand-born (14\%). Overall however, social gatherings are certainly the most important site for Gujarati use outside the home.

\subsubsection{Gujarati speaking interlocutors; outside the home}

When we examine respondents' interlocutors we see that Gujarati is not yet addressed only to those who have no alternative, but it is moving in that direction. Respondents were asked to indicate if they spoke Gujarati to friends their own age, older friends, older relatives, young children other than their own, the priest or new immigrants. They were also asked to indicate other people to whom they might speak Gujarati.

- $25(18 \%)$ respondents only speak Gujarati outside the home with people who are older than they are or with new immigrants. The assumption here is that these respondents are confining their Gujarati use to interaction with those who cannot readily function in English; most of these respondents (11 of 15) were between 26 and 40 years old.

- A large majority of people ( $72 \%$ of all respondents) who did use Gujarati outside the home included 'friends my own age' in the list of interlocutors, suggesting that there is still generally widespread bilingualism within the community.

However there were some signs of declining use of Gujarati.

- Among the 35 New Zealand-born respondents only $42 \%$ indicated that they spoke Gujarati with friends their own age.

- Only 56 respondents (40\%) used Gujarati outside the home with children other than their own. While this is still a substantial number it does indicate that Gujarati use is beginning to be curtailed and that many people do not find it a suitable medium for interaction with all community members. 


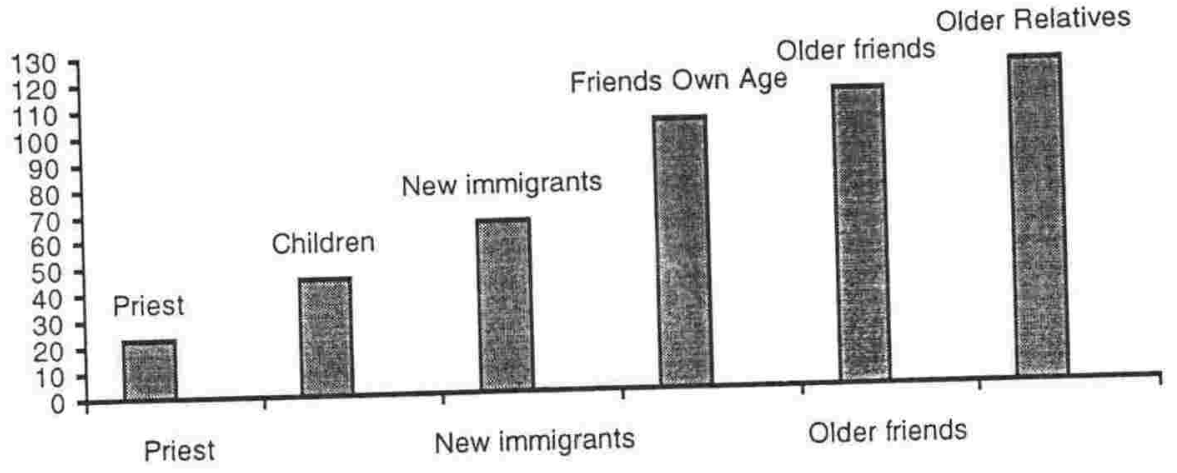

Figure 7-9: Interlocutors to whom respondents spoke Gujarati (in numbers not percentages)

It is clear that older friends and older relatives are the largest groups of interlocutors. The 'other' category was very small for this question, perhaps indicative of the shrinking range of Gujarati interlocutors. The "other" responses were; in teaching raj yoga, with Indian patients at the hospital, teaching Gujarati at primary school, with people who find it easier to speak Gujarati, and with the Indian community. This last was really the only response which seemed to indicate a sense of Gujarati being used anywhere and everywhere with anyone.

\subsubsection{Summary: language profile}

Overall we have a picture of a society composed of a generally harmonious mixture of New Zealand and Indian born members where Gujarati speaking ability is still valued highly but where there are clear signs of English encroaching into domains formerly reserved for the MT

\subsection{Language Proficiency}

\subsubsection{Self-reporting of proficiency}

The respondents were all asked to rate their level of language ability in Gujarati, English and Hindi. The general problems of self-report proficiency measures have been discussed in the methodology section. Discussed below are some of the specific problems that arose in looking at the responses of the Gujarati respondents, followed by an analysis of their responses to the proficiency questions. 


\subsubsection{Possible under-reporting of proficiency}

In the case of the Gujarati respondents it would seem that being asked about three languages in some ways prevented under-reporting. If you speak Gujarati, Hindi and English at differing levels of proficiency, and you are aware of these different levels, and you have only a five point scale (the bottom two points of which are comprehension only and no ability) then you really have to put your 'best' language at level one if you are going to indicate that it is the language in which you are going to function most easily (of course you may speak more than one language fluently and some respondents indicated this in their replies). Somewhat over a quarter of respondents (27.6\%) assessed their fluency in the three languages using a different level of assessment for each language. This certainly suggests that respondents were doing more than unthinkingly or mechanically assessing their abilities in all three languages as being at the same level. Only five of the 141 respondents (3.5\%) did not describe themselves as fluent in any language. These five were equally reluctant to give themselves a "can write easily' rating for the literacy proficiency question. Four of the respondents were male (three born in Gujarat, one in New Zealand) and one was a Gujarat-born female. The New Zealandborn man was in the 41- 45 age group, the others were all over 46 years of age.

In reporting proficiency in literacy skills, ten respondents (7\%) reported that they could not 'write easily' in any language. Five of these ten were the five who reported that they were not fluent in any language. Of the other five, one was illiterate in any language and the person who filled out her questionnaire for her indicated this (this respondent was a Gujarat-born woman of over 60 who speaks Gujarati fluently and a little English), three (two men, one woman) were Gujarat-born and fluent in Gujarati and one was a Gujarat-born man who came to New Zealand under ten years of age and who considered himself to be fluent in English. It seems reasonable to consider that the five respondents who report themselves as not fluent in any language and as unable to write easily in any language were under-reporting their true abilities. There seems however to be no reason to consider that the five who report themselves as fluent speakers of at least one of the three languages are necessarily under-reporting their literacy abilities. Possibly none of them is highly literate in any language.

\subsubsection{Possible over-reporting of proficiency}

Nine respondents $(6 \%)$ recorded that they were fluent in and could write easily in all three languages. All of these respondents were born outside New Zealand, seven were born in Gujarat, two in Africa. Seven of the nine were male, two female. There seems to be no 
particular reason to regard this as over-reporting. In a sample where so many of the respondents are trilingual, it is reasonable that $9 \%$ of the sample should be highly skilled in all three languages.

\subsubsection{No Response to proficiency question}

Apart from the question of accuracy in reporting language ability there is also the question of what to do with 'no response' returns. This is a problematic point because so many 'no response' returns occurred for these two questions (about oral and written proficiency levels in the three languages).

Six respondents (4\%) did not enter a response to any of the questions about oral language proficiency. There is no obvious reason for this. Five of the six were New Zealand-born (three women, two men) the sixth was a Gujarat-born woman. They were all comparatively young ( $31-40)$, they all filled out the questions about literacy; the five New Zealand-born could all write easily in English and one of them could write 'fairly easily' in Gujarati (the other four could not read or write in Gujarati); the Gujarat-born respondent could write 'easily' in Gujarati. Given the disproportionate number of New Zealand-born, it is possible that these respondents did not fill out the oral proficiency section because they were disinclined to indicate how poor their Gujarati actually was. All these respondents said in answer to question 1 that Gujarati was one of the languages that they spoke. Perhaps they were then embarrassed to record just how poorly they spoke it. However, it is not really possible to know why this small group of respondents did not respond to this question.

All respondents answered at least one of the questions about literacy proficiency. I would propose that in most cases, apart from the six who did not answer any of question 21 (oral proficiency), a 'no response' answer is equivalent to 'can't read or write' the language - or, more accurately as some respondents ticked (for example) 'can't read or write' for Gujarati but gave 'no response' for Hindi - it is equivalent to something like "there is no reason why I should be able to speak/understand/read/write this language". This is how most of the "no response' answers will be regarded. The answers (or lack thereof) provided by the six who skipped all of question 21 will be entered as 'skipped'. A few of the other 'no response' answers will be treated differently, taking into account answers from other sections of the questionnaire. These answers will be discussed as they become relevant. 


\subsubsection{Not fluent in any language}

It was not obvious what should be done about the respondents who did not rate themselves as 'fluent' in any language. It seems in some way misleading to include their responses of 'fairly fluent' with the other 'fairly fluent' responses as there is a difference between the value of 'fairly fluent' when it is the best rating a respondent gives themselves and 'fairly fluent' when a respondent rates themselves 'fluent' in another language. In the end it was decided to let the entries stand as respondents had recorded them. There were two main reasons for this. In the first place it was not possible to decide (if respondents had recorded themselves as 'fairly fluent' in two languages) on what principle to choose the language for which they should, as it were, be promoted to 'fluent'. In the second, looking at the age, and immigration histories of the respondents, it seemed that their answers might reflect not so much an under-reporting caused by modesty, but rather a genuine feeling, whether true or not, that they no longer spoke Gujarati 'fluently' but that their English was also not 'fluent'.

\subsubsection{Oral proficiency}

\subsubsection{Gujarati: see Table 7-11}

A substantial majority (73.8\%) of respondents considered themselves to be 'fluent' in oral Gujarati. Of the Gujarat-born $85.1 \%$ considered themselves to be 'fluent' and all of the 12 respondents born in places other than Gujarat or New Zealand considered themselves to be 'fluent' speakers of Gujarati. No respondent claimed to be unable to speak or understand Gujarati and only one respondent considered that he could understand but not speak the language. The place of Gujarati within the community would appear to be strong. When we turn to the New Zealand-born respondents this strength is still evident, but perhaps it is beginning to wane. Only slightly over a third of the $35 \mathrm{New}$ Zealand-born respondents (34.3\%) thought that they were fluent in Gujarati. More thought that they were fairly fluent (42.9\%) and five of them skipped the question on oral proficiency altogether. 
Table 7-11: Proficiency in oral Gujarati: \%

\begin{tabular}{|l|c|c|c|c|c|c|c|}
\hline Birthplace & Fluent & Fairly Fluent & Not Very Fluent & Comp. Only & Unclear & Skipped & $\mathbf{N}=$ \\
\hline Gujarat & 85.1 & 7.4 & 4.3 & 1.1 & 1.1 & 1.1 & 94 \\
N.Z. & 34.3 & 42.9 & 8.6 & 0 & 0 & 14.3 & 35 \\
Other & 100 & 0 & 0 & 0 & 0 & 0 & 12 \\
& & & & & & & \\
All & 73.8 & 15.6 & 5 & 0.7 & 0.7 & 4.3 & 141 \\
N= & 104 & 22 & 7 & 1 & 1 & 6 & 141 \\
\hline
\end{tabular}

\subsubsection{English: See Table 7-12}

Most respondents thought that they were 'fluent' or 'fairly fluent' in English. Overall, slightly over half $(54.6 \%)$ thought that they were 'fluent' and another $26.6 \%$ thought that they were 'fairly fluent'. Somewhat under half $(43.6 \%)$ of the Gujarat-born and two thirds of the otherborn $(66.7 \%)$ thought that they were 'fluent' in English. Only 80\% of the New Zealand-born are recorded as being 'fluent' in English but this is largely because five of the New Zealandborn respondents skipped this question. One Gujarat-born respondent claimed only comprehension skills in English and another four Gujarat-born respondents gave no response to the English oral proficiency question. Three of these four received help to fill out the form, two of them recorded at question 1 that they could not speak English. These three also gave no response to the question about English literacy skills. It seems likely that in their case their English was extremely limited or non-existent. The two men were both over sixty and the one woman was in the 56-60 age group. The fourth respondent to enter 'no response' to this question speaks English and can write it easily. Her 'no response' entry appears to be an oversight. A small number of the sample recorded themselves as 'not very fluent' in English; $11.3 \%$ overall and $16 \%$ of the Gujarat-born answered in this way. This pattern of English proficiency shows that there is still plenty of occasion for Gujarati use in the community. It is not possible to assume that any Gujarati person you meet is necessarily a fluent speaker of English. In fact it is more likely, based on this survey, that they will be a fluent speaker of Gujarati. 
Table 7-12: Proficiency in oral English \%

\begin{tabular}{|l|c|c|c|c|c|c|c|}
\hline Birthplace & Fluent & $\begin{array}{c}\text { Fairly } \\
\text { Fluent }\end{array}$ & $\begin{array}{c}\text { Not Very } \\
\text { Fluent }\end{array}$ & Comp. Only & NR & Skipped & N= \\
\hline Gujarat & 43.6 & 34 & 16 & 1.1 & 4.3 & 1.1 & 94 \\
N.Z. & 80 & 5.7 & 0 & 0 & 0 & 14.3 & 35 \\
Other & 66.7 & 25 & 8.3 & 0 & 0 & 0 & 12 \\
All Respondents & 54.6 & 26.2 & 11.3 & 0.7 & 2.8 & 4.3 & 141 \\
N= & 77 & 37 & 16 & 1 & 4 & 6 & 141 \\
\hline
\end{tabular}

\subsubsection{Hindi: See Table 7-13}

When we turn to Hindi we see a change occurring in the linguistic composition of the community: a split appears along lines indicated by a respondent's place of birth. Almost a fifth $(19.9 \%)$ of the respondents were 'fluent' in Hindi but none of them was born in New Zealand. None of the New Zealand-born respondents considered themselves to be 'fairly fluent' in Hindi either. It is not until we come to 'not very fluent' that $5.7 \%$ of the New Zealand-born respondents show up in the responses. The single largest number of New Zealand-born respondents (37.1\%) consider themselves to have comprehension skills only in Hindi. Another $28.6 \%$ say that they 'can't speak or understand' Hindi and another $14.3 \%$ entered no response. None of these eight respondents can speak Hindi and they all entered no response for the question about literacy skills in Hindi. I am assuming that they in fact have no skills in Hindi, so that $42.9 \%$ of the New Zealand-born have no skills in Hindi at all.

Amongst the Gujarat-born however $65.9 \%$ of the respondents rated themselves as 'not very fluent' to 'fluent'. And all of the twelve respondents born elsewhere than New Zealand and Gujarat rated themselves in these three categories. Half of them rated themselves as 'fluent'. Hindi has not been much used in New Zealand. It is a second language for many Gujarati speakers in India, one that is learnt and used outside the home in India. It is rarely used inside the home in New Zealand (only one couple in this survey ever spoke it at home). Not surprisingly, Hindi has not been handed on to many of the New Zealand-born Gujarati community. 
Table 7-13: Proficiency in oral Hindi: $\%$

\begin{tabular}{|l|c|c|c|c|c|c|c|c|}
\hline Birthplace & Fluent & $\begin{array}{c}\text { Fairly } \\
\text { Fluent }\end{array}$ & $\begin{array}{c}\text { Not Very } \\
\text { Fluent }\end{array}$ & $\begin{array}{c}\text { Comp. } \\
\text { Only }\end{array}$ & $\begin{array}{c}\text { No } \\
\text { Ability }\end{array}$ & NR & Skipped & N= \\
\hline Gujarat & 23.4 & 22.3 & 20.2 & 14.9 & 6.4 & 11.7 & 1.1 & 94 \\
N.Z. & 0 & 0 & 5.7 & 37.1 & 28.6 & 14.3 & 14.3 & 35 \\
Other & 50 & 8.3 & 41.7 & 0 & 0 & 0 & 0 & 12 \\
All Respondents & 19.9 & 15.6 & 18.4 & 19.1 & 11.3 & 11.3 & 4.3 & 141 \\
N= & 28 & 22 & 26 & 27 & 12 & 20 & 6 & 141 \\
\hline
\end{tabular}

\subsubsection{Written proficiency}

\subsubsection{Gujarati: see Table 7-14}

In the area of literacy proficiency there is a bigger gap between the New Zealand-born respondents and the overseas-born respondents than there is in the area of oral proficiency. Overall, slightly over half of respondents $(55.3 \%)$ considered that they could write Gujarati easily. Only $5.7 \%$ of the New Zealand-born respondents thought they could write easily. Over a third $(37.1 \%)$ said that they could not read or write Gujarati. Almost half of them (48.6\%) could read and write fairly easily or with difficulty. A handful (three respondents) could read but not write.

The Gujarat-born respondents were much more likely to be confidently literate in Gujarati: $71.3 \%$ of them could write easily as could $75 \%$ of the other-born. A few of these two groups (four of the Gujarat-born and two of the other-born) could not read or write in Gujarati.

Table 7-14: Proficiency in written Gujarati \%

\begin{tabular}{|l|c|c|c|c|c|c|c|}
\hline Birthplace & $\begin{array}{c}\text { Can write } \\
\text { easily }\end{array}$ & $\begin{array}{c}\text { Fairly } \\
\text { easily }\end{array}$ & $\begin{array}{c}\text { With } \\
\text { Difficulty }\end{array}$ & $\begin{array}{c}\text { Can read } \\
\text { only }\end{array}$ & $\begin{array}{c}\text { No } \\
\text { Ability }\end{array}$ & Unclear & N= \\
\hline Gujarat & 71.3 & 13.8 & 9.6 & 0 & 4.3 & 1.1 & 94 \\
N.Z. & 5.7 & 28.6 & 20 & 8.6 & 37.1 & 0 & 35 \\
Other & 75 & 8.3 & 0 & 0 & 16.7 & 0 & 12 \\
All Respondents & 55.3 & 17 & 11.3 & 2.1 & 13.5 & 0.7 & 141 \\
N= & 78 & 24 & 16 & 3 & 19 & 1 & 141 \\
\hline
\end{tabular}

\subsubsection{English: see Table 7-15}

Well over half the respondents (61.7\%) said that they could 'write easily' in English. Not surprisingly $97.1 \%$ of the New Zealand-born gave this response (the only one not in this category being able to write 'fairly easily'), as did $66.7 \%$ of the other-born and almost half (47.9\%) of the Gujarat-born. Five of the Gujarat-born said that they could not read or write 
English and another five gave no response to this question. These five were all older (three men over 60, one woman in the 56-60 age group and another in the 41-45 age group). They either gave no response to the question about oral English proficiency or said that they were 'not very fluent'. Two of them in answer to question one, did not tick 'English' as a response. Four of them could write Gujarati 'easily' and one could write it 'fairly easily'. It seems likely that their no response to the question about English literacy is really indicative of no ability. So, despite the sample's overall strong confidence in their English literacy skills, $10 \%$ of the Gujarat-born were illiterate in English.

Table 7-15: Proficiency in written English: \%

\begin{tabular}{|l|c|c|c|c|c|c|c|c|}
\hline Birthplace & $\begin{array}{c}\text { Can write } \\
\text { easily }\end{array}$ & $\begin{array}{c}\text { Fairly } \\
\text { easily }\end{array}$ & $\begin{array}{c}\text { With } \\
\text { Difficulty }\end{array}$ & $\begin{array}{c}\text { Can read } \\
\text { only }\end{array}$ & $\begin{array}{c}\text { No } \\
\text { Ability }\end{array}$ & NR & Unclear & N= \\
\hline Gujarat & 47.9 & 26.6 & 11.7 & 2.1 & 5.3 & 5.3 & 1.1 & 94 \\
N.Z. & 97.1 & 2.9 & 0 & 0 & 0 & 0 & 0 & 35 \\
Other & 66.7 & 16.7 & 16.7 & 0 & 0 & 0 & 0 & 12 \\
All Respondents & 61.7 & 19.9 & 9.2 & 1.4 & 3.5 & 3.5 & 0.7 & 141 \\
N= & 87 & 28 & 13 & 2 & 5 & 5 & 1 & 141 \\
\hline
\end{tabular}

\subsubsection{Hindi: See Table 7-16}

As in the area of Hindi oral proficiency so, when it comes to Hindi literacy skills, there is a gap between those born in New Zealand and those born elsewhere. Slightly over half (56.4\%) of the Gujarat-born respondents could, to some extent, read and write Hindi and $23.4 \%$ of them could read and write 'easily'. A third of the other-born could also write 'easily', and half of them could write 'fairly easily' or 'with difficulty'. None of the New Zealand-born were at all confident in their Hindi literacy abilities. Two of them (5.7\%) could 'write with difficulty'. All the New Zealand-born respondents answered the question about Gujarati literacy skills, although $37.1 \%$ of them could not read or write Gujarati. None of the New Zealand-born respondents who answered 'no response' to the Hindi literacy question could speak Hindi' Looking at this pattern of response it seems likely that these respondents could not read or write Hindi so that a total of $94.2 \%$ of New Zealand-born respondents had no Hindi literacy skills.

\footnotetext{
${ }^{52}$ This claim is based on the answers to q. 1 (what language/s do you speak) and questionnaire. 21 (how do you rate your speaking skills in Gujarati, English Hindi). None of the New Zealand-born respondents listed Hindi at q.1. At q. 21, 3 said they could understand but not speak Hindi, 8 gave no response and 4 skipped q. 21 .
} 
Table 7-16: Proficiency in written Hindi: \%

\begin{tabular}{|c|c|c|c|c|c|c|c|c|}
\hline Birthplace & $\begin{array}{l}\text { Can write } \\
\text { easily }\end{array}$ & $\begin{array}{l}\text { Fairly } \\
\text { easily }\end{array}$ & $\begin{array}{c}\text { With } \\
\text { Difficulty }\end{array}$ & $\begin{array}{c}\text { Can read } \\
\text { only }\end{array}$ & $\begin{array}{c}\text { No } \\
\text { Ability }\end{array}$ & NR & Unclear & $\mathrm{N}=$ \\
\hline Gujarat & 23.4 & 14.9 & 18.1 & 17 & 9.6 & 16 & 1.1 & 94 \\
\hline N.Z. & 0 & 0 & 5.7 & 0 & 57.1 & 37.1 & & 35 \\
\hline Other & 33.3 & 33.3 & 16.7 & 0 & 16.7 & 0 & 0 & 12 \\
\hline All & 18.4 & 12.8 & 14.9 & 11.3 & 22 & 19.9 & 0.7 & 141 \\
\hline $\mathrm{N}=$ & 26 & 18 & 21 & 16 & 27 & 31 & 1 & 141 \\
\hline
\end{tabular}

\subsubsection{Monotonic decline}

Following Fishman's suggestion (see section 5.5.1.4) the proficiency responses for Gujarati oral and written media were examined for monotonic decline as a minor check on accuracy. Only one respondent did not exhibit the expected progression in which oral skills would be reported as being at a higher level of competence than written skills. The one respondent reported speaking skills that were 'not very fluent' but said that they could write 'fairly easily'.

\subsubsection{Age and Gujarati proficiency}

In this sample, the older a Gujarati person is, the more likely they are to be a fluent speaker of Gujarati. The percentage of respondents assessing themselves as 'fluent' rises fairly steadily with age from a low of $44 \%$ at age group 31-35 to a high of $100 \%$ in the over-60 age group (see Figure 7-10). There are a couple of insignificant disruptions to this pattern

- $78 \%$ of respondents in the age-group 41-45 are 'fluent' compared to $75 \%$ in agegroup 46-50

- $85 \%$ of respondents in age-group 51-55 are 'fluent' compared to $80 \%$ in agegroup 56-60

but the only major disruption to the pattern is at the beginning where six of the seven respondents in the 26-30 age group rate themselves as 'fluent'. Only one of the six was New Zealand-born. The few respondents in this age group, and the fact that there are a disproportionately small number of New Zealand-born respondents in the 26-30 category, means that we cannot regard these responses as typical for this age group. Overall, the responses show that fluency in Gujarati, while present at all age levels in the community, is strongly age-graded as we would expect in a largely immigrant community. That this is recognised in the community is shown by interviewees' comments, such as, 
"Well like if you were in party you might meet your say a relative which is older speak to him in Gujarati you might speak to the buddy that goes to school with ya in English so .. bit of both" (Respondent . ID140. Male. New Zealand-born. 36-40)

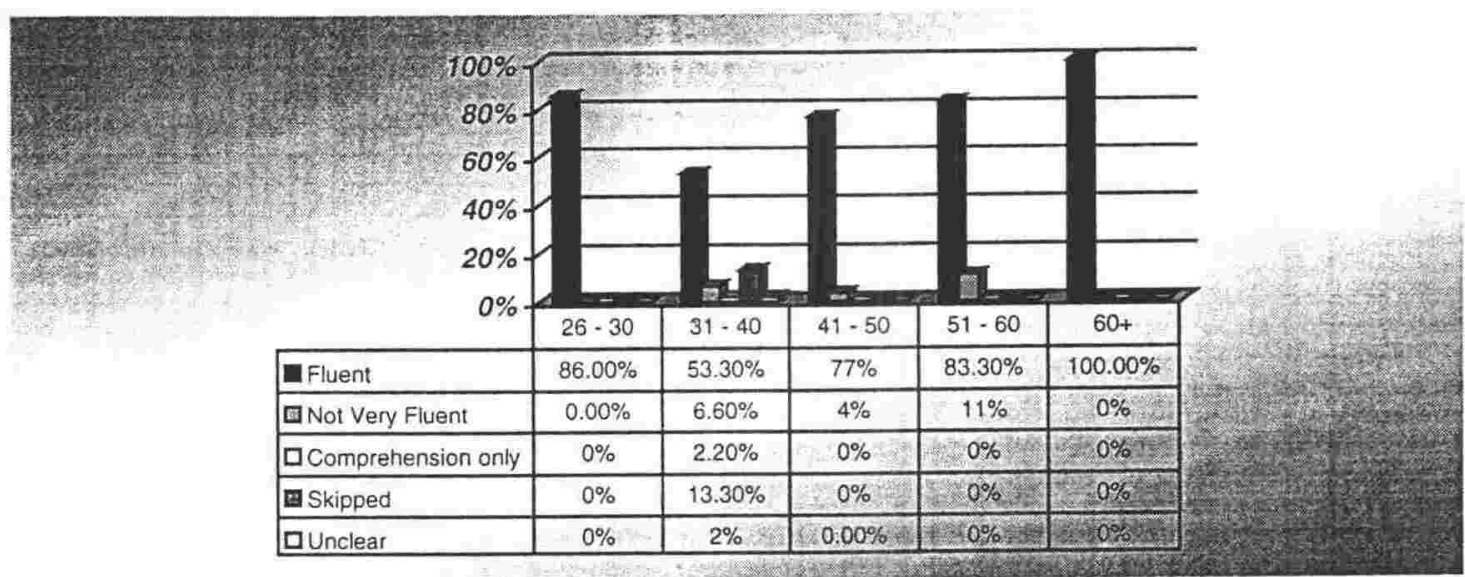

Figure 7-10: Gujarati language proficiency by age group of respondents: parallels Dutch divisions

\subsubsection{Gender and Language proficiency: see Table 7-17 and Table 7-18}

There is no marked difference between men and women when it comes to language proficiencies except, perhaps, in Hindi. Men (23.8\% of all respondents) are more likely to be fluent in Hindi than women (14.8\% of all respondents), presumably reflecting their greater educational opportunities in India. As Hindi is not much used in New Zealand and is not really spoken by the New Zealand-born members of the community, it will not be discussed in any detail.

Slightly more men than women rate themselves as 'fluent' speakers of Gujarati.

- $77.5 \%$ of male respondents rate themselves as 'fluent' speakers of Gujarati

- $68.9 \%$ of female respondents rate themselves as 'fluent' speakers of Gujarati

This despite the fact that more New Zealand-born women than men rate themselves as 'fluent'. More New Zealand-born men are also likely to rate themselves as 'not very fluent' speakers of Gujarati'.

- $38.1 \%$ of New Zealand-born women rate themselves as 'fluent'.

- $28.6 \%$ of New Zealand-born men rate themselves as 'fluent'

- $4.8 \%$ of New Zealand-born women rate themselves as 'not very fluent'

- $14.3 \%$ of New Zealand-born men rate themselves as 'not very fluent'

The New Zealand-born women's more positive view of their language skills is maintained when we look at the responses for English proficiency. The same proportion (14.3\% of each) of New Zealand-born men and women skipped the response to this section. Of the remainder, all of the women $(85.7 \%)$ rated themselves as 'fluent'. Of the men, $71.4 \%$ chose 'fluent' and 
$14.3 \%$ chose 'fairly fluent'. This may suggest that the New Zealand-born men were more pessimistic raters as a group than the New Zealand-born women.

Turning to those born outside New Zealand.

- $30.3 \%$ of the Gujarat-born women rate themselves as fluent in English

- $50.8 \%$ of the men chose that option

The women are also much more likely to rate themselves as 'not very fluent' in English than the men.

- $30.3 \%$ of the non-New Zealand-born women rate themselves as 'not very fluent'

- $8.2 \%$ of the non-New Zealand-born men rate themselves as 'not very fluent'

The Gujarat-born women are also the only group in which there are respondents who cannot speak English (3\%).

There is an interesting result for the Other-born respondents, although given their small numbers it is hard to know what to make of it.

- $85.7 \%$ of the women rate themselves as 'fluent' in English

- $40 \%$ of the men rate themselves as 'fluent'

The differences are not marked but they generally fall into the pattern that we would expect. The immigrant men from Gujarat are more likely to be confident in their English fluency than are the immigrant women from Gujarat The New Zealand-born women are more likely to be confident in their Gujarati fluency than are the New Zealand-born men. This is a similar result to that of the 1990 survey of the Cantonese in Wellington where

[New Zealand-born] women rated their abilities in these areas [Cantonese speaking and comprehension skills] slightly more highly than did men (Roberts 1990).

and similar findings in the Dutch community in Australia have been commented on by Bennett (1992: 64-66). The only possibly anomaly is in the small group of immigrants who are not Gujarat-born. They are all fluent in Gujarati but the women are more likely to report fluency in English than the men. However, these findings are not dissimilar to those of Solé who found that, in her sample of U.S-born Mexican Americans (50\% of whom claimed Spanish as a MT), women were more likely to use English than men.

The linguistic differences that emerge between males and females show a consistent pattern. Females tend to claim mostly and only English. More often than do males, who, by and large, favour code-switching, that is, Spanish and English with equal frequency (Solé 1978:34) 
It seems that there is a very rich field to be further explored here: gender as a factor in immigrant language claiming and language proficiency. The findings of this research are not conclusive in any way and there is obviously much more to be investigated in this area.

Table 7-17: Proficiency in oral Gujarati: \%: Men as a \% of all male respondents and women as a \% of all female respondents

\begin{tabular}{|c|c|c|c|c|c|c|c|}
\hline & Fluent & $\begin{array}{l}\text { Fairly } \\
\text { Fluent }\end{array}$ & $\begin{array}{c}\text { Not Very } \\
\text { Fluent }\end{array}$ & Comp. Only & Unclear & Skipped & $\mathrm{N}=$ \\
\hline Gujarat Born F. & 81.8 & 12.1 & 0 & 0 & 3 & 3 & 33 \\
\hline Gujarat Born M & 86.9 & 4.9 & 6.6 & 1.6 & 0 & 0 & 61 \\
\hline N.Z. Born F. & 38.1 & 42.9 & 4.8 & 0 & 0 & 14.3 & 21 \\
\hline N.Z. Born M. & 28.6 & 42.9 & 14.3 & 0 & 0 & 14.3 & 14 \\
\hline Other Born F. & 100 & 0 & 0 & 0 & 0 & 0 & 7 \\
\hline Other Born M. & 100 & 0 & 0 & 0 & 0 & 0 & 5 \\
\hline All Respondents F. & 68.9 & 21.3 & 1.6 & 0 & 1.6 & 6.6 & 61 \\
\hline All Respondents M. & 77.5 & 11.3 & 7.5 & 1.3 & 0 & 2.5 & 80 \\
\hline$N=$ & 104 & 22 & 7 & 1 & 1 & 6 & 141 \\
\hline
\end{tabular}

Table 7-18: Proficiency in oral English \%: Men and women as \% of each gender

\begin{tabular}{|l|c|c|c|c|c|c|c|}
\hline & Fluent & Fairly Fluent & Not Very Fluent & Comp. Only & NR & Skipped & N= \\
\hline Gujarat Born F & 30.3 & 27.3 & 30.3 & 3 & 6.1 & 3.0 & 33 \\
Gujarat Born M & 50.8 & 37.7 & 8.2 & 0 & 3.3 & 0 & 61 \\
N.Z. Born F. & 85.7 & 0 & 0 & 0 & 0 & 14.3 & 21 \\
N.Z. Born M. & 71.4 & 14.3 & 0 & 0 & 0 & 14.3 & 14 \\
Other Born F. & 85.7 & 0 & 14.3 & 0 & 0 & 0 & 7 \\
Other Born M. & 40 & 60 & 0 & 0 & 0 & 0 & 5 \\
& & & & & & & \\
All Respondents F. & 55.7 & 14.8 & 18 & 1.6 & 3.3 & 6.6 & 61 \\
All Respondents M. & 43 & 35 & 6.3 & 0 & 2.5 & 2.5 & 80 \\
N= & 77 & 37 & 16 & 1 & 4 & 6 & 141 \\
\hline
\end{tabular}

\subsubsection{Summary: language proficiency}

Most of the respondents, regardless of birthplace could speak 'fluent' or 'fairly fluent'

Gujarati. Hindi is not much used in the community and most of the New Zealand-born are unable to speak it but many of the Gujarat-born have some knowledge of Hindi. Literacy in a given language was strongly related to birthplace. The New Zealand-born were likely to be confident of their English literacy abilities and non-New Zealand-born more confident of Gujarati, and to some extent Hindi, abilities. Proficiency is linked to age (older respondents are more likely to be fluent in Gujarati, younger respondents in English) and not very strongly correlated with gender, although there are some minor variations that may be gender-linked. 


\subsection{Attitudes}

In addition to respondents' assessments of their language abilities and patterns of language use, the attitudes and opinions held by community members about the language processes that are underway in their community were also investigated. Attitudes were assessed by asking respondents a range of questions concerning language use in the community (see Appendix 1).

\subsubsection{Community school}

Respondents were asked if they thought that the Wellington Indian Association School was 'a good idea', 'not a good idea' or 'not sure'. The school has been established since the late 1940s (Kasanji 1994: 7)and runs for three hours every Sunday. Virtually all the respondents indicated that the Wellington Indian Association School was 'a good idea'. Overwhelmingly people were in favour of this type of language maintenance effort on the part of the community.

- 134 of the 141 respondents (95\%) thought that the school was 'a good idea'

- of the remaining 7 respondents, all born in Gujarat, two thought it was 'not a good idea' and five were 'not sure'

- the New Zealand and Other-born all thought that the school was 'a good idea'

When the question of state support for these activities is considered, the situation becomes a little more complex.

\subsubsection{Gujarati and Hindi within the state school system}

Respondents to the long questionnaire (LQ, see Appendix 1 for numbers) were asked their opinions about the teaching of Gujarati and Hindi in the state school system. Hindi was included because many of the respondents (49\%) speak Hindi and it has a special status as a national language in India. 
Table 7-19: Reply to question 31: should Gujarati be taught in state schools

\begin{tabular}{|l|l|l|l|l|l|}
\hline & Yes & No & $\begin{array}{l}\text { Not } \\
\text { Sure }\end{array}$ & NR & $N=$ \\
\hline All respondents (LQ) & $35.6 \%$ & $41.7 \%$ & $21.7 \%$ & $0.9 \%$ & 115 \\
Gujarat Born & $36.5 \%$ & $37.8 \%$ & $24.3 \%$ & $1.4 \%$ & 74 \\
NZ Born & $43.7 \%$ & $37.5 \%$ & $18.8 \%$ & 0 & 32 \\
Other Born & 0 & $89 \%$ & $11 \%$ & 0 & 9 \\
\hline
\end{tabular}

Table 7-20: Reply to question 32: should Hindi be taught in state schools

\begin{tabular}{|l|l|l|l|l|l|}
\hline & Yes & No & $\begin{array}{l}\text { Not } \\
\text { Sure }\end{array}$ & NR & $N=$ \\
\hline All respondents (LQ) & $25.2 \%$ & $53 \%$ & $19.1 \%$ & $2.6 \%$ & 116 \\
Gujarat Born & $25.7 \%$ & $48.6 \%$ & $24.3 \%$ & $1.4 \%$ & 74 \\
NZ Born & $31.2 \%$ & $53.1 \%$ & $9.4 \%$ & $6.3 \%$ & 33 \\
Other Born & 0 & $89 \%$ & $11 \%$ & 0 & 9 \\
\hline
\end{tabular}

As can be seen respondents were fairly evenly divided on the question of teaching Gujarati although a large middle ground is occupied by the 'not sure' responses. It is interesting to note that all the Other-born respondents were opposed to teaching both Gujarati and Hindi in the state system however, the total number of Other-born respondents to the question is so low that it is hard to draw any conclusions. The response of this group may be influenced by the attitude shown in one Other-born interviewee's comment to me that where she came from (Africa) the community supported its own flourishing schools and had no need of government assistance. The respondents are somewhat less supportive of the idea of teaching Hindi in state schools but there is still the same 'not sure' middle ground. One interviewee thought that Hindi ought to be taught as part of a general ethnic education in NZ schools.

Many of those who answered 'no' to the question about Gujarati, explicitly did so on logistical and practical grounds. That is, because Indian children are dispersed through the wider Wellington community with comparatively little residential concentration, people found it hard to imagine how a practical scheme for teaching Gujarati could be devised, given that Gujarati was obviously not going to be taught in every school. It is partly this factor that accounts for the large percentage of 'not sure' responses. Respondents liked the idea of teaching Gujarati or Hindi but were not certain about how this could be achieved. In reply to the question about Gujarati being taught in NZ schools.

- One interviewee answered 'no' on logistic grounds but thought that it would be a good idea if Gujarati language resources could be allocated in some way.

- Another interviewee also commented that there would never be more than one or two Indian children in a class and added that it was embarrassing to be the focus of attention when things Indian came up. He said that when you were, for 
instance, studying India at school, all eyes would turn to the Indian child in the class and he thought that this was undesirable.

- Another respondent's doubts about teaching Gujarati and Hindi in the state school system arose from a concern as to how useful these languages would be to non-Indians.

\subsubsection{Funding for community school}

Virtually everyone, on the other hand, thought that some government funding should be made available to the community school. Ninety of 115 Gujarati extraction respondents $(78.3 \%)$ thought funding should be made available, as did 27 of the 32 New Zealand-born respondents (84.4\%) to this question. Comments about government funding for Wellington Indian Association School ranged across the following topics and concerns

- funding for the WIA school was 'very necessary'

- any funding to the Indian community school should be targeted and dedicated funding

- funding to Indian community schools should only be made available on the basis that such funding is available to all community schools

- government funding for the WIA school was not practical at the moment but it would be appreciated

The high proportion of positive replies to this question would seem to indicate that there is both a generally high level of support for the community school and also a prevalent feeling that some government support would be fair. There was also a concern indicated that government funds would have to be targeted and/or strictly accounted for. The very high proportion of positive replies from the New Zealand-born respondents indicates, I tentatively suggest, that the New Zealand-born are more likely to perceive themselves as having a legitimate claim on their share of the national purse.

\subsubsection{General views}

Respondents were asked three questions that were intended to reflect their general views about linguistic and cultural maintenance and shift.

- 'Is it important to keep Gujarati as a living language?'

- 'Should Indian people see themselves as part of an Indian NZ community?' or

- 'Should Indian people forget about being Indian and see themselves simply as New Zealanders?'

The overwhelming majority of respondents gave answers that indicated their strong positive feelings for linguistic maintenance and some degree of community cultural cohesion and several of the respondents and interviewees added their own comments about these matters. 
[it is important to keep Gujarati as a living language in order to distinguish oneself from Europeans ... Europeans will never fully accept you so assimilation is not possible or desirable $]^{53}$

"I feel that, we have retained a little more Indian culture which is a good thing ... I was brought up as a Kiwi, but I have still kept my culture, I wonder if my children will?"

"I am a "Westernised" Indian but deeply value the importance to retain my Indian identity"

"My beliefs in language and Indian heritage is very strong. I would like to see every Indian child to be able to at least speak the language"

One interviewee commented on the retention of Gujarati culture in New Zealand in a slightly less positive vein

[Gujaratis are more conservative, less integrated than Punjabis - also more economically more successful. The community feels it has done well by sticking with the old ways - why change?]

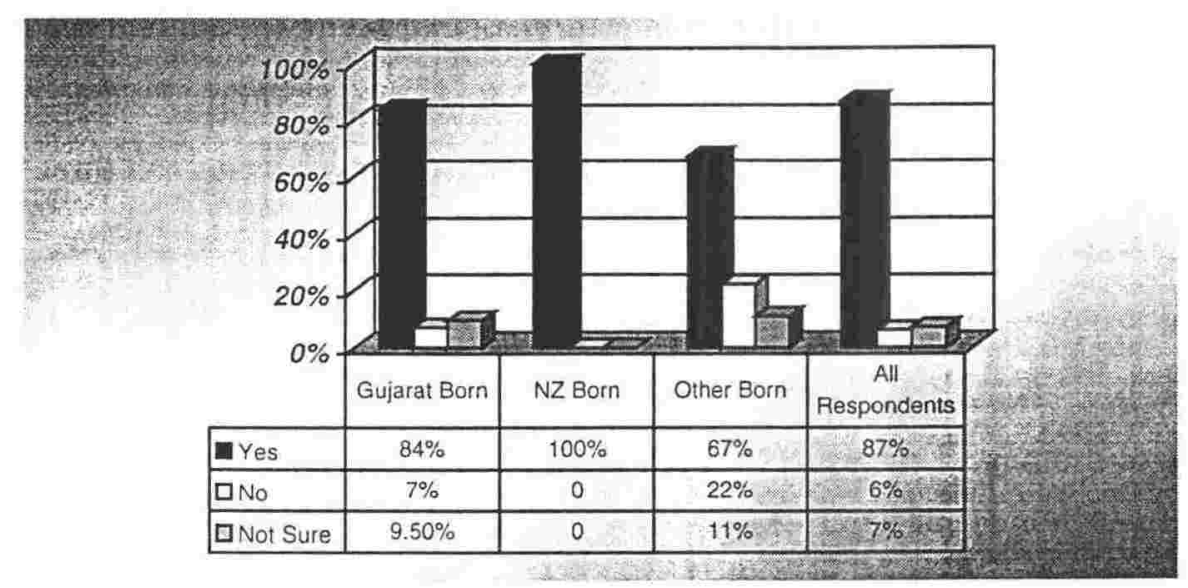

Figure 7-11: Respondent answers to 'Is it important to keep Gujarati as a living language in NZ. Percentages by birthplace

It is interesting to note in Figure 7-11 that all the New Zealand-born respondents replied that it was important to keep Gujarati as a living language in New Zealand. Those born in places other than Gujarat and New Zealand (Fiji and Africa) were slightly less positive, and they are the only group where more people responded than 'no' to this question than responded 'not

\footnotetext{
${ }^{53}$ Square brackets [...] are used for paraphrases of spoken comments and double quotation marks "..." for direct quotation of written comments or comments transcribed from tape recording.
} 
sure. The numbers involved are very small but the response of this group to this question falls into a pattern of responses from the 'Other-born' that seems to indicate a lower level of concern with issues of language and culture maintenance (See section 12.4.1.2).

When we turn to the questions about whether New Zealand Indians should see themselves as part of a Indian/New Zealand community or whether they should forget about being Indian and see themselves simply as New Zealanders we find, unsurprisingly perhaps, that most respondents chose the first option

- $95.7 \%$ think that Indians in New Zealand should see themselves as part of an Indian/New Zealand community

- $10.4 \%$ of respondents said that Indian people in New Zealand should forget about being Indian and see themselves simply as New Zealanders

The two figures add up to 106.1 because some respondents answered both questions in the same way (and two failed to respond to the 'simply as New Zealanders' question).

One person answered 'no' to both questions and another nine people answered 'yes' to both questions. The person who answered 'no' to both may simply be an aberration, but the nine respondents who answered that Indians in New Zealand should not only see themselves as part of an Indian/New Zealand community but also should forget about being Indian and see themselves simply as New Zealanders were, it seems, trying to get at a more complex range of attitudes than the framework of the questionnaire allowed. This group also contained three of the eight respondents who were 'not sure' if it was important to retain Gujarati as a living language in New Zealand. Some of the demographic characteristics of this group are displayed Table 7-21. The most notable features are that they are mainly male, mainly born in Gujarat and that only one of them is 51 or over ( $25 \%$ of the respondents are 51 or over). 
Table 7-21: Respondents who thought Gujarati people in New Zealand be part of an Indian/NZ community and at the same time should see themselves only as New Zealanders

\begin{tabular}{|l|l|l|l|l|l|}
\hline $\begin{array}{l}\text { Gujarati as a living } \\
\text { language }\end{array}$ & Gender & Age group & Birthplace & $\begin{array}{l}\text { Indian/NZ } \\
\text { community }\end{array}$ & Simply as NZers \\
\hline No & Male & $46-50$ & Gujarat & Yes & Yes \\
Not Sure & Female & $46-50$ & Gujarat & Yes & Yes \\
Not Sure & Male & $26-30$ & Gujarat & Yes & Yes \\
Not Sure & Male & $51-55$ & Gujarat & Yes & Yes \\
Yes & Female & $31-35$ & Gujarat & Yes & Yes \\
Yes & Male & $26-30$ & Gujarat & Yes & Yes \\
Yes & Male & $36-40$ & Gujarat & Yes & Yes \\
Yes & Male & $36-40$ & New Zealand & Yes & Yes \\
Yes & Male & $41-45$ & Gujarat & Yes & Yes \\
\hline
\end{tabular}

\subsubsection{Summary: Attitudes}

The responses to this section of the questionnaire indicate that overall attitudes to Gujarati were positive and in favour of maintaining the language in New Zealand. There was conditional support for some government assistance for community language maintenance efforts. Several respondents spontaneously linked issues of ethnic identity and language.

\subsection{Interviewees' responses to radio, government services and state school questions}

The Gujarati interviewees were asked a series of questions about the provision of government services in Gujarati and Hindi, radio broadcasting in Gujarati and whether or not Gujarati and Hindi should be taught in mainstream schools. In this section, the answers to these questions are discussed.

\subsubsection{Gujarati language radio programmes}

All the 33 interviewees were aware that there was Gujarati language programming available on radio. Just over half of them (57.5\%) were aware that the radio station which carries Gujarati programming is Radio Access.

- over half the interviewees (54.5\%)thought that it was 'quite' important to have such programmes,

- a substantial minority (39.4\%) thought that it was 'very' important

- only two interviewees (6.1\%) thought that it was 'not at all' important. 
Just over half the interviewees (51.5\%) knew the dates and times of the Gujarati language broadcasts about a quarter $(24.2 \%)$ did not know when they were available and the remainder $(24.2 \%)$ were 'not sure' whether they knew or not. There were minor differences between the New Zealand-born and non-New Zealand-born in response to these questions but no major differences.

\subsubsection{Gujarati language provision in government services}

Most interviewees (75.8\%) thought that government services should be made available in Gujarati and or Hindi. Almost all the New Zealand-born and Gujarat-born interviewees were of this opinion ( $80 \%$ of each group). However, only one of the three other-born interviewees thought that government services should be provided in Gujarati or Hindi. Of the 26 interviewees who thought that such services should be provided, $65.4 \%$ thought that they should be available to anyone who requested them and $34.6 \%$ thought that they should be available only for those who 'did not speak English well enough'. Interviewees were offered a choice of services that might be provided and were also asked to specify any others that they wanted to add. The services that were mentioned in the interview were

- court interpreters

- hospital interpreters

- community interpreters (for Social Welfare, Housing Corporation etc)

- information about social services (in pamphlets)

- major forms (e.g. taxation forms, election forms)

New Zealand-born and non-New Zealand-born respondents tended to have rather different ideas about what services would be most useful. The respective choices are shown, rankordered, below. There were 15 respondents in each group. 
Table 7-22: Areas in which New Zealand-born respondents would like to see translating and interpreting facilities made available

\begin{tabular}{|l|l|}
\hline $\begin{array}{l}\text { Service where translating and interpreting facilities } \\
\text { are needed }\end{array}$ & Number of respondents who \\
mentioned it
\end{tabular}

One respondent simply said that they should be available 'according to demand'. The nonNew Zealand-born respondents had somewhat different priorities.

Table 7-23: Areas in which non-New Zealand-born respondents would like to see translating and interpreting services made available

\begin{tabular}{|l|l|}
\hline $\begin{array}{l}\text { Service where translating and interpreting facilities } \\
\text { are needed }\end{array}$ & $\begin{array}{l}\text { Number of respondents who } \\
\text { mentioned it }\end{array}$ \\
\hline hospital interpreters & 10 \\
court interpreters & 9 \\
Community interpreters & 8 \\
major forms & 6 \\
Immigration & 5 \\
Medical & 4 \\
Information about social services & 3 \\
accident services & 1 \\
Education programmes for recent immigrants & 1 \\
Legal & 1 \\
Marriage & 1 \\
School & 1 \\
social welfare & 1 \\
taxation/IRS & 1 \\
TV programming & 1 \\
\hline
\end{tabular}

New Zealand-born and non-New Zealand-born respondents place considerable emphasis on the need for hospital interpreters and, indeed, on the need for interpreters in the whole area of medical services. This reflects. I believe. not onlv the insecuritv that the individual faces when 
trying to deal with a medical problem in a language in which they are not fully proficient, but also the fact that New Zealand medical services tend to rely on friends, relatives or staffmembers who happen to speak the language in question rather than using professional interpreters. The Health and Disability Commissioner Act 1994 states that health care providers should be able to communicate with consumers, and section 20 (d) says that this includes 'the provision of interpreters' (Kasanji 1995: 27). The Code of Rights for Consumers of Health and Disability Services asserts the right to 'effective communication' which includes 'where necessary and where reasonably practicable ... the right to a competent interpreter' (Right 5, Health and Disability Commissioner (Code of Health and Disability Services Consumers' Rights) Regulations 1996). According to the Manager of the Wellington Community Interpreting Service, the promulgation of the code (which happened after these interviews took place) is beginning to have some slight effect on the attitude of health providers towards employing properly qualified interpreters but there is still a long way to go (personal communication July 1998). The deep embarrassment of having to deal with extremely personal medical matters through family members who may be younger and of the opposite sex is a well known phenomenon in immigrant communities in New Zealand and matters are not much improved if the 'interpreter' is a friend or a staff member who can speak the language. Quite apart from the personal embarrassment experienced, people are also aware that such non-professional interpreting compromises the standard of medical care that is offered. Kasanji gives some relevant examples of such experiences

A child was asked to interpret for his mother who had pneumonia. 'Pneumonia' was a word he did not know. He was too proud to admit this, so he did not ask for clarification. Instead, he told his mother she had an illness 'something like cancer'.

A boy was interpreting for his mother about her cervical smears and problems with vaginal discharge. A boy is not an appropriate person to translate his mother's personal health details.

An orderly was called in to interpret for a pregnant woman with a heart problem. She had to have a caesarean birth which she refused. The untrained interpreter told her to do as she was told, as she had come for help and had no right to say 'no' to the doctor (Kasanji 1995: 13-14)

Both New Zealand-born and non-New Zealand-born respondents thought that interpreters in court were important, presumably because of the seriousness of the situation and the weight of the potential outcomes of a court case. The New Zealand Bill of Rights Act 1990 provides that 
defendants must have an interpreter provided by the court if the defendant does not speak English. The judge determines whether or not witnesses need an interpreter (Kasanji 1995: 29). Respondents in both groups also tended to say that interpreting and translation services in the area of immigration were important and the significance of this area to an immigrant group is self-explanatory.

Hospital and medical matters, court matters and immigration were areas where all the respondents, regardless of birthplace tended to think that there should be some provision of interpreting and translation services. In other areas however, birthplace seemed to be a factor in the services singled out by respondents. Non-New Zealand-born respondents placed more emphasis on the need for 'community' interpreters, on the need for the translation of 'major forms', and on the need for MT pamphlets giving information about social services. All of this presumably reflects their lower proficiency in English and specifically their lower proficiency in written English. The New Zealand-born on the other hand were more likely to single out the driving test/driver's licence ${ }^{54}$ as an area where interpreters/translators were needed and were also more likely to mention the need for assistance with lawyers and legal matters (as opposed specifically to court appearances). I am not sure why these matters should be more to the forefront of the minds of the New Zealand-born respondents.

In Aoteareo, Waite singled out justice and health care as the two areas in which high quality interpreting were particularly important and the findings of this current research seem to bear out his opinion. Waite went on to say

the ad hoc recourse to untrained interpreters, whether they be relatives, neighbours, friends or fellow staff members, is too fraught with risks to be acceptable in a professional environment. Interpreting services require professionals with high-level linguistic and non-linguistic expertise; those selected as interpreters need to have professional training, whether in a formal setting or as part of work experience (Waite 1992b: 54)

\footnotetext{
${ }^{54}$ The Transport (Drivers Licensing) Regulations 1987, Regulation 12 provides that interpreters may be used but that the person sitting the test is responsible for all arrangements and payment (Kasanji 1995:28)
} 


\subsubsection{Interviewees' opinions of state school provision of Indian language instruction}

Of the 30 interviewees who had children, 27 replied positively to the question in the postal version questionnaire about state school provision of Gujarati/Hindi ${ }^{55}$ language education. A similar question was asked of Cantonese respondents in research reported on in Roberts 1990. The responses of the Gujarati interviewees have been compared with the responses of the Cantonese interviewees.

In the postal questionnaire (which was filled out by 12 of the 33 interviewees) respondents were asked if Gujarati and Hindi should be offered in the state school system (questions 31 and 32). In interviews with those who had not filled out the postal questionnaire, interviewees were asked these questions first and were later asked, as were the interviewees who responded positively to those questions in the postal questionnaire, a series of questions about how they envisaged Gujarati/Hindi being taught within the state school system (questions c37a -c37d).

Most of the interviewees thought that it would be a good idea to teach Gujarati/Hindi language in the state school system. It was noticeable in interviews that there was a division between those who thought that it was a good idea and a thoroughly practicable one and those who thought that it was a 'nice idea' but, perhaps, a bit of a pipe dream. It is, however, hard to pin these differences down and the only case that I have noted is that of the interviewee who was very clear and insistent that his positive replies to the series of questions about Gujarati/Hindi in state schools were 'hypothetical'.

There were some minor discrepancies between the responses given in the postal questionnaire and those given in the interview. For example, no respondent to the postal questionnaire specified that Hindi rather than Gujarati should be taught in New Zealand schools. However one respondent when interviewed said that he thought that teaching Hindi would be better than teaching Gujarati and I have included him along with two interviewees (who were only interviewed - they never filled out a postal questionnaire) as specifying Hindi not Gujarati. Some interviewees, after filling in the postal questionnaire to the effect that no Indian languages should be taught in the New Zealand state school system then changed their minds at the interview and decided that one or other language should be taught. Some interviewees

\footnotetext{
${ }^{55}$ Respondents were asked about both languages and replied positively to one or the other or both or neither.
} 
changed their minds in the course of the interview or were persuaded by their spouse to a different point of view. This was the case with one woman who originally said that neither Gujarati not Hindi should be taught because it was 'too much of a burden' (D085: NZB female) but she eventually agreed with her husband that it would be a good idea if Hindi was taught in New Zealand schools. They make up two of the three interviewees who specified Hindi. The responses given in interviews have been treated as the definitive responses for the purposes of analysis. This is not a perfect decision because in some cases the interview responses appear to me to represent one interviewee 'giving in' to the opinion of their spouse, but, conversely, it also seemed to me as the interviewer that in some cases where the interview response differed from the postal questionnaire response or where the final interview response differed from an earlier interview response to a similar question, the change had come about because in the elapsed time, the interviewee had thought more about the issue involved.

- $61 \%$ of interviewees thought Gujarati was the language that should be taught

- $10 \%$ thought that Hindi was more appropriate

One interviewee specified that his answer was 'yes, hypothetically', that is, he thought it was a good idea but he did not think it was practical. Interestingly, the general response was very similar to the responses given by members of the Cantonese community when asked the same questions (Roberts 1990:152). 
Table 7-24: Comparison of Cantonese and Gujarati responses

\begin{tabular}{|c|c|c|c|c|}
\hline & $\begin{array}{l}\text { Should there be state } \\
\text { school community } \\
\text { languages }{ }^{56} \text { education }\end{array}$ & $\begin{array}{l}\text { Should it be } \\
\text { community } \mathrm{MT}^{57}\end{array}$ & $\begin{array}{l}\text { Should it be } \\
\text { national language }{ }^{58}\end{array}$ & $\begin{array}{l}\text { Should it } \\
\text { be both }\end{array}$ \\
\hline $\begin{array}{l}\text { Gujarati } \\
\text { interviewees: yes }\end{array}$ & $76.6 \%{ }^{59}$ & $33.3 \%$ & $10 \%$ & $33.3 \%$ \\
\hline $\begin{array}{l}\text { Gujarati } \\
\text { interviewees: no }\end{array}$ & $23.3 \%$ & & & \\
\hline $\begin{array}{l}\text { Cantonese } \\
\text { interviewees: yes }\end{array}$ & $74.5 \%$ & $43.1 \%$ & $13.7 \%$ & $17.6 \%$ \\
\hline $\begin{array}{l}\text { Cantonese } \\
\text { interviewees: no }\end{array}$ & $25.5 \%$ & & & \\
\hline
\end{tabular}

It is interesting to see that both interviewees in both communities are almost identically divided as to whether or not community languages education in the state school system is a good idea. In neither community were interviewees particularly supportive of teaching the national language. Both sets of interviewees were, by and large, much more interested in MT language maintenance. Those Gujarati interviewees who did think that Hindi not Gujarati should be taught tended to suggest it because Hindi was the national language and, in some cases, because non-Indian students would be more interested in learning Hindi than in learning Gujarati.

There is no obvious reason why so many more of the Gujarati interviewees than the Cantonese should have opted for teaching both national language and MT. Possibly the results are due to the fact that the Gujarati community still contains many individuals who are competent speakers of Hindi whereas the Cantonese community from which the Cantonese interviewees were drawn does not contain many Mandarin speakers (Roberts 1990:101-2).

\footnotetext{
${ }^{56}$ Used here to denote both MT and national language

${ }^{57}$ Community MT: Gujarati for Gujarati community; Cantonese for Cantonese community

${ }^{58}$ National language: Hindi for Gujarati community; Putonghua/Guoyu (mandarin) for Cantonese community

${ }^{59}$ Included in this figure, and in the $33.3 \%$ figure for 'both', is the response of one interviewee who wished to make it very clear that his response was 'hypothetical' only. He thought it would be nice to teach Indian language at New Zealand schools but he did not think that it was practical to do so.
} 


\subsubsection{At what level of schooling should the Indian language be taught}

The largest group of interviewees (of those who responded positively to the initial question about provision of Gujarati language education) thought that Gujarati language education would best be provided at primary school level.

$45.5 \%{ }^{60}$ chose primary school level

$18.1 \%$ of the interviewees thought that secondary school would be more appropriate

$13.5 \%$ chose primary and secondary school or secondary school and polytechnic

There were a variety of other choices each favoured by one interviewee

- kindergarten

- kindergarten and primary

- primary and intermediate

- intermediate

- primary and polytechnic

It is interesting that the two interviewees who suggested tertiary level provision of Gujarati both specified that it should be at polytechnic. Perhaps a polytechnic was seen as a more appropriate venue for community language teaching in contrast to the more formal and academic connotations of the university.

In comparison with the Cantonese community, it is striking that similar proportions of interviewees in both surveys opted for primary school ( $48.7 \%$ in the Cantonese community). Pre-school was a more popular choice in the Cantonese survey - $15.3 \%$ compared to $9 \%$ in the Gujarati survey. However, if all the combinations in which secondary school appeared in the Gujarati interviewees' responses are counted, then the proportion of both groups who wanted to see their MT taught in secondary schools is roughly equal; $33.3 \%$ of the Cantonese and $30.4 \%$ of the Gujarati interviewees (Roberts 1990:152).

\footnotetext{
${ }^{60}$ One interviewee did not reply to this question or the question about skill areas and hours. Her 'NR' has been included with the 7 who thought Gujarati/Hindi should not be taught at all. Thus the percentages given in 7.5.3.1 are out of 22 not 23 )
} 


\subsubsection{How many hours a week should the language be taught}

This question was included to try to get some sense of whether interviewees thought that Gujarati/Hindi should be offered as a 'normal' subject and have the same number of hours per week allotted it as any other subject such as English or science, or whether they thought it should be offered as what is known as an 'option' or an 'elective' in some schools that is, one of a number of additional (to the regular curriculum) subjects that the students chooses from and that typically is taught for fewer hours a week than the 'normal' subjects. Some interviewees simply did not have an opinion on this question.

- Half the interviewees thought that Gujarati/Hindi should be taught for fewer hours a week than 'normal' subjects

- Not quite a quarter (22.7\%) thought that Gujarati/Hindi should be offered as a normal subject for the same hours a week as any subject

This contrasts quite strongly with the Cantonese survey where $56.4 \%$ of the interviewees who responded positively to the question about state school provision of a Chinese language thought that the language should be offered for as many hours a week as a normal subject (Roberts 1990:152). One interviewee said the number of hours a week was not a relevant consideration because she thought the subject should be offered only at kindergarten level. One interviewee was not sure ( 1 'NR') and three interviewees had very definite numbers of hours per week in mind; one of them opting for two hours a week and the other two nominating five hours a week.

\subsubsection{What language skills should be taught}

Most interviewees (59\% of those who responded positively to the question about Gujarati/Hindi in state schools) thought that if Gujarati and/or Hindi were taught in state schools then both oral language skills and literacy skills should be taught. Several interviewees (18.1\%) did not have an opinion on this question. One interviewee said that the question was not relevant because she thought that Gujarati/Hindi should only be taught at kindergarten by which I understood her to mean that the children would not be being given structured lessons in any particular aspect of language skills. One interviewee thought that the emphasis should be on learning to read and write and three interviewees (13.6\%) thought that reading and writing were not as important and the emphasis should be on speaking and comprehension skills. 
There is quite a marked difference between the Cantonese and Gujarati responses in this area. A substantial majority of the Cantonese interviewees (69.2\%) thought that if Cantonese/Mandarin were to be taught in state schools (and, of course, the written language is essentially the same for both Cantonese and Mandarin) then the emphasis should be on speaking and comprehension skills. Only $20.5 \%$ of Cantonese interviewees thought that the emphasis should be on oral language skills and literacy skills and $10.2 \%$ thought that the emphasis should be on reading and writing (Roberts 1990:153). For the Cantonese

There was general agreement that the extreme difficulty learning to read and write Chinese, and the limited, not to say artificial contexts in which the skill could be exercised in New Zealand, were all factors in the decline of literacy (Roberts 1990:139)

These factors do not, however, apply so strongly to the Gujarati community. Hindi and Gujarati are both alphabetic (or, as they are sometimes described, sylalphabetic) languages and are thus easier to learn to write in than Chinese (Cheng 1978:375). The fact that quite lengthy family visits home are still comparatively common in the community may also mean that literacy skills are seen as having some practical use that many of the Cantonese interviewees did not perceive for Chinese literacy.

\subsubsection{Attitude to government funding of community schools and to teaching an Indian language in state schools}

Most interviewees (83.3\%) thought that some government funding should be made available to the Indian community schools. Of the three interviewees who thought such funding was not a good idea, two thought that Gujarati should be offered in the state school system, one thought it should not and all three thought that Hindi should not be offered. Two interviewees were not sure whether funding should be made available to community schools but they were both certain that neither Gujarati or Hindi should be taught within the state school system.

Of the 25 interviewees who thought that funding should be made available to community schools,

- $32 \%$ thought that neither Gujarati or Hindi should be taught in the state school system

- $68 \%$ thought that some combination of Gujarati and/or Hindi should be taught 
As with the respondents in general, support was stronger for government funding of community schools than it was for the community language/s being taught in the state school system.

\subsection{Gujarati children and their use of Gujarati language}

The 141 Gujarati respondents came from 126 households. All respondents answered the questions about children's attendance at language maintenance school. Only the respondents to the long version of the questionnaire answered the questions about the languages spoken by oldest and youngest children; these questions were answered by 100 households, 97 of which had children. There were

- 97 oldest children

- 89 youngest children

Information on the language/s spoken by the eldest and youngest children was thus gathered on 186 children. Information on whether or not children had attended, were attending or were going to attend Gujarati language maintenance school was gathered from the 119 households (accounting for 133 respondents) from which respondents with children answered the long questionnaire. All respondents answered the question about the age of their eldest and youngest children. The youngest child in the data is 7 months old and the oldest is 58 years old. There is a noticeable difference between the Gujarati language skills of the oldest and youngest children within each family.

- $80.4 \%$ of oldest children speak Gujarati

- $56.0 \%$ of youngest children speak Gujarati

In total 128 , or $68.8 \%$, of the 186 children can speak Gujarati. 


\subsubsection{Languages used by oldest and youngest Gujarati children of respondents to the questionnaire}

Table 7-25: Languages used by oldest and youngest Gujarati children

\begin{tabular}{|c|c|c|}
\hline Languages spoken ${ }^{61}$ & $\begin{array}{l}\text { Oldest children of all Gujarati } \\
\text { respondents. As a \% of } 97 \text { households } \\
\text { with oldest children }\end{array}$ & $\begin{array}{l}\text { Youngest children of all Gujarati } \\
\text { respondents. As a \% of } 89 \\
\text { households with youngest children }\end{array}$ \\
\hline Speak Gujarati and English & 63.9 & 49.4 \\
\hline Speak English understand Gujarati & 12.0 & 21.3 \\
\hline Speak Guj/Eng understand Hindi & 12 & 3.3 \\
\hline Speak English only & 3.0 & 4.4 \\
\hline Speak Gujarati/English/Hindi & 3.0 & 2.2 \\
\hline Speak Gujarati only & 1.0 & 1.1 \\
\hline Understand Gujarati only & 1.0 & 0 \\
\hline Speak Guj understand Eng/Hindi & 1.0 & 0 \\
\hline Understand Gujarati/English & 0 & 2.2 \\
\hline Speak English understand Guj/Hindi & 0 & 1.1 \\
\hline Too young & 1.0 & 8.9 \\
\hline No response & 3.0 & 5.6 \\
\hline $\begin{array}{l}\text { Oldest children of Gujarati-born } \\
\text { respondents }\end{array}$ & $\begin{array}{l}\text { As \% of } 60 \text { households with } \\
\text { oldest children }\end{array}$ & $\begin{array}{l}\text { As \% of } 58 \text { households with } \\
\text { youngest children }\end{array}$ \\
\hline Speak Gujarati and English & 63.3 & 56.8 \\
\hline Speak Guj/Eng understand Hindi & 13.3 & 3.4 \\
\hline Speak English understand Gujarati & 10.0 & 17.2 \\
\hline Speak Gujarati/ English/Hindi & 5.0 & 3.4 \\
\hline Speak English only & 1.7 & 1.7 \\
\hline Speak English understand Guj/Hindi & 0 & 1.7 \\
\hline Too young & 0 & 8.6 \\
\hline No response & 5.0 & \\
\hline $\begin{array}{l}\text { Oldest children of Other-born } \\
\text { respondents }\end{array}$ & $\begin{array}{l}\text { As \% of } 8 \text { households with oldest } \\
\text { children }\end{array}$ & $\begin{array}{l}\text { As } \% \text { of } 7 \text { households with } \\
\text { youngest children }\end{array}$ \\
\hline Speak Gujarati and English & 62.5 & 42.8 \\
\hline Speak Guj/Eng understand Hindi & 25.0 & 14.2 \\
\hline Speak English understand Gujarati & 12.5 & 28.5 \\
\hline Too young & 0 & 14.2 \\
\hline $\begin{array}{l}\text { Oldest children of NZ-born } \\
\text { respondents }\end{array}$ & $\begin{array}{l}\text { As \% of } 29 \text { households with } \\
\text { oldest children }\end{array}$ & $\begin{array}{l}\text { As \% of } 24 \text { households with } \\
\text { youngest children }\end{array}$ \\
\hline Speak English and Gujarati & 65.5 & 33.3 \\
\hline Speak English understand Gujarati & 13.8 & 29.1 \\
\hline Speak English only & 6.8 & 12.5 \\
\hline Speak Guj/Eng understand Hindi & 3.5 & 0 \\
\hline Speak Gujarati only & 3.4 & 4.1 \\
\hline Understand Gujarati only & 3.4 & 0 \\
\hline Understand Gujarati/English & 0 & 8.3 \\
\hline Too young & 3.4 & 8.3 \\
\hline No response & 0 & 4.1 \\
\hline
\end{tabular}

\footnotetext{
${ }^{61}$ The subsets in this table, Table 8-19 and Table 9-24 are rank ordered from hightest to lowest percentages of oldest children in each subset.
} 


\subsubsection{Attendance at Gujarati language maintenance school}

Most of the children were attending, had attended or were going to attend a Gujarati language maintenance school. Only 15 (13.4\%) of' 119 households answered 'no' to the question about attendance at language maintenance school. There were 19 respondents from these 15 households and their responses to the questionnaire were analysed to see if there was any obvious reason why they had not sent or did not intend to send their children to language maintenance school. There was no clear-cut reason that could be deduced from the data. The respondents who did not send their children to language maintenance school were reasonably evenly divided between New Zealand-born and Gujarat-born, there was no obvious difference in occupational background, the children did not cluster in any particular age-group. Given the small proportion of families who chose not to send their children to language maintenance school and the lack of any salient common factor linking those families, it seems likely that the reasons are probably family specific; often logistics can be a problem with weekend school and children's non-attendance may well be a result of such reasons. One point worth noting is that almost all the parents whose children did not attend language maintenance school were 'fluent' or 'fairly fluent' speakers of Gujarati. It cannot be suggested that this was a common reason linking them in their decision not to send their children to language maintenance school, as many fluent speakers of Gujarati have sent their children. It does suggest however that parents who are confident of their Gujarati language abilities might feel less concerned about their children attending language maintenance school whereas those who are less confident as to their own language skills might be more determined to make sure their children attend such a school.

\subsubsection{Interviewees and their children's Gujarati language use}

Thirty of the 33 interviewees had children. Altogether interviewees had 47 children between them. In some cases both the parents were interviewed and in some cases only one parent was interviewed, so the 47 children are drawn from 18 households. There was a slight imbalance in favour of female children.

- $59.6 \%$ of the interviewees' children were female

- $40.4 \%$ of the interviewees' children were male

Most of the children (70\%) were between the ages of 10 months and 21 years. The oldest child was 42 years old. 


\subsubsection{Gujarati language proficiency}

Table 7-26: Children's language proficiency as rated (mainly) by mother ${ }^{62}$ in \%

\begin{tabular}{|l|l|l|l|l|}
\hline & Comprehension & Speaking & Reading & Writing \\
\hline Very good & 17 & 12.8 & 2.1 & 2.1 \\
Good & 40.4 & 23.4 & 6.4 & 6.4 \\
Fair & 25.5 & 19.1 & 19.1 & 8.5 \\
Limited & 14.9 & 29.8 & 12.8 & 19.1 \\
Not at all & 0 & 10.6 & 44.7 & 48.9 \\
Too young & 2.1 & 4.3 & 14.9 & 14.9 \\
\hline
\end{tabular}

Age, position in the family, gender, and parent's Gujarati language fluency were all investigated to see if they correlated with the proficiency ratings given to the children.

Parental fluency and gender of the child were found to have the strongest correlation.

Birthplace of parent would have been an interesting factor to consider but the groupings involved were too small; 7 of the households were made up of a New Zealand-born spouse and a non-New Zealand-born spouse, in three households both spouses were Gujarat-born, in two both were New Zealand-born, one household consisted of a New Zealand-born spouse and spouse of Gujarati extraction who was not born in either New Zealand or Gujarat. There were also six interviewees whose partners were not interviewed and/or did not complete a questionnaire.

\subsection{Age}

As can be seen in the graph below, there is no strong correlation between the age of child and the proficiency rating he or she receives from a parent. The only really noticeable differences are that younger children are more likely to receive ratings at either extreme of the scale; they are more likely to be rated 'very good' and more likely to be assessed as having 'no ability' at all. It is also noticeable that the 'limited' rating is more likely to be chosen for children in the 16 to 25 age grouping. I would tentatively suggest that this is because it is at this point in an individual's life, that they are likely to use the least Gujarati. Young children are more likely to spend more time within the immediate family circle than teenagers or young adults and in families that encourage Gujarati use, this will mean that they have more opportunity to use Gujarati (whether they like it or not). Teenagers and young adults operate in a wider sphere of action and are less likely to be

\footnotetext{
${ }^{62}$ Where the mother or both parents were interviewed the mother's rating has been used. Where only the father was interviewed, it is of course, his rating of his children which is shown.
} 
concerned with issues of language maintenance than slightly older adults who are starting their own families and coming to grips with issues of language and culture maintenance as they affect their own young families. One interviewee made this point when she said

[Some people] say things and then suddenly you'll, you know, your whole line of thinking within five years can change... So many young people - you'll find today I'm think about people like NAME... who might tell you one thing now ... will tell you in ten years time something different. Just the way we are. (ID 141)

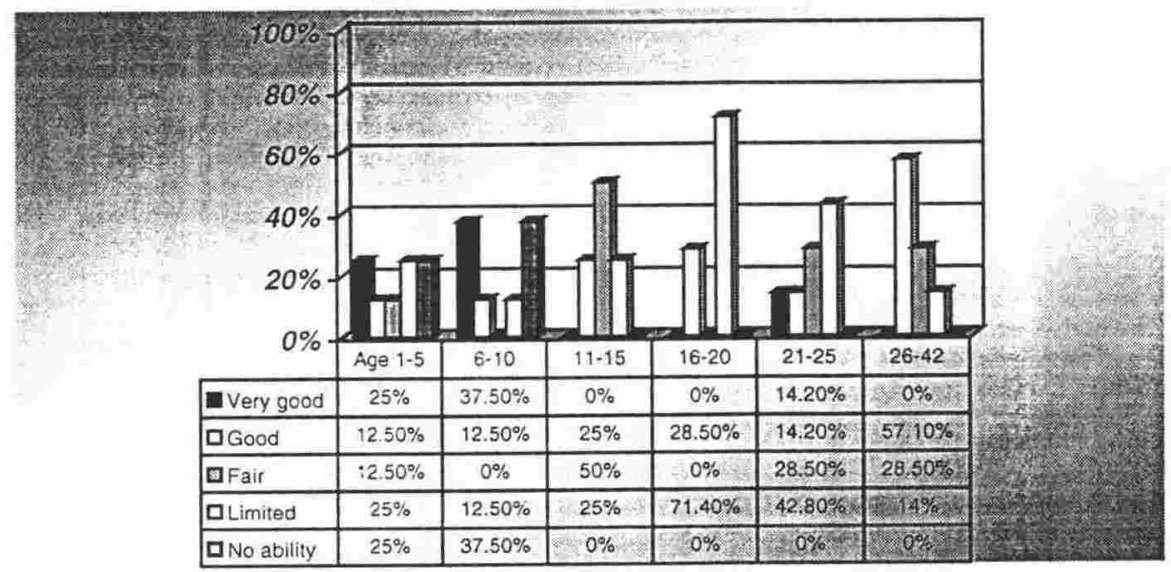

Figure 7-12: Children of Gujarati interviewees. Age and spoken Gujarati

\subsection{Position in family in relation to spoken Gujarati}

Position in the family did not seem to have a strong correlation to proficiency in Gujarati as assessed by a parent. Second children were more likely to be assessed as 'very good' than either first or third, fourth or fifth children but if 'very good' and 'good' are combined then the differences are not great between first and second children. Third, fourth and fifth children however do seem to be more likely to be rated as 'good' and 'very good' as a combined category; $45.3 \%$ were rated as either 'very good' or good' as compared to 36.8 of the first/only children and $33.3 \%$ of the second children.

At first glance, the impression runs contrary to the general agreement in the literature that MT proficiency decreases as one goes down the family (Desai 1994: 11) and with the finding of this research that oldest children were considerably more likely to use the MT than youngest ones. However, it is noticeable that if oldest children are compared with youngest children the figures look slightly different. There are no children in the group of third, fourth and fifth children who have 'no ability' in Gujarati at all, but $20 \%$ of the group of youngest children fall into this category. The numbers involved are small and individual circumstances carry a lot of weight in such a small group; one of the fourth children and the only fifth child come from a family that had recently returned from a visit of some months to Gujarat - their 
Gujarati language skills had obviously benefited. It would be worth investigating with a larger group to see exactly how numerical family position as a factor in MT proficiency ranked in comparison with, as it were, absolute family position. That is, are the language skills of a second or third child in a family of five or six, likely to be different from those of a child who is second or third and also last in their family.

\section{Of 19 first or only children}

- $10.5 \%$ were rated 'very good'

- $26.3 \%$ were rated good

- $21.0 \%$ were rated 'fair'

- $31.5 \%$ were rated 'limited'

- $10.5 \%$ were rated 'no ability'

Of 15 second [includes some youngest] children (total of 15 excludes 2 who were 'too young' to speak)

- $20.0 \%$ were rated 'very good'

- $13.3 \%$ were rated 'good'

- $26.6 \%$ were rated 'fair'

- $20.0 \%$ were rated 'limited'

- $20.0 \%$ were rated 'no ability'

Of 11 third, fourth, fifth [includes some youngest] children

- $9.0 \%$ were rated 'very good'

- $36.3 \%$ were rated 'good'

- $9.0 \%$ were rated 'fair'

- $45.4 \%$ were rated 'limited'

Of 15 youngest children (total of 15 excludes 2 who were 'too young' to speak)

- $20.0 \%$ were rated 'very good'

- $20.0 \%$ were rated 'good'

- $13.3 \%$ were rated 'fair'

- $26.6 \%$ were rated 'limited'

- $20.0 \%$ were rated 'no ability'

\subsection{Gender}

Gender of the child was clearly related to the rating for spoken Gujarati proficiency that the child received from their parents. Female children were more likely to receive a high rating than male children. 


\section{Of 28 females}

- $17.8 \%$ were rated 'very good'

- $28.5 \%$ were rated 'good'

- $21.4 \%$ were rated 'fair'

- $7.1 \%$ were rated 'no ability'

- $3.5 \%$ were rated 'too young'

\section{Of 19 males}

- $5.2 \%$ were rated 'very good'

- $15.7 \%$ were rated 'good'

- $15.7 \%$ were rated 'fair'

- $15.7 \%$ were rated 'no ability'

- $5.2 \%$ were rated 'too young'

There is no obvious reason why the female children are rated so much better than the male children, and it is possible that the rating reflects parental attitudes that are not directly connected to an objective assessment of language abilities. However, when the respondents to the questionnaire assessed their own Gujarati language skills, the New Zealand-born women were more likely to assess themselves as 'fluent' than the New Zealand-born men (38.1\% compared to $28.6 \%$ ). New Zealand-born men were more likely to rate themselves as 'not very fluent' speakers of Gujarati' ( $14.3 \%$ compared to $4.8 \%$ of the women). Perhaps the parents' assessments of their daughters' and sons' respective level of Gujarati language skills are a realistic diagnosis of the fact that Gujarati girls become more competent speakers of Gujarati than boys in the New Zealand environment.

\subsection{Fluency of parent correlated with spoken Gujarati proficiency}

The ratings used in this correlation are based primarily on the female respondent. That is, where both parents, or only the mother, were interviewed, it is the mother's assessment of the child's ability and the mother's assessment of her own Gujarati proficiency that are compared. Where only the father was interviewed, his assessments are used.

There appears to be quite a strong correlation between parental fluency and child's ability in Gujarati .

- $6(12.7 \%)$ children were rated 'very good'

- $11(23.4 \%)$ children were rated 'good' 
All of these children had at least one parent who rated their own abilities as a Gujarati speaker as 'fluent'.

- $9(19.1 \%)$ children were rated 'fair'

- $14(29.7 \%)$ children were rated 'limited'

Of these 23 children, $39.1 \%$ had at least one parent who rated themselves as 'fairly fluent', $56.5 \%$ had at least one parent who rated themselves as 'fluent' and one parent (4.3\%) who gave themselves a rating of 'not very fluent'.

\section{- $5(10.6 \%)$ children were rated as 'no ability'}

All of these children had at least one parent with a self-rating of 'fairly fluent'

There were two children who were 'too young' to speak.

The figures suggest, perhaps unsurprisingly, that only fluent speakers of Gujarati are likely to have children who are also fluent speakers of the language. They also show that simply being a fluent speaker is not enough. It would appear to be a necessary although not a sufficient condition for one's children's MT fluency.

\subsubsection{Interviewees goals' for children's Gujarati language skills}

Interviewees were asked if they wanted their children to be able to speak, comprehend, read and write Gujarati. All the interviewees wanted their children to be able to speak and comprehend Gujarati but only $70 \%$ said that they wanted their children to be able to read and write. Taft and Cahill (1989: 139) also found that all but one of their Lebanese respondents wanted their children to a have a good command of oral Lebanese. Slightly fewer parents (although, at $80 \%$, more than amongst the Gujarati interviewees) wanted them to be literate in the MT. Interviewees were also asked if they were happy with their children's level of competence in Gujarati. The mothers tended to be more satisfied with their children's performance than the fathers. Both mothers and fathers were more likely to be satisfied with their children's Gujarati speaking and comprehension skills and less likely to be satisfied with their Gujarati reading and writing skills.

- $57.4 \%$ of mothers were happy with children's Gujarati speaking skills

- $48.9 \%$ of fathers were happy with children's Gujarati speaking skills

- $61.7 \%$ of mothers were happy with children's Gujarati comprehension skills

- $53.2 \%$ of fathers were happy with children's Gujarati comprehension skills

- $23.4 \%$ of mothers were happy with children's Gujarati reading and writing skills

- $17.0 \%$ of fathers were happy with children's Gujarati reading and writing skills 
Taft and Cahill's respondents do not appear to have been asked whether they were happy with their children's MT skills, but it is interesting to note that the fathers emphasised the importance of MT literacy more than did the mothers (1989: 139). This finding seems to be echoed here by the finding that fathers were less likely than mothers to be happy with their children's level of literacy.

Interviewees were also asked why they wanted their children to be able to speak Gujarati. Most of their responses fell into three broad categories; cultural heritage reasons, return visits to India and communication with the older generation especially grandparents.

- $23(76.6 \%)$ of interviewees mentioned cultural heritage reasons

- 18 ( $60 \%)$ of interviewees mentioned return visits to India

- $15(50 \%)$ of interviewees mentioned speaking to grandparents

In addition to reasons that could be fairly easily grouped into one of these categories there were a few other reasons advanced by parents. Four parents mentioned the link between knowing your MT language and personal identity. Three parents mentioned identity issues specifically, one saying that it was a matter of identity and necessary in order to "keep the person whole'. A fourth parent said that you needed to be able to speak your MT in order to 'know your background', which I have interpreted as an issue of identity. Other people mentioned reasons such as; aesthetics, maintaining an ancestral link with the land, having the best of both worlds, having a private language, and the value of being bilingual. Overall, the interviewees seemed to place a relatively high value on bilingualism. Most interviewees thought that learning Gujarati would have a beneficial (43.3\%) or neutral (50.0\%) effect on their children's English abilities and on their English schooling. Those interviewees who were born in New Zealand and had grown up bilingual in New Zealand seemed to regard the effects on their own lives and education as largely positive. They certainly did not seem to think that their own bilingualism had had any negative educational consequences. One New Zealand-born woman talking about her five year old son who is a fluent speaker of Gujarati said

I think it'll have no effect when you look at a detrimental type of effect. I think it'll have a beneficial effect in that thinking patterns are different and I think that that stretches the mind a bit. If you bring them up in a way where they can use and take advantage of the fact that they've got two languages - um - I think that has a better effect. I think it has a good effect on learning other languages? As well. I know it did for me. (ID 141) 
In an effort to ascertain interviewee parents' attitudes to language learning in general and not just to MT language maintenance in particular, parents were also asked if they wanted their children to learn languages other than Gujarati and English. Most parents (53.3\%) simply said that it was up to the child whether or not they pursued such an interest. However, only two parents said 'no', nine said 'yes', and three specified the language/s they had in mind; French, Hindi and, in the case of one New Zealand-born parent, Maori language and Samoan cultural studies. This parent specifically mentioned these two languages as being of particular relevance to children growing up in New Zealand.

\subsubsection{Summary}

The children of the Gujarati respondents and interviewees are still more likely to be speakers of Gujarati than not. They are most unlikely to speak Hindi. The parents are keen that their children should speak Gujarati. They are not so concerned about their children's ability to read and write Gujarati although they are not happy with the extremely limited skills that most of them have in this area. Overall, roughly half the parents are 'happy' with their children's abilities in spoken Gujarati and mothers are more likely to be satisfied than fathers. Almost all parents have sent their children to Gujarati language maintenance school. The respondents and interviewees clearly care about language and culture maintenance in New Zealand, have gone to some lengths to try to achieve a certain level of maintenance and a small majority of them are reasonable pleased with their success.

Female children and children with 'fluent' Gujarati speakers as parents are more likely to be rated as 'very good' speakers of Gujarati by their parents. Oldest children are more likely to be speakers of Gujarati than youngest children.

\subsection{Patterns of Gujarati and Hindi use during respondents' childhood in New Zealand}

Respondents to the postal questionnaire were not asked questions about their childhood but interviewees answered a series of questions, questions 13-22b, about language use in their childhood (see Appendix 1). Interviewees who were born outside of New Zealand were also able to tell me if the age at which they came to New Zealand constituted 'childhood' in their opinion. Altogether eight Gujarat-born respondents said that they had spoken Gujarati in New Zealand during their childhood; the oldest of these interviewees were 13 when they came to 
New Zealand. Fifteen interviewees were born in New Zealand. Thus of the 33 interviewees, $23(70 \%)$ had spent all or part of their childhood in New Zealand.

\subsubsection{Was Gujarati spoken in your home in New Zealand}

All the interviewees indicated that Gujarati had been spoken in their childhood homes in New Zealand. Curiously, it was only amongst the New Zealand-born that any interviewees (20\% of the New Zealand-born) claimed that Gujarati was 'always' spoken in their childhood home. Three-quarters of the Gujarati-born said that Gujarati was 'mostly' spoken in their home and a quarter that Gujarati was 'sometimes' spoken in their childhood home. A third of the New Zealand-born said that Gujarati was 'mostly' spoken in their home in childhood and $40 \%$ that it was 'sometimes' spoken.

Table 7-27: Language spoken in your home in New Zealand when you were a child

\begin{tabular}{|l|c|c|c|c|}
\hline & NZ-Born & $\begin{array}{c}\text { Came to NZ } \\
\text { under } \mathbf{1 0}\end{array}$ & $\begin{array}{c}\text { Came to NZ } \\
\text { under 13 }\end{array}$ & All respondents \\
\hline Gujarati & $26.7 \%$ & $20 \%$ & $12.5 \%$ & $21.7 \%$ \\
Gujarati English & $66.7 \%$ & $80 \%$ & $87.5 \%$ & $73.9 \%$ \\
NR & $6.7 \%$ & 0 & 0 & $4.3 \%$ \\
$\mathrm{~N}=$ & 15 & 5 & 8 & 23 \\
\hline
\end{tabular}

Table 7-28: How much was Gujarati spoken in your home when you were a child

\begin{tabular}{|l|c|c|c|c|}
\hline & NZ-Born & $\begin{array}{c}\text { Came to NZ } \\
\text { under 10 }\end{array}$ & $\begin{array}{c}\text { Came to NZ } \\
\text { under 13 }\end{array}$ & All respondents \\
\hline Always & $20.0 \%$ & 0 & 0 & $13.0 \%$ \\
Mostly & $33.3 \%$ & $60.0 \%$ & $75.0 \%$ & $47.8 \%$ \\
Sometimes & $40.0 \%$ & $40.0 \%$ & $25.0 \%$ & $34.8 \%$ \\
$\mathrm{NR}$ & $6.7 \%$ & 0 & 0 & $4.3 \%$ \\
$\mathrm{~N}=$ & 15 & 5 & 8 & 23 \\
\hline
\end{tabular}

\subsubsection{Did your parents speak Gujarati to each other}

All the interviewees had Gujarat-born fathers and most of the mothers were also born in Gujarat except for a couple who were born in Africa of Gujarati extraction.

- $69.6 \%$ of parents 'always' spoke Gujarati to each other in the interviewee's childhood home.

\footnotetext{
${ }^{63}$ Includes respondents from previous column 'came to New Zealand under 10'

${ }^{64}$ Includes respondents from previous column 'came to New Zealand under 10'
} 
There was a slight difference between the New Zealand-born and Gujarat-born interviewees. All but one $(87.5 \%)$ of the Gujarat-born interviewees said that their parents 'always' spoke Gujarati with each other. The one exception occurred because this interviewee's mother never came to New Zealand and thus, of course, his parents could not speak Gujarati to each other in New Zealand. The household in which he grew up was still, however, largely Gujarati speaking.

Amongst the New Zealand-born

- $60 \%$ of the interviewees grew up in homes where the parents 'always' spoke Gujarati to each other

- $26.7 \%$ said that their parents had 'mostly' spoken Gujarati to each other

- 1 New Zealand-born interviewee said that their parents had 'sometimes' spoken Gujarati to each other.

Table 7-29: Did your parents speak Gujarati to each other when you were a child

\begin{tabular}{|l|c|c|c|c|}
\hline & NZ-Born & $\begin{array}{c}\text { Came to NZ } \\
\text { under 10 }\end{array}$ & $\begin{array}{c}\text { Came to NZ } \\
\text { under 13 }\end{array}$ & All \\
\hline Always & $60.0 \%$ & $100 \%$ & $87.5 \%$ & $69.6 \%$ \\
Mostly & $26.7 \%$ & 0 & 0 & $17.4 \%$ \\
Sometimes & $6.7 \%$ & 0 & 0 & $4.3 \%$ \\
NA & 0 & 0 & $12.5 \%^{66}$ & $4.3 \%$ \\
NR & $6.7 \%$ & 0 & 0 & $4.3 \%$ \\
N= & 15 & 5 & 8 & 23 \\
\hline
\end{tabular}

\subsubsection{Did your parents speak Gujarati to you}

Not quite half of the interviewees had parents who 'always' spoke Gujarati to them.

- $50 \%$ of the Gujarat-born had parents who 'always' spoke Gujarati to them

- $40 \%$ of the New Zealand-born had parents who 'always' spoke Gujarati to them.

Amongst the Gujarat-born the other $50 \%$ had parents who 'mostly' spoke Gujarati to them in childhood. Amongst the New Zealand-born

- $26.7 \%$ had parents who 'mostly' spoke Gujarati to them

- $26.7 \%$ had parents who 'sometimes' spoke Gujarati to them

\footnotetext{
${ }^{65}$ Includes respondents from previous column 'came to New Zealand under 10'

${ }^{66}$ Mother did not emigrate to NZ
} 
Table 7-30: Did your parents speak Gujarati to you when you were a child

\begin{tabular}{|l|c|c|c|c|}
\hline & NZ-Born & $\begin{array}{c}\text { Came to NZ } \\
\text { under 10 }\end{array}$ & $\begin{array}{c}\text { Came to NZ } \\
\text { under 13 }\end{array}$ & All respondents \\
\hline Always & $40.0 \%$ & $60.0 \%$ & $50.0 \%$ & $43.5 \%$ \\
Mostly & $26.7 \%$ & $40.0 \%$ & $50.0 \%$ & $34.8 \%$ \\
Sometimes & $26.7 \%$ & 0 & 0 & $17.4 \%$ \\
NR & $6.7 \%$ & 0 & 0 & $4.3 \%$ \\
N= & 15 & 5 & 8 & 23 \\
\hline
\end{tabular}

\subsubsection{Did you speak Gujarati at home as a child}

There are some clear differences between the responses of the New Zealand-born and the Gujarat-born to this question although the relatively small numbers of the sample make it hard to know if these differences are significant or not.

- none of the New Zealand-born 'always' spoke Gujarati as child

- one New Zealand-born interviewee (6.7\%) 'never' spoke it.

The rest of the New Zealand-born interviewees were fairly evenly divided between those who 'mostly' spoke Gujarati and those who 'sometimes' spoke it.

- $40 \%$ 'mostly' spoke Gujarati

- $46.7 \%$ 'sometimes' spoke it

Amongst the Gujarat-born

- $12.5 \%$ (one interviewee) 'always' spoke Gujarati at home as a child and

- $37.5 \%$ 'mostly' spoke it

- $50 \%$ 'sometimes' spoke Gujarati

${ }^{67}$ Includes respondents trom previous column 'came to New Zealand under 10' 
Table 7-31: Did you speak Gujarati at home as a child

\begin{tabular}{|l|c|c|c|c|}
\hline & NZ-Born & $\begin{array}{c}\text { Came to NZ } \\
\text { under 10 }\end{array}$ & $\begin{array}{c}\text { Came to NZ } \\
\text { under 13 }\end{array}$ & All respondents \\
\hline Always & 0 & 0 & $12.5 \%$ & $4.3 \%$ \\
Mostly & $40.0 \%$ & $40.0 \%$ & $37.5 \%$ & $39.1 \%$ \\
Sometimes & $46.7 \%$ & $60.0 \%$ & $50.0 \%$ & $47.8 \%$ \\
Never & $6.7 \%$ & 0 & 0 & $4.3 \%$ \\
NR & $6.7 \%$ & 0 & 0 & $4.3 \%$ \\
N= & 15 & 5 & 8 & 23 \\
\hline
\end{tabular}

\subsubsection{Did your parents speak any other Indian language to you as a child}

As many of the Gujarat-born and raised parents of interviewees would be trilingual in English, Gujarati and Hindi, some questions were included about the use of other Indian languages in the home in New Zealand. The only Indian language other than Gujarati that was spoken in interviewees' childhood homes was Hindi and its use was infrequent. Hindi was not spoken in the New Zealand homes of any of the Gujarat-born interviewees but it was spoken in the homes of $26.7 \%$ of the New Zealand-born interviewees. A couple of interviewees said that watching Hindi movies would trigger their mother's use of Hindi and one interviewee said that her father spoke Hindi to her occasionally. As an interviewer I got the impression that these parents were trying to give their children some idea of the linguistic riches of India without actually expecting their children, in the New Zealand context, to become fluent speakers of Hindi.

Table 7-32: Did your parents speak any other Indian language to you when you were a child

\begin{tabular}{|l|c|c|c|c|}
\hline & NZ-Born & $\begin{array}{c}\text { Came to NZ } \\
\text { under } 10\end{array}$ & $\begin{array}{c}\text { Came to NZ } \\
\text { under 13 }\end{array}$ & All respondents \\
\hline No & $66.7 \%$ & $100 \%$ & $100 \%$ & $78.3 \%$ \\
Yes: Hindi & $26.7 \%$ & 0 & 0 & $17.3 \%$ \\
NR & $6.7 \%$ & 0 & 0 & $4.3 \%$ \\
N= & 15 & 5 & 8 & 23 \\
\hline
\end{tabular}

\subsubsection{Attendance at language maintenance school}

Of the 141 Gujarati respondents, 76 said they had not spent any part of their childhood in New Zealand. Of the remaining 65 respondents who had spent part of their childhood here, 37 $(56.9 \%)$ had attended a language maintenance school in New Zealand. Most of these had

\footnotetext{
${ }^{68}$ Includes respondents from previous column 'came to New Zealand under 10 '

${ }^{69}$ Includes respondents from previous column 'came to New Zealand under 10'
} 
attended a community-run language maintenance school. One person had attended a Hindi language course at a polytechnic. Most of the respondents were between the ages of 5 and seven when they started going to language maintenance school and most of them attended for 5 to 10 years. Most respondents said that they had attended classes for three hours a week. The Wellington Indian Association classes run for three hours a week and it is highly likely that the majority of respondents attended that school ${ }^{70}$. Fifteen respondents were taught to read and write Gujarati by a family member.

\subsubsection{Responses from siblings}

As mentioned above in section 6.2.7, it is possible that not all the family relationships between interviewees were traced. There are two known pairs of siblings amongst the interviewees a brother and sister born in Gujarat and New Zealand respectively and a pair of sisters both born in New Zealand. Their overall impressions of MT use in the home do not vary dramatically but neither are they identical. The variation that does occur may be caused by change in family MT use patterns over time or by two differing recollections of essentially the same language use patterns.

\subsubsection{Sibling pair f135/f131}

In this pair the older brother was born in Gujarat and the younger sister in New Zealand. They agreed that both Gujarati and English were spoken in their childhood home but the brother said that Gujarati was 'mostly' spoken and the sister that it was 'sometimes' spoken. This falls into the pattern of use of the MT declining, at least in interactions with host-country-born children, as the period of residence in the host country increases. Both these siblings rated themselves as 'fairly fluent' in Gujarati. They agreed that their parents 'mostly' spoke Gujarati to them when they were children. Interestingly, although they both rate themselves as 'not very fluent' in Hindi, only the younger, New Zealand-born sibling said that her parents spoke Hindi to her as a child. I would tentatively suggest that this bears out the impression that the handful of parents who did speak Hindi to their New Zealand-born children, did so in order to give them a taste of India's linguistic riches and, specifically, the national language. The older sibling would have already have spoken some Hindi when he arrived in New

\footnotetext{
${ }^{70}$ The questions about hours, age of beginning language maintenance school and years attending were only asked on the long version questionnaire and thus the answers came from 30 respondents rather than 37.
} 
Zealand at the age of 10 and thus would not need this input in the same way as his New Zealand-born sibling. Both siblings agree that their parents 'always' spoke Gujarati to each other. The older brother said that he "mostly "spoke Gujarati in the childhood home and the sister said that she 'sometimes' did so. Once again this falls in with the perception that younger children speak less of the MT than older children.

\subsubsection{Sibling pair $\mathrm{f} 134 / \mathrm{f} 141$}

Both these New Zealand-born sisters rate themselves as 'fluent' speakers of Gujarati who can write 'with difficulty'. The younger sister perceives more Gujarati as having been spoken in the childhood home than does the older sister. They agree that their parents 'always' spoke Gujarati with each other and that neither parent spoke any other Indian language to them. The younger sister said that Gujarati was 'always' spoken in the family home and the older sister that it was 'mostly' spoken. They agreed that their parents 'always' spoke Gujarati to them when they were children. However the younger sister said that she 'mostly' spoke Gujarati in the childhood home whereas the older sister said that she 'sometimes' spoke it.

\subsubsection{Speaking Gujarati outside the home in childhood}

Gujarati interviewees were asked if they spoke Gujarati outside the home in their childhood in New Zealand and, if they did, in what places and to whom did they speak (Appendix 1 q.s 2020b). Three interviewees (20\%) said that they never spoke Gujarati outside the home leaving 20 interviewees who did use Gujarati outside the home as children.

Table 7-33: Did you speak Gujarati outside the home as a child

\begin{tabular}{|l|c|c|c|c|}
\hline NZ-Born & $\begin{array}{c}\text { Came to NZ } \\
\text { under } \mathbf{1 0}\end{array}$ & $\begin{array}{c}\text { Came to NZ } \\
\text { under } 13^{71}\end{array}$ & All respondents \\
\hline No & $20.0 \%$ & 0 & 0 & $13.0 \%$ \\
Yes & $73.3 \%$ & $100 \%$ & $100 \%$ & $82.6 \%$ \\
NR & $6.7 \%$ & 0 & 0 & $4.3 \%$ \\
N= & 15 & 5 & 8 & 23 \\
\hline
\end{tabular}

\footnotetext{
${ }^{71}$ Includes respondents from previous column 'came to New Zealand under 10'
} 


\subsubsection{Where interviewees spoke Gujarati outside the home}

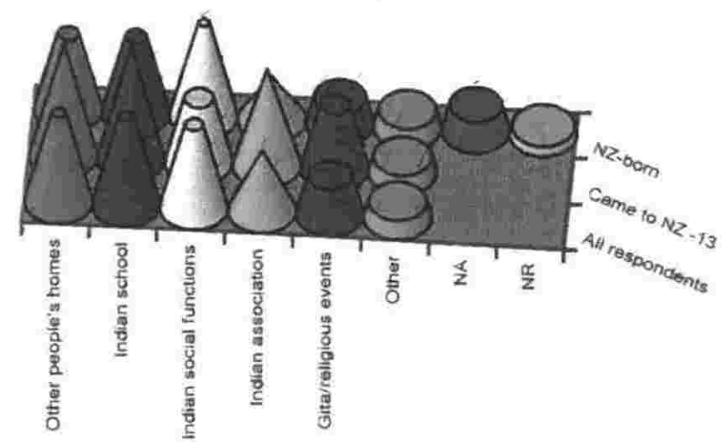

\begin{tabular}{|c|c|c|c|}
\hline & NZ-born & Came to NZ-13 & All respondents \\
\hline Wothet people's horres & $60 \%$ & $87.50 \%$ & $6950 \%$ \\
\hline Indian schooi & $60 \%$ & $8750 \%$ & $69.50 \%$ \\
\hline Dindian social functions & $73.30 \%$ & $50 \%$ & $65.20 \%$ \\
\hline a indian association & $33.30 \%$ & $75 \%$ & $47.80 \%$ \\
\hline Gita/rellgious events & $20 \%$ & $50 \%$ & $30.40 \%$ \\
\hline Dother & $1330 \%$ & $12.50 \%$ & $13 \%$ \\
\hline INA & $20.00 \%$ & & \\
\hline GNR & $6.70 \%$ & & \\
\hline
\end{tabular}

Figure 7-13: Where respondents spoke Gujarati outside the childhood home in NZ

Other people's homes and the Indian school were the two most common places for interviewees to have spoken Gujarati as children outside their family home.

- $69.5 \%$ of the New Zealand-raised interviewees had spoken Gujarati in these two domains.

- $65.2 \%$ said they had spoken Gujarati at social functions

- $47.8 \%$ said they had spoken Gujarati at the 'Indian Association'

No doubt there is some overlap between these three categories.

- $30.4 \%$ had used Gujarati at Gita class and 'religious events'

A few other domains were mentioned by $13 \%$ of the interviewees; the sports field was mentioned by a couple of interviewees as a domain of Gujarati use in childhood and one interviewee specified 'trips back to India' which I have included in the 'other' category although it does not, strictly speaking, fit into the pattern of New Zealand usage that is assumed in this question.

There were some minor differences between the New Zealand-born and the Gujarat-born in response to this question. Both groups agreed that

- other people's homes and the Indian school were the domains where most of them spoke Gujarati outside the home but they were slightly less important to the New Zealand-born (60\% of NZ-born interviewees spoke Gujarati in each 
domain) than to the Gujarat-born (87.5\% of Gujarat-born interviewees spoke Gujarati in each domain).

- Gita class and religious events were more important to the Gujarat-born as domains of Gujarati use (50\%) than they were to the New Zealand-born (20\%)

- the Indian Association was comparatively less important to the New Zealandborn as domain of Gujarati use (33.3\%) than to the Gujarat-born (75\%) and Indian social functions in general were comparatively more important $(73.3 \%)$ than they were to the Gujarat-born (50\%).

\subsubsection{Gujarati-speaking interlocutors outside the home in childhood}

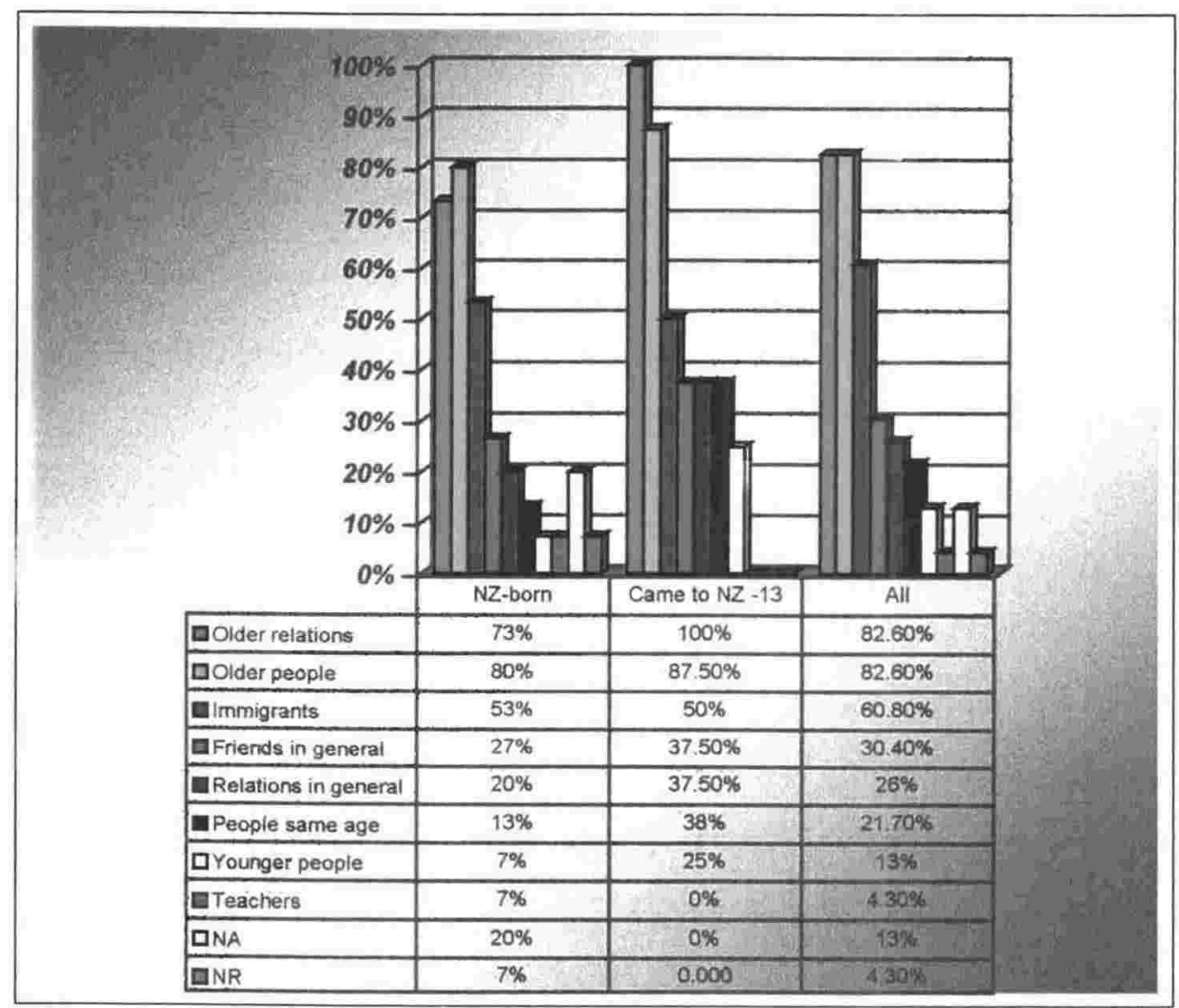

Figure 7-14: Respondents' interlocutors outside the childhood home

Unlike the Dutch respondents, discussed in section 8.6.7.2, who exhibited fairly marked differences between the Dutch-born and the New Zealand-born in response to this question, there was not a great deal of difference between the Gujarati- and the New Zealand-born in response to this question. Overwhelmingly older friends, older relations and new immigrants were the most common Gujarati speaking interlocutors both for the New Zealand-born and the Gujarat-born.

- $80 \%$ of the New Zealand-born had spoken Gujarati with older people generally

- $73.3 \%$ of the New Zealand-born had spoken Gujarati with older relations

- $53.3 \%$ of the New Zealand-born had spoken Gujarati with immigrants,

- $100 \%$ of the Gujarat-born had spoken Gujarati with older relatives,

- $87.5 \%$ of the Gujarat-born had spoken Gujarati with older people generally 
- $50 \%$ of the Gujarat-born had spoken Gujarati with immigrants.

Roughly similar numbers from each group had also spoken Gujarati with relations in general although the Gujarati-born were certainly more likely to do so: $20 \%$ of the New Zealand-born and $37.5 \%$ of the Gujarat-born. Such differences as there were came in the area of younger interlocutors. Amongst the Gujarat-born

- $25 \%$ had spoken Gujarati with children younger than they were

- $37.5 \%$ with children the same age

- $37.5 \%$ had also used Gujarati with friends in general when they were children

Amongst the New Zealand-born only

- $26.6 \%$ had spoken Gujarati with friends in general

- $13.3 \%$ had used Gujarati with children the same age

- $7.3 \%$ (one person) had spoken Gujarati with children younger than themselves

A pattern of restricted Gujarati use amongst the New Zealand-born seems to appear here. Those interviewees who spent part of their childhood in Gujarat, perhaps still associated Gujarati with speaking to children their own age whereas those born in New Zealand associated Gujarati with speaking to Indian adults and English with speaking to everyone else, One New Zealand-born interviewee specified ‘teachers' as Gujarati speaking interlocutors in childhood - logically this probably applies to all the respondents who attended Gujarati school but it is interesting that only one person specified it.

\subsubsection{Gujarati language proficiency of respondents born or raised in NZ}

Some Gujarati was spoken in all the childhood homes of respondents raised in New Zealand and all those respondents had at least some Gujarati language skills. 
Table 7-34: Present proficiency in spoken Gujarati

\begin{tabular}{|l|c|c|c|c|}
\hline & NZ-born & $\begin{array}{c}\text { Gujarat-born arrived in NZ } \\
\text { under } \mathbf{1 0}^{\mathbf{7 2}}\end{array}$ & $\begin{array}{c}\text { Gujarat-born arrived in NZ } \\
\mathbf{1 0 - 2 0}\end{array}$ & $\mathbf{N}=$ \\
\hline Fluent & $26.6 \%$ & $40 \%$ & $100 \%$ & 9 \\
Fairly fluent & $60 \%$ & $20 \%$ & & 10 \\
Not very fluent & $13.3 \%$ & $20 \%$ & & 3 \\
Comp. Only & 0 & $20 \%$ & 3 & 1 \\
$\mathrm{~N}=$ & 15 & 5 & & \\
\hline
\end{tabular}

Table 7-35: Present proficiency in written Gujarati

\begin{tabular}{|l|c|c|c|c|}
\hline & NZ-born & $\begin{array}{c}\text { Gujarat-born arrived in NZ } \\
\text { under } \mathbf{1 0}\end{array}$ & $\begin{array}{c}\text { Gujarat-born arrived in NZ } \\
\mathbf{1 0 - 2 0 ^ { 7 5 }}\end{array}$ & $\mathbf{N}=$ \\
\hline Write easily & $6.6 \%$ & 0 & $100 \%$ & 4 \\
Fairly easily & $26.6 \%$ & 0 & & 4 \\
With difficulty & $26.6 \%$ & $60 \%$ & & 7 \\
Read only & $6.6 \%$ & 0 & & 1 \\
No ability & $33.3 \%$ & $40 \%$ & 3 & 7 \\
N= & 15 & 5 & & 23 \\
\hline
\end{tabular}

The numbers involved are small but they follow the intuitively likely pattern. In general, those born in New Zealand are less likely to be fluent in Gujarati, those who arrived under the age of 10 are more likely to be so and all those who arrived in New Zealand over the age of 10 are confident speakers of Gujarati. Literacy skill does not follow the pattern quite so closely although, once again, the respondents who arrived over the age of 10 are all confident in their Gujarati literacy skills. . Bennett comments on a similar phenomenon when she says of Dutch language maintenance in Australia

The situation of informants who arrived in Australia as very young children is likely to have provided them with more opportunities to use Dutch and a greater knowledge of the language than those born in Australia. They may have had considerable exposure to Dutch in their early years, whereas the parents of those born in Australia may already have been living in that English-speaking environment for a number of years and have moved to a greater use of English. Similarly, any older siblings of Dutchborn informants are more likely to be and additional positive influence on language maintenance than those of Australian-born informants (Bennett 1992:63).

\footnotetext{
${ }^{72}$ Age range was from $03-05$ years

${ }^{73}$ Age range was from $11-13$ years

${ }^{74}$ Age range was from 03-05 years

75 Age range was from $11-13$ years
} 
The numbers are small and the differences slight but it can be seen that the respondents who born outside New Zealand are more likely to speak Gujarati fluently and write it easily. This outcome can be related to the patterns of childhood home language use (in New Zealand) than have been discussed in the forgoing pages and that are summarised below, showing that nonNew Zealand-born respondents were likely to hear more Gujarati used at home than New Zealand-born respondents.

\section{Parents always spoke Gujarati to each other}

- $66 \%$ for those who arrived in New Zealand between the ages of $10-20$

- $100 \%$ for those who arrived in New Zealand under the age of 10

- $87.5 \%$ for those who arrived in New Zealand under the age of $13^{76}$

- $60 \%$ for the New Zealand-born

\section{Parents always spoke Gujarati to the respondent}

- $33.3 \%$ for those who arrived in New Zealand between the ages of $10-20$

- $60 \%$ for those who arrived in New Zealand under the age of 10

- $50 \%$ for those who arrived in New Zealand under the age of $13^{77}$

- $40 \%$ for the New Zealand-born

\section{Respondent always spoke Gujarati at home}

- $33.3 \%$ for those who arrived in New Zealand between the ages of $10-20$

- $0 \%$ for those who arrived in New Zealand under the age of 10

- $12.5 \%$ for those who arrived in New Zealand under the age of $13^{78}$

- $0 \%$ for the New Zealand-born

\subsubsection{Summary}

Most of the respondents who spent all or part of their childhood in New Zealand grew up in homes where a lot of Gujarati was used. However, they did not necessarily use a lot of Gujarati themselves; the single largest group spoke Gujarati 'sometimes'. Most of them also used Gujarati outside the family home, often at other Gujarati people’s homes, at social functions and at the Indian language maintenance school. There was not a great difference

\footnotetext{
${ }^{76}$ This is the combined figure for the 2 groups of non-New Zealand-born respondents (because the oldest respondent in the 10-20 group was 13)

77 This is the combined figure for the 2 groups of non-New Zealand-born respondents (because the oldest respondent in the 10-20 group was 13)

${ }^{78}$ This is the combined figure for the 2 groups of non-New Zealand-born respondents (because the oldest respondent in the 10-20 group was 13)
} 
between the responses of those who were born in New Zealand and those who came here as children.

\subsection{Conclusion}

Gujarati is still widely used amongst both non-New Zealand-born and New Zealand-born Gujaratis, but its use is definitely declining amongst the New Zealand-born. There is strong support for the goals of linguistic and cultural maintenance and both individuals and the community as a whole have gone to considerable effort to achieve those goals. There is widespread but not universal support for some government assistance in the areas of interpreting and translating services and in language maintenance teaching. Over half the children of respondents can speak Gujarati but they are less likely to be Gujarati literate. Older children and female children are more likely to be rated as having good Gujarati language skills by their parents. 


\section{ANALYSIS OF THE DUTCH RESPONDENTS' RESPONSES TO THE QUESTIONNAIRE}

\subsection{Demographic profile of Dutch respondents}

The Dutch survey responses were obtained from 184 adults who answered postal questionnaires. These respondents also answered questions about their oldest and youngest children (228 children in total) so that information on a total of 412 (excluding the information about the language use of respondents' parents during the respondents childhood) people was obtained.

The respondents were almost all born in the Netherlands, or born in the Dutch East Indies or New Zealand of Dutch parentage (see Methodology chapter describing how respondents to the questionnaire were targeted section.6.5.2).

\subsubsection{Census data}

The 1991 Census showed that 24,733 people ( $0.73 \%$ of the New Zealand population) gave their ethnicity as Dutch (Thomson 1993:15-22) but as Thomson points out

[the Dutch] appear to have fewer than average children although this may not indicate fewer descendants. Rather, this may indicate that the descendants are more inclined to designate themselves as 'New Zealand European'. (Thomson 1993:21).

Unlike the other groups studied in this survey, the national distribution of the Dutch population is very similar to the distribution of the general New Zealand population. This is partly as a result of a deliberate policy of dispersal or 'pepper-potting' of immigrants in order to encourage 'successful integration' (Schouten 1992: 117). Consequently, the greatest percentage of the Dutch population is in the Auckland region (nearly a third) and about a tenth of the population (3047 people) is in the Wellington region (Thomson 1993:87, 95). The 184 respondents to this questionnaire represent $6 \%$ of those in the Wellington regional population who gave their ethnicity as Dutch in the 1991 Census.

\subsubsection{Birthplace}

Most of the respondents were born in the Netherlands, a handful were born in what is now Indonesia (the Dutch East Indies at the time of their birth) and forty were born in New 
Zealand. One respondent was born in elsewhere in Europe. She was born to Dutch-born parents, spoke Dutch and another European language as her first languages, received her primary and secondary education in the Netherlands, speaks Dutch now, amongst others, to her parents and children. For all these reasons, her birth outside the Netherlands is regarded as largely irrelevant to this questionnaire and she is counted as one of the Dutch-born.

Table 8-1: Birthplace

\begin{tabular}{|l|c|c|}
\hline Birthplace & Number & Percentage \\
\hline Netherlands & 131 & $71 \%$ \\
New Zealand & 40 & $22 \%$ \\
Indonesia & 13 & $7 \%$ \\
$\mathrm{~N}=$ & 184 & 100 \\
\hline
\end{tabular}

\subsubsection{Gender}

Of the 233 people to whom the questionnaire was sent

- $45 \%$ were men

- $54.5 \%$ were women

- one person $(0.5 \%)$ was of unknown gender ${ }^{79}$.

The ratio of female to male respondents followed the ratio of the mail-out

- $55 \%$ of respondents (101) were women

- $45 \%$ (83) were men.

These proportions are substantially the same for the Dutch-born respondents

- $54 \%$ women

- $46 \%$ men

but are somewhat exaggerated amongst the New Zealand-born respondents where

- $65 \%$ of the respondents are female

- $35 \%$ male $e^{80}$.

The proportions are reversed amongst the Indonesian born

- $69 \%$ male

- $31 \%$ female

\footnotetext{
${ }^{79}$ The respondent who gave me this person's name identified them only as Dr. NAME

${ }^{80}$ Because respondents did not give me the birthplaces of the people whose names they suggested, it is not possible to know how many Dutch-, New Zealand- or D.E.I.-born people received the questionnaire.
} 
but the numbers involved are very small. In New Zealand as a whole, there are slightly more men (54\%) than women (46\%) in the Dutch population (Thomson 1993:22).

Table 8-2: Gender of respondents to questionnaire

\begin{tabular}{|l|c|c|c|c|}
\hline & All Respondents & $\begin{array}{c}\text { Born in } \\
\text { Netherlands }\end{array}$ & Born in New Zealand & Born in D.E.I \\
\hline Male & $45 \%$ & $46 \%$ & $35 \%$ & $69 \%$ \\
Female & $55 \%$ & $54 \%$ & $65 \%$ & $31 \%$ \\
$\mathrm{~N}=$ & 184 & 131 & 40 & 13 \\
\hline
\end{tabular}

The gender balance for the Dutch New Zealand-born respondents is similar to that for the New Zealand-born Gujarati respondents (40:60 male:female) and the reasons may also be similar to those that were suggested for the Gujarati respondents. New Zealand-born respondents may see issues of language and culture maintenance as 'women's issues' rather than as matters of general responsibility.

\subsubsection{Age}

There was a heavy concentration in the over 60 age group as there was amongst the Gujarati respondents. As with the Gujarati questionnaire, the subject matter of the questionnaire meant that respondents were more likely to have children. In the case of the friend-of-friend methodology used with the Dutch questionnaire it seems possible that respondents were more likely to suggest the names of people who were older and who had children. Recipients of the questionnaire were also probably more likely to answer it if they had children (although, of course, not many recipients failed to answer the questionnaire.) There is only a handful of respondents under thirty. The survey was not designed to seek respondents in proportion to the age structure of the general New Zealand population, but it should be noted that the Dutch population in New Zealand does have a disproportionate number of people in the 60-64 age group, reflecting the migration patterns of the 1950s (Thomson 1993:2). 12.5\% of the Dutch population in New Zealand is in the 60-64 age group compared to slightly over $4 \%$ of the New Zealand population (Thomson 1993:26). 
Table 8-3: Age Group of Respondents

\begin{tabular}{|l|c|c|c|c|}
\hline Age range & $\begin{array}{c}\text { All Respondents: } \\
\text { Number }\end{array}$ & $\begin{array}{c}\text { All Respondents: } \\
\text { Percentage }\end{array}$ & $\begin{array}{c}\text { NZ-born } \\
\text { Respondents: } \\
\text { Number }\end{array}$ & $\begin{array}{c}\text { NZ-born } \\
\text { Respondents: } \\
\text { Percentage }\end{array}$ \\
\hline $21-25$ & 3 & $1.6 \%$ & 2 & $5 \%$ \\
$26-30$ & 8 & $4.3 \%$ & 5 & $12 . \% 5$ \\
$31-35$ & 24 & $13 \%$ & 13 & $32.5 \%$ \\
$36-40$ & 35 & $19 \%$ & 18 & $45 \%$ \\
$41-45$ & 11 & $6 \%$ & 2 & $5 \%$ \\
$46-50$ & 14 & $7.6 \%$ & 0 & 0 \\
$51-55$ & 9 & $4.9 \%$ & 0 & 0 \\
$56-60$ & 16 & $8.7 \%$ & 0 & 0 \\
$60+$ & 64 & $34.7 \%$ & 0 & 0 \\
\hline
\end{tabular}

The New Zealand-born respondents are concentrated heavily in the child-rearing years of 2645. That there are no New Zealand-born respondents over 45 years reflects the very limited Dutch immigration to New Zealand before the 1950s. These respondents are, mostly, the children of those who came in that first big influx. Most of the D.E.I-born (69\%) are over 60.

\subsubsection{Marital status}

Most of the respondents (85\%) were married. A few ticked 'living with a partner', a few were 'formerly married' and even fewer ticked 'never married'.

Table 8-4: Marital status

\begin{tabular}{|l|c|c|c|c|}
\hline Status & $\begin{array}{c}\text { All Respondents } \\
\text { Number }\end{array}$ & $\begin{array}{c}\text { All Respondents } \\
\text { Percentage }\end{array}$ & $\begin{array}{c}\text { NZ-born } \\
\text { Respondents } \\
\text { Number }\end{array}$ & $\begin{array}{c}\text { NZ-born } \\
\text { Respondents } \\
\text { Percentage }\end{array}$ \\
\hline Married & 157 & $85.3 \%$ & 29 & $72.5 \%$ \\
Formerly married & 8 & $4.3 \%$ & 2 & $5 \%$ \\
Never married & 6 & $3.3 \%$ & 2 & $5 \%$ \\
Living with partner & 12 & $7 \%$ & 7 & $17.5 \%$ \\
N= & 184 & 99.9 & 40 & 100 \\
\hline
\end{tabular}

There were no great discrepancies in marital status between any of the groups. All the D.E.I. respondents were married except for one who was 'formerly married'. There were 42 couples amongst the 184 respondents.

\subsubsection{Partner's Birthplace}

Dutch respondents were asked where their partners were born. Some respondents answered this question even when their partner was dead or divorced so the figures given here do not correlate exactly with those in Table 8-4. 
Table 8-5: Partner's birthplace

\begin{tabular}{|c|c|c|c|c|c|c|c|c|c|c|c|c|}
\hline $\begin{array}{l}\text { R's } \\
\text { Birthplace }\end{array}$ & $\begin{array}{l}\text { Par } \\
\text { in: } N\end{array}$ & $\begin{array}{l}\text { orn } \\
\text { ands }\end{array}$ & $\begin{array}{l}\text { Par } \\
\text { in } N\end{array}$ & $\begin{array}{l}\text { born } \\
\text { Dutch }\end{array}$ & $\begin{array}{l}\text { Part } \\
\text { NZ: }\end{array}$ & $\begin{array}{l}\text { Dorn in } \\
\text { Dutch }\end{array}$ & & $\begin{array}{l}\text { tner } \\
n \text { in } \\
\text { E.I. }\end{array}$ & & $\begin{array}{l}\text { ner } \\
\text { in: } \\
\text { her }\end{array}$ & NR & \\
\hline Netherlands & 85 & $65 \%$ & 5 & $4 \%$ & 23 & $17.5 \%$ & 1 & $0.5 \%$ & 13 & $10 \%$ & 4 & $3 \%$ \\
\hline $\mathrm{NZ}$ & 2 & $5 \%$ & 8 & $20 \%$ & 26 & $65 \%$ & 0 & & 2 & $5 \%$ & 2 & $5 \%$ \\
\hline D.E.I. & 3 & $23 \%$ & 1 & $7.6 \%$ & 1 & $7.6 \%$ & 7 & $54 \%$ & 1 & $7.6 \%$ & 0 & \\
\hline $\mathrm{N}=$ & 90 & & 14 & & 50 & & 8 & & 16 & & 6 & \\
\hline
\end{tabular}

Unsurprisingly we find that most Dutch-born respondents are married to people born in the Netherlands, most New Zealand-born respondents are married to others of New Zealand birth and most of the small number of respondents born in the D.E.I. are married to fellow colonials. It is perhaps worth noting that $20 \%$ of the New Zealand-born are married to fellow New Zealand-born of Dutch descent and that $10 \%$ of the Dutch-born are married to partners who are not Dutch or New Zealanders (or indeed born in the D.E.I.).

\subsubsection{Children}

Most of the respondents had children (87.5\%). Two respondents gave no answers to the questions about how many children they had and what language the children spoke but both respondents recorded earlier in the questionnaire that they spoke English with their children. It is assumed that they had children but for some reason chose not to answer the later questions. They are recorded in the total number of respondents with children but, of course, we do not know how many children they have.

The numbers of New Zealand-born respondents with children were slightly lower - $75 \%$ of the New Zealand-born respondents had children. Looking at the figures by household, we find that $84.5 \%$ of households had children. Family sizes ranged from one child in the family ( $8 \%$ of households) to eight children in the family (one household) but most households had 2 to 4 children (66\% of households).

\subsubsection{Family structure}

The 184 respondents to the questionnaire lived in 142 households. A very small majority $(51 \%)$ of these households consisted of the respondent, respondent's spouse or partner and children. Another large section (36\%) of respondents lived with their spouse only; this reflects the large number of comparatively older respondents. These respondents had children but the children were not living at home. A tiny number of respondents (two households) lived in an 
extended family of some kind (here extended family is defined as "spouse, children and other family members'). An almost equally small number of households (three) consisted of respondent, spouse and another person or persons.

Table 8-6: Family Structure

\begin{tabular}{|l|l|l|}
\hline Members of respondent's household & No. of households & Percentage \\
\hline Spouse, children & 73 & $51.4 \%$ \\
Spouse & 51 & $35.9 \%$ \\
Children & 3 & $2.1 \%$ \\
Spouse, other & 3 & $2.1 \%$ \\
Spouse, children, other & 2 & $1.4 \%$ \\
Flatmates & 2 & $1.4 \%$ \\
Older relatives & 1 & $0.7 \%$ \\
N/A & 6 & $4.2 \%$ \\
N/R & 1 & $0.7 \%$ \\
N $=$ & 142 & $100 \%$ \\
\hline
\end{tabular}

\subsubsection{Education}

\subsubsection{Where educated}

Table 8-7: Countries in which the respondents were educated

\begin{tabular}{|c|l|l|}
\hline No. & $\%$ & Place of education \\
\hline 92 & $50 \%$ & educated entirely in the Netherlands \\
44 & $23.9 \%$ & educated entirely in New Zealand \\
36 & $19.6 \%$ & educated in the Netherlands and New Zealand \\
7 & $3.8 \%$ & educated in Indonesia and the Netherlands \\
1 & $0.5 \%$ & educated in New Zealand, the Netherlands, Britain, West Germany \\
1 & $0.5 \%$ & educated in Indonesia, the Netherlands, New Zealand \\
1 & $0.5 \%$ & educated in New Zealand, Australia \\
1 & $0.5 \%$ & educated in the Netherlands, Britain \\
1 & $0.5 \%$ & educated unknown, the Netherlands \\
\hline
\end{tabular}

Of the 36 educated in the Netherlands and New Zealand

- 10 completed primary and secondary education in the Netherlands then tertiary in New Zealand

- 16 completed primary secondary and tertiary in the Netherlands and also completed a tertiary course in New Zealand

- 6 completed primary in the Netherlands and completed a tertiary course in New Zealand

- 2 received primary and secondary education the Netherlands and also secondary and tertiary education in New Zealand

- 1 received primary and secondary education in both the Netherlands and New Zealand 
- completed primary education the Netherlands, secondary education elsewhere in Europe and tertiary education in New Zealand ${ }^{81}$

Table 8-8: Dutch respondents: level of education attained

\begin{tabular}{|clr|}
\hline No. & Level of education $^{82}$ & $\%$ \\
\hline 55 & received university education & $29.9 \%$ \\
43 & received secondary education & $23.4 \%$ \\
14 & completed apprenticeship & $7.6 \%$ \\
13 & completed apprenticeship/polytechnic & $7.1 \%$ \\
38 & received polytechnic education & $20.7 \%$ \\
5 & teacher training & $2.7 \%$ \\
5 & nursing & $2.7 \%$ \\
1 & library qualifications & $0.5 \%$ \\
6 & other tertiary & $3.3 \%$ \\
Tertiary other than university & $44.5 \%$ \\
4 & completed primary & $2.2 \%$ \\
184 & TOTAL & $100 \%$ \\
\hline
\end{tabular}

It is, unfortunately, not possible to make a comparison between the level of education attained by respondents to the questionnaire and the level of education of the Dutch respondents to the 1991 Census, as those figures are not available. The closest comparison that can be made is with 'European' ${ }^{\prime 33}$ (Thomson 1993:75). With all of these comparisons, it should be noted that respondents were not asked what secondary qualifications they had gained; merely what level of education they had completed. It is possible of course that a respondent without secondary qualifications could regard themselves as having 'completed' secondary school. Thus there may be some respondents in this category who would, in Thomson's classification, be included in the category of 'no qualifications'.

\footnotetext{
\$I Because there is only one respondent with this education pattern I have included them in the Netherlands/NZ group

82 The categories in this table are derived from Thomson in the same way as the categories used for the Gujarati respondents.

${ }^{83}$ Dutch, Greek, Polish, Yugoslav, Italian, Other European Groups (Thomson: 1993:73)
} 
Table 8-9: Highest level of education attained by Dutch respondents to the survey compared with level of education attained by European respondents to 1991 census (Thomson 1993:78)

\begin{tabular}{|l|c|c|}
\hline Level of education & Dutch respondents & European respondents to 1991 Census \\
\hline Completed uni education & $29.9 \%$ & $15.5 \%$ \\
Completed secondary & $23.4 \%$ & $30 \%$ \\
Completed tertiary & $44.5 \%$ & $35 \%$ \\
No qualifications & $2.2 \%$ & $19 \%$ \\
$\mathrm{~N}=$ & $100 \%$ & $99.5 \%{ }^{84}$ \\
\hline
\end{tabular}

Table 8-10: Highest level of education attained by Dutch male and female respondents to the survey compared with level of education attained by male and female European respondents to 1991 census (Thomson 1993:78)

\begin{tabular}{|l|c|c|c|c|}
\hline Level of education & Dutch men & European men & Dutch women & European women \\
\hline University & $42 \%$ & $17 \%$ & $20 \%$ & $14 \%$ \\
Secondary & $11 \%$ & $26 \%$ & $34 \%$ & $34 \%$ \\
Other tertiary & $45 \%$ & $39 \%$ & $44 \%$ & $31 \%$ \\
No qualifications & $2 \%$ & $17 \%$ & $2 \%$ & $21 \%$ \\
N= & $100 \%$ & $99 \% 85$ & $100 \%$ & $100 \%$ \\
\hline
\end{tabular}

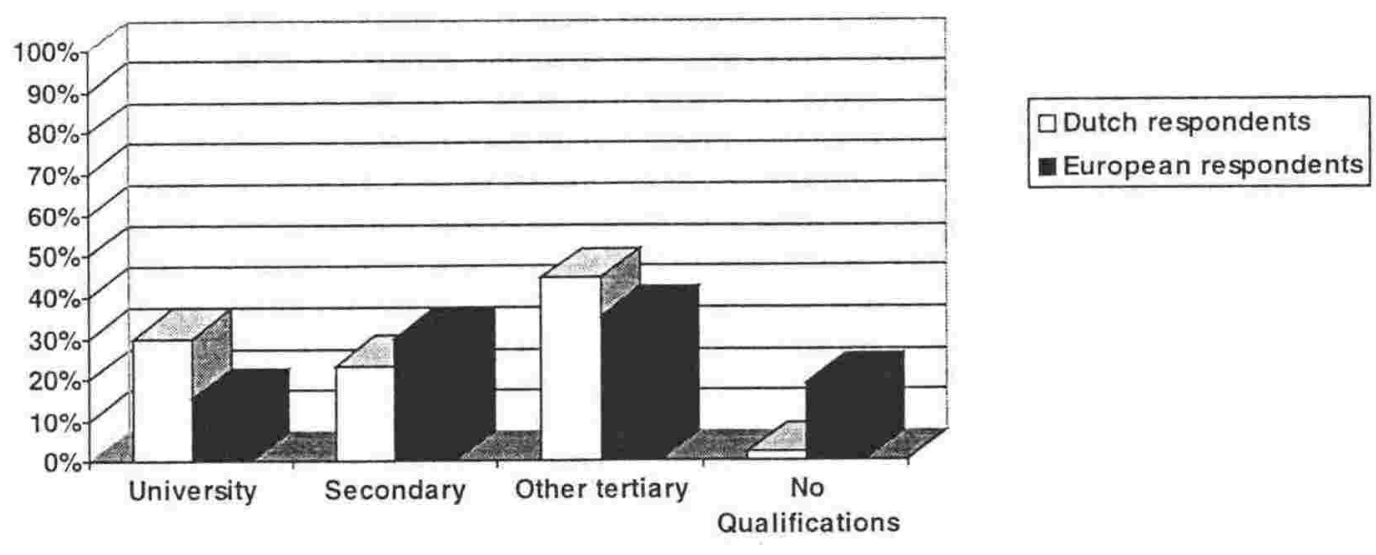

Figure 8-1: Highest level of education attained by all Dutch respondents to the survey compared with level of education attained by 'European' respondents to 1991 census (Thomson 1993:78)

\subsubsection{Summary}

Over two thirds of the Dutch respondents were born in the Netherlands, just under a quarter in New Zealand, and the remainder in what is now Indonesia. Roughly equal proportions of men and women responded to the questionnaire. Slightly more than a third of the respondents were

\footnotetext{
${ }^{84}$ 'Still at school' not included

85 “not specified', 'still at school' not included
} 
over 60 years of age, reflecting the immigration patterns of the Dutch to New Zealand. There were only 11 respondents under 30 . Most of the respondents were married and there were 42 couples among the 184 respondents. Most of the non-New Zealand-born had partners of Dutch origin and most of the New Zealand-born did not. Most of the respondents had children and a small majority live in a two generation nuclear family. Over a third of the respondents lived only with their spouse; presumably they had raised their children in a two generation nuclear family and the children had now left home. Half the respondents were educated entirely in the Netherlands, and almost a quarter of them were educated entirely in New Zealand. The remainder were educated in more than one country. Many of the respondents have trade qualifications; $44.5 \%$ have a non-university tertiary qualification. This reflects the 1950s demand for qualified tradespeople as immigrants (Pearson 1990:114-115). Under a third have completed a university education. In comparison with the 'European' respondents to the 1991 Census, the Dutch questionnaire respondents are more likely to have a university or some other tertiary qualification.

\subsection{Dutch community: patterns of language use}

This section gives an overview of patterns of language use within the Dutch community.

\subsubsection{Language first spoken}

Unsurprisingly, given the preponderance of Dutch-born respondents a substantial majority (78.3\%) of the 184 respondents spoke Dutch as their first language. Even amongst the New Zealand-born, slightly over a third (35\%) spoke Dutch first. Perhaps the most interesting thing about first language/s spoken is the small but noticeable number of non-New Zealand-born respondents whose first language was not Dutch, or who spoke another language as well as Dutch as their first languages. Several of the D.E.I-born spoke Javanese, Indonesian or Malay in addition to Dutch as a first language, several respondents spoke Limburgs or 'Dialect' first and one respondent spoke Fries first.

Table 8-11: Language first spoken

\begin{tabular}{|l|l|l|l|l|l|l|l|l|}
\hline Birthplace & Dutch & English & $\begin{array}{l}\text { Dutch/ } \\
\text { Eng }\end{array}$ & $\begin{array}{l}\text { Dutch/ } \\
\text { Other }\end{array}$ & Limburgs & Fries/ 'Dialect' & Other & $\mathrm{N}=$ \\
\hline Netherlands & 123 & 1 & 0 & 2 & 2 & 2 & 1 & 131 \\
NZ & 14 & 25 & 1 & 0 & 0 & 0 & 0 & 40 \\
D.E.I. & 7 & & 1 & 5 & 0 & 0 & 0 & 13 \\
\hline
\end{tabular}




\subsubsection{Language most used}

Overwhelmingly English is the language most used on a day-to-day basis by the respondents.

- all of the New Zealand-born respondents use English most

- $70 \%$ of the Dutch-born use English most

- $69 \%$ of the D.E.I.-born use English most

Very few respondents said that they used Dutch most. The seven respondents (4\%) who did indicate that Dutch was their most used language were all born in the Netherlands. Thirty-five of the respondents (Dutch or D.E.I.) picked '50/50 Dutch English' as the 'language' they used most. Overall, although Dutch still has some place in the community, English is undoubtedly the dominant language for most of the respondents. One Dutch-born respondent indicated that English and Limburgs were the two languages that he used equally.

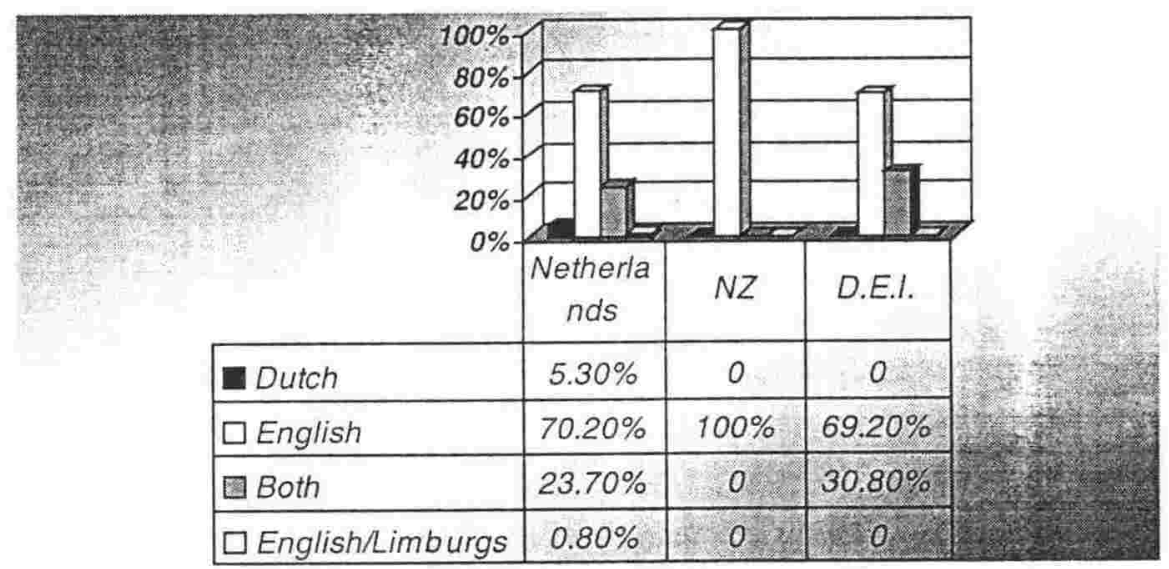

Figure 8-2: Dutch respondents: most used languages by birthplace

\subsubsection{Linguistic background of respondents}

Most of the respondents are bilingual or multilingual; only $5.4 \%$ were monolingual. All the monolinguals could speak only English and all but one of them were born in New Zealand. The Dutch-born respondents were almost equally divided between those who were bilingual in Dutch and English (49\%) and those who were trilingual or multilingual. German was the most common third language followed by French.

- 66 of the Dutch-born respondents (50\%) spoke German

- 42 of the Dutch-born respondents (32\%) spoke French

The other languages spoken by the Dutch-born respondents make up a fascinating mixture.

- a handful of Dutch 'dialects'

- two Fries speakers

- three Limburgs speakers

- two speakers of what one calls 'Dutch Dialect' and the other 'a dialect which is between German and "Dutch"[sic]' 
- three speakers of Japanese

- three speakers of Spanish

- three speakers of Indonesian. and

- speakers of Javanese, Mandarin, Greek, 'Swiss' and Swedish

It appears to be a community rich in language resources and of individuals proud of those resources. One Dutch-born respondent wrote of her children

their schooling [was] deficient in my eyes because they were taught only ONE language: English... An insularity inherited from the English forebears has been enhanced by our truly isolated geographic position and it will take a major effort and years of gentle indoctrination to convince people of the necessity to speak GOOD English plus a workable knowledge of at least two other languages of our main trading partners ... Neither is there any appreciation of the time and effort it takes to learn another language proficiently. Nor of the infinite pleasure one gains from it.

(Emphasis in the original) (Female, Dutch-born, 60s, came to New Zealand 21-30).

The D.E.I.-born respondents display the same richness of languages. Most of them speak an Indonesian language in addition to English and Dutch. German and French are widely spoken and Spanish and Maori are also spoken by one of these respondents. It is noticeable that the New Zealand-born are comparatively linguistically impoverished. Although well over half speak Dutch and English (62.5\%) and the remaining 15\% speak French and/or German as well as Dutch and English, a substantial minority (22.5\%) speak only English.

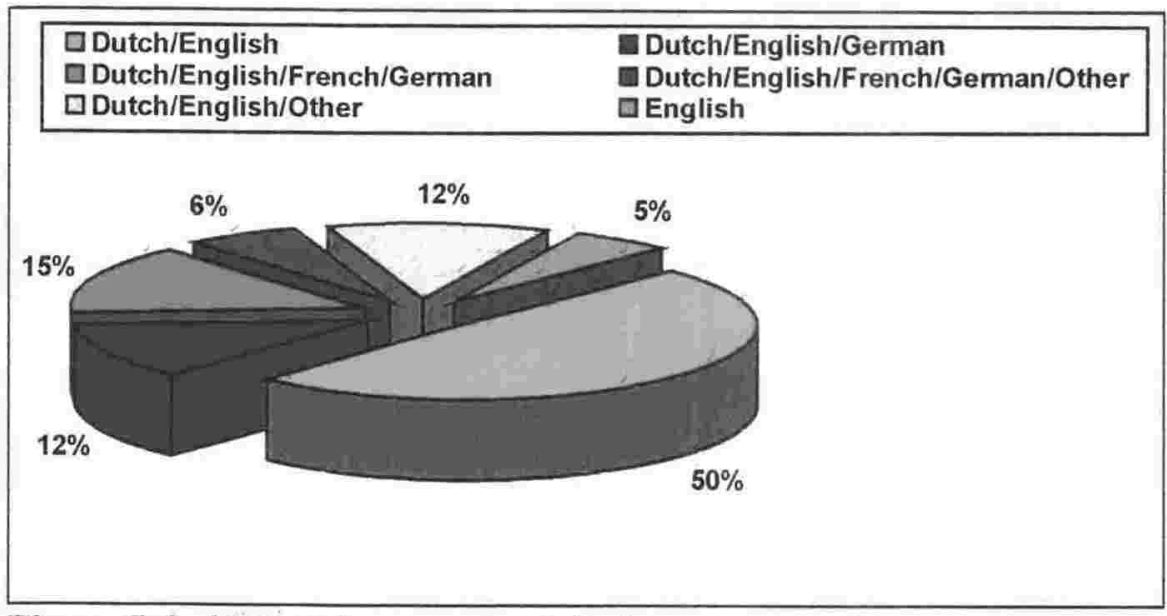

Figure 8-3: All Dutch respondents by languages spoken

\subsubsection{Language use in the last month}

Respondents were asked what languages they had spoken in the month prior to filling out the questionnaire. Although most of the respondents had not used all the languages at their command, nonetheless they had still used an impressive range. Some sections of the community appear to be operating multilingually. 
All of the respondents had spoken English in the last month

- $84 \%$ of all respondents had spoken Dutch in the last month

- $52.5 \%$ of New Zealand-born respondents had spoken Dutch in the last month

- $38 \%$ of the D.E.I.-born had spoken a language other than English or Dutch in the last month, as had

- $17.4 \%$ of the Dutch-born, and

- one of the New Zealand-born (French).

German, French, 'Swiss', Dialect, Limburgs, Japanese, Indonesian and Malay were the third or fourth languages that respondents recorded themselves as having used in the month before filling out the questionnaire.

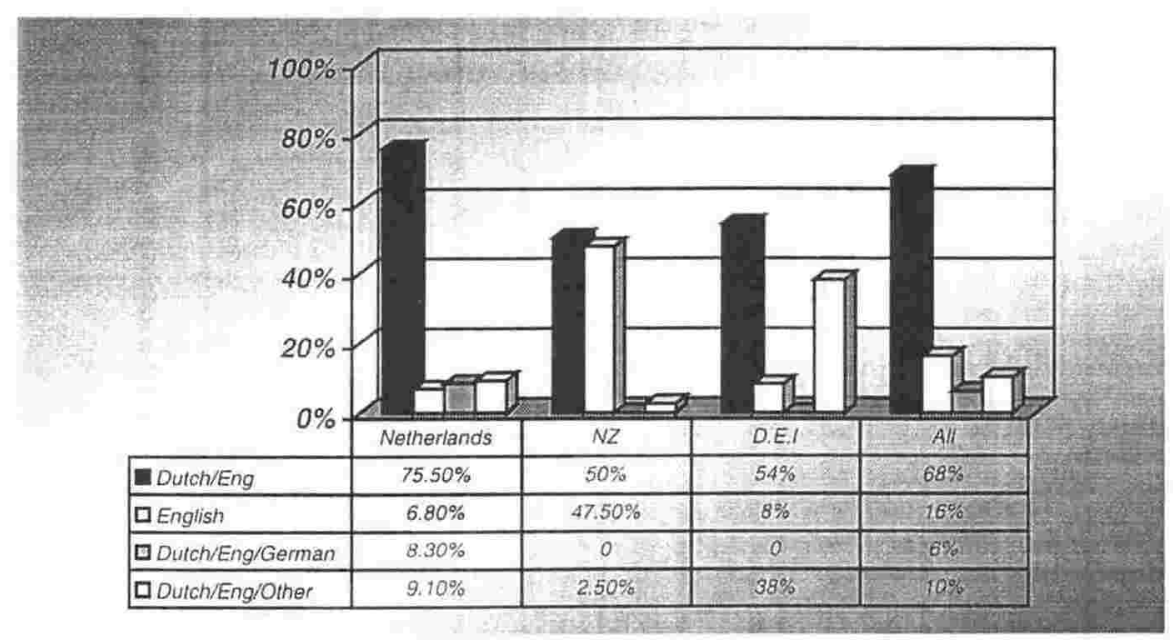

Figure 8-4: Languages spoken in month preceding survey: By Birthplace

\subsubsection{Language use in the home}

A substantial proportion of respondents used only English at home

- $41 \%$ of all respondents

- $65 \%$ of the New Zealand-born (the only group in which a majority of the respondents spoke only English at home)

- $35 \%$ of the Dutch-born respondents

- $31 \%$ of the D.E.I.-born

A tiny proportion of the Dutch-born ( $8 \%$ of the whole sample) made up the only respondents who claimed to use solely Dutch at home. Half the respondents $(50 \%)$ said that they spoke both Dutch and English at home. A handful these respondents spoke another language as well; one spoke 'Dialect', another Indonesian, and three respondents spoke Limburgs at home as well as Dutch and English. One respondent reported speaking only Dutch and 'German Swiss' at home. 


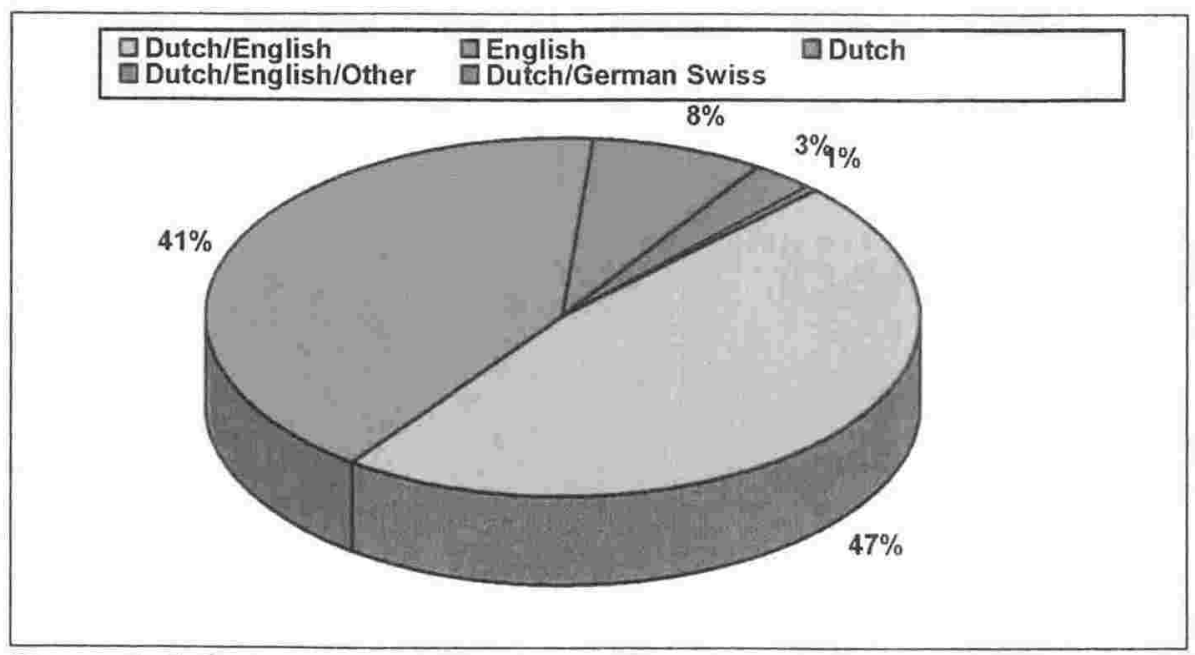

Figure 8-5: Languages spoken in the home by respondents

\subsubsection{Language spoken with spouse/partner}

Not all respondents were married or living with a partner. Eleven respondents ticked 'not applicable' for this question, leaving 173 respondents (two of whom did not answer the question but who were known to be married not only because of their answers to other questions, but also because their spouses answered the questionnaire as well). Most respondents $(63 \%)^{86}$ spoke English to their spouses most of the time. The difference in birthplace was quite marked in this area

- $97 \%$ of the New Zealand-born spoke mostly English to their spouses (one New Zealand-born respondent spoke mostly Dutch)

- $75 \%$ of the D.E.I.-born spoke mostly English

- $52 \%$ of the Dutch-born spoke mostly English

A fairly substantial minority of respondents (18.5\%) spoke Dutch to their spouses most of the time and three of the Dutch-born (2\%) spoke Limburgs to their spouses most of the time. Another fairly substantial minority (16\%) spoke 50/50 Dutch/English to their spouse most of the time.

For the New Zealand-born, many of whom are married to non-Dutch partners, English has clearly taken over in the home. While Dutch is still spoken by many non-New Zealand-born respondents to their spouses, when we turn to the languages spoken to children we see that Dutch use in the home is in a state of rapid decline.

\footnotetext{
${ }^{86}$ The percentages in this section are given as a $\%$ of all the respondents who did not tick 'not applicable'.
} 


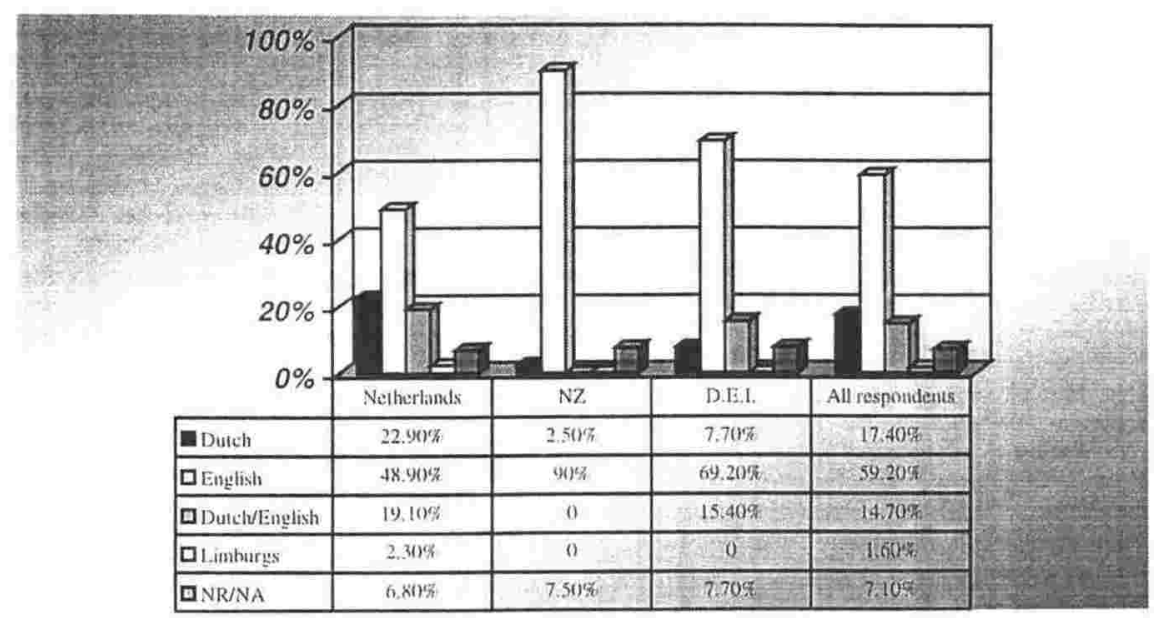

Figure 8-6: Language/s spoken to spouse most of the time

\subsubsection{Language spoken with children}

Of the respondents with children, 82.6\% (161) of them spoke mostly English to their children. All of the D.E.I.-born spoke mostly English and all but one of the New Zealand-born.

Amongst the Dutch-born, the situation was slightly different but a substantial majority spoke English most of the time

- $77 \%$ of the Dutch-born spoke mostly English to their children

- $11 \%$ of the Dutch-born spoke mostly Dutch to their children

- $12 \%$ of the Dutch-born spoke 50/50 Dutch/English

Because it had been thought that the majority of respondents would indicate that they spoke mostly English to their children, another question was added to the Dutch questionnaire asking respondents whether (if they spoke mainly English to their children) they made an attempt to speak Dutch to them as well. The results of this question were very interesting. Half the respondents who said that they spoke mostly English to their children, indicated that they made an effort to speak some Dutch to their children as well. For the Dutch-born and New Zealand-born respondents the proportions were very similar;

- $41 \%$ of the New Zealand-born made an attempt to speak some Dutch to their children

- $48 \%$ of the Dutch-born made an attempt to speak some Dutch to their children

The D.E.I.-born respondents, all of whom spoke mainly English to their children, responded somewhat differently, $77 \%$ of them said that they made some effort to speak Dutch to their children. There was no indication what kind of an effort was being made or how much Dutch parents were attempting to speak to their children. Obviously they were not speaking enough Dutch for them to choose the 50/50 Dutch/English option. The response does indicate however that a considerable proportion of the respondents felt that they should attempt to 
provide some Dutch language background for their children. Perhaps for many families the result is similar to that noted by the respondent who wrote

Our children say a Dutch prayer at night. They know a little bit of Dutch but don't really understand it. Only the odd word [Female, 30s, New Zealand-born]

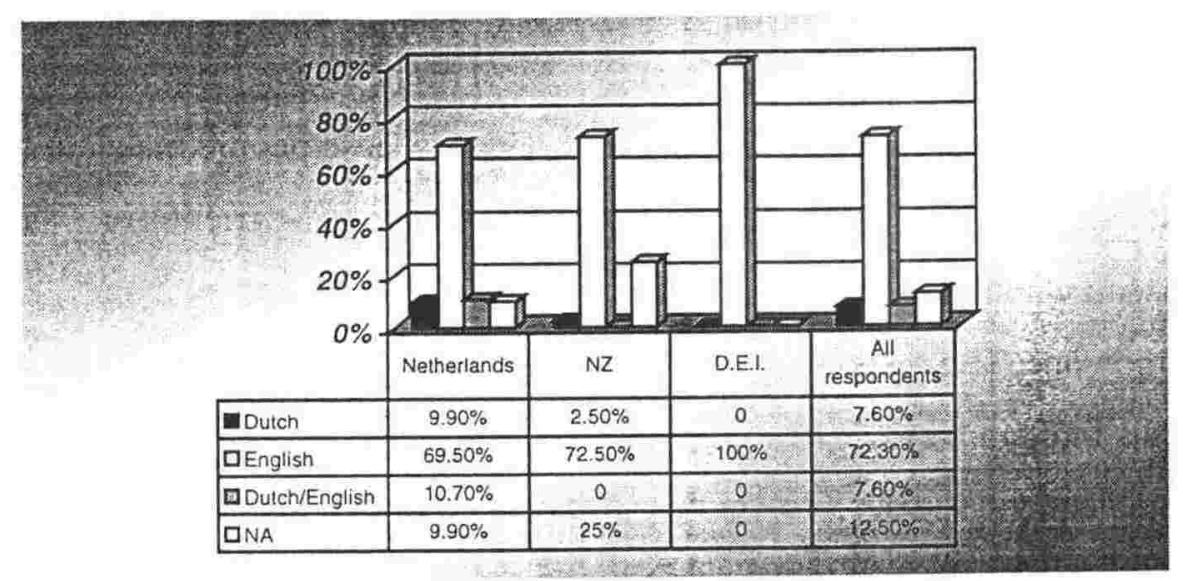

Figure 8-7: Language/s spoken to children most of the time

\subsubsection{Dutch spoken outside the home}

Most of the respondents $(82 \%)$ did have some occasion to use Dutch outside the home. All of the D.E.I.-born and most (89\%) of the Dutch-born said that they used Dutch outside the home. One Dutch-born respondent added that s/he used 'Dialect' as well. Amongst the New Zealand-born respondents however, only $52.5 \%$ used Dutch outside the home.

\subsubsection{Dutch-speaking interlocutors, outside the home}

- Overall, most respondents (56.5\%) spoke Dutch to friends their own age. In fact 25 respondents $(13.6 \%)$ spoke Dutch outside the home only to friends of their age. The New Zealand-born respondents were notably, and unsurprisingly, the odd ones out in this group; only four $(10 \%)$ of the New Zealand-born spoke Dutch to friends their own age.

- Older friends (42.4\%) formed the next largest group of interlocutors for the respondents. The New Zealand-born and the D.E.I.-born both stand out in relation to older friends as interlocutors; the D.E.I.-born because they were well over the group average with older friends being interlocutors for $76.9 \%$ of them and the New Zealand-born because older friends were interlocutors for only $22.5 \%$ of them.

- Immigrants $(28.8 \%)$ on the other hand were interlocutors for roughly equal numbers from each group; ranging from $23.1 \%$ for the D.E.I.-born to $30.5 \%$ to the Dutch-born.

- Younger friends (22.3\%) and younger relatives (16.3\%) were Dutch-speaking interlocutors for somewhat smaller proportions of each group although in the case of the New Zealand-born, none of them spoke Dutch to younger friends and only two $(2.5 \%)$ spoke Dutch to younger relatives. 
- A handful of respondents (six) spoke Dutch to young children other than their own and an even smaller group (three) spoke Dutch to the priest.

- Only 21 respondents wrote in an 'other' option. These options were: visitors from Holland, Dutch club/Dutch functions, colleagues, customers/clients/patients and (from 4 respondents) 'anybody who speaks/likes to speak Dutch'.

The range of interlocutors available for Dutch conversations is strongly affected by the distinctive immigration pattern of the Dutch in New Zealand. Most of the Dutch-born people in New Zealand arrived in a 20-30 year age cohort in the early 1950s. These people make up the over 60 s in this sample and most of them do not have older Dutch speaking friends or relatives in New Zealand with whom they can speak. This is why the 'friends my own age' response is the most common one. The responses of the New Zealand-born give some indication of how Dutch has fared in New Zealand. Only 10\% of the New Zealand-born speak Dutch to friends their own age, none speaks it to younger friends, $2.5 \%$ speak it to young children other than their own, none speaks it to their priest, and only $2.5 \%$ wrote in other possible interlocutors.

- older friends $(22.5 \%)$

- older relatives $(45 \%)$, and

- recent immigrants $(25 \%)$

make up the only substantial groups of Dutch-speaking interlocutors for the New Zealandborn.

\subsubsection{Where Dutch was spoken outside the home}

Social gatherings were the most common place for respondents to speak Dutch outside the home. Almost half the respondents $(44.6 \%)$ only spoke Dutch outside the home at social gatherings, and altogether, $64.7 \%$ of the respondents spoke Dutch at social gatherings.

Work was not a strong site of Dutch use but a surprising $11.4 \%$ of respondents did use at least some Dutch at work. This group included some respondents who worked as support staff at the Netherlands Embassy, but it also included three G.P.s and two nurses who said that they used Dutch with patients, several small business managers (e.g. builder, café operator, retailer) who said they had occasion to use Dutch with clients and one respondent who said she used Dutch at work, gave her occupation as 'mother'. 
Church was unimportant as a site of Dutch use. Only $4.9 \%$ of all respondents said that they spoke Dutch at church. Only two of the New Zealand-born (5\%) used Dutch in church and seven of the non-New Zealand-born (3.8\%).

A small number of respondents (18.5\%) wrote in an 'other' option for where they spoke Dutch. This reinforced the impression of Dutch being used almost exclusively in a context of maintaining Dutch friendship bonds in New Zealand. Of the 34 respondents who wrote in an option, a third specified that they used Dutch at friends' homes and a quarter said that they used Dutch either when at general family gatherings or when at a particular family member's home. Another two respondents said that they used Dutch to speak only to specific (in the case of one respondent only to a single) friend/s. Only two respondents said that they used Dutch with anyone who spoke Dutch. One of these respondents added the rider that this was only if the interlocutor's English was poor, and the other said that she would not use Dutch if there were English speakers present.

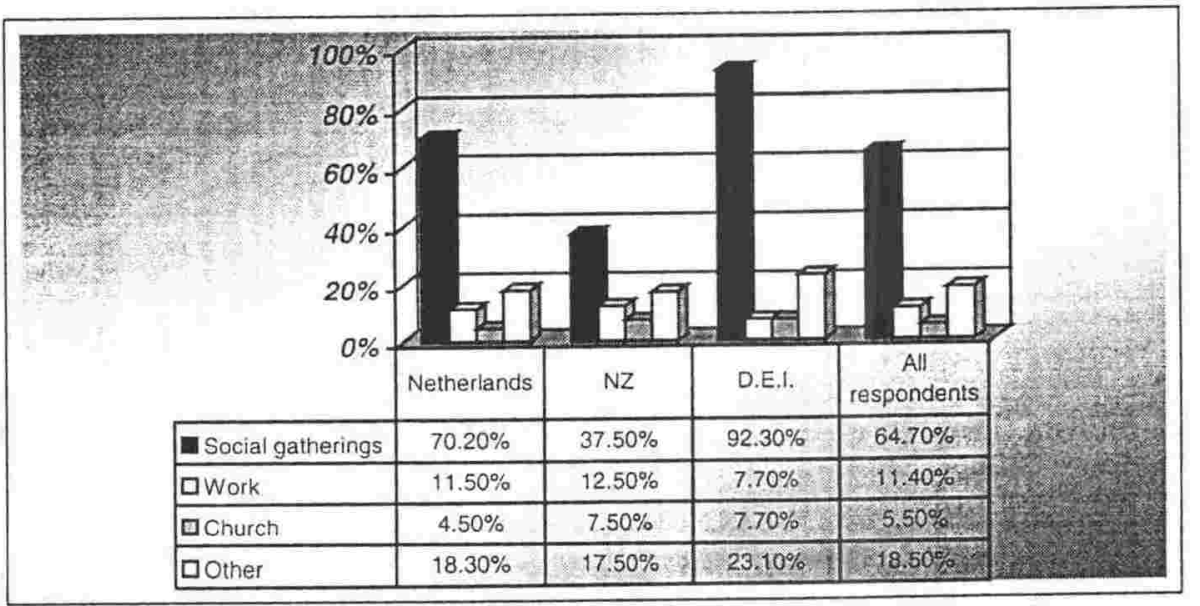

Figure 8-8: Where Dutch respondents spoke Dutch outside the home

\subsubsection{Summary}

Overall, we have a picture of a community where there has been limited transfer of MT skills from parents to child and where the domain of the parents' MT has rapidly shrunk to immediate friends and family so that the New Zealand-born generation can only be confident of being able to use Dutch to older people or recently arrived immigrants. The community closely resembles stage 7 on Fishman's GID scale where users are socially integrated, ethnolinguistically active and past child-bearing age (Fishman 1990:19-20). 


\subsection{Language proficiency}

\subsubsection{Self-reporting of proficiency}

As with the section on the Gujarati respondents, this section explores some possibilities of over- or under-reporting of proficiency specific to the language group in question and then reports their responses to the questions. The Dutch respondents were asked only about their proficiency in two languages, Dutch and English.

\subsubsection{Possible under-reporting of proficiency}

Most of the Dutch respondents reported that they were fluent in either English and/or Dutch. Only 4 respondents $(2.1 \%)$ reported themselves as not fluent in either language, 2 respondents gave no response to any of the language proficiency questions and one respondent reported herself as 'fairly fluent' in Dutch and gave no response for English. In total seven respondents reported themselves as not 'fluent' in either language. Only one respondent seems to have under-reported his ability out of motives of modesty (see section 8.3.1.4 below).

\subsubsection{Possible over-reporting of proficiency}

Most respondents reported themselves as 'fluent' speakers of Dutch (70.1\%) and most also considered themselves to be 'fluent' speakers of English (80.4\%). Slightly over half the respondents (54.3\%) thought that they were 'fluent' in both languages and slightly under half $(43.4 \%)$ thought that they were not only 'fluent' speakers of both languages but that they could write 'easily' in both languages as well. Against such a general high level of confidence it is hard to say whether any one respondent is over-rating his or her capabilities

\subsubsection{3 'No Response' to proficiency question}

One respondent said that she was 'fairly fluent' and could write 'with difficulty' in Dutch and gave no response to the questions about English. She was born in New Zealand and has been educated to Polytechnic and teacher training level; it seems reasonable to assume that her English is fluent - she might have ignored the question on the grounds that the response was self evident. Of the two respondents who gave no response to any of these questions, one seems to have mistakenly assumed that the proficiency questions were part of the series of questions about childhood in New Zealand (he has scored through all of this section because 
it was not relevant to him). There is no clue as to why the other respondent did not answer this section.

\subsubsection{Not fluent in any language}

This leaves the four respondents who answered all of the proficiency questions and did not rate themselves as 'fluent' in either language. One of them says he can write 'easily' in English (he rates himself as 'not very fluent' in both languages), another that she can write 'easily' in Dutch and a third that he can write 'easily' in both Dutch and English. None of these respondents seems to suffer from a disinclination to choose the highest rating option (as shown by their willingness to rate their writing skills at the top of the scale) and I interpret these answers to mean that the respondents, for some reason, do not feel completely fluent in either language - perhaps because of the long time since immigration and the lack of opportunity to speak Dutch in their daily lives. Only one respondent has not rated himself at the top of any of the proficiency scales. He rates himself as 'fairly fluent' in both languages and as able to write 'fairly easily' in both; it does seem possible that he is underreporting his abilities in one or both languages out of modesty but as it is impossible to tell which language might deserve 'promotion', his answers have been left unaltered.

\subsubsection{Oral proficiency}

\subsubsection{Dutch: see Table 8-12}

Overall most respondents $(70.1 \%)$ considered themselves to be 'fluent' in Dutch. There is however a big difference between the New Zealand-born respondents and the others. Of those born in New Zealand only $12.5 \%$ considered that they can speak Dutch 'fluently'. However all but one of the 13 D.E.I.-born respondents considered themselves 'fluent' speakers of Dutch as did $85.5 \%$ of the Dutch-born respondents. A small number of the non-New Zealandborn respondents considered themselves to be 'fairly fluent' or 'not very fluent' in Dutch (most of those who considered themselves to be 'not very fluent' had arrived in New Zealand under the age of ten). Amongst the New Zealand-born however, slightly less than two thirds of the respondents thought that they were 'fairly fluent' or 'not very fluent' and a handful claimed that they had comprehension skills only (15\%) or could not speak or understand any Dutch $(7.5 \%)$. We can see here a rapid decline in Dutch proficiency amongst the New Zealand-born. 
Table 8-12: Proficiency in oral Dutch: \%

\begin{tabular}{|l|c|c|c|c|c|c|c|}
\hline & Fluent & Fairly Fluent & $\begin{array}{c}\text { Not Very } \\
\text { Fluent }\end{array}$ & $\begin{array}{c}\text { Comprehension } \\
\text { Only }\end{array}$ & No Ability & NR & N= \\
\hline Dutch Born & $85.5 \%$ & $9.1 \%$ & $3.8 \%$ & 0 & 0 & $1.5 \%$ & 131 \\
NZ Born & $12.5 \%$ & $32.5 \%$ & $30 \%$ & $15 \%$ & $7.5 \%$ & $2.5 \%$ & 40 \\
D.E.I. Born & $92.3 \%$ & $7.7 \%$ & 0 & 0 & 0 & 0 & 13 \\
Non-N.Z.B. 10+ ${ }^{87}$ & 91 & 6 & 1.5 & 0 & 0 & 1.5 & 133 \\
All non-N.Z.B. & 86.1 & 9 & 3.5 & 0 & 0 & 1.4 & 144 \\
All Respondents & $70.1 \%$ & $14.1 \%$ & $9.2 \%$ & 3.3 & $1.6 \%$ & $1.6 \%$ & \\
N= & 129 & 26 & 17 & 6 & 3 & 3 & 184 \\
\hline
\end{tabular}

\subsubsection{English: See Table 8-13}

More respondents thought that they were 'fluent' in English than thought they were 'fluent' in

Dutch; this striking result is caused by the fact that all the New Zealand-born and all the

D.E.I.-born respondents thought that they were 'fluent' in English. Of the Dutch-born respondents, most (73.3\%) thought that they were 'fluent' in English and just under a quarter $(22.9 \%)$ thought that they were 'fairly fluent'. Two respondents thought they were 'not very fluent' and three respondents gave no response to this question. As a community, the Dutch appear to be confident in their English abilities and it would be reasonable to expect most people of Dutch background to speak good English and to be happy to speak English.

Table 8-13: Proficiency in oral English \%

\begin{tabular}{|l|c|c|c|l|l|}
\hline & Fluent & Fairly Fluent & Not Very Fluent & NR & N= \\
\hline Dutch Born & $73.3 \%$ & $22.9 \%$ & $1.5 \%$ & $2.3 \%$ & 131 \\
NZ Born & $100 \%$ & 0 & 0 & 0 & 40 \\
D.E.I. Born & $100 \%$ & 0 & 0 & 0 & 13 \\
Non-N.Z.B. 10+ & 73.7 & 22.6 & 1.5 & 2.3 & 133 \\
All non-N.Z.B. & 75.7 & 20.8 & 1.4 & 2.1 & 144 \\
All Respondents & $80.9 \%$ & $16.3 \%$ & $1.1 \%$ & $1.6 \%$ & \\
N= & 149 & 30 & 2 & 3 & 184 \\
\hline
\end{tabular}

\subsubsection{Written proficiency}

\subsubsection{Dutch: see Table 8-14}

Not quite two thirds (64.1\%) of the sample can write 'easily' in Dutch. Most of the Dutchborn $(80.9 \%)$ and of the D.E.I.-born (84.6\%) responded that they could write 'easily' in Dutch. Amongst those who did not think they could write 'easily' the rest of the D.E.I.-born

\footnotetext{
${ }^{87}$ Arrived in NZ ten years old or over
} 
(15.5\%) and $10.7 \%$ of the Dutch-born thought that they could write 'fairly easily'. A handful of the Dutch-born responded that they could write 'with difficulty', could 'read only' and one Dutch-born respondent (who came to New Zealand under the age of ten) could not read or write at all. Two Dutch-born respondents did not reply to this question.

The comparatively low number of respondents who replied that they could 'write easily' is caused by the fact that only one of the New Zealand-born respondents chose this option (and he was educated in Holland). Of the rest of the New Zealand-born;

- $10 \%$ said that they could write 'fairly easily'

- $30 \%$ could write 'with difficulty'

- $27.5 \%$ could not write Dutch but could read it

- $30 \%$ could neither read nor write Dutch

Table 8-14: Proficiency in written Dutch

\begin{tabular}{|l|c|c|c|c|c|c|c|}
\hline & $\begin{array}{c}\text { Can write } \\
\text { easily }\end{array}$ & $\begin{array}{c}\text { Fairly } \\
\text { easily }\end{array}$ & $\begin{array}{c}\text { With } \\
\text { Difficulty }\end{array}$ & $\begin{array}{c}\text { Can read } \\
\text { only }\end{array}$ & $\begin{array}{c}\text { No } \\
\text { Ability }\end{array}$ & NR & N= \\
\hline Dutch Born & $80.9 \%$ & $10.7 \%$ & $4.6 \%$ & $1.5 \%$ & $0.8 \%$ & $1.5 \%$ & 131 \\
NZ Born & $2.5 \%$ & $10 \%$ & $30 \%$ & $27.5 \%$ & $30 \%$ & 0 & 40 \\
D.E.I. Born & $84.6 \%$ & $15.5 \%$ & 0 & 0 & 0 & 0 & 13 \\
Non-N.Z.B. 10+ & 87.2 & 9.6 & 1.5 & 0 & 0 & 1.5 & 133 \\
All non-N.Z.B. & 81.3 & 11.1 & 4.2 & 1.4 & 0.7 & 1.4 & 144 \\
All Respondents & $64.1 \%$ & $10.9 \%$ & $9.8 \%$ & $7.1 \%$ & $7.1 \%$ & $1.1 \%$ & \\
N= & 118 & 20 & 18 & 13 & 13 & 2 & 184 \\
\hline
\end{tabular}

\subsubsection{English: see Table 8-15}

Most of the respondents (79.3\%) are confident of their ability to write English and responded that they could do so 'easily'. The D.E.I.-born (92.3\%) and the New Zealand-born (97.5\%) were almost all confident of their abilities in this area (the remaining $7.7 \%$ and $2.5 \%$ in each group responded that they could write English 'fairly easily'). Amongst the Dutch-born, $72.5 \%$ thought that they could write English 'easily'. $21.4 \%$ thought that they could do so 'fairly easily' and a handful (4.6\%) thought that they could do so 'with difficulty'. Only two respondents entered 'no response' to this question. As with the answers to the question about speaking English, we see a picture of a community secure in the language of its adopted land. 
Table 8-15: Proficiency in written English: \%

\begin{tabular}{|l|c|c|c|c|c|}
\hline & Can write easily & Fairly easily & With Difficulty & NR & N= \\
\hline Dutch Born & $72.5 \%$ & $21.4 \%$ & $4.6 \%$ & $1.5 \%$ & 131 \\
NZ Born & $97.5 \%$ & $2.5 \%$ & 0 & 0 & 40 \\
D.E.I. Born & $92.3 \%$ & $7.7 \%$ & 0 & 0 & 13 \\
Non-N.Z.B. 10+ & 72.2 & 21.8 & 4.5 & 1.5 & 133 \\
All non-N.Z.B. & 74.3 & 20.1 & 4.2 & 1.4 & 144 \\
& & & & & \\
All Respondents & $79.3 \%$ & $16.3 \%$ & $3.3 \%$ & $1.1 \%$ & \\
N= & 146 & 30 & 6 & 2 & 184 \\
\hline
\end{tabular}

\subsubsection{Monotonic decline}

Six of the 184 Dutch respondents did not exhibit a straightforward monotonic decline of proficiency in oral and written language skill areas. They were all born in the Netherlands and all reported slightly better written proficiency than oral proficiency. Five rated themselves as 'fairly fluent' speakers who could 'write easily' and one as a 'not very fluent' speaker who could write 'fairly easily'. The distinctions are so fine as to make it difficult to know whether or not the difference is such as to violate the implicational scale that Fishman proposed (see section 5.5.1.4).

\subsubsection{Age and Dutch proficiency}

Fluency in Dutch is, as we would expect, strongly age graded. The percentage of respondents reporting themselves as 'fluent' rises steadily from a low of $36.3 \%$ in the $21-30$ age group to a high of $92.1 \%$ in the $60+$ age group. Seven of the 11 respondents in the 21-30 age group were born in New Zealand and only one of them is a 'fluent speaker'. The other three 'fluent' speakers in this age group were all born in the Netherlands ${ }^{88}$. Fluency in age cohorts is directly linked to place of birth.

\footnotetext{
${ }^{88}$ One of them is the non-Dutch, European-born respondent who is counted as Dutch-born for the purposes of this survey.
} 


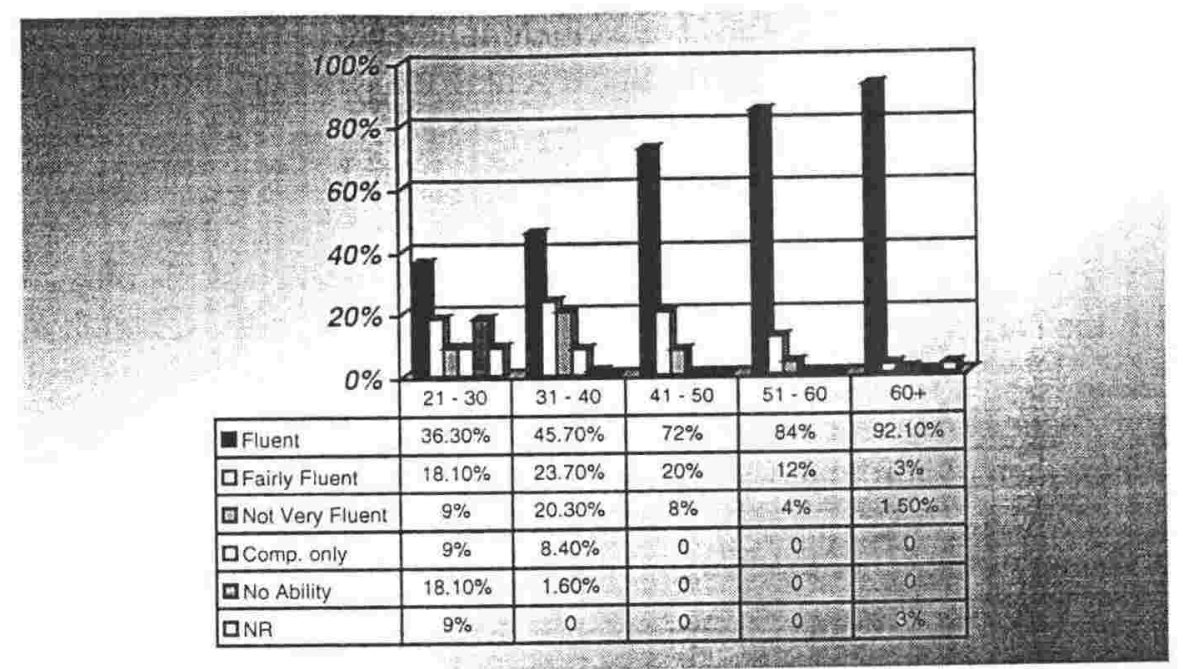

Figure 8-9: Dutch language proficiency by age group of respondents

\subsubsection{Gender and Language proficiency: see Table 8-16 and Table 8-17}

There are no differences worth mentioning between the men's and women's responses to the questions about English proficiency. All the D.E.I.-born and New Zealand-born respondents thought that they were 'fluent' in English. Amongst the Dutch-born an equal percentage of men and women thought that they were 'fluent' speakers of English

- $73.3 \%$ of men thought that they were 'fluent' speakers of English

- $73.2 \%$ of women thought that they were 'fluent' speakers of English

and most of the remainder thought that they were 'fairly fluent'. Perhaps the only very slight anomaly is that all the three respondents who gave 'no response' to this question were men.

Table 8-16: Proficiency in oral English \%: Men and women as \% of each gender

\begin{tabular}{|l|c|c|c|c|c|}
\hline & Fluent & Fairly Fluent & Not Very Fluent & NR & N= \\
\hline Dutch Born F. & $73.2 \%$ & $26.8 \%$ & 0 & 0 & 71 \\
Dutch Born M. & $73.3 \%$ & $18.3 \%$ & $3.3 \%$ & $5 \%$ & 60 \\
NZ Born F. & $100 \%$ & 0 & 0 & 0 & 26 \\
NZ Born M. & $100 \%$ & 0 & 0 & 0 & 14 \\
D.E.I. Born F. & $100 \%$ & 0 & 0 & 0 & 4 \\
D.E.I. Born M. & $100 \%$ & 0 & 0 & 0 & 9 \\
All Respondents F. & $81.1 \%$ & $19.6 \%$ & 0 & 0 & 101 \\
All Respondents M. & $80.7 \%$ & $13.3 \%$ & $2.4 \%$ & $3.6 \%$ & 83 \\
\hline
\end{tabular}

In response to the question about Dutch oral proficiency skills there is also very little difference between the responses of the men and the women but it may be worth commenting on a few. 
- All the D.E.I.-born women said that they were fluent in Dutch, the one D.E.Iborn man who said that he was only 'fairly fluent' came to New Zealand under the age of ten.

- It is only amongst the New Zealand-born men that any respondents claim to have no skills in Dutch at all.

- Five of the New Zealand-born women claim to have comprehension skills only in Dutch - none of the New Zealand-born women claim to have no skills in Dutch at all.

- One of the New Zealand-born men claims to have comprehension skills only in Dutch and three of them claim to have no ability at all.

The figures are too small to be anything other than suggestive but they do suggest the possibility that New Zealand-born male respondents might choose to be more absolute about their language skills (that is, if their Dutch skills are very weak they are more likely to say that they are non-existent) whereas the women are more likely to concentrate on the positive fact that they do have some comprehension skills even if they cannot speak the language.

Table 8-17: Proficiency in oral Dutch: \%: Men as a $\%$ of all male respondents and women as a $\%$ of all female respondents

\begin{tabular}{|c|c|c|c|c|c|c|c|}
\hline 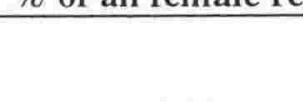 & Fluent & $\begin{array}{l}\text { Fairly } \\
\text { Fluent }\end{array}$ & $\begin{array}{l}\text { Not Very } \\
\text { Fluent }\end{array}$ & $\begin{array}{c}\text { Comprehension } \\
\text { Only }\end{array}$ & No Ability & NR & $\mathrm{N}=$ \\
\hline Dutch Born F. & $88.7 \%$ & $8.5 \%$ & $2.8 \%$ & 0 & 0 & 0 & 71 \\
\hline Dutch Born M. & $81.7 \%$ & $10 \%$ & $5 \%$ & 0 & 0 & $3.3 \%$ & 60 \\
\hline NZ Born F. & $11.5 \%$ & $30.8 \%$ & $34.6 \%$ & $19.2 \%$ & 0 & $3.8 \%$ & 26 \\
\hline NZ Born M. & $14.3 \%$ & $35.7 \%$ & $21.4 \%$ & $7.1 \%$ & $21.4 \%$ & 0 & 14 \\
\hline D.E.I. Born F. & $100 \%$ & 0 & 0 & 0 & 0 & 0 & 4 \\
\hline D.E.I. Born M. & $88.9 \%$ & $11.1 \%$ & 0 & 0 & 0 & 0 & 9 \\
\hline All Respondents F. & $69.3 \%$ & $13.9 \%$ & $10.9 \%$ & $5 \%$ & 0 & $1 \%$ & 101 \\
\hline All Respondents M. & $71.1 \%$ & $14.4 \%$ & $7.2 \%$ & $1.2 \%$ & $3.6 \%$ & $2.4 \%$ & 83 \\
\hline
\end{tabular}

\subsubsection{Religious affiliation and language proficiency}

The Dutch respondents were asked to indicate the religious affiliation of the household in which they had been brought up. The vast majority of respondents (84.7\%) were brought up in either a Protestant or a Catholic household. For those born outside New Zealand, their religious affiliation makes no difference to their fluency in Dutch. Taking all the non-New Zealand-born respondents together, $85.9 \%$ of the Catholic respondents and $85.7 \%$ of the Protestant respondents assess their present-day oral skills in Dutch as 'fluent'. In the case of the New Zealand-born respondents however, there is an interesting difference to be noted. Of the 40 New Zealand-born respondents

- $19(47.5 \%)$ were brought up in a Protestant household

- $16(40 \%)$ were brought up in a Catholic household 
(of the remaining five respondents, four were brought up in households of no religion and one respondent chose 'other'). Only one of the respondents of Catholic background and three of the respondents of Protestant background rated themselves as 'fluent' but if the 'fluent' and 'fairly fluent' groups are combined then it can be seen that

- $24.9 \%$ of those brought up in a Catholic household consider themselves to be either 'fluent' or 'fairly fluent'

- $57.8 \%$ of those brought up in a Protestant household assess themselves in this way

The numbers involves are too small to allow any conclusions to be drawn about the link between religious affiliation and language maintenance. The discrepancy does however bring to mind the comment often made in the USA immigrant situation that the Catholic church has not traditionally been as supportive of language maintenance as the Protestant churches (Glazer 1966: 364). It must be borne in mind however that in New Zealand both the Catholic and the Protestant churches were interested in quick assimilation by Dutch immigrants to New Zealand (see section 10.4.2 for further discussion of this issue) and deliberately chose not to establish Dutch language congregations. It is also worth noting that some of the Protestant Dutch became members of the Reformed Church in New Zealand. As this was, in essence, a Dutch church, it provided a regular, extra environment in which Dutch could be spoken (Schouten 1992: 166).

\subsubsection{Summary}

Most of the non-New Zealand-born respondents rate themselves highly in all the language skill areas for both Dutch and English. The New Zealand-born respondents rate themselves highly for English but are unlikely to do so for Dutch. Competence in Dutch is strongly agegraded, but in this group age is virtually a proxy for place of birth. Gender does not appear to be a factor in respondents' language proficiency. Amongst the New Zealand-born, respondents raised in Protestant households were more likely to rate themselves highly as speakers of Dutch than respondents raised in Catholic households.

\subsection{Attitudes}

The Dutch respondents were asked a variety of questions about their opinions of or attitudes to aspects of Dutch in New Zealand. Gujarati and Samoan respondents were asked if they thought that the relevant language schools existing in Wellington were a good idea. There was no Dutch language school in Wellington at the time the questionnaire was sent out, so the 
Dutch respondents were asked if they thought that a Dutch school for children, operating after school hours or on a Saturday, would be a good idea. A question about the desirability of Dutch classes for adults was also added to the questionnaire. The rest of the questions in this section were the same as in the Gujarati and Samoan questionnaires.

\subsubsection{Dutch after hours school for children}

Very nearly half the respondents $(49.5 \%)$ thought that a Dutch after hours or Saturday school was 'a good idea'.

- $69.2 \%$ of the D.E.I.-born supported the idea

- $48.1 \%$ of the Dutch-born

- $47.5 \%$ of the New Zealand-born

A fairly large number of respondents were simply 'not sure' (27.7\%). The New Zealand-born were the most uncertain at $37.5 \%$.

Those who were certain that such a school was 'not a good idea' made up $20.7 \%$ of all respondents.

- $23.7 \%$ of the Dutch-born thought it was 'not a good idea'

- $15.4 \%$ D.E.I.-born

- $12.5 \%$ of the New Zealand-born

One respondent replied 'good idea, not sure' and three respondents gave no response. It is interesting to note that the New Zealand-born are the least likely to think that such after-hours schools are 'not a good idea'. There seem to be several possible reasons, perhaps acting in combination, for this. It may be because, as New Zealanders born and bred they feel they do not have to worry about the fact that running a language maintenance school might be interpreted as a sign of not assimilating fully. In general, the New Zealand-born are younger than the other respondents, and they may be more likely to be sympathetic to concepts of language and culture maintenance which have become more prevalent in New Zealand society in the last two decades. Or it may be that because they have all suffered from some degree of language loss, they may be more aware of the need for such a school.

\subsubsection{Dutch classes for adults}

Interestingly, there was much more support for Dutch classes for adults. This may be, at least in part, because such classes have been conducted for some years as evening classes by a community institute in Wellington and several respondents had had experience of them. The 
stronger support for adult classes may also be because respondents felt that children should not be 'forced' into language maintenance classes but that adults could make their own decision to attend such classes. Fairly typical comments about classes for children were 'only if the child shows an interest' or, 'if parents and children want this, but I doubt it'. One respondent wrote as a comment on the questions about classes for children and adults

Have mixed feelings about this. While I think it is important to retain our ties with our heritage, we are living in New Zealand where English is the main language and children should (I believe) be encouraged to speak and write English well. Dutch should be an optional extra! [Female, Age 31-35, NZB]

- $81 \%$ of the respondents thought Dutch classes for adults were 'a good idea'

- $6 \%$ thought they were 'not a good idea'

- $12.5 \%$ were 'not sure'

- one respondent did not answer this question

All the D.E.I.-born respondents thought that adult classes were 'a good idea', as did $90 \%$ of the New Zealand-born respondents. The Dutch-born were only slightly less enthusiastic

- $76.3 \%$ thought they were 'a good idea'

- $15.3 \%$ were 'not sure'

- $7.6 \%$ thought that they were 'not a good idea'

\subsubsection{Dutch within the state school system}

By and large, respondents were opposed to the idea of Dutch being taught within the state school system. Over half the respondents $(59.8 \%)$ thought that it should not be offered.

Table 8-18: Should Dutch be taught in the state school system

\begin{tabular}{|l|c|c|c|c|}
\hline & Yes & No & Not Sure & $\mathrm{N}=$ \\
\hline Dutch-born & $16.8 \%$ & $68.7 \%$ & $13.7 \%$ & 131 \\
D.E.I-born & $30.8 \%$ & $53.6 \%$ & $15.4 \%$ & 13 \\
NZ -born & $42.5 \%$ & $32.5 \%$ & $15 \%$ & 40 \\
\hline
\end{tabular}

The New Zealand-born are the only group in which more respondents were in favour of the idea than were opposed to it. It is possible the New Zealand-born respondents were more likely to support Dutch in schools for reasons related to those suggested above in the section on after hours classes; they are less worried about 'assimilating', more aware of issues of language and culture maintenance and identity and more aware of the negative effects of language loss. Respondents who responded negatively to this question made comments such as 
- 'Dutch should not be taught in New Zealand schools at the expense of English and Maori'

- 'it would overburden the already crowded curriculum'

- 'what would be the advantage for the children?'

All these comments suggest that the respondents who made them were more concerned with assimilation to New Zealand (English and Maori) and if not unaware of issues of language, identity and language loss, were certainly according them low priority. Presumably you would not write 'what would be the advantage to the children?' in answer to such a question if you were concerned about such issues.

\subsubsection{Funding for community schools}

Because there was no community school in Wellington the Dutch respondents could not be asked if they supported government funding for the school. Instead they were asked if they supported government funding for community language schools in general. Support was strongest amongst the D.E.I.-born

- $53.8 \%$ of the D.E.I.-born supported government funding

- $47.3 \%$ of the Dutch-born supported government funding

- $25 \%$ of the New Zealand-born supported government funding

Overall

- $42.9 \%$ of respondents thought community schools should receive funding

- $38.9 \%$ thought that they should not

- $17.9 \%$ were 'not sure'

- 2 respondents made no answer

The level of uncertainty was highest amongst the New Zealand-born where $32.5 \%$ of respondents were 'not sure' as opposed to $7.7 \%$ of the D.E.I.-born and $14.5 \%$ of the Dutchborn.

Compared to the Gujarati and Samoan respondents the Dutch respondents were here being asked to reply to a more general question of less personal or community interest, and this may well have affected their responses. There was some strongly expressed support for such an idea. It is interesting that funding for community schools gets least support from the New Zealand-born (in contrast with the Gujarati respondents where New Zealand-born were the strongest supporters of such funding). It is unclear why this should be so. Perhaps the comment of one New Zealand-born respondent that 'it would be good but there is so little money available it may be better spent on more essential need in education' illustrates the 
main reason. Overall, however, it does not appear to be an issue on which the community has a very uniform view.

\subsubsection{General Views}

\subsubsection{Is it important to keep Dutch as a living language in New Zealand?}

Respondents were divided equally as to whether it was important to keep Dutch as a living language in New Zealand; $40.8 \%$ of respondents thought that it was and $40.8 \%$ thought that it was not important. A small number of respondents (17.9\%) were not sure (one respondent did not answer this question).

The Dutch-born and the D.E.I.-born gave very similar answers to this question;

- $46.2 \%$ of the D.E.I.-born and

- $46.8 \%$ of the Dutch-born

thought that it was not important to keep Dutch as a living language in New Zealand.

- $38.5 \%$ of the D.E.I.-born and

- $34.4 \%$ of the Dutch-born

thought that it was important.

Those who were not sure, made up $15.4 \%$ of the D.E.I-born and $19.1 \%$ of the Dutch-born.

The New Zealand-born respondents were more likely to give a positive answer to the question.

- $62.5 \%$ thought that it was important

- $22.5 \%$ thought that it was not important

- $15 \%$ were not sure.

The stronger positive response from the New Zealand-born may well reflect their greater awareness of the personal consequences of language loss. This analysis is strengthened when we look at the responses from those of the Dutch-born who came to New Zealand under the age of 10 (and thus are also English-dominant). Of these 11 respondents, 6 (54.5\%) thought that it was important to keep Dutch as a living language in New Zealand (compared to the $32.5 \%$ of the 120 Dutch-born who came to New Zealand over the age of 10 ). The numbers involved are small (in the case of those who arrived under the age of 10) but suggestive, even if nothing more. 


\subsubsection{Should Dutch people see themselves as part of a Dutch/NZ community?}

A majority of respondents in each group thought that Dutch people in New Zealand should see themselves as part of a Dutch/NZ community. The strongest support came from the D.E.I.-born.

- $84.6 \%$ of the D.E.I.-born supported the proposition, as did

- $67.5 \%$ of the New Zealand-born

- $57.3 \%$ of the Dutch-born

If we turn once again to the Dutch-born who came to New Zealand under the age of ten we see that $81.8 \%$ of them think that Dutch people should see themselves as part of a Dutch/NZ community.

Only $15.2 \%$ of respondents were not sure about this question (one respondent did not answer). Fifteen percent of the New Zealand-born and $15.4 \%$ of the D.E.I.-born thought that Dutch people should not see themselves as part of such a community, as did a somewhat larger proportion (26\%) of Dutch-born respondents.

\subsubsection{Should Dutch people in New Zealand see themselves simply as New Zealanders?}

Of all the attitude questions, this one got the largest majority response; $77.2 \%$ of respondents thought that Dutch people should not see themselves simply as New Zealanders. Only 15.2\% thought that they should do so and a mere $5.4 \%$ were not sure (one respondent did not answer this question, three respondents answered yes/no).

- $92.3 \%$ of the D.E.I.-born thought Dutch people in New Zealand should not see themselves simply as New Zealanders.

- $87.5 \%$ of the New Zealand-born shared their opinion.

The proportions drop slightly with the Dutch-born, $72.5 \%$ of whom thought that Dutch people in New Zealand should not see themselves simply as New Zealanders but $20.6 \%$ of whom thought that they should.

Although support for Dutch language and Dutch language maintenance in New Zealand was muted (compared to the Gujarati and Samoan respondents), it is interesting that support for a Dutch identity in New Zealand is somewhat stronger. It is also interesting that that there was a stronger negative response to the question 'Should Dutch people in New Zealand forget about being Dutch and see themselves simply as New Zealanders?' than there was positive response to 'Should Dutch people in New Zealand see themselves as part of a Dutch/NZ community?'. 
The reasons for this may be summed up in the comments made by two respondents on these questions. One respondent wrote

I see the identification as being Dutch or Netherlander as a personal event; in my case, whereas I view myself as Dutch, I have no desire to be identified with a "Dutch/NZ" community. [Male, 31-35, DB, came to New Zealand 10-20 years old].

And another respondent commented on the question about forgetting being Dutch and being simply New Zealanders

Those born Dutch will never forget their Dutch background, but most, if not all who become New Zealanders will in fact be New Zealanders in hearts and mind with pride of origin. Male, $60+$, D.E.I.-born, came to New Zealand 21-30 years old

Both respondents seem to be making the point that they cannot forget about being Dutch. The first respondent goes on to state explicitly that although he views himself as Dutch he does not want to be part of a Dutch/New Zealand community. This, of course, means that he answered negatively to both questions - he does not want to forget about being Dutch nor does he want to part of a Dutch/New Zealand community.

\subsubsection{Summary}

It is noticeable that the Dutch respondents are less whole-hearted than the Gujaratis and Samoans in their support for the MT and for MT language maintenance in New Zealand. There is a lack of support for child language maintenance classes although, when contrasted with the support for adult language maintenance classes, it seems that fear of forcing language maintenance on children is a concern here rather than an outright disapproval of language maintenance classes. There is a comparative lack of support for Dutch in the state school system. This springs at least partly from a world view that places English above Dutch as a ‘useful' language. Government funding for community schools was not strongly supported. This may be related more to ideas about what government should and should not be responsible for funding, but it suggests that such schools are not a very high priority for the respondents.

Place of origin is an important factor in how respondents answered the general attitude questions about language and identity in New Zealand. The D.E.I.-born were most likely to think that they should see themselves as part of a Dutch/NZ community and that they should not see themselves simply as New Zealanders, followed by the New Zealand-born. The 
Dutch-born were the least likely to hold these opinions. The New Zealand-born were most likely to support maintaining Dutch as a living language in New Zealand, followed at some distance by the D.E.I.-born. The responses suggest that issues of language and identity have become more salient for New Zealand-born Dutch than for their parents, who were more likely to be committed to a straightforward concept of assimilation. The Dutch-born, naturally, did not have to forgo their Dutch language competence in order to assimilate. The choices they made however, often led to such an outcome for their children and this may have affected their children's responses. The D.E.I.-born, of course, were also born outside the Netherlands in a context that undoubtedly caused people to think about issues of language and identity, so it is perhaps not surprising that although of a similar age to the Dutch-born respondents their responses are closer to those of the younger, New Zealand-born generation.

\subsection{Dutch children and their use of Dutch language}

The 184 Dutch respondents were distributed amongst 142 households which, between them had

- 120 oldest children

- 108 youngest children

This meant that information was gathered on 228 children of Dutch respondents. The children ranged in age from six weeks to 66 years old.

\subsubsection{Languages used by oldest and youngest children of Dutch respondents to questionnaire}

Respondents were asked what languages their children used. The responses show that the non-New Zealand-born respondents were quite likely to have children who spoke or understood some Dutch. The New Zealand-born respondents were however, most unlikely to have children who spoke or understood Dutch. Oldest children were more likely to speak Dutch than youngest children, although the differences were slight.

- $27.5 \%$ of oldest children speak Dutch and English

- $23.2 \%$ of youngest children speak Dutch and English

It is often the case in immigrant communities that older children are more likely to speak the MT than younger ones (Roberts 1990: 125, Desai 1994: 11). 
Table 8-19: Languages used by oldest and youngest Dutch children

\begin{tabular}{|c|c|c|}
\hline Languages spoken & $\begin{array}{l}\text { Oldest children of all Dutch } \\
\text { respondents. As a \% of } 120 \\
\text { households with oldest children }\end{array}$ & $\begin{array}{l}\text { Youngest children of all Dutch } \\
\text { respondents. As a \% of } 108 \\
\text { households with youngest children }\end{array}$ \\
\hline Speak English only & $43.3 \%$ & $48 \%$ \\
\hline Speak Dutch and English & $27.5 \%$ & $23.2 \%$ \\
\hline Speak English understand Dutch & $24.1 \%$ & $19.4 \%$ \\
\hline Speak Dutch understand English & $0.8 \%$ & $0 \%$ \\
\hline Too young & $2.5 \%$ & $7.5 \%$ \\
\hline No response & $1.6 \%$ & $1.9 \%$ \\
\hline $\begin{array}{l}\text { Oldest children of Dutch-born } \\
\text { respondents }\end{array}$ & $\begin{array}{l}\text { As a \% of } 84 \text { households with } \\
\text { oldest children }\end{array}$ & $\begin{array}{l}\text { As a } \% \text { of } 75 \text { households with } \\
\text { youngest children }\end{array}$ \\
\hline Speak Dutch and English & $35.7 \%$ & $28.0 \%$ \\
\hline Speak English only & $30.9 \%$ & $38.6 \%$ \\
\hline Speak English understand Dutch & $27.4 \%$ & $26.6 \%$ \\
\hline Speak Dutch understand English & $1.2 \%$ & $0 \%$ \\
\hline Too young & $2.4 \%$ & $4.0 \%$ \\
\hline No response & $2.4 \%$ & $2.6 \%$ \\
\hline $\begin{array}{l}\text { Oldest children of D.E.I-born } \\
\text { respondents }\end{array}$ & $\begin{array}{l}\text { As a } \% \text { of } 9 \text { households with oldest } \\
\text { children }\end{array}$ & $\begin{array}{l}\text { As a } \% \text { of } 8 \text { households with } \\
\text { youngest children }\end{array}$ \\
\hline Speak English understand Dutch & $44.4 \%$ & $12.5 \%$ \\
\hline Speak English & $33.3 \%$ & $50.0 \%$ \\
\hline Speak English and Dutch & $22.2 \%$ & $37.5 \%$ \\
\hline $\begin{array}{l}\text { Oldest children of NZ-born } \\
\text { respondents }\end{array}$ & $\begin{array}{l}\text { As a \% of } 26 \text { households with } \\
\text { oldest children }\end{array}$ & $\begin{array}{l}\text { As a } \% \text { of } 25 \text { households with } \\
\text { youngest children }\end{array}$ \\
\hline Speak English & $88.4 \%$ & $76 \%$ \\
\hline Speak English understand Dutch & $7.8 \%$ & $0 \%$ \\
\hline Speak English and Dutch & $3.8 \%$ (1 h'hold) & $4 \%$ (1 h'hold) \\
\hline
\end{tabular}

\subsubsection{Attendance at Dutch language maintenance school}

Dutch respondents were asked if their children attended a Dutch language school and, if they did, why their parents sent them. The question was included, even thought there was no Dutch school at the time the questionnaire was sent out, because it seemed possible that there might have been short-lived Dutch schools in the past. Most respondents simply said that their children had never been to such a school but a handful replied differently. Nine respondents from seven households said that their children did attend, would attend in the future, were too young to attend, or had attended Dutch language school (four respondents did not respond to this question). It was obvious that some of the children had attended or were attending evening classes as adults; their parents specified that they were evening classes or said that it was 'purely their own initiative', another couple specified that it had been the children's 'own choice'. One respondent said that her children had had a chance to attend Dutch classes 
because she worked for a Dutch company. Four respondents said that both language and culture were important in their choice to send their children to Dutch language maintenance school and one of them added 'so they may have continued contact with Dutch cousins'. In the cases where respondents did not specify that the classes were classes for students old enough to make up their own minds about attending, it is hard to know exactly what kind of class the respondents had in mind. It seems likely that in all cases, adult classes are intended although it is possible that some other parents were also able to benefit from classes run by a Dutch company. In the course of this research, no information has come to light about any community run language school in the past. Those who said that their children were "too young' or 'will attend' may have been aware of moves afoot to establish the community run school that now exists.

\subsubsection{Summary}

The Dutch respondents were not asked to evaluate their children's proficiency in Dutch, so there is no information on that point. Approximately a quarter of the children of Dutch respondents can speak Dutch. Almost all of these are the children of the non-New Zealandborn Dutch respondents. Almost none of the children of New Zealand-born respondents can speak Dutch. Because the Dutch community had, at the time of the questionnaire, never organised a Dutch language maintenance school for children, very few of the respondents had ever attended any kind of language maintenance instruction as children.

\subsection{Patterns of Dutch use during respondents' childhood in New Zealand}

Respondents were asked to reply to questions 17 to 33 (see Appendix 2) if they 'were born in, or raised for part of [their] childhood in New Zealand'. Although one respondent commented that it would have been helpful if the term 'childhood' had been defined, the term was deliberately left vague in order not to preclude responses by setting a lower age than some respondents might have chosen if left to their own devices. In addition to the $40 \mathrm{New}$ Zealand-born respondents, another 16 respondents (one Dutch East Indies-born, the remainder all born in the Netherlands) answered these questions. Of the 16, 11 came to New Zealand before they were ten and the other five came between the ages of 10-20. 


\subsubsection{Responses from siblings}

As far as can be established there are three pairs of siblings in this data (see 8.6 .6 below for discussion of family members within respondent group). One set of siblings was born in New Zealand, one set has one member born in the Netherlands the other in New Zealand and the third set has one member born in the Dutch East Indies and the other born in New Zealand.

\subsubsection{Was Dutch spoken in your home in New Zealand?}

All the respondents indicated that Dutch was, at least sometimes, spoken in their childhood homes in New Zealand. For about an eighth of the respondents Dutch was 'always' spoken in the home. For slightly over a third of the New Zealand-born respondents and slightly over a half of the Dutch-born respondents Dutch was 'mostly' spoken at home and for half the New Zealand-born respondents and a third of the Dutch-born, Dutch was 'sometimes' spoken at home $^{89}$. It was in response to this question that the New Zealand-born and the Dutch-born showed the least divergence in their answers to questions about Dutch use in the home.

Given that some of the New Zealand-born replied 'never' to all the subsequent questions about Dutch use in the home (that is their parents never spoke Dutch to each other or the respondent and the respondent never spoke Dutch) the frequency of usage must have been comparatively low in some households. All the fathers of respondents were Dutch- or D.E.I.born but four of the respondents had New Zealand-born mothers and four had mothers who were born elsewhere (two respondents had mothers born in the U.K., and two respondents had a mother born in another European country ${ }^{90}$ ). In those households where the mother was not Dutch, Dutch use was likely to be very low.

\footnotetext{
${ }^{89}$ The one D.E.I.-born respondent is not included in the discussion when respondents are divided according to country of birth but his responses are included in the figures for all Dutch respondents and are noted in the accompanying tables.

${ }^{90}$ There were 56 respondents to the childhood in New Zealand questions. As this includes three sets of siblings, this means that the responses to the questions include information on 112 parents of respondents. In fact, of course, for the responses from each set of siblings only one pair of parents is referred to - so only 106 parents are represented. Because siblings did not always give the same response about parental language use, the responses will generally be treated as though 112 parents are involved.
} 
Table 8-20: Was Dutch spoken in your home in New Zealand

\begin{tabular}{|l|c|c|c|c|c|c|}
\hline & All Dutch-born & $\begin{array}{c}\text { Came to NZ } \\
\mathbf{1 0 - 2 0}\end{array}$ & $\begin{array}{c}\text { Came to NZ } \\
-\mathbf{1 0}\end{array}$ & NZ-born & D.E.I.-born & All \\
\hline Always & $13.3 \%$ & & $20 \%$ & $12.5 \%$ & & $12.5 \%$ \\
Mostly & $53.3 \%$ & $100 \%$ & $30 \%$ & $37.5 \%$ & $1^{91}$ & $42.9 \%$ \\
Sometimes & $33.3 \%$ & & $50 \%$ & $50 \% \%^{92}$ & & $44.7 \%^{93}$ \\
$\mathrm{~N}=$ & 15 & 5 & 10 & 40 & 1 & 56 \\
\hline
\end{tabular}

\subsubsection{Did your parents speak Dutch to each other?}

- two thirds of the respondents said that their parents 'always' or 'mostly' spoke Dutch to each other

- A quarter said that their parents 'sometimes' spoke Dutch to each other (three of this group had non-Dutch mothers)

- $\quad 9 \%$ said that their parents 'never' spoke Dutch together (all of this group had non-Dutch mothers)

All of those whose parents 'never' spoke Dutch to each other were born in New Zealand (most of these respondents had New Zealand-born mothers, two had U.K.-born mothers).

Amongst the Dutch-born respondents

- over half had parents who 'always' spoke Dutch to each other

- 20\% 'mostly' spoke Dutch together

- just over a quarter 'sometimes' used Dutch with each other

Amongst the New Zealand-born

- a quarter had parents who 'always' spoke Dutch to each other

- a quarter had parents who 'sometimes' spoke Dutch together

- over a third of the parents of the New Zealand-born 'mostly spoke Dutch together.

The five New Zealand-born respondents with non-Dutch mothers, whose parents 'never' spoke Dutch to each other, make up $12.5 \%$ of the New Zealand-born respondents.

${ }^{91}$ Because there is only one D.E.I.-born respondent who spent part of their childhood in New Zealand the figure is not given as a percentage.

92 This category includes one respondent who noted that Dutch was spoken 'always' until the respondent was three years old and after that time Dutch was spoken 'sometimes'.

${ }^{93}$ As with the NZ-born this category contains the respondent who answered both 'always' and 'sometimes'. 
Table 8-21: Did your parents speak Dutch to each other

\begin{tabular}{|l|c|c|c|c|c|c|}
\hline & All Dutch-born & Came to NZ 10-20 & Came to NZ -10 & NZ-born & D.E.I.-born & All \\
\hline Always & $53.3 \%$ & $80 \%$ & $40 \%$ & $25 \%$ & & $32.1 \%$ \\
Mostly & $20 \%$ & $20 \%$ & $20 \%$ & $37.5 \%$ & 1 & $33.9 \%$ \\
Sometimes & $26.7 \%$ & & $40 \%$ & $25 \%$ & & $25 \%$ \\
Never & & & & $12.5 \%$ & & $8.9 \%$ \\
N= & 15 & 5 & 10 & 40 & 1 & 56 \\
\hline
\end{tabular}

\subsubsection{Did your parents speak Dutch to you?}

There are, perhaps not surprisingly, some big differences here between the Dutch-born respondents and those born in New Zealand in their responses to this question.

- $5 \%$ of the New Zealand-born indicated that their parents 'always' spoke Dutch to them

- $40 \%$ of those born in the Netherlands said their parents 'always' used Dutch with them

This difference is even more apparent when the Dutch-born respondents are divided into those who came here before they were 10 years old and those who came in the 10-20 age range.

- $20 \%$ of those who came to New Zealand under the age of 10 replied that their parents 'always' spoke Dutch to them

- $80 \%$ of those who came to New Zealand between the ages of 10 and 20 responded 'always' to this question.

It seems that the older the family members were at the time of immigration, the more likely the family was to remain Dutch-speaking (at least for the period of time that the respondent considered to be his or her 'childhood'). This is discussed in some more detail in section 11.7.6).

In the other categories of possible responses the differences are not so marked. About a quarter of the Dutch-born and somewhat over a third (37.5\%) of the New Zealand-born said that the parents 'mostly' spoke Dutch to them. A third of the Dutch-born and not quite half (47.5\%) of the New Zealand-born said that their parents 'sometimes' spoke Dutch to them. Four New Zealand-born (all with non-Dutch mothers) said that their parents 'never' spoke Dutch to them. 
Table 8-22: Did your parents speak Dutch to you

\begin{tabular}{|l|c|c|c|c|c|c|}
\hline & All Dutch-born & Came to NZ 10-20 & Came to NZ-10 & NZ-born & D.E.I.-born & All \\
\hline Always & $40 \%$ & $80 \%$ & $20 \%$ & $5 \%$ & & $14.3 \%$ \\
Mostly & $26.7 \%$ & $20 \%$ & $30 \%$ & $37.5 \%$ & 1 & $35.7 \%$ \\
Sometimes & $33.3 \%$ & & $50 \%$ & $47.5 \%$ & & $42.9 \%$ \\
Never & & & & $10 \%$ & & $7.1 \%$ \\
$\mathrm{~N}=$ & 15 & 5 & 10 & 40 & 1 & 56 \\
\hline
\end{tabular}

\subsubsection{Did you speak Dutch at home?}

- $7.1 \%$ said that they 'always' spoke Dutch at home

- $14.3 \%$ 'mostly' spoke Dutch at home as children

- $51.8 \%$ replied that they 'sometimes' spoke Dutch at home as children

- $26.8 \%$ said that they 'never' spoke Dutch.

Most of those who 'never' spoke Dutch were born in New Zealand (12 out of 15 respondents) and six of the eight respondents with non-Dutch mothers were in this group (the other two respondents with non-Dutch mothers responded 'sometimes').

The differences between the New Zealand and Dutch-born were fairly marked here

- $20 \%$ of the Dutch-born 'always' spoke Dutch

- $2.5 \%$ of the New Zealand-born 'always' spoke Dutch

- $26.7 \%$ of the Dutch-born 'mostly' spoke Dutch

- $10 \%$ of the New Zealand-born 'mostly' spoke Dutch

Table 8-23: Did you speak Dutch at home

\begin{tabular}{|l|c|c|c|c|c|c|}
\hline & All Dutch-born & $\begin{array}{c}\text { Came to NZ } \\
10-20\end{array}$ & $\begin{array}{c}\text { Came to NZ } \\
-10\end{array}$ & NZ-born & D.E.I.-born & All \\
\hline Always & $20 \%$ & $20 \%$ & $20 \%$ & $2.5 \%$ & & $7.1 \%$ \\
Mostly & $26.7 \%$ & $60 \%$ & $10 \%$ & $10 \%$ & & $14.3 \%$ \\
Sometimes & $33.3 \%$ & $20 \%$ & $40 \%$ & $57.5 \%^{94}$ & 1 & $51.8 \%{ }^{95}$ \\
Never & $20 \%$ & & $30 \%$ & $30 \%$ & & $26.8 \%$ \\
N= & 15 & 5 & 10 & 40 & 1 & 56 \\
\hline
\end{tabular}

\subsubsection{Differences in sibling responses}

In designing the Dutch questionnaire, and with the knowledge of what had happened in the Gujarati interviews, it was obvious that the 'friend-of-friend' methodology employed might lead to several members of one family responding to the survey. This in fact has happened

\footnotetext{
${ }^{94}$ This category contains one respondent who replied that she always spoke Dutch at home until she was three. It is not clear from her response what language/s she spoke after that age. The category also contains a respondent who answered that they never spoke Dutch at home except when grandparents came to visit.

${ }^{95}$ As above.
} 
and we can to use those relationships that we know of to add some depth and colour to the data. In the case of the childhood language use it is interesting to note that the siblings in the data do not always have the same perceptions of family language use patterns.

\subsubsection{Sibling pair d094/d035}

These are a brother (41-45) and a sister (36-40) both born in New Zealand. He answered 'sometimes' to all the questions about Dutch use in the childhood home and she answered 'mostly'.

\subsubsection{Sibling pair d078/d076}

These are sisters one born in the Netherlands (41-45) and one born in New Zealand (31-35). The Dutch-born older sister answered 'sometimes' to all the questions. The New Zealandborn sister answered 'sometimes' to the questions about Dutch being spoken in the home and parents speaking Dutch to each other but she answered 'never' to the questions about her parents speaking Dutch to her and whether or not she ever spoke Dutch. The answers from these sisters reinforce the impression that within the same family, Dutch-born children were more likely to be addressed and to respond in Dutch than New Zealand-born children.

\subsubsection{Sibling pair $\mathrm{d} 183 / \mathrm{d} 145$}

However, it must be admitted that this impression is somewhat contradicted by the evidence from the next two brothers. The elder (36-40) was born in Indonesia and he indicated that Dutch was 'mostly' spoken in the home, by his parents to each other and by his parents to him however he says that he only 'sometimes' spoke Dutch at home. The younger brother (31-35) born in New Zealand replied 'mostly' to all questions.

\subsubsection{Speaking Dutch outside the home in childhood}

Respondents were asked if they had spoken Dutch outside the home as children in New Zealand. If they replied 'yes' they were asked to indicate where or on what occasions they had spoken Dutch and to whom they had spoken it. (qs 22-24, Appendix 2). Thirty-two respondents, all of whom spoke Dutch at home as children ${ }^{96}$, also spoke Dutch outside the

\footnotetext{
${ }^{96} 57 \%$ of the 56 who said they spoke Dutch at home
} 
home (one respondent answered 'no' to this question' and then went on to indicate that they had spoken Dutch outside the home when visiting Dutch friends (Q. 23). They did not answer the subsequent question about who their interlocutors had been. The answers have simply been counted as given because a basis could not be found on which to rationalise them).

\subsubsection{Where respondents spoke Dutch outside the home in childhood}

Respondents were asked to indicate if they spoke Dutch outside the home as children (in New Zealand) when visiting Dutch friends, visiting relatives, at Dutch social gatherings at Dutch clubs and organisations or at Dutch school or classes, and respondents were also, of course given an opportunity to fill in an 'other' category. No respondent attended a Dutch school or class in New Zealand as a child and only two respondents filled in anything in the 'other' category.

For the respondents as a whole 'visiting Dutch friends' was the single most important occasion of Dutch use outside their childhood homes. Of the 33 respondents who answered this question

- $84.8 \%$ indicated that they spoke Dutch when visiting the homes of Dutch friends.

- $60.6 \%$ said visiting relatives was an occasion of Dutch use

- $45.4 \%$ spoke Dutch at Dutch social gatherings

- $21.2 \%$ said that they had spoken Dutch at Dutch clubs or organisations when they were children.

One respondent wrote that she had 'worked for the Netherlands Embassy' in this 'childhood' period (it is not really possible to know what she meant by this - perhaps as a very young secretary?) and another said that, as a child, they had spoken Dutch on the telephone to relatives.

There was quite a marked difference between the Dutch-born respondents and the New Zealand-born respondents in their answers to this question.

All the Dutch-born respondents said that visiting Dutch friends was an occasion of Dutch use as children but other occasions were comparatively less important.

- $60 \%$ of them nominated Dutch social gatherings as another such occasion

- $30 \%$ indicated that visiting relatives had been a time for Dutch use

- $20 \%$ had spoken Dutch at Dutch clubs or organisations

For the New Zealand-born however, visiting Dutch friends and visiting relatives were almost equally important in terms of providing occasions for Dutch use outside the home. 
- $78.2 \%$ of New Zealand-born respondents spoke Dutch when visiting Dutch friends

- $73.9 \%$ of New Zealand-born respondents spoke Dutch when visiting relatives

Dutch social gatherings were comparatively less important, only $39.1 \%$ of the New Zealandborn respondents speaking Dutch at such occasions. As with the Dutch-born 20\% (strictly speaking $21.7 \%$ ) had occasion to speak Dutch at Dutch clubs or organisations.

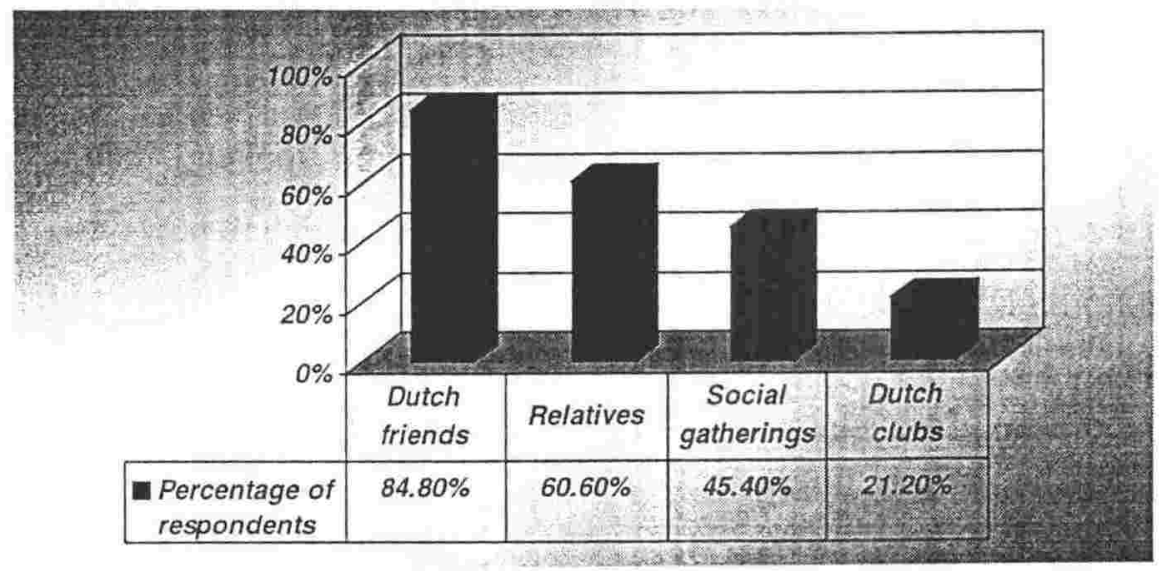

Figure 8-10: Where respondents spoke Dutch outside the childhood home in New Zealand

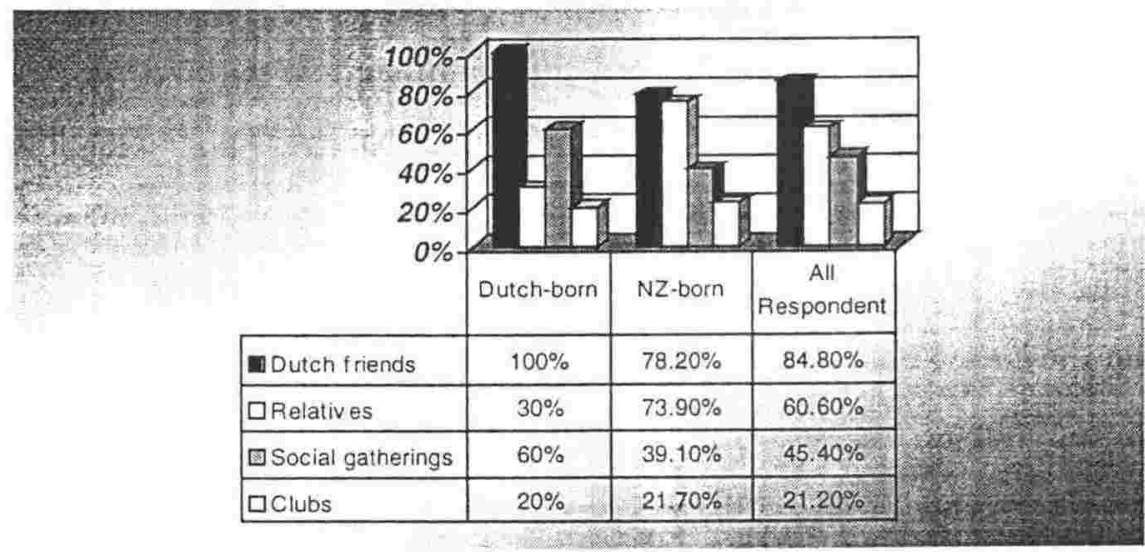

Figure 8-11: Where respondents spoke Dutch outside the childhood home in New Zealand by birthplace

\subsubsection{Dutch-speaking interlocutors outside the home in childhood}

Respondents were asked to indicate if they had spoken Dutch outside the home to 'older people', 'older relatives', 'new immigrants' or 'other children'. Thirty-two respondents replied to this question. Most of them spoke Dutch to older people and older relatives. Under half had spoken Dutch to immigrants and other children.

- $71.8 \%$ spoke Dutch to older people

- $62.5 \%$ spoke Dutch to older relatives

- $37.5 \%$ spoke Dutch to new immigrants 
- $28.1 \%$ spoke Dutch to other children

Once again there are some marked differences between the Dutch-born and the New Zealandborn. All the Dutch-born respondents had, as children, spoken Dutch to older people and half of them had spoken Dutch to immigrants. Many of them had spoken Dutch to older relatives and to other children.

- $100 \%$ spoke Dutch to older people

- $50 \%$ spoke Dutch to older relatives

- $40 \%$ spoke Dutch to new immigrants

- $40 \%$ spoke Dutch to other children

Amongst the New Zealand-born respondents more people had, as children, spoken Dutch to older relatives than to older people in general. About a third had spoken Dutch to new immigrants and a small minority had spoke Dutch to other children.

- $59.0 \%$ spoke Dutch to older people

- $72.7 \%$ spoke Dutch to older relatives

- $31.8 \%$ spoke Dutch to new immigrants

- $22.7 \%$ spoke Dutch to other children

It seems clear from these responses that the Dutch-born respondents and the New Zealandborn respondents grew up in New Zealand in somewhat different Dutch social circles. The New Zealand-born respondents seem to have had a larger Dutch family circle with $73.9 \%$ of them speaking Dutch when visiting relatives and $72.7 \%$ of indicating that they spoke Dutch to older relatives. There seems to be no reason to suggest that if the Dutch-born respondents did visit relatives in New Zealand they would confine themselves to English therefore the implication seems to be that the New Zealand-born had more Dutch relatives here and the families of the Dutch-born respondents had to rely more on friends to provide a Dutchspeaking social circle ${ }^{97}$. The predominance of family and friends as a focus of Dutch use certainly points up both the relatively circumscribed opportunities for speaking Dutch in New Zealand and also the fact that Dutch had a role to play in maintaining bonds of family and friendship in New Zealand.

\footnotetext{
${ }^{97}$ Possibly families that had been here longer (long enough to have New Zealand-born children), were more likely to have other family members in New Zealand as a consequence of chain-migration processes.
} 


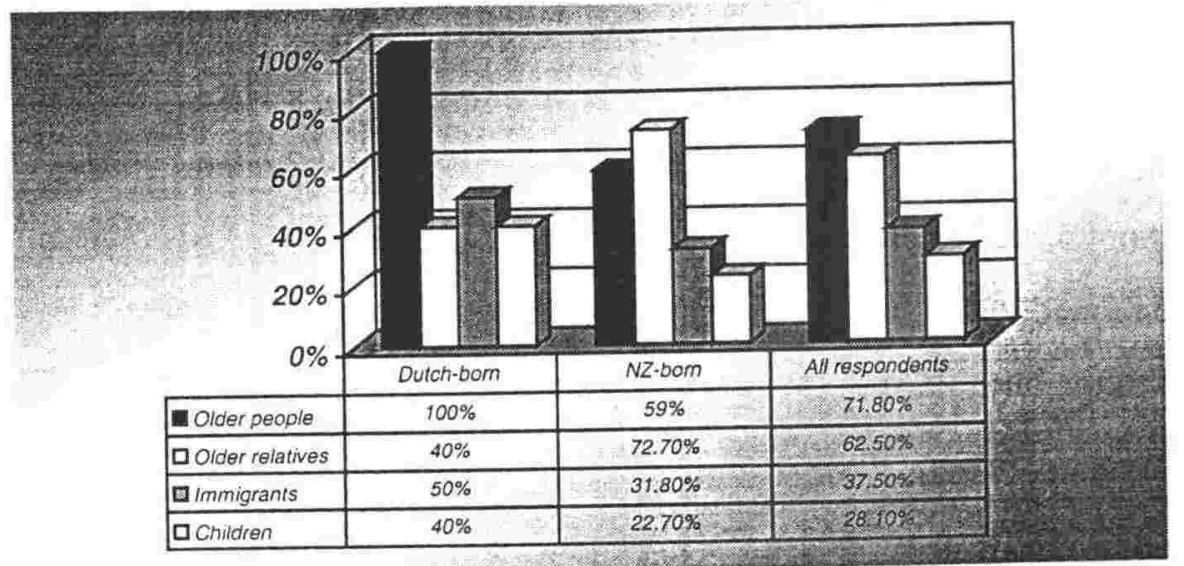

Figure 8-12: Respondents' interlocutors outside the childhood home in NZ

\subsubsection{Dutch language proficiency of respondents born or raised in New Zealand}

Table 8-24: Present proficiency in spoken Dutch

\begin{tabular}{|l|c|c|c|c|}
\hline & Born in NZ & Came to NZ under 10 & Came to NZ 10-20 & All \\
\hline Fluent & $12.5 \%$ & $30.0 \%$ & $80.0 \%$ & $21.4 \%$ \\
Fairly fluent & $32.5 \%$ & $40.0 \%$ & $20.0 \%$ & $33.9 \%$ \\
Not very fluent & $30.0 \%$ & $30.0 \%$ & 0 & $26.8 \%$ \\
Comp. Only & $15.0 \%$ & 0 & 0 & $10.7 \%$ \\
No ability & $7.5 \%$ & 0 & 0 & $5.4 \%$ \\
N= & 40 & 10 & 5 & $55^{99}$ \\
\hline
\end{tabular}

Table 8-25: Present proficiency in written Dutch

\begin{tabular}{|l|c|c|c|c|}
\hline & Born in NZ & Came to NZ under 10 & Came to NZ 10-20 & All \\
\hline Write easily & $2.5 \%$ & $10 . \%$ & $40.0 \%$ & $7.1 \%$ \\
Fairly easily & $10.0 \%$ & $20.0 \%$ & $40.0 \%$ & $16.1 \%$ \\
With difficulty & $30.0 \%$ & $40.0 \%$ & $20.0 \%$ & $30.4 \%$ \\
Read only & $27.5 \%$ & $20.0 \%$ & 0 & $23.2 \%$ \\
No Ability & $30.0 \%$ & $10.0 \%$ & 0 & $23.2 \%$ \\
N= & 40 & 10 & 15 & 55 \\
\hline
\end{tabular}

As is to be expected there is a cline of proficiency that runs from least proficient (born in New Zealand) though those who came here under the age of ten to the most proficient who came to New Zealand between the ages of ten and 20. It is only among the New Zealand-born that

\footnotetext{
${ }^{98}$ One NR is not included in this table

${ }^{99}$ The single D.E.I.-born respondent is not included in this table

${ }^{100}$ The single D.E.I.-born respondent is not included in this table
} 
there are any respondents who have no ability in spoken Dutch at all. Ability in written Dutch is more limited however. Over half the New Zealand-born have only reading skills (27.5\%) or no ability to read Dutch (30\%) and almost a third of those who came to New Zealand under the age of ten can read but not write Dutch (20\%) or have no ability at all (10\%). This cline in ability would appear to be related to the similar cline in Dutch language use in the home which declines in relation to the birthplace of the respondent and the age of immigration to New Zealand.

\section{Parents 'always' spoke Dutch to each other}

- $80 \%$ for those who arrived in New Zealand between the ages of 10-20

- $40 \%$ for those who arrived in New Zealand under the age of ten

- $25 \%$ for the New Zealand-born

\section{Parents 'always' spoke Dutch to respondent}

- $80 \%$ for those who arrived in New Zealand between the ages of 10-20

- $20 \%$ for those who arrived in New Zealand under the age of ten

- $5.0 \%$ for the New Zealand-born

Respondent 'always' spoke Dutch at home

- $20 \%$ for those who arrived in New Zealand between the ages of 10-20

- $20 \%$ for those who arrived in New Zealand under the age of ten

- $2.5 \%$ for the New Zealand-born 


\subsubsection{Summary}

There was a noticeable difference between the New Zealand-born and the non-New Zealandborn in the area of childhood language use in New Zealand. The New Zealand-born are unlikely to have heard their parents speaking a lot of Dutch to each other and they are highly unlikely to have had much Dutch addressed to them or to have spoken much Dutch themselves. The non-New Zealand-born who arrived here over the age of ten are, on the contrary, very likely to have heard their parents speaking Dutch most of the time, very likely to have been addressed in Dutch and quite likely to have spoken in Dutch themselves. Those who arrived in New Zealand under the age of ten are somewhere between the other two groups. The information on language use in the home shows the patterns of use that contribute to the not unexpected finding that the New Zealand-born are less likely to be competent speakers of Dutch than those born overseas. Both groups used Dutch outside the home. Visiting Dutch friends and relatives were the most important occasions of Dutch use. The New Zealand-born were somewhat more likely than the non-New Zealand-born to use their Dutch when visiting relatives.

\subsection{Conclusion}

The Dutch show the greatest degree of language shift of any of the three groups in this research. Although most of the respondents to the survey are fluent speakers of Dutch, this is because most of them were born outside New Zealand. Very few of the New Zealand-born are fluent Dutch speakers and some report no speaking ability at all. They also report very poor literacy skills in Dutch. As a group, the Dutch do not strongly support language and culture maintenance activities although some individuals see this as very important. There is, compared to the Gujarati and Samoan respondents, only weak support for government assistance for community language schools. The strong assimilationist ethic that prevailed at the time that most of the Dutch came to New Zealand has left its mark very clearly on the community. 


\section{ANALYSIS OF THE SAMOAN RESPONDENTS' RESPONSES TO THE QUESTIONNAIRE}

\subsection{Demographic profile of Samoan respondents}

The Samoan survey responses were obtained from 93 adults who answered questionnaires. These respondents also answered questions about their children so that information on a total of 226 people was obtained.

Most of the respondents were born in Samoa or born in New Zealand of Samoan parentage. One respondent was born in Tokelau, one in Tuvalu and two respondents did not give a clear indication of their birthplace (see section 6.4.1 describing how respondents to the questionnaire were targeted section).

\subsubsection{Census data}

In the 1991 Census, 85,743 people said that they were of Samoan ethnicity, making the Samoans the largest Pacific Islander group in New Zealand by a considerable margin (the next largest group is Cook Island Maori at 37,857). The Samoan population is predominantly urban and $66 \%$ of the population lives in the Auckland region, compared to $28 \%$ of all New Zealanders. Nineteen percent of the Samoan population of New Zealand lives in the Wellington urban area (Statistics 1995: 16). Wellington region has the second highest number of Pacific Islanders, making up 6\% of Wellington's population, compared to Auckland where Pacific Islanders make up $11 \%$ of the population (Krishnan et al 1994: 31-39). Samoans in the Wellington Local Authority Region numbered 16,275 in the 1991 Census (Pacific Island Population and Dwellings: Table 2), thus the 97 respondents in this research constituted approximately $0.6 \%$ of the Wellington Samoan population.

\subsubsection{Birthplace}

Most of the respondents were born in Samoa (73\%). Just under a quarter were born in New Zealand (23\%), two were born in Tokelau and Tuvalu respectively. One respondent chose not to say where she was born and one respondent, who did not reply to the question about gender, did not indicate their birthplace clearly on the questionnaire. In most cases the group will be divided into non-New Zealand-born (including the Tokelau and Tuvaluan born respondents) and New Zealand-born. Fairly arbitrarily, the 'unclear' and 'no response' 
respondents have also been included in the non-New Zealand-born category in most cases. All in all, $77.4 \%$ of the respondents were born outside New Zealand. This is comparable with Stockwell's random survey of a far larger group of Pacific Islanders ${ }^{101}$, which found that $78 \%$ of respondents were born outside New Zealand. In the 1991 Census half the Samoans in New Zealand were born in New Zealand but the population was very young, 50\% were under 20 and thus unlikely to be included in this survey (Statistics New Zealand 1995: 11,18). The proportion of non-New Zealand-born to New Zealand-born in this survey thus seems to be at least roughly similar to the proportions in the child-rearing and post-child-rearing age-groups in the New Zealand Samoan population.

Table 9-1: Birthplace

\begin{tabular}{|l|l|l|}
\hline Birthplace & Number & Percentage \\
\hline Samoa & 68 & $73.1 \%$ \\
New Zealand & 21 & $22.6 \%$ \\
Tokelau & 1 & $1.1 \%$ \\
Tuvalu & 1 & $1.1 \%$ \\
Unclear & 1 & $1.1 \%$ \\
NR & 1 & $1.1 \%$ \\
N $=$ & 93 & 100.1 \\
\hline
\end{tabular}

\subsubsection{Gender}

Overall, there are slightly more female than male respondents to the Samoan questionnaire. Initially most of the respondents were female and male respondents were deliberately sought out in the later stages of information gathering (see section 6.4.1 for a more detailed discussion of this process). Respondents to the Samoan questionnaire were deliberately sought out by researchers rather than choosing whether to reply to a postal questionnaire (as with the Dutch respondents and the first pass over the Gujarati respondents). Thus, it is not really possible to draw any conclusions about the proportion of men and women answering the questionnaire and how this might reflect attitudes either to answering questionnaires in general or to the specific subject matter of the questionnaire.

${ }^{101}$ Roughly $47 \%$ of whom were Samoan (Stockwell 1995:71) 
Table 9-2: Gender of respondents to questionnaire

\begin{tabular}{|l|c|c|c|}
\hline & Male & Female & $\mathrm{N}=$ \\
\hline All respondents, number & 44 & 48 & 92 \\
All respondents, \% & 47.3 & 51.6 & 98.9 \\
Non-New Zealand-born, number & 33 & 38 & 71 \\
Non-New Zealand-born, \% & 45.8 & 52.8 & 98.6 \\
New Zealand-born, number & 11 & 10 & 21 \\
New Zealand-born, \% & 52.4 & 47.6 & 100 \\
\hline
\end{tabular}

1 respondent did not reply clearly to the question about gender

\subsubsection{Age}

Compared to the Gujarati and Dutch respondents, the Samoan respondents were a much younger group. Only four respondents were over the age of 50. To some extent this reflects the fact that the Samoan immigrant population in New Zealand is a young population and the Dutch immigrant population is older. It also reflects the fact that interviewers deliberately chose younger respondents.

- 88 respondents (94.6\%) were age 21 to 50 (inclusive)

- the four respondents over the age of 50 were all non-New Zealand-born

- the New Zealand-born respondents were age $15-35$.

Once again, the comparatively young ages of the New Zealand-born (most of whom, $81 \%$, were in the $21-30$ age group) can be accounted for by the fact that the Samoan population New Zealand is a young population group. Well over half the Samoan population in New Zealand is under 60 (68.7\%) whereas only $47.8 \%$ of the general New Zealand population falls into this age group (Krishnan et al 1994: 30). 
Table 9-3: Age Group of Respondents

\begin{tabular}{|l|c|c|c|c|}
\hline Age range & $\begin{array}{c}\text { All Respondents: } \\
\text { Number }\end{array}$ & $\begin{array}{c}\text { All Respondents: } \\
\text { Percentage }\end{array}$ & $\begin{array}{c}\text { NZ-born } \\
\text { Respondents: } \\
\text { Number }\end{array}$ & $\begin{array}{c}\text { NZ-born } \\
\text { Respondents: } \\
\text { Percentage }\end{array}$ \\
\hline $15-20$ & 1 & $1.1 \%$ & 1 & $4.8 \%$ \\
$21-25$ & 11 & $11.8 \%$ & 6 & $28.6 \%$ \\
$26-30$ & 23 & $24.7 \%$ & 11 & $52.4 \%$ \\
$31-35$ & 14 & $15.1 \%$ & 3 & $14.3 \%$ \\
$36-40$ & 21 & $22.6 \%$ & 0 & 0 \\
$41-45$ & 7 & $7.5 \%$ & 0 & 0 \\
$46-50$ & 10 & $10.8 \%$ & 0 & 0 \\
$51-55$ & 2 & $2.2 \%$ & 0 & 0 \\
$56-60$ & 1 & $1.1 \%$ & 0 & 0 \\
$60+$ & 1 & $1.1 \%$ & 0 & 0 \\
$41-50$ (FB) 102 & 1 & $1.1 \%$ & 0 & 0 \\
unclear $26-30$ & 1 & $1.1 \%$ & 0 & 0 \\
N= & 93 & 100.2 & 21 & 100.1 \\
\hline
\end{tabular}

\subsubsection{Marital status}

Most of the respondents $(75.3 \%)$ were married, 17 respondents (18.3\%) were not married and six respondents indicated some other marital status.

Table 9-4: Marital status

\begin{tabular}{|l|l|l|l|l|}
\hline Status & $\begin{array}{l}\text { All } \\
\text { Respondents } \\
\text { Number }\end{array}$ & $\begin{array}{l}\text { All } \\
\text { Respondents } \\
\text { Percentage }\end{array}$ & $\begin{array}{l}\text { NZ-born } \\
\text { Respondents } \\
\text { Number }\end{array}$ & $\begin{array}{l}\text { NZ-born } \\
\text { Respondents } \\
\text { Percentage }\end{array}$ \\
\hline Married & 70 & $75.3 \%$ & 16 & $76.2 \%$ \\
Never married & 17 & $18.3 \%$ & 4 & $19.0 \%$ \\
Formerly married & 3 & $3.3 \%$ & 0 & 0 \\
Married but spouse not in household & 1 & $1.1 \%$ & 0 & 0 \\
Living with partner & 1 & $1.1 \%$ & 0 & 0 \\
'boyfriend' & 1 & $1.1 \%$ & 1 & $4.8 \%$ \\
N= & 93 & 100.2 & 21 & 100 \\
\hline
\end{tabular}

\subsubsection{Children}

Most of the respondents ( $82.8 \%$ ) have children. The percentage of respondents with children is slightly lower (71.4\%) amongst the New Zealand-born respondents. Family size ranged from one child per family to seven children per family. There were 89 households represented

\footnotetext{
102 This respondent did not give her age but FB placed her in the 41 - 50 age group.

${ }^{103}$ It is unclear exactly what age this respondent intended to indicate on the questionnaire but 26-30 appears the most likely intention and the respondent is counted in this age group.
} 
in the survey and of those 89 households, $82 \%$ had children (not all of whom were living at home). Of the 89 households

- $14.6 \%$ had only one child

- $2.2 \%$ ( 2 households) had seven children

- $62.9 \%$ had two to five children.

\subsubsection{Family structure}

The 93 respondents lived in 89 households. The single largest proportion of respondents lived in a two-parent nuclear family but many of them lived in more extended families. Samoans in the general New Zealand population are much more likely to live in households that extend beyond a couple and their children. Thirty-eight percent of the Samoans in the 1991 Census lived in a 'shared household' (Statistics 1995: 23), as did approximately 36\% of the respondents to the survey (if one combines the $28 \%$ who answered 'spouse, children, other' with the $7.8 \%$ who answered 'children, other', most of whom were living with other family members). The number of respondents living as couples without children (5.5\%) was also similar to the 1991 Census findings (4\%). In general the family structures represented in the survey seem to be fairly typical, and to occur in roughly the same proportion, as the family structures in the general Samoan population.

Table 9-5: Family Structure

\begin{tabular}{|l|l|l|}
\hline Members of respondent's household & No. of households & Percentage \\
\hline Spouse, children & 28 & 31.4 \\
Spouse, children, other & 25 & 28 \\
Spouse, other & 6 & 6.7 \\
Spouse & 4 & 5.5 \\
Children & 6 & 6.7 \\
Children, other & 7 & 7.8 \\
Flatmates & 1 & 1.1 \\
Relatives & 2 & 2.2 \\
Under 25 years of age - living at home & 6 & 6.7 \\
N/A & 3 & 3.3 \\
N/R & 1 & 1.1 \\
N= & 89 & 99.5 \\
\hline
\end{tabular}




\subsubsection{Education}

\subsubsection{Where educated}

Table 9-6: Countries in which the respondents were educated

\begin{tabular}{|l|c|c|}
\hline Samoa only & 30 & $32.3 \%$ \\
\hline New Zealand only & 21 & $22.6 \%$ \\
Samoa and New Zealand & 34 & $36.6 \%$ \\
Samoa and 'other' & 3 & $3.2 \%$ \\
Tokelau & 1 & $1 \%$ \\
Unclear & 4 & $4.3 \%$ \\
N= & 93 & $100 \%$ \\
\hline
\end{tabular}

Of the 34 educated in Samoa and New Zealand

Table 9-7: Samoan respondents: level of education attained

\begin{tabular}{|l|l|l|}
\hline Level of Education in Samoa & Level of Education in NZ & No. Of Respondents \\
\hline Primary & Primary, secondary, tertiary & 3 \\
Primary & Secondary, tertiary & 2 \\
Primary & Secondary & 1 \\
Primary & Tertiary & 2 \\
Primary, secondary & Secondary & 1 \\
Primary, secondary & Primary, secondary, tertiary & 1 \\
Primary, secondary & Tertiary & 10 \\
Primary, secondary & Still studying & 1 \\
Primary, secondary, tertiary & Tertiary & 6 \\
Primary, secondary, tertiary & Secondary & 1 \\
Unclear & Secondary, Tertiary & 2 \\
Unclear & Tertiary & 1 \\
NR/unclear & NR/unclear & 3 \\
N= & & 34 \\
\hline
\end{tabular}




\subsubsection{Level of education}

Table 9-8: Level of education

\begin{tabular}{|lll|}
\hline No. & Level of education & Percentage \\
\hline 17 & received university education & $=18.2 \%$ \\
31 & received secondary education & $=33.3 \%$ \\
& & $=2.1 \%$ \\
02 & completed apprenticeship & $=3.2 \%$ \\
03 & completed apprenticeship/polytechnic & $=15.0 \%$ \\
14 & received polytechnic education & $=10.7 \%$ \\
10 & teacher / a'oga amata training & $=3.2$ \\
03 & polytechnic / other training & $=1.1 \%$ \\
01 & apprenticeship / teacher & $=35.4 \%$ \\
Tertiary other than university & $=5.3 \%$ \\
& & $=1.1 \%$ \\
4 & completed primary & $=6.4 \%$ \\
1 & still studying & \\
7 & NR/ unclear & $=99.6 \%$ \\
& & \\
& &
\end{tabular}

How do the respondents to the survey compare with the general Samoan population in New Zealand. Krishnan, Schoeffel and Warren point out that

The ability to provide their children with a good education was, and remains, for many Pacific Island families, a strong motivation in their decisions to migrate to New Zealand (Krishnan, Schoeffel and Warren 1994: 39).

Krishnan et al also point out that Samoans (and Fijians) are more likely than other Pacific Islander groups in NZ to have post school qualifications, and less likely to have no qualifications at all (Krishnan, Schoeffel and Warren 1994: 40).

Comparing the figures, we can see that the Samoan respondents to the questionnaire were, as a group, significantly more highly educated than average. As with the Dutch and Gujarati respondents, I have assumed that respondents who indicated that they completed secondary school have a secondary school qualification. As it is unlikely that this is, in fact, always the case, the number of respondents shown as having 'no qualifications' probably underrepresents the real numbers of those who have no educational qualification. 
Table 9-9: Level of education of respondents compared to Census findings

\begin{tabular}{|l|c|c|c|c|}
\hline & $\begin{array}{c}\text { NZB Samoans } \\
\text { Survey }\end{array}$ & $\begin{array}{c}\text { NZB Samoans } \\
\text { 1991 Census }\end{array}$ & $\begin{array}{c}\text { Non NZB Samoans } \\
\text { Survey }\end{array}$ & $\begin{array}{c}\text { Non NZB Samoans } \\
\text { 1991 Census }\end{array}$ \\
\hline No Qualifications & 0 & $21 \%$ & $7 \%$ & $48 \%$ \\
Secondary School & $29 \%$ & $46 \%$ & $35 \%$ & $29 \%$ \\
Post School & $71 \%$ & $24 \%$ & $48 \%$ & $21 \%$ \\
Still at school & N/A & $9 \%$ & $1.3 \%$ & $2 \%$ \\
Still studying & 0 & 0 & $10 \%$ & $0 \%$ \\
NR/Unclear & 21 & & 72 & \\
N= & & & & \\
\hline
\end{tabular}

(Source of Census figures. Statistics 1995: 25)

Table 9-9 shows that although respondents to the questionnaire had, as group, significantly more post school educational qualifications than the general Samoan population, nonetheless, the pattern of distribution of educational qualifications was similar in both groups. The New Zealand-born in both groups were less likely to have no qualifications and more likely to have post school qualifications.

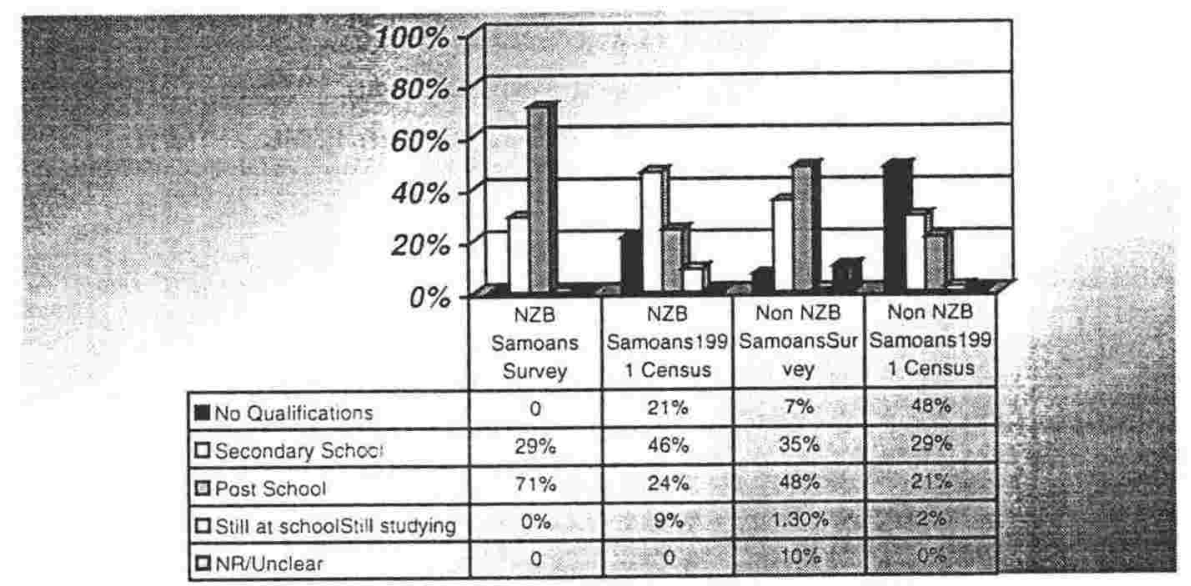

Figure 9-1: Highest level of education of all Samoan respondents to the survey compared to highest level of education attained by Samoan respondents to the 1991 Census ( Census figures from Statistics 1995: 25)

\subsubsection{Gender and education}

Amongst the respondents to the questionnaire men were more likely than women to have completed a university education and women were slightly more likely than men to have a tertiary qualification other than a university degree. Women were more likely than men to have completed only a primary or secondary education. 
Table 9-10: Highest level of education attained by male and female respondents to the survey

\begin{tabular}{|l|c|c|c|}
\hline Level of Education & $\begin{array}{c}\text { Samoan Men } \\
\%\end{array}$ & $\begin{array}{c}\text { Samoan Women } \\
\%\end{array}$ & $\mathrm{~N}=$ \\
\hline University & $24.9 \%$ & $12.4 \%$ & 17 \\
Secondary & $29.5 \%$ & $35.4 \%$ & 31 \\
Other Tertiary & $29.5 \%$ & $31.8 \%$ & 33 \\
Primary & $4.5 \%$ & $6.2 \%$ & 4 \\
$\mathrm{~N}=$ & & & 85 \\
\hline
\end{tabular}

Seven $(7.5 \%)$ of the responses were unclear or returned 'no response' for either gender or educational level. One male respondent, who already had secondary qualifications, is 'still studying'.

The respondents to the questionnaire differed from the general Samoan population not only in the very high proportion of people with school and post school qualifications but also in the disparity between male and female achievement at tertiary level. Although women in the general New Zealand Samoan population were a little more likely to have an 'other tertiary' qualification than men (as were the women in the survey), they were also more likely to have a university qualification than men. Whereas women in the survey were half as likely as men to have a university qualification. 
Table 9-11: Highest level of education attained by male and female respondents to the survey compared to 1991 Census data

\begin{tabular}{|c|c|c|c|c|c|c|}
\hline & $\begin{array}{l}\text { Samoan } \\
\text { women: } \\
\text { survey }\end{array}$ & $\begin{array}{l}\text { NonNZB } \\
\text { Samoan } \\
\text { women: } \\
1991 \\
\text { Census }\end{array}$ & $\begin{array}{l}\text { NZB } \\
\text { Samoan } \\
\text { women: } \\
1991 \\
\text { Census }\end{array}$ & $\begin{array}{l}\text { Samoan } \\
\text { men: } \\
\text { survey }\end{array}$ & $\begin{array}{l}\text { NonNZB } \\
\text { Samoan } \\
\text { men: } 1991 \\
\text { Census }\end{array}$ & $\begin{array}{l}\text { NZB } \\
\text { Samoan } \\
\text { men: } 1991 \\
\text { Census }\end{array}$ \\
\hline $\begin{array}{l}\text { Primary 104/No } \\
\text { Qualifications }\end{array}$ & 6.2 & 46.3 & 18.2 & 4.5 & 50.6 & 22.8 \\
\hline $\begin{array}{l}\text { Secondary/School } \\
\text { qualifications }\end{array}$ & 35.4 & 30.7 & 45.9 & 29.5 & 26.1 & 45.7 \\
\hline $\begin{array}{l}\text { Other Tertiary/ } \\
\text { Other Tertiary } 105\end{array}$ & 31.8 & 20.2 & 23.6 & 29.5 & 20.1 & 19.2 \\
\hline $\begin{array}{l}\text { University/ } \\
\text { Degrees }\end{array}$ & 12.4 & 0.9 & 3.2 & 24.9 & 1.3 & 2.6 \\
\hline $\begin{array}{l}\text { Still studying/ } \\
\text { Still at school } \\
\mathrm{N}=\end{array}$ & $\begin{array}{l}\text { N/A } \\
48\end{array}$ & 1.8 & 9.1 & $\begin{array}{l}2.2 \\
44 \\
\end{array}$ & 1.8 & 9.7 \\
\hline
\end{tabular}

(1991 Census data based on Statistics 1995: 26. Data in publication inaccurate, corrected data supplied by Statistics)

\subsubsection{Age and education}

One area in which the survey sample was noticeably different from Samoans nationally was in regard to age and education. Amongst Samoans as a group, nation-wide, the level of educational qualification goes up, as age goes down. Amongst the survey respondents almost the opposite is true. I am at a loss to suggest why this might be so. Tentatively, it seems possible that as most of the Research Group had a university education, they were more likely to move in tertiary educated circles.

${ }^{10+}$ The first listed category in each cell is the classification used in this research, the second listed category is the Census classification.

105 This represents a collapse of the 5 Census categories into one. 
Table 9-12: Level of education by age

\begin{tabular}{|l|c|c|c|c|c|c|}
\hline Samoan Survey & $\begin{array}{c}\mathbf{1 5 -} \\
\mathbf{2 5}\end{array}$ & $\mathbf{2 6 - 3 5}$ & $\mathbf{3 6 - 4 5}$ & $\mathbf{4 6 - 5 5}$ & $\mathbf{5 6 +}$ & $\mathbf{N}=$ \\
& $\mathbf{2 0 - 2 4}$ & & $\mathbf{3 5 - 4 4}$ & $\mathbf{4 5 - 5 5}$ & $\mathbf{5 5 +}$ & \\
\hline Samoan Census & $8.3 \%$ & 0 & $10.3 \%$ & $8.3 \%$ & 0 & 5 \\
Cenoan primary completed & $29 \%$ & $35 \%$ & $54 \%$ & $62 \%$ & $75 \%$ & \\
Samoan secondary completed & $25 \%$ & $39.4 \%$ & $37.9 \%$ & $8.3 \%$ & 0 & 30 \\
Census school qualifications & $43 \%$ & $36 \%$ & $24 \%$ & $17 \%$ & $12 \%$ & \\
& & & & & & \\
Samoan post-school completed & $66.6 \%$ & $47.3 \%$ & $44.8 \%$ & $75 \%$ & $100 \%$ & 50 \\
Census Tertiary qualifications & $28 \%$ & $28 \%$ & $22 \%$ & $21 \%$ & $13 \%$ & \\
Samoan Still studying & 0 & 0 & $3.4 \%$ & 0 & 0 & 1 \\
Samoan NR/ Unclear & 0 & $13.1 \%$ & $3.4 \%$ & $8.3 \%$ & 0 & 7 \\
Samoan N= & 12 & 38 & 29 & 12 & 2 & 93 \\
\hline
\end{tabular}

(Source of Census 1991 figures Statistics 1995: 27)

\subsubsection{Summary}

Almost three quarters of the respondents were born in Samoa, just under a quarter in New Zealand and the remainder in Tokelau and Tuvalu. Unlike the Gujarati and the Dutch groups, there were slightly more female than male respondents. The Samoan respondents were also much younger than the other two groups. Almost none of them were over 60 and most were between 21 - 50 years of age. Three quarters of the respondents were married. Most of the respondents had children. The two generation nuclear family is less common amongst the Samoan respondents. Under one third of respondents lived in such a family compared to over half of the Gujarati and Dutch respondents. The extended family was common amongst the Samoan respondents.

A third of respondents were educated in Samoa only, somewhat over a third in Samoa and New Zealand, under a quarter in New Zealand and the remainder elsewhere. Over a third had non-university tertiary qualifications and $18 \%$ had university qualifications. Compared to Samoans in New Zealand as a whole, the respondents had a high level of post school qualifications.

\footnotetext{
${ }^{100}$ Includes 11 respondents in the 21-25 age bracket and one respondent in the $15-20$ bracket.
} 


\subsection{Samoan community: patterns of language use}

This section gives an overview of patterns of language use within the Samoan community. Most of the respondents were born in Samoa and, unsurprisingly, most of them spoke Samoan as their first language. Most respondents were bilingual in Samoan and English. Compared to the Dutch and Gujarati respondents, the Samoan respondents were less likely to be trilingual. If they spoke a third language it was a Polynesian language. All the New Zealand-born respondents were bilingual in Samoan and English and two of them could, in addition, speak Maori.

\subsubsection{Language first spoken}

Perhaps the most interesting feature of the responses to this question is the small but noticeable proportion of non-New Zealand-born respondents who spoke both Samoan and English as their first languages. As mentioned in section 3.3.4.2, English is widely used in Samoa, and the fact that $16.7 \%$ of the non-New Zealand-born respondents spoke it as a language of infancy is a good indication of its currency.

Table 9-13: Language first spoken

\begin{tabular}{|l|c|c|c|c|c|}
\hline Birthplace & Samoan & English & Samoan/Eng & Other & $\mathrm{N}=$ \\
\hline Non-NZ & $77.8 \%$ & $2.8 \%$ & $16.7 \%$ & $2.8 \%$ & 72 \\
New Zealand & $38.1 \%$ & $38.1 \%$ & $23.8 \%$ & 0 & 21 \\
\hline
\end{tabular}

\subsubsection{Language most used}

For the respondents as a whole, Samoan is the language that is used most;

- $59.1 \%$ said that Samoan was the language they used most

- $19.4 \%$ said that they used English most

- $20.4 \%$ said that used English and Samoan equally.

- 1 respondent used Maori and Samoan equally.

For those born outside New Zealand the preponderance of those who use Samoan most in their daily life increases to $72.2 \%$, with only $9.7 \%$ saying that they use English most. A slightly larger group (16.7\%) uses English and Samoan equally and the one person who uses Samoan and Maori equally is in the non-New Zealand-born group.

Amongst the New Zealand-born

- $52.4 \%$ say that English is the language they use most of the time

- $33.3 \%$ say that they use Samoan and English equally

- $14.3 \%$ say that they use Samoan most of the time 


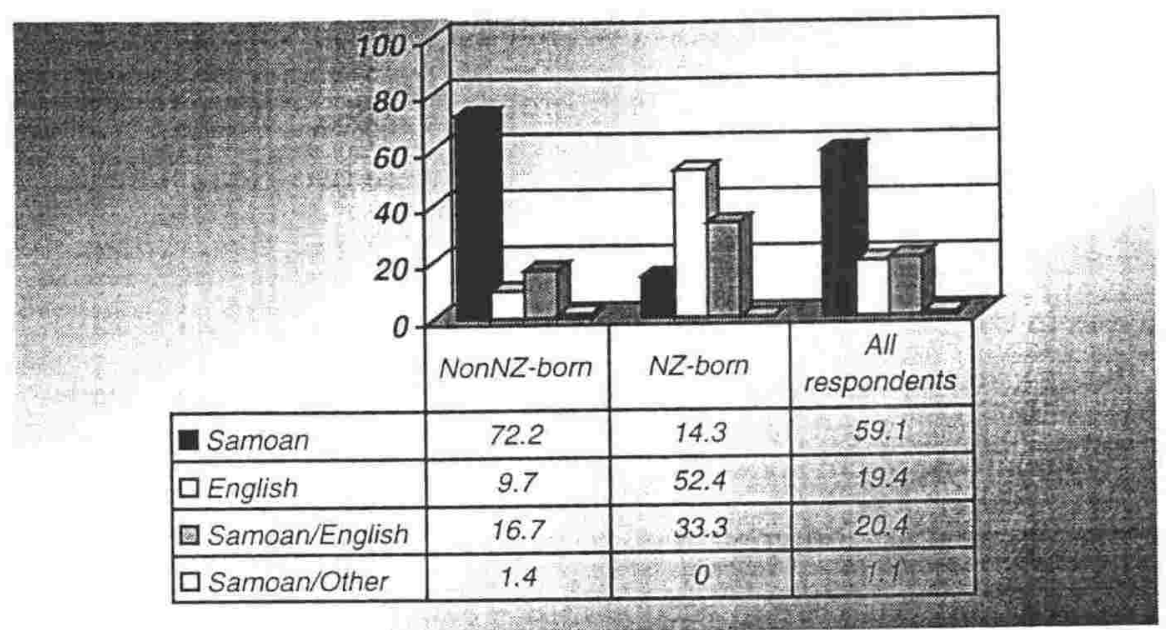

Figure 9-2: Language most used: All respondents by birthplace

At first glance it seemed unlikely that such a large proportion of the respondents could, in fact, use Samoan as their main language and I wondered if the respondents had tended to over-report their use of Samoan - as, in general, they were undoubtedly proud users of the language. A small majority (55\%) of the respondents who reported that they used Samoan most of the time also reported that they used only Samoan at home and the remainder used both Samoan and English at home (with some adding Tokelauan or Maori to the languages spoken at home). However, when we turn to the occupations of those who report Samoan as their main language the claim becomes more understandable. Of the 55 who report Samoan as their main language, 14 (25.4\%) gave their occupation as teachers, childcare workers, teachers in a'oga amata; most of these respondents worked in a'oga amata where part of their daily working life is to speak Samoan. These respondents made up the single biggest group of those who nominated Samoan as their main language. After the a'oga amata workers (in terms of numbers) came the five ( $9 \%$ ) respondents who designated themselves as either caregiver, homemaker or housewife and the five who worked as cleaners. The members of the first group are at home in the course of their working day and thus do not have much interaction with monolingual English speakers. The members of the second group work in an occupation which is known to provide workers with MT language working environment (Holmes and 'Aipolo 1991: 21). The next largest group after the homemakers/caregivers was the four (7.2\%) bus-drivers. According to Gail Reeves, Operations Manager of Stagecoach, the largest bus company in Wellington city ${ }^{107}$, the company employs a substantial proportion of Pacific Islanders drivers (roughly $30 \%$ of their driver workforce) and many of the non-New Zealand-

${ }^{107}$ Spoken to in February 1997. 
born drivers speak mainly to fellow countrymen in their own language during breaks. After the bus-drivers the largest group was the three unemployed (probably, like the homemakers, at home in a Samoan language environment most of the time). Next were two kitchen hands (also a job which tends to allow MT use \{Holmes and 'Aipolo 1991:21\}), two factory hands, two printers and two managers in administrative structures set up specifically to deal with Pacific Islanders. All of these people were working in jobs where it is possible to envisage that much of their working day could be spent speaking Samoan, as it was for the one building labourer and one road worker. The other eleven (20\%) of respondents who reported that the used mainly Samoan on a daily basis are in occupations where it is harder to see that English might not be much used:

- 1 carpenter

- 1 chief cook

- 1 electrician

- 1 dairy owner

- 1 public servant

- 1 receptionist

- 1 senior typist

- 1 shop assistant

- 1 student

- 1 taxi driver

- 1 office worker

Although, in all cases, if the respondent was working for a specifically Samoan organisation then of course, they would be able to use Samoan.

\subsubsection{Linguistic background of respondents}

All of the respondents are bilingual in Samoan and English. Only $15 \%$ of the respondents were trilingual and one respondent speaks four languages; Samoan, English, Tokelauan and Cook Islands Maori. Of the other trilingual respondents, two speak Cook Islands Maori, three speak Tokelauan, one speaks Tuvaluan and seven speak Maori. Maori is the most commonly spoken third language. Only two of the New Zealand-born respondents are trilingual - both speak Maori. One interesting point is that many respondents, when answering the question 'what language/s do you speak', only indicated Samoan but answers to later questions such as 'what language/s do you speak at home' or 'how do you rate your proficiency in English', showed that they also speak English. If answers to subsequent questions showed that the respondent spoke English then English was included as one of the languages spoken by the respondent even although the respondent had not recorded as such. 


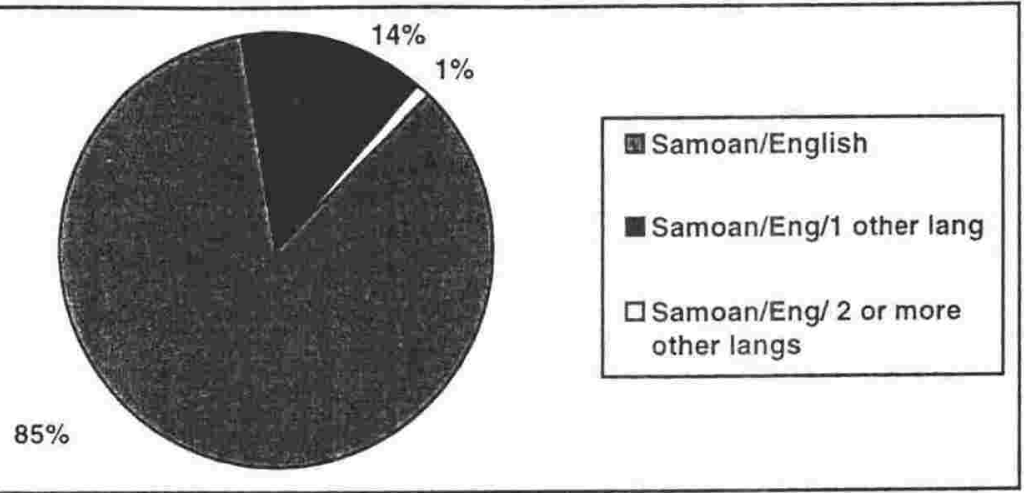

Figure 9-3: All Samoan respondents by languages spoken

\subsubsection{Language use in the last month}

Most respondents had spoken Samoan and English in the month prior to answering the questionnaire. Two respondents appear to have indicated that they had spoken only Samoan in the preceding month but it is difficult to know if this is, in fact what they intended to indicate (see discussion in section 6.5.1 regarding the difficulty of interpreting replies to question 4). Although $7.5 \%$ of respondents said that they spoke Maori in response to question one "what language/s do you speak?', 17.2\% of respondents listed Maori as one of the languages they had spoken in the last month. The discrepancy between the two sets of figures is greater than it appears as of the seven respondents who said that they spoke Maori in response to question one, only two had spoke it in the last month - another 14 respondents (all of whom had nominated only Samoan and English as the languages they could speak) said that they had spoken Maori in the last month. It is not clear what causes this discrepancy but it seems possible that those who listed Maori as one of the languages they spoke, feel more confident about their abilities in speaking Maori, whereas the remaining $10 \%$ or so of respondents are talking about a more limited use of Maori; of course this can only be a guess but it raises interesting questions about what respondents mean when they indicate that they can 'speak' a language. This is discussed in greater detail below in the section on Samoan language proficiency.

There is a similar slight discrepancy in the responses concerning Tokelauan and Tuvaluan. Of the four $(4.3 \%)$ respondents who said that they could speak Tokelauan, three had spoken it in the month previous to the survey and another three, who had not nominated it as one of the languages that they could speak, said that they had spoken it in the past month (thus 6 respondents (6.4\%) had spoken Tokelauan in the previous month); one respondent said that they could speak Tuvaluan but two claimed to have spoken it in the past month. Of the three 
respondents who said that they could speak Cook Islands' Maori, two had spoken it in the last month and one other respondent (who listed only Samoan and English in answer to question one) said that they had spoken it in the last month (along with Samoan, English and Maori).

One respondent who listed only Samoan and English as the languages that they could speak, had spoken not only Maori in the previous month, but also Niuean.

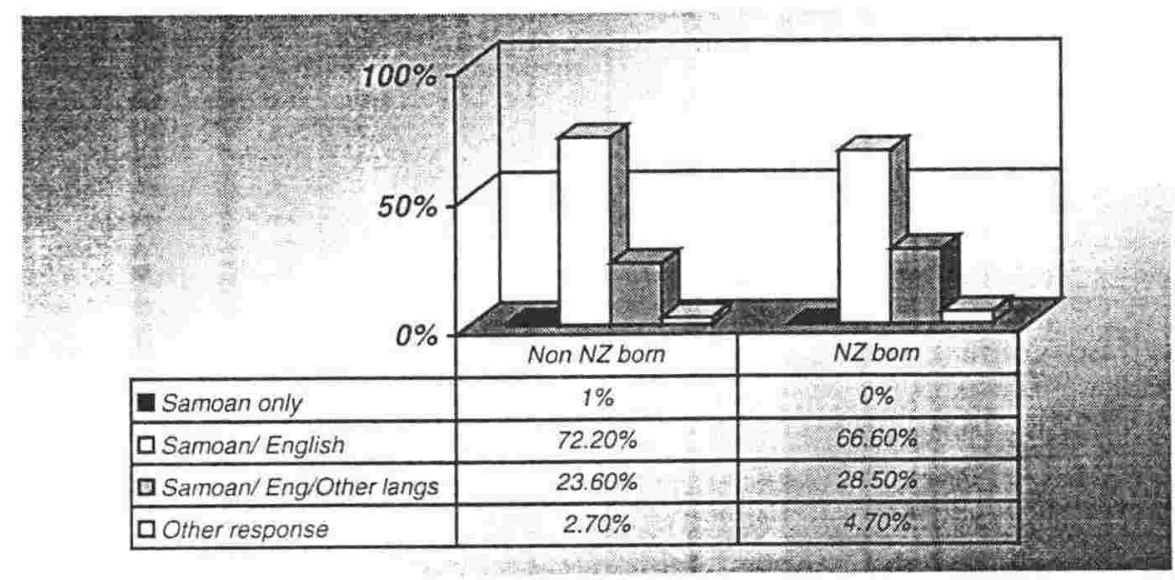

Figure 9-4: Language use in the month preceding the survey: by birthplace

\subsubsection{Language use in the home}

A very small majority of respondents reported that they spoke both Samoan and English at home.

- $50.5 \%$ spoke both Samoan and English at home

- $38.7 \%$ spoke only Samoan at home

- $5.4 \%$ ( five people) spoke only English at home

- $5.4 \%$ spoke Samoan, English and another language at home

Three respondents spoke Maori at home as well as English and Samoan and two respondents spoke Tokelauan in addition to English and Samoan. If these five are added to the 47 who speak both Samoan and English at home then the total of respondents speaking both languages at home is $55.9 \%$. One of the respondents who claimed Maori as a language spoken at home and one who claimed Tokelauan did not list these languages in response to question one $^{10 s}$

- $76.2 \%$ of the New Zealand-born used Samoan and English in the home

\footnotetext{
${ }^{10 s}$ It is perhaps worth noting that respondent 72 who did list Maori as one of the languages she could speak and who also listed it as a language that she had spoken in the last month and one that she used at home, added a note to the question about language/s used at home, stipulating that the Maori that was used at home was "basic - just greeting words'.
} 
- $9.5 \%$ (two) of the New Zealand-born used only Samoan at home

9.5\% (two) of the New Zealand-born used only English at home

Amongst the non-New Zealand-born however, a substantial minority reported that they used only Samoan at home

- $47.2 \%$ used only Samoan at home.

- $43.1 \%$ used both Samoan and English in the home

- two used Maori at home as well as Samoan and English

- another two used Tokelauan as well as Samoan and English.

Amongst the New Zealand-born only one respondent used Maori as well as Samoan and English at home and there were no other trilingual households. As with the Dutch and the Gujarati, being born in New Zealand is predictive of a more limited range of language use.

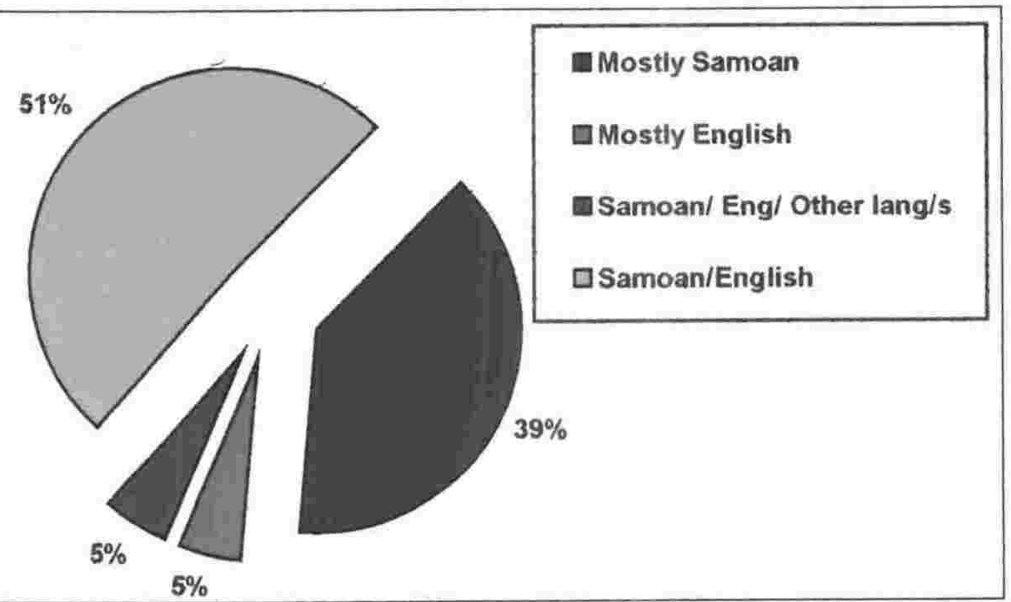

Figure 9-5: Language use in the home: all respondents

\subsubsection{Language spoken with spouse/partner}

Most respondents $\left(49.3 \%{ }^{109}\right)$ spoke Samoan with their partners most of the time.

- $31.1 \%$ spoke both Samoan and English equally

- $16.8 \%$ spoke mainly English

- two respondents (not married to each other) spoke Samoan English and Tokelauan with their spouses

Amongst the non-New Zealand-born, the percentage of those who spoke mainly Samoan to their spouses rose to $60 \%$ whereas amongst the New Zealand-born it fell to $11.7 \%$. Amongst the New Zealand-born the percentage of those who spoke only English to their spouses rose

${ }^{109}$ Percentages in this section are percentages of the group of respondents that have partners. 
to $23.5 \%$ and most New Zealand-born respondents (63.7\%) thought that they spoke fairly equal amounts of Samoan and English to their spouses.

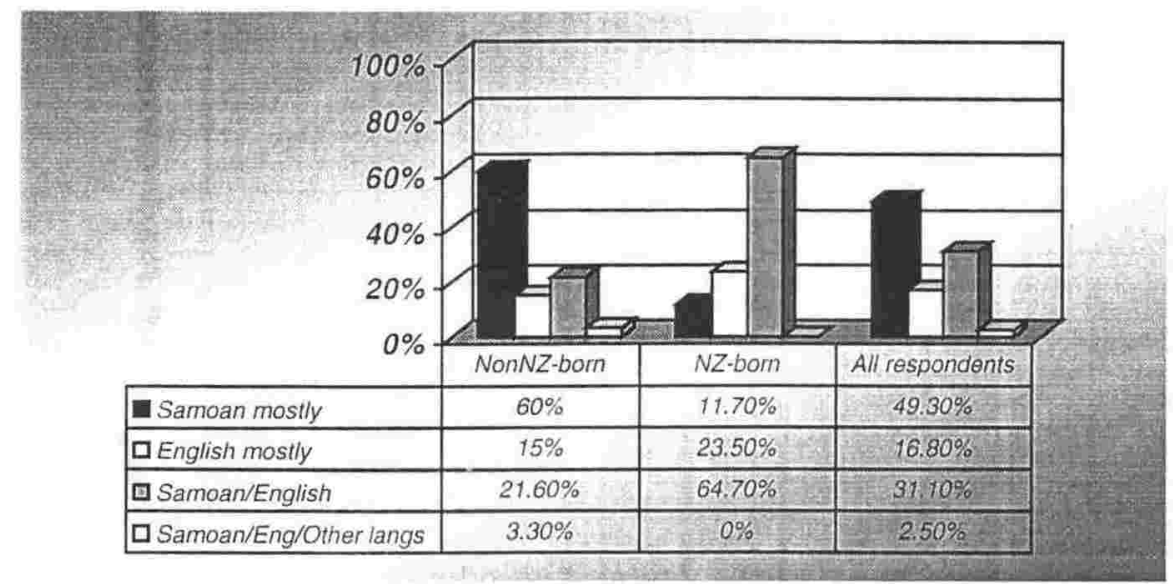

Figure 9-6: Language/s spoken with spouse: by birthplace

\subsubsection{Language spoken with children}

Of the 77 respondents who had children, most of them said that they spoke mainly Samoan to their children

- $53.2 \%$ spoke mainly Samoan to their children

- $32.4 \%$ considered that they spoke Samoan and English equally to their children

- $10.3 \%$ spoke English to their children most of the time and

- two respondents spoke Tokelauan as well as to Samoan and English to their children

- one respondent spoke English, Tokelauan and Cook Islands' Maori to their children

Amongst the 62 non-New Zealand-born respondents who have children, the percentage of those who spoke mainly Samoan to their children rises.

- $61.2 \%$ spoke mainly Samoan to their children

- $25.8 \%$ spoke more or less equal amounts of Samoan and English

- $8 \%$ spoke mainly English

The two respondents who spoke Samoan, English and Tokelauan and the one respondent who spoke English, Tokelauan and Cook Islands' Maori are, as one would expect, in the non-New Zealand-boin group.

Amongst the 15 New Zealand-born respondents who have children,

- $60 \%$ consider that they speak equal amounts of Samoan and English to their children

- $20 \%$ speak mainly Samoan

- $20 \%$ speak mainly English. 
Although a lot of Samoan is still being spoken in the respondents' homes, the signs of language shift can be clearly seen. The non-New Zealand-born respondents are likely to speak mainly Samoan to spouses (60\%) and children (61.2\%). The New Zealand-born are less likely to use only Samoan at home and are more likely to use Samoan and English. They are less likely to speak mainly Samoan to their spouses and children. It is interesting to note however that the New Zealand-born respondents are more likely to speak Samoan to their children than to their spouses which suggests that they are actively promoting some degree of Samoan language maintenance for their children. Perhaps these parents are akin to those described by MacPherson as providing 'environment two' in which 'languages are presented as alternatives' (MacPherson 1984: 120).

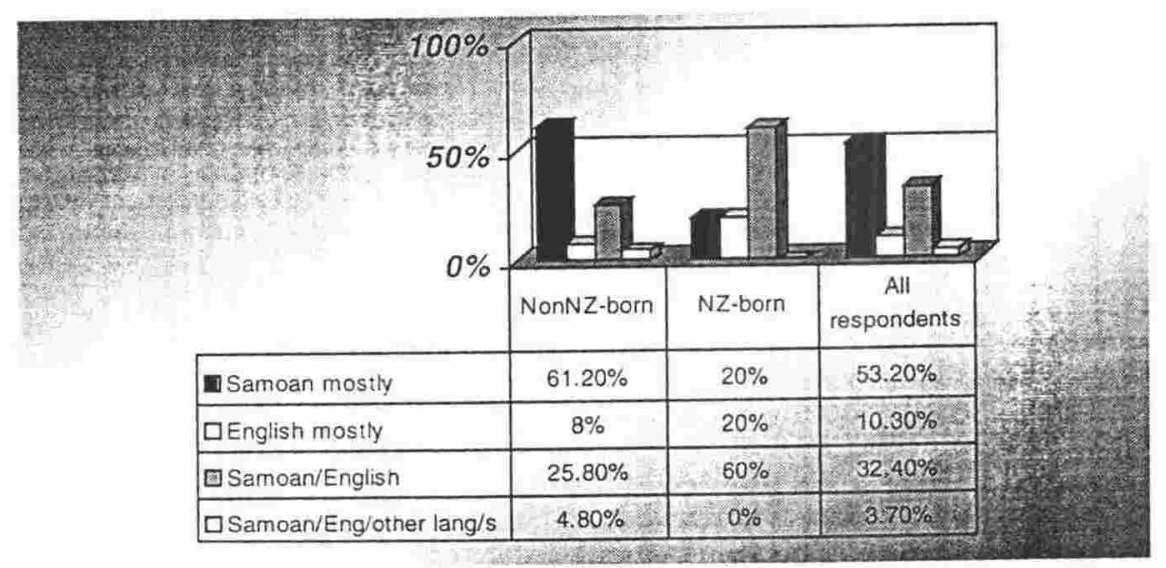

Figure 9-7: Language/s spoken with children most of the time

\subsubsection{Samoan spoken outside the home}

All the non-New Zealand-born respondents used Samoan outside the home. One of the New Zealand-born respondents did not.

\subsubsection{Samoan-speaking interlocutors, outside the home}

The pattern of Samoan language use outside the home fits the pattern of language shift in progress in that fewer New Zealand-born respondents use Samoan to a full range of interlocutors, but the differences in use between the New Zealand-born and the non-New Zealand-born, are not very great.

Over half $(56.9 \%)$ the non-New Zealand-born respondents used Samoan to all the possible interlocutors listed and many of them added other interlocutors to the list; a typical addition was 'to all Samoan people people' or 'whenever I see a Samoan person'. Over a third (38\%) of the New Zealand-born respondents were in the same situation. 
The respondents were asked to choose the type of people they spoke Samoan with outside the home from a list of six types of interlocutor (and they could, of course, add other types if they so wished). When we rank order their choices we can see that there are differences between the New Zealand-born and non-New Zealand-born respondents, but they are not great. Perhaps the most noticeable difference is that the percentage of New Zealand-born respondents who choose a given type of interlocutor, is always lower than the percentage of non-New Zealand-born respondents who choose that particular type of respondent as one with whom they speak Samoan.

Table 9-14: Interlocutors outside the home, by birthplace

\begin{tabular}{|l|l|l|l|l|}
\hline New Zealand Born & & & Non-New Zealand Born & \\
\hline Older relatives & $76.1 \%$ & & Older relatives & $95.8 \%$ \\
Minister & $71.4 \%$ & & Minister & $90.2 \%$ \\
Friends own age & $71.4 \%$ & & Older friends & $86.1 \%$ \\
Children (other than own) & $57.1 \%$ & & Children (other than own) & $83.3 \%$ \\
Immigrants & $57.1 \%$ & & Friends own age & $81.9 \%$ \\
Older friends & 47.6 & & Immigrants & $69.4 \%$ \\
$\mathrm{~N}=$ & 21 & & & 72 \\
\hline
\end{tabular}

We can see that although Samoan use outside the home has declined amongst the New Zealand-born it is still widely used with friends their own age and its use is certainly not confined to older people or new immigrants who don't speak much English. Plenty of New Zealand-born respondents are speaking Samoan to children other than their own and this too is a healthy sign for the language in New Zealand ${ }^{110}$. It is noticeable in both groups that older relatives and the minister are the two sets of interlocutors who are most commonly addressed in Samoan. Stockwell also found that 'in a relative's home' or 'at church' were places that Pacific Island children were very likely to hear their MT being spoken (Stockwell 1995: unnumbered page opposite p. 62).

Very few respondents nominated fewer than three sets of interlocutors. One respondent nominated only children, another only friends their own age, another the minister. Two respondents (one New Zealand-born, one born outside New Zealand) nominate only older relatives and the minister and one person said they only used Samoan at the a'oga amata.

\footnotetext{
${ }^{110}$ Although it must be remembered that some of the respondents speaking Samoan to children outside the home are doing it in their professional capacity as teachers in a'oga amata.
} 
Only six respondents (three New Zealand-born, three born outside New Zealand) nominated only older people and/or the minister as Samoan speaking interlocutors outside the home.

\subsubsection{Where Samoan was spoken outside the home}

Unlike the Dutch community where we see a pattern of rapidly contracting opportunities for MT use, the Samoan community presents a picture of a community where it is still possible to use the MT relatively freely. Most respondents (68.8\%) said that they used Samoan at social gatherings, work and church and many of them added that they used Samoan at other places as well. Some common additions to the list of places where Samoan could be used were at the shops / market, the bus, the railway station, sports and the beach. 'If Samoans are around', 'where I meet any Samoan' were also amongst the replies to this question. Stockwell also found that 'shopping' and 'out in the community' were common responses to the question about where the respondent's child would have been likely to hear its Pacific Island MT (Stockwell 1995: unnumbered page opposite p. 62). Holmes and 'Aipolo reported a similar wide-ranging use of Tongan in New Zealand (1991:17).

Unlike the Gujarati and Dutch respondents, most of the Samoan respondents used their MT at work, although it is hard to know just how much Samoan they spoke at work. The workplace was the least likely place for respondents to speak Samoan but, even so, many did use Samoan at work.

- $81.9 \%$ of the non-NZ-born respondents used Samoan at work

- $61.9 \%$ of the New Zealand-born used Samoan at work

Samoan use at work has already been discussed in section 9.2.2 where it was noted that most of the respondents who claimed to speak predominantly Samoan were engaged in jobs where it was likely that they would have plenty of opportunity to speak Samoan but that some were employed in areas where it was not so easy to envisage that they would speak Samoan throughout most of the working day. Focussing on those respondents who say that they speak Samoan (though not necessarily, mainly Samoan) in their working day, we find a very wide range of occupations. All those respondents who said that they spoke mainly Samoan at work are included of course but some of the other respondents who speak some Samoan at work include; bank tellers, clerks, Plunket health workers and students.

Even more common than Samoan use at work was Samoan use at social gatherings and, most common of all, Samoan use at church. Stockwell also found that 'church activities' were the 
single group of 'language related activities' that her Pacific Island respondents were most likely to describe themselves as 'very involved' in, followed by 'cultural activities', which presumably overlap with 'social gatherings' (Stockwell 1995: 67).

Table 9-15: Where respondents used Samoan outside the home

\begin{tabular}{|l|l|l|l|}
\hline & Non-NZ-born & NZ-born & All Respondents \\
\hline At work & $81.9 \%$ & $61.9 \%$ & $77.4 \%$ \\
At social gatherings & $88.8 \%$ & $80.9 \%$ & $87 \%$ \\
At church & $95.8 \%$ & $80.9 \%$ & $93.5 \%$ \\
N= & 72 & 21 & 93 \\
\hline
\end{tabular}

Although more non-New Zealand-born respondents said that they used Samoan at social gatherings and work and church than did New Zealand-born respondents, nonetheless over half the New Zealand-born respondents did use Samoan in all three places.

- $72.2 \%$ of non-New Zealand-born used Samoan in all three places

- $57.1 \%$ of New Zealand-born used Samoan in all three places

\subsubsection{Low levels of Samoan language use}

Because levels of Samoan use outside the home are so high, it is interesting to look at the small number of respondents who did not report such high levels of use. Only 16 respondents fell into this group. They are respondents who ticked neither all the interlocutors in question 12 nor all the sites of Samoan use in question 13. This can only be a rough measure of Samoan use outside the home but it does seem likely that those who had fewer types of interlocutor outside the home and fewer places where they spoke Samoan were in fact less frequent users of Samoan outside the home. The most noticeable trait shared by the respondents in this group is their youth.

- nine of the 16 are 30 years of age and under

- they make up $52.9 \%$ of the 30 -and-under segment of the respondents.

- the remaining seven respondents range in age from 31-50 and make up 16.6\% of that age-group in the respondents to the survey.

- half of the 16 respondents are New Zealand-born (38\% of all the New Zealandborn respondents)

- half are non-New Zealand-born (11.1\% of all the non-New Zealand-born respondents).

Thus, although Samoan use is high amongst the respondents in general, when we look closely at the figures we can see the signs of language shift occurring in the community; reduced range of use of a language is one of the classic signs of language shift (Fishman 1966a: 433434 ) and here we see range of language use both in terms of interlocutor and domain of use 
being reduced in the young and the host-country born members of the community, both groups where we would expect to find incipient shift.

\subsubsection{Attitudes}

\subsubsection{Samoan after hours school for children}

All but two of the respondents thought that Samoan language schools were a good idea. The two respondents who were not in this group were both 'not sure' whether such schools were a good idea or not. Both these respondents were non-New Zealand-born.

\subsubsection{Samoan within the state school system}

- $95.7 \%$ of respondents thought that Samoan should be available within the state school system

- one person (non-New Zealand-born) gave no response to this question

- one person (non-New Zealand-born) answered both yes and no, which I interpret to mean they were unsure

- two respondents (one born in New Zealand, one born outside New Zealand) said that Samoan should not be taught in New Zealand schools.

Stockwell also found that $71 \%$ percent of her Pacific Island respondents thought that it was 'very important' that their children learn their MT at primary school and over $90 \%$ thought it was either 'important' or 'very important' (Stockwell 1995: 19-20). A somewhat smaller total of 66\% thought that MT instruction was important at secondary level (Stockwell 1995: 42).

\subsubsection{Funding for community schools}

Most respondents (97.8\%) thought that funding should be available for Samoan community run schools. The two dissenters both replied 'not sure' rather than 'no' and were both born in New Zealand.

\subsubsection{General Views}

9.2.11.1 Is it important to keep Samoan as a living language in New Zealand? All respondents thought Samoan should be a living language in New Zealand. 


\subsubsection{Should Samoan people see themselves as part of a Samoan/NZ community?}

There was slightly less unanimity on this and the subsequent question. Most respondents (90.3\%) thought that Samoans in New Zealand should see themselves as part of a Samoan/New Zealand community but seven were not sure (two ticked not sure, five answered both yes and no) and two respondents answered 'no' to the question.

There were small but noticeable differences between the New Zealand-born and non-New Zealand-born respondents to this question. Both of those who answered 'no' were New Zealand-born and only $81 \%$ of the New Zealand-born answered 'yes', 9.5\% (two respondents) were not sure. Amongst the non-New Zealand-born, 93.1\% thought that Samoans in New Zealand should see themselves as part of a Samoan/New Zealand community and $6.9 \%$ were not sure.

\subsubsection{Should Samoan people in New Zealand see themselves simply as New} Zealanders? Most respondents (94.6\%) thought that Samoans in New Zealand should not see themselves simply as New Zealanders. Three respondents thought that they should do so (all born outside New Zealand) and two respondents (one born in New Zealand, one born outside) answered both yes and no.

\subsubsection{Summary}

The Samoan respondents to the questionnaire still live in a world where Samoan can be freely used in almost all contacts with Samoans. There are signs that this is changing however. The New Zealand-born respondents are generally less likely to use Samoan in all areas of their lives and it seems clear that some of them are bringing their children up in environments where comparatively little Samoan is spoken. Of all three respondent groups, the Samoans are the group that gives the strongest impression of MT use, but it must be remembered that this may be a least partly a function of their comparatively recent arrival in New Zealand and not wholly due to strong language maintenance processes within the community. The strong desire for language maintenance certainly is there, as can be seen from the responses to the attitude questions, but as Jamieson has pointed out, desire for a language maintenance goal and achieving the goal do not necessarily coincide (Jamieson 1980: 107-108). 


\subsection{Language proficiency}

\subsubsection{Self-reporting of proficiency}

As in the previous two sections, some specific reporting problems are investigated and then the respondents answers to the proficiency questions are examined. The Samoan respondents were asked about proficiency in three areas; English, everyday Samoan and formal Samoan.

\subsubsection{Possible under-reporting of proficiency}

As with the Gujarati respondents, the Samoan respondents were asked to answer proficiency questions relating to three languages; in the case of the Samoan respondents these were Samoan, English and Formal Samoan. This, as with the Gujarati respondents, seems to have prompted each respondent to compare the three levels of ability in each language and to have, to some extent, guarded against false modesty in reporting. That is, if you speak all three languages and if you know that your Formal Samoan is better than your English and your everyday Samoan is better than your Formal Samoan then you really have to rank your Samoan abilities as 'fluent' so that you leave room in the ranking, as it were, to place Formal Samoan and English below Samoan at 'fairly fluent' and 'not very fluent' respectively. Respondents seem to have taken advantage of this with the result that most of the non-New Zealand-born respondents claimed they were 'fluent' in Samoan, over half claimed fluency in Formal Samoan and somewhat over a third claimed it in English.

- $86.1 \%$ of the non-New Zealand-born respondents claimed fluency in Samoan

- $56.9 \%$ claimed fluency in Formal Samoan

- $38.8 \%$ claimed fluency in English

With the New Zealand-born the order was clearly different. Most of the respondents said that they were 'fluent' in English, over a third of them thought they were 'fluent' in Samoan and only one New Zealand-born respondent claimed to be 'fluent' in formal Samoan.

- $85.7 \%$ of New Zealand-born respondents claimed fluency in English

- $38.1 \%$ claimed fluency in Samoan

- $4.8 \%$ (= 1) New Zealand-born respondent claimed fluency in Formal Samoan

Altogether there were 18 respondents (19.3\%) who chose to rate themselves at a different level of competency for each of the three languages. Fifteen of them rated themselves across a spread of 'fluent', 'fairly fluent' or 'not very fluent' for the three languages. The other three all chose 'can't speak but can understand' for formal Samoan and some combination out of 'fluent', 'fairly fluent' and 'not very fluent' for the other two languages. 
The same proportion of respondents (19.3\%) said that they were 'fluent' in all three languages.

\subsubsection{Possible over-reporting of proficiency}

This brings us to the question of possible over-reporting of ability. If respondents have said that they can speak fluently and write easily in both languages then the question arises as to whether the are making sufficiently nice distinctions as to their abilities. Fourteen Samoan respondents (15\%) said that they were 'fluent' in Samoan, English and Formal Samoan and that they could write 'easily' in both languages.

- 8 of the 14 were female ( $16.3 \%$ of the female respondents) and

- 6 were male (13.6\% of the male respondents)

Only one of these respondents was New Zealand-born. In the case of the non-New Zealandborn respondents, their assessment of their abilities, at least as far as can be told from their answers to the questionnaire, seem plausible. Most of them say that they use Samoan to all possible categories of interlocutor and 10 of the 13 non-New Zealand-born respondents say that they use Samoan at work. At the same time most of them work in white collar jobs where a sound mastery of spoken and written English would also be necessary; receptionist, senior typist, teacher, public servant, office worker, manager etc. and seven of the 13 have a tertiary education of some kind. The only respondent whose assessment of her own abilities does not altogether fit in with her answers to the rest of the questionnaire, is the New Zealand-born respondent. She is under 25 , has a white collar job and a tertiary education and it seems clear that her assessment of her English abilities is likely to be accurate. However she speaks Samoan to friends her own age only and at social gatherings and church. She says that English is the language that she uses most in her everyday life and it is hard to see, on the evidence of the questionnaire, how she has the opportunity for both her everyday and Formal Samoan to be 'fluent', or for her to be able to write 'easily' in Samoan. There may well be, however, factors not revealed in the responses to the questionnaire that explain her high and unusual level of proficiency.

\subsubsection{No response to proficiency question}

Six respondents $(6.4 \%)$ gave 'no response' to any of the questions about proficiency in the spoken language. All the respondents were male, five of them were in the 36-40 age group and one was in the 46-50 age group. They all answered the questions about proficiency in the 
written language. They could all write 'easily' in Samoan, two of the six could write 'fairly easily' in English, the others 'with difficulty. They were all born in Samoa. There seems to be no obvious reason why they did not answer the questions about proficiency in the spoken language. It seems likely that they were all fluent in Samoan and that their ability in English would have ranged from fluent to not very fluent.

Several other respondents gave 'no response' to some of the language proficiency questions. In most of these cases, it seems likely that the respondents did not want to be explicit about just how poor the particular language skill was. For instance the one respondent who answered all the questions about Samoan language proficiency ('fluent' in both everyday and Formal Samoan, and able to write Samoan 'easily') but neither of the questions about English language proficiency, was under 30 years of age and had come to New Zealand between the ages of $21-30$, she works as a mother help in an a'oga amata and it seems possible that her English is not very strong. The area in which a single 'no response' return (when all the other language questions had been answered) was most obvious was in the responses to the Formal Samoan question. Altogether 15 respondents gave 'no response' to the question about Formal Samoan proficiency but six of these were the six men who did not answer any of the oral language proficiency questions. Of the remaining nine, all but one answered all the other language proficiency questions, the remaining respondent gave 'no response' to the question about Formal Samoan and written Samoan. The nine respondents (six female, three male) were either born in New Zealand or (once again with one exception) they had come to New Zealand under the age of 20. It seems likely therefore that their Formal Samoan skills would not be strong and that they either did not answer the question because they felt that it was not relevant to them or because they did not was to state explicitly that their Formal Samoan skills were poor.

\subsubsection{Not fluent in any language}

Only one respondent said that they were not fluent in either English or Samoan and as they were born in Tokelau and spoke Tokelauan as their first language, it is possible that neither Samoan nor English is their strongest language. 


\subsubsection{Oral proficiency}

\subsubsection{Samoan: see Table 9-16}

In general there was a high level of claimed ability to speak everyday Samoan. Three-quarters of the respondents (75.3\%) said that they could speak Samoan 'fluently'. Unsurprisingly there was a considerable difference between the New Zealand-born and the non-New Zealand-born. All the non-New Zealand-born who replied to this question thought that they were either 'fluent' or 'fairly fluent' in Samoan (there was a 'no response' rate of 8.3\%).

- $86.1 \%$ of the non-New Zealand-born respondents said they were 'fluent'

- $5.6 \%$ of the non-New Zealand-born respondents said they were 'fairly fluent'

- The New Zealand-born respondents were fairly evenly divided between those who thought they were 'fluent', 'fairly fluent' and 'not very fluent'.

- $38.1 \%$ of New Zealand-born respondents thought they were 'fluent'

- $33.3 \%$ of New Zealand-born respondents thought they were 'fairly fluent'

- $28.6 \%$ of New Zealand-born respondents thought they were 'not very fluent'

There were no respondents who said that they were unable to speak Samoan. This is not dissimilar to Stockwell's findings; $92 \%$ of Pacific Island respondents knew their MT and two thirds to three quarters of respondents rated themselves as completely fluent (Stockwell 1995: 66).

Table 9-16: Proficiency in oral Samoan: \%

\begin{tabular}{|l|l|l|l|l|l|}
\hline & Fluent & Fairly Fluent & Not Very Fluent & NR & N= \\
\hline Non-NZ-born & $86.1 \%$ & $5.6 \%$ & 0 & $8.3 \%$ & 72 \\
N.Z. Born & $38.1 \%$ & $33.3 \%$ & $28.6 \%$ & 0 & 21 \\
Non-N.Z.B 10+ & $87.7 \%$ & $3.1 \%$ & 0 & $9.2 \%$ & 65 \\
& & & & & \\
All Respondents & $75.3 \%$ & $11.8 \%$ & $6.5 \%$ & $6.5 \%$ & \\
N= & 70 & 11 & 6 & 6 & 93 \\
\hline
\end{tabular}

\subsubsection{English: see Table 9-17}

Amongst the New Zealand-born respondents 18 (85.7\%) thought that they were 'fluent' in English and another three (14.3\%) said that they were 'fairly fluent' although, given that they have probably spent most of their lives in New Zealand, this should perhaps be taken as an example of modesty on the part of the respondents causing them to under-report their ability in comparison with the other respondents. Amongst the non-New Zealand-born respondents most thought that they were either 'fluent' or 'fairly fluent' in English.

- $38.8 \%$ thought they were 'fluent'

- $44.4 \%$ though they were 'fairly fluent'

- $4.2 \%$ thought that they were 'not very fluent' 
One respondent claimed that she had no ability in English at all but Feauai'i Burgess, who knows the respondent, has commented that the respondent can, in fact, speak English but that she is 'shy to speak' and that this has caused her to say that she cannot speak or understand English. Overall just under half the respondents (49.4\%) said that they could speak English 'fluently'.

- $\quad 49.4 \%$ said that they could speak English 'fluently'

- $37.6 \%$ said that they could speak it 'fairly fluently'

- $3.2 \%$ were 'not very fluent'

- $8.6 \%$ returned 'no response'

Table 9-17: Proficiency in oral English \%

\begin{tabular}{|l|l|l|l|l|l|l|}
\hline & Fluent & Fairly Fluent & Not Very Fluent & No Ability & NR & N= \\
\hline Non-NZ- Born & $38.8 \%$ & $44.4 \%$ & $4.2 \%$ & $1.4 \%$ & $11.1 \%$ & 72 \\
N.Z. Born & $85.7 \%$ & $14.3 \%$ & 0 & 0 & 0 & 21 \\
Non-N.Z.B 10+ & $33.8 \%$ & $47.7 \%$ & $4.6 \%$ & $1.5 \%$ & $12.3 \%$ & 65 \\
& & & & & & \\
All Respondents & $49.4 \%$ & $37.6 \%$ & $3.2 \%$ & $1.1 \%$ & $8.6 \%$ & \\
N= & $46 \%$ & 35 & 3 & 1112 & 8 & 93 \\
\hline
\end{tabular}

\subsubsection{Formal Samoan: see Table 9-18}

Over half the non-New Zealand-born respondents considered themselves to be 'fluent' in Formal Samoan and a handful thought that they were 'fairly fluent' but there were some who said that they were 'not very fluent'.

- $56.9 \%$ of the non-New Zealand-born respondents considered themselves to be 'fluent'

- $9.7 \%$ thought that they were 'fairly fluent'

- $16.7 \%$ said that they were 'not very fluent'

One non-New Zealand-born respondent said that they 'could not speak but could understand' and $15.3 \%$ entered 'no response'. Amongst the New Zealand-born respondents there was one respondent who had no ability at all, two who said that they had comprehension skills only and the majority said that the were 'not very fluent'. One New Zealand-born respondent

\footnotetext{
111 One respondent entered 'NR' for the question on oral English but said that she could 'write easily'. I have counted her as a 'fluent' speaker of English.

${ }^{112}$ I asked Feaua'i Burgess if, in her opinion, this respondent really did not speak or understand English. FB replied that, in her opinion, the respondent did speak and understand English but that she was 'shy to speak' and this had caused her to respond as she had. I have left the entry to stand as it was given by the respondent but note that, in fact, the respondent did have some English ability.
} 
considered that they were 'fluent' in Formal Samoan and three (14.3\%) thought that they were 'fairly fluent'.

Table 9-18: Proficiency in formal Samoan \%

\begin{tabular}{|l|c|c|c|c|c|c|c|}
\hline & Fluent & $\begin{array}{c}\text { Fairly } \\
\text { Fluent }\end{array}$ & $\begin{array}{c}\text { Not Very } \\
\text { Fluent }\end{array}$ & $\begin{array}{c}\text { Comprehension } \\
\text { Only }\end{array}$ & $\begin{array}{c}\text { No } \\
\text { Ability }\end{array}$ & NR & N= \\
\hline Non-NZ- Born & $56.9 \%$ & $9.7 \%$ & $16.7 \%$ & $1.4 \%$ & 0 & $15.3 \%$ & 72 \\
N.Z. Born & $4.8 \%$ & $14.3 \%$ & $47.6 \%$ & $9.5 \%$ & $4.8 \%$ & $19 \%$ & 21 \\
Non-N.Z.B 10+ & $61.5 \%$ & $6.2 \%$ & $15.4 \%$ & $1.5 \%$ & 0 & $15.4 \%$ & 65 \\
All Respondents & $45.2 \%$ & $10.8 \%$ & $23.6 \%$ & $3.2 \%$ & $1.1 \%$ & $16.1 \%$ & \\
N= & 42 & 10 & 22 & 3 & 1 & 15 & 93 \\
\hline
\end{tabular}

\subsubsection{Written proficiency}

\subsubsection{Samoan: see Table 9-19}

Most of the respondents (80.6\%) said that they could write Samoan 'easily'. A solid majority of the non-New Zealand-born respondents thought that they could write Samoan 'easily', although the numbers drop quite significantly when we come to the New Zealand-born respondents.

- $90.3 \%$ of the non-New Zealand-born respondents said they could write Samoan 'easily'

- $47.6 \%$ of the New Zealand-born respondents they could write Samoan 'easily'.

Amongst the New Zealand-born $14.3 \%$ thought they could write 'fairly easily' and just under a quarter $(23.8 \%)$ considered that they could only write Samoan 'with difficulty'. Obviously there were very few non-New Zealand-born respondents in any of these categories and there were none who could read but not write Samoan although two of the New Zealand-born were in this category. One of the New Zealand-born did not reply to this question.

\footnotetext{
113 One New Zealand-born respondent's entry for this question was unclear but it seemed that they intended to indicate "not very fluent" and I have counted it as such.
} 
Table 9-19: Proficiency in written Samoan \%

\begin{tabular}{|l|c|c|c|c|c|c|c|}
\hline & $\begin{array}{c}\text { Can write } \\
\text { easily }\end{array}$ & $\begin{array}{c}\text { Fairly } \\
\text { easily }\end{array}$ & $\begin{array}{c}\text { With } \\
\text { difficulty }\end{array}$ & $\begin{array}{c}\text { Can read } \\
\text { only }\end{array}$ & No Ability & NR & N= \\
\hline Non-NZ-born & $90.3 \%$ & $8.3 \%$ & $1.4 \%$ & 0 & 0 & 0 & 72 \\
N.Z. Born & $47.6 \%$ & $14.3 \%$ & $23.8 \%$ & $9.5 \%$ & 0 & $4.8 \%$ & 21 \\
Non-N.Z.B 10+ & $92.3 \%$ & $6.2 \%$ & $1.5 \%$ & 0 & 0 & 0 & 65 \\
& & & & & & & \\
All Respondents & $80.6 \%$ & $9.7 \%$ & $6.5 \%$ & $2.2 \%$ & 0 & $1.1 \%$ & \\
N= & 75 & 9 & 6 & 2 & 0 & 1 & 93 \\
\hline
\end{tabular}

\subsubsection{English: see Table 9-20}

Just over half the respondents (51.6\%) thought that they could write English 'easily'.

Unsurprisingly, most of the New Zealand-born respondents thought that they could write

English 'easily'

- $81 \%$ of the New Zealand-born respondents said they could write English 'easily'

- $19 \%$ said they could write English 'fairly easily'

Amongst the non-New Zealand-born, the level of confidence in their English literacy skills was much lower.

- $43.1 \%$ of the non-New Zealand-born respondents said they could write English 'easily'

- $37.5 \%$ chose 'fairly easily'

- $16.7 \%$ said that they could write English only 'with difficulty'

Only two, non-New Zealand-born respondents, failed to respond to this question.

Table 9-20: Proficiency in written English: \%

\begin{tabular}{|l|c|c|c|c|c|}
\hline & Can write easily & Fairly easily & With difficulty & NR & N= \\
\hline Non-NZ-born & $43.1 \%$ & $37.5 \%$ & $16.7 \%$ & $2.8 \%$ & 72 \\
N.Z. Born & $81 \%$ & $19 \%$ & 0 & 0 & 21 \\
Non-N.Z.B 10+ & $38.5 \%$ & $40 \%$ & $18.5 \%$ & $3.1 \%$ & 65 \\
& & & & & \\
All Respondents & $51.6 \%$ & $33.3 \%$ & $12.9 \%$ & $2.2 \%$ & \\
N= & 48 & 31 & 12 & 2 & 93 \\
\hline
\end{tabular}

\subsubsection{Monotonic decline}

Only one respondent showed an unexpected pattern of proficiency; a 'not very fluent', New Zealand-born, Samoan speaker who said they could write 'easily'. Overall, the implicational 
scale that Fishman predicts (section 5.5.1.4) is found amongst the Samoans as well as the Gujarati and Dutch respondents ${ }^{114}$.

\subsubsection{Age and Samoan proficiency}

Amongst the Samoan respondents as with the Dutch and Gujarati respondents, proficiency in the MT is age-graded and linked to place of birth. Fluency ratings ranged from $66.6 \%$ of the 15 - 25 age group rating themselves as 'fluent' speakers of Samoan to $100 \%$ of the $56+$ age group choosing this option. Admittedly, the 56+ age group in the database consists of only two people but when we look the 46 - 55 age group we find that $83.3 \%$ selected 'fluent' as the rating for their Samoan proficiency and, in fact, there is a steady rise in the percentage of respondents choosing 'fluent' from the youngest to the oldest age groups.

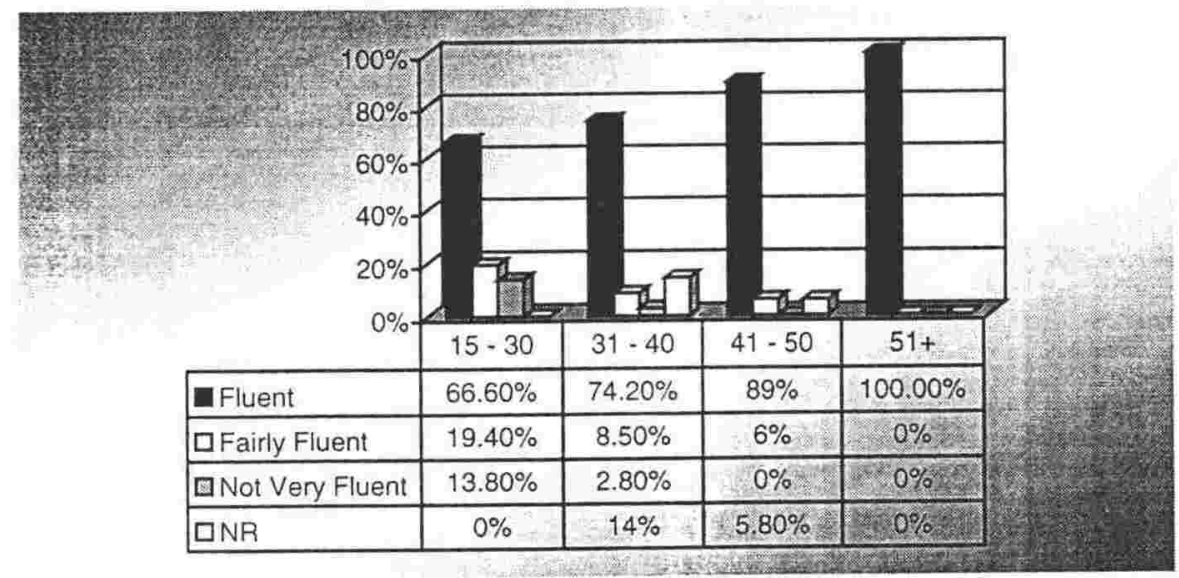

Figure 9-8: Samoan language proficiency by age group of respondents: version 2: parallels Dutch divisions

\subsubsection{Gender and Language proficiency: see Table 9-21, Table 9-22, Table 9-23}

There are some interesting differences between the responses given by the male and female respondents to the questions about language proficiency. There is a fairly notable discrepancy between the percentage of non-New Zealand born women who consider themselves 'fluent' speakers of Samoan and the percentage of non-New Zealand-born men who make the same judgement about their abilities.

- $94.9 \%$ of non-New Zealand born women consider themselves 'fluent' speakers of Samoan

\footnotetext{
${ }^{114}$ The six respondent who gave 'no response' for the question about oral language abilities could all write 'easily'. As mentioned in section 9.3.1.3, it seems likely that they could all speak Samoan fluently.
} 
- $75.8 \%$ of non-New Zealand-born men consider themselves 'fluent' speakers of Samoan

This probably has to be ascribed to the $18.2 \%$ of non-New Zealand born men who did not respond (see section 9.3.1.3) to any of the questions about oral language skills (had they all responded 'fluent', as seems at least possible, then the percentage of non-New Zealand-born women and men answering 'fluent' to that questions would have been almost identical; $94.9 \%$ and $94 \%$ respectively).

Amongst the New Zealand-born respondents however there is a discrepancy that is not so easily explained. Only a handful of the New Zealand-born women thought that they were 'fluent' in Samoan as opposed to over half of the men.

- $20 \%$ of the New Zealand-born women thought that they were 'fluent' in Samoan

- $54.5 \%$ of the New Zealand-born men thought that they were 'fluent' in Samoan

More of the New Zealand-born women (40\%) rated themselves as 'fairly fluent' (only $27.3 \%$ of the men chose that option) and $40 \%$ of the women thought that they were 'not very fluent' an option selected by only $18.2 \%$ of the men. Whether these differences represent real differences in the abilities of the men and women, whether they are a fluke produced by the small number of New Zealand-born respondents, or whether the women are more modest raters of their own abilities, is hard to determine.

For the section on Formal Samoan however, the women do not appear to be particularly more modest as raters than the men (although three of the New Zealand-born women (30\%) and only one of the New Zealand-born men (9.1\%) chose not to answer this section). A woman was the only New Zealand-born respondents to rate herself as a 'fluent' speaker of Formal Samoan and another rated herself as 'fairly fluent' as did two of the New Zealand-born men. Exactly half the women and almost half of the men rated themselves as 'not very fluent' and two of the men rated themselves as having comprehension skills only, an option chosen by none of the women. Given the fairly similar ratings in formal Samoan, it seems possible that the self assessments for everyday Samoan should be taken at face value and that we should conclude that the New Zealand-born men in this sample had somewhat better everyday Samoan skills than the women ${ }^{115}$.

\footnotetext{
${ }^{11.5}$ It also seems possible to me that the women who did not respond to the question were in a sense, pessimistic raters of their own abilities i.e. they did not choose to respond because they felt they could only say they had no
} 
Amongst the non-New Zealand born respondents, the women were also more likely to rate themselves as 'fluent' speakers of Formal Samoan (64.1\% as opposed to $48.5 \%$ of the men) but, once again, this seems to be a result of the larger number of men who did not respond to the oral proficiency questions. Almost equal proportions of men and women said that they were 'fairly fluent' or 'not very fluent' in Formal Samoan.

In English, the New Zealand-born woman were also very confident of their abilities; they all said that they were 'fluent' speakers of English. However, three of the 11 New Zealand-born men chose 'fairly fluent' as opposed to 'fluent' as the best assessment of their English abilities and once again this suggests that the differences in their ratings of fluency for Samoan are not simply a product of the women rating themselves more modestly than the men.

Amongst the non-New Zealand-born respondents, a substantially smaller percentage of women than men rated themselves as fluent'.

- $30.7 \%$ of women rated themselves as 'fluent'

- $48.5 \%$ of men rated themselves as 'fluent'

However, once again, it is hard to make a comparison because of the $21.2 \%$ of non-New Zealand-born men who did not answer this question (2.6\% of non-New Zealand-born women did not answer). Interestingly, most of the women $(61.5 \%)$ rated themselves as 'fairly fluent' an option chosen by only a quarter $(24.2 \%)$ of the men and slightly more men $(6.1 \%)$ than women $(2.6 \%)$ rated themselves as 'not very fluent' in English.

Table 9-21: Proficiency in oral Samoan: Men as a \% of all male respondents and women as a \% of all female respondents

\begin{tabular}{|l|c|c|c|c|c|}
\hline & Fluent & Fairly Fluent & Not Very Fluent & NR & N= \\
\hline Non-NZ-Born F. & $94.9 \%$ & $5.1 \%$ & 0 & 0 & 39 \\
Non-NZ-born M. & $75.8 \%$ & $6.1 \%$ & 0 & $18.2 \%$ & 33 \\
N.Z. Born F. & $20 \%$ & $40 \%$ & $40 \%$ & 0 & 10 \\
N.Z. Born M. & $54.5 \%$ & $27.3 \%$ & $18.2 \%$ & 0 & 11 \\
& & & & & \\
All Respondents F. & $79.6 \%$ & $12.2 \%$ & $8.2 \%$ & 0 & 49 \\
All Respondents M. & $70.5 \%$ & $11.4 \%$ & $4.5 \%$ & $13.6 \%$ & 44 \\
\hline
\end{tabular}

ability whereas the men who responded that they had comprehension skills only were optimistically rating what was, possibly, a similar level of ability in Formal Samoan. 
Table 9-22: Proficiency in oral English \%: Men and women as \% of each gender

\begin{tabular}{|l|c|c|c|c|c|c|}
\hline & Fluent & Fairly Fluent & Not Very Fluent & No Ability & NR & N= \\
\hline Non-NZ-born F. & $30.7 \%$ & $61.5 \%$ & $2.6 \%$ & $2.6 \%$ & $2.6 \%$ & 39 \\
Non-NZ-born M. & $48.5 \%$ & $24.2 \%$ & $6.1 \%$ & 0 & $21.2 \%$ & 33 \\
N.Z. Born F. & $100 \%$ & 0 & 0 & 0 & 0 & 10 \\
N.Z. Born M. & $72.7 \%$ & $27.3 \%$ & 0 & 0 & 0 & 11 \\
& & & & & & \\
All Respondents F. & $44.8 \%$ & $49 \%$ & $2 \%$ & $2 \%{ }^{116}$ & $2 \%$ & 49 \\
All Respondents M. & $54.5 \%$ & $25 \%$ & $4.5 \%$ & 0 & $15.9 \%$ & 44 \\
\hline
\end{tabular}

Table 9-23: Proficiency in formal Samoan \%: Men and women as \% of each gender

\begin{tabular}{|c|c|c|c|c|c|c|c|}
\hline & Fluent & $\begin{array}{l}\text { Fairly } \\
\text { Fluent }\end{array}$ & $\begin{array}{l}\text { Not Very } \\
\text { Fluent }\end{array}$ & $\begin{array}{c}\text { Comprehension } \\
\text { Only }\end{array}$ & $\begin{array}{c}\text { No } \\
\text { Ability }\end{array}$ & NR & $\mathrm{N}=$ \\
\hline Non-NZ-born F. & $64.1 \%$ & $10.3 \%$ & $17.9 \%$ & 0 & 0 & $7.7 \%$ & 39 \\
\hline Non-NZ-born M. & $48.5 \%$ & $9.1 \%$ & $15.2 \%$ & $3.5 \%$ & 0 & $24.2 \%$ & 33 \\
\hline N.Z. Born F. & $10 \%$ & $10 \%$ & $50 \%$ & 0 & 0 & $30 \%$ & 10 \\
\hline N.Z. Born M. & 0 & $18.2 \%$ & $45.5 \%$ & $18.2 \%$ & $9.1 \%$ & $9.1 \%$ & 11 \\
\hline All Respondents F. & $53.1 \%$ & $10.2 \%$ & $24.4 \%^{117}$ & 0 & 0 & $12.2 \%$ & 49 \\
\hline All Respondents M. & $36.4 \%$ & $11.4 \%$ & $22.7 \%$ & $6.8 \%$ & $2.3 \%$ & $20.5 \%$ & 44 \\
\hline
\end{tabular}

\subsubsection{Summary}

Levels of Samoan proficiency are still very high amongst the respondents to the questionnaire. The non-New Zealand-born respondents mostly have high levels of proficiency in both everyday and Formal Samoan. Their English is comparatively weak however, certainly they are not such confident raters of their English abilities as either the Gujarati or Dutch respondents. The New Zealand-born respondents are confident of their English abilities and rate themselves fairly highly as speakers of everyday Samoan although there are also quite a substantial proportion of the New Zealand-born who say that they are 'not very fluent' speakers of Samoan. The non-New Zealand-born can read and write Samoan easily. Amongst the New Zealand-born, all the respondents are literate in Samoan but under half of them think

\footnotetext{
${ }^{116}$ I asked Feaua $i$ Burgess if, in her opinion, this respondent really did not speak or understand English. FB replied that, in her opinion, the respondent did speak and understand English but that she was 'shy to speak' and this had caused her to respond as she had. I have left the entry to stand as it was given by the respondent but note that, in fact, the respondent did have some English ability.

${ }^{117}$ One New Zealand-born respondent's entry for this question was unclear but it seemed that they intended to indicate 'not very fluent' and I have counted it as such.
} 
that they can write easily. Unlike the non-New Zealand-born, very few of the New Zealandborn are confident of their abilities in Formal Samoan. The immigrant generation has handed on a high level of MT skills to the New Zealand-born generation but even so, the signs of considerable shift to English are very clear.

\subsection{Samoan children and their use of Samoan language}

The 93 Samoan respondents came from 89 households with

- 73 oldest children

- 60 youngest children

Basic information about 133 children was thus gathered on which languages children used and whether or not they attended Samoan language school. The oldest child was 35 years old and the youngest was 18 months. Oldest children were slightly more likely to speak Samoan than youngest children but the difference is slight and there is virtually no difference between the children of non-New Zealand-born respondents and New Zealand-born respondents.

- $93 \%$ of oldest children spoke Samoan

- $88 \%$ of youngest children spoke Samoan

Overall, $94.7 \%$ of the children spoke (or in the case of 4 children, understood) Samoan. A survey conducted by the Ministry of Education found an almost equally high proportion, $85 \%$, of Pacific Island ${ }^{118}$ children were able to understand their MT (Stockwell 1995: 64). Given that the overall figures for Pacific Island children were lowered by including Cook Island children, we can assume that the figures for the Samoan children in Stockwell's research would have been higher.

\subsubsection{Children who spoke only Samoan}

Several respondents said that their children spoke only Samoan (11 oldest children and 10 youngest children). In most cases ( $80 \%$ of the youngest children and $45 \%$ of the oldest children) the children were preschool age and it seems entirely likely that they did not speak English, or did not speak very much English. There were only two respondents who claimed to have children who were considerably over 5 years old and who spoke only Samoan. One respondent (f095), who said that her oldest child of 28 years spoke only Samoan, was very

${ }^{118}$ At least 47\% of the Pacific Island respondents were Samoan (Stockwell 1995: 73). 
unclear in her responses to this section and it is possible that she was unclear about the questions she was being asked and consequently her replies are unclear ${ }^{119}$. The other of the two respondents (f097), said that her 14 year old oldest and 4 year old youngest both spoke only Samoan. It is possible, looking at her demographic data, that she has not been resident in New Zealand for long enough for her children to become users of English. The other possibility is that she correctly ticked off her youngest child as speaking Samoan and unthinkingly ticked the same box when she gave the answers for her oldest child.

Table 9-24: Languages used by oldest and youngest Samoan children

\begin{tabular}{|c|c|c|}
\hline Languages spoken & $\begin{array}{l}\text { Oldest children of all Samoan } \\
\text { respondents. As \% of } 73 \text { households } \\
\text { with oldest children }\end{array}$ & $\begin{array}{l}\text { Youngest children of all Samoan } \\
\text { respondents. As a \% of } 60 \\
\text { households with youngest children }\end{array}$ \\
\hline Speak Samoan and English & 79.4 & 71.6 \\
\hline Speak Samoan & 13.7 & 16.7 \\
\hline $\begin{array}{l}\text { Speak Eng understand } \\
\text { Samoan }\end{array}$ & 2.7 & 3.3 \\
\hline Speak English only & 2.7 & 3.3 \\
\hline $\begin{array}{l}\text { Speak Samoan understand } \\
\text { Eng }\end{array}$ & 0 & 3.3 \\
\hline \multirow{2}{*}{$\begin{array}{l}\text { Too young/speak Samoan } \\
\text { Too young }\end{array}$} & 1.4 & 1.7 \\
\hline & $\begin{array}{l}\text { Oldest children of non NZ-born } \\
\text { respondents. As a } \% \text { of } 59 \\
\text { households with oldest children }\end{array}$ & $\begin{array}{l}\text { Youngest children of non NZ-born } \\
\text { respondents. As a \% of } 51 \\
\text { households with youngest children }\end{array}$ \\
\hline Speak Samoan and English & 83 & 74.5 \\
\hline Speak Samoan only & 10.2 & 13.7 \\
\hline Speak English only & 3.4 & 3.9 \\
\hline $\begin{array}{l}\text { Speak Eng understand } \\
\text { Samoan }\end{array}$ & 1.7 & 3.9 \\
\hline $\begin{array}{l}\text { Speak Samoan understand } \\
\text { Eng }\end{array}$ & 0 & 3.9 \\
\hline \multirow{2}{*}{$\begin{array}{l}\text { Too young/speak Samoan } \\
\text { Too young }\end{array}$} & 1.7 & 0 \\
\hline & $\begin{array}{l}\text { Oldest children of NZ-born } \\
\text { respondents. As a } \% \text { of } 14 \\
\text { households with oldest children }\end{array}$ & $\begin{array}{l}\text { Youngest children of NZ-born } \\
\text { respondents. As a \% of } 9 \text { households } \\
\text { with youngest children }\end{array}$ \\
\hline Speak Samoan and English & 64.3 & 55.5 \\
\hline Speak Samoan only & 28.6 & 33.3 \\
\hline $\begin{array}{l}\text { Speak Eng understand } \\
\text { Samoan }\end{array}$ & 7.1 & 0 \\
\hline Too young & 0 & 11.1 \\
\hline
\end{tabular}

\footnotetext{
${ }^{119}$ I checked her responses with the person who had gathered the data from her and the data gatherer knew that some of the replies in this section were wrong.
} 


\subsubsection{Attendance at Samoan language school}

Virtually all the respondents had sent, were sending or intended to send their children to Samoan language school. Only $9.6 \%$ of respondents answered 'no' to the question about whether or not their children went to language maintenance school.

\subsubsection{Samoan children's Samoan language proficiency}

In addition to the oldest and youngest children, 24 Samoan respondents answered further questions about all their children's Samoan language skills providing more detailed information about 54 children from 18 households. Parents were asked to rate their children's Samoan language proficiency and to answer some basic demographic questions (see Appendix 3).

Table 9-25: Proficiency of children's Samoan language skills as rated by parent. Shown in percentages

\begin{tabular}{|l|l|l|l|l|}
\hline & Speaking & Comprehension & Reading & Writing \\
\hline Very good & 44.4 & 55.6 & 44.4 & 42.6 \\
Good & 29.6 & 29.6 & 18.5 & 7.4 \\
Fair & 14.8 & 9.3 & 5.6 & 14.8 \\
Limited & 5.6 & 0 & 11.1 & 7.4 \\
Not at all & 5.6 & $5.6^{120}$ & 9.3 & 11.1 \\
Too young & 0 & 0 & 11.1 & 16.7 \\
\hline
\end{tabular}

Overall, as can be seen, the parents ${ }^{121}$ who responded to this section of the questionnaire were pleased with their children's Samoan language ability. The proficiency ratings they gave are consistently fairly high. They follow the expected pattern, with more parents rating their children as 'very good' for comprehension followed by speaking, reading and writing. What is perhaps slightly unexpected is that as many parents thought their children's reading abilities were 'very good' as thought that their speaking abilities fell into this category. If we look as

${ }^{120}$ These three children, who appear as having no ability in either speaking or understanding Samoan, all come from one family.

${ }^{121}$ Only three New Zealand-born respondents answered this section of the questionnaire and their responses have not been looked at separately. In most cases, the birthplace of the spouses of respondents is not known and it may well be the case that some of the non-New Zealand-born respondents had New Zealand-born spouses. Thus the children of the non-New Zealand-born respondents might also well have a New Zealand-born parent. It does not seem reasonable to investigate the children of the three respondents whom are known to be New Zealand-born, when other children in the database are probably in the same situation. 
'very good' and 'good' as one category, allowing for the fact that some parents might be more pessimistic raters than others, we see the categories separating out slightly more definitely although the differences are still not great.

- $74 \%$ of parents rated their child/ren as 'very good' or 'good' for speaking

- $85.2 \%$ of parents rated their child/ren as 'very good' or 'good' for comprehension

- $62.9 \%$ of parents rated their child/ren as 'very good' or 'good' for reading

- $50 \%$ of parents rated their child/ren as 'very good' or 'good' for writing

Stockwell found that $57 \%$ of Pacific Island parents rated their children's MT language capacities as about the same or better than their capacities for English (Stockwell 1995: 64). The assessment of 'the same or better than English' is roughly comparable to the assessment 'very good' or 'good'. Comparison of the two figures shows that the respondents to the questionnaire rated their children more highly than Stockwell's respondents (and we must remember that Stockwell's research included non-Samoan respondents, some of whom, especially the Cook Islanders had much lower levels of MT use than the rest). However, both sets of figures are high and Stockwell's research indicates that although the present research was undertaken among a group of respondents, many of whom had a particularly high interest in issues of language maintenance, nonetheless a more general and random survey also shows very high levels of Samoan language use. Stockwell found that

Pacific Island children had a greater likelihood of being exposed to their own language in their own, or relatives' and friends' homes than did Maori children. They were also significantly more likely to have heard their own language at church (Stockwell 1995: 61).

It was not very obvious what might be a factor in a child having a higher or lower level of Samoan language ability. Fluency of parents was not a factor, because almost all the parents rated themselves as "fluent" ${ }^{\prime 22}$. Age, position in the family and gender were all considered. It would have been interesting to consider birthplace of parent/s as a factor in Samoan language proficiency but only three of the 23 respondents who answered this section were born in New Zealand (two of them were not married to a respondent and one of them was married to a nonNew Zealand-born respondent) and thus it was not worth making such a comparison.

\footnotetext{
122 Only 4 of the children had parents who were 'fairly fluent' rather than 'fluent' and two children had a parent who gave no response to the question about fluency
} 


\subsubsection{Age and Samoan proficiency}

Amongst the Samoan respondents, age of the respondent's child correlated quite strongly with the proficiency rating for spoken Samoan given by the responding parent. It is possible that in the youngest age group ( 2 to 5 years old) fewer children received a 'very good' rating than in other age groups because there were more children in the youngest group whose language skills (in any language) were not yet fully developed. There seems to be no such reason however that could apply to the older age groups. Overall, the number of 'very good' ratings is high but it definitely increases with age. Stockwell (1995: 64) also found that Pacific Island parents were more likely to rate older children as being able to understand their MT than younger ones.

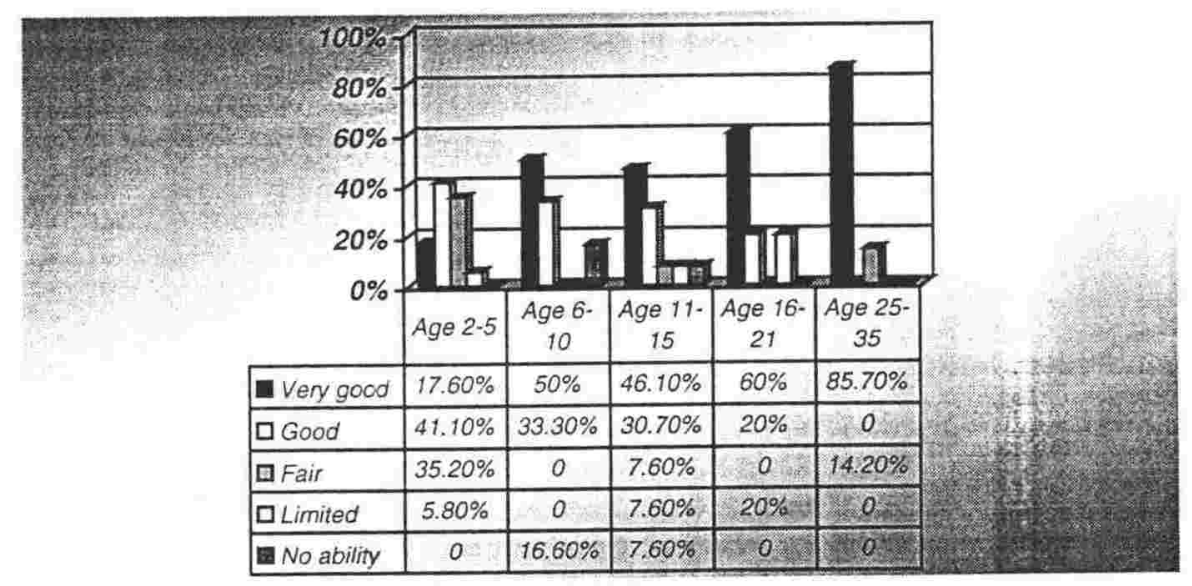

Figure 9-9: Children of Samoan respondents: Age and spoken Samoan

\subsubsection{Position in the family in relation to proficiency in spoken Samoan}

Position of the child in the family did not seem to bear a strong relationship to a child's fluency as rated by parents. First children were slightly more likely than second children to be rated 'very good' and slightly less likely to be rated neither 'very good' nor 'good'. But third, fourth and fifth children were more likely to be rated 'very good' than first children. Given the high number of 'very good' ratings that appear in the data, it is possible that the relatively small numbers of third and fourth children are acting to obscure a gradation of proficiency linked to family position that would show up in a larger sample.

\section{Of 24 first or only children}

- $41.6 \%$ were rated as 'very good'

- $33.3 \%$ were rated as 'good'

- $25.0 \%$ were rated as neither 'very good' nor 'good' 
- $37.5 \%$ were rated as 'very good'

- $31.2 \%$ were rated as 'good'

- $31.2 \%$ were rated as neither 'very good' nor 'good'

\section{Of 7 third [and youngest] children}

- $57.1 \%$ were rated as 'very good'

- $28.5 \%$ were rated as 'good'

- $14.2 \%$ were rated as neither 'very good' nor 'good'

\section{Of 6 fourth [and youngest] children}

- $50.0 \%$ were rated as 'very good'

- $16.6 \%$ were rated as 'good'

- $33.3 \%$ were rated as neither 'very good' nor 'good'

There was one fifth and youngest child who was rated as 'very good'

\subsubsection{Gender in relation to proficiency in spoken Samoan}

Gender was the only area in which there appeared to be a fairly strong relationship to Samoan language proficiency as rated by parents. Daughters were definitely more likely to receive a higher proficiency rating than sons.

\section{Of 23 females}

- $56.5 \%$ were rated as 'very good'

- $21.7 \%$ were rated as 'good'

- $21.5 \%$ were rated as neither 'very good' nor 'good'

\section{Of 31 males}

- $35.8 \%$ were rated as 'very good'

- $35.4 \%$ were rated as 'good'

- $29.0 \%$ were rated as neither 'very good' nor 'good'

Interestingly, this is the opposite result to that obtained from the New Zealand-born respondents to the question about Samoan language proficiency. The New Zealand-born men were more likely to rate themselves highly than the New Zealand-born women. It is not really possible to interpret this result clearly. Perhaps Samoan parents are more likely to rate daughters' abilities highly, perhaps the New Zealand-born female respondents were modest raters of their own ability, or perhaps the difference is co-incidental. 


\subsubsection{Summary}

The Samoan children in this survey are still strong users of Samoan. Most of the children can speak Samoan and many of them can speak it well and also read and write the language. This suggests that Samoan is certainly being transmitted to a sizable proportion of the second and third generation in New Zealand. Most of the children attend or have attended Samoan language school (often organised by the church) and this is undoubtedly the reason for the comparatively high levels of literacy. Birthplace of parent, position of child in family and fluency of parent did not appear as strong factors in children's Samoan usage, but age and gender of the child did appear to have a relationship to Samoan proficiency, with females being more likely to be highly rated than males and older children being more likely to be rated as highly proficient than younger one.

\subsection{Conclusion}

Overall, the Samoan respondents present a picture of a community where MT use is still frequent in all areas of life and where the MT is highly valued for its own sake as well as for the cultural values it enshrines and the communicative opportunities it affords. There is strong support for language and culture maintenance and respondents use the MT with their own children and support language maintenance schooling for their children. They also support government assistance for MT schooling, both at community level and in the mainstream system. Despite the high levels of positive attitude to MT use and maintenance in New Zealand, there are clear signs that use is declining amongst the New Zealand-born and that shift is underway. 


\section{COMPARISON AND ANALYSIS: DEMOGRAPHIC DATA, LANGUAGE USE AND PROFICIENCY}

The next three chapters compare the three with communities with each other using the integrated model of Fishman's theories as a framework. Chapter 10 focuses briefly upon some of the basic demographic data from the three groups, pointing up similarities and differences and then examines patterns of habitual language use. Issues of institution/locale and interlocutor outside the home are presented in section 10.7, issues of interlocutor and role relations within the family are addressed in sections $11.1,11.4$ and 11.5 as part of that Chapter's focus upon the family and language maintenance. Degree of bilingualism is addressed in sections 10.2, 10.3 and 10.4 and parents' degree of bilingualism is examined to see if it has any affect upon their children's fluency in the MT.

Issues of competence are addressed in sections 10.9 and 10.10 and children's proficiency in section 11.6.2. Performance is discussed in sections 10.5, 10.6, 10.7, 11.6.1, 11.2 and 11.3.

Chapter 11 focuses upon the family. The question of habitual language use within the family is covered in $11.1,11.2$ and 11.3 and there is also extensive examination of the factors that influence children's acquisition of the MT in sections 11.5, 11.6 and 11.7. As the family is the primary institution for transmitting the MT, the process is examined in considerable detail.

Chapter 12 considers behaviours and attitudes towards language, examines their causative role in the processes of language maintenance and shift as well as highlighting their importance as part of a description of habitual language use undergoing change.

In the following chapters a selection of the data that has been presented in the preceding three chapters is analysed. Each of the three communities is compared with the other two and the information is also considered in the light of what we know about other immigrant communities and other language maintenance and shift research both in New Zealand and elsewhere. It is particularly useful to be able to look at three data sets gathered using very similar questionnaire instruments. It is clear that the language maintenance and shift process in each community is unique. Immigrant language maintenance and shift is a set of processes that occurs in varying ways in different communities. Indeed, one of the interesting things about this set of sociolinguistic phenomena is, that although immigrant language shift is very common in immigrant communities all over the world, it does not follow a single pattern. The 
three communities under investigation here demonstrate this very clearly. Language maintenance too, although it also is a common immigrant phenomenon, is motivated by a range of impulses in different communities and is practised in a range of ways that depend upon the circumstances of a given community. Once again, this is borne out by the three communities reported on here.

In the following section the answers that the respondents gave to the demographic questions and to some of the language use proficiency questions are compared. The comparison shows both points of similarity and variance between the three communities.

\subsection{Comparative demographies}

Table 10-1: Birthplace

\begin{tabular}{|l|l|l|l|}
\hline & Gujarati & Dutch & Samoan \\
\hline Homeland & $66 \%$ & $71 \%$ & $73.1 \%$ \\
NZ & $25 \%$ & $22 \%$ & $22.6 \%$ \\
Other & $9 \%$ & $7 \%$ & $4.3 \%$ \\
N= & 141 & 184 & 93 \\
\hline
\end{tabular}

As can be seen, the proportion of respondents in each group who come from their respective homelands (Gujarat province, The Netherlands and Western Samoa) is roughly similar, as is the proportion born in New Zealand or born elsewhere. Birthplace is one of the most clear-cut and obvious measures of physical, demographic, social and cultural dislocation - all important factors within the framework of the integrated model.

Table 10-2: Gender

\begin{tabular}{|l|l|l|l|}
\hline & Gujarati & Dutch & Samoan \\
\hline Male & $57 \%$ & $45 \%$ & $47.3 \%$ \\
Female & $43 \%$ & $55 \%$ & $51.6 \%$ \\
Unclear/NR & 0 & 0 & $1.1 \%$ \\
$\mathrm{~N}=$ & 141 & 184 & 93 \\
\hline
\end{tabular}

There are roughly equal proportions of men and women in each group, the slight imbalance within each group has been discussed in Chapter 6. 
Table 10-3: Age

\begin{tabular}{|l|l|l|l|}
\hline & Gujarati & Dutch & Samoan \\
\hline $15-25$ & 0 & $1.6 \%$ & $12.9 \%$ \\
$26-35$ & $18 \%$ & $17.3 \%$ & $39.8 \%$ \\
$36-45$ & $42 \%$ & $25 \%$ & $31.2 \%$ \\
$46-55$ & $23 \%$ & $12.5 \%$ & $31.2 \%$ \\
$56+$ & $16 \%$ & $43.4 \%$ & $2.2 \%$ \\
Unclear / NR & $1 \%$ & 0 & $1.1 \%$ \\
$\mathrm{~N}=$ & 141 & 184 & 93 \\
\hline
\end{tabular}

Age is an important demographic factor in the integrated model. Asking the age of the respondents enables changes to be tracked over time and predictions about the future of the language to be made. For instance, it there are no MT speakers of child-bearing age then the MT is in a bad way, a point made very strongly in Fishman's discussion of the GIDS scale (see section 13.5).

Each of the survey groups has a very different age structure and this is, to some extent, related to the differing age structures of those communities within the New Zealand population. The Indian community as a whole is conspicuous for its greater proportions (in comparison with the New Zealand population) of people between the ages of 20 and 39 (Thomson 1993: 24), and the Dutch community for its greater proportions of people between the ages of 30 - 44 and 55 - 64 (Thomson 1993:22). The Dutch population in New Zealand is especially notable for its big bulge in the 60 - 64 age group (Thomson 1993: 26). This is of course directly related to the mass arrival of young twenty somethings in the $1950 \mathrm{~s}$ and explains why $43.3 \%$ of the Dutch survey is over 56. In the case of the Indian population, where the percentage of people over 45 is proportionately smaller than in the general New Zealand population, it is less obvious why $16 \%$ of the Gujarati respondents should have been over 56 years old. This question is further discussed in section 7.1.5.

The Pacific Island population in New Zealand is very young and this is reflected in the structure of the Samoan survey group. The extreme youth of this group (in comparison with the Gujarati and Dutch groups) is a function not only of the comparative youth of the Pacific Island population in New Zealand but also of the fact that just under a quarter of the survey group were New Zealand-born. The New Zealand born segment of the Pacific Island population is particularly young (as one would expect in such a recently established 
immigrant community). These two factors - the overall youth of the community and the extreme youth of the New Zealand-born community are summed up as follows

In contrast the Pacific Island population was under-represented among the older age groups, only accounting for one percent of people aged 60 years and over [the Pacific Island population as a whole makes up $5 \%$ of the New Zealand population \{ Krishnan et al: $1994: 28\}$ ]. This is due to the fact that this age group is under-represented amongst those who migrate to New Zealand. The Pacific Island population is however, expected to take on an older age profile in the future ... The New Zealand born Pacific Island population is more youthful than those born outside of New Zealand ... New Zealand-born Pacific Island people are mainly under 15 years of age, with the 0-4 years age group representing a significant proportion of this population (Krishnan et al 1994: 33-34).

Table 10-4: Marital status

\begin{tabular}{|l|l|l|l|}
\hline & Gujarati & Dutch & Samoan \\
\hline Married & $89 \%$ & $85.3 \%$ & $75.3 \%$ \\
Never Married & $2 \%$ & $3.3 \%$ & $18.3 \%$ \\
Other & $9 \%$ & $11.4 \%$ & $6.4 \%$ \\
$\mathrm{~N}=$ & 115 & 184 & 93 \\
\hline
\end{tabular}

Most of the respondents to the survey were married, a natural effect of the concentration on language maintenance in a family context. There were slightly fewer married respondents in the Samoan survey because of the greater number of very young respondents. The 'other' category includes, widows, widowers, people living with partners (who of course might also be 'never married' but if they specified they were living with a partner then they were counted in that category), and divorced people.

Table 10-5: respondents with children

\begin{tabular}{|l|l|l|l|}
\hline & Gujarati & Dutch & Samoan \\
\hline With children & $94 \%$ & $87.5 \%$ & $82.8 \%$ \\
$\mathrm{~N}=$ & 141 & 184 & 93 \\
\hline
\end{tabular}

Table 10-6: Family Structure

\begin{tabular}{|l|l|l|l|}
\hline & Gujarati & Dutch & Samoan \\
\hline Nuclear family & $52 \%$ & $51.4 \%$ & $31.4 \%$ \\
Extended family $^{123}$ & $19 \%$ & $1.4 \%$ & $28 \%$ \\
Couple & $5 \%$ & $35.9 \%$ & $5.5 \%$ \\
Other & $24 \%$ & $11.3 \%$ & $35.1 \%$ \\
$\mathrm{~N}=$ & 115 & 184 & 93 \\
\hline
\end{tabular}

\footnotetext{
${ }^{123}$ Extended family here means mother, father, children and other/s. In most cases (for each of the three groups) the other/s consisted of family members.
} 
Family structure is also an important factor in language maintenance and shift processes. It falls into part 1 (b) of the model, antecedent and concurrent social processes related to stability or change in habitual language use. It is interesting to note that while slightly over half the Gujarati and Dutch respondents are living in a nuclear family of mother, father and children, only a third of the Samoan respondents are in a similar family situation. On the other hand over a quarter of the Samoan respondents are living in an extended family as are just under a fifth of the Gujarati respondents. Only a tiny number of the Dutch respondents are living in an extended family situation ${ }^{124}$.

- $28 \%$ of the Samoan respondents are living in an extended family

- $19 \%$ of the Gujarati respondents are living in an extended family

- $1.4 \%$ of the Dutch respondents are living in an extended family

It is possible that this is a factor in the higher rates of language maintenance in the Gujarati and Samoan communities. Extended families, especially those that consist of three generations, are more likely to provide MT speaking interlocutors for the children of those families. Desai (1994: 12) comments that "the language [Gujarati] was reinforced" because Gujarati people lived in extended families, where there were many opportunities to speak Gujarati.

Education is another important social process that is related, in complex ways, not only to habitual language use, but also to a wide range of other social factors.

\section{Table 10-7: Place of Education}

\begin{tabular}{|l|l|l|l|}
\hline & Gujarati & Dutch & Samoan \\
\hline Educated in homeland & $33 \%$ & $50 \%$ & $32.2 \%$ \\
Educated in NZ & $35 \%$ & $23.9 \%$ & $22.6 \%$ \\
Educated in both & $20 \%$ & $19.6 \%$ & $36.6 \%$ \\
Other & $12.5 \%$ & $6.5 \%$ & $8.6 \%$ \\
$\mathrm{~N}=$ & 115 & 184 & 93 \\
\hline
\end{tabular}

${ }^{12+}$ Extended family here means mother, father, children and other/s. In most cases (for each of the three groups) the other/s consisted of family members. 
Table 10-8: Highest level of education

\begin{tabular}{|l|l|l|l|}
\hline & Gujarati & Dutch & Samoan \\
\hline Completed university & $33 \%$ & $29.9 \%$ & $18.2 \%$ \\
Completed other tertiary & $20 \%$ & $44.5 \%$ & $35.4 \%$ \\
Completed secondary & $37 \%$ & $23.4 \%$ & $33.3 \%$ \\
Completed primary & $5 \%$ & $2.2 \%$ & $5.3 \%$ \\
Other & $5 \%$ & 0 & $7.5 \%$ \\
$\mathrm{~N}=$ & 115 & 184 & 93 \\
\hline
\end{tabular}

All three groups had relatively high levels of education in comparison with the general levels of education within their communities in New Zealand and this is discussed in more detail in section 10.4.5.

\subsection{Language use data}

The data considered in this section all pertain to part 1(a) of the integrated model and focus on language performance, patterns of habitual language use at different points in time, domains of use, interlocutors and role relationships.

\subsection{Language first spoken}

Most of the comparisons in this section of the thesis are between four different analyses of each community group

- all the members of the group

- all those who were born outside New Zealand

- all those who were born in New Zealand

- all those who were born outside New Zealand and arrived in New Zealand at the age of ten years or older

Those respondents who were born in New Zealand and arrived between the ages of 0 to 9 years old are not included in a separate analysis. This is because there are not many of them ${ }^{125}$ and because they are a disparate group in their immigration histories. Some arrived in New Zealand before they could speak any language and others arrived not only well after they had acquired their MT but after several years schooling in that MT. The age of ten is already a fairly arbitrary boundary and, for such a comparatively small group of respondents, there does not seem to be any age below that of ten which makes a satisfactory dividing point between 
those who are more like respondents who were born overseas and arrived as adults and those who are more like respondents who were born in New Zealand (although see comments in sections 8.6.4 and 11.7.6).

For this first comparison however only at two groupings are used; those who were born outside New Zealand and those who were born in New Zealand. There is no particular interest in looking at each group of respondents as a whole in order to see what language they spoke first as this is not an aspect of each community's present day language use and, for this particular question, there is little point in separating those who arrived in New Zealand aged 10 and over from those who arrived at a younger age. As we would expect most of the respondents who were born outside New Zealand spoke their MT as their first language. The only minor variation is the small number of Samoan respondents who spoke both English and Samoan as their first languages. A handful of Dutch (6) and Samoan (2) respondents spoke languages other than their MT. The two Samoan respondents spoke Tokelauan and Tuvaluan respectively and of the six Dutch respondents one spoke English first, one French and the other four spoke a Dutch dialect as their first language. It is also worth noting the seven Dutch respondents who spoke Dutch and a language other than English as their first languages - five of these respondents spoke Dutch and one or more Indonesian languages as their first language.

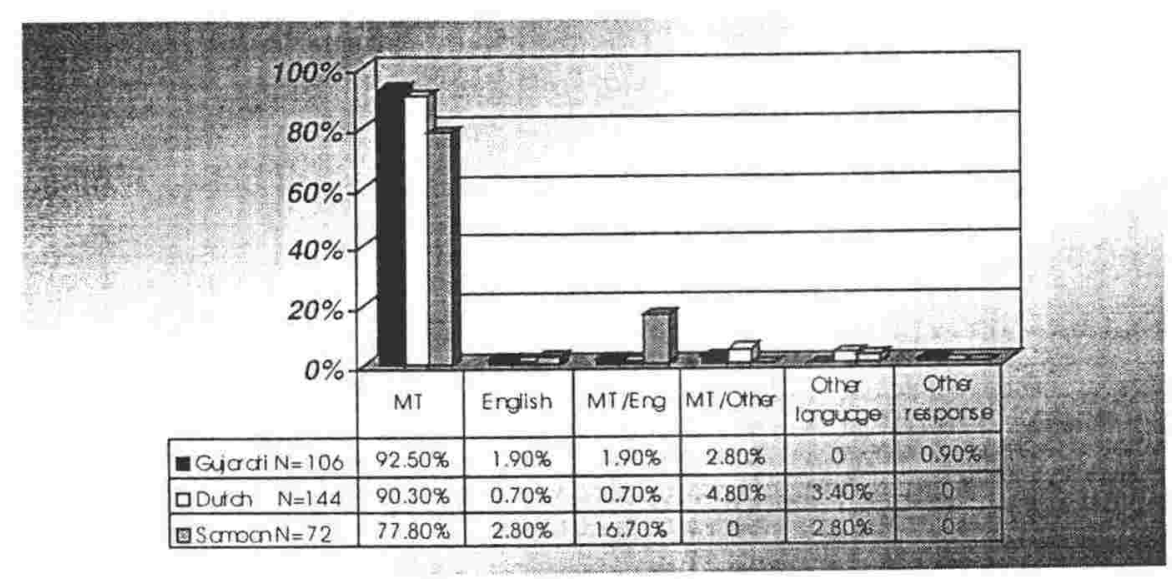

Figure 10-1: Language first spoken by respondents: All non-New Zealand-born respondents 


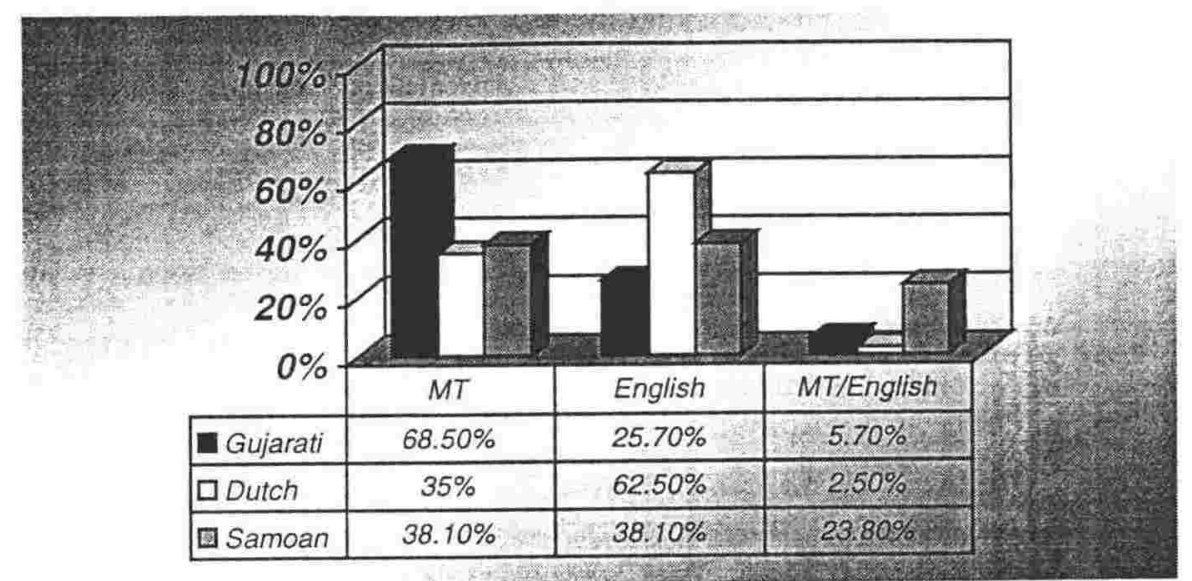

Figure 10-2: Language first spoken by respondents: All New Zealand-born respondents

Amongst the New Zealand-born respondents, a sizeable proportion in each group spoke the MT as their first language but the Gujarati respondents considerably outstripped both the Samoan and the Dutch respondents in this area. In fact each group had a very different pattern from the others.

- most of the Gujarati respondents (68.5\%) spoke their MT as their first language

- a substantial minority (25.7\%) spoke English first

- a tiny number spoke both languages first

Amongst the Dutch, English was the first language of a solid majority of the New Zealandborn respondents.

- most of the New Zealand-born respondents (62.5\%) spoke English as their first language

- a substantial minority (35\%) spoke their MT as their first language

- and tiny number spoke both English and Dutch as their first language

The Samoan respondents had yet a different pattern. They were evenly divided between those who had spoken Samoan and those who had spoken English as a first language, but a substantial minority said that they had spoken both languages as a first language.

- $38.1 \%$ of the New Zealand-born Samoan respondents spoke Samoan as their first language

- $38.1 \%$ of the New Zealand-born Samoan respondents spoke English as their first language

- $23.8 \%$ spoke both their MT and English as a first language

All three groups have the same kind of correlation between language first spoken and self reported proficiency in the MT today. Those respondents who spoke the MT as their first language (or who, perhaps more accurately, remember themselves as speaking their MT first) are more likely to rate themselves as 'fluent' or 'fairly fluent' in the MT today than those who spoke English first. Because only one Dutch respondent and two Gujarati respondents spoke a 
mixture of MT and English first, it is not really possible to look meaningfully at how that correlates with present day proficiency. Amongst the Samoan respondents only those groups of respondents who spoke Samoan or English and Samoan first contained some members who rated themselves as 'fluent' speakers of Samoan. Of the four Samoan respondents who spoke English first, two rated themselves as 'fairly fluent' and two as 'not very fluent'.

Table 10-9: Language spoke first compared to present day fluency. Percentages are of fluency rating/language spoken first

\begin{tabular}{|l|l|l|l|l|}
\hline & English First & MT/English First & MT First & N= \\
\hline Gujarati Fluent & $0 \%$ & $50 \%(1)$ & $45.8 \%$ & 12 \\
Dutch Fluent & $8 \%$ & $100 \%(1)$ & $14.8 \%$ & 5 \\
Samoan Fluent & $0 \%$ & $60 \%$ & $62.5 \%$ & 8 \\
Gujarati Fairly Fluent & $44.4 \%$ & $50 \%(1)$ & $41.6 \%$ & 15 \\
Dutch Fairly Fluent & $28 \%$ & $0 \%$ & $42.6 \%$ & 13 \\
Samoan Fairly Fluent & $50 \%$ & $20 \%$ & $25 \%$ & 7 \\
Gujarati Not Very fluent & $22.2 \%$ & $0 \%$ & & \\
Dutch Not Very Fluent & $28 \%$ & 05 & $4.1 \%$ & 3 \\
Samoan Not Very Fluent & $50 \%$ & $20 \%$ & $35.7 \%$ & 12 \\
& & & $12.5 \%$ & 6 \\
Gujarati Comprehension only & $0 \%$ & $0 \%$ & & \\
Dutch Comprehension Only & $20 \%$ & $0 \%$ & $0 \%$ & 0 \\
Samoan Comprehension Only & $0 \%$ & $0 \%$ & $7.1 \%$ & 6 \\
Gujarati No Ability & $0 \%$ & $0 \%$ & $0 \%$ & 0 \\
Dutch No Ability & $12 \%$ & $0 \%$ & $0 \%$ & 0 \\
Samoan No Ability & $0 \%$ & $0 \%$ & $0 \%$ & 3 \\
Gujarati 'Other' & $33.3 \%$ & $0 \%$ & $0 \%$ & 0 \\
Dutch 'Other' & $4 \%$ & $0 \%$ & $8.3 \%$ & 5 \\
Samoan 'Other' & $0 \%$ & $0 \%$ & $0 \%$ & 1 \\
\hline
\end{tabular}

The Dutch were the only group to return ratings of 'comprehension only' and 'no ability'. All of these respondents spoke English as their first language. This seems to suggest that the language first spoken to the child in the immigrant family home might have some long term influence on whether or not that child, as an adult, is likely to speak the MT.

The current research can be compared with Jamieson's (1980) findings on language maintenance and shift in the Wellington suburb of Newtown. ${ }^{126}$. Jamieson interviewed, amongst others, 21 Indian mothers ${ }^{127}$ and 54 Samoan mothers (Jamieson 1980: 103). Only one

\footnotetext{
${ }^{126}$ Below, some of the survey findings are compared with those of the Australian Census but as that Census has never had a 'language tirst used' question (Clyne \& Kipp 1996: 2), it can provide no basis for comparison here.

${ }^{127}$ Mostly Gujarati. There were 14 Gujarati households, 4 Hindi, 2 Singalese and 1 Bengali.
} 
Dutch mother was interviewed so it is not possible to make any useful comparison between the two sets of Dutch findings. She asked mothers what language/s they spoke to their preschool children and their answers can be usefully compared with the questions about what language/s respondents to the questionnaire spoke as their first language/s. Note that the respondents would, in most but not all cases, have been acquiring their first language/s some time before Jamieson's research was undertaken.

Table 10-10: Comparison of languages spoken by Indian mothers to pre-school children in Jamieson's research with language's first learnt by Gujarati respondents

\begin{tabular}{|c|c|c|c|}
\hline & English & English /MT & MT \\
\hline $\begin{array}{l}\text { Language spoken to children } \\
\text { by Indian mothers in } 1976\end{array}$ & $25 \%$ & $32 \%$ & $43 \%$ \\
\hline $\begin{array}{l}\text { Language spoke as first language } \\
\text { by Gujarati respondents in } \\
\text { childhood }\end{array}$ & $25.7 \%$ & $5.7 \%$ & $68.5 \%$ \\
\hline
\end{tabular}

The assumption made in comparing these figures is that the language/s spoken by the mother to the child will bear a fairly close relation to the language first spoken by the child. Because Jamieson only asked about pre-school children, her sample was not affected by the children having gone to school, and therefore the language spoken by the mother, and consequently the child, is likely to be the first language the child learnt. The most interesting point is that almost exactly a quarter of each Gujarati/Indian sample has recorded English as the dominant language. Both groups have also recorded the MT as the language used by the largest proportion of each group. The biggest discrepancy is between the use of both languages. Most of the respondents say that they did not learn English and Gujarati together as their first language whereas almost a third of the Indian mothers in Jamieson's 1980 sample record themselves as using both English and MT with their pre-school children.

When we turn to the comparison of the two Samoan groups, we see that the Samoan mothers recorded similar rates of usage to the Indian mothers and not utterly dissimilar from the rates of first language spoken that were recorded by the Samoan respondents to the present survey. It is interesting to note however that, more respondents claimed to have spoken English as their first language than mothers who claimed to speak English only with their pre-school children. Also more Samoan mothers claim to have spoken MT only with their pre-school children than the percentage of respondents who claimed to speak Samoan as their first language. 
Table 10-11: Comparison of languages spoken by Samoan mothers to pre-school children in Jamieson's research with languages first learnt by Samoan respondents

\begin{tabular}{|l|l|l|l|}
\hline & English & English /MT & MT \\
\hline $\begin{array}{l}\text { Language spoken to children } \\
\text { by Samoan mothers in } 1976\end{array}$ & $21 \%$ & $31 \%$ & $48 \%$ \\
Language spoken as first language by Samoan respondents in childhood & $38.1 \%$ & $23.8 \%$ & $38.1 \%$ \\
\hline
\end{tabular}

Macpherson (1984) and Yee (1981) have both picked out three different types of immigrant family dynamics with regard to language use. The three types are fairly logically; (a) dominated by MT in the home, (b) dominated by English in the home and (c) using a mixture of both languages.

Macpherson's typology springs from the observation of Samoan families in New Zealand and posits three 'environments' created by Samoan families

The first environment is characterized by the deliberate and systematic promotion of Samoan values and institutions... In the second environment, Samoan values and institutions are present but are neither deliberately and systematically promoted nor criticized ... In the third environment, deliberate and systematic attempts are made to limit exposure to, and involvement with, Samoan values and institutions and culture (Macpherson 1984:113-114).

Macpherson goes on to say that in the first of these environments "[Samoan] is [the children's] first language and is the basis of communication with their primary group.' The second environment tends 'not to be dominated by Samoan language' but 'Samoan is routinely spoke to the children in the home'. In the third environment however '[p]arents may use Samoan in the home among themselves but speak English to their children and encourage its use' (Macpherson 1984: 115-120).

Macpherson's comments are not based on research into particular Samoan families but Yee conducted questionnaire based research with 62 Chinese mothers in Sydney. Yee found that 29 of the mothers $(46.7 \%)$ described themselves as predominately using Chinese to their children, 16 (25.8\%) used mainly English and 17 (27.4\%) used a mixture of both (Yee 1981: 67).

\footnotetext{
${ }^{12 \times}$ This figure contlates the $19 \%$ who reported using MT and English equally and the $12 \%$ who reported using mostly MT.
} 
When we look at the three communities under investigation we find that each one of them tends to typify one type of interaction. Amongst the respondents born in New Zealand, the Dutch were more likely to speak English as a first language, the Gujaratis were more likely to speak the MT as a first language and the Samoans were the only New Zealand-born group in which a considerable proportion of the group perceived themselves as having spoken a mixture of MT and English as their first languages. In terms of Fishman's model, the family is indeed acting as bulwark against the forces of language shift in the case of the Gujarati families, but despite the high value placed on MT maintenance by the Samoan respondents , the family is, on the basis of this research, less likely to provide a strong MT environment for Samoan children. In the casea of the Dutch respondents, the family barely, in most cases, provided a MT environment at all - in terms of the respondents' own language use. The parents may well have spoken Dutch to each other (see section 8.6.3) but there was no expectation that the children should speak Dutch.

\subsection{Degree of bilingualism/multilingualism}

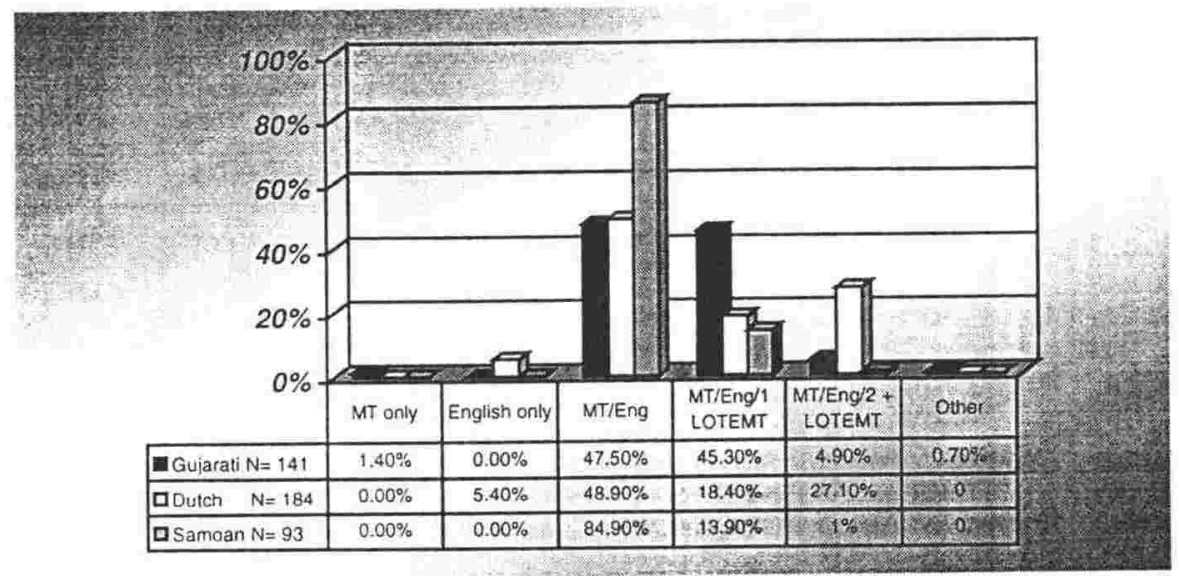

Figure 10-3: Languages spoken by respondents: All respondents ${ }^{129}$

As can be seen, the bulk of respondents in each group are bilingual in their MT and English although there are some interesting variations on this theme. All the Samoan and Dutch respondents born outside New Zealand speak English, but a handful of non-New Zealandborn Gujarati respondents speak only Gujarati and, in one case, Hindi. On the other hand, it is

\footnotetext{
${ }^{129}$ This includes all the non-New Zealand-born respondents of Gujarati extraction who answered the short version of the questionnaire. They did not answer the questions about age of arrival in New Zealand or whereabouts of education so it is not possible to filter them out on the grounds of answers to those questions. I have included them in the count of respondents arriving at ten years of age or older because most Gujarati immigrant respondents (84\%) did arrive in that age group.
} 
only amongst the Dutch that we find respondents who are monolingual in English. The Samoans are the only group in which all the respondents speak at least English and the MT.

\subsubsection{Non-New Zealand-born respondents}

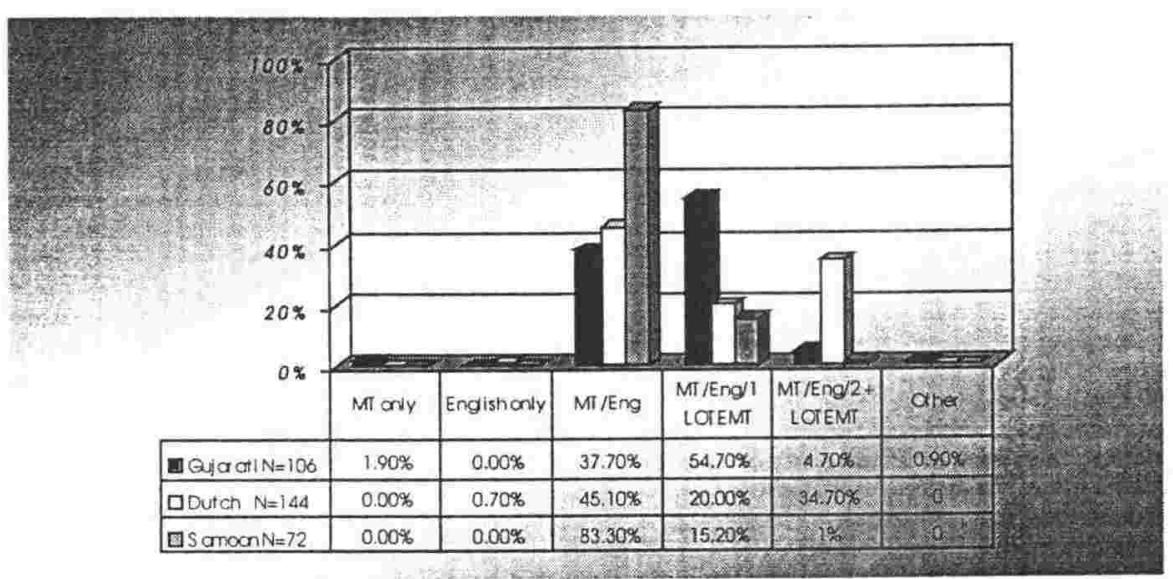

Figure 10-4: Languages spoken by respondents: All non-New Zealand-born respondents

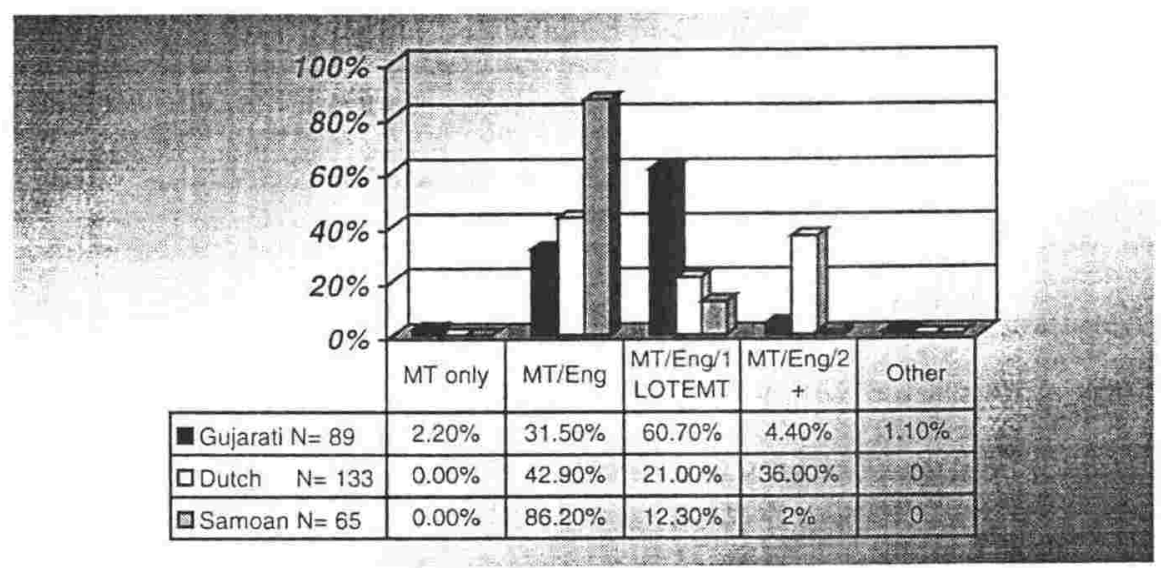

Figure 10-5: Languages spoken by respondents: All non-New Zealand-born respondents who arrived in New Zealand ten years and older

It is interesting to note that many of the non-New Zealand-born respondents are multilingual; that is they speak their MT, English and another one or two or more languages. This is most evident amongst the Dutch and the Gujarati respondents. The non-New Zealand-born Gujarati respondents are very likely to be trilingual; speaking Gujarati, Hindi and English (LMP also found a high degree of multilingualism in the Gujarati communities they investigated in England. LMP 1985: 182). The Dutch respondents are likely to have French or German as a third language. The non-New Zealand-born Dutch is the only group amongst whom speaking four or more languages is common. It is not uncommon for one of the Dutch respondents to speak French and German as well as English and Dutch - and in the case of those born in what was the Dutch East Indies, one or more Indonesian languages is often added to the list. 


\subsubsection{New Zealand-born respondents}

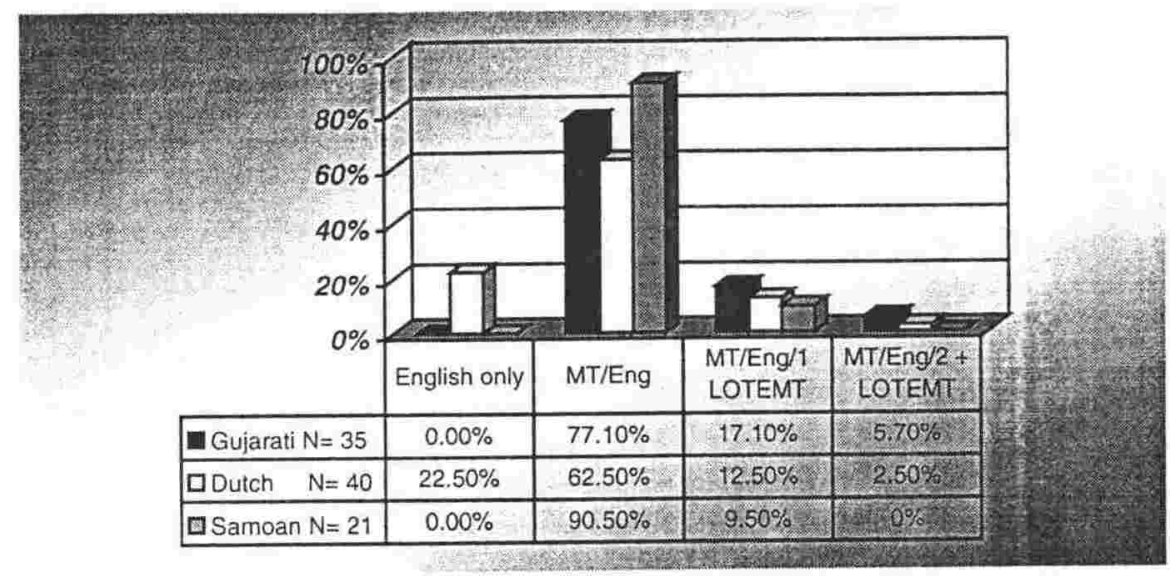

Figure 10-6: Languages spoken by respondents: All New Zealand-born respondents

One of the noticeable effects of being born and raised in New Zealand is that the likelihood of being multilingual drops significantly for all groups. The Dutch are the only group to produce English monolinguals (almost a quarter of the New Zealand-born respondents) but all groups show a decline in multilingualism. Only $15 \%$ of the Dutch New Zealand-born respondents are multilingual compared to $57 \%$ of the Dutch non-New Zealand-born respondents who arrived in New Zealand over the age of 10. For the Gujarati sample, the rate of multilingualism drops from $65.1 \%$ amongst those who arrived here age 10 and over to $22.8 \%$ amongst the New Zealand-born and for the Samoan respondents, far fewer of whom are multilingual, the rate drops from $15 \%$ to $9.5 \%$. It is amongst the Dutch that the drop is most spectacular. The drop in rates of multilingualism can be attributed to the different educational and social context of New Zealand compared to both The Netherlands and India. Both India and The Netherlands are countries in which multilingualism is common (Asher 1994:2779, Sridhar in draft: 1-3). The immigrants to New Zealand from these two countries brought the languages that they spoke with them but New Zealand was, and in many ways still is, a country with a stubborn tradition of monolingualism. So much so that at least three Dutch immigrants, living in temporary hotel accommodation in the 1950s, were forbidden to speak Dutch together at the hotel (Schouten 1992: 150). Not only did the immigrants receive no support for maintaining their MT they also found that even when, as in the case of many of the Dutch immigrants, they spoke a nominally statusful foreign language such as French or German, the New Zealand educational and social system did not encourage their children to acquire these languages. The attitude faced by Dutch immigrants in the 1950 s and 1960 s is summed up by a Dutch immigrant of the 1950 s quoted below. 
It's also that New Zealanders had hardly any experience with foreign language. So as soon as they hear anything of a foreign tongue and expression they lose their confidence. And why should you do that? Nevertheless we couldn't give up that language is a terribly important thing and for example with the headmaster of the boy's high school we had a personal discussion about it and we asked him - what do the children learn when they learn French here - because they never never can experience the fun of translating and understanding foreign language. - Yes but French is on the programme. In some cases Latin and we had a very good intermediate school headmaster who was aware of languages - But I said why don't you teach Maori? - Oh but we do teach Maori in high school the headmaster said. I said but it's not in curriculum. - No. No we give it outside school hours. It's done by a Maori teacher and it's only for Maori children. ....... I think that our background of many languages has helped in New Zealand to promote the idea that foreign languages is good to learn are good to learn.

(Male immigrant to New Zealand arrived in 1955. Anton Everts. New Zealand/ Netherlands Foundation. Interviewer Kees Snoek. Interviewed 16/11/1992).

For the multilingual Gujarati immigrants the chances of passing on their multilingualism to their children received even less support. The most common third language spoken in the community was Hindi, which is not a traditionally statusful language in New Zealand and which, to this day, is not taught at any state funded educational establishment in New Zealand. It is ironic then, that it is amongst the Gujarati community that we see the highest rate of multilingualism amongst the New Zealand-born. It seems likely that this is because of the greater importance attached consciously and unconsciously to the project of cultural maintenance that has been undertaken by the Gujarati community in New Zealand (see also Sridhar (draft: 17) for comment on Gujaratis in America and their relative lack of assimilation). The Dutch immigrants were much more committed to a project of assimilation. This commitment to assimilation was also found in Dutch immigrants to Australia at the same time, where it had similar effects (Bennett 1992: 54, de Bot and Clyne 1994: 18).

\subsubsection{Correlation of multilingualism with respondents' fluency in MT}

In examining the relationship of the degree of bilingualism/multilingualism to language maintenance, it seemed possible that multilingualism might be related to language maintenance. This relationship was investigated by comparing multilingual Gujarati and Dutch respondents with bilingual Dutch and Gujarati respondents (because there were so few monolinguals, these were not considered). There are relatively few multilingual Samoan respondents so they are not considered in this comparison. The points chosen for comparison, as indicators of language maintenance, were 
- did respondents use the MT outside the home in New Zealand?

- did respondents rate themselves as fluent speakers of the MT?

- did respondents rate themselves as able to speak the MT 'fluently' and write it 'easily'?

Table 10-12: Correlation of bilingualism and multilingualism with Dutch language use and proficiency

\begin{tabular}{|c|c|c|c|c|}
\hline & $\begin{array}{l}\text { Dutch } \\
\text { multilinguals } \\
\text { Non-NZ-born } \\
\mathrm{N}=78\end{array}$ & $\begin{array}{l}\text { Dutch } \\
\text { bilinguals } \\
\text { Non-NZ-born } \\
\mathrm{N}=65\end{array}$ & $\begin{array}{l}\text { Dutch } \\
\text { multilinguals } \\
\mathrm{NZ} \text {-born } \\
\mathrm{N}=6\end{array}$ & $\begin{array}{l}\text { Dutch } \\
\text { bilinguals } \\
\text { NZ-born } \\
\mathrm{N}=25 \\
\end{array}$ \\
\hline $\begin{array}{l}\text { Speak Dutch } \\
\text { outside the house }\end{array}$ & $93.5 \%$ & $87.6 \%$ & $66.6 \%$ & $56 \%$ \\
\hline Speak Dutch 'fluently' & $92.3 \%$ & $80 \%$ & $16.6 \%$ & $16 \%$ \\
\hline $\begin{array}{l}\text { Speak Dutch 'fluently' } \\
\text { write it 'easily' }\end{array}$ & $89.7 \%$ & $69.2 \%$ & 0 & $4 \%$ \\
\hline
\end{tabular}

Table 10-13: Correlation of bilingualism and multilingualism with Gujarati language use and proficiency

\begin{tabular}{|c|c|c|c|c|}
\hline & $\begin{array}{l}\text { Gujarati } \\
\text { multilinguals. } \\
\text { Non-NZ-born } \\
\mathrm{N}=63\end{array}$ & $\begin{array}{l}\text { Gujarati } \\
\text { bilinguals. } \\
\text { Non-NZ-born } \\
\mathrm{N}=40\end{array}$ & $\begin{array}{l}\text { Gujarati } \\
\text { multilinguals } \\
\mathrm{NZ} \text {-born } \\
\mathrm{N}=8\end{array}$ & $\begin{array}{l}\text { Gujarati } \\
\text { bilinguals } \\
\text { NZ-born } \\
N=27\end{array}$ \\
\hline $\begin{array}{l}\text { Speak Gujarati } \\
\text { outside the house }\end{array}$ & $96.8 \%$ & $95 \%$ & $100 \%$ & $100 \%$ \\
\hline $\begin{array}{l}\text { Speak Gujarati } \\
\text { 'fluently' }\end{array}$ & $92 \%$ & $77.5 \%$ & $50 \%$ & $29.6 \%$ \\
\hline $\begin{array}{l}\text { Speak Gujarati } \\
\text { 'fluently', write it } \\
\text { 'easily' }\end{array}$ & $80.9 \%$ & $50 \%$ & $25 \%$ & 0 \\
\hline
\end{tabular}

As the tables show, there does appear to be some relationship between multilingualism and the factors selected as indicators of language maintenance, although there are some interesting differences between the two groups. Dutch multilinguals are more likely than Dutch bilinguals to speak Dutch outside the home whereas it makes no difference whether Gujarati respondents are bi- or multilingual, they are equally likely to speak Gujarati outside the home. Presumably this is because almost all the Gujarati respondents do speak Gujarati outside the home regardless of any other factor.

For the Dutch-born respondents, and for all the Gujarati respondents regardless of birthplace, being multilingual is correlated with being more likely to rate their MT proficiency as 'fluent'

${ }^{130}$ this does not include the one Gujarati/Hindi bilingual 
and with being both 'fluent' and being able to write the MT 'easily'. The only group for which being bilingual or multilingual seems to make no difference is the New Zealand-born Dutch. Several possible reasons for the correlation between multilingualism and higher rates of MT fluency suggest themselves. It is possible that being multilingual may make one value one's language skills more highly and thus make one more enthusiastic about using those skills. Speaking more than two languages may give a respondent a greater range of competencies over which to rate themselves, as mentioned in section 7.3.1.1. Thus if you speak only MT and English you may rate English as 'fluent' and MT as 'fairly fluent' but if you speak a couple of other languages as well, you may rate English and MT as 'fluent', language 3 as 'fairly fluent' and language 4 as 'not very fluent'. For the New Zealand-born respondents, being brought up bilingual may encourage them to acquire other languages. It is not possible to be sure which of these factors or combinations of factors is the most important but it certainly suggests interesting avenues for further exploration.

Given that multilingualism appears to be related to an individual's language maintenance, can we see if it is related to their children's language maintenance? That is, is a child of multilingual parentage more likely to speak their MT than a child of bilingual parentage?

\subsubsection{Correlation of multilingual and bilingual parents with children's ability to speak the MT}

The following two tables show the ability of the oldest and youngest children of the respondents to speak the MT and correlate this data with whether or not the parents are multilingual or bilingual and with the parents' place of birth. 
Table 10-14: Correlation of multilingual and bilingual parents with children's ability to speak Dutch

\begin{tabular}{|c|c|c|c|c|}
\hline & $\begin{array}{l}\text { Dutch multilinguals. } \\
\text { Non-NZ-born } \\
\text { Oldest } \mathrm{N}=70^{131} \\
\text { Youngest } \mathrm{N}= \\
63 / 61^{132}\end{array}$ & $\begin{array}{l}\text { Dutch bilinguals. } \\
\text { Non-NZ-born } \\
\text { Oldest } N=62 / 60 \\
\text { Youngest } N=59\end{array}$ & $\begin{array}{l}\text { Dutch multilinguals } \\
\text { NZ-born } \\
\text { Oldest } \mathrm{N}=4 \\
\text { Youngest } \mathrm{N}=5 / 4\end{array}$ & $\begin{array}{l}\text { Dutch Bilinguals } \\
\text { NZ-born } \\
\text { Oldest } \mathrm{N}=19 \\
\text { Youngest } \mathrm{N}=24 / 19\end{array}$ \\
\hline $\begin{array}{l}\text { Oldest child speaks } \\
\text { Dutch }\end{array}$ & $46.3 \%^{13.3}$ & $34.4 \%$ & $0 \%$ & $10.5 \%$ \\
\hline $\begin{array}{l}\text { Youngest child } \\
\text { speaks Dutch }\end{array}$ & $32.2 \%$ & $26.7 \%$ & $0 \%$ & $14.2 \%$ \\
\hline
\end{tabular}

Table 10-15: Correlation of multilingual and bilingual parents with children's ability to speak Gujarati

\begin{tabular}{|c|c|c|c|c|}
\hline & $\begin{array}{l}\text { Gujarati } \\
\text { multilinguals. } \\
\text { Non-NZ-born } \\
\text { Oldest } \mathrm{N}=49 \\
\text { Youngest } \mathrm{N}=53 / 48\end{array}$ & $\begin{array}{l}\text { Gujarati bilinguals. } \\
\text { Non-NZ-born } \\
\text { Oldest } \mathrm{N}=31 \\
\text { Youngest } \mathrm{N}=32 / 30\end{array}$ & $\begin{array}{l}\text { Gujarati multilinguals } \\
\text { NZ-born } \\
\text { Oldest } \mathrm{N}=8 \\
\text { Youngest } \mathrm{N}=9 / 7\end{array}$ & $\begin{array}{l}\text { Gujarati Bilinguals } \\
\text { NZ-born } \\
\text { Oldest } N=24 / 23 \\
\text { Youngest } N=18 / 17\end{array}$ \\
\hline $\begin{array}{l}\text { Oldest child } \\
\text { speaks Gujarati }\end{array}$ & $83.6 \%$ & $77.4 \%$ & $87.5 \%$ & $72.7 \%$ \\
\hline $\begin{array}{l}\text { Youngest child } \\
\text { speaks Gujarati }\end{array}$ & $69.7 \%$ & $67.8 \%$ & $60 \%$ & $37.5 \%$ \\
\hline
\end{tabular}

Once again there does seem to be some relationship between number of languages spoken and a language maintenance indicator, in this case, the ability of the respondent's children to speak the MT. It is most noticeable in the case of the non-New Zealand-born Dutch and the New Zealand-born Gujaratis, where the children of multilinguals are considerably more likely to speak the MT than the children of bilinguals. The correlation is not so marked in the case of the non-New Zealand-born Gujaratis and in the case of the New Zealand-born Dutch the

${ }^{131}$ This is the total for the children of all the parents. Some children are counted twice because both their mothers and fathers were respondents. If each child is counted only once then the opinion of one parent (in the cases where both parents answered questionnaires) on whether the child speaks the MT has to be discounted. As a check, the figures 'by child' were compared with the figures 'by parent' for the children of non-New Zealandborn Dutch multilingual parents and they are very similar. 'By child' the figures are $42.5 \%$ of the oldest children and $26 \%$ of the youngest children speak Dutch. The total number of children (and all the other totals given) includes all the oldest children including those who were 'too young' to speak. There was one child in this group who was 'too young' to speak any language and one child whose parent returned 'no response' for the question about language use.

${ }^{132}$ The double figures in this and the following tables are to be interpreted thus: the first figure includes all the oldest or youngest children, the second figure excludes those who were 'too young' to speak, the percentages are calculated on the second figure (which includes the small number of children whose parents entered "no response' to the question about the languages used by the children).

${ }^{133}$ The percentage is of those children who spoke the MT out of the total of children in the group who were old enough to speak a linguage. Where a respondent has indicated that their child was 'too young' to speak, that child has not been included in the total out of which the percentage is calculated. Children for whom the respondent returned 'no response' to the question about language use, have been included in the total from which the percentage was calculated. 
correlation is inverse. None of the New Zealand-born Dutch multilingual parents have children who can speak Dutch at all, but there are only four children in this group and it is really too small to tell us anything useful.

\subsubsection{Interaction between university education and multilingualism and its possible influence upon language maintenance}

The higher the educational level attained by a respondent the greater the more likely they are to speak three or more languages. It was possible therefore that the important relationship was not between multilingualism and language maintenance but between level of education and language maintenance and that multilingualism was merely acting as a proxy for a tertiary level of education. This was investigated by looking at the highest level of education achieved by respondent and whether or not the respondent's oldest and youngest children speak the MT. Firstly the differences in educational level in the multilingual and bilingual groups are examined. It is quite clear from Table 10-16 and Table 10-17 that multilingual Dutch and Gujarati respondents whether born in New Zealand or overseas, are more likely to have had a university education and less likely to have had an education that stopped at primary or secondary level. How does this correlate with language maintenance? For the answer we must turn to Table 10-18 and Table 10-19.

Table 10-16: Multingualism and bilingualism related to highest level of education: Dutch

\begin{tabular}{|c|c|c|c|c|}
\hline Highest level of education & $\begin{array}{l}\text { Multilingual } \\
\text { Non-NZB } \\
\mathrm{N}=78\end{array}$ & $\begin{array}{l}\text { Bilingual Non-NZB } \\
N=65\end{array}$ & $\begin{array}{l}\text { Multilingual } \\
\text { NZB } \\
N=6\end{array}$ & $\begin{array}{l}\text { Bilingual NZB } \\
N=2^{134}\end{array}$ \\
\hline University & $43.5 \%$ & $12.3 \%$ & $100 \%$ & $20 \%$ \\
\hline Other tertiary & $41 \%$ & $49.2 \%$ & 0 & $40 \%$ \\
\hline Secondary & $15.3 \%$ & $32.3 \%$ & 0 & $40 \%$ \\
\hline Primary & 0 & $6.1 \%$ & 0 & 0 \\
\hline
\end{tabular}

\footnotetext{
${ }^{13+4}$ The total adds up to 174 because 10 Dutch respondents are English monolinguals.
} 
Table 10-17: Multingualism and bilingualism related to highest level of education: Gujarati (percentage out of the respondents who answered the long version of the questionnaire)

\begin{tabular}{|l|l|l|l|l|}
\hline Highest level of education & $\begin{array}{l}\text { Multilingual } \\
\text { Non-NZB } \\
\mathbf{N = 5 2}\end{array}$ & $\begin{array}{l}\text { Bilingual Non-NZB } \\
\mathbf{N = 3 0}\end{array}$ & $\begin{array}{l}\text { Multilingual } \\
\text { NZB } \\
\mathbf{N = 8}\end{array}$ & $\begin{array}{l}\text { Bilingual NZB } \\
\mathbf{N = \mathbf { 2 4 }}\end{array}$ \\
\hline University & $46.1 \%$ & $16.6 \%$ & $50 \%$ & $20.8 \%$ \\
Other tertiary & $5.7 \%$ & $20 \%$ & $37.5 \%$ & $45.8 \%$ \\
Secondary & $38.4 \%$ & $46.6 \%$ & $12.5 \%$ & $33.3 \%$ \\
Primary & $9.6 \%$ & $6.6 \%$ & 0 & 0 \\
\hline
\end{tabular}

The multilingual and bilingual respondents are combined (giving a total of 174 Dutch respondents) and the correlation between level of education and language maintenance is examined.

Table 10-18: Children's ability to speak MT related to parent's highest level of education: Dutch respondents, non-NZ-born

\begin{tabular}{|c|c|c|c|c|}
\hline & 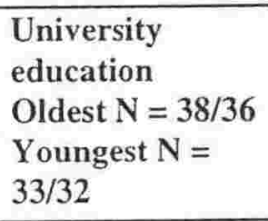 & $\begin{array}{l}\text { Other tertiary } \\
\text { education } \\
\text { Oldest } \mathrm{N}=60 \\
\text { Youngest } \mathrm{N}= \\
56 / 53\end{array}$ & $\begin{array}{l}\text { Secondary } \\
\text { education } \\
\text { Oldest } N=29 / 28 \\
\text { Youngest } N=27\end{array}$ & $\begin{array}{l}\text { Primary } \\
\text { education } \\
\text { Oldest } \mathrm{N}=4 \\
\text { Youngest } \mathrm{N}=4\end{array}$ \\
\hline $\begin{array}{l}\text { Oldest speaks } \\
\text { Dutch }\end{array}$ & $38.8 \%$ & $40 \%$ & $42.8 \%$ & $50 \%$ \\
\hline $\begin{array}{l}\text { Youngest } \\
\text { speaks Dutch }\end{array}$ & 31.25 & $31.4 \%$ & $31.8 \%$ & $25 \%$ \\
\hline
\end{tabular}

In addition to the respondents represented in the above tables, there are 31 bilingual or multilingual New Zealand-born Dutch respondents. No table has been constructed for this group, because only one of these respondents has children (both youngest and oldest) who speak Dutch. The group is evenly divided between 10 respondents with secondary level education, 11 with university level education and 10 with other tertiary education. Once again, there does not appear to be a strong relationship between level of parental education and language maintenance in the children.

\footnotetext{
${ }^{135}$ One respondents has no formal schooling of any kind, there was one 'no response' and one response was unclear.
} 
Table 10-19: Children's ability to speak MT related to parent's highest level of education: Gujarati respondents, non-NZ-born

\begin{tabular}{|c|c|c|c|c|}
\hline & $\begin{array}{l}\text { University } \\
\text { education } \\
\text { Oldest } \mathrm{N}=27 \\
\text { Youngest } \mathrm{N}= \\
24 / 21\end{array}$ & $\begin{array}{l}\text { Other tertiary } \\
\text { education } \\
\text { Oldest } N=9 \\
\text { Youngest } N=9 / 8\end{array}$ & $\begin{array}{l}\begin{array}{l}\text { Secondary } \\
\text { education }\end{array} \\
\text { Oldest } \mathrm{N}=35 \\
\text { Youngest } \mathrm{N}= \\
35 / 33\end{array}$ & $\begin{array}{l}\text { Primary education } \\
\text { Oldest } \mathrm{N}=6 \\
\text { Youngest } \mathrm{N}=6\end{array}$ \\
\hline $\begin{array}{l}\text { Oldest speaks } \\
\text { Gujarati }\end{array}$ & $70.3 \%$ & $77.7 \%$ & $88.5 \%$ & $100 \%$ \\
\hline $\begin{array}{l}\text { Youngest speaks } \\
\text { Gujarati }\end{array}$ & $47.6 \%$ & $62.5 \%$ & $78.7 \%$ & $100 \%$ \\
\hline
\end{tabular}

(There were three respondents who came into different categories; one was unclear about the highest level of education question, one gave no response and one had never been to school. They all had oldest children who spoke Gujarati. Two of the youngest children also spoke it and respondent returned 'no response' to the question about youngest child's language use.)

The New Zealand-born Gujarati respondents exhibit a similar pattern to the non-New Zealand-born. There are no New Zealand-born respondents who have completed only a primary level of education but it is amongst those whose education was completed at secondary level that we find the greatest proportion who have children who can speak the MT. The respondents with a university education are slightly more likely to have Gujarati speaking oldest children than those with a non-university tertiary education. This reverses the findings for the non-New Zealand-born Gujarati respondents, but the numbers involved are small and it seems safest to conclude that those with a secondary education only, are more likely than those with a tertiary education, of whatever kind, to have Gujarati speaking children.

Table 10-20: Children's ability to speak MT related to parent's highest level of education: Gujarati respondents, NZ-born

\begin{tabular}{|l|l|l|l|}
\hline & $\begin{array}{l}\text { University education } \\
\text { Oldest } \mathrm{N}=9 \\
\text { Youngest } \mathrm{N}=\mathbf{7 / 5}\end{array}$ & $\begin{array}{l}\text { Other tertiary education } \\
\text { Oldest } \mathrm{N}=\mathbf{1 3 / 1 2} \\
\text { Youngest } \mathrm{N}=9\end{array}$ & $\begin{array}{l}\text { Secondary education } \\
\text { Oldest } \mathrm{N}=\mathbf{9} \\
\text { Youngest } \mathrm{N}=\mathbf{8} / 7\end{array}$ \\
\hline $\begin{array}{l}\text { Oldest speaks Gujarati } \\
\text { Youngest speaks } \\
\text { Gujarati }\end{array}$ & $\begin{array}{l}77.7 \% \\
40.0 \%\end{array}$ & $66.6 \%$ & $88.8 \%$ \\
$57.1 \%$ & \\
\hline
\end{tabular}

The figures show that multilingualism is not acting merely as a proxy for university education. It is true that multilinguals in the Gujarati and Dutch communities are more likely to have a university education. However, respondents with a university education are no more likely than any of the other respondents, to have Gujarati-speaking children. In fact, amongst the Gujarati respondents, those with a secondary education are more likely to have Gujarati speaking children than those with a university education, and the situation is not dissimilar amongst the Dutch respondents, although the differences are slight. 
In section 11.5.2 it is shown that level of education correlates with whether or not respondents use the MT with their children. Both Gujarati and Samoan respondents with tertiary education were more likely to use English with their children than the Gujarati and Samoan respondents with secondary education. There was no such relationship demonstrated amongst the Dutch respondents. Respondents with a tertiary education are less likely to use the MT with their children (amongst the Gujarati and Samoan respondents) and the children of tertiary educated respondents are less likely to speak the MT (amongst all respondents). There are some variations from one group of respondents to another depending on whether university education or other (non-university) tertiary education is taken as the key factor.

For the sake of completeness, even although there are too few multilingual Samoan speakers to include them in the analysis in sections 6 and 7, the figures for level of education related to language spoken by children are given here for the Samoan respondents. Most of the children of Samoan respondents speak Samoan, and therefore the differences are not dramatic. However, they do suggest that a tertiary-educated parent may be more likely to have a child who does not speak Samoan than a secondary-educated parent. The results for the non-New Zealand-born respondents with a primary level of education appear to break the, so far, fairly stable inverse correlation of level of respondents' education with ability of respondents' children to speak the MT, however, the numbers are so small that they cannot be regarded as indicative of anything. Because of the high proportion of Samoan speakers amongst the children, a larger sample is needed before it would be possible to make any stronger statements about the link between parental education and children's ability to speak the MT. 
Table 10-21: Children's ability to speak MT related to parent's highest level of education: Samoan respondents, non-NZ-born

\begin{tabular}{|c|c|c|c|c|}
\hline & $\begin{array}{l}\text { University } \\
\text { education } \\
\text { Oldest } N=12 \\
\text { Youngest } \mathrm{N}=12\end{array}$ & $\begin{array}{l}\text { Other tertiary } \\
\text { education } \\
\text { Oldest } \mathrm{N}=21 \\
\text { Youngest } \mathrm{N}=17\end{array}$ & $\begin{array}{l}\text { Secondary } \\
\text { education } \\
\text { Oldest } N=19 \\
\text { Youngest } N=17\end{array}$ & $\begin{array}{l}\text { Primary } \\
\text { education } \\
\text { Oldest } \mathrm{N}=3 \\
\text { Youngest } \mathrm{N}=1\end{array}$ \\
\hline $\begin{array}{l}\text { Oldest speaks } \\
\text { Samoan }\end{array}$ & $83.3 \%$ & $100 \%$ & $100 \%$ & $66.6 \%$ \\
\hline $\begin{array}{l}\text { Youngest speaks } \\
\text { Samoan }\end{array}$ & $75 \%$ & $100 \%$ & $100 \%$ & $0 \%$ \\
\hline
\end{tabular}

Table 10-22: Children's ability to speak MT related to parent's highest level of education: Samoan respondents, NZ-born

\begin{tabular}{|l|l|l|l|}
\hline & $\begin{array}{l}\text { University education } \\
\text { Oldest } \mathrm{N}=\mathbf{3} \\
\text { Youngest } \mathrm{N}=\mathbf{2}\end{array}$ & $\begin{array}{l}\text { Other tertiary education } \\
\text { Oldest } \mathrm{N=9} \\
\text { Youngest N=6 }\end{array}$ & $\begin{array}{l}\text { Secondary education } \\
\text { Oldest } \mathrm{N}=\mathbf{3} \\
\text { Youngest N=1 }\end{array}$ \\
\hline $\begin{array}{l}\text { Oldest speaks Samoan } \\
\text { Youngest speaks Samoan }\end{array}$ & $100 \%$ & $77.7 \%$ & $100 \%$ \\
$100 \%$ & $100 \%$ & $100 \%$ \\
\hline
\end{tabular}

\subsubsection{Summary}

All the Dutch and Samoan non-New Zealand-born respondents and virtually all the Gujarati non-New Zealand-born respondents were at least bilingual. Over half the non-New Zealandborn Gujarati and Dutch respondents were multilingual as were $16 \%$ of the Samoan non-New Zealand-born.

All the New Zealand-born Gujarati and Samoan respondents were at least bilingual in English and the MT. Change over time is most evident amongst the Dutch New Zealand-born respondents, almost a quarter of whom were monolingual in English. Very few of any of the New Zealand-born respondents were multilingual. In the area of multilingualism, the New Zealand-born respondents, as a group, all exhibited considerable change in patterns of language acquisition and use when compared to the non-New Zealand-born as a group.

The importance of the family as a site of language maintenance is shown by the fact that those respondents who spoke the MT as their first language were more likely to rate themselves as 'fluent' or 'fairly fluent' MT speakers than those who did not speak the MT first.

Multilingual respondents were more likely to have children who used the MT.

\subsection{Language most used}

The answer to the question 'which language/s do you use most?' gives a rough global assessment of patterns habitual daily language use. 


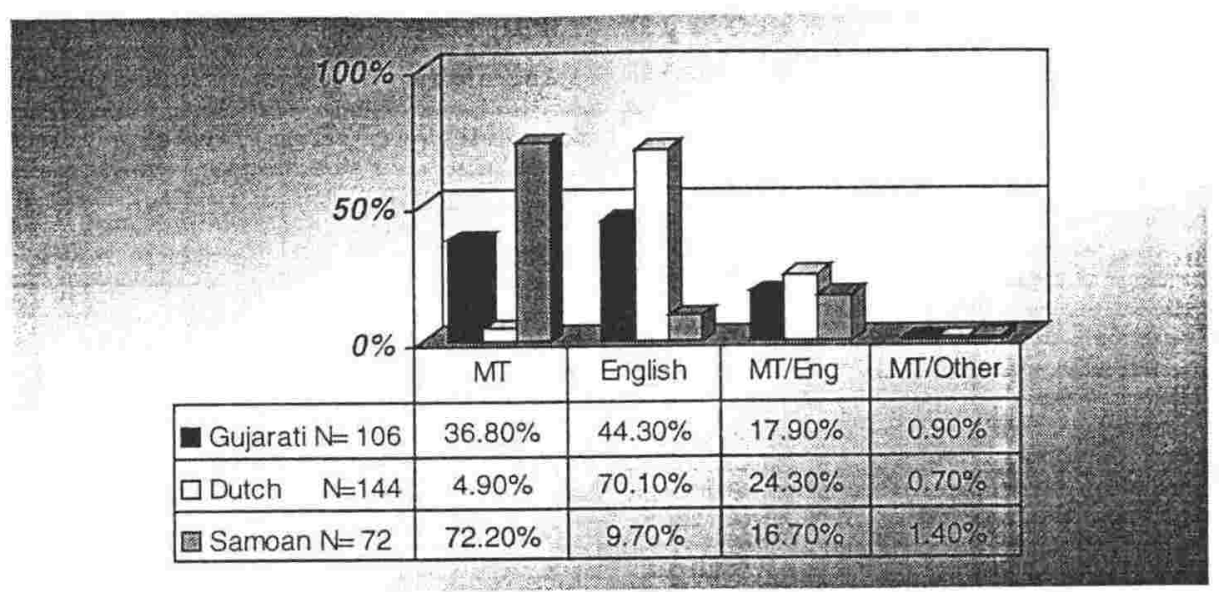

Figure 10-7: Language most used by respondents: All respondents

It is very interesting, looking at respondents' answers to the question 'what language/s do you use most?' to see that 'English' does not have the overwhelming preponderance that might be expected, at least for each community as a whole. It is only amongst the Dutch respondents that English is the main language used by a significant majority of respondents. Just over half the Gujarati respondents report that English is their most frequently used language and under a quarter of the Samoan respondents thought that this was the case.

- $76.6 \%$ of the Dutch respondents used English most

- 54.6 of the Gujarati respondents used English most

- $19.4 \%$ of the Samoan respondents used English most

It is equally interesting to note that 50/50 MT/English was not the second ranked choice for any of the groups. In fact roughly equal numbers, all well under a quarter of each group, chose this as their option. Most of the Samoan respondents said that Samoan was the language that they used most and over a quarter of Gujarati respondents said that Gujarati was the language they used most. However, only a tiny number of Dutch respondents chose this option

- $59.1 \%$ of the Samoan respondents said that that they used Samoan most

- $27.7 \%$ quarter of Gujarati respondents said that they used Gujarati most

- $3.8 \%$ of Dutch respondents said that they used Dutch most 


\subsubsection{Non-New Zealand-born respondents}

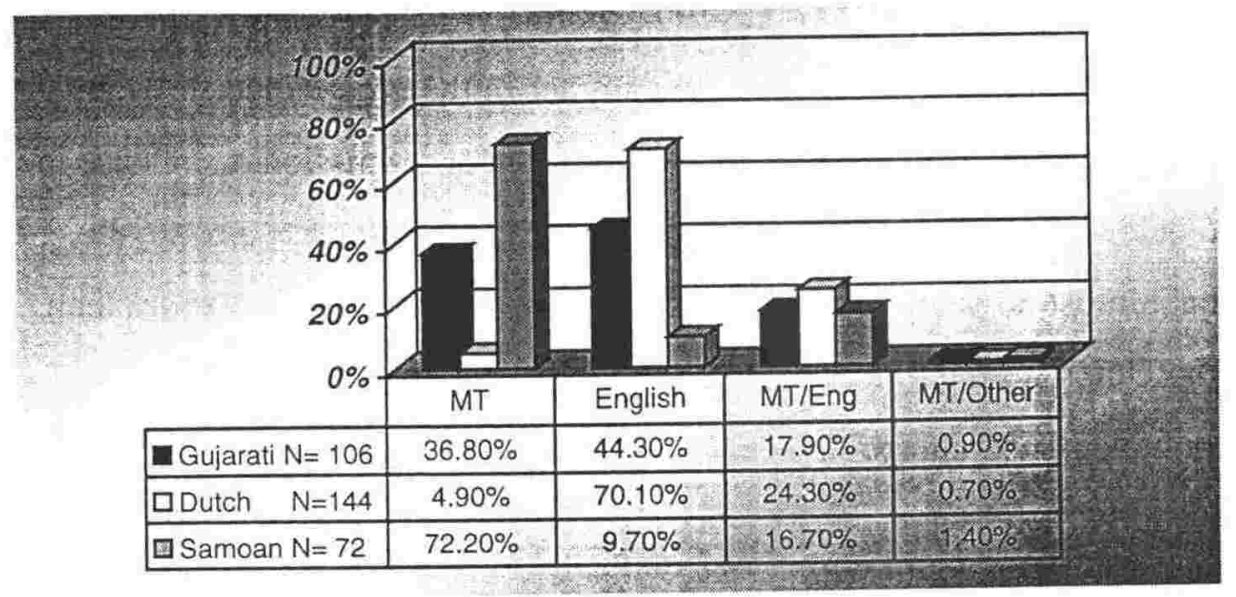

Figure 10-8: Language most used by respondents: All non-New Zealand-born respondents

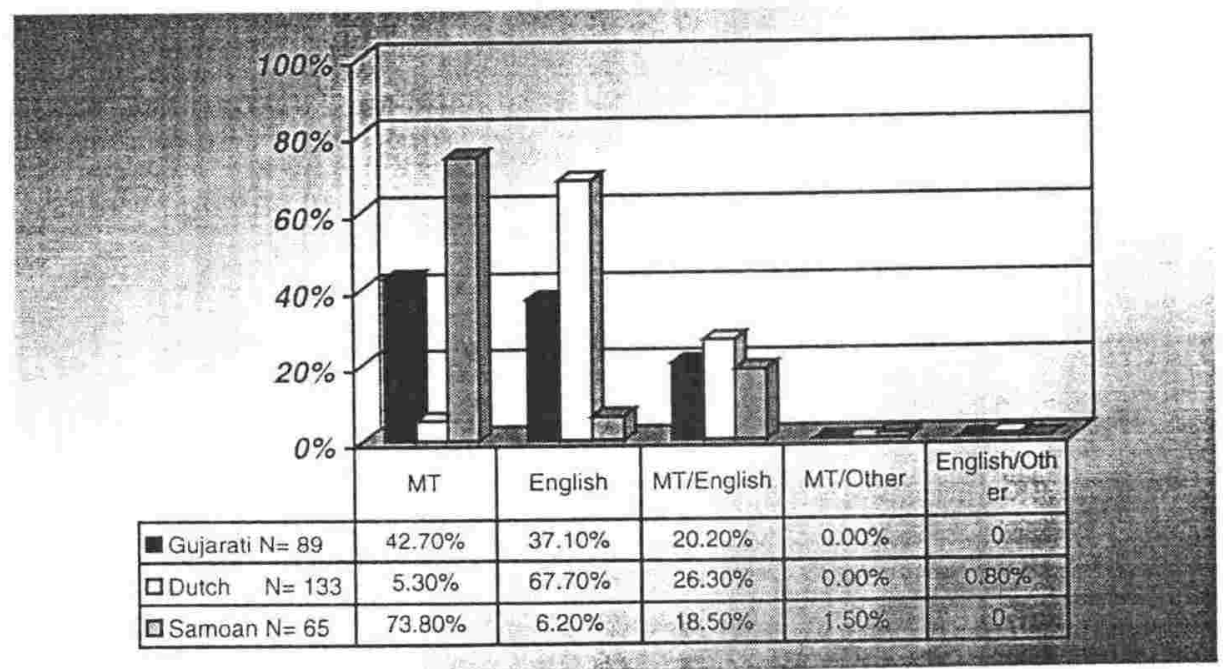

Figure 10-9: Language most used by respondents: All non-New Zealand-born respondents who arrived in New Zealand $10+$

Not unexpectedly, amongst those who were born outside New Zealand and especially those who arrived in New Zealand aged 10 or older, the tendency to use MT most, increases although not very much in the case of the Dutch respondents.

The percentage of Dutch respondents who said that they used English most of the time can usefully be compared with the non-Australian-born Dutch respondents to the 1976 Australian census who were asked to list all the languages they used regularly (Clyne 1985: 195) ${ }^{136}$. The rate of shift recorded by the Dutch in New Zealand is considerably greater (70.1\%) than that

\footnotetext{
${ }^{136}$ There was no language question asked in the 1981 Census, and in 1986 the question changed to 'language used at home' (Ozolins 1993: 195-197).
} 
recorded by those in Australia (43.55\%). Given that these are essentially very similar immigrant groups (Bennett 1992, de Bot and Clyne 1994, Folmer 1992) it is interesting that the rate of first generation shift seems to have been even higher in the group under review than amongst the Dutch in Australia (although see section 11.1.1 for discussion of MT use in the home). It must also be borne in mind that the Australian data is census data, not small survey data and also that almost 20 years separates the two sampling periods. It is more than possible that some of the Dutch immigrants to Australia who in 1976 had not shifted completely from Dutch, have now done so.

The proportion of respondents using a mixture of MT and English is higher in the Gujarati and Dutch non-New Zealand-born groups than in the New Zealand-born. It is higher still in the 'arrived in New Zealand aged 10 and older' group for the Gujarati and Dutch respondents.

- $26.3 \%$ of Dutch respondents who arrived in New Zealand aged 10 or older, report that they use a roughly equal mixture of Dutch and English

- $20.2 \%$ of Gujarati respondents in the same category use roughly equal amounts of Gujarati and English.

Amongst the Samoan respondents however, the use of a 50/50 mixture of Samoan and English is lower amongst the non-New Zealand-born and rises amongst the New Zealandborn to a third of the New Zealand-born respondents. This would seem to be another effect of the fact that language shift is less advanced amongst the New Zealand-born Samoan respondents. All the Dutch and most of the Gujarati New Zealand-born respondents have completed the shift to using English most of the time but because shift is not so far advanced amongst the Samoan respondents there are more of them who use both languages fairly equally. 


\subsubsection{New Zealand-born respondents}

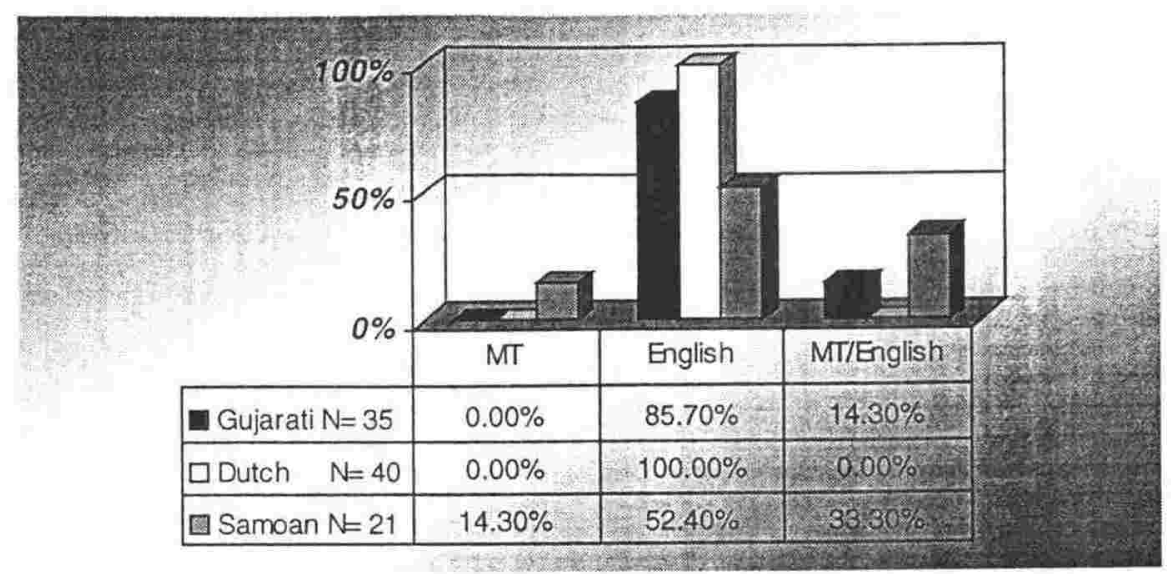

Figure 10-10: Language most used by respondents: All New Zealand-born respondents

Amongst the New Zealand-born respondents it is definitely the Samoan respondents who perceive themselves as using their MT most. All the Dutch respondents and most of the Gujarati respondents (85.7\%) report that English is the language they use most of the time.

However only just over half of the Samoan respondents think that this is the case. None of the Gujarati or Dutch respondents report that they use the MT most of the time but $14.3 \%$ of the Samoan respondents say that they use Samoan most of the time and, as already mentioned, a third of them use a roughly equal mixture of the two.

\subsubsection{Summary}

Language shift is usually taken to be a matter of the gradual encroaching of the dominant language into the territory of the MT.

Mastery of A [the dominant language] among Bs [the minority group] thus no longer serves merely as an indicator of social dependency upon and interactive frequency with As. But it also becomes a desideratum and, finally, a hallmark of leadership status within the B community itself. At this point, language spread becomes language shift. Ultimately this transition reaches the B family unit per se. Bs learn A not outside of the family context (in school, at work, "outside") but, precisely within the family context, from parents, older siblings and other adult relatives whose status within the family is enhanced by the fact that they have mastered A (Fishman 1966). Finally, Bs learn $\mathrm{A}$ as a mother tongue from $\mathrm{B}$-mother-tongue parents who have become $\mathrm{A}$ speakers (Fishman 1985: 60. Emphasis in original).

This data suggests that language shift, as described by Fishman, is more advanced in the Dutch and Gujarati communities and less advanced in the Samoan community. Below we will investigate in more detail the different domains in which this shift is occurring. 


\subsection{Language use in the last month}

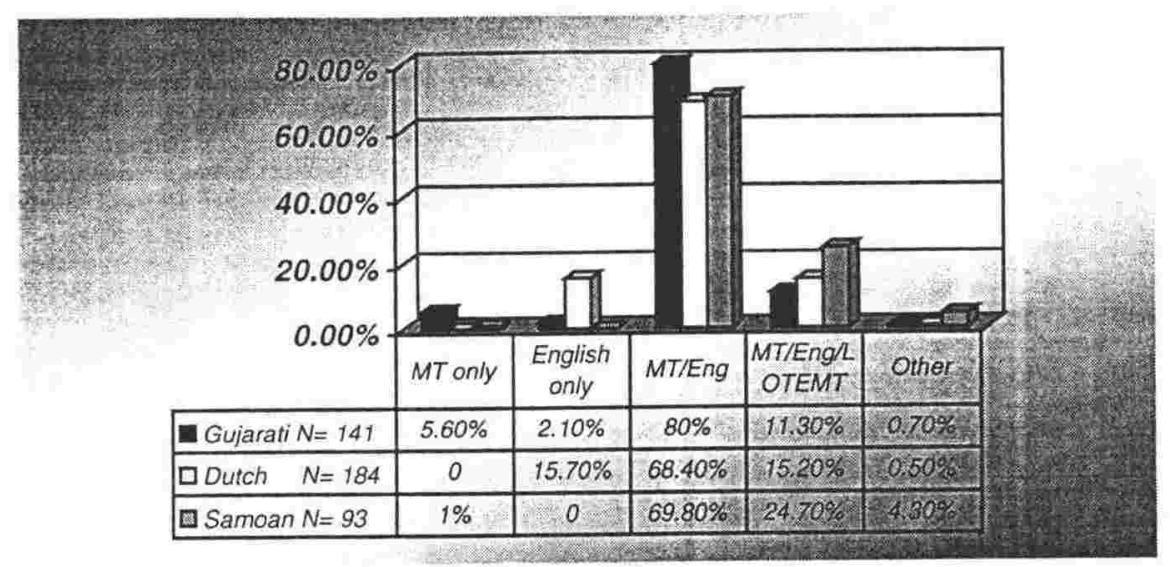

Figure 10-11: Language use in the last month: All respondents

Most respondents, as would be expected, had used both their MT and English in the month preceding the survey and for most respondents, these are the only two languages that they had used. However, there were some slight differences between the groups.

- $16.7 \%$ of Dutch respondents had used only English in the preceding month; most of these respondents were New Zealand-born

- $5.6 \%$ of Gujarati respondents had used only Gujarati

Interestingly, although the Samoan respondents are least likely to be trilingual, they are most likely to have used three languages in the last month.

- $24.7 \%$ of the Samoan respondents had used their MT, English and one or more languages, as had

- $15.2 \%$ of the Dutch respondents and

- $11.3 \%$ of the Gujarati respondents

Overall, in terms of present day patterns of language use, the communities are all still bilingual and even, to some extent multilingual. The Gujarati respondents to the present survey seem to be in a similar situation to those studied by Sridhar. (Sridhar draft:18) comments that most of the Gujarati respondents in her New York study spoke English at work and

interact[ed] socially on a regular basis primarily with members of their own language groups. During these get-togethers, the language of conversations is usually the ethnic tongue (Sridhar draft: 17). 


\subsubsection{Non-New Zealand-born respondents}

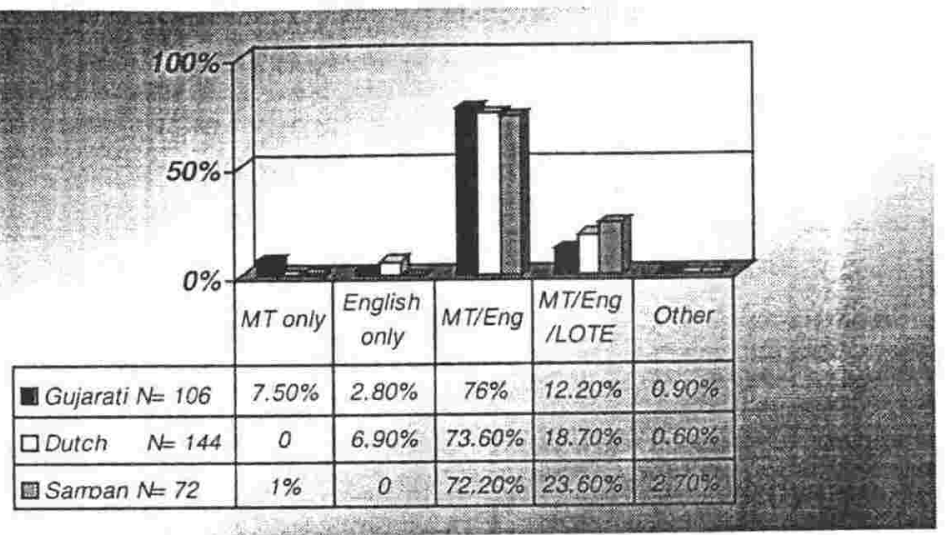

Figure 10-12: Language use in the last month: All non-NZ-born respondents

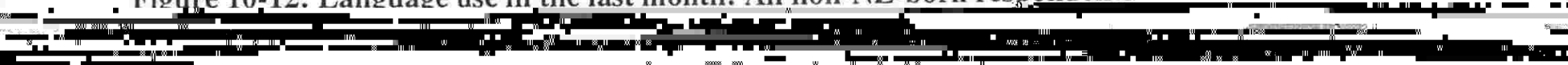
: n

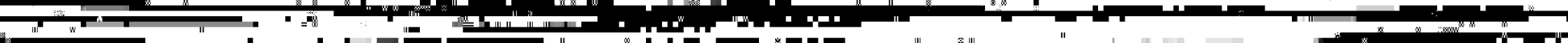

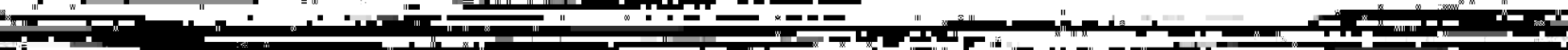

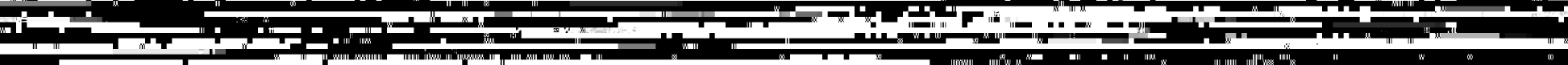

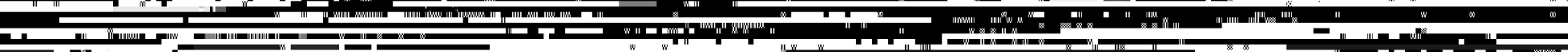

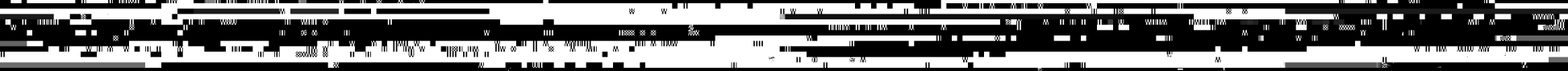

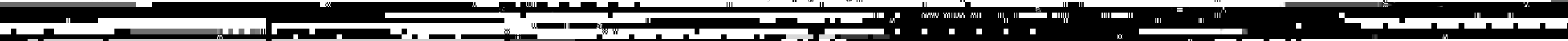

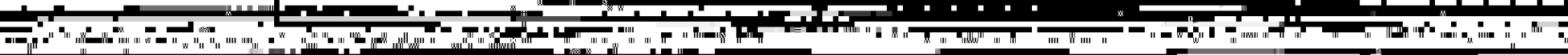

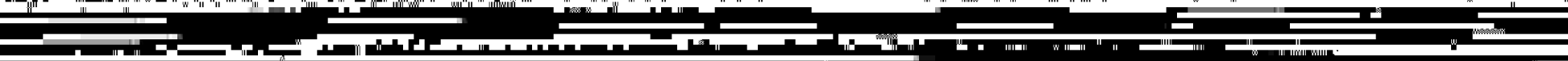

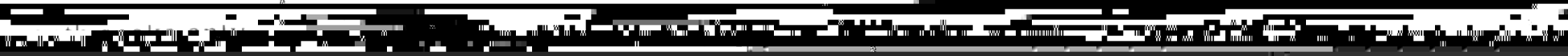

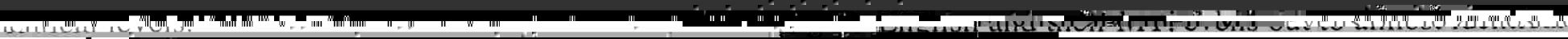

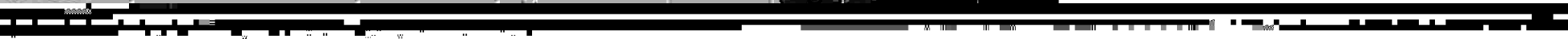

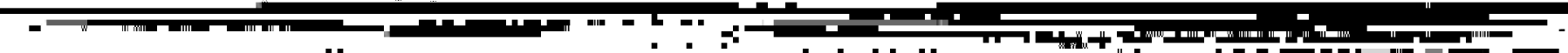
-

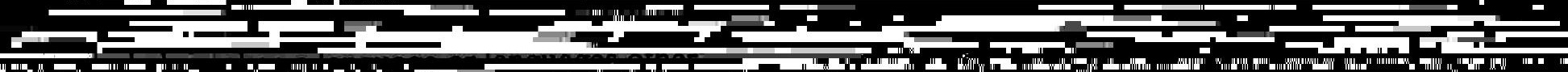

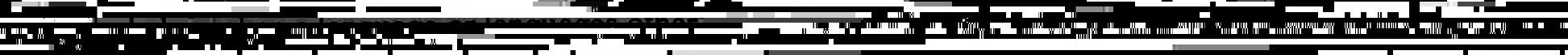

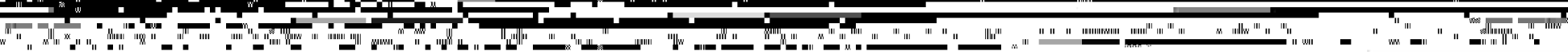

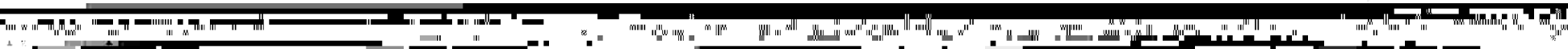

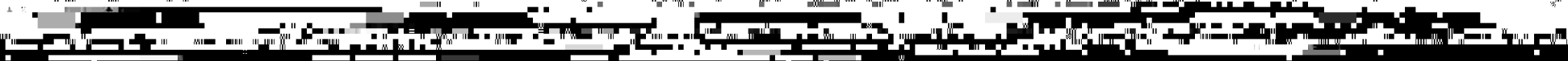

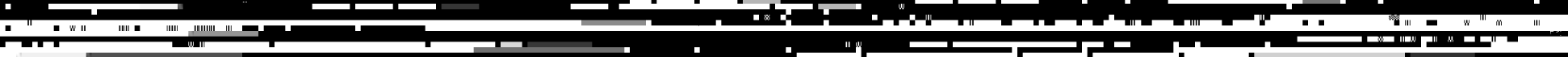
Cif

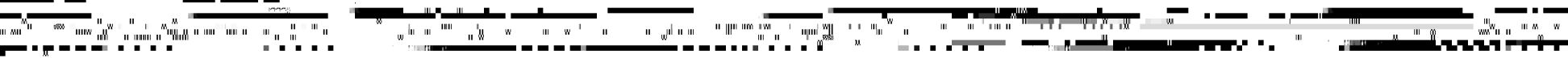


LMP did not examine their data by birthplace or age of immigration, but they found a similar high rate of MT use amongst their 'minority language speakers'. They found that

Across most of the local linguistic minorities, in those family settings where bilingual language use is a realistic possibility [which it was, in the current survey, for most of the respondents who arrived in New Zealand age ten or older] the majority of interactions do take place in the minority language rather than in English, and that it is very rarely that English is used to the total exclusion of the minority language (LMP 1985: 196).

\subsubsection{New Zealand-born respondents}

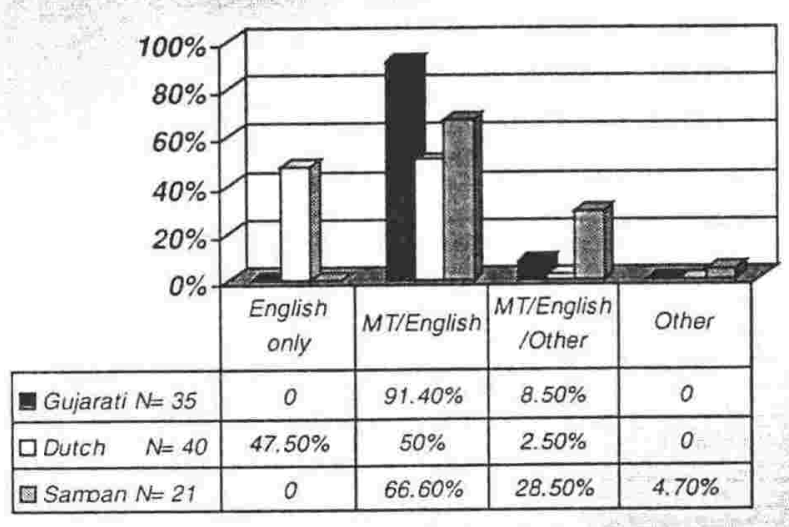

Figure 10-14: Language use in the last month: All New Zealand-born respondents

It is only once we turn to the New Zealand-born respondents that we see any significant differences in patterns of language use in the month preceding the questionnaire. Almost half the New Zealand-born Dutch respondents had used only English in the preceding month. None of the Gujarati or Samoan New Zealand-born respondents gave this response. Most of the Gujarati respondents (91.4\%) had used Gujarati and English in the month prior to answering the questionnaire and most of the New Zealand-born Samoan respondents had used either English and Samoan (66.6\%) or English, Samoan, and one or more other languages $(28.6 \%)$.

- $47.5 \%$ of the New Zealand-born Dutch respondents had used only English in the preceding month

- $100 \%$ of the New Zealand-born Gujarati respondents had used MT and English (and possibly other language/s) in the preceding month

- $95.3 \%$ of the New Zealand-born Samoan respondents had used MT and English (and possibly other language/s) in the preceding month

- $52.5 \%$ of the New Zealand-born Dutch respondents had used MT and English (and possibly other language/s) in the preceding month 
Exactly half the New Zealand-born Dutch respondents had used both Dutch and English (and no other language) in the month prior to answering the questionnaire. In her 1986 research into second-generation Dutch informants in Australia, Bennett asked her informants to 'describe their current use of Dutch in the four skill areas' of speaking, understanding, reading and writing (Bennett 1992: 58). Respondents to the current survey were asked simply if they had 'used' Dutch in the month prior to filling out the question. For purposes of comparison Bennett's 'speaking' category will be used as the most similar to the more global question presented to the New Zealand-born Dutch respondents. Bennett (1992: 58) found that $30 \%$ of the Australian-born respondents had 'sometimes' or 'often' used Dutch. Another 48\% 'rarely' used Dutch, but this seems at least likely to put the respondents outside the month time frame under consideration here. The percentage of New Zealand-born respondents who said that they had spoken only English in the month before answering the questionnaire (47.5\%) was more than double the percentage of Australian born respondents who said that they 'never' spoke Dutch (Bennett 1992: 58). It seems that Dutch use amongst the New Zealand-born respondents to this survey may well have been somewhat lower than Dutch use among the Australian-born respondents surveyed by Bennett.

The high rate of Gujarati use by the New Zealand-born Gujarati respondents seems to demonstrate a similar pattern to that found in Gujarati communities in South Africa (Desai 1994:6) and New York (Sridhar draft: 20-21). Both of these authors consider the Gujarati Indians to have had higher rates of MT maintenance than other Indian groups in their respective countries although they attribute this to different reasons. Desai suggests that the higher socio-economic status of Gujaratis as compared to other Indian groups in South Africa, is the explanation for successful language maintenance. She points out that this has meant that the Gujarati community could afford to hire vernacular teachers from India (Desai 1994:6). Sridhar on the other hand suggests that the lower educational level of the Gujarati mothers could be the reason for the greater rates of language maintenance in the Gujarati community (Sridhar draft: 20). Sridhar also points out that when her respondents were presented with the option of choosing the statement 'Children would be better off with English', only $19 \%$ of the Gujarati parents chose this option, compared with $36 \%$ of the Kannadiga parents and $80 \%$ of the Malayali parents (Sridhar draft: 22). 
There is less international data available for Samoan immigrant communities but in research done in 1984 in Wellington high rates of Samoan language competence were recorded amongst the Samoan children ${ }^{137}$ who were studied. Fairburn-Dunlop found that $78 \%$ of the children spoke Samoan fluently and another 13 percent 'were reasonably competent speakers' (Fairburn-Dunlop 1984: 101). Altogether 91\% of the children could speak Samoan well or fairly well. This is comparable both with the $100 \%$ of New Zealand-born respondents who said that they could speak Samoan and the $95.2 \%$ who said that they have used Samoan in the last month.

\subsubsection{Summary}

Once again it is clear that the Dutch community shows a greater rate of shift than the Gujarati or Samoan communities. Although all the first generation of immigrants in each group show quite a high degree of MT usage in conjunction with English usage, the picture is quite different when we turn to the New Zealand-born generation. MT usage is still high amongst the New Zealand-born Samoan and Gujarati respondents, but shift to English is considerable amongst the New Zealand-born Dutch respondents.

The importance of a range of measures for assessing habitual patterns of language use can be seen here. The figures in the previous section, showing language most used by respondents, gave the impression that MT use was still, comparatively, flourishing amongst the New Zealand-born Samoan respondents while declining at a roughly similar rate amongst the New Zealand-born Gujarati and Dutch respondents. The figures from this section showing language/s used in the month prior to responding to the questionnaire, do not contradict that picture, but they do refine it, showing that the shift is more absolute amongst the New Zealand-born Dutch than the New Zealand-born Gujarati respondents.

137 137 . Six of the 40 families studies had emigrated as families. In the remaining 34 families, the children had all been born in NZ (Fairburn-Dunlop 1984: 100) 
10.7 MT Language spoken outside the home

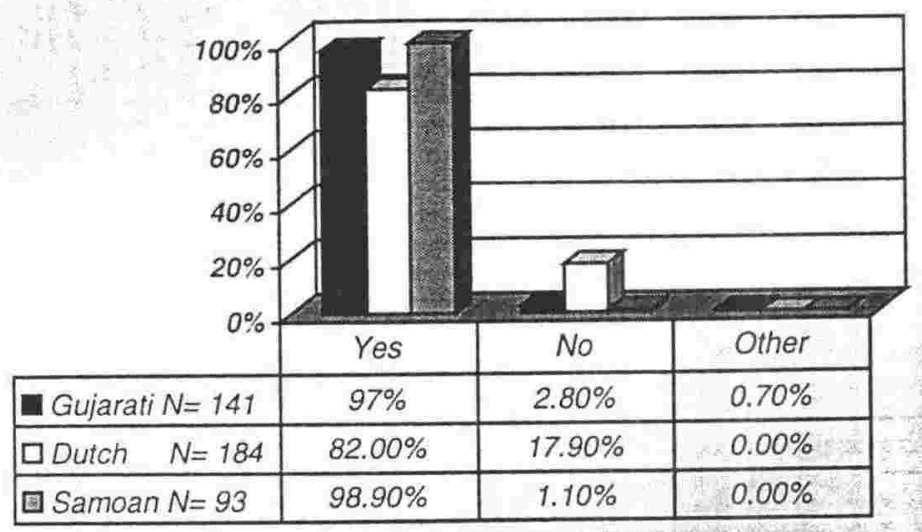

Figure 10-15: MT Language spoken outside the home: All respondents

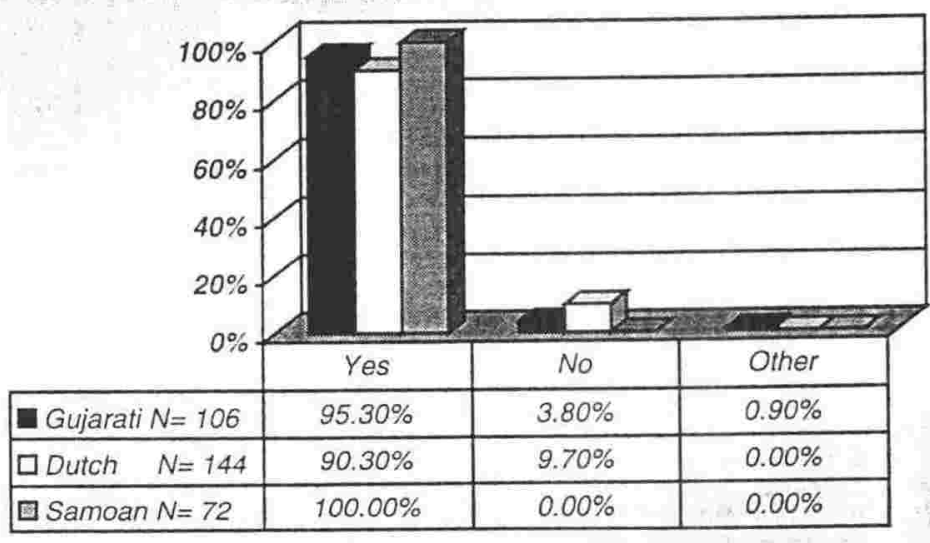

Figure 10-16: MT used outside home: All non-New Zealand-born respondents

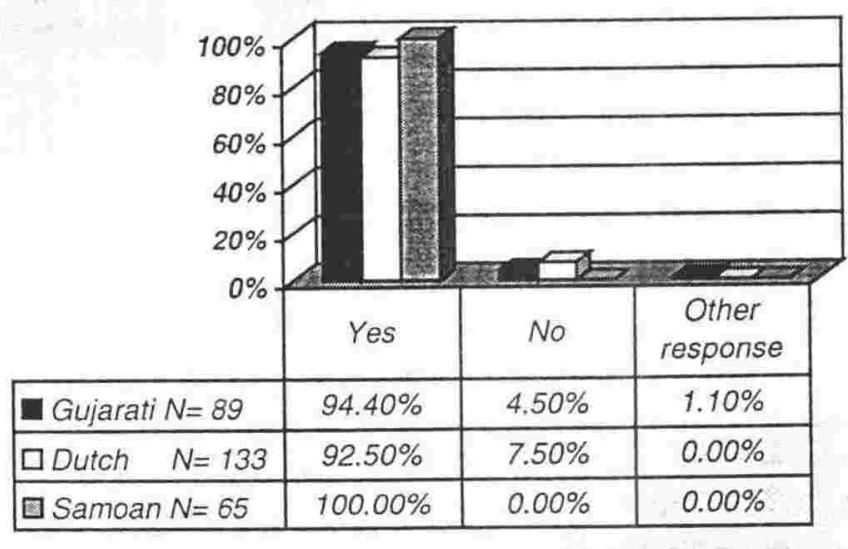

Figure 10-17: MT spoken outside home: All non-New Zealand-born respondents arrived in New Zealand $10+$

The non-New Zealand born respondents from all three groups were likely to use their MT outside the home, as indeed were the New Zealand-born Gujarati and Samoan respondents. It 
is only amongst the New Zealand-born Dutch respondents that there is a sizeable group of respondents $(47.5 \%)$ who do not use their MT outside the home.

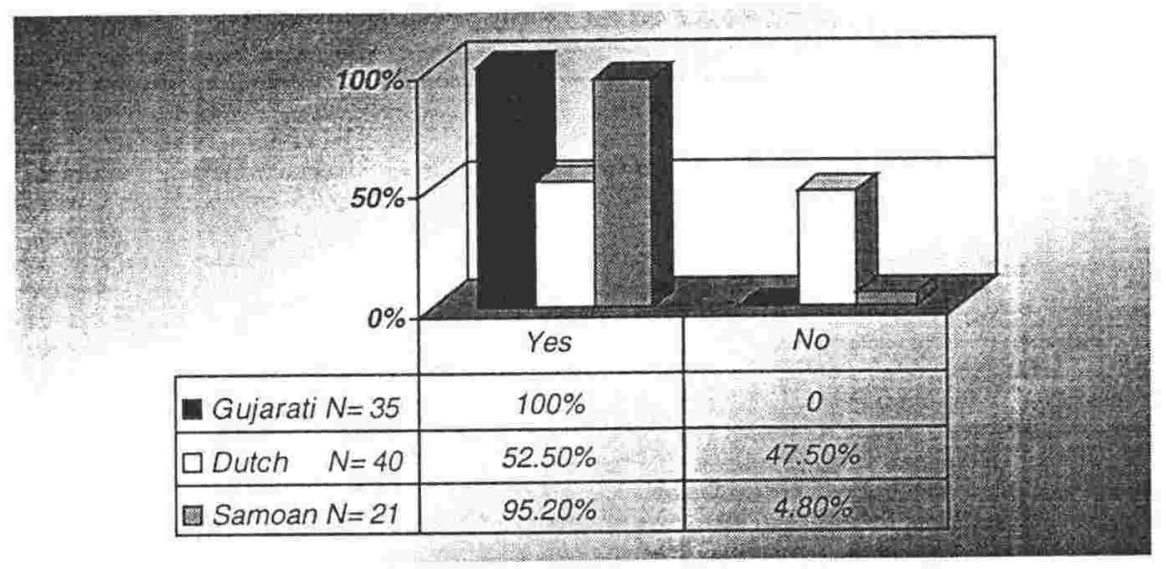

Figure 10-18: MT spoken outside home: All New Zealand-born respondents

Within the seeming similarity of usage in the Samoan and Gujarati (both New Zealand-born and non-New Zealand-born) groups, however, there is considerable variation to be seen, and the three groups considered as a whole or as non-New Zealand-born also show variation.

\subsubsection{MT use outside the home by domain}

When considering MT use outside the home in the light of where respondents spoke the MT, the whole group (regardless of birthplace) has been used for analysis. This gives some indication of the range of language use within the community as a whole and shows how all members of the community experience the possibilities for MT language use outside the home. This is followed by an analysis based on only the New Zealand-born respondents in order to give some idea of future ranges of MT language use within each community.

As can be seen below, MT language use in the Samoan community is still widespread in all the areas that respondents were asked about; there were high numbers of users at social gatherings and at church and most of the respondents used some Samoan in the workplace as well. It is particularly noticeable that MT language use at religious worship which was very low in the Dutch community and affected under a third of the Gujarati community, was almost universal amongst the Samoan respondents. This has been noted by others as an important factor in Samoan language maintenance in New Zealand.

Attendance at these churches indicated the way the migrants wished to live their lives, and the amounts of time spent within the all-Samoan programme these churches offered, had a profound effect on language maintenance. There were Bible Study groups, choir practices, men's and women's fellowships, sports afternoons, and the 
Mormon church ran English classes for second language learners. Families attending [certain churches] were also heavily involved in fundraising for building and modernization programmes. Tremendous sacrifices of time, money and effort were expended in fulfilling their family's obligations, and these extra engagements exposed the children even more to the Samoan language and customs. In addition, many of these churches ran Pastor's schools where the children received a systematic and deliberate instruction in the reading and writing of Samoan, using the Bible as the textbook of instruction ${ }^{1.38}$ (Fairbairn-Dunlop 1984: 108, see also Macpherson 1984: 115).

Amongst the Gujarati respondents MT use was very high at social gatherings but the workplace and Gita class were comparatively infrequently reported as sites of MT use. It must be noted that these low figures occur for opposite reasons however. Most of the sample are in paid employment but do not tend to use Gujarati at work. Most of the sample do not attend Gita class, but those who do, are likely to use Gujarati in that environment [personal communication Wellington Indian Association temple priest]. Amongst the Dutch respondents, social gatherings were also the most likely site of MT use outside the house. Work and church were a long way behind. Church was the least likely place (of the three named in the questionnaire) for MT use for the Dutch. Figures were not gathered on Church attendance. Most of the sample were in paid employment and did not use Dutch at work. Dutch immigrants were directly encouraged to join English-speaking congregations (see section 5.2.2) and it seems possible that more that $5 \%$ of the Dutch sample attended Church but that the churches would be English speaking. MT use in formal religious worship is certainly not a major part of the respondents' lives. Folmer in her 1990/1991 study noted that amongst her Dutch subjects '[i]n the domain of church the shift to English was considerable' (Folmer 1992: 10). It is often acknowledged that if religion provides a site for MT language use for an immigrant community this can strengthen the processes of language and cultural maintenance for the community (Clyne 1985: 199, Fairburn-Dunlop 1984; 107-08, Garner 1989: 215, Janik 1996:6, Macpherson 1984: 115).

\footnotetext{
13.. I can testify from my own experience of teaching at tertiary level that Samoan students can often give chapter and verse for a Biblical quotation whereas most of the other New Zealand students would be hard put to tell you whether you were quoting from the Bible or from secular literature.
} 
Table 10-23: Where respondents spoke their MT outside the home (all respondents)

\begin{tabular}{|l|c|c|c|}
\hline & $\begin{array}{c}\text { Gujarati } \\
\text { respondents }\end{array}$ & $\begin{array}{c}\text { Dutch } \\
\text { respondents }\end{array}$ & $\begin{array}{c}\text { Samoan } \\
\text { respondents }\end{array}$ \\
\hline At social gatherings & $90.8 \%$ & $64.7 \%$ & $87 \%$ \\
At work & $17 \%$ & $11.4 \%$ & $77.4 \%$ \\
At religious worship & $29.8 \%$ & $4.9 \%$ & $93.5 \%$ \\
$\mathrm{~N}=$ & 141 & 184 & 93 \\
\hline
\end{tabular}

Amongst the New Zealand-born, the figures decline in each category for the Samoan respondents, but there are some interesting twists amongst the Dutch and Gujarati New Zealand-born. For both groups, the percentage of respondents using the MT in the work place actually rises slightly by comparison with the group as a whole, only by one percentage point in the case of the Dutch but by almost 12 percentage points in the case of the Gujarati. The reasons for the increased use of Gujarati at work amongst the New Zealand-born respondents have been discussed in the section on Gujarati language use (7.2.6.1). One of the reasons suggested for this is simply that more of the non-New Zealand-born were retired. This, of course, is also true for the Dutch. Although the rate for MT use at work is low in both groups of Dutch respondents (all respondents and New Zealand-born respondents) it does not rise amongst the elderly as might be expected if retirement in the non-New Zealand-born group is one of the reasons for a rise. A tentative explanation as to why it does not rise might be that more Dutch clients (remembering that a lot of the Gujarati workplace use appeared to be client based) are likely to speak English, as are recently arrived Dutch visitors or immigrants. There is also the fact that fewer of the New Zealand-born Dutch speak their MT with confidence in comparison with the New Zealand-born Gujarati respondents. Folmer found that regardless of birthplace, the Dutch subjects she studied

usually spoke English [at work], so that non-Dutch-speaking colleagues could also take part in the conversation. All subjects accommodated to the language choice of Dutch clients (Folmer 1992: 10).

MT use at religious events remains stable between the two Dutch groups (all respondents and New Zealand-born respondents), but declines amongst the Gujarati New Zealand-born when compared with all the Gujaratis. MT use at social gatherings declines heavily amongst the Dutch New Zealand-born when compared to the whole group but amongst the New Zealandborn Gujarati respondents MT use at social gatherings actually increases slightly in comparison with the Gujarati group as a whole. The fact that fewer New Zealand-born Dutch respondents use Dutch at social events than do the Dutch respondents as a whole is, of course, 
because of the sizeable proportion (almost half) of the New Zealand-born respondents who do not use Dutch outside the home at all.

Table 10-24: Where respondents spoke their MT outside the home (New Zealand-born respondents)

\begin{tabular}{|l|c|c|c|}
\hline & $\begin{array}{c}\text { Gujarati } \\
\text { respondents }\end{array}$ & $\begin{array}{c}\text { Dutch } \\
\text { respondents }\end{array}$ & $\begin{array}{c}\text { Samoan } \\
\text { respondents }\end{array}$ \\
\hline At social gatherings & $94.3 \%$ & $37.5 \%$ & $80.9 \%$ \\
At work & $28.6 \%$ & $12.5 \%$ & $61.9 \%$ \\
At religious worship & $14.3 \%$ & $5 \%$ & $80.9 \%$ \\
$\mathrm{~N}=$ & 35 & 40 & 21 \\
\hline
\end{tabular}

Once again a pattern of accelerated decline amongst the Dutch respondents can be discerned. The Samoan community is still providing an environment in which it is possible to use Samoan in a wide range of circumstances (at least for some people). In the Gujarati community there might be fewer places where it is suitable to use Gujarati outside the home, but at least on Gujarati-centred social occasions, most New Zealand-born respondents will still use some Gujarati (the exact proportion, depends on the situation). Amongst the New Zealand-born Dutch however, MT use outside the home is comparatively unlikely, and the range of occasions on which it is likely to occur is limited. Respondents in all three groups could, of course, write in other options in addition to the three specified by the questionnaire and very few of the Dutch New Zealand-born respondents chose to do so.

In general these figures fall into the pattern which has become familiar; the Samoan respondents show, overall, the least attrition in terms of the range of places where they use their MT (it should be remembered that several of the Samoan respondents wrote in answers such as 'wherever I see Samoans' in response to this question) followed by the Gujarati respondents and then lastly, the Dutch, with the most limited range of MT usage. It is perhaps worth noting however, the slight anomaly in this familiar pattern: the New Zealand-born Gujarati respondents are slightly more likely than the New Zealand-born Samoan respondents to use their MT at social occasions. Although the numbers involved are small, and although the difference is fairly slight, nonetheless, it might be a sign of the Gujarati community's longer experience of cultural and language maintenance. That is, as a community that has successfully maintained a certain level of linguistic and cultural competence over several generations in New Zealand, the Gujarati community might be more practiced in providing occasions for its locally-born members where MT use is common. Clyne makes a similar point in a discussion of core value 
If a culture regards language as central to ethnicity, it is likely to be maintained as a matter if policy rather than merely in an instrumental way (for communicative purposes). So functions will be found for its use (Clyne 1985: 199).

The responses of the Gujarati respondents to the questionnaire give a picture of an immigrant Gujarati community similar to that described by Sridhar in her discussion of Gujaratis in New York. Gujarati is widely used outside the home at social and religious occasions but there is a fair amount of code-mixing with English (Sridhar draft: 10,17,18).

\subsubsection{MT use outside the home by interlocutor}

In this section the two groups considered are the non-New Zealand-born respondents and the New Zealand-born respondents, as the focus is on individual responses rather than opportunities for group use.

Amongst the non-New Zealand-born respondents MT use outside the home still occurred with a fairly wide range of interlocutors. There were relatively few respondents in any of the three groups who confined their MT use only to those older than they were or to recent immigrants. Most of the non-New Zealand-born respondents at least used their MT outside the home to friends their own age as well as to other interlocutors. If we take MT use to interlocutors younger than oneself as a sign of a healthy language maintenance situation in which intergenerational transmission is occurring we can see that, not unexpectedly, the Samoan community is in better shape than the Gujarati and Dutch communities. Slightly less expected perhaps, is that the Dutch and Gujarati respondents were roughly similar in the way in which they responded to this question. A solid majority of non-New Zealand-born Samoan respondents spoke their MT to those younger than themselves, but under half of the non-New Zealand-born Gujarati and Dutch respondents used their MT to those younger than themselves outside the home. 
Table 10-25: Respondents' MT interlocutors outside the home (non-New Zealand-born respondents)

\begin{tabular}{|l|c|c|c|}
\hline Interlocutors & Gujarati & Dutch & Samoan \\
\hline Only older \& immigrants & $10.3 \%$ & $10.4 \%$ & $2.7 \%{ }^{139}$ \\
Younger and others & $42.5 \%$ & $37.5 \%$ & $83 \%$ \\
'Own age' and others & $83 \%$ & $70.8 \%$ & $81.9 \%$ \\
$\mathrm{~N}=$ & 106 & 144 & 72 \\
\hline
\end{tabular}

Amongst the New Zealand-born respondents, the Gujarati and the Dutch respondents exhibit differing patterns of use. The Samoan respondents continue to show the strongest rates of MT language use. Very few of the New Zealand-born Samoan respondents speak their MT with older people or immigrants only, outside the home whereas this is the case for almost half the Gujarati respondents. There appears to be a smaller proportion of Dutch respondents who spoke their MT to older people or immigrants only but in fact the smaller percentage is merely a reflection of the fact that all the New Zealand-born Gujarati respondents (and virtually all the New Zealand-born Samoan respondents) did speak their MT outside the home whereas only just over half of the Dutch New Zealand-born did so. Of those New Zealandborn Dutch respondents who did speak their MT outside the home, $61.9 \%$ of them spoke only to immigrants or those older than themselves.

A tiny handful of New Zealand-born Dutch respondents spoke their MT outside the home with interlocutors who were their own age or who were younger than themselves. Amongst the Samoan respondents a substantial proportion were still using Samoan outside the home with friends their own age but usage was declining somewhat with those who were younger than themselves. A similar pattern can be seen amongst the New Zealand-born Gujarati respondents although the proportion of Gujarati respondents speaking their MT to interlocutors their own age or under was considerably smaller than was the case for the New Zealand-born Samoan respondents. Under half the Gujarati respondents used their MT outside the home with friends their own age or with those younger than themselves. Both the Samoan New Zealand-born and the Gujarati New Zealand-born respondents showed that that MT use with the younger generation outside the home was declining. Amongst the Dutch, it had virtually ceased altogether. 13\%. These two respondents also spoke Samoan with their minister. There were no Samoan respondents who only spoke to
older people and immigrants. 
Table 10-26: Respondents' MT interlocutors outside the home (New Zealand-born respondents)

\begin{tabular}{|l|c|c|c|}
\hline Interlocutors & Gujarati & Dutch & Samoan \\
\hline Older \& immigrants & $45.7 \%$ & $32.5 \%$ & $14.2 \%$ \\
Younger and others & $31.4 \%$ & $7.5 \%$ & $61.9 \%$ \\
'Own age' and others & $40 \%$ & $10 \%$ & $71.4 \%$ \\
$\mathrm{~N}=$ & 35 & 40 & 21 \\
\hline
\end{tabular}

\subsubsection{Summary}

The MT is used outside the home by virtually all the respondents except for $47.5 \%$ of the New Zealand-born Dutch. The range of domains and interlocutors is, however, shrinking considerably for all groups except, perhaps, the non-New Zealand-born Samoans. Amongst the New Zealand-born respondents, MT use with interlocutors their own age or younger has almost ceased amongst the Dutch, is declining amongst the Gujaratis, but is still quite strong amongst the Samoans.

\subsection{Conclusion: language use data}

Sections 10.2 to 10.7 have examined a range of measures of degree of bilingualism/multilingualism. These measures have assessed which language was acquired first by respondents, which is/are most used, which are frequently (within a one month timespan) used and locales or institutions in which they are spoken: home, work, religious institutions, social gatherings. The same measures that served to assess degree of bi/multilingualism also help to establish patterns of habitual language use and in order to add to our understanding of patterns of habitual language use, the interlocutors with whom respondents use the MT were examined. The relationship of bi/multilingualism to MT fluency both in the respondent and the respondent's children was also investigated. Multilingualism on the part of the respondent was found to be related to higher assessments of MT fluency both in respondents and in their children. The analysis of the data in sections 10.2 to 10.7 also showed that there is not a straightforward progression from Samoan to Gujarati to Dutch in which language behaviours that relate to or affect language maintenance show a steady change for the worse in terms of language maintenance within those three communities. As mentioned in section 10.6.3, the figures from the question about language/s most used suggest that the rate of decline in MT use amongst New Zealand-born Dutch and Gujarati respondents is similar, and that MT use in both communities is declining faster than amongst the New Zealand-born Samoan respondents. This is partly true, but the figures regarding language use in the last month show that the New Zealand-born Gujarati are more likely to have used their 
MT in that time than the New Zealand-born Dutch respondents. Similar complex patterns are displayed in the other data in this section. The New Zealand-born Gujarati are more likely to have spoken their MT as a first language than the New Zealand-born Samoan or Dutch respondents and more likely to use their MT outside the home at social occasions than the Samoans or Dutch. However, the New Zealand-born Gujarati respondents are more likely than the Samoans to rate themselves as using mainly English. Both the New Zealand-born Samoan and Gujarati respondents are considerably more likely to use their MT outside the home than the Dutch (all the Gujaratis, virtually all the Samoans). On the other hand, fewer than half the non-New Zealand-born Dutch and Gujarati respondents used their MT to people younger than they whereas $83 \%$ of the non-New Zealand-born Samoan respondents did so.

It can clearly be seen that language shift is more advanced in the Dutch community than amongst the Gujaratis and Samoans. The demarcations between the progress of language shift in the Gujarati and Samoan communities are, however, far from clear.

\subsection{Language proficiency self-ratings}

The foregoing part of this chapter has examined the issue of MT performance, where and with whom the MT is spoken. The following section examines the issue of MT (and English and third language) competence; how do the respondents rate their abilities in these languages. The issue of competence is clearly a vital one in the area of language maintenance and shift for at least two reasons. In the first case, degree of competence is obviously diagnostic for the process of language shift. If there are fluent MT speakers throughout all the age ranges of the community then language shift is less advanced than if only the older members of the community can speak it. Secondly, if language maintenance or language revival is the aim of the community then if there are competent speakers of the MT, either or both goals are than much easier to achieve. 


\subsubsection{Oral proficiency in MT}

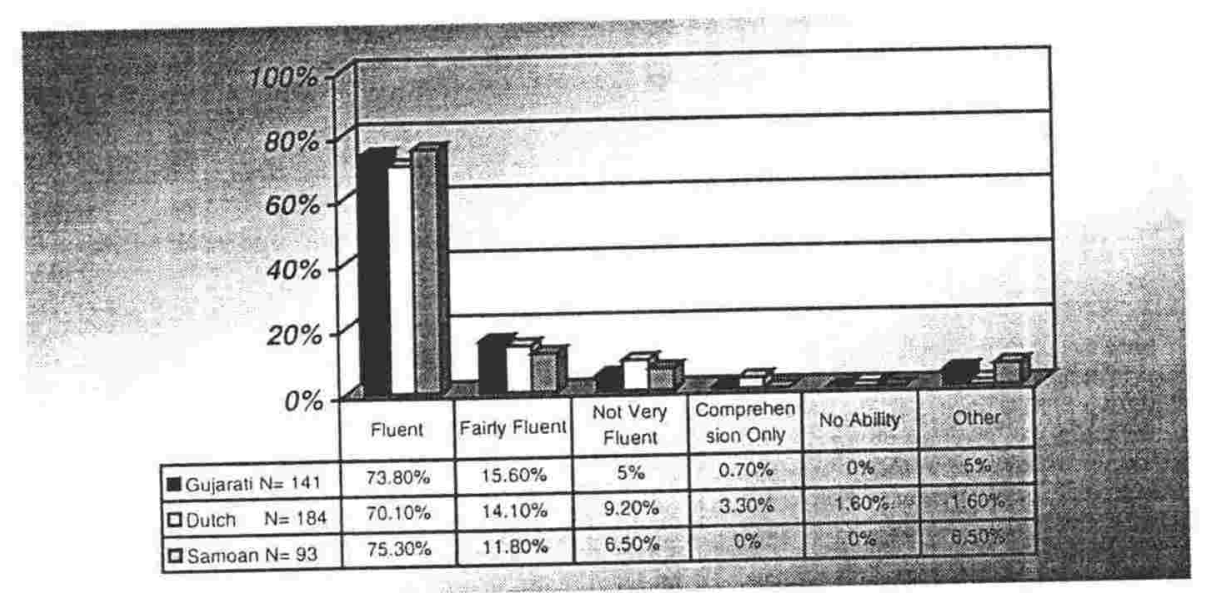

Figure 10-19: Oral proficiency in MT: all respondents

Each of the three groups is similar to the others in terms of oral proficiency self-assessment ratings. This is because roughly three-quarters of the respondents in each group are born outside New Zealand and are confident speakers of their MT. Turning to those respondents born in New Zealand however, a more varied pattern emerges.

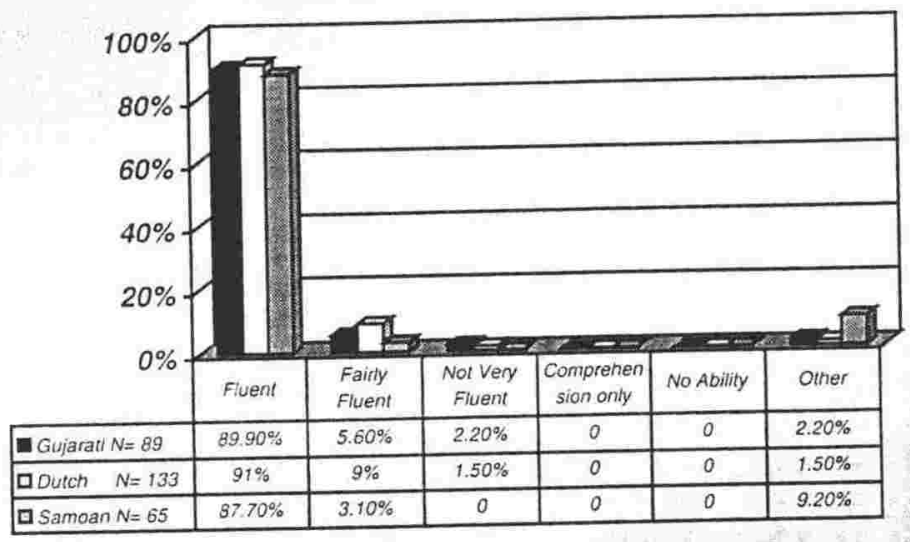

Figure 10-20: Oral proficiency in MT: all non-New Zealand-born respondents who came to New Zealand 10+ 


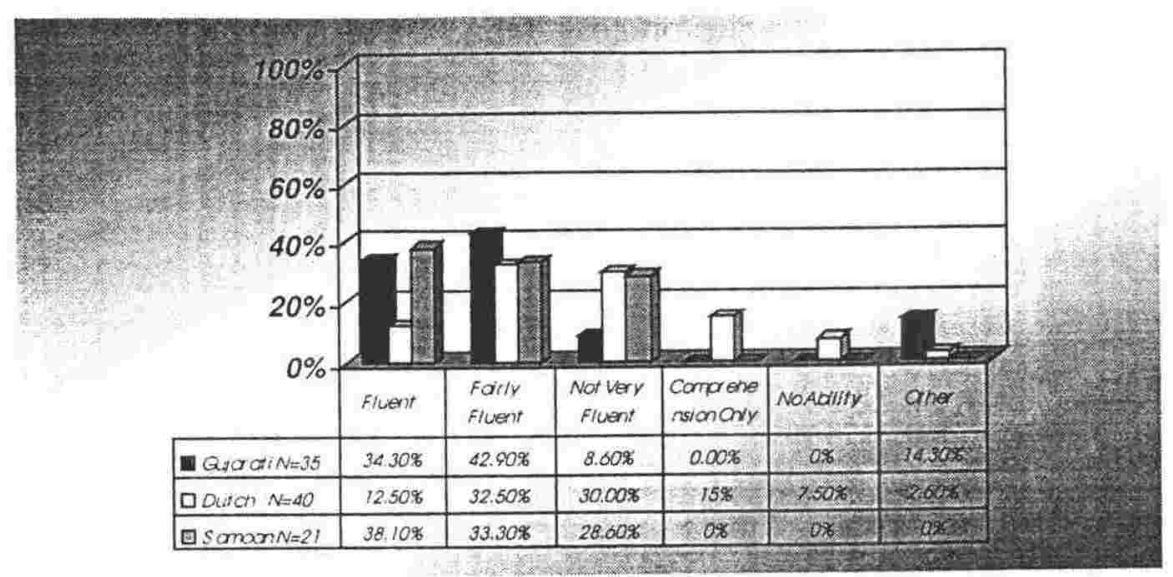

Figure 10-21: Oral proficiency in MT: New Zealand-born respondents

The New Zealand-born Dutch respondents are noticeably less confident of their MT speaking abilities. Only $12.5 \%$ of the New Zealand-born Dutch respondents think that they are 'fluent' speakers of Dutch whereas over a third of both the Gujarati and Samoan New Zealand-born respondents are prepared to asses themselves at this level. Even if we add assessments of 'fluent' and 'fairly fluent' together the Dutch are still noticeably less confident

- $45 \%$ of New Zealand-born Dutch respondents assessed themselves as being 'fluent' or 'fairly fluent'

- $71.4 \%$ of the New Zealand-born Samoan respondents assessed themselves as being 'fluent' or 'fairly fluent'

- $77.2 \%$ of the New Zealand-born Gujarati respondents assessed themselves as 'fluent' or 'fairly fluent'

As might be expected, the Dutch also show up in the 'can't speak but can understand' category' as well as 'can't speak or understand'; options that were not chosen by any of the Gujarati or Samoan New Zealand-born respondents.

It is also worth noting that very few New Zealand-born Gujarati respondents show up in the 'not very fluent' category (8.6\%) whereas almost a third of the New Zealand-born Dutch and Samoan respondents placed themselves in this category.

The figures for the Dutch respondents are similar to those for Canadian Ukrainians in Chumak-Horbatsch's study. She reports that $83 \%$ of the first generation reported fluency in Ukrainian (similar to the findings reported here) but that only $15 \%$ of the second generation reported that they were fluent in Ukrainian (Chumak-Horbatsch 1987:102). Demos, researching Greek Orthodox Americans, reported a pattern similar to that found in this survey for the Gujarati and Samoan respondents; $83 \%$ of the first generation reported that they spoke Greek 'well' as did 33\% of the second generation (Demos 1988:66). Once again, it is obvious 
that immigrant language shift is not a straightforward process, rates of shift can vary markedly for different groups in different situations.

\subsubsection{Oral proficiency in English}

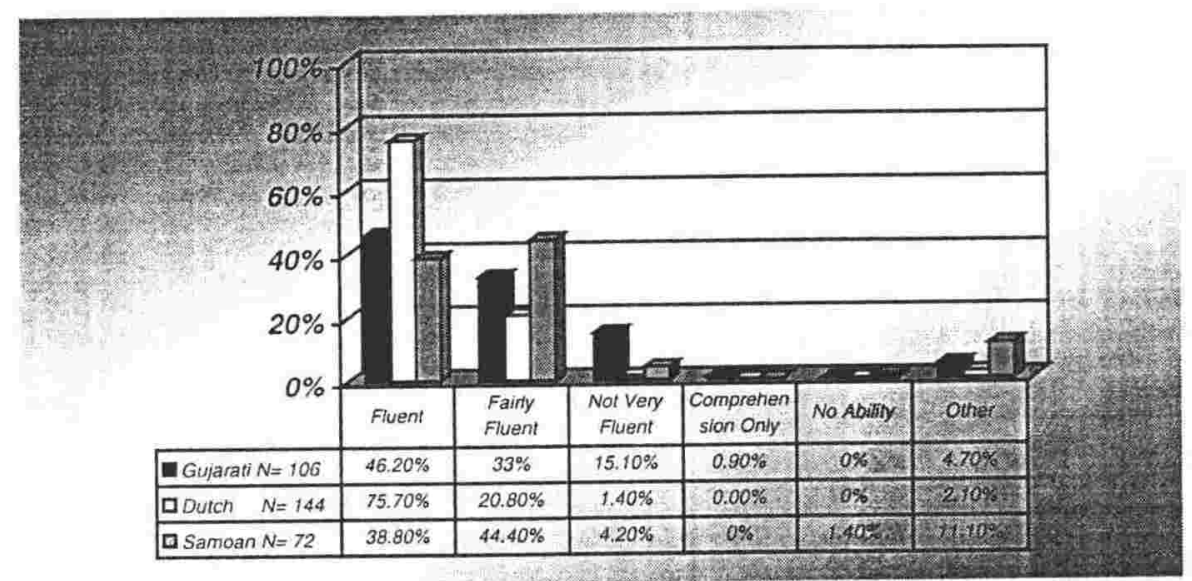

Figure 10-22: Oral proficiency in English: Non-New Zealand-born respondents

Looking at respondents' proficiency in English, the pattern is strikingly different. The Dutch are by far and away the most confident raters of English speaking abilities (suggesting that their low rating as speakers of Dutch was not simply due to modesty); the New Zealand-born Dutch were the only group of New Zealand-born respondents in which all members of the group rated themselves as 'fluent' speakers of English). More Dutch respondents thought they were 'fluent' in English than in Dutch.

- $80.9 \%$ of Dutch respondents thought they were 'fluent' in English

- $70.1 \%$ of Dutch respondents thought they were 'fluent' in Dutch

The Dutch formed the only group in which more respondents thought they were fluent in English than in their MT.

- $73.8 \%$ of Gujarati respondents thought they were 'fluent' in Gujarati

- $54.6 \%$ of Gujarati respondents thought they were 'fluent' in English

- $75.3 \%$ of Samoan respondents thought they were 'fluent' in Samoan

- $49.4 \%$ of Samoan respondents thought they were 'fluent' in English 


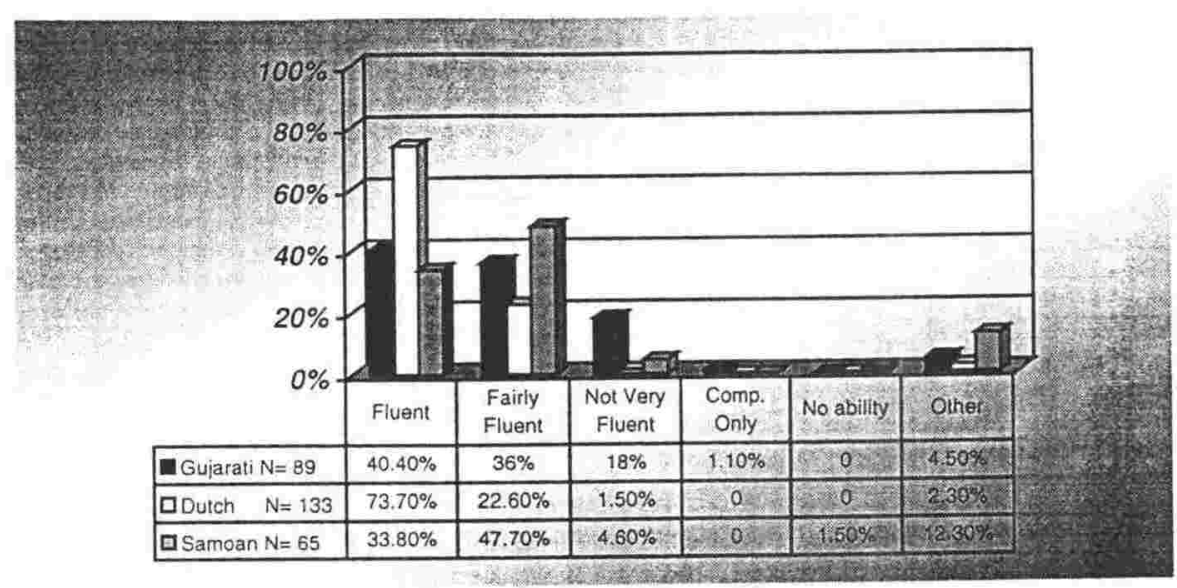

Figure 10-23: Oral proficiency in English: all non-New Zealand-born respondents who arrived in New Zealand 10+

\subsubsection{Oral proficiency in third languages}

The Dutch were not asked to rate their proficiency in a third language because it was not possible to nominate one third language that was relevant to the whole group, but undoubtedly there would have been some of the many multilingual non-New Zealand-born Dutch respondents who were fluent in their third or even fourth languages.

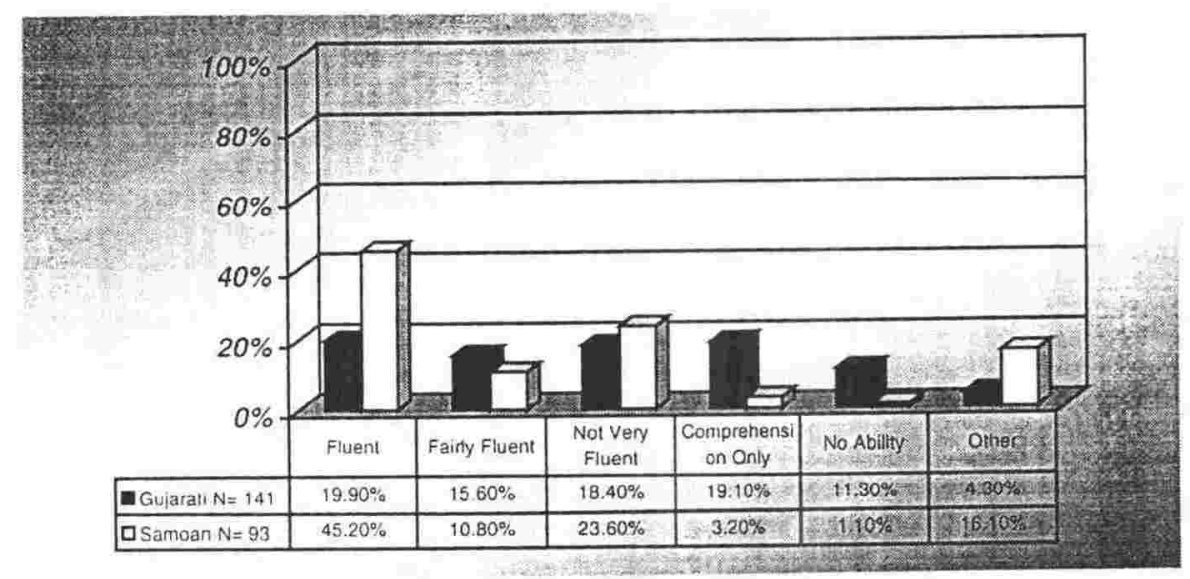

Figure 10-24: Oral proficiency in Hindi compared with Formal Samoan: all Gujarati and Samoan respondents 


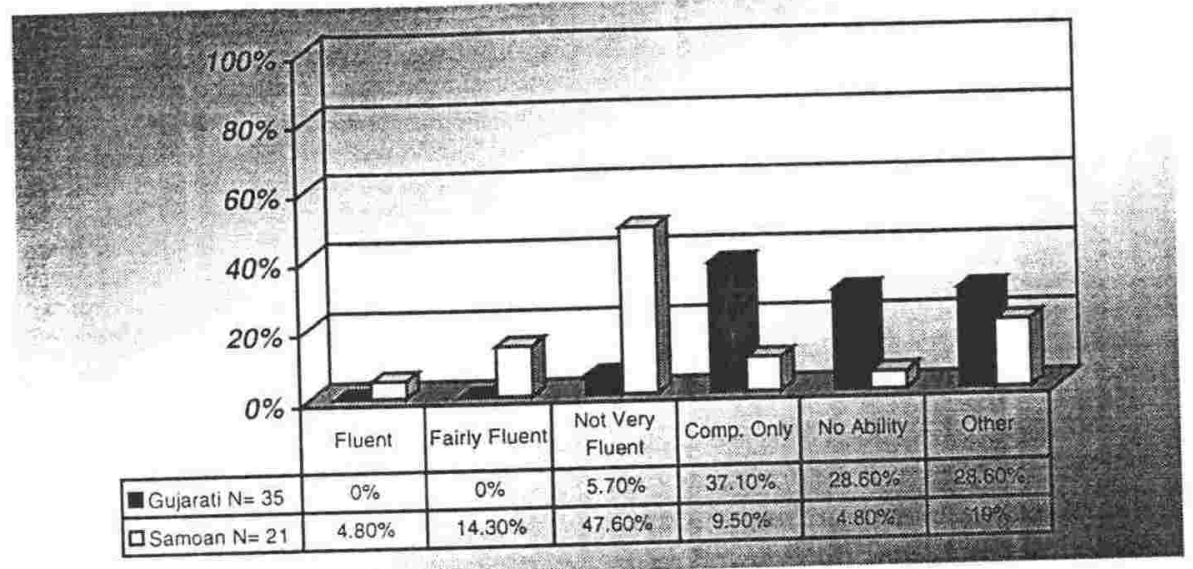

Figure 10-25: Oral proficiency in Hindi and Formal Samoan: New Zealand-born Gujarati and Samoan respondents

It is noticeable that the New Zealand-born Samoan respondents are considerably more confident about their Formal Samoan skills than the New Zealand-born Gujarati respondents are about their Hindi skills. This is at least partly explained by the fact that Hindi and Gujarati are different languages with different writing systems whereas Formal Samoan is, in effect, acquired, at least partially in the process of learning to read and write Samoan. New Zealandborn Samoans who go to Samoan school in New Zealand learn to read and write Formal Samoan whereas New Zealand-born Gujaratis, if they go to MT classes, learn to read and write Gujarati, not Hindi. It may also be related to the fact that more of the non-New Zealandborn Samoan respondents are 'fluent' in formal Samoan than non-New Zealand-born Gujaratis are 'fluent' in Hindi. However although there are no 'fluent' or 'fairly fluent' speakers of Hindi amongst the New Zealand-born Gujarati respondents there is a substantial minority (42.8\%) who have some Hindi skills, either comprehension skills or 'not very fluent' speaking skills.

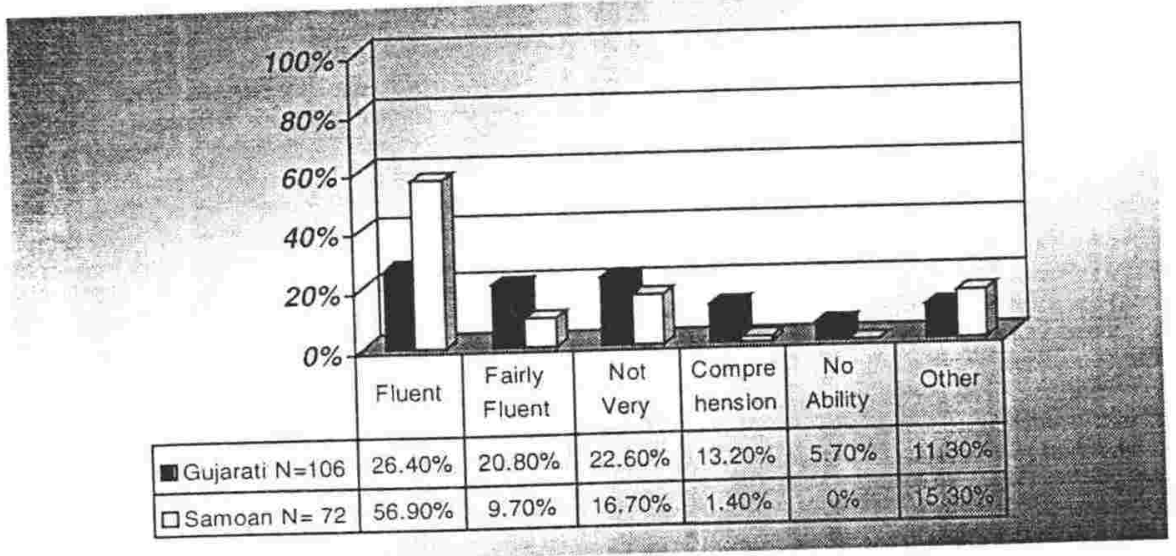

Figure 10-26: Oral proficiency in Hindi and Formal Samoan: all non-NZ-born Gujarati and Samoan respondents 
Amongst the non-New Zealand-born Gujarati and Samoan respondents the same pattern shows up, the Gujarati speakers are less confident raters of their fluency in the third language. Overall however, roughly similar proportions of respondents in both groups rate themselves as being able to speak the third language to some extent

- $83.3 \%$ of the non-New Zealand-born Samoan respondents are either 'fluent', 'fairly fluent' or 'not very fluent' in Formal Samoan

- $77 \%$ of the non-New Zealand-born Gujarati respondents either 'fluent', 'fairly fluent' or 'not very fluent' in Hindi

It is noticeable though, that a greater proportion of Gujarati respondents is in the "fairly fluent' and 'not very fluent' categories.

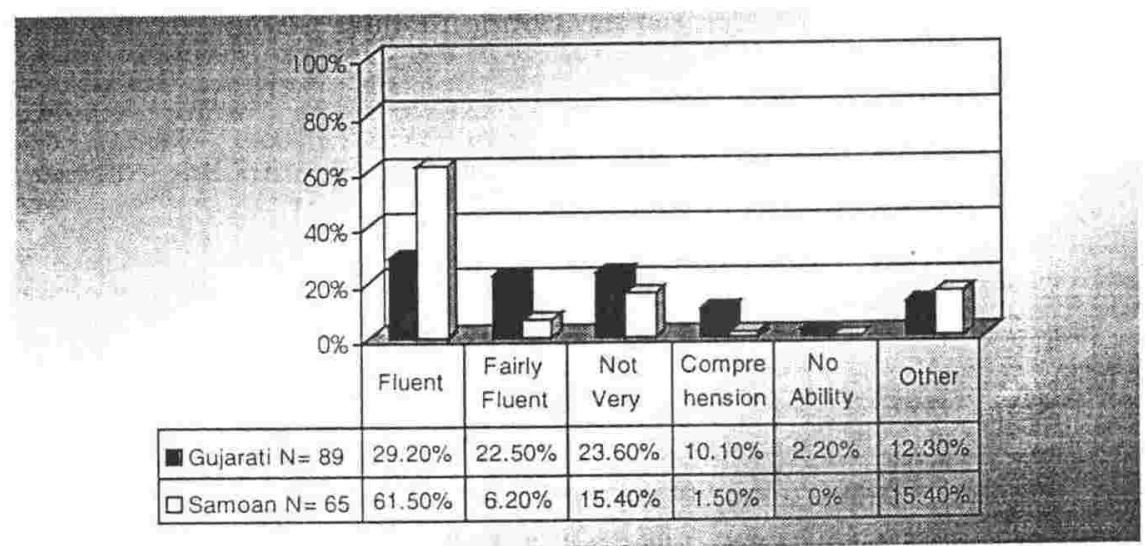

Figure 10-27: Oral proficiency in Hindi and Formal Samoan: all non-NZ-born Gujarati and Samoan respondents who arrived in New Zealand $10+$

\subsubsection{Summary: oral proficiency}

At a superficial glance, the three communities are the same in terms of MT competence. The preponderance of homeland-born and raised respondents ensures an overall high level. Turning to the New Zealand-born respondents however, a high rate of language shift can be discerned amongst the Dutch. They are less likely to be confident speakers of Dutch and some have no MT ability at all. Amongst the Gujarati and Samoan New Zealand-born respondents everyone has some measure of MT ability and a high proportion of each group rated themselves as 'fluent' or 'fairly fluent'. A third of the Samoan respondents however, rated themselves as 'not very fluent' (only $8 \%$ of the New Zealand-born Gujarati respondents chose this option), suggesting a greater rate of shift in MT oralcy amongst the New Zealand-born Samoans than amongst the New Zealand-born Gujarati respondents. Rate of proficiency amongst the children of Samoan and Gujarati respondents (the Dutch were not asked this question) can be seen in section 11.6 and show that the MT skills of Samoan children are rated more highly by their parents than the MT skills of Gujarati children. 
Most of the non-New Zealand-born are fluent MT speakers. The non-New Zealand-born Dutch are also highly likely to be 'fluent' in English. A greater proportion of the non-New Zealand-born Gujarati and Samoan respondents is likely to be rated as 'fairly fluent' speakers of English. This confident attitude to English on the part of the Dutch respondents may be related to the high rate of language shift in the community. More research needs to be done, but given the importance of attitude in the area of language use of all kinds, it seems likely that high confidence in English competence is related to language shift and that conversely, comparatively low confidence in English abilities is related to MT maintenance.

Most of the non-New Zealand-born Gujarati and Samoan respondents have some (often limited) ability in Hindi and formal Samoan. There are some 'fluent' and 'fairly fluent' speakers of formal Samoan amongst the New Zealand-born Samoan respondents but none of the New Zealand-born Gujarati respondents can speak Hindi fluently.

\subsection{Literacy skills in MT}

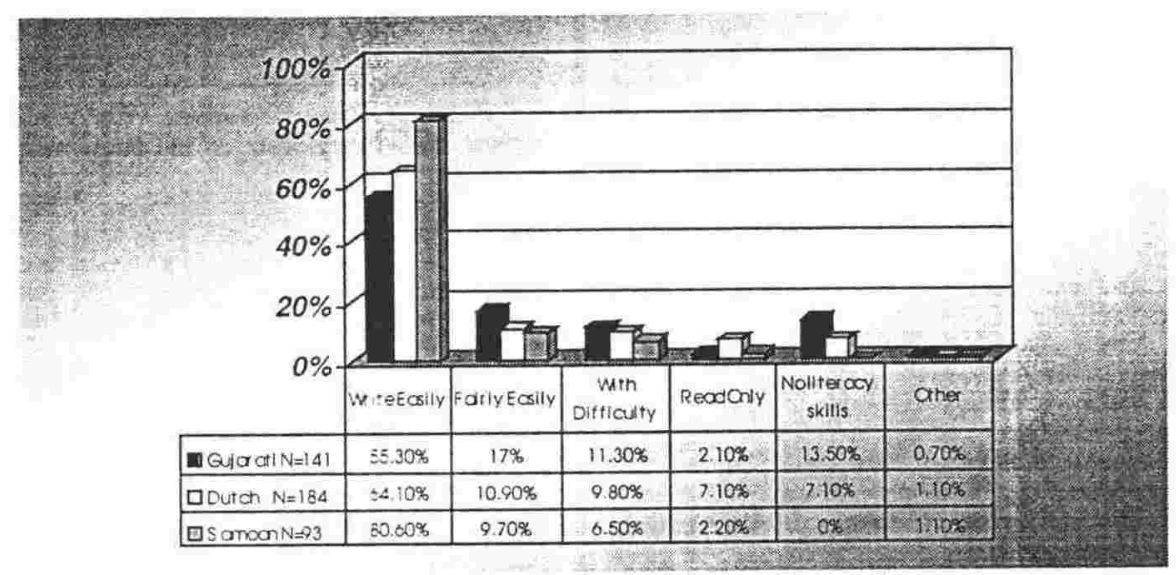

Figure 10-28: Literacy proficiency in MT: all respondents

All three communities have, as communities, reasonably high levels of MT literacy ranging from the Gujaratis at the lowest end, through the Dutch to the Samoan respondents at the highest end.

- $55.3 \%$ of the Gujarati respondents could write their MT 'easily'

- $64.1 \%$ of the Dutch respondents could write their MT 'easily'

- $80.6 \%$ of the Samoan respondents could write their MT 'easily'

Adding together all the respondents in each group who said that they could write 'easily', 'fairly easily' or 'with difficulty' shows that

- $96.8 \%$ of the Samoan respondents could read and write their MT

- $84.8 \%$ of the Dutch could read and write their MT 
- $83.6 \%$ of the Gujarati respondents could read and write their MT

If we add in those who said they could read but not write their MT then the numbers are very high indeed. All the Samoan respondents had some ability to read or write Samoan (there was one 'no response' to this question). Most of the Dutch (91.9\%) and the Gujarati respondents $(85.7 \%)$ fell into this category as well.

These figures, of course, are for all the respondents including those born in New Zealand and this reduces the overall levels of literacy, especially amongst the Gujarati and Dutch respondents.

In order to have some idea of the comparative levels of literacy amongst those members of the community who are immigrants to New Zealand, it is useful to look at literacy ratings given by those respondents who immigrated here at ten years of age or older. It is assumed that those who arrived here under the age of ten would not have had the opportunity to become fully literate before leaving their own country. Of course, not every immigrant who arrives in New Zealand ten years old or older, is fully literate in their MT, but it was not the intention of this study to gather a detailed literacy history of each of the 418 respondents and the age of ten is being used as an, admittedly crude, dividing line.

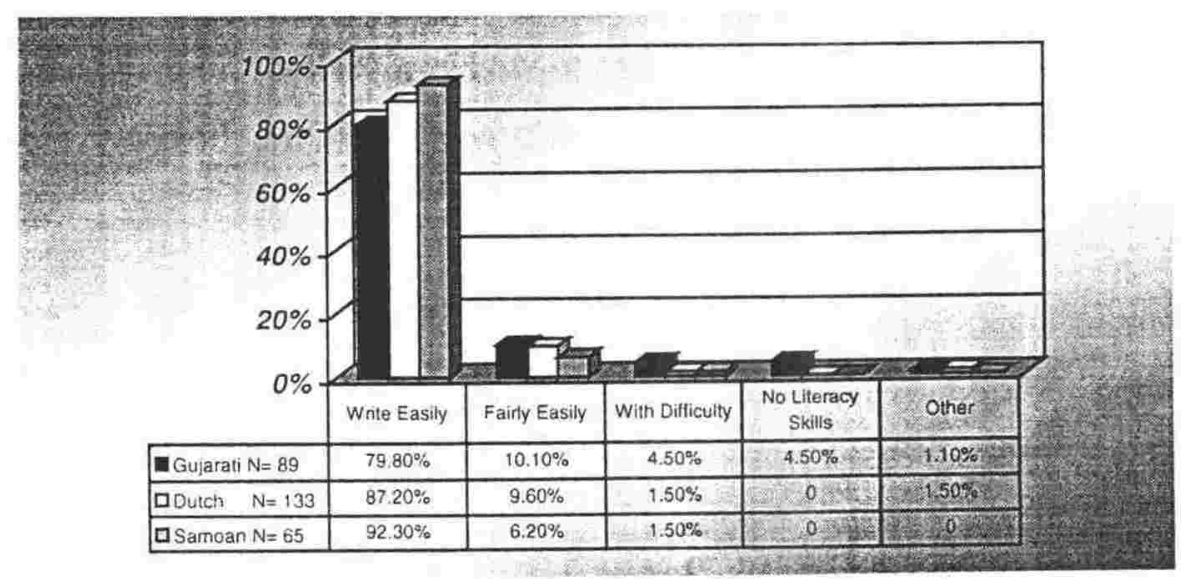

Figure 10-29: Literacy proficiency in MT: all non-New Zealand-born respondents who arrived in New Zealand 10 years old or older

It can immediately be seen that the differences in literacy abilities, as rated by the respondents decline noticeably once we look only at respondents who arrived in New Zealand at 10 years of age or older. In fact all the Dutch (excluding $1.5 \%$ who gave 'no response') and all the Samoans can read and write their MT 'easily', 'fairly easily' or 'with difficulty'. Amongst the non-New Zealand-born Gujarati respondents who arrived in New Zealand at ten years of age 
or older, most of them $(94.4 \%)$ rated themselves in one of those three categories but the response of one person was unclear and four respondents were illiterate in their MT. The Gujarati respondents were the only group in which this was the case. One of these respondents was a woman over 60 who was illiterate in any language (the questionnaire was filled out by her daughter). The other three respondents all answered the short version of the questionnaire so it is not possible to know how old they were when they arrived in New Zealand. Two of them however, a man and a woman, both under 40, arrived in New Zealand from Fiji, they are both 'fluent' speakers of Gujarati and English and can read and write English 'easily', one can write Hindi 'with difficulty' and the other is illiterate in Hindi. Possibly, their illiteracy in Gujarati is a result of their Fiji background. The remaining illiterate non-New Zealand-born respondent is a woman under 30 who rates herself as having no skills in Hindi, as being able to speak English 'fluently' and read and write it 'easily'. She rates her Gujarati oral proficiency as 'fairly fluent' but can't read or write Gujarati. She was born in Gujarat and spoke Gujarati as her first language, she now speaks English most of the time. It is possible that she came to New Zealand as a child and this is why she failed to acquire any Gujarati literacy skills but, as she responded to the short version of the questionnaire, it is not really possible to know.

Overall, MT literacy rates are high amongst the respondents to the questionnaire who immigrated here at ten years of age or older. When we turn to the New Zealand-born respondents we can see what rates of literacy maintenance have been like in the three communities.

The New Zealand-born Samoan respondents have the highest rates of MT literacy, followed by the Gujarati and then the Dutch. Many interesting questions are raised by these figures. If one was to hazard a guess as to likely rates of maintenance one might have suggested that the Samoan respondents would show the highest rates of literacy as the most recently arrived of the three immigrant groups and as one that used the same script for both English and the MT. Following this logic the group with the next highest rate of maintenance should be the Dutch, as the next most recently arrived immigrant group and as one that also uses the same script as the language of the host country. Lastly one would hypothesise that one would find the Gujarati community in final position, as the longest established immigrant community and also as one that used a different script from the host community. Instead, of course, we find that the Samoans are indeed at the top of the maintenance league table where this hypothesis placed them, but the position of the New Zealand-born Dutch and Gujarati respondents is 
rather dramatically reversed. Very few of either the New Zealand-born Gujarati respondents or the Dutch respondents are confident enough about their MT literacy skills to rate themselves as able to write 'easily' (and the single Dutch respondent who chose that option was educated in The Netherlands despite being born in New Zealand). By contrast almost half the New Zealand-born Samoan respondents chose this option.

- $2.5 \%$ of New Zealand-born Dutch respondents could write their MT 'easily'

- $5.7 \%$ of New Zealand-born Gujarati respondents could write their MT 'easily'

- $47.6 \%$ of New Zealand-born Samoan respondents could write their MT 'easily'

However when we combine ratings for 'easily' and 'fairly easily' the Gujarati percentage rises to over a third, the Samoan increases to almost two thirds, but the Dutch rises to only an eighth.

- $61.9 \%$ of New Zealand-born Samoan respondents could write their MT 'easily' or 'fairly easily'

- $34.3 \%$ of New Zealand-born Gujarati respondents could write their MT 'easily' or 'fairly easily'

- $12.5 \%$ of New Zealand-born Dutch respondents could write their MT 'easily' or 'fairly easily'

When all three levels of writing ability are examined, the difference is maintained. The gap between Gujarati and Dutch respondents, however, is not so striking because $30 \%$ of the New Zealand-born Dutch respondents can write Dutch 'with difficulty'. Most of the Samoan respondents rated themselves as having some writing ability in their MT as did over half the New Zealand-born Gujarati respondents and under half the Dutch respondents.

- $\quad 85.7 \%$ of New Zealand-born Samoan respondents could write their MT 'easily', 'fairly easily', or 'with difficulty'

- $54.3 \%$ of New Zealand-born Gujarati respondents could write their MT 'easily', 'fairly easily', or 'with difficulty'

- $42.5 \%$ of New Zealand-born Dutch respondents could write their MT 'easily', 'fairly easily', or 'with difficulty'

It is not until the rating 'read but can't write' the MT is added to the previous three rankings, indicating some degree of ability to write the MT, that the Dutch outstrip the Gujarati respondents. Adding together the New Zealand-born respondents in each group who say that can 'write easily, 'fairly easily', with difficulty' or can 'read but can't write' the MT we find that most of the Samoan respondents fall into this category as do many of the Dutch and somewhat fewer of the Gujarati respondents.

- $95.2 \%$ of the Samoan respondents could write their MT 'easily', 'fairly easily', or 'with difficulty or 'read but not write'

- $70 \%$ of the Dutch respondents could write their MT 'easily', 'fairly easily', or 'with difficulty or 'read but not write' 
- $62.9 \%$ of the Gujarati respondents could write their MT 'easily', 'fairly easily', or 'with difficulty or 'read but not write'

The proportion of New Zealand-born Gujarati respondents who have no MT literacy skills is high. Over a third (37.1\%) say that they cannot read or write Gujarati and this is almost matched by the $30 \%$ of New Zealand-born Dutch respondents who say the same thing about Dutch. By contrast, none of the New Zealand-born Samoan respondents gave such a response although one respondent (4.8\%) gave 'no response' to this question and it is possible that she was simply embarrassed to admit that her Samoan literacy skills were very low ${ }^{140}$.

It seems likely that the difference of the Gujarati script may have some influence on the comparatively high number of New Zealand-born Gujarati respondents who have no literacy skills in their MT and, conversely, it seems likely that the familiarity of script and language has an effect on the comparatively high number of Dutch respondents who say that they can read but not write Dutch or write 'with difficulty'. If one speaks some Dutch and can read and write English, then it is not impossible (as I know from personal experience) to combine these two skills to puzzle out the meaning of a simple Dutch text. When one has to learn the Gujarati alphabet before literacy can be accomplished then such stratagems are not available to the English-literate Gujarati speaker.

Why then, is the proportion of Gujarati respondents in the 'write easily' and 'fairly easily' categories so much higher for the New Zealand-born Gujarati respondents than for the New Zealand-born Dutch respondents and why do the New Zealand-born Gujarati respondents outstrip not only the Dutch but also the Samoans when it comes to maintenance of the oral MT?

- $77.2 \%$ of the New Zealand-born Gujarati respondents rated themselves as 'fluent' or 'fairly fluent' speakers of their MT

- $71.4 \%$ of the New Zealand-born Samoan respondents gave themselves these ratings

- $45 \%$ of the New Zealand-born Dutch respondents gave themselves these ratings

As noted in the previous section very few New Zealand-born Gujarati respondents rate themselves as 'not very fluent' $(8.6 \%)$ whereas almost a third of the New Zealand-born Dutch and Samoan respondents appear in this category. 
All of these facts directly rebut the hypothesis, based on length of time as an immigrant community in New Zealand and difference of language and script from English, that suggested that Gujarati would be the least well maintained of the three languages. What is the reason for this? One possible reason could be that the Gujarati community has maintained a language maintenance school and the Dutch community has not. Another reason could simply be that the Gujarati community has valued language maintenance more highly than the Dutch community, with its strong emphasis on assimilation, and literacy education has been part of the process of maintenance. It could also be the case that neither length of time nor difference of script are as important as the original hypothesis assumed.

In fact, difference of script probably is an important constituent in rates of Gujarati literacy shift. As already noted above there is a sizeable proportion of the New Zealand-born Gujarati respondents who cannot read or write Gujarati at all, and it seems reasonable to assume that the different script is the cause of such widespread MT illiteracy. The Gujarati script may have contributed to a more rapid decline in the maintenance of Gujarati literacy amongst the New Zealand-born than would otherwise have been the case. Given the obvious enthusiasm in the Gujarati community for oral and literacy maintenance, it sees reasonable to suggest that if English and Gujarati shared a script (as English and Samoan do) then rates of literacy maintenance would have been even higher amongst the Gujarati New Zealand-born. It may be however, that length of time is not as important was assumed in the hypothesis. On balance, it would seem that the fact that the Gujarati community in New Zealand is longer established than the Dutch community and thus contains more people who are second or third generation New Zealanders ${ }^{1+1}$, is outweighed by the importance that the Gujarati community has allocated to the task of language and cultural maintenance and by the community's willingness to embody that sense of importance in the community school. It could even, perhaps, be argued that the length of time the community has established is an advantage in that it has given the community a change to develop a range of language maintenance strategies.

\footnotetext{
${ }^{140}$ The respondent filled out a Samoan language questionnaire, so her Samoan literacy skills cannot have been non-existent. She was born in New Zealand to a New Zealand-born father and an English-born mother and she rates her English as 'fluent' and says she can write it 'easily'.

${ }^{1+1}$ Although, of course, the 'broken' nature of Gujarati immigration means that difference is not as extreme as might be expected given the different periods of time at which the two communities were established in New Zealand.
} 


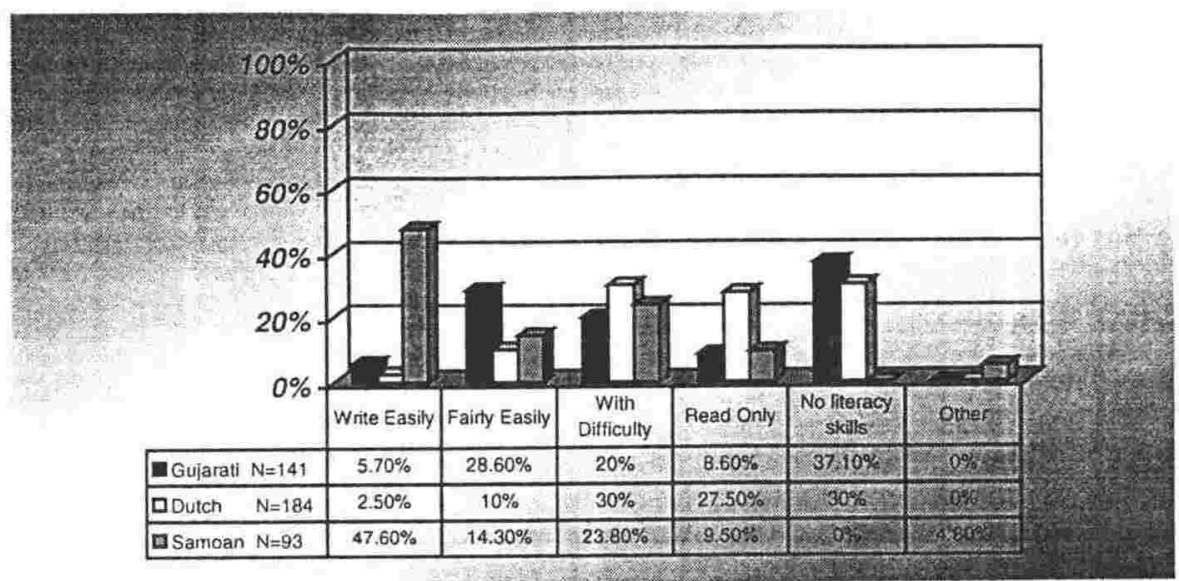

Figure 10-30: Literacy proficiency in MT: all New Zealand-born respondents

\subsubsection{Literacy skills in English}

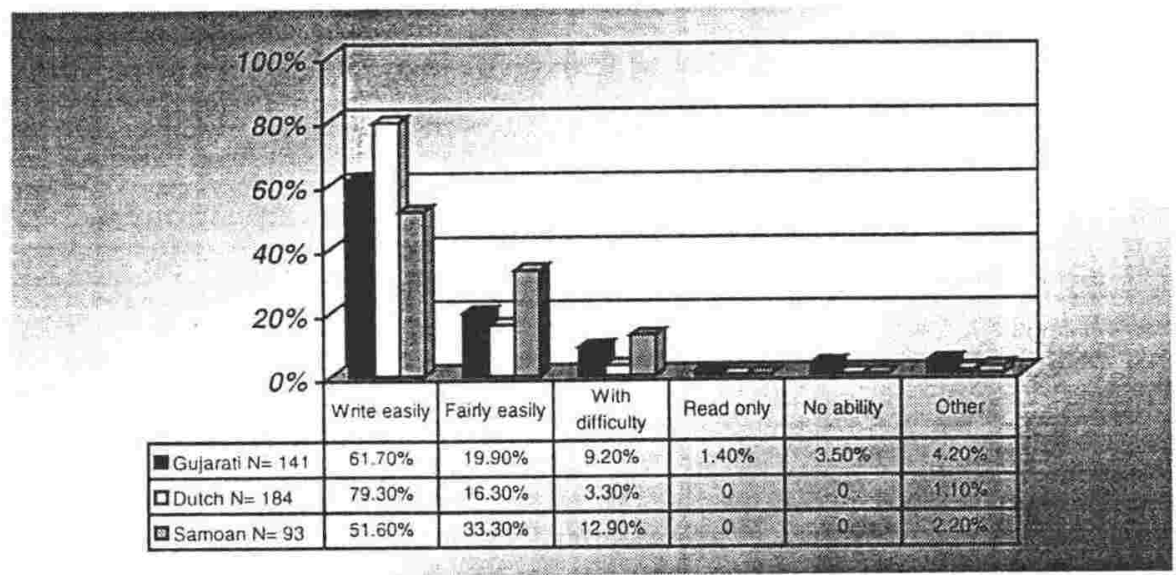

Figure 10-31: Literacy proficiency in English: all respondents

It is noticeable that the Dutch are considerably more confident than either the Gujarati or the Samoan respondents about their English language abilities, almost $80 \%$ of all Dutch respondents think that they can write English 'easily'. If the categories of 'easily' and 'fairly easily' are combined for all the respondents, the ranking of

- $\operatorname{Dutch}(95.6 \%)$

- Samoan $(84.9 \%)$

- Gujarati $(81.5 \%)$

is unchanged and the Dutch respondents are still considerably more confident in the ranking of their abilities than either the Samoan or the Gujarati respondents. The ranking is somewhat modified when we look at the results for respondents who arrived in New Zealand age ten or older. The Dutch respondents are still at the top but the Gujarati respondents in this category are noticeably less confident in their English literacy abilities.

- 93.9 of Dutch respondents who arrived in New Zealand age 10 or older rated themselves as able to write English 'easily' or 'fairly easily' 
- $78.4 \%$ of Samoan respondents who arrived in New Zealand age 10 or older rated themselves as able to write English 'easily' or 'fairly easily'

- $71.9 \%$ of Gujarati respondents who arrived in New Zealand age 10 or older rated themselves as able to write English 'easily' or 'fairly easily'

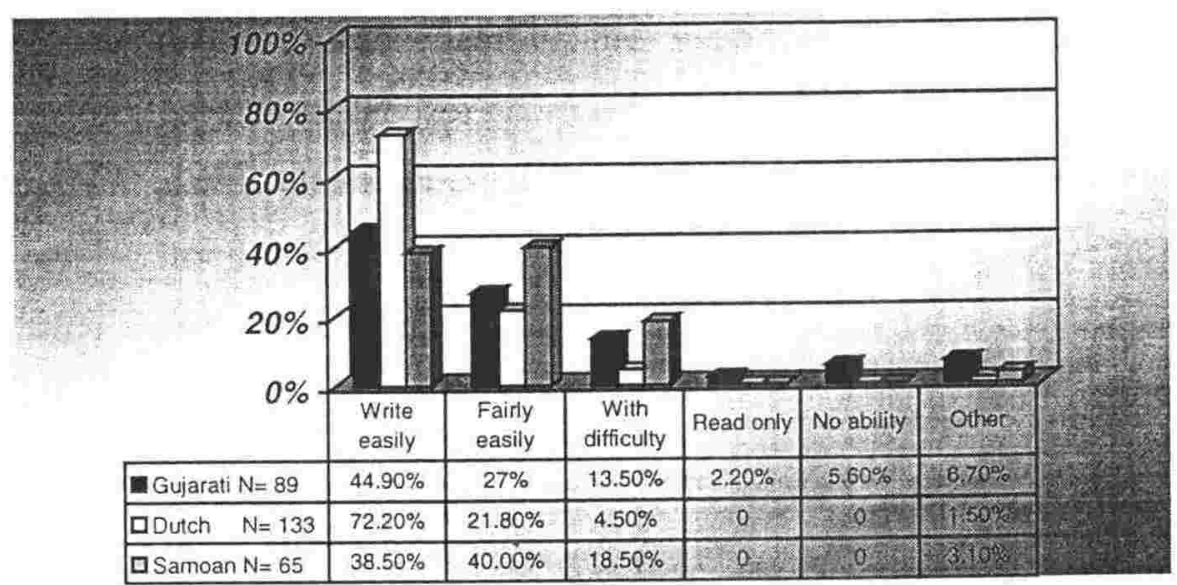

Figure 10-32: Literacy proficiency in English: all non-New Zealand-born respondents who arrived in New Zealand $10+$ years old

English literacy rates are quite high in all the communities but amongst those who emigrated to New Zealand age ten and over the rates are low enough to cause concern about access to information that is available only in English. Although provision of basic information (about such things as voting, or the national census) is usually available in Samoan, it is not available in Gujarati. Working on the figures from the respondents to the survey, this would indicate that well over a quarter of the immigrant population of Gujarati extraction (i.e. not including people of Gujarati extraction born in New Zealand) does not have ready access to basic information affecting their position as a permanent resident or citizen of New Zealand ${ }^{142}$.

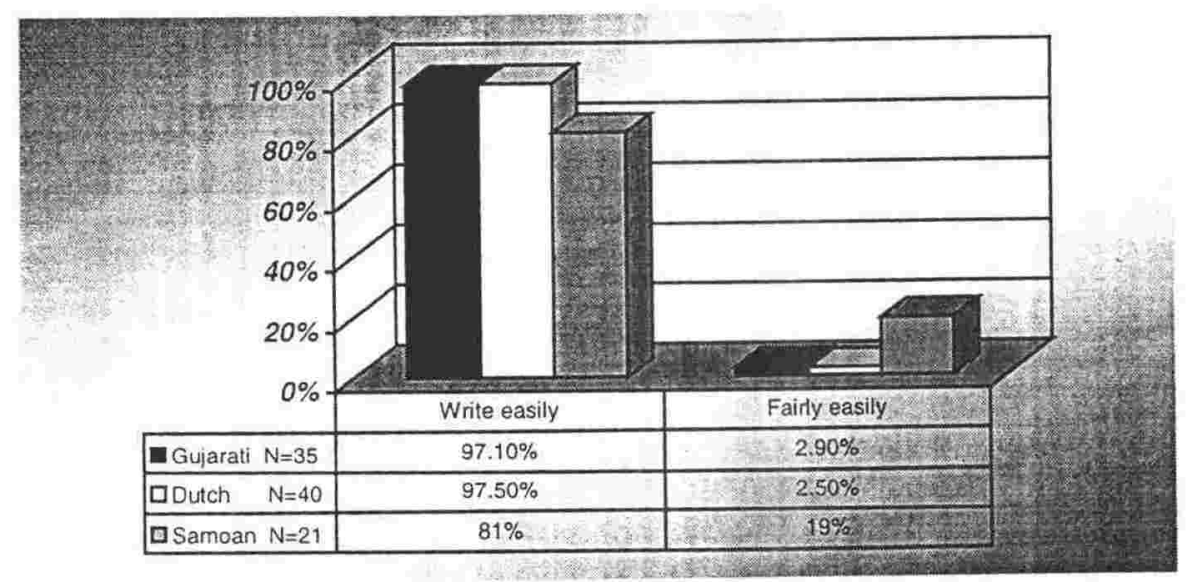

${ }^{142}$ Given that respondents to this questionnaire had, on average, a higher level of education than the general Indian population in New Zealand, the percentage is probably somewhat larger still amongst the general Indian population. 
Figure 10-33: Literacy proficiency in English: all New Zealand-born respondents

As was to be expected, the New Zealand-born respondents all recorded very high rates of confidence in their English literacy abilities. Most respondents said that they could write English 'easily. One Dutch respondent (2.5\%) and one Gujarati respondent (2.9\%) chose 'fairly easily'. In contrast, four of the New Zealand-born Samoan respondents (19\%) chose 'fairly easily'. The numbers involved are small, and it is hard to know exactly how to interpret them, but the fact that a somewhat greater percentage of Samoan New Zealand-born respondents chose 'fairly easily' as a response suggests at least that the Samoan respondents were less confident about their English language abilities.

\subsubsection{Summary: literacy skills}

Almost all the non-New Zealand-born respondents are literate in their MT. Most of the nonNew Zealand-born Dutch are also confident of their English literary skills but the Samoan and Gujarati respondents are more likely to report that their English literacy skills are not high.

Amongst the New Zealand-born, almost all the respondents (except for a handful of Samoans) report that they can write English 'easily'. The Samoan New Zealand-born are most likely to be confident of their MT literacy skills, followed by the Gujarati. The New Zealand-born Dutch report the lowest level of confidence in their MT literacy skills. Declining ability to read and write the MT (in those cases where MT literacy is widespread amongst the original immigrant group), is part of the process of language shift. All three non-New Zealand-born groups in this research were (largely) MT literate. As has been the pattern in the data so far, the New Zealand-born Dutch have shown the greatest rate of shift. The New Zealand-born Gujarati and Samoan respondents exhibit reasonable rates of MT literacy maintenance. This is particularly interesting in the case of the New Zealand-born Gujarati respondents who, in order to be MT literate have to master an entirely different script. The comparatively high rates of MT literacy attained in this community are interpreted here as a product of the considerable commitment of the Gujarati community language maintenance in both oral and written media. This commitment has resulted in the comparatively high rates of oral and written MT maintenance and shows the importance both what Fishman has called 'behaviour towards language' (such as establishing and maintaining a language maintenance school) and attitudinal and affective behaviours such as believing language maintenance to be an important community and family project. 
The greatest concern of most Indian parents was the real threat of a communication breakdown between them and their children due to a lack of knowledge of Gujarati language among the latter (Tiwari: 1980: 47).

That concern has led to considerable success in achieving the language maintenance goals implicit within it.

\subsection{Conclusion}

The three survey populations were similar in proportions of non-New Zealand-born to New Zealand-born respondents and male to female respondents. They were very different in age structure, which reflects the different immigration histories of the three groups.

Language maintenance and language shift were investigated in this chapter by considering factors such as languages spoken by respondents, domains of MT language use, interlocutors with whom MT is used, proficiency in MT, English and some other languages, and the relationship between multilingualism, level of education and language maintenance. Using these factors as indicators of language maintenance, the Dutch can unequivocally be said to have exhibited the greatest degree of language shift. It is harder to assess the relative rates of language shift and language maintenance amongst the Gujarati and Samoan respondents. In many respects, the Samoan respondents show a greater degree of language maintenance; higher MT literacy amongst the New Zealand-born, more MT use with interlocutors their own age and younger amongst the New Zealand-born for example. The Samoan community is however, more recently established in New Zealand than the Gujarati community and these differences may be more an indication of that recent establishment (ie. There has not yet been much time in which language shift can occur within the Samoan community) rather than of language maintenance. There are a few signs that the longer established Gujarati community, in which one would expect (because of the length of time involved) to see more language shift, has developed some effective strategies for language maintenance; using the MT at social gatherings that are predominantly Gujarati (section 10.7.10 and using the MT as a first language (as was the case for $68.5 \%$ of the New Zealand-born Gujaratis and only $38.1 \%$ of the New Zealand-born Samoans, section 10.3). This is not to say that the Samoan community has no commitment to language maintenance. Clearly, the community does have such a commitment but it remains to be seen how effective that commitment is. 


\section{THE FAMILY AND LANGUAGE MAINTENANCE}

Almost from the beginning of language maintenance studies, the importance of the home as a site for language maintenance has been acknowledged (Hayden 1966: 198, Lemaire 1966: 265). Fishman has pointed out that the most important site for language maintenance is the family and that without "transmissibility across the intergenerational link" (Fishman 1990:18) there can be no long-term language maintenance. Studies have also noted that use in the home is hard to maintain. Hayden's 1966 study in the USA, found that of the two Ukrainian, two Spanish and one French speaking communities studied, only the two Spanish speaking communities still had some families who used only the MT at home. Interestingly, it was in the longest established community (the San Antonio Spanish) that people were most likely to use only Spanish in the home (Hayden 1966:197). This reinforces the findings of this research that the age of the immigrant community does not directly correlate with language shift. The Dutch community is more recently established in New Zealand than the Gujarati community, but it has undergone a greater rate of language shift. With this is mind it is interesting to examine a little more closely the dynamics of language use with the families of the respondents and to see if there are any noticeable differences between the groups.

The first section of this chapter looks at the answers that respondents gave to the questions about language use in the home and which language/s were spoken with respondents' spouses and children. The second section looks at the links between childhood language use and language maintenance. Two different sets of data are considered in the second section. The data gathered from the Gujarati and Dutch respondents about language use in their childhood homes in New Zealand is examined and related to their responses about their current, adult proficiency and patterns of use. The other data set is the information about the MT language use and proficiency of the children of the Gujarati interviewees and the Samoan respondents. The responses concerned with language use with children have all been incorporated into this chapter despite the fact that some children are, of course, adult and not living in the parental home any longer. For the purposes of this analytical framework 'children' have been included in the 'home' domain regardless of whether children and parents are living under one roof or not. The answers to the first question discussed here give a global view of habitual language use in the home. This is an important part of identifying, in terms of the integrated model, the basic trends of language maintenance and language shift within the domain that has long been identified as a particularly important site for language maintenance efforts. The global view 
allows broad comparisons to be made between the three groups in this study but more detailed and local views of habitual language use are also needed to construct an accurate picture. The questions about language use with spouse and children deepen the understanding of language use and transmission patterns.

\subsection{Language use in the home}

Each of the three groups exhibits a very different pattern of language use in the home

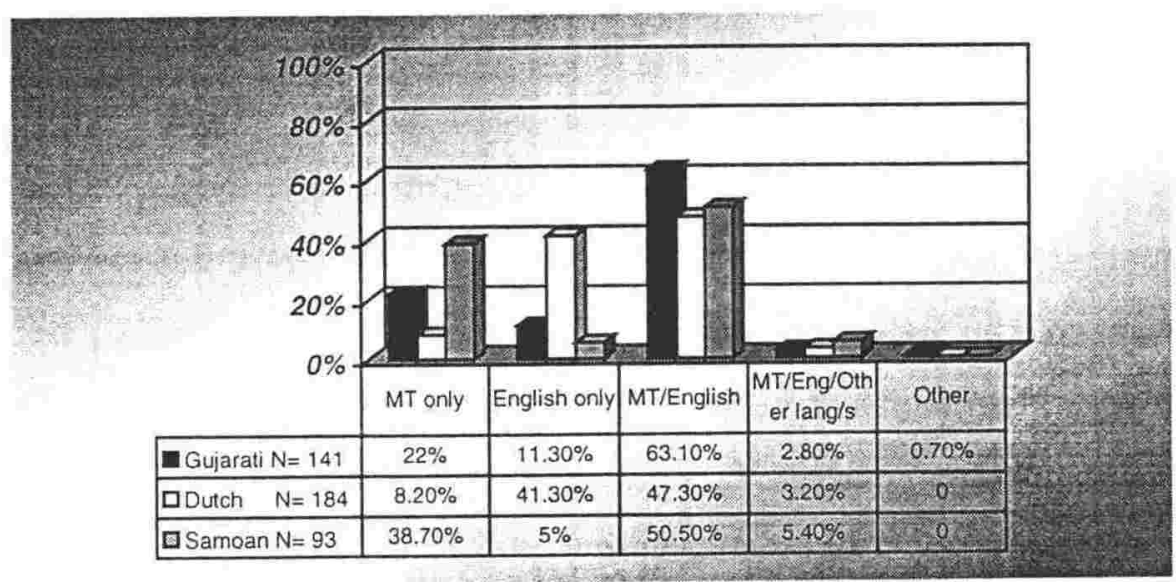

Figure 11-1: Language use in the home: All respondents

There are some superficial similarities between the Dutch and Samoan respondents.

- $50.5 \%$ of the Samoan respondents say that they use English and MT at home

- $47.3 \%$ of the Dutch respondents say that they use English and MT at home

However, many of the Dutch respondents say they use only English at home and a tiny handful use only Dutch. For the Samoan respondents these proportions are reversed, many use only Samoan at home and a few report that they use only English at home.

- $41.3 \%$ of the Dutch respondents say they use only English at home

- $8.2 \%$ use only Dutch

- $38.7 \%$ of the Samoan respondents say that they use only Samoan at home

- $5.4 \%$ report that they use only English at home.

The Gujarati respondents demonstrate yet another pattern of language use in the home. Most of the Gujarati respondents use both English and Gujarati in their home, almost a quarter use only Gujarati and a few use only English. A handful of respondents from all three groups use English, the MT and one or more other languages in the home.

- $63.10 \%$ of the Gujarati respondents use both English and Gujarati

- $22 \%$ use only Gujarati

- $11.3 \%$ use only English 
Overall the pattern of responses shows that MT language use in the home is strongest amongst the Samoan respondents, still fairly strong amongst the Gujarati respondents and weakest amongst the Dutch respondents.

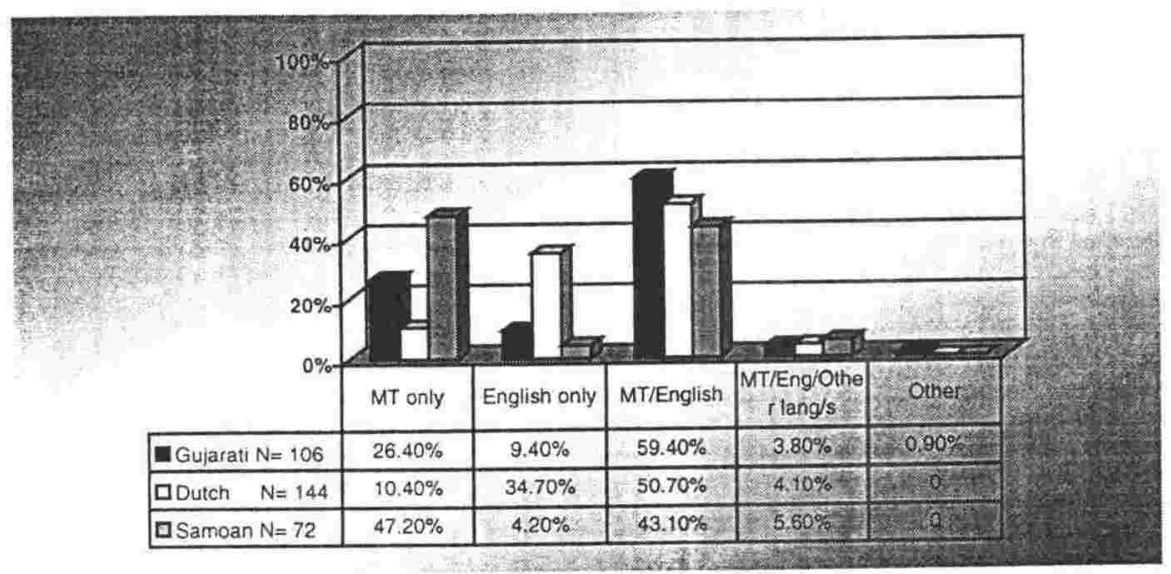

Figure 11-2: Language use at home: All Non-new Zealand-born respondents

\subsubsection{MT use in the home: non-New Zealand-born respondents}

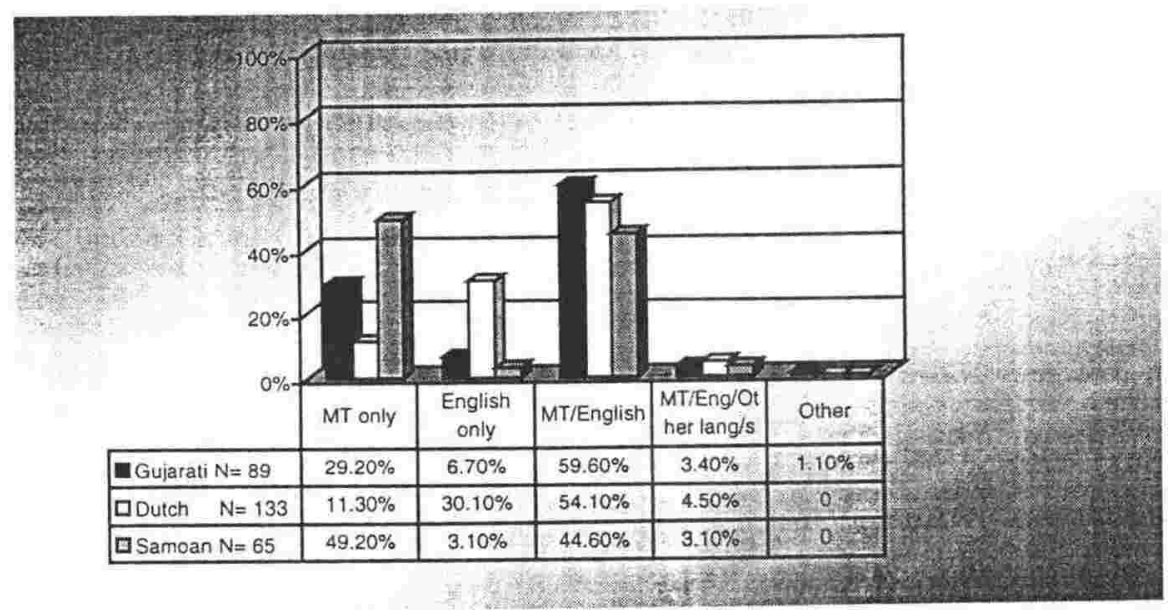

Figure 11-3: Language use at home: All Non-new Zealand-born respondents, arrived in NZ 10+

Amongst the non-New Zealand born respondents this pattern is retained. The proportion of Dutch respondents who arrived in New Zealand aged 10 and over and who speak only English at home, is somewhat lower than the figure for all the Dutch respondents (including New Zealand-born) but it is still high (30.1\%) compared to $6.7 \%$ of the Gujarati and $3.1 \%$ of the Samoan respondents who arrived in New Zealand aged 10 and over, who speak only English at home. 
Overall, amongst the respondents who arrived in New Zealand aged 10 and over, most of the Gujarati and Samoan respondents and a substantial proportion of the Dutch respondents speak their MT at home at least some of the time.

- $96.9 \%$ of Samoan respondents

- $92.2 \%$ of Gujarati respondents

- $69.9 \%$ of the Dutch respondents

The figures for language use in the home of the Dutch respondents can be compared to the figures for language use in the home of the Dutch in the Australian census.

Table 11-1: Language shift to English only in the home: 1st generation Dutch

\begin{tabular}{|l|l|}
\hline & English only in the home \\
\hline Australian Census 1986 & $48 \%$ \\
Australian Census 1991 & $57 \%$ \\
New Zealand respondents & $34.7 \%$ \\
\hline
\end{tabular}

(Australian figures from Clyne \& Kipp 1996: 5)

It is not clear why the respondents to the survey report such a noticeably lower rate of complete shift to English than their Australian counterparts. A partial explanation is perhaps provided by the friend of a friend methodology of the survey (where Dutch people gave the names of those they thought would be interested in replying to the survey questions see section 6.5 .2 for more discussion of this issue.).

The relatively high rate of MT use in the home amongst Gujarati immigrant communities has also been noted by Desai in South Africa (Desai 1994:12) and Sridhar in New York (draft: 19). Sridhar also comments that code mixing with English is 'a way of life' in India (Sridhar draft: 23) and that the families she studied in New York also showed a high degree of codeswitching and code-mixing (Sridhar draft:18). The high rate of code-mixing and switching that Sridhar comments on both in India amongst Indian communities in New York, may well be related to the fact that the Gujarati respondents were the group with the highest response rate for using both English and MT in the home.

Both the Gujarati and the Samoan non-New Zealand-born respondents report fairly high proportions of MT only in the home. These reports need to be viewed with some caution in the light of Chumak-Horbatsch's findings in a study of Ukrainian homes in Toronto. She commented

That signs of English are found in 'Ukrainian only' homes, that the presence of the majority language is felt in the minority-language home is unavoidable, inevitable, 
and not surprising. What is surprising, however, is the extent to which signs of English can be found in these homes, parental attitudes to the situation (their unawareness of the presence of English and also their unawareness of English in their speech addressed to children), and their conviction that the home is free of English (ChumakHorbatsch: 1987:113-14).

LMP (1985: 39) make the point that self-report data can be faulty in both directions, as it were. People who say they use only the MT with their children may be observed using English and people who say they use only English may be observed using the MT. There is no reason however, to think that the Samoan and Gujarati respondents are notably more selfdeluding in this respect than the Dutch and it is reasonable, at the very least, to take from the data that the MT is used much more in the homes of non-New Zealand-born Gujarati and Samoan respondents than in the homes of the non-New Zealand-born Dutch respondents.

\subsubsection{MT language use in the home: New Zealand-born respondents}

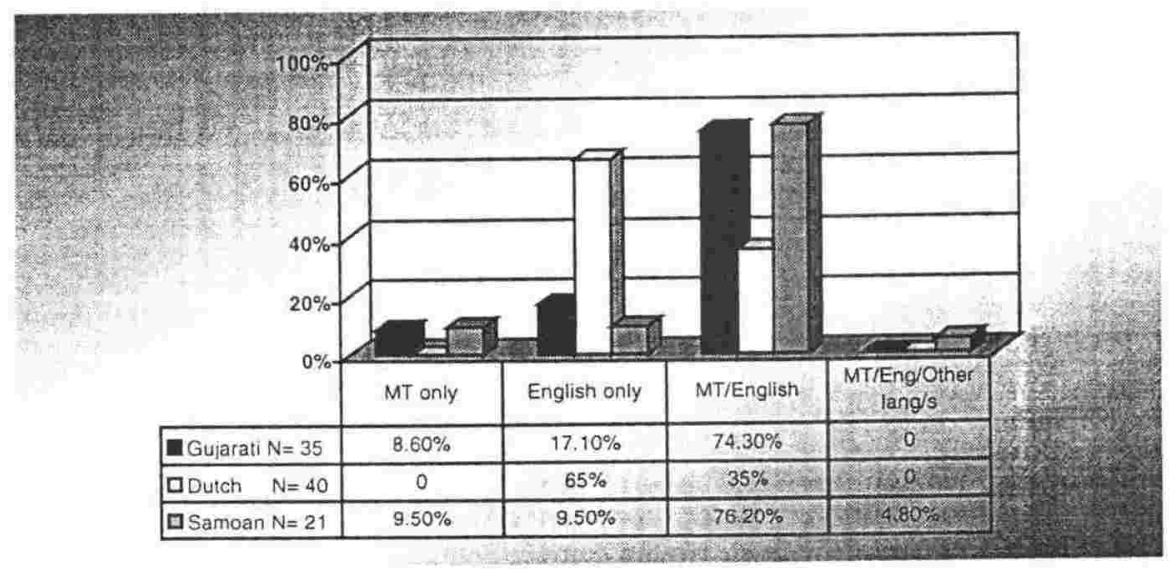

Figure 11-4: Language use at home: All New Zealand-born respondents

Amongst the New Zealand-born respondents the differences between the Gujarati and Samoan respondents are, to some extent, evened out. Fairly small numbers from both groups speak only the MT at home and roughly the same proportion of respondents in each group speak both English and the MT at home. However, there are still some differences, almost double the percentage of Gujarati respondents speak only English at home when compared to the Samoan respondents.

- $9.5 \%$ of New Zealand-born Samoan respondents speak only English at home

- $17.1 \%$ of New Zealand-born Gujarati respondents speak only English at home

- $65 \%$ of New Zealand-born Dutch respondents speak only English at home

Once again the Dutch respondents follow a distinctly divergent path. None of the New Zealand-born Dutch respondents speaks only Dutch at home. Most speak only English and 
just over a third speak both Dutch and English. Language shift in terms of performance has been almost complete in one generation. Compared to the responses from Dutch respondents to the Australian census however, New Zealand-born respondents of two Dutch parents exhibit a higher rate of Dutch use in the home (the New Zealand data includes both Dutchborn and D.E.I.-born parents). It is interesting to note that although the number of New Zealand-born respondents from exogamous marriages is tiny, nonetheless, the $100 \%$ figure for languages shift to English is very similar to the figure from the Australian Census.

Table 11-2: Language shift to English only in the home: Adult 2nd generation Dutch reporting on use of MT in their own homes (i.e. not parent's home)

\begin{tabular}{|l|l|l|}
\hline & $\begin{array}{l}\text { English only in the home: Where } \\
\text { Respondent's parents are in } \\
\text { endogamous marriage }\end{array}$ & $\begin{array}{l}\text { English only in the home: Where } \\
\text { Respondent's parents are in } \\
\text { exogamous marriage }\end{array}$ \\
\hline Australian Census 1986 & $85.4 \%$ & $92 \%$ \\
Australian Census 1991 & $88.7 \%$ & $97.5 \%$ \\
NZ respondents & $57.6 \%$ & $100 \%$ \\
New Zealand respondents N= & 33 & 7 \\
\hline
\end{tabular}

(Australian figures from Clyne \& Kipp 1996: 8-9).

It is not clear why the New Zealand-born respondents should report a lower rate of language shift in the home than their Australian counterparts but it is, at least, consistent with the finding reported above that the first generation Dutch respondents in the New Zealand data reported a higher rate of Dutch use in the home than did the first generation Dutch in Australia. There appears to be a considerable difference between the Australian and the New Zealand Dutch responses depending on whether MT use in general is the focus or whether the focus is on MT use in the home. If MT use in the home is considered then the New Zealand Dutch, both first and second generation, report more MT in the home than the Australian Dutch both first and second generation. If MT use in general is considered the Australian Dutch seem to report higher rates of usage (see section 10.6.2 for the Australian-born generation and section 10.5.1 for the non-Australian-born generation) - although the comparison of the two sets of first generation (non-Australian/non-New Zealand-born) data has to be considered very warily because the Australian data is census data and the New Zealand data is small scale survey research. It is not easy to know how to interpret these figures, gathered as they were, in such varying ways. At the very least however, they suggest that there is a considerable difference in the question of MT use in general and MT use in the home (a point also made by Clyne \& Kipp with reference to the Australian Census questions (1997:451)). 


\subsection{Language spoken with spouse}

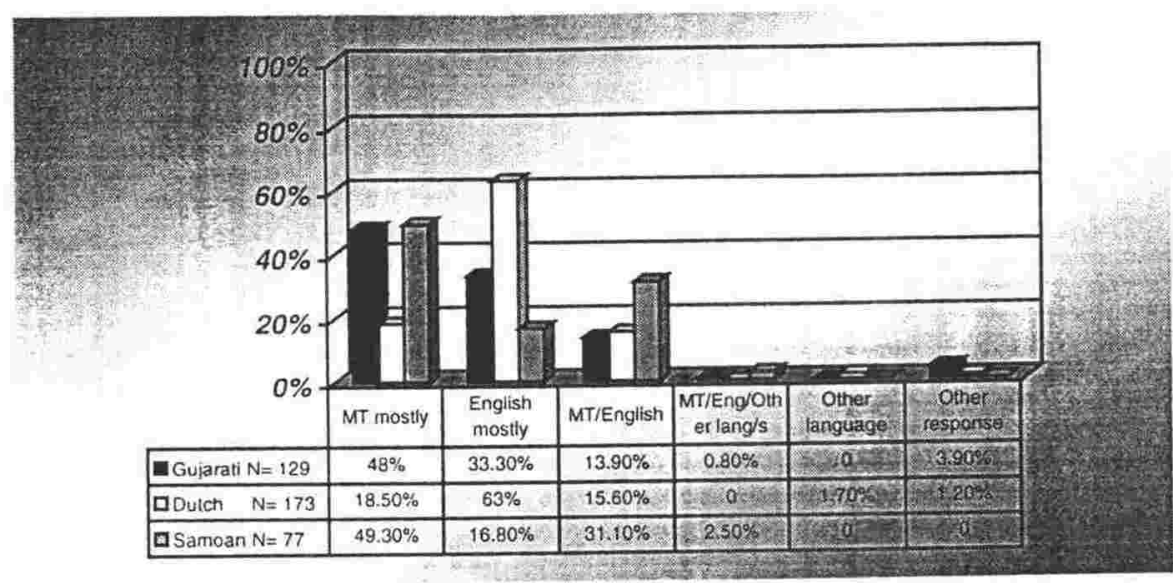

Figure 11-5: Language spoken with spouse: All respondents

Language use with spouses followed different patterns in the three groups and, once again, the Dutch differed most in comparison with the Gujarati and Samoan respondents.

- almost half the Samoan and Gujarati respondents used their MT with their spouse most of the time

- only $18.5 \%$ of the Dutch respondents used Dutch most of the time with their spouses

Conversely, almost two thirds of the Dutch respondents (63\%) used mainly English with their spouses whereas only one third of the Gujarati respondents and only a sixth of the Samoan respondents said that they used mainly English with their spouses. Interestingly, the rates of reported equal MT/English use were roughly similar for the Gujarati respondents and Dutch respondents.

- $13.4 \%$ of Gujarati respondents used equal amounts of MT/English with their spouse

- 15.6 of Dutch respondents used equal amounts of MT/English with their spouse

Almost a third of the Samoan respondents however, reported that they used both Samoan and English equally.

Thus each of the communities presents a somewhat different picture. The Dutch are the most likely overall to speak mainly English with their spouses, the Gujarati and Samoan respondents are about equally likely to speak mainly their MT with their spouses but, if they don't use mainly their MT, the Samoans are more likely to use both MT and English than the Gujaratis. The Gujarati respondents of course, are more likely to use mainly English than the Samoan respondents but less likely to do so than the Dutch. 


\subsubsection{Language spoken with spouse. Non-New Zealand-born respondents}

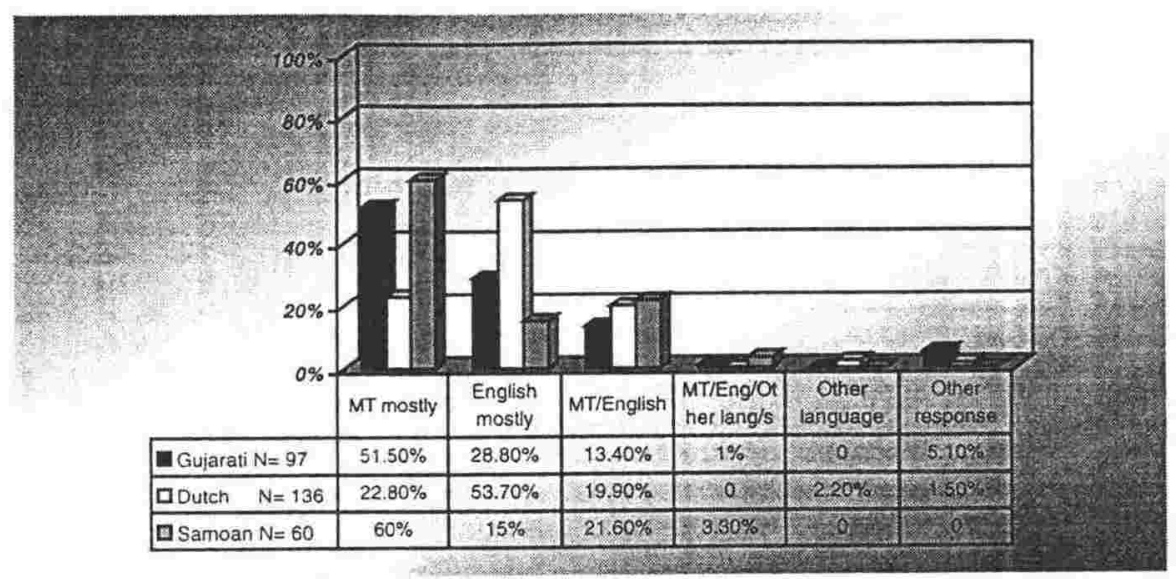

Figure 11-6: Language spoken with spouse: All Non-New Zealand-born respondents

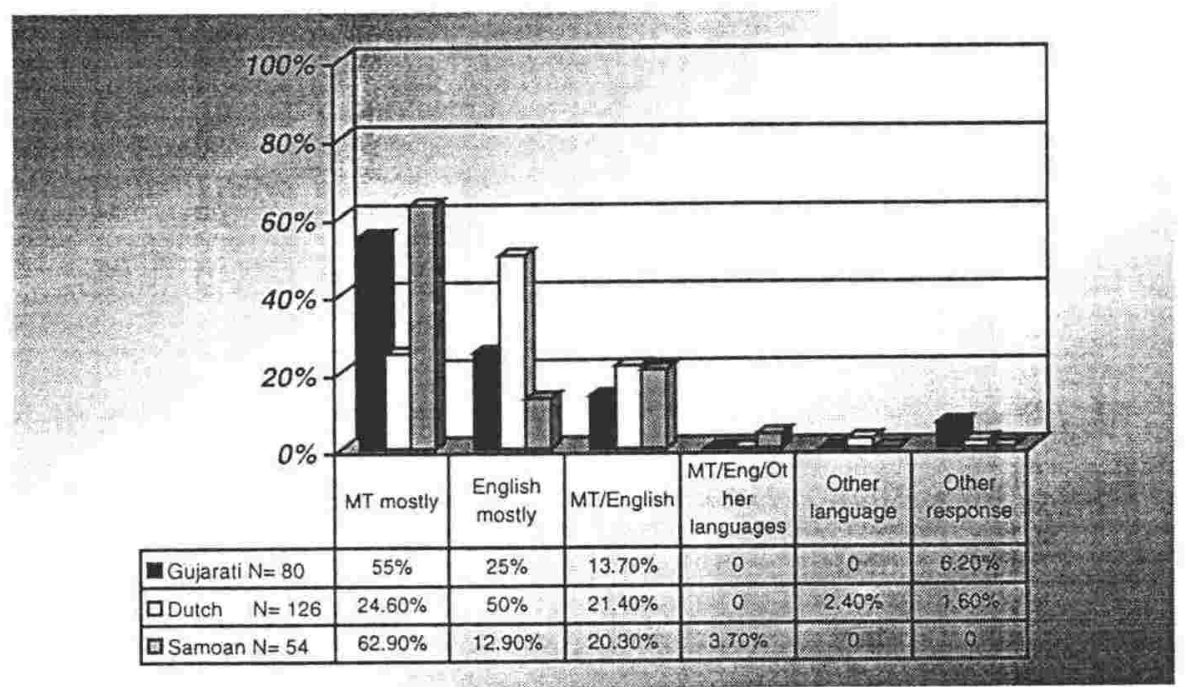

Figure 11-7 Language spoken with spouse: All Non-NZ-born respondents who arrived in NZ $10+$

Examining those respondents who arrived in New Zealand aged 10 or older we see that over half the Gujarati respondents and well over half the Samoan respondents use mainly their MT with their spouse but only a quarter of the Dutch respondents fall into this category.

- $55.0 \%$ of the Gujarati respondents use mainly their MT with their spouse

- $62.9 \%$ of the Samoan respondents use mainly their MT with their spouse

- $24.5 \%$ of the Dutch respondents use mainly their MT with their spouse

Turning to the proportion of each group who speak mainly English with their spouse the figures are surprisingly neat.

- half the Dutch respondents

- a quarter of the Gujarati respondents

- an eighth of the Samoan respondents

speak mainly English with their spouses. 
Relatively few respondents in any of the three groups thought that they used both the MT and English equally when speaking to their spouse. The Gujarati respondents were the least likely to choose this option; the Dutch and the Samoans slightly more likely to do so.

- $13.7 \%$ of the Gujarati respondents reported using both languages equally

- $21.4 \%$ of the Dutch respondents

- $20.3 \%$ of the Samoan respondents

\subsubsection{Language used with spouse. New Zealand-born respondents}

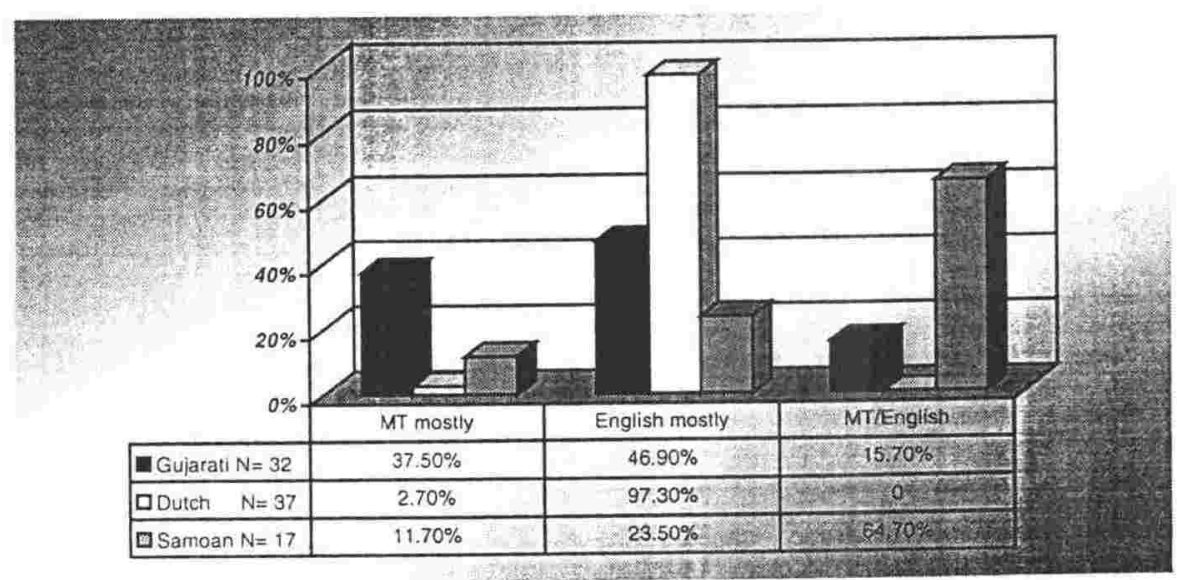

Figure 11-8: Language spoken with spouse: All New Zealand-born respondents

Amongst the non-New Zealand-born respondents, the Samoans were the most likely to speak mainly MT with their spouse. Amongst the New Zealand-born however, it is the Gujarati respondents who are most likely to use their MT with their spouse. This seems to support the suggestion made in section 10.11 that although the more recently established Samoan community has high rates of language use, the longer established Gujarati community has higher rates of MT maintenance. However, it should be borne in mind that there might be several reasons for this result. One is the very widespread practice of New Zealand-born Gujaratis marrying non-New Zealand-born Gujaratis, another factor may well be the very small number of married New Zealand-born Samoan respondents in the sample.

As with the non-New Zealand-born respondents, the New Zealand-born Dutch respondents were the most significant group in the category of those who spoke mostly English to their spouse $(97.3 \%)$. This is at least partly caused by the higher rate of exogamous marriage amongst the New Zealand-born Dutch respondents. Almost half the Gujarati respondents and just under a quarter of the Samoan respondents spoke mainly English to their spouses. 
The New Zealand-born Samoan respondents were very likely (64.7\%) to use a roughly equal amount of both MT and English. The Gujarati respondents were considerably less likely (15.7\%) to do so. None of the Dutch respondents fell into this category, mainly because were likely to use English most of the time. The New Zealand-born Gujarati respondents were also likely to use mainly English, but it is interesting that, in comparison to the Samoan respondents, they are more likely to see themselves as speaking mainly MT to their spouse. If this is an accurate perception then it may be a good indicator of resistance to language shift and the Samoan willingness to use a mixture of both languages may be an ominous sign for the future of Samoan language maintenance.

\subsection{Language/s spoken with children}

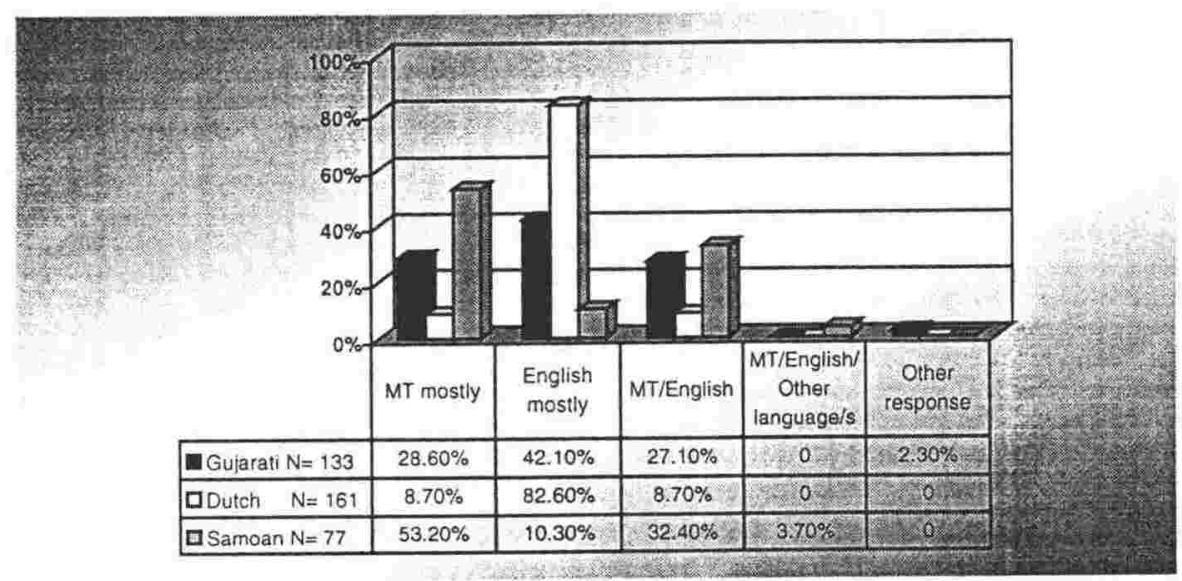

Figure 11-9: Language spoken with children: All respondents

As with the language spoken to respondent's spouse, it was noticeable that the Dutch respondents were less likely than either the Samoan or Gujarati respondents to speak their MT to their children.

- $8.7 \%$ of Dutch respondents spoke mainly the MT to their children

- $8.7 \%$ of Dutch respondents spoke a 50/50 mixture of English and MT to their children

- $82.6 \%$ of Dutch respondents spoke mainly English to their children

Overall the Samoan respondents were more likely to speak mainly their MT or a 50/50 mixture of English and MT to their children. The Samoans were the group least likely to speak mainly English with their children.

- $53.2 \%$ of Samoan respondents spoke mainly the MT to their children

- $32.4 \%$ of Samoan respondents spoke a 50/50 mixture of English and MT to their children

- $10.3 \%$ of Samoan respondents spoke mainly English to their children 
The Gujarati respondents were in between the other two groups. They were more likely to speak mainly English to their children but a substantial minority still spoke mainly their MT to their children and an almost equal number of respondents spoke roughly equal amounts of English and Gujarati to their children.

- $42.1 \%$ of Gujarati respondents spoke mainly English to their children

- $28.6 \%$ of Gujarati respondents spoke mainly Gujarati to their children

- $27.1 \%$ of Gujarati respondents spoke roughly equal amounts of English and Gujarati to their children

\subsubsection{Language/s used with children: non-New Zealand-born respondents}

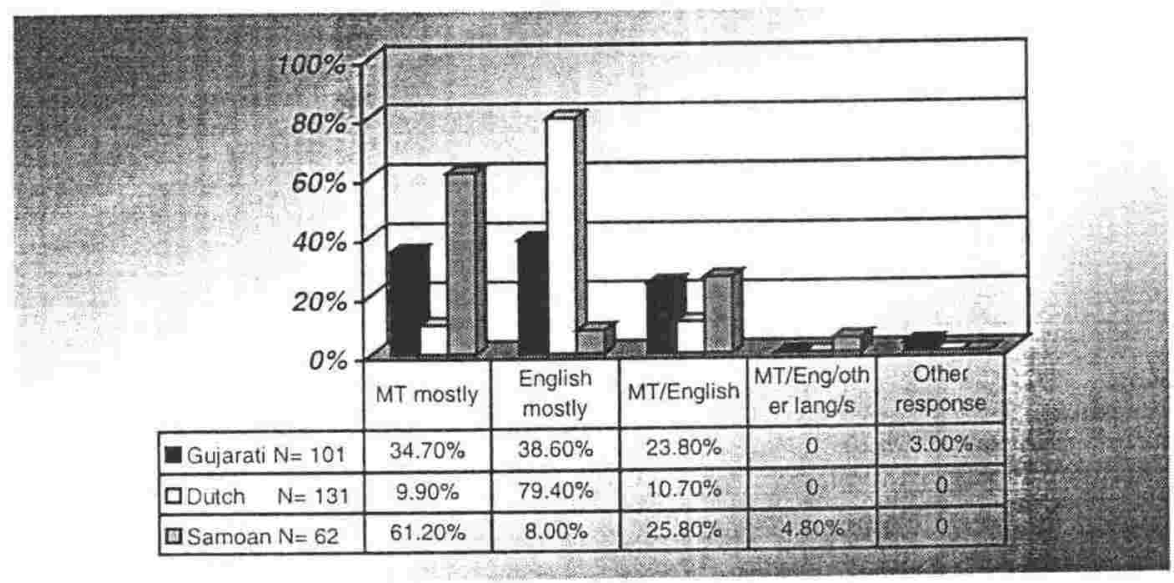

Figure 11-10: Language spoken with children: All Non-New Zealand-born respondents

In Jamieson's 1980 survey in Wellington, she investigated the language use of parents who were born outside New Zealand and arrived in the country 'at varying times during their childhood, early adolescence and early adulthood' (Jamieson 1980: 103). Jamieson asked parents about their language use with pre-school children. Language use with pre-school children was not a specific question in the present survey, so for purposes of comparison only those respondents whose youngest or only child was a pre-schooler have been selected. The results from the two surveys are shown below. 
Table 11-3: Language use with pre-school children. Gujarati and Samoan respondents compared with 1980 survey

\begin{tabular}{|l|l|l|l|l|}
\hline & English $^{143}$ & 50/50 MT and English & MT & $\mathbf{N}^{144}$ \\
\hline Indian (1980) & $25 \%$ & $32 \%$ & $43 \%$ & 28 \\
Gujarati (1998) & $38.8 \%$ & $38.8 \%$ & $22.2 \%$ & 18 \\
& & & & \\
Samoan (1980) & $21 \%$ & $19 \%$ & $60 \%$ & 67 \\
Samoan (1998) & $9.5 \%$ & $9.5 \%$ & $80.9 \%$ & 21 \\
\hline
\end{tabular}

The figures are not very directly comparable, but they do show that across a distance of almost 20 years the non-New Zealand-born Gujarati respondents in both cases were more evenly divided between the three language use options and the non-New Zealand-born Samoan respondents were more likely to use only or mainly their MT.

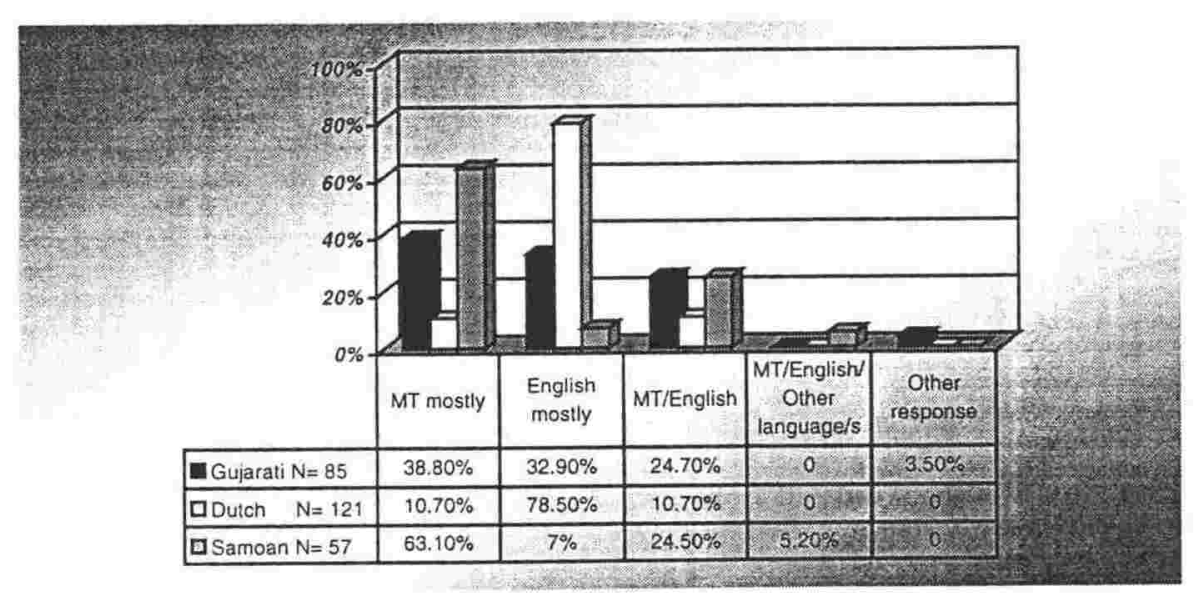

Figure 11-11: Language spoken with children: All non-New Zealand-born respondents who arrived $10+$

Amongst those respondents who arrived in New Zealand age 10 and older, almost two thirds of the Samoan respondents are very likely to speak mainly Samoan to their children and most of the remaining third speak roughly equal amounts of Samoan and English; only a tiny proportion of Samoan respondents reported that they spoke mainly English with their children.

- $63.1 \%$ of Samoan respondents spoke mainly their MT to their children

- $24.5 \%$ spoke roughly equal amounts of MT/English

- $7.0 \%$ spoke mainly English

\footnotetext{
143 Jamieson's respondents were asked to differentiate between 'English only', Mostly English', '50/50 MT/English', 'Mostly $\mathrm{MT}$ ' and 'All MT'. Because the respondents to the present survey were not asked to make a distinction between 'Mostly' and 'All' of a language, these two categories have been conflated in this table.

${ }^{1+4}$ The numbers in Jamieson's research refer to the number of children (and include more than one child per mother) the numbers in the current research refer to parents.
} 
The Gujarati respondents were almost equally divided between those who spoke mainly MT and those who spoke mainly English to their children.

- $38.8 \%$ of Gujarati respondents spoke mainly their MT to their children

- $32.9 \%$ spoke mainly English

- $24.7 \%$ spoke roughly equal amounts of both languages.

Yee (1981: 69) found roughly similar proportions amongst a group of adult immigrant

Chinese mothers in Australia where $46.7 \%$ spoke mainly 'Chinese' to their children, $25.8 \%$ spoke mainly English and the remaining $27.4 \%$ spoke a mixture of both.

Even amongst those who arrived in New Zealand age 10+, most of the Dutch respondents spoke English to their children (78.5\%). The remainder were equally divided between those who spoke mainly Dutch to their children and those who spoke a 50/50 mixture of Dutch and English.

\subsubsection{Languages used with children: New Zealand-born respondents}

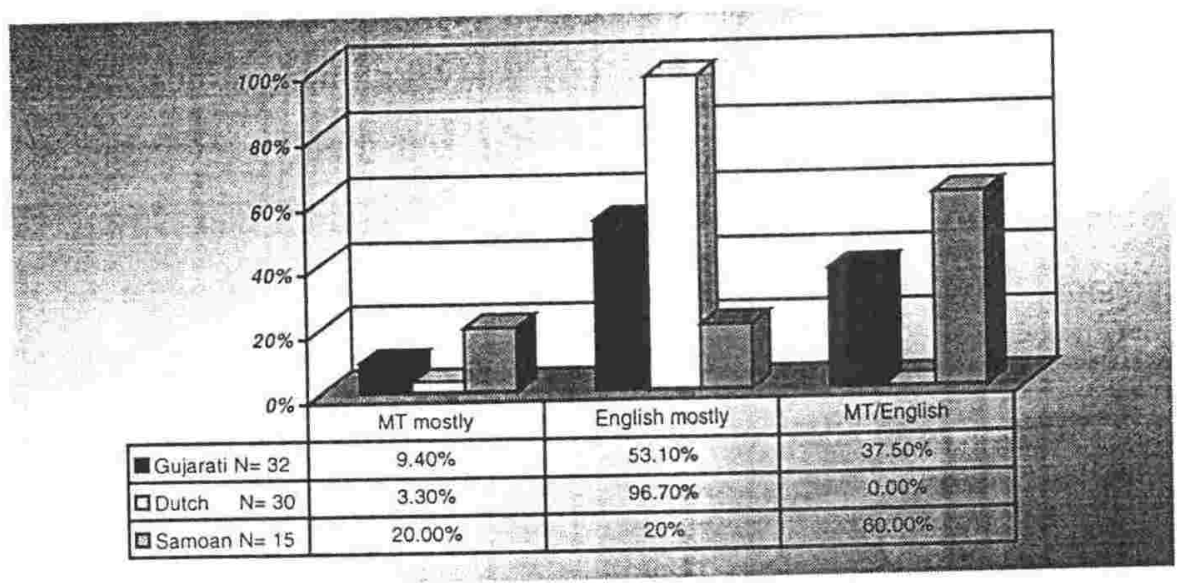

Figure 11-12: Language spoken with children: All NZ-born respondents

The respondents born in New Zealand exhibit a fairly predictable pattern.

- virtually all the New Zealand-born Dutch respondents speak mainly English to their children

The New Zealand-born Gujarati respondents are also likely to speak mainly English with their children.

- over half the Gujarati respondents speak mainly English to their children

- a substantial minority (37.5\%) speak 50/50 English/Gujarati

- a small number $(9.4 \%)$ speak mainly Gujarati to their children

Just as the Gujarati respondents who arrived in New Zealand age ten and over were not dissimilar from the adult Chinese immigrants studied by Yee, so the New Zealand-born 
Gujarati respondents were not dissimilar from the New Zealand-born Cantonese respondents studied by Roberts (1990). That study found that $51 \%$ of the 51 Cantonese respondents used exclusively English with their children and 7.8\% used mainly Cantonese. A sizeable $41.2 \%$ used both Cantonese and English but this includes people who used only a small amount of Cantonese along with those who used roughly equal amounts of both languages (Roberts 1990: 130).

Amongst the Samoan respondents (and it must be borne in mind that they are a small group) most speak roughly 50/50 English and Samoan to their children, and the remainder are equally divided between those who speak mainly English and those who speak mainly Samoan.

- $60 \%$ speak roughly equal amounts of MT/English

- $20 \%$ speak mainly English

- $20 \%$ speak mainly Samoan

Hayden in 1966 found that his second-generation respondents varied considerably in their use of the MT to their children. Curiously the lowest and the highest rates of usage were both reported by Ukrainian respondents ${ }^{145}$ (Hayden 1966: 199-200). The Ukrainians of Olyphant reported the lowest usage with $3 \%$ of respondents using Ukrainian with their children, and in Newark, $69 \%$ of the Ukrainian respondents used Ukrainian with their children. This strongly suggests that ethnic background is not the only, nor even the main, variable in language maintenance processes. Rather the social background, immigration and settlement histories of the immigrants (which were different in the case of the two Ukrainian groups) are just as important if not more so.

\footnotetext{
${ }^{145}$ It is not possible to establish from the article whether Hayden's respondents are all male or not. He consistently refers to them as 'he' but the usage may possibly be generic.
} 


\subsubsection{Comparison of MT use with spouse and with children}

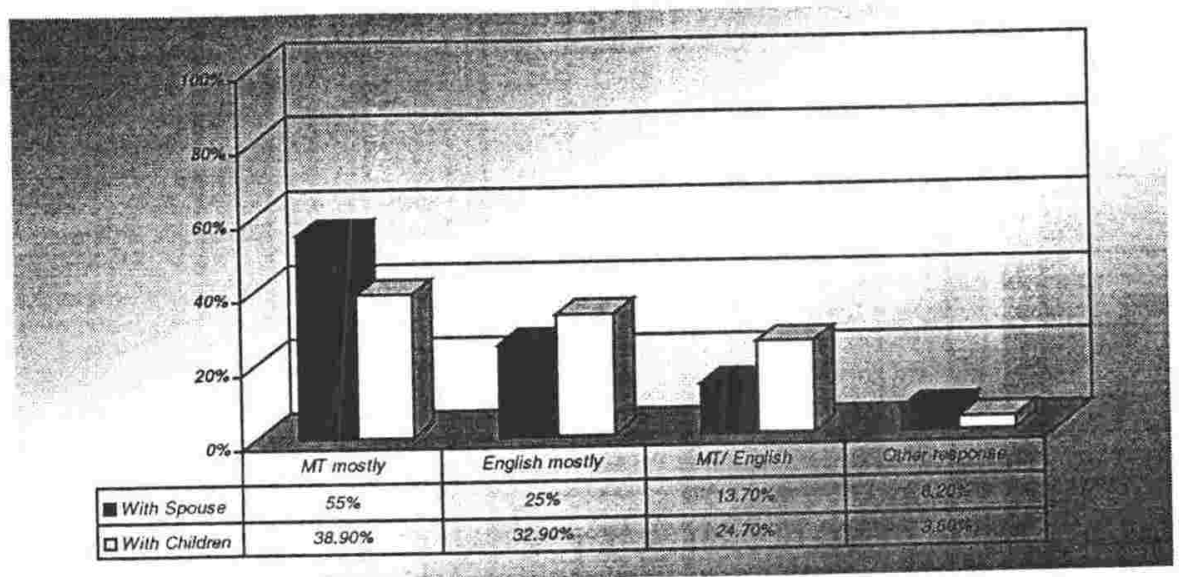

Figure 11-13: Gujarati respondents arrived in NZ 10+: languages spoken with spouse and children

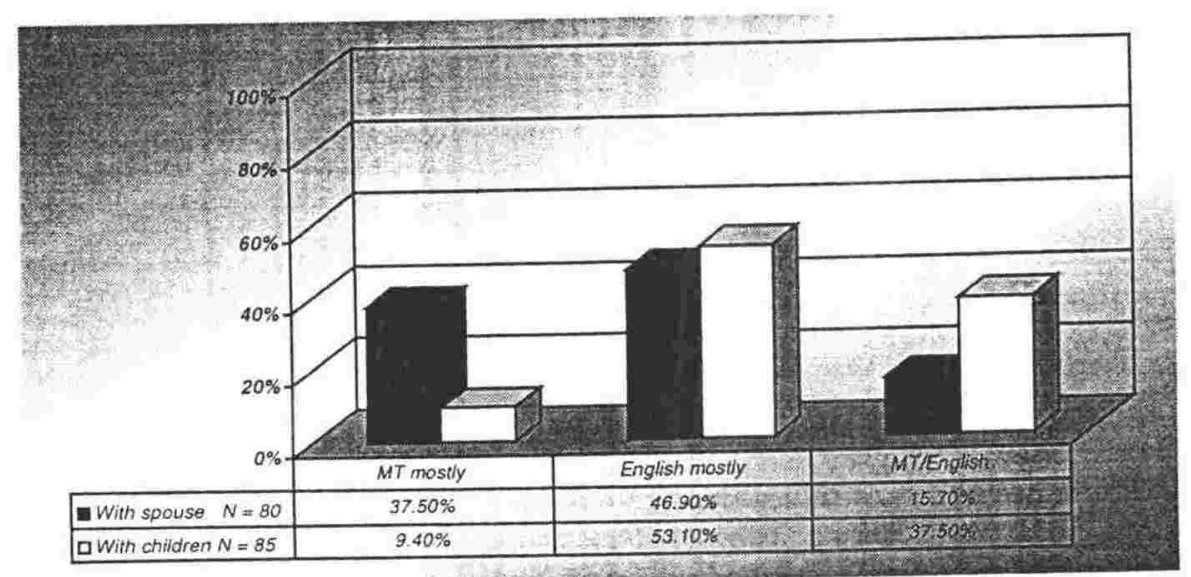

Figure 11-14 Gujarati respondents born in NZ: languages spoken with spouse and children

In the Gujarati community respondents were more likely to speak Gujarati with their spouses and more likely to use English with their children but there was still a substantial proportion (38.9\%) of non-New Zealand-born respondents who arrived in New Zealand age 10 and over who spoke mainly Gujarati to their children. Amongst the New Zealand-born it was noticeable that although relatively few respondents spoke mainly Gujarati to their children, nonetheless a substantial minority reported that they spoke roughly 50/50 English and Gujarati to their children. 


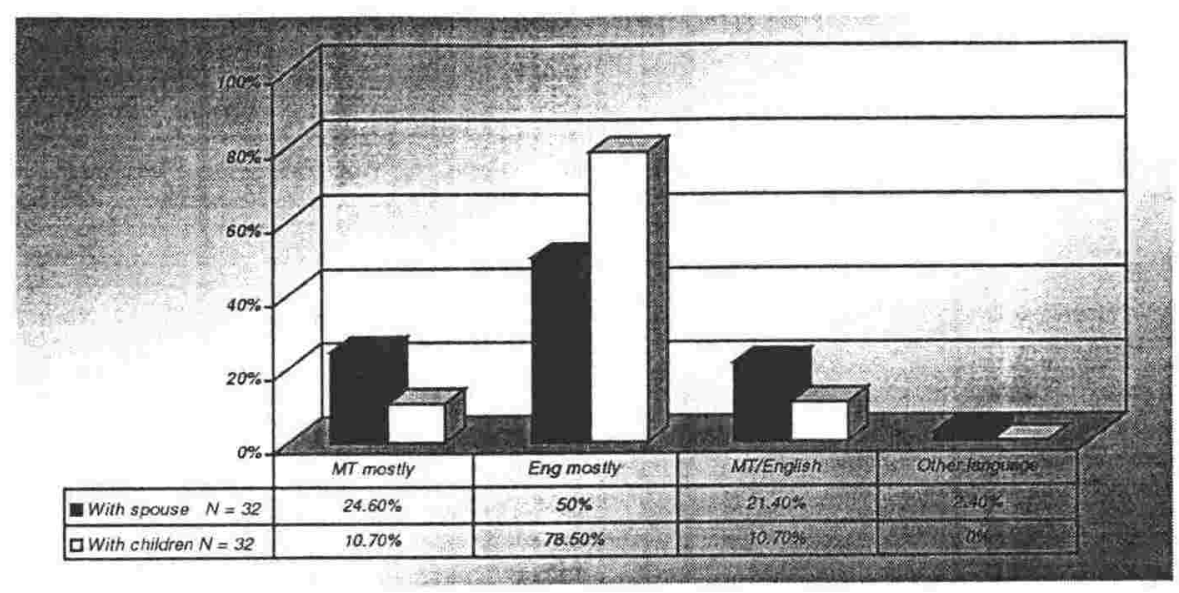

Figure 11-15: Dutch respondents arrived in NZ 10+: languages spoken with spouse and children

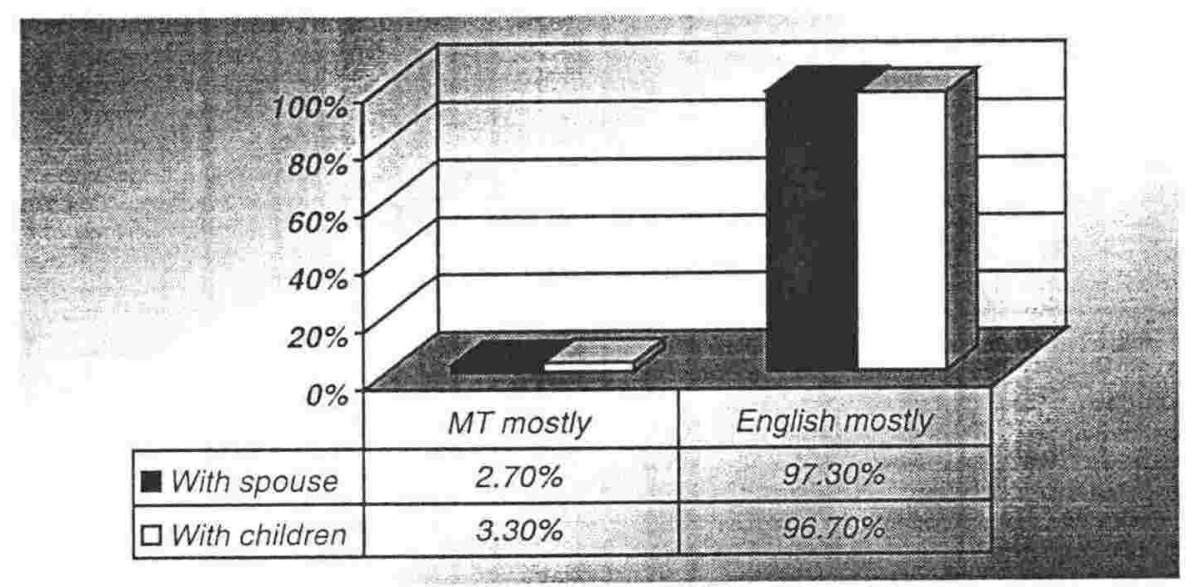

Figure 11-16: Dutch respondents born in NZ: languages spoken with spouse and children

The non-New Zealand-born Dutch respondents are slightly more likely to use Dutch with their spouses than with their children, although half of them do use English most of the time. The New Zealand-born respondents simply use English, and it makes almost no difference whether they are speaking with their spouse (who, in many cases, is not of Dutch extraction) or their children. 


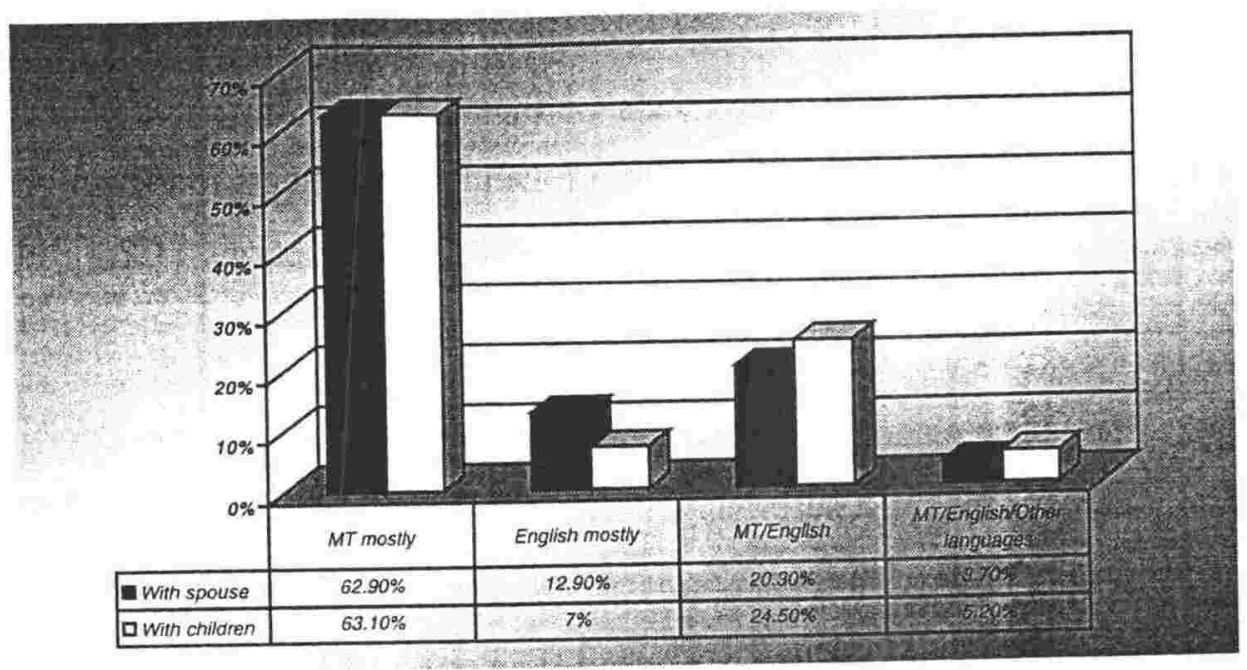

Figure 11-17: Samoan respondents arrived in NZ 10+: languages spoken with spouse and children

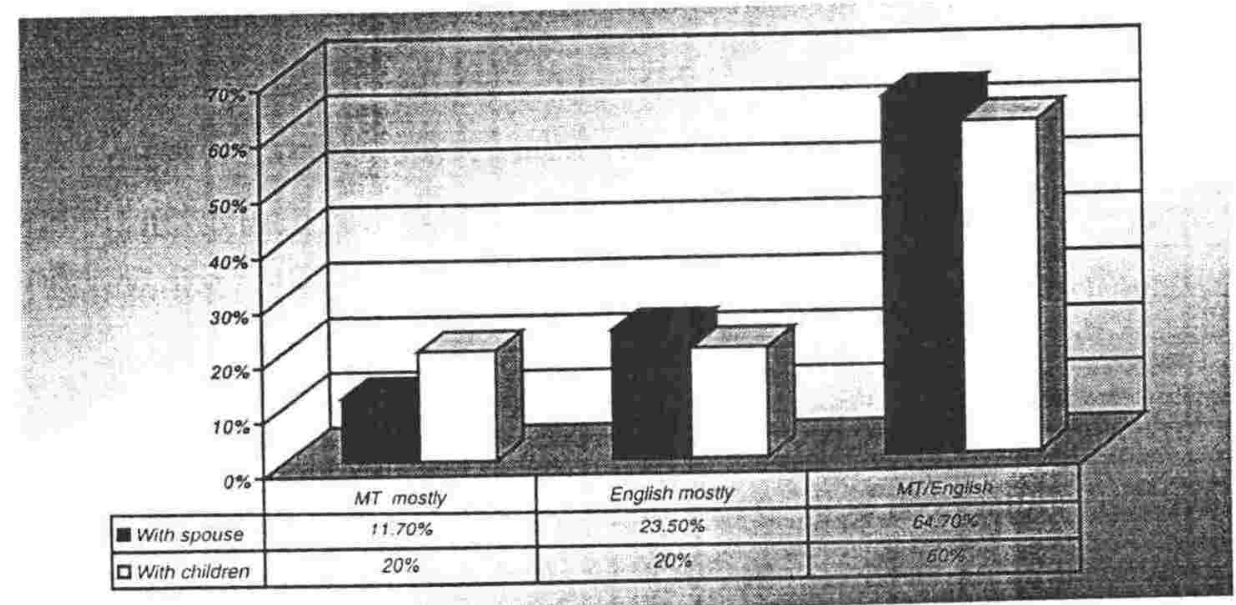

Figure 11-18: Samoan respondents born in NZ: languages spoken with spouse and children

Most Samoan-born respondents spoke mainly Samoan to their spouses and children and most of the New Zealand-born Samoan respondents spoke roughly 50/50 Samoan and English to their spouses and children. The New Zealand-born Samoan respondents differed from the New Zealand-born Gujarati and Dutch respondents in that there was not a substantial shift to speaking mainly English in their households.

It is interesting to note that the New Zealand-born respondents were more likely to speak 'mostly' Samoan to their children than to their spouses which suggests a certain amount of conscious effort at language maintenance.

\subsection{Summary: language use in the home with spouse and children}

If speaking MT to one's children is a necessary condition for language maintenance, then we can see that the Gujarati and Samoan immigrant respondents have tended to fulfil that 
condition and that, in turn, the New Zealand-born respondents from those groups, tend to be able to speak their MT. The immigrant Dutch respondents, on the other hand, have not tended to use their MT with their children and the New Zealand-born Dutch respondents to the questionnaire have, correspondingly, a lesser competence in their MT (see sections 11.7.4 and 11.7.5).

Only a few of the New Zealand-born respondents in any of the three groups use a lot of the MT with their children but perhaps the most surprising disparity appears in the New Zealandborn Gujarati respondents. Over a third of the New Zealand-born Gujaratis speak Gujarati 'most of the time' with their spouses, but under $10 \%$ of them speak it, 'most of the time', with their children ${ }^{146}$. This is obviously not because of either inability or unwillingness to speak Gujarati, as they are speaking it regularly with their spouses. Admittedly, many of these respondents are married to non-New Zealand-born spouses and they may be relying on their spouses to provide the Gujarati language input for their children. Nevertheless, it is a considerable disparity in language use within a single household. There was perhaps, a slight gender imbalance here, but the numbers are so small as to be merely suggestive. Half of the 12 respondents who spoke mainly Gujarati to their spouses, spoke mainly English to their children. Four of these six respondents were men and two were women. Of the two respondents who spoke mainly Gujarati to both spouse and children, one was male, one female. The remaining four respondents who spoke 50/50 Gujarati/English to their children. This group was also equally divided; two mothers, two fathers. Thus of the New Zealand-born respondents who spoke mainly Gujarati with their spouses (and are therefore presumed to be reasonably fluent and confident users of Gujarati) under half the women (two out of five) and over half the men (four out of seven) used mainly English with their children.

The foregoing sections of this chapter address themselves to the first part of the integrated model derived from Fishman's theories of language maintenance and shift, issues of habitual daily language use in one particular domain, the home, acknowledged as vitally important in the process of language change. The focus is on domain as represented by locale and interlocutor/s, and also on the role relationships of spouse-to-spouse, parent-to-child communication. The degree of bilingualism in terms of daily practice and the issue of

\footnotetext{
${ }^{146}$ There was one New Zealand-born respondent who spoke English 'most of the time' with her husband but Gujarati with her children.
} 
performance - that is, the respondent's actual use of the MT and English has also been investigated - language shift has been shown to be most advanced amongst the Dutch and less advanced amongst the Gujarati and Samoan respondents. On most measures, global amount of MT used at home, less likely to use mainly English with spouse, more likely to speak mainly MT with children, the Samoans seemed to use more MT than the Gujarati. However there were some signs of more language maintenance amongst the Gujarati respondents. New Zealand-born Gujarati respondents were more likely than New Zealand-born Samoan respondents to speak MT with their spouses and, conversely, the New Zealand-born Samoans were more likely to use a mix of MT/English than the New Zealand-born Gujarati respondents. It seems possible that while, because the Samoan community is newer in New Zealand than the Gujarati, there is still considerable 'natural' MT use in the community, that the longer established Gujarati community has 'better' language maintenance habits. Habitual patterns of language use in the family/home domain having been presented, the next sections turn to the questions of causes. What influences successful MT acquisition within the immigrant family context?

\subsection{MT use in the family: what influences successful acquisition?}

If the family is the foremost bastion of MT language maintenance then it is particularly important to know how the MT is being handed on within the family environment and what factors appear to be linked both with MT use with children and with successful acquisition of the MT by children. It is taken for granted here that without environmental, preferably parental, use of the MT, there can be no childhood MT acquisition, but it is also assumed than this is a necessary rather than a sufficient condition for the successful acquisition.

The factors discussed in this section that appear on the basis of this research, to be linked in some way with the respondents' use of MT with their children are all related to section 1(b) of the integrated model. They concern processes of dislocation, sociocultural processes and their relationship to habitual language use; the age of the respondent's ${ }^{147}$ children, the level of education attained by the respondent, the gender of the respondent, the contexts in which the respondent uses the MT outside the home, whether or not the respondent has married

\footnotetext{
${ }^{147}$ In this section, some families are reported on twice because both the wife and the husband were respondents to the questionnaire. As the focus is on the individual actions of each respondent, the answers of couples have not been conflated into a 'family' answer but it should be born in mind that, in most cases, the number of respondents does not equal the number of families.
} 
endogamously, and last but very far from least, where the respondent was born are all examined to see how they might relate to language maintenance and shift amongst the three immigrant groups under consideration.

\subsubsection{The age of the respondent's children}

This is a difficult area in which to come to any definite conclusions. To some extent, age of child acts as a proxy for the sociocultural processes from section 1 (b) of the integrated model. Younger children are likely to have younger parents, who are more likely to be New Zealandborn (highlighting the importance of birthplace as a major indicator of immigrant dislocation) and more likely to have had a university education either in New Zealand or the homeland (highlighting the importance of education as a sociocultural process affecting language use and its possible role as a culturally dislocating factor, see section 11.5 .2 below). It is also possible however that use of the MT is part of a life-cycle process. In the following sections, the Dutch appear to provide the most clear-cut example of a change in habitual language use patterns. The Samoans still use mainly MT and the Gujarati patterns of use are hard to interpret.

\subsubsection{Gujarati respondents and age of children}

In the case of the Gujarati respondents, older children were more likely to be spoken to in Gujarati and younger children in English. It must be stressed that this is only a tendency and not a rule. It is generally the case, of course, that if the children are older, so are the parents. It does not seem to be possible to disentangle these two variables completely but there are two points that should be mentioned. The younger respondents are more likely to have had a university education and, amongst the Gujarati respondents, this too has been correlated with using English to children. However, it is certainly not the case that all respondents who speak English to their children have a university education.

If the parents are very old and retired from the work-force, a shift away from English and towards the MT might be expected. As only $12 \%$ of the total Gujarati sample were age 60 or over, this does not seem to be a very strong factor although it is true that none of the respondents who were age 60+ spoke mainly English with their children. Age of child is linked to age of respondent, which is linked to birthplace, education, and employment status of the respondent - all important parts of the integrated Fishman model. Birthplace is one of 
the basic measures of dislocation and education is an important measure of sociocultural processes relating to language change. The complicated interaction of these factors within the Gujarati respondent group makes it very hard to draw any hard and fast conclusions.

\subsection{Spoke mainly Gujarati to children}

Parents who spoke Gujarati to children were likely to have older children. Only 15 of the 38 respondents (39.4\%) who spoke mainly Gujarati to their children had families where the youngest or only child was 18 years old or younger.

There were only three New Zealand-born respondents who spoke mainly Gujarati to their children and they, as might be expected, all had young families. Two of the respondents had one five year old child each, and one respondent had an oldest child of nine years and a youngest of two years (because of the design of the questionnaire we do not know how many children he had in total). Two of the respondents said they spoke mainly Gujarati with their spouse and one said that she spoke mainly English (but her husband was able to speak Gujarati).

\subsection{Spoke mainly English to children}

Just under half (17) of the New Zealand-born respondents with children spoke English most of the time with their children and all of these respondents had families where the youngest or only child was 18 years old or younger (for 15 of the 17 , the oldest child was 17 years old or younger).

Of the 39 non-New Zealand-born respondents who spoke English to their children perhaps the most noticeable fact was that for 34 of them (87.1\%) their youngest child was aged 18 or under. Amongst the Gujarati respondents as a whole $68.7 \%$ had an only child or a youngest child aged 18 and under. This suggests that non-New Zealand-born respondents were more likely to speak to their children in English if the children were younger (and in many cases still living at home), and more likely to use Gujarati if their children were older.

\subsection{Spoke Gujarati and English to children}

Parents who spoke roughly 50/50 Gujarati and English with their children were also likely to have younger children. Of the 36 respondents who did report that they used both languages 
equally, 27 (75\%) had families where the youngest or only child was 18 or younger and in 16 of those 27 families, the oldest child was 16 years old or younger.

\subsubsection{Dutch respondents and age of children}

\subsection{Spoke Dutch to children}

Perhaps the most noticeable feature of the Dutch respondents who spoke mainly Dutch to their spouse and/or their children, is that there were so few of them. The handful (14) who did speak Dutch to their children, also spoke mainly Dutch to their spouse except for one respondent who was married to a non-Dutch spouse. All the respondents and their spouses (except for the exception already mentioned) were raised in The Netherlands (two respondents were born elsewhere but raised in $\mathrm{Holland}^{148}$ ). The other noticeable characteristic is that, on the whole, their children are still quite young.

Table 11-4: Age range of children in families where Dutch is the main language

\begin{tabular}{|l|l|l|}
\hline Family & Oldest Child & Youngest child \\
\hline 1 & 27 & 16 \\
2 & 22 & 15 \\
3 respondent a & 16 & 07 \\
3 respondent b & 16 & 07 \\
4 & 16 & 04 \\
5 & 08 & N/A \\
6 & 07 & 05 \\
7 respondent a & 05 & 03 \\
7 respondent b & 05 & 03 \\
8 respondent a & 02 & 1.5 \\
8 respondent b & 02 & 1.5 \\
9 & 02 & N/A \\
10 & 01 & N/A \\
\hline
\end{tabular}

As can be seen from the above table (which also shows that there are three couples included in the 14 respondents who speak mainly Dutch to their children) most of the children are very young; primary school age or younger, and even in the families with older children, two of them include primary school age or younger children. The three respondents with children of $20+$, also have teenage children who are probably still at home. My very tentative guess is

\footnotetext{
${ }^{14 x}$ One of them was born in New Zealand which is why there is one respondent in the 'Born in New Zealand' data who appears as speaking Dutch to his children and spouse - but as he was raised in The Netherlands, it is a misleading figure.
} 
that these parents, whose children were all born comparatively recently, have been less affected by the 1950s - 1960s drive to assimilation, with its emphasis on ceasing to use the MT and becoming monolingual speakers of English. These parents have chosen to attempt to maintain Dutch in their families in New Zealand. The establishment of Dutch language maintenance classes for children in Wellington (in 1995) shows that there has been a change of mood in the last few years among members of the Dutch community in NZ and these respondents seem to be part of that change. Even so, these respondents are in a minority. There are 69 respondents with youngest children age 18 and under, and another eight respondents who have only children in that age bracket. Only 14 of those 77 respondents have decided to speak Dutch to their children as their main language. This is an area where the high rate of exogamy in the Dutch community also comes into play. As noted above all those respondents who spoke mainly Dutch to their children were raised in the Netherlands and all but one of them was married to a partner who was raised in the Netherlands. The eight respondents who spoke 50/50 Dutch English to their children were also born in the Netherlands and married to partners born in the Netherlands.

\subsection{Spoke English to children}

A hundred and thirty three $(82.6 \%$ ) of the 161 Dutch respondents with children spoke English to their children most of the time. It has already been shown that having children who are still young enough to be at school is a factor which correlates with respondents using mainly Dutch with their children. In this section the Dutch respondents with younger children, who spoke English to their children, are examined. Is there a reason why these respondents, unlike the others with young children, are using English rather than Dutch with their children?

There were 55 respondents (whose youngest or only child was age 18 or under) who spoke mainly English to their children. What factors appeared to influence their choice? 29 were born and raised in New Zealand, which is probably the major factor in their decision to speak English to their children. The remaining 26 were born in the Netherlands or Indonesia. Of those 26 , only four were married to partners who were born in the Netherlands. Thus only four of this group were in an endogamous marriage where it would have been comparatively easy for them to speak Dutch to their children. This means that of 18 non-New Zealand-born respondents who are still raising teenage and younger children at home and who are married to non-New Zealand-born partners, 14 (77.7\%) are speaking mainly Dutch to their children. This lends weight to the suggestion made in 11.5.1.2.1 that there may have been a change in 
the attitude of Dutch parents in New Zealand to raising their children in a Dutch speaking household, and that today they are much more likely to do so than they were in the past. Only $51.5 \%$ of the 33 New Zealand-born respondents with both mother and father born in D.E.I. or the Netherlands reported that their parents 'always' or 'mostly' spoke Dutch to them.

\subsubsection{Samoan respondents and age of children}

Most of the Samoan respondents speak Samoan to their children. When we look at the small number who do speak English to their children we see that most of them have children who are very young. Six of the eight respondents have families in which the oldest child is ten years or younger, one has a family in which the oldest child is 14 and the youngest seven. Only one of the respondents in this group has any adult children; his oldest child is 24 and the youngest is 16 . However, age of children is not, in this case, a proxy for birthplace of parents. Four of the respondents were born in Samoa and three in New Zealand (one is 'unclear'). In three of the eight families, the respondent has a university education (of the 41 respondents who speak mainly Samoan to their children only four have a university education.

\subsubsection{Summary: parental use of MT and age of children}

Broadly speaking, having young children who are still living at home seems to be linked to English use in the case of the Gujarati and Samoan communities and linked to MT use in the case of the Dutch community. Analysis of this factor (age of children) in MT usage is complicated by the fact, already noted, that age of child correlates to some extent with age of respondent and this correlates in turn, to some extent, with the birthplace of the respondent and the likelihood of university education. It is not possible to disentangle these strands completely, but it does seem to be possible to say that there seems to have been a change of attitude in the Dutch community, and that more Dutch parents now want to use Dutch with their children (the accuracy of this conclusion is supported by the creation of Dutch language maintenance schools in the last few years). It also seems possible that non-New Zealand-born Gujarati and Samoan respondents with younger children may be using less MT with their children than those with older children. It is hard to know whether this is a life cycle phenomenon, and they will start to use more MT with their children eventually or whether it signals a change in attitude to MT use in the home in those communities. This is an area where longitudinal research would yield very interesting results. Amongst the Dutch respondents it seems at least possible that age of children is a marker for a point in time when 
the attitudes of the Dutch immigrant community in New Zealand towards assimilation and language and culture maintenance began to change. No such conclusions are possible for the Gujarati and Samoan communities.

\subsubsection{The level of education attained by the respondent}

Sridhar, in her study of language maintenance amongst various Indian communities in New York, found that it was only amongst the Gujarati community that fairly high levels of MT use were maintained (Sridhar draft:20) and she suggests that this might be because the Gujarati mothers were 'less educated' than the mothers in the other groups. Thus she draws a direct correlation between level of education and level of MT use. This survey found a similar correlation for the Gujarati and Samoan respondents (see also section 10.4.5 for discussion of the effects of university education on language maintenance processes). The relationship between level of education and MT use with children falls into category $1(b)$ of the integrated model: 'antecedent social and cultural processes and their relationship to stability or change in language use'. It might seem that university education is a product of New Zealand upbringing and/or education and thus it is a part of immigrant process of social and cultural dislocation that helps cause language shift. This may be partially true, but many of the university-educated Dutch and Gujarati respondents received their university education outside New Zealand so there is obviously not straightforward relationship of immigrant dislocation in this case. It could perhaps be argued that the dislocation occurs outside the immigration nexus - that university education is, in itself, a process of dislocation the student from a local set of references and a parochial framework and putting her in conjunction with global references and an internationalising framework. There is some truth in this argument, and to that extent the social and cultural dislocation of a university education may be argued to be a factor in language shift. However, the relationship is not unambiguous, it does not appear to exist at all in the case of the Dutch respondents and the Gujarati respondents with a purely university education are more likely to speak Gujarati with their children than those with other kinds of tertiary education. Level of education appears to be an antecedent sociocultural process that is related to MT use (or lack of it) with children but the exact nature of the relationship is still opaque. 


\subsubsection{Gujarati respondents use of MT with children and respondent's level of education}

Amongst the Gujarati respondents, higher levels of education correlate with an increased tendency to speak English to one's children. There were 111 respondents with children, 79 non-New Zealand-born and 32 New Zealand-born, who answered the questions about education and about language spoken to children.

There were six respondents (all Gujarat-born) who had completed only a primary education. Two of them spoke mainly English to their children and four spoke mainly Gujarati.

Of the 43 people who had completed secondary education

- $25.5 \%$ spoke mainly English to their children and

- $37.2 \%$ spoke mainly Gujarati

- $34.8 \%$ Gujarati / English

Turning to those respondents who have completed some kind of tertiary education we find they are more likely to speak English to their children than those who have completed only primary or secondary education. Those who have completed a tertiary but non-university education are less likely to speak Gujarati to their children than those who have completed a solely university-based education.

- Just over half (52.3\%) of those 21 respondents (13 New Zealand-born, 8 nonNew Zealand-born) who have completed a non-university tertiary education speak mainly English to their children; exactly a third speak Gujarati / English and only $9.5 \%$ speak mainly Gujarati.

- The 13 respondents ( 10 non-New Zealand-born, 3 New Zealand-born) with both a non-university and a university qualification (teaching or librarian qualifications in addition to university degrees for instance) are not likely to speak predominantly Gujarati to their children; $69 \%$ speak mainly English and $30 \%$ speak Gujarati / English.

- The 23 respondents (17 non-New Zealand-born, 6 New Zealand-born) who have a university qualification but no other tertiary qualification, are more likely $(34.7 \%)$ to speak mainly Gujarati to their children. Slightly over half of them speak mainly English and 13\% speak Gujarati / English. I am at a loss to suggest a reason for this unless it is that the more liberal, less vocational nature of university education has encouraged a less utilitarian view of language than the more vocationally oriented education represented by the other tertiary qualifications. 


\subsubsection{Dutch respondents use of MT with children and respondents' level of} education

Amongst the Dutch respondents, level of education did not appear to correlate very strongly, if at all, with the language spoken to children. There were four respondents with only a primary education; two spoke mainly English and two spoke Dutch / English.

Of the remaining respondents, over $80 \%$ of the 37 secondary educated, 59 non-university tertiary educated and 47 university educated respondents spoke mainly English with their children. A handful in each category spoke mainly Dutch or Dutch / English.

\subsubsection{Samoan respondents use of MT with children and respondents' level of education}

Amongst the Samoan respondents, as with the Gujarati, there was a correlation between increasing level of education and increasing likelihood of speaking English with children.

Three of the respondents with children had attended only primary school. Two of them spoke Samoan to their children, while one spoke English, Tokelauan and Rarotongan. There were seven respondents whose level of education was unclear and they spoke Samoan (1 respondent), English (2 respondents) and Samoan / English (4 respondents) to their children.

The respondents with a secondary school education tended to speak mainly Samoan to their children (77.2\%), 9\% speak mainly English to their children and 13.6\% speak Samoan / English to their children.

There were 30 respondents with children with a tertiary but non-university education, ten with a tertiary and university education and five respondents with a university education. As there are so few respondents with solely a university education, the tertiary university and solely university categories will be combined.

A substantial number (60\%) of respondents with a non-university tertiary education spoke mainly Samoan to their children, 6.6\% spoke mainly English and the remaining third spoke Samoan/English. Amongst those with a tertiary and/or university education, a third spoke 
mainly English to their children, just over a quarter (26.6\%) spoke Samoan and $40 \%$ spoke Samoan/English ${ }^{149}$

If one takes a university qualification as the highest level of educational qualification, the Samoan respondents exhibit a straightforward progression of higher education being associated with higher levels of English speaking to children.

\subsubsection{Summary: level of education and use of MT with children}

Level of education appears to be a factor in language spoken with children in the Gujarati and Samoan communities but not the Dutch community. It should also be noted that the Gujarati and Samoan respondents do not show exactly the same pattern. Tertiary educated respondents in both groups are more likely to use English with their children than secondary educated respondents, but the Gujarati respondents with a non-university tertiary education are less likely to use their MT than those with a solely university education, whereas amongst the Samoan respondents those with a non-university tertiary education are more likely to use MT than those with a solely university education. Because of the comparatively small numbers and non-random nature of this survey, these findings can only be indicative, but they do suggest the complexity of the nature of the relationship of education to attitudes and behaviours towards language.

Samoans overall have the highest reported usage of the MT. Hayden (1966:197) links appreciation of 'cultural bilingualism' with higher levels of education and a non-'peasant' origin. As already noted, Sridhar proposes a completely opposite causal link between education and language maintenance for the Gujarati community in New York. The Samoans in this study, with a generally lower educational level than the Gujarati and Dutch respondents seem to support Sridhar's theory (in a New Zealand context at least). On the other hand, the Dutch in Wellington may well be like the Franco-Americans in Fall River and the Ukrainians in Olyphant. These are the least MT retentive communities in Hayden's study and he suggests that this is not necessarily because of external practical pressures "but rather because of internalized preferences for English' (Hayden 1966:201).

\footnotetext{
${ }^{1+9}$ This $40 \%$ (6 respondents) includes two respondents who spoke Samoan, English and Tokelauan with their children.
} 
In section 10.4.5 parental level of education was correlated with children's ability to speak the MT. Gujarati respondents with secondary education were more likely than those with tertiary education to have children who used the MT, which would appear to be related to the fact that Gujarati respondents with secondary education were more likely to speak Gujarati with their children.

In the case of the non-New Zealand-born Dutch respondents (too few of the New Zealandborn had Dutch speaking children to make a comparison worthwhile) there appeared to be a slight relationship for eldest children between parental level of education and the children's use of Dutch (the lower the level, the greater the likelihood of Dutch usage). The weakness of the relationship is perhaps connected to the fact noted here that there is only a weak connection between educational level of parents and use of Dutch with children is weak.

Because most of the Samoan children speak Samoan, the results of a correlation of parental level of education with children's use are not dramatic (section 10.4.5). The fact that parents with higher levels of education are less likely to use Samoan with children may, at this stage at least, be offset by the spouses of those parents still using mainly Samoan.

\subsubsection{The gender of the respondent}

The gender of the respondent falls across two categories of the integrated model. It falls in 1 (a) as part of the consideration of 'role relations' in language use, as the gender of the respondent is inextricably linked here with their role as 'mother' or 'father', and it falls into 1 (b) as an antecedent or concurrent sociocultural process. It is assumed that a respondent's relationship with the MT (or any other language) is mediated, partially, through sociocultural constructs of gender. These constructs and their effect in mediating an individual's relationship with language in general, also, obviously, effects language use decisions in a bilingual individual.

\subsubsection{Samoan}

Gender did appear to influence the language/s spoken by Samoan respondents with their children.

- $62.2 \%$ of the 45 female respondents with children spoke mainly Samoan to those children

- $43.7 \%$ of the 32 male respondents with children spoke mainly Samoan to those children 
This result may well be influenced by the disproportionate number of female Samoan respondents who were training to work in ao'ga amata. Jamieson, for instance, found that Samoan fathers were slightly more likely than mothers to use the MT to their pre-school age children (Jamieson 1980: 104)

\subsubsection{Gujarati and Dutch}

The gender of the respondent does not appear to have been a major factor for either the Dutch or the Gujarati respondents.

- $10.5 \%$ of the 101 Dutch mothers

- $6.7 \%$ of the 83 Dutch fathers spoke Dutch to their children most of the time.

Amongst the Gujarati respondents

- $33.9 \%$ of the 61 mothers

- $30.5 \%$ of the 80 fathers spoke Gujarati to their children most of the time

This, just, bears out Jamieson's finding that Indian (mainly Gujarati) mothers were more likely than fathers to speak their MT to pre-school children (Jamieson 1980: 104), but the difference is very slight. It also shows the same slight tendency for mothers to use the MT more than fathers as was seen in section 11.4. The Gujarati and Dutch respondents showed the same tendency as the Samoan respondents for the mothers to be more likely to use predominantly the MT with their children but in the case of those two groups the tendency is weak whereas in the case of the Samoan respondents it is quite strongly marked.

\subsubsection{Exogamous marriage and use of MT to children}

Exogamous marriage also falls into the category of 'social process' affecting language maintenance and shift. It is, in fact, one of the best known of such factors. However, the extremely low rates of exogamous marriage amongst the Gujarati and Samoan respondents and the extremely high rates amongst the Dutch, make it hard to come to any conclusion.

It was not easy to decide what to count as 'exogamous' marriage in the case of the Dutch. Language shift is so advanced amongst the New Zealand-born that at first it seemed that it might be reasonable to include the New Zealand-born Dutch respondents as 'exogamous' partners. Finally, however it was decided to follow the more standard definition and include all those of Dutch extraction, regardless of birthplace, as being an endogamous partner for any of the respondents. 
Amongst the non-New Zealand-born respondents, exogamous marriage could be said to be influential in that only one of the 33 non-New Zealand-born respondents who married exogamously, spoke mainly Dutch to her children. Endogamous marriage however was hardly a guarantee of MT use with children as only 13 of the 98 non-New Zealand-born respondents ${ }^{150}$ who married endogamously spoke Dutch with their children. It was amongst the endogamous speakers also that the 14 respondents who spoke a fairly equal amount of Dutch and English to their children were found.

Amongst the New Zealand-born and raised, marriage, whether endogamous or exogamous, made no difference as they all spoke mainly English with their children.

It is a common pattern in many immigrant groups for exogamous marriage to encourage or lead to language shift (see Clyne 1985: 196 for a discussion of the situation in Australia). Amongst the Dutch, the pattern is muted by the extreme shift from Dutch to English that has occurred throughout the community regardless of any or all variables that might be considered. Nonetheless, it can be noted that endogamous marriage within the first generation of Dutch immigrants to New Zealand can be linked to a greater likelihood of Dutch language use with between the respondent and the respondent's children. Amongst the New Zealandborn, marriage makes no difference. Taking a very broad-brush view it can be seen that language shift and exogamous marriage co-occur amongst the Dutch respondents and comparatively, language maintenance and endogamous marriage co-occur amongst the Gujarati and Samoan respondents. It may be that rather than a strictly causative relationship (i.e. a spouse who does not speak the MT cannot play a part in helping to maintain the MT) the relationship, while being in part causative, might also be more global. It may be that individuals and communities for whom culture and language maintenance are important are less likely to marry out and more likely to use the MT (and vice versa). Thus both behaviours (marriage and language use) are part of the same set of attitudes and behaviours towards culture and language.

\subsubsection{Parental proficiency in the MT and use of MT with children}

Competence or proficiency in the MT is an important part of the integrated model because it both gauges degree of language shift and can be related to performance or use of the MT.

${ }^{150}$ The total of 13 in fact includes the one New Zealand-born respondent who was raised in the Netherlands. 
Here proficiency in the MT is considered as a causative factor in MT or English use with children. As such, proficiency may be viewed as related to sociocultural dislocation, as it is the dislocation of immigration that leads to lower proficiency in the MT. Here parental competence is linked to language use with children. As one would expect, there is some relationship between proficiency in the MT and language spoken to children, in that those who are not proficient are unlikely to speak mainly the MT with their children. The reverse however, does not hold. If a respondent rates themselves as a proficient speaker of the MT, this is no guarantee that they will speak mainly the MT to their children. Yee (1981:69) found the same thing in a study of Chinese adult immigrants to Australia. Yee studied 62 Chinese families in Australia: the parents were adult immigrants to Australia (Yee 1981: 66) and hence, presumably fluent MT speakers and the children were born in Australia. Despite being fluent MT speakers, $16(25.8 \%)$ of the mothers spoke predominantly English with their children and another 27.4\% spoke both English and Chinese (Yee 1981: 69).

Percentage of respondents who are 'fluent' MT speakers and who speak mainly English to their children.

- 32 (57.1\%)of the 56 Gujarati respondents who speak mainly English to their children are fluent in Gujarati

- $87(65.4 \%)$ of the 133 Dutch respondents who speak mainly English to their children are fluent in Dutch

- 3 of the $8(37.5 \%)$ Samoan respondents who speak mainly English to their children are fluent in Samoan

Here, general attitudes to the importance of language maintenance seem more important than actual proficiency in the MT. That is, respondents are able to speak the MT (competence is not lacking) but they do not choose to speak the MT (the volition or attitude to do so is not there) and thus, they speak mainly English to their children (performance). This follows a predictable pattern. Despite fluency in the MT, the Dutch are most likely and the Samoans least likely to speak mainly English to their children. The Gujarati respondents fall between the other two groups. Those respondents in each group who did speak mainly the MT with their children were all 'fluent'. ${ }^{|5|}$

\footnotetext{
${ }^{151}$ There was one Gujarati respondent in this category who skipped the proficiency question and one who entered no response. Other than this all respondents were 'fluent'.
} 


\subsubsection{Where the respondent was born and use of MT with children}

The integrated model derived from Fishman's theories of language maintenance and shift places considerable stress upon dislocation as a cause of language shift. Nothing shows this more clearly than the overwhelming importance of birthplace as an indicator of MT use.

The birthplace of a respondent is probably the single strongest indicator of whether or not that respondent will speak mainly English or mainly MT with their children, although its strength varies considerably for each group. Overall it is true that if a respondent is born outside the linguistic and cultural centre for their group, they are unlikely to speak mainly their MT to their children. Thus African-born, Fijian-born and New Zealand-born Gujarati respondents will not speak mainly Gujarati to their children. D.E.I.-born and New Zealand-born Dutch respondents will speak mainly English to their children and New Zealand-born Samoan respondents will speak Samoan/English to their children.

11.5.6.1 Language spoken by Gujarati respondents with children by birthplace

- $37.1 \%$ of the 89 respondents born in Gujarat spoke mainly Gujarati to their children

- $16.6 \%$ of the 12 respondents born elsewhere spoke mainly Gujarati to their children

- $9.4 \%$ of the 32 respondents born in New Zealand spoke mainly Gujarati to their children

- $34.8 \%$ of the 89 respondents born in Gujarat spoke mainly English to their children

- $66.6 \%$ of the 12 respondents born elsewhere spoke mainly English to their children

- $53.1 \%$ of the 32 respondents born in New Zealand spoke mainly English to their children

- $24.7 \%$ of the 89 respondents born in Gujarat spoke Gujarati / English to their children

- $16.6 \%$ of the 12 respondents born elsewhere spoke Gujarati / English to their children

- $34.3 \%$ of the 32 respondents born in New Zealand spoke Gujarati / English to their children ${ }^{152}$

\footnotetext{
${ }^{152}$ Totals do not necessarily add up to $100 \%$ as 'no response' returns have not been included.
} 
- Respondents born in Gujarat were roughly equally likely to speak mainly Gujarati or mainly English to their children and somewhat less likely to speak Gujarati /English with them.

- Respondents born in New Zealand and elsewhere were more likely to speak mainly English to their children and quite likely to speak Gujarati /English with them. They were very unlikely to speak mainly Gujarati.

- Respondents born elsewhere were likely to speak mainly English to their children.

\subsubsection{Language spoken by Dutch respondents with children by birthplace}

For the Dutch respondents the correlation between birthplace and language spoken to children is very simple; all the respondents born in D.E.I. or born and raised in New Zealand ${ }^{153}$ speak mainly English to their children, as do $77 \%$ of the respondents born in The Netherlands.

There is however, a handful of the 118 Dutch-born respondents with children who do speak mainly Dutch (11\%) or Dutch / English (12\%).

\subsubsection{Language spoken by Samoan respondents with children by birthplace}

For the Samoan respondents birthplace also affects the extent to which they use the MT to their children. Although New Zealand-born respondents still use Samoan, they also report that they use quite a lot of English with their children.

- $61.2 \%$ of the 62 Samoan-born respondents with children spoke mainly Samoan with their children

- $60 \%$ of the 15 New Zealand-born respondents with children spoke Samoan / English with their children.

\subsubsection{The contexts in which the respondent uses the MT outside the home}

Fishman observes that

The consequences that are of primary concern to the student of language maintenance and language shift are ... degrees of maintenance or displacement in conjunction with several sources and domains of variance in language behavior Fishman 1971: 302)

It seemed possible that parental use of the MT with children, the degree of maintenance or displacement within the parent-child role relationship, would be related to maintenance or displacement of the MT in environments outside the home as well. If this was the case then

\footnotetext{
${ }^{153}$ There is one New Zealand-born respondent who was raised in The Netherlands and who speaks mainly Dutch to his children.
} 
we would expect to find that respondents who reported that they commonly used the MT with only one type of interlocutor or in only one kind of domain would be more likely to speak only English with their children. As the following tables show, speaking the MT outside the home in only one domain seems to be quite strongly linked to speaking only English to one's children.

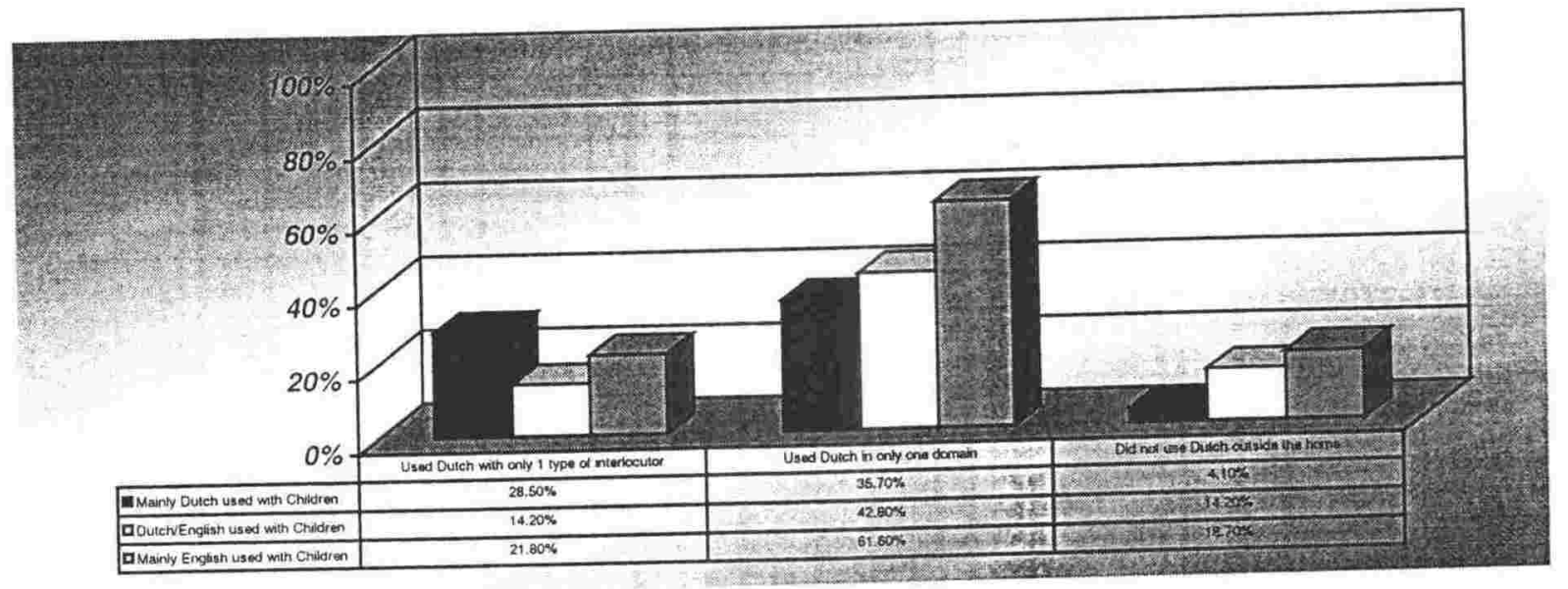

Figure 11-19: Dutch respondents; limited MT use outside the home

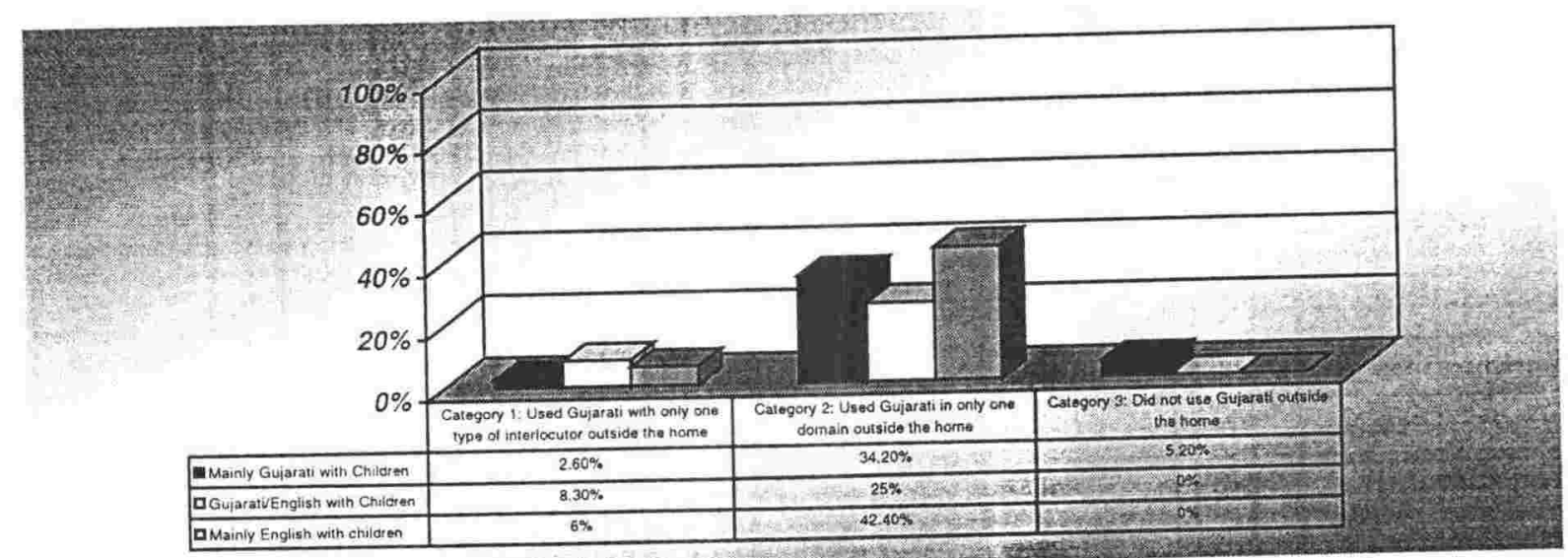

Figure 11-20: Gujarati respondents; limited use of MT outside the home 


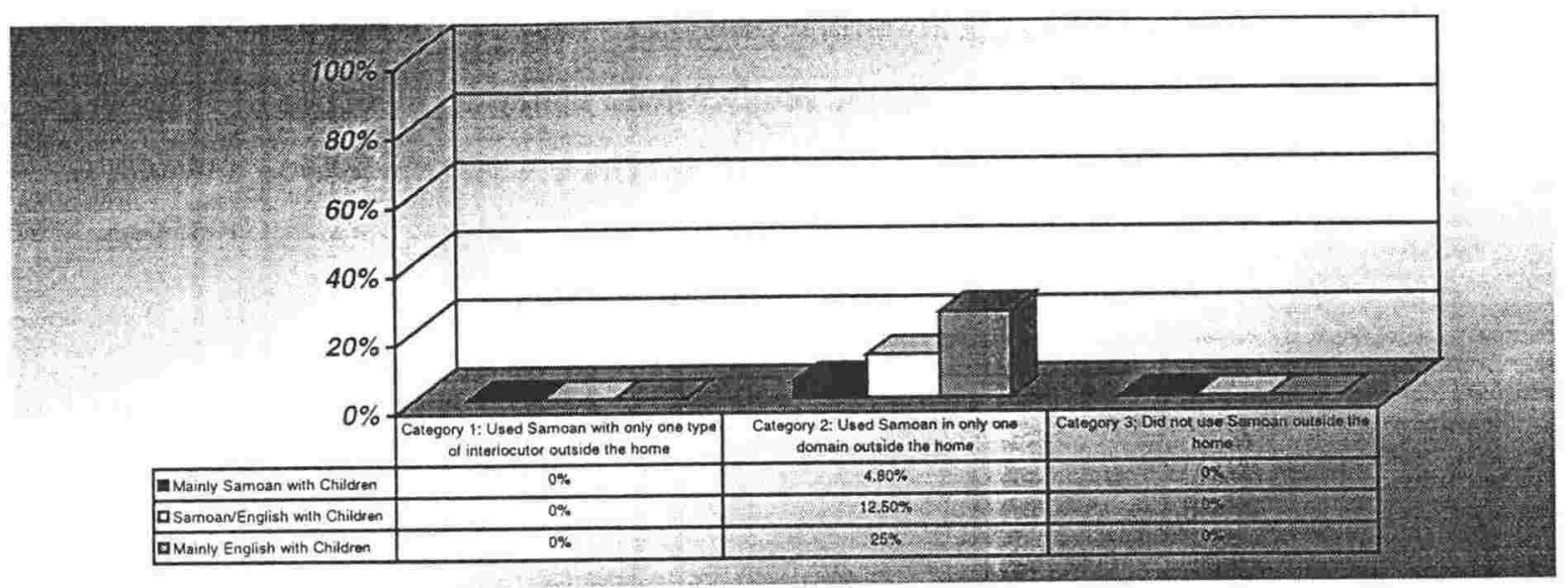

Figure 11-21: Samoan respondents; limited use of MT outside the home

Respondents appear in these tables only if they fill one (or more) of the following criteria.

- not using MT outside the house

- using the MT outside the house with only one interlocutor

- using MT outside the house in only one domain

Thus this analysis selects only respondents whose of the MT is very restricted. Most of the Samoan and under half the Gujarati respondents who speak MT to their children do not appear in this table. It is only amongst the Dutch, whose MT use outside the home is so restricted, that over half the respondents who spoke mainly Dutch to their children appear in this table (but this is out of a very small total). There are more respondents in category 2 (speak MT to children) and those who speak mainly English to their children are very strongly represented in the table. The relationship between English use to children and restricted MT use outside the home is clearest in the case of the Samoan and Dutch respondents but is less clear in the case of the Gujarati respondents.

The Gujarati respondents who spoke only English to their children seem slightly more likely to use Gujarati in only one domain. Amongst the Dutch respondents, speaking Dutch only at home was related to speaking mainly English to one's children. Amongst Samoan respondents there seemed to be quite a strong correlation between using the MT in only one domain and with only one type of interlocutor and speaking mainly English to one's children. There are only eight Samoan respondents in this category and therefore we cannot make very strong claims for this relationship. The evidence here is not conclusive but it certainly suggests a pattern of generally restricted MT use related to increased likelihood of English use to children. 


\subsubsection{Summary: factors affecting parental use of MT with children}

In the integrated model, the gross sociocultural dislocations of the immigration process outlined in part ( 3 ) of the model, are assumed to have explanatory power for immigrant language maintenance and shift and so are the smaller scale sociocultural processes and attitudes and behaviours towards language that are outlined in parts 1 (b) and 1 (c) of the model. This section has looked at factors that fall into these three parts of the model and found some links between each of them and the changes in language use in each group.

There were only two of the factors that were examined that seemed to have the same links with language use in all three groups. The factor of birthplace (one of the most basic measures of immigrant dislocation) was linked to language use. In all three groups, birth in the homeland was linked to increased likelihood of MT use. The factor of domain/s of language use was very interesting. The description of the locations of MT use in terms of domain falls into part 1(a) of the model. The decrease in the range of domains in which MT is used falls into 1(c) behaviour towards language, and 1(b) social changes (i.e. mixing in the wider host society, education in the host society etc.), part of the explanation of language change. In the groups reported on here, it was found that if MT use was confined to just one domain then the respondent was more likely to use English with their children. Sociocultural factors and processes such as the age of children (in some respects a proxy for other sociocultural factors), gender of the respondent and level of education all seemed to have links with increased MT or English use for some of the groups and not for others.

Exogamous marriage, another fairly gross measure of the extent of dislocation within the community, was so uncommon in the Gujarati and Samoan communities and so widespread in the New Zealand-born Dutch community that it was hard to draw any conclusion. The Dutch community exhihited both exogamous marriage and language shift and the other two groups 
MT competence did not seem to be a particularly important causal factor in MT use. Low competence was certainly linked to English use, but high MT competence was not necessarily linked to MT use.

ADDENDUM: A SMALL-SCALE STUDY

Only eight of the Samoan respondents reported speaking 'mainly English' to their children. One of these did not respond clearly to the questions about gender, birthplace or level of education and so has not been included in the following analysis. Because there are only seven respondents to consider, it is possible to consider them individually. Each respondent has been assessed on the factors that have been investigated from section 11.5.1.2.2 to section 11.5.7.

Age of children respondent more likely to use English if children are young (Gujarati and Samoan)

Level of education respondent more likely to use English if tertiary educated (Gujarati and Samoan)

Gender respondent slightly more likely to use English if male (Samoan)

Contexts of use respondent more likely to use English if contexts limited (all three groups)

Exogamy respondent more likely to use English if married exogamously (nonNew Zealand-born Dutch)

MT proficiency respondent more likely to use English if MT proficiency limited (all three groups)

Birthplace respondent more likely to use English if born outside homeland (all three groups)

In addition to these factors, the question of language used with the respondent's spouse was also considered, as it affected the language background of the home. 


female
New Zeulund-born
speuks English with spouse
Samest child 6 yeurs speuking skills 'not very fluent'
speaks Samoan at social gatherings, work, church
tertiury education
spouse speaks Samoan and English

Nemale
Speaks English with spouse
oldest child 3 yeurs
Sumoun specking skills 'not very fluent'
omly uses Samoun when visiting kindergarten
secondary - still studying
spouse speaks Samoan and English

female

New Zealand-bom

speaks Samoan/English with spouse

oldest child 6 years

Sumwan speaking skills 'not very fluent'

only when visiting auga amata

secondary education

spouse speaks Samoan and English

male

Samoan-born

speaks English with spouse

oldest child 14 years

Samoan speaking skills 'fluent'

social gatherings, work, church

tertiary

spouse speaks English male

Samoan-born

speaks English with spouse

oldest child $2+$ years, youngest 16 years

Samoan speaking skills 'fluent'

work, chiurch

tertiary

spouse speaks Sumocan and English 


\begin{tabular}{|l|} 
male \\
Samoan-born \\
speaks Samoan/English with spouse \\
oldest child 6 years \\
Samoan speaking skills 'fluent' \\
work, church \\
'NR' for education (managerial job, married to \\
tertiary-educated wife) \\
spouse speaks Samoan and English
\end{tabular}

male

Samoan-born

speaks English with spouse

oldest child 6 yeurs -

Samoan speaking skills 'fluent'

work, church

tertiary

spouse speaks Samoan/English 
The factors which, on the basis of the foregoing analysis seem likely to lead to English use with children, have been printed in italic. It can be seen that the lowest number of factors is four, most of the respondents have five. It can also be seen that the factors to some extent counterbalance each other. For example, the fluent Samoan speakers, born in Samoa who might be expected to use Samoan with their children are not only male (which, possibly, according to this research might be correlated with a greater likelihood of English use) but are all tertiary educated (or similar), all have young children and all have limited Samoan use outside the home except for one' and he is married to a wife who speaks only English. It is obvious that there is no one set of criteria conducive to language shift or language maintenance but rather a basket of possible factors that are weighted towards either shift or maintenance. The long term prognosis for shift or maintenance with the family depends on the mix of factors present in parents' interactions with their children.

\subsection{Children's proficiency in the MT}

Information was gathered on the MT language use of all the oldest children and all the youngest children of respondents to the questionnaires (except for the respondents to the short version of the Gujarati questionnaire). In addition the Gujarati interviewees and some of the Samoan respondents to the questionnaire, answered questions about their children's proficiency in their MT.

\subsubsection{Language use of oldest and youngest children of respondents}

The following table compares the MT and language use of the oldest and youngest children of respondents. The table shows how many children in each group speak both the MT and English. This excludes quite large numbers of Dutch children who are monolingual in English and smaller numbers of Gujarati and Samoan children who are monolingual in either their MT or English (see chapters on each group for more detail), and does not discuss the issue of MT proficiency related to position in the family, which is also discussed in more detail in the chapters on each of the groups. 
Table 11-5: All respondents: language use of oldest and youngest children in MT and English

\begin{tabular}{|l|l|l|l|}
\hline Speak MT and English ${ }^{154}$ & $\begin{array}{c}\text { Gujarati } \\
\%\end{array}$ & $\begin{array}{c}\text { Dutch } \\
\%\end{array}$ & $\begin{array}{l}\text { Samoan } \\
\%\end{array}$ \\
\hline Oldest children of Home-born ${ }^{155}$ respondents & 81.6 & 36.5 & 84.4 \\
Youngest children of Home-born respondents & 64.9 & 28.7 & 74.5 \\
& 87.5 & 22.2 & N/A \\
Oldest children of Other-born respondents & 66.6 & 37.5 & N/A \\
Youngest children of Other-born respondents & & & \\
& 74 & 3.8 & 64.3 \\
Oldest children of New Zealand-born respondents & 40 & 5 & 62.5 \\
Youngest children of New Zealand-born respondents & & & \\
& 80 & 28.2 & 80.5 \\
Oldest children of all respondents & 62 & 25 & 72.8 \\
Youngest children of all respondents & &
\end{tabular}

There are several points to be noted about this table. First of all, it gives a slightly misleading impression as to the proportion of Samoan children who speak Samoan. Considerably more children speak Samoan than appear on this chart but their parent/s have listed them as monolingual in Samoan and therefore they are not included here (see Chapter 9 for more details). The table shows, in most cases, a higher proportion of oldest children who speak both MT and English than youngest children. This difference is most marked in the case of the Gujarati respondents and the gap between oldest and youngest children has increased considerably in the case of the children of the New Zealand-born respondents, suggesting that although rates of MT maintenance are still quite high, English is gaining considerable ground. The Samoan figures show the same difference but, in the case of the Samoan children, the difference is not great which suggests that the perception that the Samoan respondents tended to have of their households still being largely Samoan speaking, may well be grounded in fact. The difference between oldest and youngest is actually reversed in the case of the children from Dutch households where the parents are D.E.I.-born or New Zealand-born, but

\footnotetext{
${ }^{154}$ All the percentages are of the total number of Gujarati, Dutch or Samoan households in which there were oldest children and/or youngest children (as the case may be) who were old enough to speak. Thus if there were 10 households with a youngest child but only eight of those children were old enough to speak, then the percentage is a percentage of eight not ten.

${ }^{155}$ The term 'home-born' is used here to signify respondents who were born in the Netherlands, Gujarat or, in the case of the Samoan respondents, outside New Zealand.
} 
the numbers involved are so small ${ }^{156}$ that they cannot really be regarded as providing a counter-example.

What the Dutch figures do show is the almost complete break in MT transmission across three generations. The Dutch parents who arrived here in the 1950s and 1960s had some degree of success in handing their language on to their children but those children, for a variety of reasons, including a very high rate of exogamy, have not handed the language on to their children. Language shift has been almost complete across three generations. This is certainly not the case for the Gujarati and Samoan respondents. The total number of New Zealand-born Samoan respondents is too small, and their children too young, to be able to come to any very clear conception of the future of Samoan language maintenance in New Zealand. It can be seen however that the MT transmission rate from the first immigrant generation has been high, much higher than that of the Dutch, mirroring that of the Gujarati respondents. It can also be seen that the Gujarati community, established in New Zealand over a much longer period than the Dutch or Samoan communities has been relatively successful at intergenerational MT transmission even in households where at least one parent is New Zealand-born. The Samoan community undoubtedly has high hopes for Samoan language and cultural maintenance in New Zealand and there are certainly signs in this research that it has started well on that path.

\subsubsection{Gujarati and Samoan children's proficiency in the MT}

Gujarati and Samoan parents rated their children's proficiency in the MT on a scale that ran from 'very good' to 'no ability'.

\footnotetext{
156 One household out of 26 in the case of the New Ze:aland-born respondents with oldests, one household out of 24 in the case of those with youngests old enough to talk. Nine households with oldests and eight households with youngests in the case of the D.E.I.-born.
} 
Table 11-6: Gujarati and Samoan children: parents' rating of children's MT proficiency

\begin{tabular}{|l|l|l|}
\hline & Gujarati speaking skills: \% & Samoan speaking skills: \% \\
\hline Very good & 12.8 & 44.4 \\
Good & 23.4 & 29.6 \\
Fair & 19.1 & 14.8 \\
Limited & 29.8 & 0 \\
Not at all & 10.6 & 5.6 \\
Too young & 4.3 & 0 \\
N of children $=$ & 47 & 54 \\
\hline
\end{tabular}

At first glance it is obvious that the Samoan respondents have rated their children's proficiency much more highly than the Gujarati respondents. There is however, quite a big difference between the two groups that must be borne in mind. In both cases the respondents and their children are drawn from 18 households. The Gujarati households include at least 10 in which at least one spouse is known to be New Zealand-born. The Samoan households include only 3 in which at least one spouse is known to be New Zealand-born. These figures partly reflect the differing immigration histories of the two groups; because the Gujaratis have been here longer it is more likely that there will be New Zealand-born Gujaratis with children ${ }^{157}$. Given the difference in background between the two groups perhaps the most useful point that can be made is that rates of language maintenance in both groups are high. Only $10.6 \%$ and $5.6 \%$ of the two groups are completely unable to speak their MT. A considerably greater proportion of the Gujarati children are given a 'limited' or 'fair' rating from their parent. This may be at least partly because more of the Gujarati children are second generation New Zealand-born, in which case it shows that there has been considerable Gujarati language maintenance into that generation but there are no Samoan figures to compare with it as there were so few Samoan children known to be in the same situation.

\subsection{Factors affecting child's proficiency in the MT}

One of the reasons, of course, for examining language maintenance and shift phenomena in terms of factors related to language maintenance and factors related to language shift is to be able to suggest to interested individuals and communities how they might best foster one (or, presumably, the other). Factors that seem to be associated with parental use of the MT to children and children's language use and proficiency as assessed by parents have been

\footnotetext{
${ }^{157}$ According to the 1991 Census, the Indian population has a much greater proportion of its population in the 20-39 age group than the general New Zealand population (Thomson 1993: 24) and the Samoan population has a much greater proportion in the under 20 age group (Statistics 1996: 11)
} 
examined. Is it possible to isolate some aspects of childhood MT language use and show that they are likely to lead to greater MT proficiency on the part of the child? In this section the data gathered about the children of respondents are used. Data from the Gujarati and Dutch respondents answers to the questions about their own childhoods in New Zealand are also examined. What conclusions can be drawn by comparing the different patterns of language use and language proficiency within the three communities?

In research done in the Cantonese community in Wellington, it was found that although the language spoken by parents to each other and to the child was an important factor in MT language ability as an adult, it was important mainly because it provided the necessary conditions for the child to speak the MT. If, despite the parents' use of the MT, the child does not use it very much, then the child is unlikely to be a confident speaker of the MT in adulthood (Roberts 1990: 116). Janik in a study conducted in the Polish community in Melbourne, concluded that the most influential factors in the successful acquisition of speaking Polish were Polish language use with grandparents and parents, Polish church attendance, Polish language use with relatives and with peers at the language maintenance school (Janik 1996: 13). The current research shows that a range of interlocutors, at least one parent who usually speaks the MT to the child and fairly substantial use of the MT at home were all important factors in successful MT acquisition amongst the children of respondents. The respondents who answered questions about their own childhood in New Zealand also provided data that show the important role of MT use in the childhood home in the development of MT proficiency.

\subsubsection{The link between MT proficiency and the range of MT interlocutors available to the child}

\subsubsection{Children of Gujarati respondents}

The present study found, unsurprisingly, that a child's proficiency levels in the MT could be correlated with the range of interlocutors with whom the child spoke the MT. The following data is taken from the material gathered in interviews with Gujarati interviewees. Almost all the children spoke Gujarati to at least three interlocutors. The most common interlocutors were the child's mother and the child's grandparents. The range of interlocutors has been assessed, somewhat crudely, by counting types or groups of interlocutors. Thus 'mother' and 
'father' count as one type each but 'younger siblings' even if there were three of them, also count as one type or group.

- $78.7 \%$ of children in the survey used Gujarati with their mothers

- $74.4 \%$ of the children used Gujarati with their grandparents

- $55.3 \%$ spoke Gujarati with their fathers

Other interlocutors were also frequently mentioned. Over half the children spoke Gujarati with their fathers and many of them spoke Gujarati with other family members and friends of the family. Some respondents specifically mentioned that their children spoke Gujarati with the village people in Gujarat. Very few children used Gujarati with only one interlocutor. Two children spoke Gujarati only with their mother and three children used it only with their grandparents. All of these children were rated as having 'limited' speaking skills or as being unable to speak Gujarati at all ( in which case the 'speaking' to the mother or grandparents must have been more a matter of listening to the adult speak Gujarati and responding appropriately). All those children who were rated as speaking 'very good' or 'good' Gujarati spoke Gujarati to a range of interlocutors.

Table 11-7: Gujarati children. Proficiency in MT related to range of interlocutors

\begin{tabular}{|l|c|c|c|c|c|c|c|c|c|}
\hline $\begin{array}{l}\text { Number of types } \\
\text { of interlocutors } \rightarrow\end{array}$ & $\mathbf{1}$ type & $\mathbf{2}$ types & $\mathbf{3}$ types & $\mathbf{4}$ types & $\mathbf{5}$ types & $\mathbf{6}$ types & $\mathbf{7}$ types & $\mathbf{8}$ types & $\mathbf{9}$ types \\
\hline Very Good & & & & 1 & 1 & 2 & 2 & & \\
Good & & & 1 & 1 & 1 & & 2 & 2 & 1 \\
Fair & & 1 & 5 & 2 & 1 & 1 & & 2 & \\
Limited & 2 & 2 & & & & 1 & & & \\
Not at all & 2 & 3 & 6 & 9 & 5 & 6 & 4 & 5 & 1 \\
Number of children & 2 & & & & & \\
\hline
\end{tabular}

Two children are too young to speak and therefore do not appear in this table. Another three children (age 17-26, from one family) didn't speak Gujarati according to their parents, although they all had some level of competence. In general, the table shows the expected pattern, children with more interlocutors are judged to be better speakers of Gujarati. The most noticeable exception to this is the two children whose mother lists six types of interlocutors and judges her children's Gujarati speaking ability as 'limited' in the case of the oldest and 'not at all' in the case of the youngest. Both the children are primary school age and the mother says that with two of the types of interlocutors they only speak 'a bit' of Gujarati. Their father makes the same qualification and reduces the total number of types of interlocutor to five. These two children are therefore probably more similar to those who have three or four types of interlocutors. The two children (not siblings) with eight types of 
interlocutors whose parents rate them both as 'limited' speakers of Gujarati are also young. One is the youngest of four which may go some way to explain the 'limited', and the other is only three years old, which may also go some way to explaining the limited rating, as parents often find it hard to distinguish between the limited linguistic command of a three year old and the limited linguistic command of a child speaking a second language.

\subsubsection{Dutch and Gujarati respondents: range of interlocutors in New Zealand as children}

\subsubsection{Gujarati interviewees: MT interlocutors inside the home}

The Gujarati interviewees were asked with whom they had spoken Gujarati both inside and outside their childhood home. Here, the responses of the 23 interviewees who spent all or part of their childhood in New Zealand are examined. There do appear to be weak but suggestive links between the range of interlocutors with whom children used Gujarati in childhood and the interviewees' present Gujarati proficiency as adults.

- 2 interviewees spoke Gujarati with only their mother inside the home. They both rated themselves as 'fairly fluent'.

- 4 interviewees spoke Gujarati with only their mother and father. Two, both born in Gujarat, rated themselves as 'fluent'. One of the others was rated as 'not very fluent' and the other could 'understand but not speak Gujarati'

- 9 interviewees spoke Gujarati only with three groups of family members (usually mother, father, siblings). Three of the nine rated themselves as 'fluent'.

- 4 interviewees spoke Gujarati with four groups of family members (usually including grandparent/s). Two of these interviewees rated themselves as 'fluent' and the other two as 'fairly fluent'

- 2 interviewees spoke Gujarati to more than four groups of family members. Both of these two rated themselves as 'fluent'

There does appear to be a slight link here. The two interviewees who spoke Gujarati with their mother only are not 'fluent' speakers and neither are the New Zealand-born respondents who spoke Gujarati with only their mother and father. As the number of interlocutors within the home with whom interviewees spoke Gujarati increases past mother and father then there is a link between number of interlocutors and a self-rating of 'fluent'. A third of those who spoke to three groups, half of those who spoke to four groups and all of those who spoke to more than four groups, rated themselves as 'fluent'. The numbers are very small, far too small to be anything other than suggestive, but at least they indicate a link in the direction that we would expect; increased range of interlocutors increases the likelihood of higher levels of MT proficiency. 


\subsubsection{Gujarati interviewees: MT interlocutors outside the home}

There is a similar pattern in the range of interlocutors outside the childhood home and adult proficiency today. Of the 23 Gujarati interviewees who were counted as having spent all or part of their childhood in New Zealand, there were three who did not use Gujarati outside the home when they were children. One of these interviewees grew up in a comparatively isolated rural area where there were no other Gujarati families, she spoke Gujarati at home to her parents and siblings and is married to a Gujarat-born husband. She rates her present day proficiency as 'fairly fluent'. The other two interviewees rate themselves as 'not very fluent'.

Of those who spoke Gujarati outside the home:-

- 1 spoke Gujarati with only 'older relatives'. This interviewee came to New Zealand from Gujarati at age 3, and rated themselves as 'fairly fluent'

- 4 spoke Gujarati with only 'older relatives and older people'. One of these, who came to New Zealand from Gujarat age 5, rates themselves as 'fluent'. Of the other three, two rate themselves as 'fairly fluent' and one 'can understand but not speak' Gujarati

- 6 spoke Gujarati with three types of interlocutor outside the home (usually combinations of older interlocutors and new immigrants). Three of these interviewees rated themselves as 'fluent', two as 'fairly fluent' and one as 'not very fluent'

- 7 interviewees spoke Gujarati outside the house to four to eight groups of interlocutors. Four of the seven rated themselves as 'fluent' and three as 'fairly fluent'.

- 1 person, who spoke to all possible groups of interlocutors outside the home in Gujarati, rated themselves as 'fluent' 158

Once again there is a weak link between the factors. Certainly, the interviewees who spoke Gujarati outside the home, as children in New Zealand, to four or more different types of interlocutor are more likely to rate themselves as 'fluent' speakers of Gujarati today.

\subsubsection{Dutch respondents : MT interlocutors inside the home}

Fifty-six Dutch respondents reported that they had spent all or part of their childhood in New Zealand. Forty-one of these respondents had spoken at least some Dutch in their childhood home in New Zealand.

- 1 who came to New Zealand between the ages of 10-20 spoke Dutch to their grandmother only and rated themselves as a 'fluent' speaker

\footnotetext{
158 The numbers add up to 22 because part of the data from one respondent was inadvertently erased.
} 
- 1 respondent spoke Dutch to their grandparents when their grandparents were visiting. They rated themselves as 'fairly fluent'

- 9 spoke Dutch to their mother and father only. Only one of these respondents rated themselves as 'fluent'

- 13 spoke Dutch in the home to three individuals or groups of speakers. Four respondents or $30.7 \%$ of this group rated themselves as 'fluent'

- 17 respondents spoke Dutch to four or more types of interlocutor. Six (35.2\%) of these respondents rated themselves as 'fluent'

The figures suggest that speaking Dutch to more people in the household than simply one's mother and father is likely to be correlated with higher levels of proficiency in adulthood. Presumably a household in which Dutch is being spoken to most of the people in the household is one in which more Dutch is used than a household in which Dutch is being directed only at the parents.

\section{Dutch respondents: MT interlocutors outside the home}

Outside the home, the same sort of pattern shows up but it is noticeable that only 33 respondents used Dutch outside the home at all and over a third of those used it only with one type of interlocutor.

- 12 respondents used Dutch with only one type of interlocutor. A quarter of them considered themselves to be 'fluent' speakers

- 9 respondents used Dutch with two types of interlocutors. Only one of these respondents $(11.1 \%)$ considered themselves to be a 'fluent' speaker of Dutch

- 12 respondents spoke Dutch to three or four types of interlocutors outside the home. Seven $(58.3 \%)$ of these considered themselves to be 'fluent' speakers of Dutch, the rest all rated themselves as 'fairly fluent'

The respondents who rated themselves as 'not very fluent', 'no ability' or 'comprehension only' all had only one or two types of interlocutors outside the home. There was not much overlap between fluency and birthplace. Of the 11 respondents who rated themselves as 'fluent', five are New Zealand-born (although one of these is the respondent who lived in the Netherlands from age 6 to 21 ). Once again the numbers are too small and the differences too slight to be more than suggestive. All four sets of Gujarati and Dutch figures however show the same trend and cumulatively they suggest that the wider the range of speakers a child has with whom they can speak the MT, the more confident they are likely to be as adult users of the language. As with section 11.5.7 where the range of domains in which a respondent used the MT was related to whether or not the respondent used the MT with their child, so with childhood range of MT use across domain (including interlocutor) and both childhood proficiency and adult proficiency. The greater the range of domains, the greater the 
proficiency - on the whole. This relationship can certainly be disrupted by a factor such as a long visit to India. The Gujarati village may provide the only set of domains in which a child uses the MT but because, of course, these domains are maximally supportive of the MT, the comparatively limited time and geographical space of the new set of habitual patterns of language use can be overcome.

The integrated model based on Fishman's theories stresses the importance of antecedent, concurrent and/or consequent social processes and their relationship to habitual patterns of language use. Leaving aside the return to the ancestral village, it can be seen that if, in New Zealand, the social processes developed by the family and by the community encourage the wide-ranging use of the MT, this is supportive of language maintenance. The data below provide more evidence for this conclusion.

\subsubsection{MT patterns of use in the home}

The information in this section was gathered from the Gujarati and Samoan responses to questions about the respondents' language use in the home and their assessment of their children's MT proficiency. 


\subsubsection{Gujarati households}

Table 11-8: Gujarati children's MT proficiency levels correlated with MT use in the home

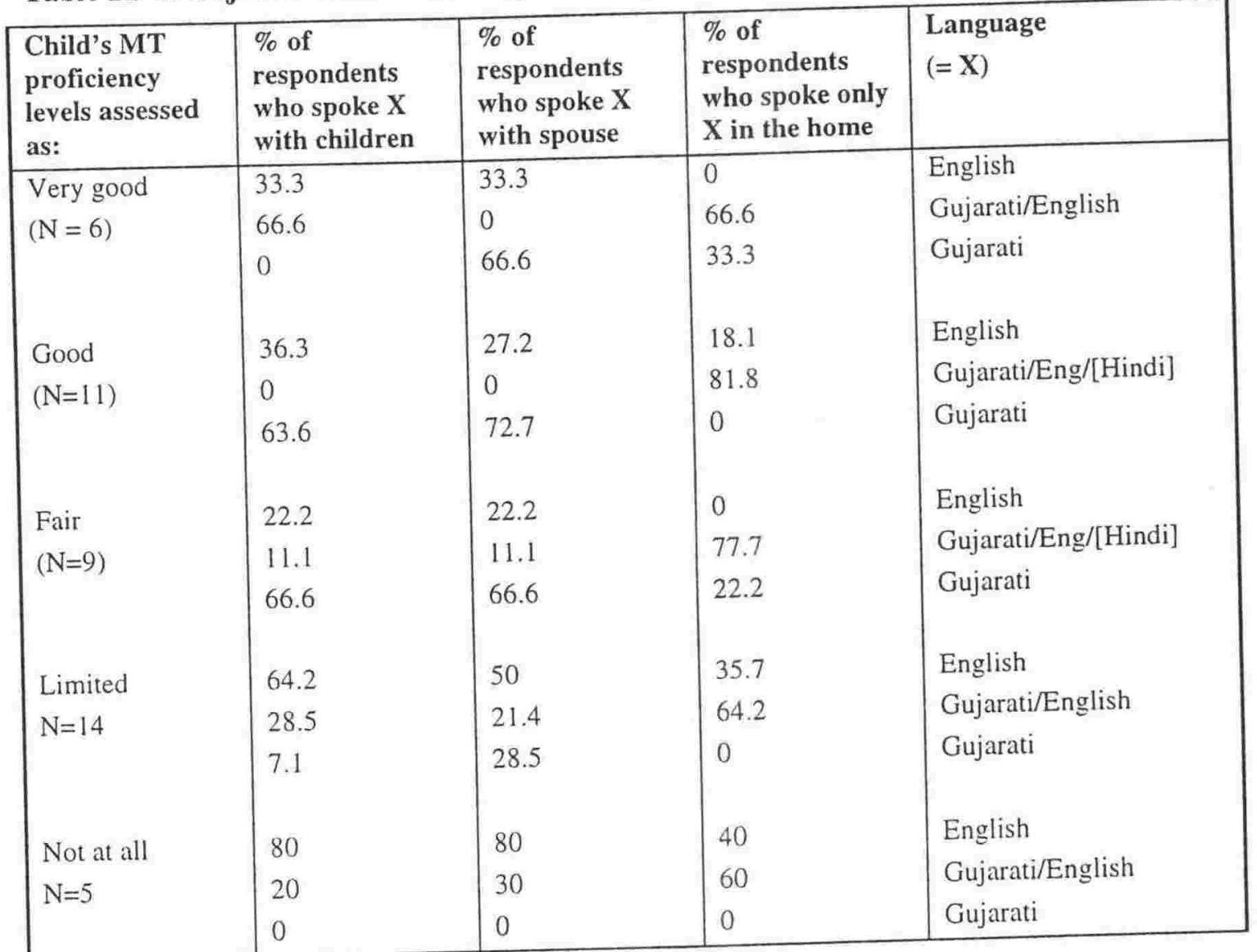

( 2 children were 'too young' to speak)

Table 11-8 shows that children who were more likely to be spoken to in Gujarati, who were more likely to hear their parents speaking Gujarati to each other and who were more likely to hear Gujarati in the household, were also more likely to be rated 'very good', 'good' or 'fair' speakers of Gujarati. Those who did not hear as much Gujarati around them or directed to them at home were more likely to be rated as 'limited' speakers or to have no ability in Gujarati at all. It should be noted that the two children rated 'very good' whose parents spoke to them mainly in English had recently come back from spending some time in Gujarat. Their New Zealand-raised mother (she came to New Zealand at the age of three) was interviewed. Their father speaks Gujarati and English to them.

\subsubsection{Samoan respondents}

The Samoan respondents showed the same, unsurprising pattern. However, as almost all the Samoan children were rated as 'very good' or 'good' by their parents, a table is not particularly informative. It is worth noting perhaps that the three children, from the one 
family, who are rated as speaking no Samoan at all come from a mainly English speaking household where are usually addressed in English and usually hear their parents speaking in English. Two of the three children who are rated as 'limited' are also spoken to in both Samoan and English and hear roughly equal amounts of Samoan and English at home. None of them come from English dominant households.

\subsubsection{Parental MT use to child and the child MT fluency}

Apart from a range of interlocutors, the other important factor for Gujarati language fluency in children appeared to be at least one parent who spoke mainly Gujarati to them. The following two tables show that, in general, children who speak Gujarati 'fluently' or 'fairly fluently' usually have at least one parent who speaks Gujarati to them. Amongst the families where both parents answered the questionnaire (Table 11-1), there is only one family where the children are both rated as speaking 'good' Gujarati and both parents speak 'mainly English' to the children. This family has, however, spent quite a lot of time in India and the New Zealand-born father is very keen that his children should speak Gujarati; in part because the family still owns land in Gujarat to which he feels strong ties.

Amongst the families where only one parent answered the questionnaire (Table 11-10), it is not possible to know what language the non-responding parent used with the child. However, the family b044, where the New Zealand-born mother speaks mainly English to all her children is another family which has spent some long periods of residence (several months usually) in Gujarat, and this has given several of the children the opportunity to acquire a good command of Gujarati. It also explains why the youngest child, b044/e, speaks 'very good' Gujarati, even though youngest children (especially in comparatively large families) are often held to be less competent in the MT than their older siblings; the family had only fairly recently returned from a trip to Gujarat when I interviewed the mother. 
Table 11-9: Gujarati children's MT use correlated with language/s spoken by parents to child. Both parents interviewed

\begin{tabular}{|c|c|c|c|c|c|}
\hline & $\begin{array}{l}\text { Child ID } \\
\text { (gender) age }\end{array}$ & $\begin{array}{l}\text { Fluency assessed } \\
\text { by mother }\end{array}$ & $\begin{array}{l}\text { Fluency assessed } \\
\text { by father }\end{array}$ & $\begin{array}{l}\text { Language used } \\
\text { to child by } \\
\text { mother }\end{array}$ & $\begin{array}{l}\text { Language used } \\
\text { to child by } \\
\text { father }\end{array}$ \\
\hline 1 & $\mathrm{~b} 023 / \mathrm{a}(\mathrm{m}) 07$ & very good & good & Gujarati English & Gujarati \\
\hline 2 & b023/b (f) 04 & very good & very good & Gujarati English & Gujarati \\
\hline 3 & b029/a (m) 11 & limited & limited & Gujarati English & Gujarati English \\
\hline 4 & b029/b (m) 06 & not at all & limited & Gujarati English & Gujarati English \\
\hline 5 & b040/a (f) 26 & fair & fair & Gujarati English & Gujarati English \\
\hline 6 & $\mathrm{~b} 040 / \mathrm{b}(\mathrm{m}) 23$ & limited & limited & Gujarati English & Gujarati English \\
\hline 7 & $\mathrm{~b} 040 / \mathrm{c}(\mathrm{f}) 17$ & limited & limited & Gujarati English & Gujarati English \\
\hline 8 & $\mathrm{~b} 047 / \mathrm{a}(\mathrm{f}) 27$ & good & good & Gujarati & English \\
\hline 9 & b047/b (f) 24 & fair & fair & Gujarati & English \\
\hline 10 & $\mathrm{~b} 047 / \mathrm{c}(\mathrm{f}) 21$ & fair & fair & Gujarati & English \\
\hline 11 & b047/d (m) 19 & limited & limited & Gujarati & English \\
\hline 12 & b050/a (m) 06 & not at all & limited & English & English \\
\hline 13 & $\mathrm{~b} 050 / \mathrm{b}(\mathrm{m}) 04$ & not at all & limited & English & English \\
\hline 14 & $\mathrm{c} 062 / \mathrm{a}(\mathrm{f}) 42$ & good & good & Gujarati & Gujarati English \\
\hline 15 & $\mathrm{c} 062 / \mathrm{b}(\mathrm{m}) 40$ & fair & fair & Gujarati & Gujarati English \\
\hline 16 & $\mathrm{c} 062 / \mathrm{c}(\mathrm{f}) 37$ & good & good & Gujarati & Gujarati English \\
\hline 17 & $\mathrm{c} 062 / \mathrm{d}(\mathrm{f}) 35$ & good & good & Gujarati & Gujarati English \\
\hline 18 & $\mathrm{f} 0130 / \mathrm{a}(\mathrm{m}) 13$ & limited & limited & English & English \\
\hline 19 & $f 0130 / b(t) 11$ & fair & fair & English & English \\
\hline 20 & $\mathrm{f} 0133 / \mathrm{a}(\mathrm{m}) 05$ & good & good & Gujarati & Gujarati English \\
\hline 21 & $\mathrm{fO} 135 / \mathrm{a}(\mathrm{m}) 16$ & good & good & English & English \\
\hline 22 & $\begin{array}{l}\mathrm{f} 0135 / \mathrm{b}(\mathrm{m}) \\
14\end{array}$ & good & good & English & English \\
\hline 23 & $\mathrm{fol} 42 / \mathrm{a}(\mathrm{m}) 03$ & limited & limited & English & English \\
\hline 24 & $\mathrm{f0} 144 / \mathrm{a}(\mathrm{m}) 03$ & fair & limited & English & English \\
\hline 25 & $\mathrm{f0144/b}(\mathrm{f}) 01$ & too young & too young & English & English \\
\hline
\end{tabular}


Table 11-10: Gujarati children's MT use correlated with language/s spoken by parents to child. One parent interviewed

\begin{tabular}{|c|c|c|c|}
\hline & Child ID (gender) age & Fluency: Assessed by parent & $\begin{array}{l}\text { Language used with child by } \\
\text { parent }\end{array}$ \\
\hline 26 & b024/a (m) 14 & fair & Gujarati \\
\hline 27 & b024/b (f) 12 & fair & Gujarati \\
\hline 28 & b044/a (f) 24 & good & English \\
\hline 29 & b044/b (f) 22 & very good & English \\
\hline 30 & b044/c (f) 20 & limited & English \\
\hline 31 & b044/d (f) 16 & good & English \\
\hline 32 & b044/e (f) 10 & very good & English \\
\hline 33 & $\mathrm{c} 055 / \mathrm{a}(\mathrm{f}) 16$ & limited & English \\
\hline 34 & $\mathrm{c} 055 / \mathrm{b}(\mathrm{m}) 08$ & limited & English \\
\hline 35 & $\mathrm{c} 066 / \mathrm{a}(\mathrm{f}) 15$ & fair & Gujarati \\
\hline 36 & $\mathrm{c} 066 / \mathrm{b}(\mathrm{f}) 11$ & good & Gujarati \\
\hline 37 & $\mathrm{c} 066 / \mathrm{c}(\mathrm{f}) 08$ & good & Gujarati \\
\hline 38 & $\mathrm{c} 075 / \mathrm{a}(\mathrm{f}) 07$ & not at all & English \\
\hline 39 & $\mathrm{c} 075 / \mathrm{b}(\mathrm{f}) 05$ & not at all & English \\
\hline 40 & b083/a (f) 27 & limited & English \\
\hline 41 & b083/b (f) 25 & limited & English \\
\hline 42 & b083/c (m) 23 & limited & English \\
\hline 43 & b083/d (f) 20 & limited & English \\
\hline 44 & $f 0132 / a(f) 06$ & very good & Gujarati English \\
\hline 45 & $\mathrm{f} 0132 / \mathrm{b}(\mathrm{f}) \quad 01.6$ & very good & Gujarati English \\
\hline 46 & f014 $1 / \mathrm{a}(\mathrm{m}) 03$ & limited & Gujarati English \\
\hline 47 & $\mathrm{fo} 014 \mathrm{l} / \mathrm{b}(\mathrm{m}) 0.10$ & too young & Gujarati English \\
\hline
\end{tabular}


11.7.5 Childhood in New Zealand. The relationship between adult fluency in the MT and MT patterns of language use in the childhood home

\subsubsection{Gujarati and Dutch respondents}

There is not the same amount of detail about the children of the Dutch and Samoan respondents as there is about the children of the Gujarati respondents. However the information about childhood language use provided by the Gujarati and Dutch respondents who were raised in New Zealand can be examined, and we see the same pattern there.

- if the childhood home was 'always' or 'mostly' a MT environment,

- if the parents 'always' spoke the MT to each other,

- if they 'always' spoke the MT to the respondent and

- if the respondent 'always' or 'mostly' spoke the MT at home,

then respondents are more likely to have reported themselves as 'fluent' or 'fairly fluent' speakers of the MT in the questionnaire. 
Table 11-11: Was MT spoken in childhood home by fluency

\begin{tabular}{|l|l|l|l|}
\hline Always & & Dutch & Gujarati \\
\hline Fluent & & 57.3 & 66.6 \\
Fairly fluent & & 28.5 & 33.3 \\
Not very fluent & & 14.2 & 0 \\
Comp. only & & 0 & 0 \\
No ability & & 0 & 0 \\
NR & & 0 & 0 \\
N= & & 7 & 3 \\
\hline Mostly & & Dutch & Gujarati \\
\hline Fluent & & 29.1 & 54.5 \\
Fairly fluent & & 37.5 & 27.2 \\
Not very fluent & & 29.1 & 9.0 \\
Comp. only & & 4.1 & 9.0 \\
No ability & & 0 & 0 \\
NR & & 0 & 0 \\
N= & & 24 & 11 \\
Sometimes & & Dutch & Gujarati \\
Fluent & & 4.0 & 12.5 \\
Fairly fluent & & 28 & 62.5 \\
Not very fluent & & 32 & 25.0 \\
Comp. only & & 0 \\
No ability & & 12 & 0 \\
NR & & 4 & 0 \\
N= & & 85 \\
NR & & 125 \\
N= & & 56 & 23 \\
\hline
\end{tabular}

Table 11-12: Did your parents speak MT to each other by fluency

\begin{tabular}{|l|l|l|l|}
\hline Always & & Dutch & Gujarati \\
\hline Fluent & & 50.0 & 50.0 \\
Fairly fluent & & 27.7 & 37.5 \\
Not very fluent & & 22.2 & 6.2 \\
Comp. only & & 0 & 6.2 \\
No ability & & 0 & 0 \\
NR & & 0 & 0 \\
N= & & 18 & 16 \\
& & \\
\hline Mostly & & Dutch & Gujarati \\
\hline Fluent & & 15.7 & 0 \\
Fairly fluent & & 36.8 & 75.0 \\
Not very fluent & & 31.5 & 25.0 \\
Comp. only & & 10.5 & 0 \\
No ability & & 0 \\
NR & & 5.2 & 0 \\
N= & & 19 & 4 \\
& & & \\
\hline Never & & Dutch & Gujarati \\
\hline Fluent & & 0 \\
Fairly fluent & & 0 & 0 \\
Not very fluent & & 25.0 & 0 \\
Comp. only & & 25.0 & 0 \\
No ability & & 50.0 & 0 \\
NR & & 0 \\
N= & & 0 \\
NR & & 1 \\
N= & & 23 \\
\hline
\end{tabular}


Table 11-13: Did your parents speak MT to you by fluency

\begin{tabular}{|c|c|c|}
\hline Sometimes & Dutch & Gujarati \\
\hline Fluent & 0 & 0 \\
\hline Fairly fluent & 42.8 & 0 \\
\hline Not very fluent & 42.8 & 100 \\
\hline Comp. only & 7.1 & 0 \\
\hline No ability & 7.1 & 0 \\
\hline NR & 0 & \\
\hline Not applicable & 0 & \\
\hline $\mathrm{N}=$ & 14 & 1 \\
\hline Never & Dutch & Gujarati \\
\hline Fluent & 0 & 0 \\
\hline Fairly fluent & 0 & 0 \\
\hline Not very fluent & 0 & 0 \\
\hline Comp. only & 60.0 & 0 \\
\hline No ability & 40.0 & 0 \\
\hline NR & 0 & 0 \\
\hline$N=$ & 5 & 0 \\
\hline NR & & 1 \\
\hline NA & & 1 \\
\hline$N=$ & 56 & 23 \\
\hline Always & Dutch & Gujarati \\
\hline Fluent & 87.5 & 60.0 \\
\hline Fairly tluent & 12.5 & 30.0 \\
\hline Not very fluent & 0 & 0 \\
\hline Comp. only & 0 & 10.0 \\
\hline No ability & 0 & 0 \\
\hline NR & 0 & 0 \\
\hline $\mathrm{N}=$ & 8 & 10 \\
\hline Mostly & Dutch & Gujarati \\
\hline Fluent & 25.0 & 37.5 \\
\hline Fairly tluent & 40.0 & 37.5 \\
\hline Not very fluent & 30.0 & 35.0 \\
\hline Comp. only & 5.0 & 0 \\
\hline No ability & 0 & 0 \\
\hline NR & 0 & 0 \\
\hline $\mathrm{N}=$ & 20 & 8 \\
\hline Sometimes & Dutch & Gujarati \\
\hline Fluent & 0 & 0 \\
\hline Fairly tluent & 37.5 & 75.0 \\
\hline Not very fluent & 37.5 & 25.0 \\
\hline Comp. only & 16.6 & 0 \\
\hline No ability & 4.1 & 0 \\
\hline NR & 4.1 & 0 \\
\hline $\mathrm{N}=$ & 24 & 4 \\
\hline
\end{tabular}

Table 11-14: Did you speak MT at home by fluency

\begin{tabular}{|c|c|c|}
\hline Always & Dutch & Gujarati \\
\hline Fluent & 100 & 100 \\
\hline Fairly fluent & 0 & 0 \\
\hline Not very fluent & 0 & 0 \\
\hline Comp. only & 0 & 0 \\
\hline No ability & 0 & 0 \\
\hline NR & 0 & 0 \\
\hline$N=$ & 4 & 1 \\
\hline Mostly & Dutch & Gujarati \\
\hline Fluent & 50.0 & 55.5 \\
\hline Fairly fluent & 37.5 & 33.3 \\
\hline Not very fluent & 12.5 & 11.1 \\
\hline Comp. only & 0 & 0 \\
\hline No ability & 0 & 0 \\
\hline NR & 0 & 0 \\
\hline $\mathrm{N}=$ & 8 & 9 \\
\hline Sometimes & Dutch & Gujarati \\
\hline Fluent & 13.7 & 27.2 \\
\hline Fairly fluent & 37.9 & 54.5 \\
\hline Not very fluent & 34.4 & 9.0 \\
\hline Comp. only & 6.8 & 9.0 \\
\hline No ability & 3.4 & 0 \\
\hline NR & 3.4 & 0 \\
\hline$N=$ & 29 & 11 \\
\hline Never & Dutch & Gujarati \\
\hline Fluent & 0 & 0 \\
\hline Fairly fluent & 26.6 & 0 \\
\hline Not very fluent & 33.3 & 4.3 \\
\hline Comp. only & 26.6 & 0 \\
\hline No ability & 13.3 & 0 \\
\hline NR & 0 & 0 \\
\hline $\mathrm{N}=$ & 15 & 1 \\
\hline NR & & 1 \\
\hline $\mathrm{N}=$ & 56 & 23 \\
\hline
\end{tabular}




\subsubsection{Childhood immigration as a factor in present day fluency}

Immigration as a child represents a greater dislocation from the homeland language and culture than immigration as an adult. Those respondents who immigrated as adults are, in general, fluent speakers of their MT. Those who arrived in New Zealand as children or teenagers however, and who are adult now, have not necessarily maintained their MT so well. In section 8.6.8 and 7.7.9 the Dutch and Gujarati interviewees' responses to questions about MT language use in the childhood home were examined. The analysis showed that respondents who arrived under the age of 10 years tended not to maintain their MT as well as those who arrived over that age. Shameem made similar findings amongst the Indo-Fijian community in Wellington (Shameem 1994: 412). Kanazawa and Loveday (1988:128-129), reporting on the Japanese immigrant community in Brazil showed that the older the adult survey respondents had been when they came to Brazil, the more likely they were to use Japanese with their children. These findings are no doubt related to those by Stock in Australia (already noted in Chapter 6) and add weight to the hypothesis that the age of 10 provides some sort of turning point for language maintenance and for language acquisition, although the reasons for this, biological, social etc are not touched upon here.

Amongst both the Gujarati and Dutch respondents who grew up in New Zealand, the respondents who were born outside the country were more likely to use their MT with a wider range of interlocutors than those born in New Zealand and in both cases the non-New Zealand-born respondents were more likely to use their MT with other children. Taft and Cahill (1989:138) found a similar pattern amongst immigrant Lebanese children in Australia, when they found that those who arrived over the age of five years were more likely to use the MT with friends than those who had arrived under that age.

\subsubsection{Attendance at language maintenance school and MT proficiency}

Fishman calls the language maintenance school a 'secondary reward system' as opposed to the more vital 'primary reward systems' (1985: 369) and says that 'nowhere in the world have major programs of language maintenance, language revival or language revitalization succeeded if their major "bet" was on the school rather than on other, more primary, processes (1985: 373 -374). The present research does not contradict this opinion, and it would certainly be inaccurate to overstate the claims of the language maintenance school in New Zealand. 
Nonetheless, it does seem to be associated with a degree of improved language maintenance. Fishman argues that language maintenance schools

will not be able to foster language maintenance of any more active or maximal sort until the communities they serve are ready to pursue such goals themselves out of school (Fishman 1985: 376)

This is undoubtedly true, but it seems that Fishman does not acknowledge sufficiently that by the mere fact of establishing and maintaining language maintenance schools the community is exhibiting considerable commitment to language and culture maintenance. In terms of the integrated model, the language school is a product of 'overt behavioural implementation' part of a range of behaviours towards language that affect or are intended to affect the language maintenance and shift outcomes in a community.

The Dutch cannot be considered here because there had been no established Dutch school at the time the research was done. There is only patchy evidence from the Gujarati and Samoan communities for almost the opposite reason; attendance at language maintenance school has been so widespread that there are not always enough respondents or children of respondents who have not attended language maintenance school to make a comparison with those who have. Only four of the 21 Samoan New Zealand-born respondents did not attend language maintenance school; two rated themselves as 'fluent', two as 'not very fluent'. Only one of the children of the Gujarati interviewees did not attend language maintenance school, this hardly provides a basis for comparison with the 46 children who did attend. The two groups that can be looked at are the New Zealand-born Gujarati respondents and the children of the Samoan respondents who filled out the questionnaire on their children's Samoan proficiency.

\subsubsection{New Zealand-born Gujarati respondents}

Thirty-seven respondents of Gujarati extraction attended language maintenance school in New Zealand but only the New Zealand-born respondents are considered here. If all the respondents who attended language maintenance school are compared with all the respondents who could have attended language maintenance school but did not do so (see section 7.7.6), there are too many imponderables (age at which the respondent came to New Zealand being the main one) to allow for an informative comparison. If the New Zealand-born are compared with the New Zealand-born, a clearer picture is presented, even if the numbers involved are smaller. 
Only eight of the 35 New Zealand-born Gujarati respondents did not attend language maintenance school, but even so it seems worth making a comparison of those who attended and those who did not, even if the numbers are somewhat unbalanced. Most of the respondents attended the Wellington Indian Association weekend school for three hours a week.

- $62.5 \%$ of those who did not attend language maintenance school rated themselves as 'fluent' or 'fairly fluent'

- 81.4 of those who attended language maintenance school rated themselves as 'fluent' or 'fairly fluent'

The difference is not great but it does suggest that attendance at language maintenance school might have a positive effect on MT acquisition. Where there does appear to be a much more obvious difference is in literacy.

- $12.5 \%$ of those who did not attend language maintenance school could "write easily' or 'fairly easily'

- $12.5 \%$ of those who did not attend language maintenance school could "write with difficulty'

- $75 \%$ of those who did not attend language maintenance school were illiterate in Gujarati

- $40.7 \%$ of those who attended language maintenance school could 'write easily' or 'fairly easily'

- $22.2 \%$ of those who attended language maintenance school could "write with difficulty'

- $22.2 \%$ of those who attended language maintenance school could 'read but not write'

- $14.8 \%$ of those who attended language maintenance school were illiterate in Gujarati

It seems clear that attendance at language maintenance school is crucial, in this community, for attaining literacy in the community language.

\subsubsection{Samoan children}

The evidence from the Samoan children is particularly hard to interpret. Fourteen of the 54 Samoan children did not attend a language maintenance school of some kind according to their parents' answers. These 14 children came from five families and five of them came from one family. The children in that family, all of whom are rated 'very good' in all language skill areas, did not attend language maintenance school because, according to the respondent, they were 'all grown up'. Indeed, the oldest of them is 35 and the youngest 21 . It is not clear from the respondent's answer whether the children used to attend a language maintenance school 
but do not do so now because they are all grown up or whether they never attended such a school. It is also possible that at least some of the children were educated in Samoa. Whatever the reason for their excellent language skills, they certainly have a positive effect on the overall figures for non-attendance at language maintenance school. Even so, the children who attend or have attended language maintenance school still score higher in their parents' rating of their Samoan language skills.

- $57 \%$ of the 14 children who did not attend language maintenance school were rated as 'very good' or 'good' speakers of Samoan

- $80 \%$ of the 40 who attended language maintenance school were rated as 'very good' or 'good' speakers of Samoan

When it comes to literacy skills several of the children were rated as 'too young' to read or write, so the numbers are slightly smaller. Partly because of the 5 highly ranked children from one family, there is not much difference between the two groups when the ratings 'very good' and 'good' are compared.

- $53.7 \%$ of 13 children who did not attend language maintenance school were rated as having 'very good' or 'good' Samoan writing skills

- $62.4 \%$ of 32 children who did attend language maintenance school were rated as having 'very good' or 'good' Samoan writing skills

If 'limited' and 'no ability' ratings are compared however the picture is somewhat different.

- $46 \%$ of 13 children who did not attend language maintenance school were rated as having 'limited' Samoan writing skills or 'no ability' at all

- $10 \%$ of 32 children who did attend language maintenance school were rated as having 'limited' Samoan writing skills or 'no ability' at all

It would be unwise to come to any definite conclusion on the basis of such slight and patchy evidence. Such as the evidence is, however, it does seem to indicate that attendance at a language maintenance school will have some positive effect on MT language skills and is likely to lead to a degree of MT literacy that would otherwise not be attained (this connection has already been noted in section 11.7.7). The Wellington survey of New Zealand-born Cantonese came to a similar conclusion (Roberts 1990: 117, 126-127, 140) and Fishman (1985: 372) also notes the importance of the MT school in assuring literacy. Janik's comments (1996: 13) have already been noted (section 11.7). These are modest gains by and large, and it is also possible that attendance at MT school is merely a symptom of greater family concern about MT maintenance and it is that concern rather than language maintenance school attendance that leads to the difference between those who attend and those who do not. While this may indeed be the case, it also seems possible that attendance at language maintenance school does, in itself, have a positive effect; that it teaches the children 
some basic literacy skills, provides an environment in which the exercise of their MT oral skills is valued and expected, and demonstrates that the community of adults around them values and is prepared make an effort for the maintenance of their language and culture. For all of these reasons it seems unsurprising that those who are attending or have attended language maintenance school should exhibit greater MT proficiency than those who have not.

\subsection{Childhood language use and adult language use}

Change in habitual language use over time is, of course, the essential nature of the language shift process and, therefore, the integrated model places particular stress on the process of change over time.

Dutch respondents raised in New Zealand were asked about patterns of habitual language use in their childhood in New Zealand and, of course about the language use as adults. Gujarati interviewees were also asked about childhood, as well as adult, patterns of language use. In the previous section these two periods were compared in terms of the effects on adult fluency. In this section, the responses to these questions are examined to see if those patterns of use have changed over time.

\subsubsection{Gujarati childhood and adult language use}

\subsubsection{Language use at home}

Only one of the 22 interviewees who were born and/or raised in New Zealand, never used Gujarati at home in New Zealand. Of the others, 11 'sometimes' used it and 10 'always' or 'mostly' used it. Today, the one interviewee who 'never' used Gujarati at home still speaks only English at home. Of the remaining 21 respondents, all of whom used Gujarati at home in their childhoods, seven now use only English, two use only Gujarati and the remaining 12 use both Gujarati and English. 
Table 11-15: Gujarati interviewees use of MT at home in childhood and adulthood

\begin{tabular}{|l|l|l|}
\hline & In childhood & In adulthood \\
\hline Never use/d Gujarati & $4.5 \%$ & $36.3 \%$ \\
Use/d Gujarati & $95.4 \%$ & $63.6 \%$ \\
$\mathrm{~N}=$ & 22 & 22 \\
\hline
\end{tabular}

\subsubsection{Language use outside the home}

Most of the interviewees (19 out of 22) spoke Gujarati outside the home as children. The three who did not do so were all New Zealand-born. As adults, all the interviewees use Gujarati outside the home. The patterns of language use outside the home seem to have changed remarkably little from childhood to adulthood. Eleven interviewees only spoke Gujarati outside the home with older people and immigrants when they were children. Ten of those 11 only use Gujarati outside the home with older people and immigrants now that they are adults. The other nine interviewees all spoke with a wide range of interlocutors as children and continued to do so as adults. One of the three who did not use Gujarati outside the home in childhood, now only uses it with older friends outside the home but the other two use it with a full age range of interlocutors. There has been a slight contraction in the range of places where Gujarati is used outside the home. Several interviewees (four) mentioned religious events/Gita class as a place of Gujarati use in childhood and one interviewee said 'everywhere'. In adulthood, only the interviewee who said 'everywhere' still uses Gujarati in Gita class. The trend, such as it was, was to Gujarati being used in fewer places now that the speakers were adult, but it was not very marked.

\subsubsection{Dutch childhood and adult language use}

Respondents born or raised in New Zealand were asked about their MT language use in childhood in New Zealand and in the present day. Fifty-six respondents ( $40 \mathrm{New}$ Zealandborn) had spent all or part of their childhoods in New Zealand and responded to these questions. 


\subsubsection{Language use at home}

Fifteen respondents never spoke Dutch at home. Fourteen of those respondents (93\%) speak only English at home as adults. One person now uses both Dutch and English at home. Of the 12 respondents who always or mostly spoke Dutch at home as children, $50 \%$ now speak English and 50\% now speak a mixture of Dutch and English at home. Of the 29 respondents who 'sometimes' spoke Dutch at home

- $58.6 \%$ now speak English at home

- $37.9 \%$ now speak Dutch/English at home

- $3.4 \%$ now speak Dutch at home (one respondent)

Table 11-16: Dutch respondents use of MT at home: in childhood and adulthood

\begin{tabular}{|l|l|l|}
\hline & In childhood & In adulthood \\
\hline Never use/d Dutch & $26.7 \%$ & $66 \%$ \\
Use/d Dutch & $73.2 \%$ & $34 \%$ \\
$\mathrm{~N}=$ & 56 & 56 \\
\hline
\end{tabular}

\subsubsection{Language use outside the home}

Twenty-four respondents (42.8\%) did not use Dutch outside the home during their childhood in New Zealand. Two-thirds of those respondents, as adults, use only English outside the home the remaining third use Dutch as well as English.

Of the 32 respondents $(57.1 \%$ ) who did use Dutch outside the home when they were growing up in New Zealand, 22\% do not use Dutch outside the home today and $78 \%$ do use it. The overall proportions of Dutch use outside the home have not changed greatly but there has been some change in individual patterns of behaviour with people moving from one pattern to the other. As with the Gujarati interviewees, the most striking fact is that shift within the home environment has been considerable whereas shift outside the home appears less marked.

Table 11-17: Dutch respondents use of MT outside the home in childhood and adulthood

\begin{tabular}{|l|l|l|}
\hline & In childhood & In adulthood \\
\hline Never use/d Dutch & $42.8 \%$ & $41 \%$ \\
Use/d Dutch & $57.1 \%$ & $59 \%$ \\
$\mathrm{~N}=$ & 56 & 56 \\
\hline
\end{tabular}

Twelve of the 35 respondents who spoke Dutch outside the home as children and as adults only used it with older people and with immigrants both then and now. Amongst the other respondents who replied positively to this question (at either time period) there was a range of responses to the questions about situations and interlocutors in which and with whom Dutch was used, but, in general, the ranges of situations and interlocutors were limited. They were 
somewhat more limited in adulthood than in childhood. For some respondents Dutch use outside their own homes had narrowed down to 'at my parents' house' or 'at X's house'. For both groups considerable change in habitual patterns of language use in the home had occurred. There are clear signs of language shift in process. The domain of the home has been more vulnerable to this process than the domains outside the home. In part this is probably because 'outside the home' in New Zealand was always a less intensively MT-saturated environment.

\subsubsection{Summary: What influences successful MT acquisition}

A parent who uses mainly MT with the child, a range of MT interlocutors inside and outside the home, attendance at language maintenance school and a trip to the homeland have all been shown to be influential in developing a child's proficiency in the MT.

An oldest child is more likely, other things being equal, than a youngest child to become a fluent speaker of the MT, but this likelihood can be lessened by an occurrence such as a trip to the homeland at an important time in the youngest child's language development.

The overall attitude of both the family and the community can affect language maintenance. This can be clearly seen by comparing the rates of language maintenance and shift in the three communities under consideration. The Dutch, with a strong commitment to assimilation, have seen a much faster shift than the Gujaratis or Samoans, both of which communities have a greater commitment to language and culture maintenance.

The lesson to be drawn by communities and individuals interested in language maintenance is that providing a wide a range of MT environments is important, community involvement is important and parents committed to MT use in the home are important ${ }^{159}$. These are not necessarily easy goals to attain and, as a researcher, I have the most heartfelt admiration for those who attain them.

\footnotetext{
${ }^{159}$ Although too harsh a regime of MT only use in the home can backfire. One woman I spoke to said that she never insisted that her children use Gujarati in the home because her father had made her and her siblings' lives so miserable by enforcing a 'Gujarati only' rule in her childhood home.
} 


\section{LANGUAGE MAINTENANCE EDUCATION AND ATTITUDES TO LANGUAGE MAINTENANCE}

This chapter examines attitudes and behaviours towards language. These are identified in the integrated model of Fishman's theories as forming both part of the description of the social location of language maintenance and language shift but also as being related to causes of language maintenance and language shift. Attitudes and behaviours straddle description and explanation. This is perhaps most obvious in the case of the language maintenance school. Individual and community attitudes to the MT and maintenance of the MT are the decisive factor in whether a school is established and continues to run successfully (at least in terms of attendance). The community behaviour - running the school - in its turn affects the language maintenance outcomes for the community. The effect is often strong in terms of MT literacy and may be somewhat weaker in terms of MT oralcy.

In this research attitudes to language maintenance schools have, to some extent, stood as proxy for attitudes to language maintenance in general. The language maintenance school (especially in the case of the Gujarati and Samoan communities) is a clear-cut social entity about which it is easy to ask questions. It is also easy to establish whether respondents and their children attended or attend. For all these reasons, it is a useful proxy for language maintenance in general. However, enquiry into attitudes and behaviours regarding the language maintenance school has been augmented by a more global enquiry into attitudes to MT maintenance in New Zealand. The answers to these questions were reported on in Chapters 7,8 and 9 and those responses area compared and discussed below.

\subsection{Language maintenance education}

\subsubsection{After hours schools for children: are they a good idea?}

N.B. - question is hypothetical for Dutch respondents 


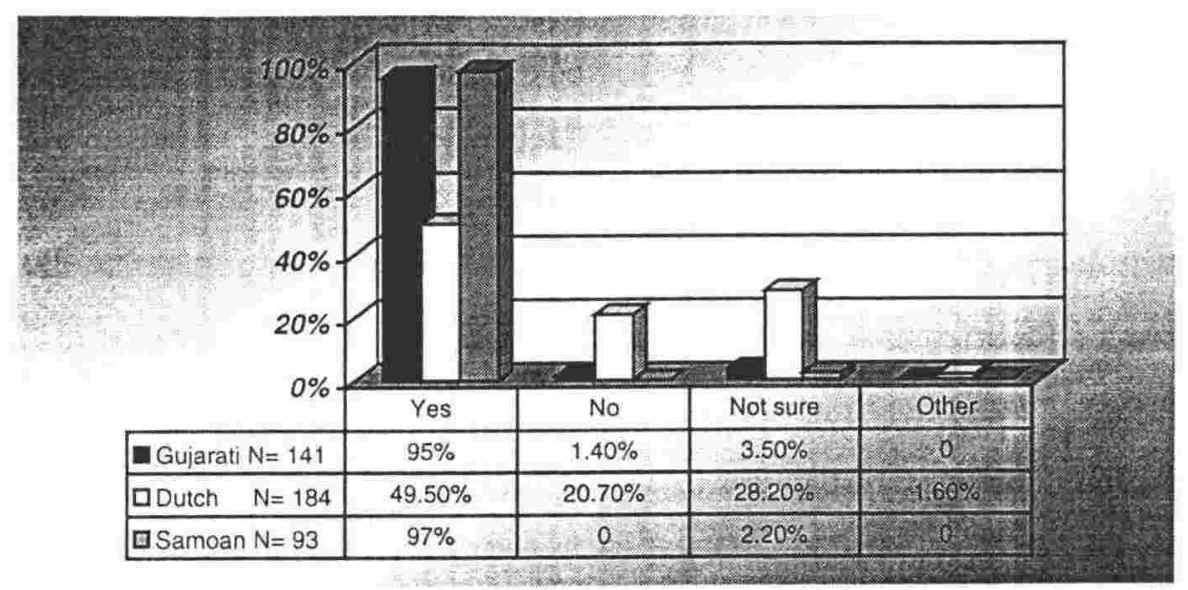

Figure 12-1: Are MT after hours schools a good idea: All respondents

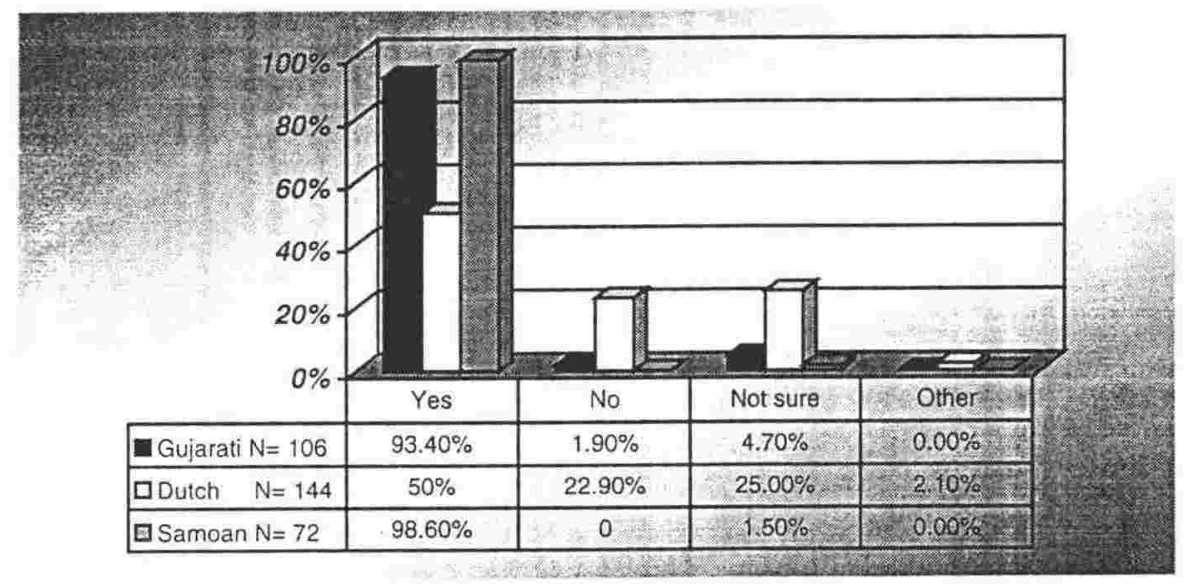

Figure 12-2: MT after-hours schools a good idea?: All non-New Zealand-born respondents

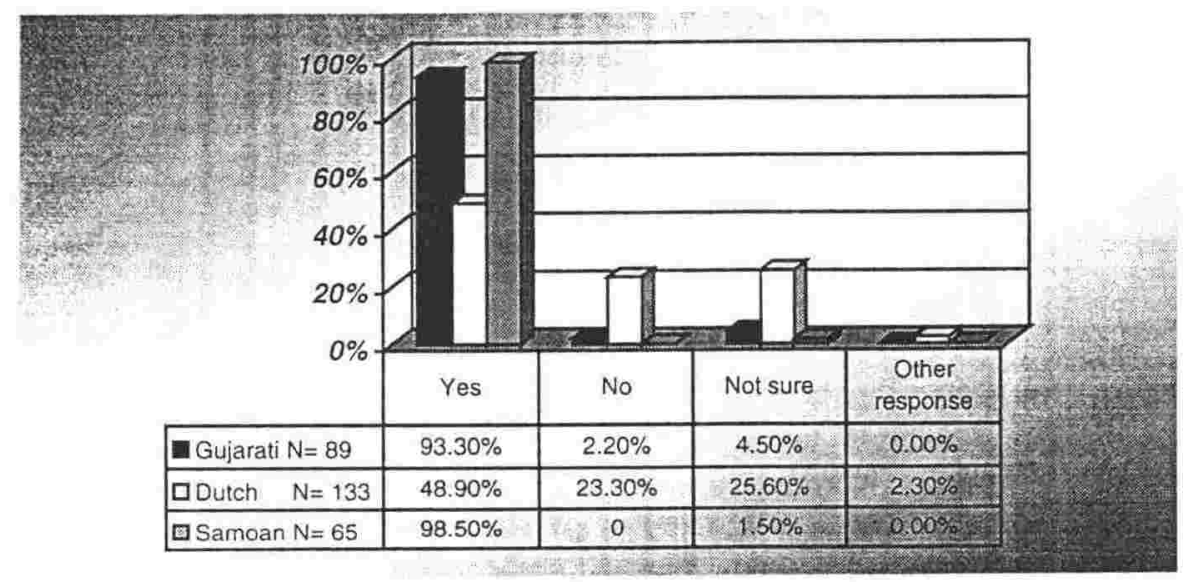

Figure 12-3: MT after hours schools a good idea?: All non-New Zealand-born respondents arrived in New Zealand 10+ 


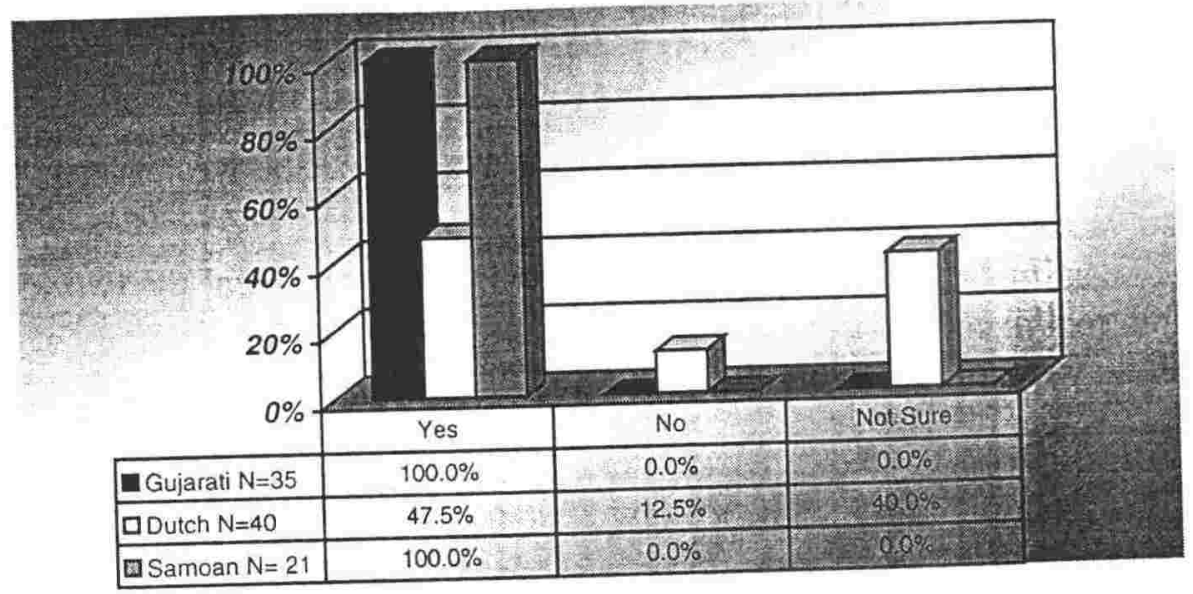

Figure 12-4: MT after hours schools a good idea?: All New Zealand-born respondents

Virtually all the Gujarati and Samoan respondents, regardless of place of birth, thought that after hours MT classes were a good idea. Both communities maintain such classes and there is obviously a high level of support for them - at least amongst the adults. Several of the Gujarati respondents whom I interviewed and who had attended such classes as children, said that they had not wanted to go as children but were now glad that their parents had insisted that they attend. Until very recently the Dutch community in Wellington has not had any MT classes for children although occasional adult education classes have been offered. The fact that after hours Dutch MT classes for children had never been run in Wellington at the time of the questionnaire must be taken into account when considering that compared to the Gujarati and Samoan respondents. Far fewer Dutch respondents thought such classes were a good idea, but it is not possible to know how much how much of this was due to the fact that they had no experience of such classes. The only exception to this is a category that generally has not been considered on its own because it consists of only 11 respondents, non-New Zealand-born Dutch respondents who arrived in New Zealand under the age of 10. Interestingly, this small group is the only one in which well over half the group ( 7 respondents or $63.6 \%$ of the group) thought that after hours MT classes would be a good idea. It is tempting to relate this to the fact that they would have spoken Dutch fluently as young children (or, if they came as babies were likely to have fluent Dutch speaking elder siblings) and that fluency would have faded as they grew up in New Zealand. Most of this group rated themselves as 'fairly fluent' speakers of Dutch and perhaps they felt that a MT after hours class would have helped them to retain 
more of their Dutch ${ }^{160}$. One respondent in this group added a comment to her response about whether her children attended language maintenance classes (they, as with all the other children of respondents, had not attended, because none had been available). She wrote

For me it may have been important, when I was a child as I felt 'in-between' the two cultures. My children feel/live/speak New Zealand and aren't torn between the cultures. If, in time, they want to know more of their heritage - they will search and find.

(R. D142. Female, Dutch-born, 41-45, came to New Zealand under 10 years of age).

This respondent has identified one of the important reasons for language and culture maintenance and one of the underlying functions of MT language maintenance schools. A simplistic model of immigrant assimilation, such as was undoubtedly widely held in at the time that this respondent arrived (see sections 2.4 to 2.7 ), posits that the quickest route to assimilation and hence social ease and a sense of social cohesion both for the immigrant and the host society is for the immigrant to immediately adopt as many of the host society's traits as possible (including language), and to abandon as many of the homeland's traits as possible (including language):

linguistic diversity continued to be unacceptable in the largely mono-cultural New Zealand of the late 1940s and 1950s....Those who could not speak English at all soon decided that remaining silent [in public] was their safest option.

[Jewish] Refugees were aware of strong pressures from the community - from their sponsors, from employers, from government officials and from New Zealand Jews - to familiarize themselves with English. No encouragement was given, for example by the schools, to maintain first languages. .....

Such attitudes were in line with the educational thinking of the day regarding how children of a different culture could best be helped to fit into school and their new country as quickly as possible. The views of educationalists about the schooling of immigrant children in Australia during those years were clearly stated in 1951 in an article by a headmaster of a primary school in a migrant holding centre. The headmaster wrote:

The child must learn to think in English from the start ... English is to be the basis of all instruction. It is the avenue to mutual understanding. It is to be the key to success

\footnotetext{
${ }^{160}$ As a non-Dutch child (of parents who did not speak much Dutch) who spent part of my childhood in the Netherlands and came back to New Zealand at the age of 7, I can remember the melancholy feeling of my Dutch language skills slipping away from me. Every time I opened my Dutch language story books, I understood less and less of what I read, no matter how much I knew I loved the story. I can sympathise with those who went through the same childhood process of decreasing control of a once familiar language.
} 
of the whole immigration project ... English must be spoken to the pupils and by them, all day and everyday, in every activity, in school and out of it [Jean I. Martin, ' Child Migrant Education in the Fifties and Sixties', in The Migrant Presence: Australian Responses 1947-1977, Studies in Society 2, Sydney 1978, pp. 85-6)]

It is likely that similar views were held in New Zealand. They certainly were in relation to Maori education. ... Often parents themselves saw no purpose in their children retaining another language. Jane remembers her father saying that there was no point in learning Czech because it was only spoken in Czechoslovakia. When a Czech refugee who held different views attempted to teach language to the children of other refugees in the 1940s, the conversation class she established at the Wellington Czech Club continued for only a few weeks.

(Beaglehole 1990: 95-97)

There are several interesting points in this rather long quotation. The first is that it adds further evidence, from the account of contemporaries, to the picture of 1940 s and 1950s New Zealand. A community with a very limited view of how immigrants might adapt to New Zealand society. It also points out that such attitudes were not confined to New Zealand and were certainly shared by her closest neighbour. Australia was, in fact, having to articulate these views much more publicly and coherently than New Zealand because of the far greater proportion of non-English speaking immigrants to Australia in the post-WWII period - hence it is much easier to find Australian comment on the subject than it is to find New Zealand comment.

There is considerable evidence that this complete and rapid assimilation into the new society is, in the first place, not really possible and in the second, is more traumatic than other models of adaptation. Eva Hoffman's Lost in Translation is a perceptive study of her transition from 1950s Poland to 1950s Canada as a teenager. She describes her first day, with her younger sister, at the new, Canadian school.

This morning, in the rinky-dink wooden barracks where the classes are held, we've acquired new names. ...nothing much has happened, except a small, seismic mental shift. The twist in our names takes them a tiny distance from us - but it's a gap into which the infinite hobgoblin of abstraction enters. Our Polish names didn't refer to us they were as surely us as our eyes or hands. These new appellations, which we ourselves can't yet pronounce, are not us. They are identification tags, disembodied signs pointing to objects that happen to be my sister and myself. We walk to our seats, into a roomful of unknown faces, with names that make us strangers to ourselves ( $P$. 105)

A little later on, commenting of the transition from using Polish to using English she says 
The worst losses come at night. As I lie down in a strange bed in a strange house ... I wait for that spontaneous flow of inner language which used to be my nighttime talk with myself, my way of informing the ego where the id has been. Nothing comes. Polish in a short time has atrophied, shrivelled from sheer uselessness. ... In English, words have not penetrated to those layers of my psyche from which a private conversation could proceed. ... I have no interior language, and without it, interior images - those images through which we assimilate the external world, through which we take it in, love it, make it our own - become blurred too. ... I'm not filled with language anymore, and I have only a memory of fullness to anguish me with the knowledge that, in this dark and empty state, I don't really exist (pp. 107-8).

Later a friend gives her a diary and she has to decide which language to use when writing in the diary

Writing in Polish at this point would be a little like resorting to Latin or ancient Greek - an eccentric thing to do in a diary, in which you're supposed to set down your most immediate experiences and unpremeditated thoughts in the most unmediated language. Polish is becoming a dead language, the language of the untranslatable past. But writing for nobody's eyes in English? That's like doing a school exercise, or performing in front of yourself, a slightly perverse act of self-voyeurism. ... [she decides to write in English] This language is beginning to invent another me. However, I discover something odd. It seems that when I write (or, for that matter, think) in English, I am unable to use the word "I". I do not go as far as the schizophrenic "she" - but I am driven, as by a compulsion, to the double, the Siamesetwin "you" (120-121).

I have quoted at some length from Hoffman because she expresses with great clarity a phenomenon that turns up again and again in accounts of immigrant childhoods; the disjunction in the individual persona caused by the competing demands of the two societies the individual inhabits - especially where, as is usually the case, one of those societies is utterly oblivious to the existence, nature and validity of the claims made by the other. Usually (not always, one thinks of the Amish in the USA or some groups of Islamic immigrants in Britain) the immigrant group is not only aware of the demands that the host society is making, it also concedes that those demands have some validity and that some of their ways will have to change in the new world. But often the host society, while it may vaguely recognise differences, grants those differences no validity at all. Name changing is a classic case (Beaglehole 1990:54, Ip, 1990: 50,124, Jansen 1990:37, Schouten 1992:121,142,184) which is often cited as symbolic of the larger disjunctures simultaneously occurring. While no-one would suggest that the process of immigration can be made completely painless or free of strain for those undergoing it, and while it is obvious that the immigrants themselves have a large part to play in defining how they experience the process, nonetheless the host society can undoubtedly be an important factor in that process. If the host society wishes to be 
cohesive then, paradoxically perhaps, it should take steps to make the social and linguistic phenomena the immigrants have brought with them acceptable, comprehensible and comprehended, ${ }^{161}$ within the framework of the host society. Immigrants who feel themselves and their language and culture to have been welcomed and accepted will, presumably, feel themselves to fit more securely within the framework of the new society than those who feel that they, their language and their culture have all had to change utterly in order to be accepted. There are at least two strands to this process. One is to make the immigrant group feel that there are aspects of their language and culture that can continue to have validity in the wider world of the host society (and not just to be practiced, semi-secretly, at home) and the other is actively to foster the host society's knowledge of the immigrant society. One obvious site for both these parts of the process is educational institutions as was seen in section 5.4, and this is discussed in more detail below when the respondents' answers to the questions about MT instruction in schools are considered.

The other point of interest is Beaglehole's informant whose father said that there was no point in learning Czech because it could not be used outside Czechoslovakia. This type of comment was fairly common amongst the Dutch respondents to the questionnaire (and nonexistent among the Samoan and Gujarati respondents).

Dutch is not a commercially important language. Better learn Chinese. (Male, 51-55, Dutch-born).

Dutch is no world language. ... As English is readily understood and spoken in the Netherlands the urgency does not exist.

(Male, 60+, DEI-born)

I think German is a better choice.

(Male, 51-55, Dutch (Limburgs ${ }^{162}$ )-born

Not really relevant language for them in terms of career plans

(R. D117.Male, 36-40, New Zealand-born)

\footnotetext{
161 This is undoubtedly a counsel of perfection. Not all societies can find the practices of all other societies equally acceptable. As my present focus is on language, where I think that full acceptance is possible without have to delve into the area of cultural and ethical relativity, I intend not to investigate this problem any further in this discussion.
}

162 The fact that this respondent is a Limburger and speaks Limburgs may well be relevant to his answer "On a purely linguistic basis, Limburgs can be said to be more of a German than a Dutch dialect." (Pauwels 1986:24) 
This seems to point up a fairly important factor in immigrant motivation for language maintenance. If an immigrant language is not widely spoken outside the homeland and if the immigrant group has no strong expectation of return to the homeland then the impulse to language maintenance in the new country will often be weakened. One of the interviewees on record in the Turnbull Oral Archive collection recalls how far away from their homeland the immigrants of the 1950s felt

And I've never felt - I've never been homesick. Some people were. And then you sort of lay awake at night and [think] God you're 6 weeks away from home - y'know - as it was then - and there was no way of flying back. Planes didn't fly here

Paul Veltman

Interviewer Adrienne Jansen

11.3.1993

Born 1928

Arrived New Zealand 1952

MSC 5409 MSC 5410

The Gujarati respondents see themselves as part of a Gujarati-speaking community that exists in East Africa, the Pacific and in India (it also exists in Britain and the USA, but these branches of it seem less close to the New Zealand respondents I spoke to); a community to which they have and intend to continue to have access. The Samoan community in New Zealand, at least in the case of many members of the community, sees itself as part of a wider Samoan community. Krishnan et al comment that

Many Samoan and Tongan extended families operate like miniature 'transnational kinship networks' facilitating the migration process among their members to New Zealand, Australia and the United States (Krishnan et al 1991994: 8).

This sense of belonging to a community that extends beyond New Zealand and which is MT speaking (in most cases) is a strong motivating factor for language maintenance. Even before the days of comparatively affordable air travel, a sojourner immigrant group such as the Gujaratis originally were in New Zealand would also have strong motivation for language maintenance. A group such as the Dutch in New Zealand, who saw themselves as having left their homeland for ever, would not have such a motivation for language maintenance although individuals might have their own motivations such as those of the woman who wrote to me 'no mother can speak to her baby in a language other than her mother tongue' (Female 60+, Dutch-born). 
It should also be observed that although under half the Dutch respondents in any category thought that after hours schools were a 'good idea', this does not mean that the majority thought that such classes were a 'not a good idea'. Only a comparatively small proportion of respondents chose that option (22.9\% of the non-New Zealand-born and only $12.5 \%$ of the New Zealand-born respondents) the remainder said that they were 'not sure'. This seems a reasonable response given their lack of experience of such schools. Unlike the Gujarati and Samoan respondents, the Dutch respondents could not refer to their own knowledge of such schools and thus were less likely to be able to make a firm judgement about them. Included in the Dutch version of the questionnaire was the option of adult language maintenance classes and there was a much higher rate of support for classes for adults: $78.5 \%$ of the non-New Zealand-born and $90 \%$ of the New Zealand-born respondents thought that such classes were a 'good idea'. In this, the New Zealand Dutch respondents were similar to the Australian Dutch investigated by Bennett who found

this sample [of second generation Dutch in Australia] expressed a clear preference for adult education classes as the method of learning more Dutch in future (Bennett 1992:69)

Some of the respondents to the questionnaire added comments to their answers to the questions and some typical additions to this question about after hours schools for children were

Only if the child shows an interest. Most Dutch children are those born in New Zealand from Dutch parents. These are interested after high school age.

(Male, DEI-born, 60+)

It is my experience that Dutch people speak (mostly) English at home, especially when there are school age children. The children will be able to speak some Dutch, but not be able to speak or write it. Then, when they are in their twenties, they want to visit the Netherlands, and go either to evening classes at Wellington High School or a private tutor. Quite often there is not enough time, but one hopes that at least it prepares them for learning faster than without any preparation at all. The availability of such classes seems therefore important.

(R. D065. Female, Dutch-born, 60+)

While I am grateful to my parents for encouraging us to concentrate on English studies (rather than Dutch), it would be good, as an adult, to have the option of improving my level of Dutch comprehension (my cousins in Holland all speak fluent English, but I would like to be able to communicate a little better with elderly relatives who don't speak English!)

(R. D076. Female, New Zealand-born, 31-35) 
Although one respondent commented 'apparently they are VERY slow and unstructured' (R. D138. Female, non-New Zealand-born, 26-30)

One respondent (Male, Dutch-born, 51-55) added that such classes should also be aimed at the New Zealand-born spouses of Dutch adults and another says that she and her non-Dutch husband both attended the classes at Wellington High School before going for an extended stay in Holland (R. D117. Female, New Zealand-born, 36-40). Yet another respondent, noting that his wife has not filled out the questionnaire I sent because she is not Dutch, added that she 'does not know any Dutch (more is the pity)' (R. D156. Male, Dutch-born, 60+). These comments certainly belie the image of Dutch immigrants having no interest at all in maintaining their MT.

\subsubsection{Summary}

In section 11.7.7 the efficacy of the language maintenance school as a support for language maintenance was discussed. In this section the language maintenance school has been further investigated and it can be seen that not only is it strongly supported by two of the groups under consideration but that the process of MT language maintenance, which is supported by the language maintenance school, is important for many immigrants and their children in the process of constructing and maintaining a sense of personal identity.

\subsubsection{Should public funds go to community language maintenance schools}

This question was asked both to find out what degree of support existed in each of the three communities for public funding of MT schools and also as another indicator of attitude to the MT in a New Zealand context. Support, or lack of it, for public funding of MT schools was taken as expressing not so much a positive or negative attitude to the MT or to language maintenance itself, but rather as expressing, at least in part, the extent to which the respondent saw the MT language maintenance process as fully integrated into New Zealand life and deserving of New Zealand support. Respondents' attitudes to language maintenance in New Zealand, as measured by responses to this question, were also related to socio-cultural processes in New Zealand. Thus, if respondents supported public funding of language maintenance schools it was taken as an indication that they perceived their language community and their language maintenance endeavours as deserving to be well-integrated into New Zealand society. 


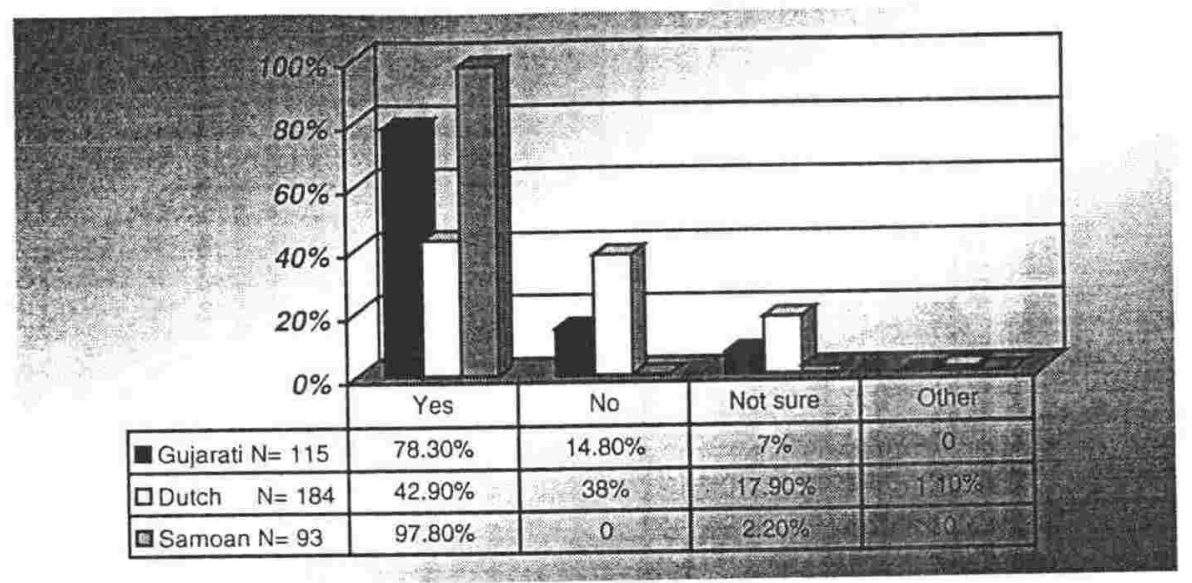

Figure 12-5: Should public funds go to community language maintenance schools: All respondents

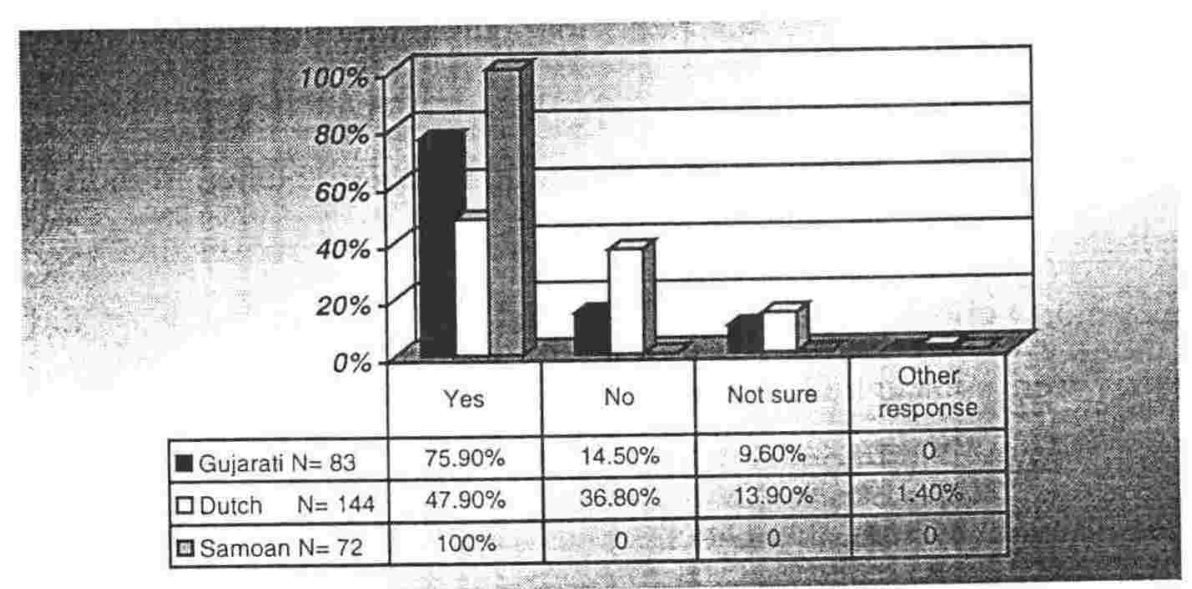

Figure 12-6: Should public funds go to community language maintenance schools: All non-New Zealand-born respondents

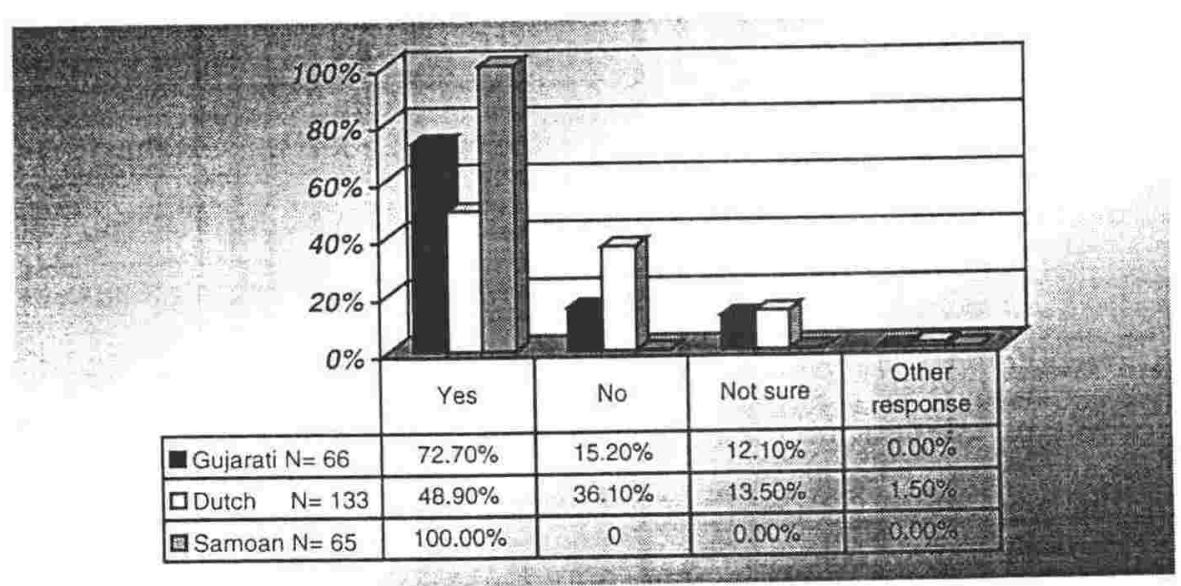

Figure 12-7: Should public funds go to community language maintenance schools: All non-New Zealand-born respondents arrived in New Zealand 10+ 


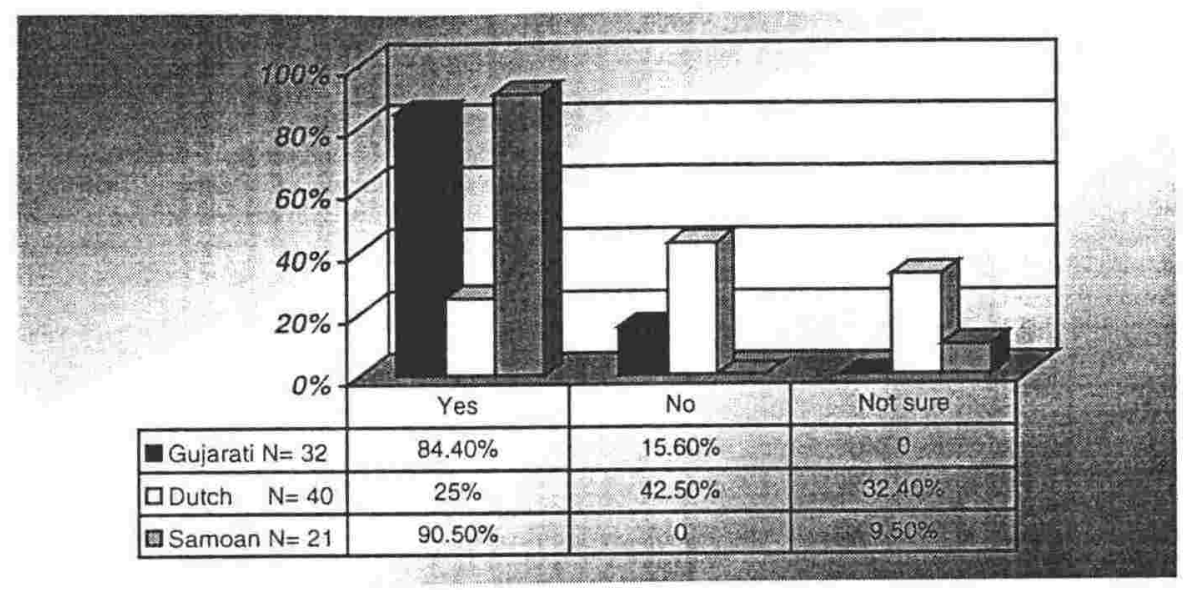

Figure 12-8: Should public funds go to community language maintenance schools: All New Zealand-born respondents

The most notable feature of the responses to the question about public funding for community language maintenance schools is the response of the New Zealand-born Dutch respondents.

The New Zealand-born Dutch tended to give responses that could broadly be taken to indicate support for MT language maintenance in New Zealand. They either gave responses that indicated they were slightly more supportive than the other Dutch respondents or at least, did not seem to indicate that they were substantially less supportive. More New Zealand-born Dutch respondents than non-New Zealand-born Dutch respondents said that Dutch should be taught within the mainstream school system, that Dutch should be a living language in New Zealand, that the Dutch in New Zealand should see themselves as part of a Dutch-New Zealand community and that they should not see themselves simply as New Zealanders. Only slightly fewer of the New Zealand-born Dutch than the non-New Zealand-born Dutch thought that community language maintenance schools were a good idea, but a considerably smaller percentage ( $25 \%$ compared to $47.8 \%$ ) thought that public funds should go to these schools. This seems to me to be an interesting variation from a general set of attitudes. Lack of support for public funding does not directly indicate lack of support for MT language maintenance and the New Zealand-born respondents' answers to the other questions in this area indicate a general level of support for MT maintenance. However, their answers to the question about public funds do perhaps indicate something about the priorities they accord language maintenance. The answers suggest that the New Zealand-born Dutch do not see maintenance as something to be achieved at all costs; a stance that would certainly fit in with the community attitudes they have been brought up with in New Zealand. They certainly do not see their language maintenance endeavours as deserving of wider New Zealand support. This view is perhaps influenced by the traditional view of the desirability of assimilation in a New 
Zealand context. Their responses to this question may also indicate that the New Zealandborn Dutch, being younger than the non-New Zealand-born, are more affected by the 1980s doctrine of 'user pays' and, given that none of them would have been involved in trying to organise such a school it may also indicate ignorance about the level of effort and expenditure involved. The New Zealand-born Gujarati and Samoan respondents are more likely to be aware of the enormous effort involved in establishing and maintaining a MT language maintenance school and thus be more likely to be sympathetic to the idea of government funding and less likely to be influenced by purist notions of 'user pays'.

One respondent wrote "no justification whatsoever for asking government to fund something like that' (male, New Zealand-born, 36-40, d177) and another New Zealand-born woman in her thirties simply wrote 'user pay' $(\mathrm{d} 178)^{163}$. Another New Zealand-born respondent (who replied 'not sure') was perhaps slightly more typical, and somewhat milder in her response when she wrote 'it would be good but there is so little money available it may be better spent on more essential needs in education' (36-40, d039). Two respondents (both non-New Zealand-born) were very emphatic that Dutch children in New Zealand should get this kind of support; one cited the UN charter (d172) and the other (d138) said that this kind of public support was provided in the Netherlands and Sweden (and by implication, should be provided in New Zealand as well).

Amongst the Gujarati respondents, the proportion who thought that public funds should go to community language maintenance schools was higher amongst the New Zealand-born $(84.4 \%)$ than it was amongst the non-New Zealand-born (75.9\%). It is interesting and suggestive that support for public funding is higher amongst the New Zealand-born respondents. It suggests that, born and raised in New Zealand, they feel, more than their immigrant parents' generation, that they and their language and culture have a place in, and a claim on New Zealand, The fact that each of the three groups exhibits a different pattern from the others shows, however, that there are no convenient generalisations to be made about this particular question. All the non-New Zealand-born Samoan respondents thought that public funds should go to community language maintenance schools but there were a handful of New Zealand-born Samoan respondents who were 'not sure' if public funds should be spent

16.3 Admittedly these two were married so may have discussed the matter before answering the questionnaire one may have influenced the other. 
in this way. None of the Samoan respondents gave an outright 'no' to this question; so the Dutch New Zealand-born respondents, $42.5 \%$ of whom responded 'no' to this question are certainly in a somewhat different position from the Samoan and Gujarati respondents. It must also be remembered of course that public funding does go to at least some of the Samoan language maintenance schools whereas it does not go to the Gujarati schools nor does it go to the very fledgling Dutch school (that did not exist at the time of the questionnaire). Walker and Stapleton found that $68 \%$ of their respondents (of differing ethnicities) in the Manawatu supported some form of government funding for first language maintenance (1998: 228).

\subsubsection{Summary}

There is strong support for public funding of community language maintenance schools amongst the Gujarati and Samoan respondents, and that support is even stronger amongst the New Zealand-born respondents from those groups. The Dutch however, are divided on this question and support for public funding is particularly weak amongst the New Zealand-born Dutch. In Chapter 11 the role of the language maintenance school as a causative factor in language maintenance, and its efficacy as a support of language maintenance was discussed. It was concluded that although far from being a sufficient or perhaps even necessary condition for oral MT language maintenance nonetheless, the language maintenance school has a valuable role to play. It signifies group commitment to language maintenance, it extends the range of contexts in which students (usually, but not always, children) can use the MT and it is instrumental in promoting at least some degree of MT literacy (see also LMP 1985: 227, 265, Taft \& Cahill 1989:132).

It was noted above that the category 'attitude and behaviours towards language' (1 (c) of the integrated model), straddles description and explanation. The existence of long established regularly attended language maintenance schools (as in the Gujarati and Samoan communities) or their absence (as in the Dutch community) describes an aspect of the social location of language maintenance in the first two communities. It also describes something about the attitudes to language maintenance in all three communities (strongly positive in the first two, not so in the third) and thus contributes to an explanation of greater rates on language maintenance in the Gujarati and Samoan communities and language shift in the Dutch. Taking the pathway provided by the integrated model a step further, it also elaborates our understanding of the causative (as regards language maintenance and shift) forces of dislocation. All immigrant experience is dislocative. The Dutch in the 1950s dealt with 
dislocation, in part, by throwing themselves into the project of assimilation. If they were to be dislocated from the Netherlands then the solution was to be completely 'at home' in New Zealand. Partly because a racist New Zealand did not hold out the offer of complete assimilation to the Gujarati and Samoan communities, they have dealt, in part, with dislocation by bringing with them and handing on to their children and grandchildren, important sociocultural practices from 'home'. These have included language, religion, caste, social hierarchy, marriage practises, dietary practices etc. Within this network of sustaining community practises, the language maintenance schools play their part.

\subsection{MT within the state school system}

Asking respondents whether they supported the teaching of the MT (or possibly the national standard, Hindi, in the case of the Gujaratis) within the state school system was also oriented to discovering not only the answer to the question but also to discovering more about attitudes to language maintenance in general. Support for MT in the mainstream schools was taken as evidence both of a positive attitude to language maintenance in New Zealand and also, as with government funding for community schools, as a sign that those who supported it considered that their language, culture and community have a valid claim on New Zealand's resources. It is, in a way, a measure both of the importance of language maintenance to the individual and community and of the self-confidence of the community vis-à-vis their language and culture in New Zealand. In terms of the integrated model, support for the MT within the school system shows a positive attitude to language maintenance and, in the case of the Samoan community, who have achieved mainstream, school-based instruction, shows successful behavioural implementation of that positive attitude. Both of these are causative factors for language maintenance. In the case of the Gujarati there has been no community-wide attempt to institute mainstream school-based MT instruction. One of the respondents however, is a school teacher and has, at times, taught Gujarati classes within the school system thus showing that at an individual level such behavioural implementations are occurring. 


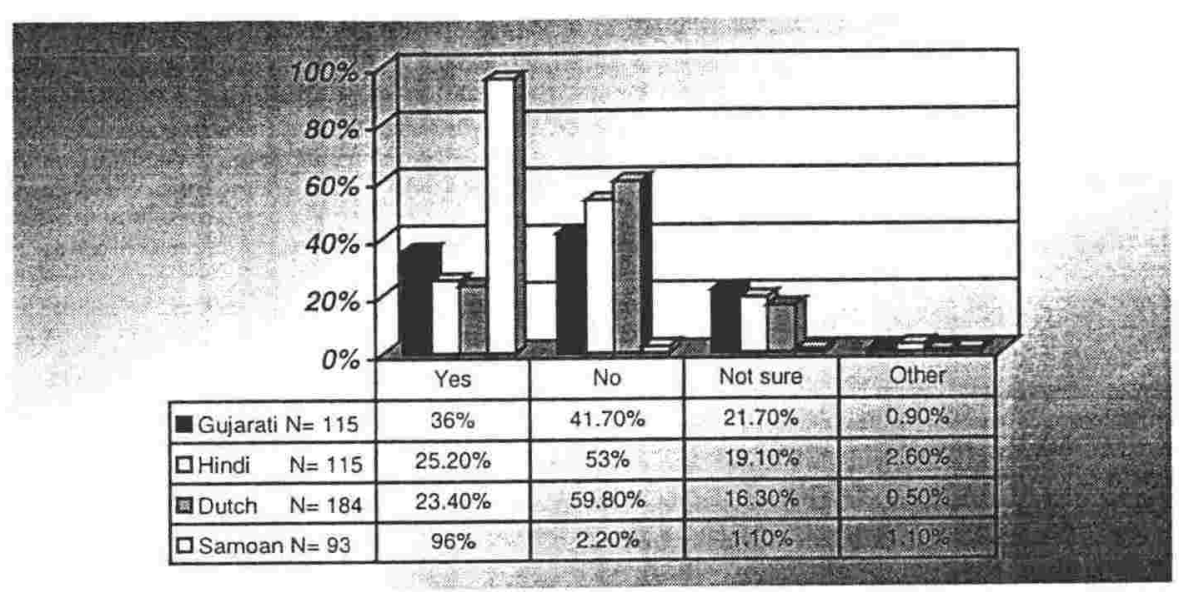

Figure 12-9: MT within state school system?: All respondents

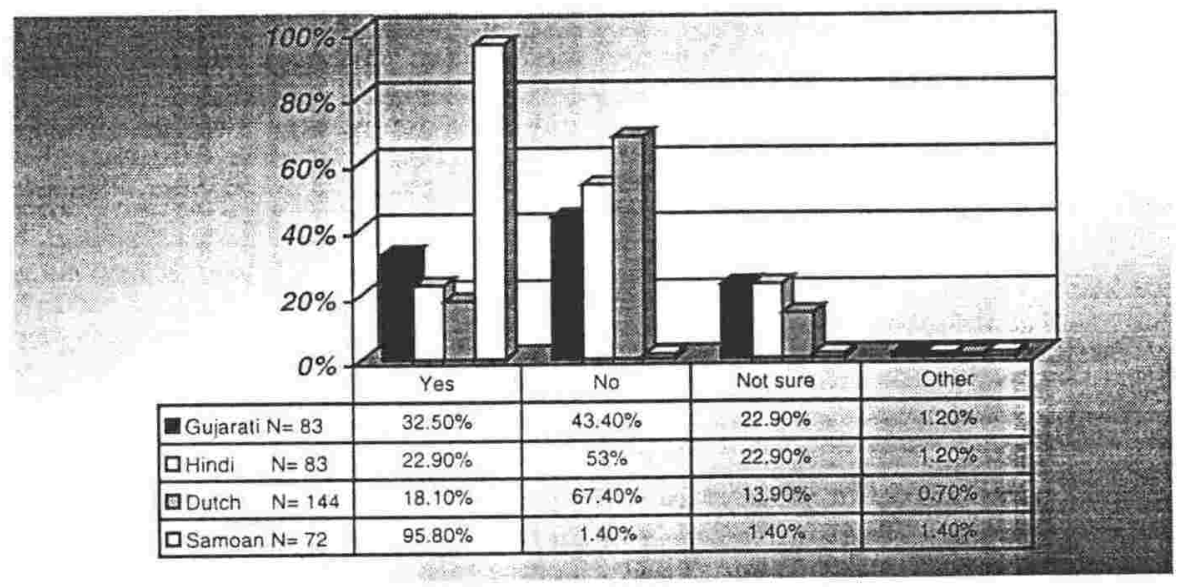

Figure 12-10: MT within state school system?: All non-New Zealand-born respondents

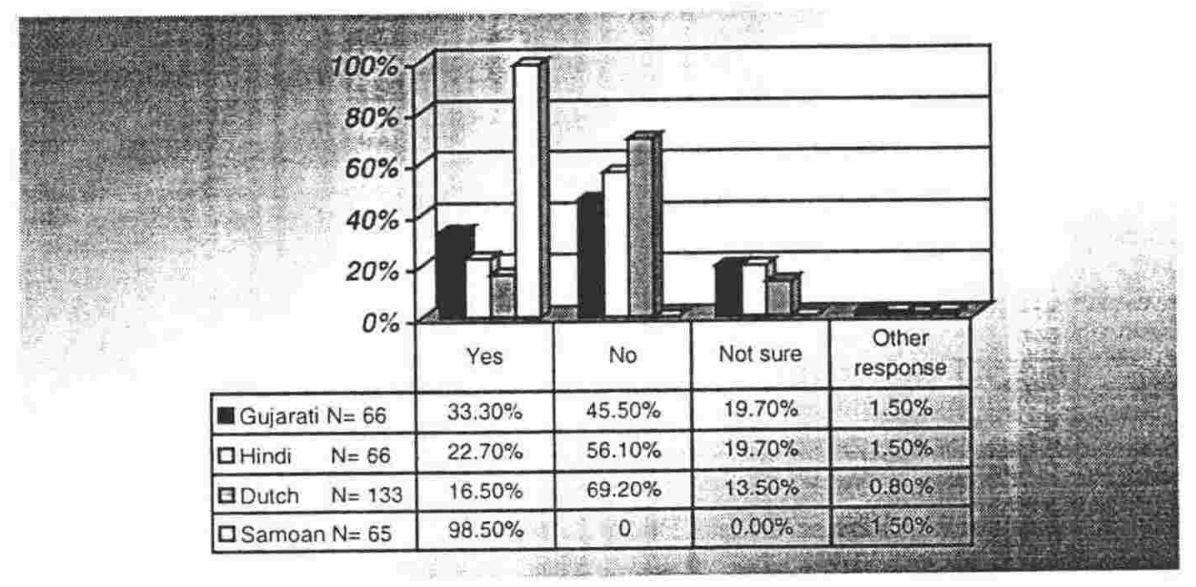

Figure 12-11: MT within the state school system?: All non-New Zealand-born respondents arrived in New Zealand 10+

It is notable that support for the teaching of the MT within the state school system is very high amongst the Samoan respondents and comparatively low amongst both the Dutch and the Gujarati respondents. Samoan is, of course, already available within the state school system and the other two languages are not. At least one Dutch-born respondent commented that 
Dutch should not be taught at the expense of English and Maori (d031, female). Respondents' attitudes to the teaching of Hindi were investigated because it was thought that respondents might feel that it would be a better choice for teaching within the state school system where pupils would be drawn from a wide range of origins both Indian (including non-Gujarati) and non-Indian. While the idea of teaching Hindi was not completely rejected by the respondents it was not as popular as the idea of teaching Gujarati in any of the Gujarati respondent groups.

It is interesting to note that the New Zealand-born Dutch and Gujarati respondents made very similar responses to this question although the responses from the non-New Zealand-born respondents vary quite markedly. Only a few of the non-New Zealand-born Dutch respondents thought it would be a good idea to teach their MT in state schools whereas almost a third of the non-New Zealand-born Gujarati respondents thought that it would be a good idea. By contrast, well over a third of the New Zealand-born Gujarati and Dutch respondents thought that it would be a good idea.

- $18.1 \%$ of the non-New Zealand-born Dutch respondents thought it would be a good idea to teach their MT in state schools

- $32.5 \%$ of the non-New Zealand-born Gujarati respondents thought that it would be a good idea

- $43.7 \%$ of the New Zealand-born Gujarati respondents thought that it would be a good idea

- $42.5 \%$ of the New Zealand-born Dutch respondents thought that it would be a good idea.

The New Zealand-born seem to feel differently about the matter of involving the wider community in their language and cultural maintenance efforts. There are a variety of possible reasons for this. One, as suggested above, may be that because they have been born and raised in New Zealand they feel that they have more right to make a claim upon the educational resources of the country, another may be that they feel the threat of language loss more keenly than their non-New Zealand-born parents and grandparents and wish to exploit every avenue to avert it. Yet another reason, related to the foregoing, may be that there are more tertiary educated respondents in the New Zealand-born groups. As was discussed in section 11.5.2.1, Gujarati respondents with a tertiary education are less likely to speak their MT to their children, this may increase their awareness of the dangers of language loss (which are of course much more likely for children not hearing the MT language at home) and thus make them more likely to think that maintenance input from other sources is a good idea. Hayden made a similar point commenting on Ukrainian communities in the USA in the 1960 s he said 
Ukrainian respondents in Newark, for example, tend to pay increased attention to schooling, as compared to their parents, in connection with maintenance of the ethnic mother tongue. The implication appears to be that a continuation of natural home and neighborhood ethnicity has become far less feasible. Ukrainians of Olyphant are even more strongly aware of the role of institutions - and of educational institutions in particular - in the maintenance of language and ethnicity, relying on schooling more than their parents did (Hayden 1966: 195).

However, he goes on to comment that the same effect is not visible in the Spanish-speaking communities he has investigated, reminding us, should any reminder be needed by now, that there is considerable variation across communities.

\subsubsection{Tertiary education as a factor in attitudes to MT in the mainstream school}

Gujarati New Zealand-born respondents who thought that their MT should be taught in state schools were slightly more likely to have a tertiary education (including university education) than those who answered 'no' or 'not sure' to the question; $71.8 \%$ of all the New Zealandborn Gujarati respondents had a tertiary level of education whereas $84.6 \%$ of those who thought Gujarati should be taught in schools were educated to that level, for a university education the proportions were $34.3 \%$ to $46.1 \%{ }^{164}$.

For the Dutch respondents however, level of education was not shown to correlate in any way with language spoken to children nor, amongst the New Zealand-born, does it appear to correlate in any clear pattern with their attitude to the teaching of the MT at state schools. $75 \%$ of all New Zealand-born Dutch respondents had a tertiary education and $32.5 \%$ had a university education. Amongst those who thought Dutch should be taught at state schools, $64.7 \%$ had a tertiary education and $35.2 \%$ had a university education. Overall $29.9 \%$ of all the Dutch respondents received a university education and $74.4 \%$ a tertiary one. Because all, or almost all, Samoan respondents supported the teaching of the MT in mainstream schools, they are not considered here.

${ }^{16+}$ Overall $33 \%$ of all the Gujarati respondents completed a university level education and $53 \%$ a tertiary one. 


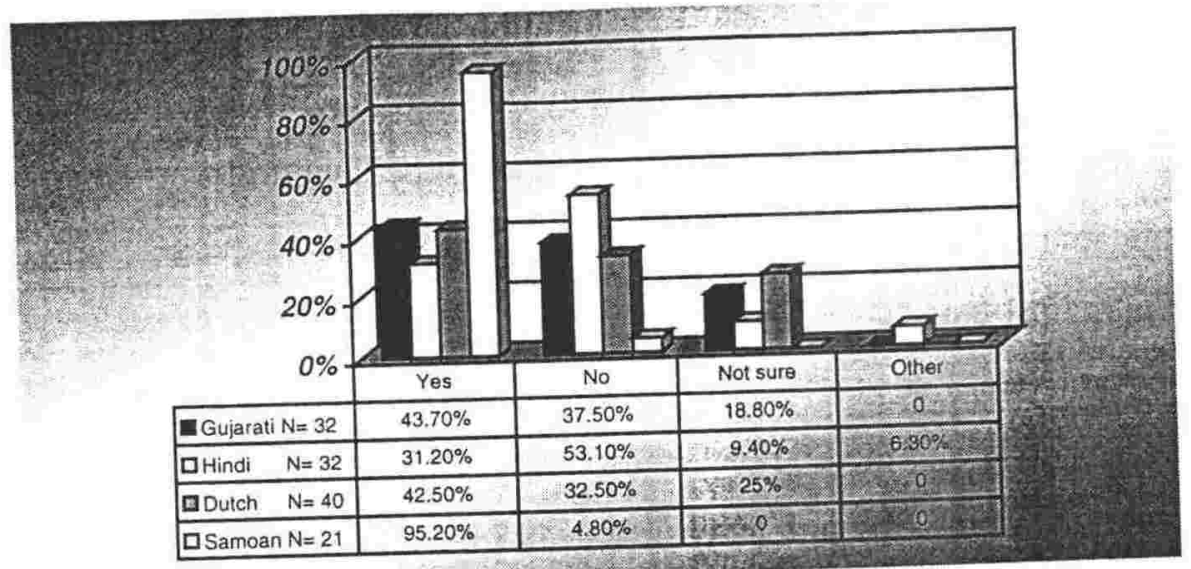

Figure 12-12: MT within the state school system?: All New Zealand-born respondents

\subsection{Summary: language maintenance education}

The Samoan respondents who have already experienced both state support for community language maintenance programmes and the teaching of their MT within the mainstream school system are obviously enthusiastic supporters of both policies. Amongst the Gujarati and Dutch respondents, support for MT teaching within the mainstream system is definitely more muted, although stronger amongst the Gujarati respondents and stronger amongst the New Zealand-born Dutch.

It is interesting to note that the existence of a programme appears (not surprisingly perhaps) to strengthen support for it. It is certainly worth noting that each of the groups appears to value the formal structures that they already have in place, even if they do not envisage the need for more. The Samoans already have community language maintenance schools (with some state support) and MT teaching in the mainstream school. Both of these are strongly supported. The Gujarati have community language maintenance (with, in general, no state support ${ }^{165}$ ) and they support both the existing provision and the idea of some state assistance. The Dutch had, at the time of the questionnaire, adult classes, and they support these strongly, with support for other types of language maintenance programme being weaker. These findings show that the respondents have tended to support the structures already familiar to them, a natural human tendency perhaps. In the case of the Gujarati respondents there is the added strong support for the idea of state assistance for community language maintenance schools (such assistance would, as outlined above, be almost entirely new to that community). The

${ }^{165}$ The Early Childhood Development Unit support one Gujarati pre-school group that I am aware of. 
investigation of opinion about language maintenance and education shows quite a strong link between attitude and behavioural implementation. It is not easy to determine in which direction the causative link might be operating. Does a higher level of behavioural implementation (i.e. more language maintenance schools, more attendance at language maintenance schools, MT in mainstream schools) engender more positive attitudes to such implementation? Or do the positive attitudes lead to the behavioural implementations? It is too early, given the relatively short life of the Samoan community in New Zealand to make the third causative link and ask do optimally high levels of positive attitudes and positive behavioural implementations lead to optimally high rates of language maintenance? It seems likely that they do. In the Gujarati and Samoan communities, these three factors, positive attitudes, positive behavioural implementations, relatively high rates of language maintenance, have so far run side by side. In the Dutch community there has been, so far, a pattern of lower support for language maintenance schools, no behavioural implementation at all and low rates of actual language maintenance. It is the Samoan community however, that has the strongest set of behavioural implementations in terms of language maintenance (range of schools, a'oga amata, mainstream schooling) and the strongest positive attitudes towards them. In time it will become clear whether they have also had the highest rates of language maintenance.

Amongst the Gujarati and Dutch respondents, support for MT in the mainstream school is comparatively weak at the moment, but it is stronger amongst the New Zealand-born in both groups than amongst the non-New Zealand-born which perhaps indicates that support for the idea will grow in both communities. What evidence there is, suggests that teaching the MT in mainstream schools in well-designed, well-integrated programmes, would be beneficial to the children undertaking the programmes and to the wider New Zealand society.

\subsection{Should the MT be a living language in New Zealand: attitudes to language maintenance}

In this section the responses to the question 'should the MT be a living language in New Zealand?' are discussed. This was the most direct of the attitudinal questions and the answers to it show the same general trend as the questions about language maintenance schools. The Samoans have the strongest ( $100 \%$ ) support for the proposition that the MT be a living language in New Zealand, the Gujaratis the next strongest and the Dutch the weakest (with some interesting variations within the group). 


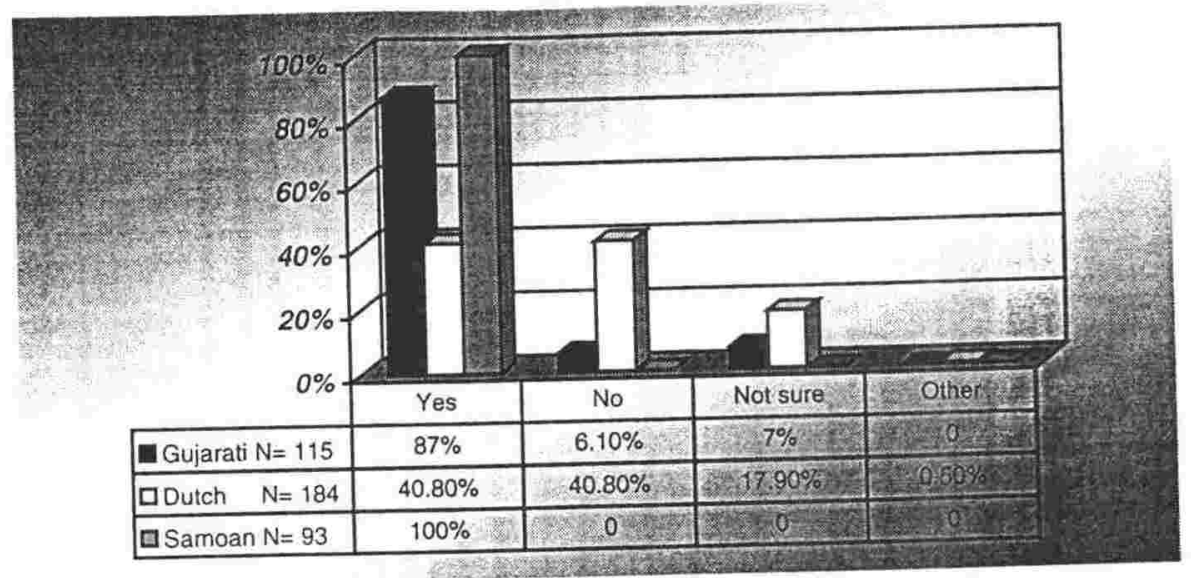

Figure 12-13: Should the MT be a living language in New Zealand?: All respondents 


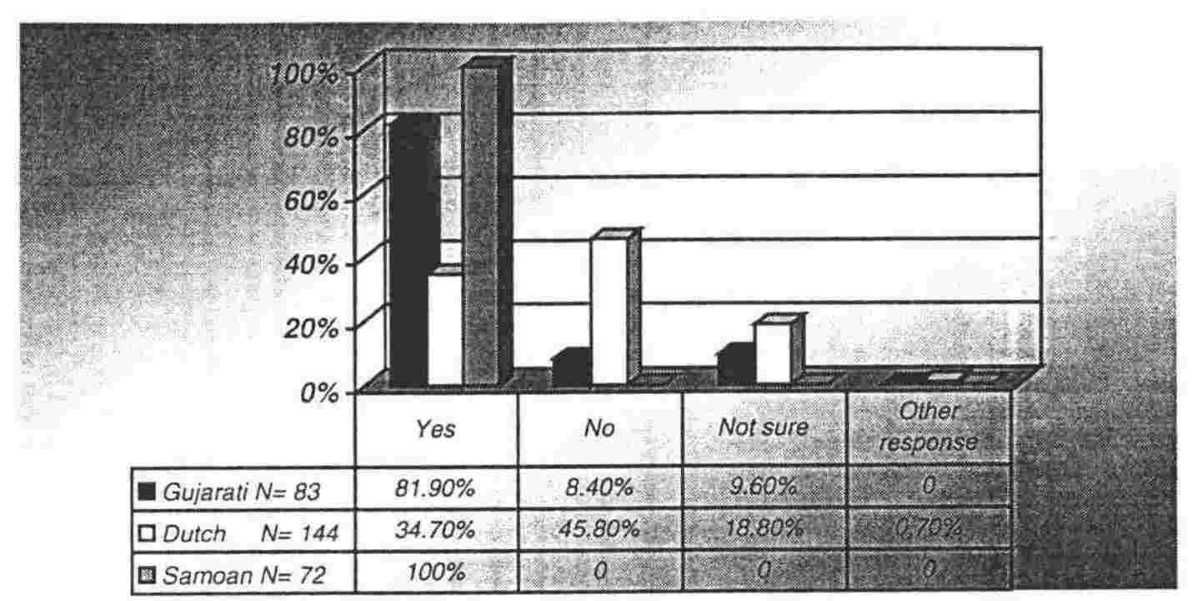

Figure 12-14: Should the MT be a living language in New Zealand?: All non-New Zealand-born respondents

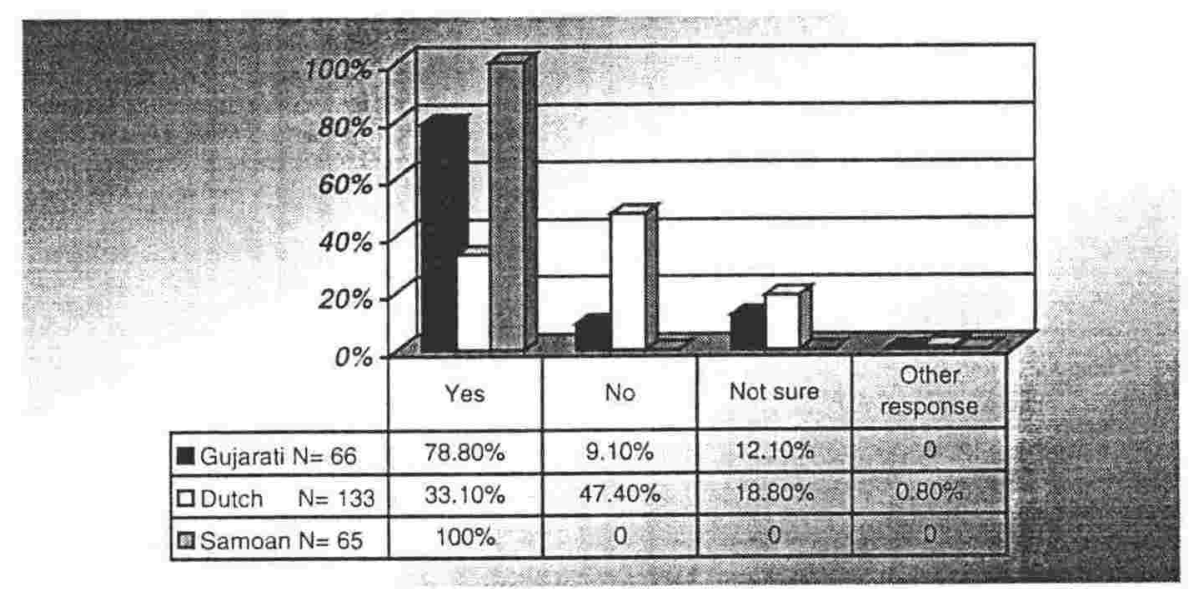

Figure 12-15: Should the MT be a living language in New Zealand?: All non-New Zealand-born respondents arrived in New Zealand $10+$

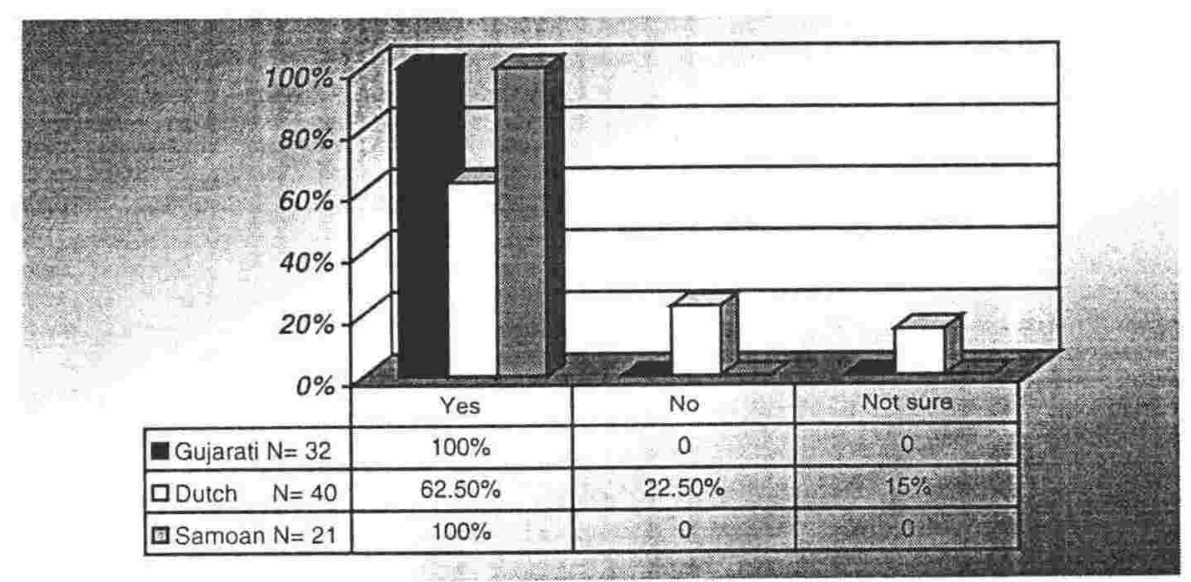

Figure 12-16: Should the MT be a living language in New Zealand?: All New Zealand-born respondents

The Gujarati and Samoan respondents are almost unanimous in their desire to see their MT as a living language in New Zealand. All the Samoan respondents, all the New Zealand-born Gujarati respondents, and most of the non-New Zealand-born Gujarati respondents, replied 
positively to this question. In this they resemble respondents to a survey carried out in the Manawatu where $98 \%$ of the respondents of differing ethnic backgrounds 'regarded the retention of their native languages as important' (Walker and Stapleton 1998: 227). The Dutch respondents, on the other hand, do not fall into this group. Only a third of those who emigrated to New Zealand age 10 and over thought that it was important that Dutch should be a living language in New Zealand. Admittedly, this figure almost doubles amongst the New Zealand-born, which is interesting in itself, but it is still nothing like the $100 \%$ support of the Gujarati and Samoan New Zealand-born respondents. Support for the MT as a living language in New Zealand notably increases amongst both the Gujarati and Dutch respondents who were born in New Zealand. Presumably this is partly because of the 'you don't know what you've got 'til it's gone' phenomenon. The Dutch-born and Gujarati-born respondents are so secure in their MT and so aware of the security of the language 'back home' that its maintenance in New Zealand does not, to some, seem so important. The New Zealand-born respondents, who have to shape an identity for themselves in New Zealand that includes their parents' homeland heritage and their own New Zealand upbringing, are perhaps more aware of the role that their MT can play in the process of identity creation and maintenance. New Zealand-born respondents also often have a better realisation than their non-New Zealand-born parents that the language could cease to be spoken altogether in New Zealand if active steps are not taken to maintain it. Hence, in part, actions such as establishing the Dutch language maintenance school in Wellington in 1995. Undoubtedly changed attitudes to the desirability of complete Dutch assimilation into New Zealand were also part of the reason for a language maintenance school being established now.

\subsection{1 language attitudes and language maintenance outcomes}

The integrated model of language maintenance and shift processes that has been used in this thesis predicts that the circumstances of immigration and settlement have at least as much to do with the processes of language and cultural maintenance and shift in the new society as the specifically ethnic identity and values that the immigrants bring with them (or indeed that indigenous people possess, Schiffman 1996:72). Some researchers, such as Smolicz, have seen language and language maintenance as a 'core value' for some immigrant groups.

The term 'core value' refers to those values that are regarded as forming the most fundamental components of a group's culture. They generally represent the heartland of the ideological system and act as identifying values which are symbolic of the groups and its membership. It is through core values that social groups can be 
identified as distinctive ethnic, religious, scientific or other cultural communities (Smolicz 1984: 26).

That is, the specifically ethnic identity and values that the immigrants bring with them have been seen as the primary causative factor in the processes of language maintenance and shift that have occurred in the community. Various writers have pointed out that there are areas of Smolicz's theory of 'core value' that remain problematic despite its widespread acceptance in Australasian consideration of language maintenance and shift. As Michael Clyne has observed

There are two aspects of the theory that need to be looked at again critically before we consider the existence or absence of an 'ethnicity' [with reference to the notion that some people consider themselves to have lost their ethnicity if they stop using their language]. What do we mean by 'language', and is it really 'use' that is all-important for identification? (Clyne 1988: 70)

We might well throw in what is meant by 'ethnic identity' as well - but that conundrum has been thoroughly canvassed elsewhere (see Chapter 1). Clyne goes on to demonstrate that the German community in Australia is a

speech community rather than an ethnic group, German speakers share features with Arabic, Spanish, French, and Chinese speakers, and even many of the 'ethnic' groups vary in their core values according to their political and religious views, migration histories, and regional origins (Clyne 1988: 81).

Fishman does not, far from it, deny the importance of these factors (they are summed up in 1 (b) and 1 (c) of the integrated model) but he gives the physical, demographic, social and cultural dislocations of the specific immigrant experience, (3) in the model, at least equal weight.

This research, and the research of many others, has found that prediction to be accurate. In Chapter 6 the question of the definition of language community was raised. For the purposes of this research, birthplace or parents' birthplace has been taken to indicate membership of a language community. Although the three groups under discussion do form three fairly clearcut communities within the wider New Zealand society nonetheless, there is, obviously, variation within them, and some of this variation manifests itself in the areas of attitude to language maintenance.

Here, I want to argue that the variation in attitudes to language maintenance that can be perceived with two of the communities, the Gujarati and the Dutch, can be linked to 
differences in immigration histories. That is, the different physical, demographic, social and cultural dislocations experienced within the communities are causative factors in producing different attitudes towards language maintenance and shift which, in their turn, are causative in producing different language behaviours which are causative in producing different language maintenance outcomes. Unfortunately the last step in this progression can only be stated speculatively here, as the information was not gathered in sufficient quantities in order to allow it to be demonstrated (there is not enough information from 'other-born' respondents and their children). It would be a most interesting area for further research.

\subsubsection{Differences between communities}

This research has shown that different immigrant communities can have very different attitudes to language maintenance and shift. The most striking differences have been noted consistently between the Dutch on the one hand and Gujarati and Samoan respondents on the other. Differences between the Gujarati and Samoan respondents have also been observed. Hayden's research also demonstrated the fact that different immigrant communities can have very different attitudes to questions of language maintenance and shift. The percentages of informants in his research who believe preservation of the MT to be necessary ranges from a low of $57 \%$ to a high of $86 \%$. This is similar to the finding of this research that all the Samoan non-New Zealand-born respondents but only a third (34.7\%) of the non-New Zealand-born Dutch respondents thought that their MT should be a living language in New Zealand. LMP however, point out that although differences between different immigrant groups are perhaps to be expected, differences within immigrant groups are also important.

The findings ... serve, above all, to illustrate the complexity of the factors involved in the process of language shift. The different patterns of language skills, use and attitudes revealed in the different linguistic minorities might be expected . . . But we have also discovered major differences between members of the same linguistic minority in different cities, for example in the extent to which they use the minority language (LMP 1985: 221).

Giles and Coupland make a similar point when they quote from a study by Mercer et al (1979) in which one interviewee was reported as saying

"If I didn't speak Gujarati, I would feel drowned" whereas according to another "Even when I met a Gujarati from Leicester [home town], we got to know each other in English and wouldn't dream of speaking anything else" (cited in Giles and Coupland 1991:104) 


\subsubsection{Differences within immigrant groups}

Hayden's 1966 research showed that one 'language community' did not necessarily have the same attitudes to language maintenance.

Table 12-1: Comparison with Hayden 1966: 195

\begin{tabular}{|l|l|}
\hline Community & \% believing preservation of MT is necessary \\
\hline Newark Ukrainian & $86 \%$ \\
Puerto Rican New York & $72 \%$ \\
Franco-American Fall River & $76 \%$ \\
San Antonio Hispanic & $57 \%$ \\
Olyphant Ukrainian & $69 \%$ \\
\hline
\end{tabular}

(Adapted from Hayden 1966: 195)

Several studies, widely separated in time and place, illustrate the fact that although members of immigrant groups may come from the same place, speak the same language and, broadly, share the same cultural background, they do not necessarily have the same opinions and attitudes regarding language maintenance in the new country. Hayden's study illustrated in Table 12-1 showed that although the Ukrainians in Newark and the Ukrainians in Olyphant in the USA in the 1960s shared a common language and point of origin, they did not have similar sets of attitudes to language and culture maintenance in the USA. The Newark Ukrainians were more enthusiastic about language maintenance than the Olyphant Ukrainians and were, in fact, maintaining their language better. This was partly because some of the Newark Ukrainians had arrived more recently in the USA than the Olyphant community (thus pointing out the importance of the arrival of 'fresh blood' in an immigrant community) but it was also because, according to Hayden, the Newark Ukrainians were more middle-class, more politicised and better educated and their strong support for language maintenance had grown out of their class, political and educational background (Hayden 1966: 191-197). Class and ethnicity are not the same thing and where immigrants to a country have been drawn predominantly from a single class (as was largely the case with the early Gujarati and Dutch immigrants to New Zealand) it is easy to confuse the social effects of two different factors. Class, education and political background may all have an effect on attitudes to language and culture maintenance. Kloss also points out that the eighteenth century German settlers in the USA had different attitudes to language maintenance depending, in his opinion, on their doctrinal backgrounds - once again, linguistic similarity was no guarantee of attitudinal similarity (Kloss 1966: 215). 
The point that shared MT background does not necessarily guarantee a shared commitment to language maintenance is made by Kouzmin (1988) in a study of the Russian community in Australia. She describes the difference between the 'second wave' (post WWII) and 'third wave' (1970s) Russian communities (the first wave was in 1917). The second wave are strongly attached to the notion of Russian language maintenance for reasons of language and cultural loyalty, in Smolicz's terms, language is a core value for this group. The third wave immigrants however do not think of Russian in these terms. They use a lot of Russian in their daily lives, partly because they are a recently arrived group but they do not have the same ideological commitment to maintaining Russian in Australia as the second wave immigrants. As Kouzmin says; language use, in itself, can not be taken as a sign of language loyalty (Kouzmin 1988: 63). She is of the opinion that Russian use will die out in the third wave community after the second generation and that although loyalty to the concept of Russian will remain strong in the second wave community, nonetheless, levels of language use will continue to decline. The attitude of the third wave of Russian immigrants to their language seems similar in some ways to the attitude of the Dutch immigrants to New Zealand - an instrumental view of language, through which one can contemplate with equanimity one's children and grandchildren not speaking one's own MT. Of course that may change, at least slightly, with the passage of time. We can see now in New Zealand that there are at least some second generation members of the Dutch community who wish to see the language passed on to the next generation, hence the establishment of language maintenance schools and it may be that the third wave Russian community in Australia may undergo something of the same process.

The research of Kloss, Hayden, Kouzmin and LMP reported here, shows clearly that there is certainly no simple relationship between a group of immigrants who speak the same language and their attitudes to maintaining that language in the new country. As Kouzmin says

perceptions of identity can alter with context. It [the question Russian or Jew] also highlights the problem of interpreting core values, including the place of language, for a community as a whole, given that it is possible for group members to have multiple loyalties (Kouzmin 1988: 56).

The differences that can occur within immigrant groups that speak the same MT are examined here by looking at some of the data from the Gujarati and Dutch respondent groups. The Samoan respondents are not considered here because they fall into only two groups - the New Zealand-born and the non-New Zealand-born. The Gujarati and Dutch groups however both 
include a small groups of 'other-born' respondents, who were born somewhere other than the homeland or New Zealand (Dutch East Indies, in the case of all the Dutch in this category, other Indian states, Africa or Fiji in the case of the Gujarati respondents in this category). These groups both had different immigration experiences from the bulk of their community members. They had, as it were, an experience of double dislocation. They also, especially in the case of the Dutch, came from a rather different social background from those who emigrated from the homeland. Thus the antecedent social processes that they had experienced were also different. As can be seen below, not only are there some interesting, if sometimes expected differences between the non-New Zealand-born and the New Zealand-born but the 'other-born' appear to make yet a third group in terms of their attitudes and practises in language maintenance. The groups have been compared on the following points, selected because they cover all the main points of the integrated model and give a relatively clear-cut picture of MT language use and of attitudes to language maintenance in New Zealand. The first two address habitual daily use,

- language mostly spoken to spouse

- language mostly spoken to children

the next four address attitudes and (to some extent) behaviours

- should MT be offered at mainstream schools?

- should MT be a living language in New Zealand ?

- should people of respondent's background $(=X)$ consider themselves part of an $\mathrm{X} / \mathrm{New}$ Zealand community?

- is a community language school for children a 'good idea'?

The different birthplaces of the three groups, of course, represent the important effects of degree of dislocation as a causative factor in language maintenance and shift.

\subsection{Gujarati respondents}

Table 12-2: respondents who thought Gujarati should be a living language in NZ

\begin{tabular}{|l|l|}
\hline & \\
\hline Gujarat-born & $83.8 \%$ \\
NZ-born & $100 \%$ \\
Other-born & $66.7 \%$ \\
\hline
\end{tabular}

Table 12-3: respondents who thought community language schools for children were a good idea

\begin{tabular}{|l|l|}
\hline & \\
\hline Gujarat-born & $92.5 \%$ \\
NZ-born & $100 \%$ \\
Other-born & $100 \%$ \\
\hline
\end{tabular}


Table 12-4: respondents who thought Gujarati at mainstream schools was a good idea

\begin{tabular}{|l|l|}
\hline & \\
\hline Gujarat-born & $36.5 \%$ \\
NZ-born & $43.7 \%$ \\
Other-born & $0 \%$ \\
\hline
\end{tabular}

Table 12-5: respondents who thought Gujarati people in NZ should see themselves as part of a Indian/NZ community

\begin{tabular}{|l|l|}
\hline & \\
\hline Gujarat-born & $95.9 \%$ \\
NZ-born & $96.9 \%$ \\
Other-born & $88.9 \%$ \\
\hline
\end{tabular}

Table 12-6: respondents who spoke mainly English with their spouse

\begin{tabular}{|l|l|}
\hline \multicolumn{1}{|c|}{} & \\
\hline Gujarat-born & $21 \%$ \\
NZ-born & $46.9 \%$ \\
Other-born & $58.3 \%$ \\
\hline
\end{tabular}

Table 12-7: respondents who spoke mainly English with their children

\begin{tabular}{|l|l|}
\hline & \\
\hline Gujarat-born & $34.0 \%$ \\
NZ-born & $53.1 \%$ \\
Other-born & $67.0 \%$ \\
\hline
\end{tabular}

Both the other-born and the New Zealand-born Gujarati respondents were born outside Gujarat, however all other-born Gujarati respondents are 'fluent' speakers of Gujarati whereas only a third of the New Zealand-born claim to be 'fluent'. Despite this, the otherborn are much more likely to speak English with their spouse and children than the Gujaratiborn and more likely to do so than the New Zealand-born. The Gujarati other-born were less likely to think that it was important to keep Gujarati as a living language in New Zealand and none of them supported the teaching of Hindi or Gujarati in the state school system. Fairly substantial minorities of both the Gujarat-born and New Zealand-born supported such mainstream teaching. On the other hand there were fairly general levels of agreement across all three groups, regardless of birthplace, that both the community language maintenance school and state funding for the school were a good idea. There was also fairly general agreement that Gujarati people in New Zealand should see themselves as part of an Indian/New Zealand community but it is noticeable that the proportion of other-born supporting this proposition was somewhat smaller. The group is so small however that it makes it hard to draw any conclusions from such relatively small variations. 
These findings do suggest that the other-born Gujarati respondents are somewhat different from both the New Zealand-born respondents and the Gujarat-born respondents. They are clearly less committed to using Gujarati in their own homes despite the fact that they are well able to speak it. This fits with the weaker level of support for maintaining Gujarati as a living language in New Zealand. They do not support any MT teaching in the mainstream system. As mentioned in section 7.4.2, this may be related to the feeling, expressed by one respondent that this was a community responsibility, and their level of support both for the community school and for state funding for the community school certainly lends support to this interpretation. The other-born were also less likely to support Gujarati language provision for government services (see section 7.5.2) although the numbers involved are really too small to be informative. Overall, in the areas investigated, the New Zealand-born and the Gujarat-born appear to be closer to each other in practise and attitude than the other-born. It is true that the New Zealand-born are considerably more likely than the Gujarat-born to use English with their spouse and children but, given their comparatively lower levels of Gujarati fluency, the fact that they use less English than the Gujarati-fluent other-born suggests a stronger level of support for Gujarati in the home. The New Zealand-born and the Gujarat-born are more likely to support the idea of maintaining Gujarati as a living language in New Zealand and they both contain small groups of supporters for the proposition that Gujarati or Hindi should be taught in mainstream schools. That the community still has substantial areas of agreement however, is shown by the widespread support for community language maintenance schooling. The different attitudes and practises found amongst the other-born may well stem from their different experiences in minority Gujarati communities in India, Africa and Fiji. Undoubtedly, if a larger sample of what is here being called other-born could be investigated on the basis, amongst other things, of their specific birthplace, differences within the other-born group that could be correlated with those birthplaces could also be found.

\subsection{Dutch respondents}

Table 12-8: respondents who thought Dutch should be a living language in NZ

\begin{tabular}{|l|l|}
\hline & \\
\hline Dutch-born & $34.4 \%$ \\
NZ-born & $62.5 \%$ \\
DEI-born & $38.5 \%$ \\
\hline
\end{tabular}


Table 12-9: respondents who thought community language schools for children were a good idea

\begin{tabular}{|l|l|}
\hline & \\
\hline Dutch-born & $48.1 \%$ \\
NZ-born & $47.5 \%$ \\
DEI-born & $69.2 \%$ \\
\hline
\end{tabular}

Table 12-10: respondents who thought Dutch at mainstream schools was a good idea

\begin{tabular}{|l|l|}
\hline & \\
\hline Dutch-born & $16.8 \%$ \\
NZ-born & $42.4 \%$ \\
DEI-born & $30.8 \%$ \\
\hline
\end{tabular}

Table 12-11: respondents who thought Dutch people in NZ should see themselves as part of a Dutch/NZ community

\begin{tabular}{|l|l|}
\hline & \\
\hline Dutch-born & $57.3 \%$ \\
NZ-born & $67.5 \%$ \\
DEI-born & $84.6 \%$ \\
\hline
\end{tabular}

Table 12-12: respondents who spoke mainly English with their spouse

\begin{tabular}{|l|l|}
\hline & \\
\hline Dutch-born & $51.6 \%$ \\
NZ-born & $97.3 \%$ \\
DEI-born & $75.0 \%$ \\
\hline
\end{tabular}

Table 12-13: respondents who spoke mainly English with their children

\begin{tabular}{|l|l|}
\hline & \\
\hline Dutch-born & $77.1 \%$ \\
NZ-born & $96.7 \%$ \\
DEI-born & $100 \%$ \\
\hline
\end{tabular}

In some respects, the pattern found amongst the Dutch respondents is not dissimilar from the pattern found amongst the Gujarati respondents. Although most of the DEI-born are 'fluent' speakers of Dutch $(92.3 \%)$ and very few of the New Zealand-born rate themselves at this level (only the one, Dutch-raised respondent, $2.5 \%$ ) most respondents in both groups speak English to their spouses and children most of the time. A substantial proportion of the Dutchborn, of course also use English most of the time with their spouses and children but not to the same extent as either the DEI- or New Zealand-born. Like the Gujarati other-born, the Dutch DEI-born were less likely than the New Zealand-born in either group to support the proposition that their MT should be a living language in New Zealand. However, whereas the Gujarat-born were quite strong supporters of this proposition, the Dutch-born were not, and, in fact, slightly more DEI-born than Dutch-born supported the idea. 
The DEI-born were comparatively enthusiastic supporters of community language maintenance schools for children; over two-thirds of them supported the idea whereas under half the Dutch-born and New Zealand-born supported it. The New Zealand-born and the DEIborn contrasted with the Dutch-born in their support for teaching the MT within the mainstream school system. Very few Dutch-born supported the idea at all whereas quite large minorities in the other two groups thought that it might be desirable.

In everything except support for community language maintenance schools the Gujarati respondents tended to exhibit a cline of support for MT use in New Zealand in which the other-born respondents evince the weakest level of support, followed (except in the case of MT use with family members) by the Gujarat-born respondents and with the NZ-born respondents as the most enthusiastic supporters.

The Dutch pattern is not so clear cut. The DEI-born choice to use mainly English with their spouses and children can not, given their high level of Dutch fluency, be seen as anything other than a lack of support for the MT. On the other hand the DEI-born are the strongest supporters of the idea of a community language maintenance school and of the proposition that Dutch people in New Zealand should see themselves as part of a Dutch/New Zealand community. The New Zealand-born and the Dutch-born report almost identical levels of support for the idea of a community language maintenance school but the New Zealand-born support the idea of a Dutch/New Zealand community rather more strongly than the Dutchborn even if not as strongly as the DEI-born. The New Zealand-born and the DEI-born are also grouped together in their support for Dutch in the mainstream schools. So the relatively simple cline that exists amongst the Gujarati respondents does not exist here. There is evidence however, that the DEI-born have a different point of view not only from the New Zealand-born but also from the Dutch-born. This may spring partly from their colonial origins. One oral archive interviewee said of the DEI-born

We noticed that the ones that came here from Indonesia adapted themselves much better than those that came from Holland. because they had already once to adapt themselves to quite a different life.

The DEI-born also tended to be from a slightly different socio-economic background from the Dutch-born. The Dutch-born were mainly, though not exclusively, artisans, the DEI-born came from the colonial administration or from the plantations. This difference in class background shows up in the educational levels achieved by the three groups. The DEI-born 
were considerably more likely to have a university education than either the New Zealandborn or the Dutch-born. Once again, this points up the fact that ethnicity is neither overarching nor monolithic and that factors such as class, education, regional experience (in this case colonial as opposed to metropolitan background) and indeed gender, religious persuasion (see section 8.3.7 for difference between Dutch Catholic and Protestant respondents) can all significantly subdivide what might look like a unitary ethnicity.

\subsubsection{Summary}

This section shows that the Gujarati and Samoan respondents support the proposition that their languages should be living languages in New Zealand very strongly indeed. The Dutch, as a whole, do not support it so strongly but the New Zealand-born respondents support it considerably more strongly than their parents' generation. There has been a substantial shift of opinion within this immigrant group between the generations. This section also demonstrates the variation of opinion between the homeland-born, other-born and New Zealand-born amongst the Gujarati and Dutch respondents and argues that the concept of 'core value', used as an explanatory tool has to be implemented with subtlety and care.

\subsection{Conclusion: comparison and analysis}

The research reported on in this chapter has clearly demonstrated how differently communities can react to the processes of immigration. Different homelands, different ethnic and cultural backgrounds, different histories of immigration and settlement, different attitudes (influenced by those backgrounds and histories) all have concrete effects on the way in which language shift and language maintenance occur.

Not only do communities differ from one another but, as has been shown here, one community can exhibit a considerable range of variation. Sub-groups within a single language community can have quite different sets of attitudes. As would be expected, there are some considerable points of difference between the first immigrant generation and the subsequent New Zealand-born generation but there can also be some major variations within the first immigrant generation.

This research also demonstrates that no matter what the general trend in language maintenance and shift processes may be, individual experience can always run counter to the 
trend. For instance, the Gujarati families in which youngest children were 'fluent' speakers of Gujarati because of family visits to Gujarat, show that language shift is never 'inevitable'.

This research has also shown how swiftly attitudes can change. The New Zealand-born Dutch respondents support MT language maintenance much more strongly than did their parents' generation. This appears to be an indication of not only a change in attitude based on the experience of the New Zealand-born, but also a change in general social attitudes - as shown by the small group of more recently arrived Dutch immigrants who are bringing their children up to speak Dutch (see section 11.5.1.2.1). This reinforces our understanding that the attitudes and behaviours of an immigrant group are not immutable, they are responsive not only to the immediate experiences of the group members but also to changes in general social attitudes, as predicted by $1(\mathrm{~b})$ of the integrated model.

This chapter has focussed on the role of language attitudes and behaviours (part 1(c) of the integrated model) and immigrant dislocations (part (3) of the integrated model) and has shown that they both appear to be important causative factors in the processes of language maintenance and shift and language use outcomes. Language attitudes and behaviours are also an important descriptive element in providing a full picture of habitual language use. 


\section{RESEARCH QUESTIONS AND LANGUAGE POLICY RECOMMENDATIONS}

The integrated model that has been used as the framework for this research enjoins the researcher to focus on the following areas

- the social location of language shift and language maintenance

- gathering data on demographic factors, language competence, language performance and language attitudes and behaviours

- the dislocation undergone by the minority language group and their effects on language maintenance and shift processes and, last but not least -

- analysis and action based on the research

The foregoing chapters of this thesis have explored the first three sections in some detail. Here I want to examine the answers to the research questions outlined at the end of Chapter 5 , thus recapitulating the investigation already undertaken of the first two areas and then move on to the fourth part of the model; to analysis and action.

The analysis is undertaken in the context of an enquiry into the GIDS schema (originally outlined in Chapter 5), I attempt to assess the workability and usefulness of the model. The action relates back to Chapter 4 and the discussion of language policy (or the lack of it). Research into the history of language policy in New Zealand has found that New Zealand has formulated very little explicit language policy other than that referring to te reo Mãori and its place in the wider New Zealand society. Some conclusions are drawn about what direction could be taken by policy for minority immigrant languages in New Zealand. Based on all the data that has been gathered, the analysis of the data by a range of means including the use of the integrated model based on Fishman's theories and of the GIDS typology, what policy recommendations, if any, can be made?

This research has examined processes of language maintenance and language shift in three immigrant communities in New Zealand. The communities were all at different stages of the immigration and settlement process and each differs from the other in important ways that profoundly effect the processes of language maintenance and shift as they play themselves out in each community. By examining three very different communities, the danger of viewing immigrant language maintenance and shift as a unitary process that operates in much the same way, regardless of the historical, social and political environment, has been averted. At the same time, it can be seen that there are aspects of the immigrant language maintenance and shift experience that are common across groups. This research has also provided the data to 
enable Fishman's GIDS scale to be tested against information drawn, under similar circumstances by the same researcher, from three different communities. This enables the usefulness of the scale as a 'heuristic device' to be tested.

\subsection{To what extent is MT language transmission occurring within the family?}

Given that transmission within the family is such an important element of language maintenance and that the cessation of transmission is an almost certain sign of language shift, one of the goals of this research was simply to measure to what extent family members were using the MT within the family home.

The research shows quite clearly that language transmission has occurred within the first generation immigrant family (where at least one, and usually both, parents have emigrated as adults to New Zealand) in all immigrant groups. After the first generation however, the picture becomes somewhat less clear. The Gujarati community, the longest established of the three, has clearly continued the process of MT language transmission within the first generation of New Zealand-born families (where one or both parents are New Zealand-born, as are the children). However, thanks to the marriage practises within the community where a New Zealand-born spouse usually has a non-New Zealand-born partner there are relatively few families where both parents are New Zealand-born. With changing marriage practises, such families will increase in number and it is not clear what the language transmission patterns in those families will be. Equally, it cannot clearly be said what might happen within the second generation of New Zealand-born Gujaratis. Although the community is well established, it has only had roughly equal numbers of men and women in the post WWII period, reducing the likelihood of there being a significant number of second generation New Zealand-born Gujaratis of child-bearing age ${ }^{166}$.

Most of the Dutch immigrants of the 1950s appear to have handed on at least some Dutch language skills to their New Zealand-born children but the Dutch community has, as a community, ceased MT language transmission within the first generation of New Zealandborn families. This research has revealed however, that attitudes to the questions of Dutch language maintenance appear to be changing in New Zealand. This has not as yet, however,

\footnotetext{
${ }^{166}$ Only one New Zealand-born Gujarati respondent had a New Zealand-born parent (mother) and three of them had African-born mothers. All the fathers of New Zealand-born Gujarati respondents were born in Gujarat.
} 
affected the language use practises of the New Zealand-born respondents to the questionnaire and their children, in general, do not speak Dutch.

The Samoan community is too recently established in New Zealand for clear predictions for the future of MT language transmission to be made. Transmission within the first generation of parents to arrive from Samoa and establish families here has obviously been strong but it is too early to tell what the long term future of the language is. The New Zealand-born respondents to this questionnaire appear to be handing on their MT to their children. This research however, does point up a potential weak spot in the language maintenance process within the Samoan community. It has been shown that the language first spoken to a child may have some long term influence on whether, as an adult, that person will be a confident user of the MT. The New Zealand-born Samoan respondents to this questionnaire however, are more likely to use Samoan/English with their children than MT only (considerably more likely than the New Zealand-born Gujarati respondents(Figure 11-12)). This was also the tendency for the respondents as children in New Zealand. The Gujarati were more likely to speak their MT first, the Samoan respondents were more likely to use MT and English first. This may well be related to the finding that the New Zealand-born Gujarati respondents are more likely to rate themselves as 'fluent' speakers of the MT than the New Zealand-born Samoan or Dutch respondents (who were more likely to speak English first). A further point of interest is that there is very little difference between the ratings of 'fluent' for the Dutch and the Samoans despite the fact that the Dutch were far more likely to speak mainly English as children.

The data is not straightforward however. Although the Gujarati New Zealand-born respondents are more likely to speak mainly their MT first and more likely to report that they now, as adults, speak it 'fluently', nonetheless, the Samoan New Zealand-born respondents are more likely to use their MT on a day to day basis along with English, while the Gujarati New Zealand-born respondents are more likely to use English only. This shows that fluency is not the only criterion for language use (although it is undoubtedly important) opportunity and attitude (as exemplified by the many Samoan respondents who said that they spoke Samoan 'anywhere' to 'any Samoan') are also important. 


\subsection{How is MT language use occurring within the family?}

If the MT is being used within the family home then it is important to know who is speaking it and to whom. This research was not designed to undertake a microanalysis of MT use but has asked more global questions, focusing on the respondent and asking who their MT and English speaking interlocutors within the family are. Some of the Dutch and Gujarati respondents were also asked about MT use during their childhood, within their family homes in New Zealand. This provides evidence across two generations of family MT use (or not, as the case may be).

\subsubsection{Language use within the family/home}

Table 13-1: Languages used at home

\begin{tabular}{|l|l|l|l|}
\hline & Dutch & Gujarati & Samoan \\
\hline MT & $8 \%$ & $22 \%$ & $42 \%$ \\
English & $41 \%$ & $12 \%$ & $7 \%$ \\
MT/Eng & $47 \%$ & $62 \%$ & $45 \%$ \\
MT/Eng/other & $4 \%$ & $4 \%$ & $6 \%$ \\
N= & 183 & 140 & 87 \\
\hline
\end{tabular}

The cline that we have come to expect when looking at these three communities manifests itself in the use of the community language or of English as the sole/main language of the home. Very few Dutch respondents used Dutch solely, whereas almost a quarter of the Gujarati respondents used Gujarati solely and $42 \%$ of the Samoan respondents, Samoan. The reverse pattern can be seen with English. Very few of the Samoan respondents used English solely, a few more of the Gujarati respondents used English solely, and $41 \%$ of the Dutch respondents used English solely. The mirror image pattern of the Dutch and Samoan respondents is most striking. When it comes to using both languages in the home however, the cline of use from Dutch to Samoan does not appear. The Gujarati respondents overwhelmingly report a pattern of mixed language use in the home - $62 \%$. The Samoans and the Dutch report a similar substantial, but not a majority, use of both languages at $45 \%$ and $47 \%$ respectively.

Turning to the languages used to the respondent's spouse and to the respondent's children it can be seen that comparatively few Dutch respondents speak mainly Dutch to their spouses and even fewer speak it to their children most of the time. English is the language of choice for the majority of Dutch respondents in speaking to both spouses and children. 
Amongst the Gujarati respondents, almost half still use Gujarati with their spouses most of the time and slightly over a quarter still use Gujarati with their children most of the time. Rates of English dominant usage are quite high with both groups of interlocutors and it is interesting to notice that Gujarati/English usage is higher with children (26\%), than with spouses (14\%). If it is true that the use of two languages in immigrant situations is the almost certain harbinger of language shift, then it seems likely that a greater shift to English is in process in the Gujarati community.

Over half the Samoan respondents use predominantly Samoan to both children and spouses. This is the only one of the two groups where slightly more (5\% more) respondents reported using Samoan most of the time to their children than to their spouses. This is interesting not only because it differs from the Gujarati and Dutch respondents but also because it differs from what is widely held to be the common immigrant language shift pattern, where language shift in the family manifests itself most strongly in the host-country born children and where the parents tend to accommodate that fact by speaking to the children in the host country language.

\subsubsection{New Zealand born respondents: Language use in the home}

The Dutch New Zealand-born respondents have, to all intents and purposes, ceased to use their MT at home. Although almost half of them make some effort to use a little Dutch with their children, their homes are predominantly English speaking. It is hard to imagine that any of their children will grow up speaking Dutch with any ease.

Amongst the Samoan and Gujarati New Zealand-born respondents, the picture is different. Their households still use quite a lot of the MT and their children are more likely to use the MT. Their children are also likely to attend a language maintenance school and this will equip them with basic MT literacy skills and provide them with at least one environment outside the home where they can use the MT. All in all it seems likely that most of these children will grow up with some degree of ability to use the MT but, in many cases, they will be English dominant and it is hard to know if they will be able to hand the MT on to their, third generation New Zealand-born, children. 


\subsection{Is community MT schooling occurring and is it effective as support for the MT?}

This question is approached both by asking respondents about the present day situation and the choices they have made about MT language maintenance education for their children and also by asking some of the respondents (the Dutch and Gujarati) about their childhood experiences. In order to judge the effectiveness of community language maintenance schooling, attendance at such schools is correlated with MT proficiency.

Community language schooling is occurring in both the Gujarati and Samoan communities and has been established for a long time in both communities. Apart from some adult education classes in Dutch, there has been no language maintenance schooling in the Dutch community until very recently (after the completion of the active research phase of this project).

Community language maintenance schools have been effective in promoting MT literacy and those respondents or their children who did not attend such schools exhibited lower rates of MT literacy. Attendance at language maintenance school was also weakly linked to higher oral proficiency in the MT. The importance of language maintenance schools in the whole process of language maintenance is demonstrated by the very high levels of support for the community language maintenance school in the Gujarati and Samoan communities and the growing support amongst the New Zealand-born Dutch respondents.

\subsection{What do people think about MT maintenance?}

This question draws on the research about the role of language in the creation and maintenance of a personal and community sense of identity. To what extent do respondents think that language maintenance is important and why do they choose to attempt to maintain the MT or, conversely, decide not to do so?

The different histories of the three groups of immigrants have influenced their attitudes to MT language maintenance in New Zealand.

The Gujarati immigrants came from a multilingual country in which multilinugalism and language maintenance were well-known and accepted phenomena. In New Zealand the immigrants faced a degree of racism that, for many years, precluded them from assimilating or integrating with the host society. Under such conditions language and culture maintenance 
were especially important. Gujarati society in New Zealand had to be very sure that its own cultural structures were well maintained as, for decades, there seemed little likelihood of Gujaratis being given the opportunity to operate within New Zealand society's cultural structures. Racist attitudes in New Zealand, a positive orientation to language and cultural maintenance brought from the homeland, and the fact that Gujarati immigrants were part of a world-wide network all committed to language and cultural maintenance, have contributed to positive attitudes to MT language maintenance in New Zealand.

The Dutch immigrants to New Zealand were in a very different situation. They shared with the Gujarati immigrants a homeland culture that valued multilingualism, but that was about all they had in common. Language maintenance was not something that Dutch speakers living in the Netherlands had to deal with (although Fries and Limburgs speakers were aware of some of the difficulties in this area). The Dutch immigrants arrived, in most cases, with a strong assimilationist ethic and were accepted in New Zealand and welcomed into New Zealand society on the condition that they were prepared to assimilate rapidly and bring their children up as good Kiwi kids (Schouten 1992:136). Most of the immigrants were happy to keep their side of the bargain. There are signs that amongst the Dutch immigrants of the 1980s and 1990 s, these attitudes are beginning to change and that the more recent arrivals set a highervalue on MT language maintenance. This research has also I Gurred that the Ataw' Zaaland-horn children of the first immigrant generation of the 1950s, are, in general, more positively oriented to issues of language maintenance than their parents generation.

The Samoan colonial experience has taught them both to be aware of the encroachments of other languages and cultures and how to negotiate with the New Zealand bureaucracy. The Samoan immigrants brought with them structures, such as the church and the pastor schools, which would help them in the project of language maintenance and perhaps, even more valuable, they brought with them an awareness of the importance of language maintenance. There were individuals who did not think language and culture maintenance were important and who were very committed to assimilation to the wider New Zealand society, its language and values, but they seem to have been in the minority. While Samoan immigrants certainly have hoped for success, in New Zealand terms for themselves, and perhaps more importantly, for their children, they have, in most cases, hoped that this can be achieved within the context of fa'aSamoa. For this, the Samoan language is vital. 


\subsection{Can the GIDS usefully be applied to an analysis of immigrant language maintenance in New Zealand?}

Because the three communities have such different immigration and language maintenance histories and because, as mentioned above, none of them was considered in the creation of the GIDS, they can be used to test the usefulness of the GIDS as an analytical tool.

Fishman's interest in processes of reversing language shift (RLS) has lead to the concept of the GIDS (Graded Intergenerational Dislocation Stages) scale. As the name suggests Fishman is crucially concerned with questions of 'transmissibility across the intergenerational link' (Fishman 1990:18). Without this transmissibility, there can be no long-term success for any RLS effort. Fishman's scale is as he says 'a heuristic device more than .... a proven fact' (Fishman 1990:18). But it offers us a useful way of focusing on communities at differing stages of language maintenance and shift processes and it may also allow us to suggest where those communities might best concentrate their efforts. Below the three communities are examined in the light of the GIDS scale.

The answers to the following questions should enable a community to be placed on the GIDS scale.

- Are there competent mother tongue speakers of the community language?

- What age of speakers?

- How fluent are the speakers?

- How much the language is spoken, to whom and in which domains?

- How widespread is literacy?

- Is it possible to receive education in the language?

- What level and/or kind of education?

- What institutional supports does the language have?

- Are there media services in the language - what kinds?

- Are there government services in the language - what kinds?

When we look at the three communities under review, we can answer the first question with ease for all three. There are competent mother tongue speakers of Dutch, Gujarati and Samoan in New Zealand, mainly, although not exclusively, because of immigration into New Zealand from the Netherlands, India and Samoa.

\subsubsection{Age and fluency of speakers}

One of the crucial points of the GIDS scale is that age of speakers is all-important. There may be plenty of fluent mother tongue speakers of the language, living in reasonable proximity to 
each other and enjoying a rich social life transacted in the language. All of this makes no difference to the long term survival of the language if all these speakers are past childbearing age. Thus the relationship between age and language proficiency and use is crucial. Respondents were asked to rate their speaking skills in the community language. There are reasonable proportions of fluent speakers of child-bearing age in all communities, although the proportions are certainly lower in the Dutch community. In looking at these figures birthplace of the speakers has not been considered. For the immediate purposes of the GIDS scale the overall proportions of fluent mother tongue speakers are more important.

Table 13-2: Percentage of fluent speakers in each age group

\begin{tabular}{|l|l|l|ll|}
\hline Age & Dutch & Gujarati & \multicolumn{2}{|l|}{ Samoan } \\
\hline $60+$ & $92 \%$ & $100 \%$ & $100 \%$ & $(=1)$ \\
$56-60$ & $75 \%$ & $83 \%$ & $100 \% \quad(=1)$ \\
$51-55$ & $100 \%$ & $92 \%$ & $100 \%$ & \\
$46-50$ & $78.5 \%$ & $75 \%$ & $80 \%$ & \\
& & & & \\
$41-45$ & $64 \%$ & $80 \%$ & $100 \%$ & \\
$36-40$ & $50 \%$ & $55.5 \%$ & $76 \%$ & \\
$31-35$ & $39 \%$ & $44 \%$ & $82 \%$ & \\
$26-30$ & $37.5 \%$ & $86 \%$ & $70 \%$ & \\
$21-25$ & $33 \%$ & NA & $73 \%$ \\
$15-20$ & NA & NA & $100 \% \quad(=1)$ \\
N= & 128 & 103 & 68 \\
\hline
\end{tabular}

We can see that the Dutch respondents show an ominous fall off in fluent speakers. While high in the 46 - 60+ age group, which might be considered as conventionally falling into the category of 'past child-bearing age', there is a steady decline in fluency rates in the under $45 \mathrm{~s}$ and in the under 40 age group, the percentage of fluent speakers never rises to $50 \%$. The Gujarati and Samoan respondents show a far less clear cut picture. There is perhaps a slight fall off in the younger age groups. The Gujarati respondents show the lowest percentage of fluent speakers in the 31-35 age group, while the Samoan respondents' lowest rate is in the 26-30 age group. But both groups maintain fairly high rates of fluency even in the youngest age groups for which responses were collected. It seems that there are still reasonable numbers of fluent speakers in the child-bearing age groups in these two communities.

\subsubsection{How much is the language spoken?}

Respondents were asked "which language do you use most" and this provides a global answer to the question of how much the language is spoken, without going into questions of 
interlocutors and domains. The Dutch respondents, overwhelmingly had shifted to English as the language they spoke most often. A small majority of Gujarati respondents thought that they spoke English more often than Gujarati while a majority of Samoan respondents considered that Samoan was the language that they used most.

Table 13-3: Language most used by respondents

\begin{tabular}{|l|l|l|l|}
\hline Language used most & Dutch & Gujarati & Samoan \\
\hline Mother tongue & $4 \%$ & $32 \%$ & $61 \%$ \\
English & $76 \%$ & $54 \%$ & $17 \%$ \\
$50 / 50$ & $20 \%$ & $19 \%$ & $21 \%$ \\
Other & & & $1 \%$ \\
\hline
\end{tabular}

\subsubsection{In which domains is the language spoken?}

Respondents were asked whether they spoke the community language outside the home and, if they answered 'yes', they were asked to specify where they spoke it. The three groups form a cline in terms of density of uses of the language outside the home environment.

- $99 \%$ of the Samoan respondents spoke Samoan outside the home

- $96 \%$ of the Gujaratis spoke Gujarati

- $81 \%$ of the Dutch spoke Dutch

The density of use followed this pattern with Samoan respondents using the language in the most situations per respondent and the Dutch respondents using the language in the fewest situations per respondent.

Table 13-4: Percentages of respondents using community language in a given domain

\begin{tabular}{|l|l|l|l|l|l|}
\hline & Social & Work & Faith & Other & All \\
\hline Dutch & $78.5 \%$ & $14 \%$ & $6 \%$ & $13 \%$ & $1 \%$ \\
Gujarati & $91 \%$ & $13 \%$ & $27 \%$ & $1 \%$ & $3 \%$ \\
Samoan & $89 \%$ & $79 \%$ & $93 \%$ & $2 \%$ & $71 \%$ \\
\hline
\end{tabular}

The 'All' category includes at least, social gatherings, work and church/gita class and may include other areas that respondents have added to the list. The most striking difference between the three groups is in the 'All' category where most of the Samoan respondents use the language in all three and in many cases more areas of their lives whereas only a tiny number of the Dutch and Gujarati respondents do this.

- $71 \%$ of the Samoan respondents use the MT in three or more areas of their lives

- $3 \%$ of the Gujarati respondents use the MT in three or more areas of their lives

- $1 \%$ of the Dutch respondents use the MT in three or more areas of their lives

The other striking differences are in the work and faith categories where once again Samoan usage rates are much higher. 
The 'Other' category occurs where respondents did not tick any of the other options on the list and ticked 'Other' only, usually adding a specification. The comparatively high $13 \%$ of Dutch respondents who reported 'other' occurs because those respondents were usually specifying a very limited number of persons and/or situations in which they spoke Dutch - in one case as limited as 'my friend $\mathrm{X}$ in Christchurch'.

\subsubsection{Interlocutors with whom community language is spoken.}

Stage six is, in Fishman's opinion, the crucial stage 'if this stage is not satisfied, all else can amount to little more than biding time' (italics in original, Fishman 1990:21). It is the crucial stage because it is the stage where the speakers of the language do not consist mainly or solely of elderly members of the community but where you get 'family-, neighbourhood-, community-reinforcement' (Fishman 1990:20). One of the measures of this is the age of a respondent's interlocutors. If they are all older than the respondent, that is, if she only ever uses the language because it is the only way she can communicate with elderly members of the community, then the language is in trouble. If she speaks to friends her own age in the community language (and she herself, is not elderly) then the situation is better. If she is in her child- bearing years and speaks to her children, her partner, other community children, friends her own age and older people in the community language, then the language is in good heart. This is why stage six is so important.

Table 13-5: Percentage of respondents speaking to interlocutors of a given age group

\begin{tabular}{|l|l|l|l|}
\hline & Dutch & Gujarati & Samoan \\
\hline Children & $5 \%$ & $33 \%$ & $73 \%$ \\
Own age & $70 \%$ & $76 \%$ & $80 \%$ \\
Older people only & $7 \%$ & $11 \%$ & 0.67 \\
\hline
\end{tabular}

Once again the three communities seem to form a cline of use. Remembering that about half the Dutch respondents are over 60 , it can be seen that in many ways this community fits Fishman's stage 7; many fluent speakers past child-bearing age, speaking to each other. Very few people have any reason to use the community language to children other than their own. In the light of the age of the Dutch respondents, the low percentage of people using the

167 There were no Samoan respondents who spoke Samoan only to people older than themselves. There was one person who speaks it only to their minister. Two who speak it only to older relatives and the minister and three who speak it only to older relatives, the minister and new immigrants. So one could suggest that $7 \%$ of the sample had a limited set of interlocutors. 
language exclusively with older interlocutors cannot really be considered an encouraging sign for the survival of the language.

The age spread throughout the Gujarati respondents is more even and therefore the figure of $11 \%$ (of the 135 respondents who spoke Gujarati outside the home) for respondents who spoke only to interlocutors older than themselves, can be considered indicative of Gujarati language use being still fairly wide-spread in the community. The fact that $33 \%$ of respondents used Gujarati to children other than their own also seems to indicate that the language is still quite widely used, but in light of the Samoan figure of $73 \%$ it is clear that, comparatively speaking, the Gujarati language is not as firmly grounded as the Samoan.

The Samoan responses seem to indicate that the language is in a very healthy state. Most people use Samoan with their contemporaries, most people use it with children in the community and no-one confines their use only to people older than themselves. This, combined with the high rate of use at home, at social gatherings, at work and in the community, seems more than adequately to fulfil Fishman's vision of 'family-, neighbourhood-, community-reinforcement' at stage six.

\subsubsection{Literacy}

Literacy is first mentioned by Fishman in discussion of stage five as part of formal linguistic socialisation but it is implied also in the discussion of stage six, as many communities would naturally use literacy as one of the tools for community-reinforcement of the language. There were reasonable rates of literacy in all communities but only amongst the Samoan respondents could everyone at least read the language. 
Table 13-6: Respondents' ability to read and write community language

\begin{tabular}{|l|l|l|l|}
\hline Can write & Dutch & Gujarati & Samoan \\
\hline Easily & $64 \%$ & $55 \%$ & $84 \%$ \\
Fairly easily & $10 \%$ & $17 \%$ & $8 \%$ \\
With difficulty & $10 \%$ & $12 \%$ & $4 \%$ \\
Read only & $7 \%$ & $2 \%$ & $3 \%$ \\
Neither & $7 \%$ & $13 \%$ & 0 \\
NR/unclear & $2 \%$ & $1 \%$ & $1 \%$ \\
N= & 183 & 140 & 87 \\
\hline
\end{tabular}

\subsubsection{Media}

When the Gujarati interviewees in this study were asked about the Gujarati language broadcasts on Radio Access, it was fairly obvious that they had little or no effect on language maintenance or RLS. Almost exclusively, the listening audience is seen to be first generation immigrants. The most usual comment from younger New Zealand born or raised interviewees was that 'my mother listens to it'. Some younger people listened to the broadcasts because they enjoyed listening to Indian music and some people mentioned the community bulletin board function but, once again, as something largely of interest to older people. It would seem that the broadcasts served a useful and valued purpose but that it is not a language maintenance purpose.

The Samoan language broadcasts, which had just started at the time of the survey, seem to serve a slightly different function again for the Samoan community. It is a matter of pride to many Samoans that there are now regular Samoan language broadcasts, whereas for the Gujarati community pride does not seem to enter into their evaluation of the Access broadcasts. The Samoan language broadcasts undoubtedly serve a similar function for first generation immigrants in the Samoan community as do the Gujarati broadcasts for the first generation Indian immigrants but it is unclear as yet whether they have a wider audience in the second generation.

\subsubsection{Summary}

Dutch seems to be between stages seven and six, mainly stage seven, where language use is quite widespread but confined largely to an older age group. Gujarati and Samoan are both at stage five, which entails 'formal linguistic socialisation' (Fishman 1990:21) i.e. community language schools. Samoan is more firmly grounded at stage six, the crucial stage, than Gujarati. This may be a product of a more recently established community and it is hard to know how long this differential will last. Samoan is the only one of the language which is at 
basic English tuition would seem to be a good start. It would also be helpful if the provision of English tuition, while divided amongst different agencies in order to maintain the diversity of provision that best accommodates the diversity of need in this field, could be coordinated through a central agency of some kind to enable most efficient use of resources.

In the second category are those policies that enlarge the possibilities for language and culture maintenance in New Zealand for all the groups that make up the wider New Zealand society. Given the importance attached to language and culture maintenance by groups such as the Gujarati and Samoans and given that this research has demonstrated the way in which even groups that appear not to have valued such things can, in time, place a more positive valuation on them, it would seem that demonstrating a social commitment to language and culture maintenance would help to forge stronger links between minority immigrant groups and the wider New Zealand society. The role of education both in the mainstream and the community school has been shown to be important to the respondents in this research and this leads to the proposal of the following two policies:-

- Provision of state support for community language maintenance schools for the communities that want them

- Some provision, where appropriate, of MT support within the mainstream school system. There will be considerable variation between communities, depending on density of population, length of settlement in New Zealand, pre-arrival history, whether adequate community schooling already exists and, last but not least, whether for these or other reasons the community considers mainstream schools to be a suitable site for MT maintenance. Taking all of these into account, it seems likely that some communities could find their language maintenance education efforts best served through the mainstream school system.

There are so many ways in which community language maintenance assistance could be provided that it is by no means clear what would be the best way to choose. It is likely that a mixture of approaches, that could be varied to support the needs of particular communities, would prove to be most efficient. Provision of premises, funding for teaching resources, subsidies for teachers' time and training for teachers are probably four of the most outstanding areas of need. Once again, an area where New Zealand could profitably follow the lead provided by Australia and an area where further research is needed.

\subsection{Conclusion}

This chapter has summed up the findings on language maintenance and shift within the family, showing that shift is occurring in all communities but at different rates. The 


\subsection{Language policy implications}

This will draw upon the wealth of information about language and identity, language and immigration, language policy to date in New Zealand and the material gathered about the three language communities in the course of this research. Considering all of this information, what are the policy implications for minority immigrant languages in New

\section{Zealand?}

The link between language and identity and the importance of identity in the establishment and maintenance of personal and social relationships has been fully canvassed in this work. It has been shown that most of the respondents support the maintenance of their MT in New Zealand and that for many of them this support is founded upon concerns about community and personal identity. The role of the MT in these areas is much more important for the Gujarati and Samoan respondents than for the Dutch but its importance is growing amongst the New Zealand-born Dutch.

Language and culture maintenance has, for many minority immigrant people in New Zealand, been something of a hidden activity. When I began research on the Gujarati community in Wellington, I was completely unaware - although I had lived here all my life - that there had been a Gujarati school for almost 50 years in Wellington. The activity was not bruited about partly because of the fear of a negative reaction from New Zealanders. This research has also shown that minority immigrant languages and culture (other than those of some Pacific Island communities) have received very little attention from New Zealand's policy makers. Minority language and culture maintenance should be supported by and integrated into a wider New Zealand society so that New Zealanders who come from these minority groups feel that their language and culture are valued in their own right in their own country and not regarded as alien and almost slightly shameful imports.

The importance of first language maintenance was highlighted by Jeffrey Waite in Aoteareo

The development of English language competence ought to go hand in hand with the maintenance of these children's first language. Bilingualism (with maintenance of the first language) fulfils many goals, including the reinforcement of family structure, strengthening of individual and group identity, enhancement of educational achievement, and contributing to the pool of New Zealanders able to use languages other than English...

To ensure that children from non-English-speaking backgrounds have the opportunity to maintain their first language into adulthood, support is needed for parents who want 
to maintain the language in the home setting, for linguistic communities who take the initiative to establish their own language programmes, as well as for schools who choose to introduce community languages into their curriculum (Waite 1992a: 20)

This has been recognised in a report published by the Research Unit of the Ministry of Education, Non-English Speaking Background Students: A Study of Programmes and Support in New Zealand Schools (Kennedy and Dewar: 1997). The authors recognize that there is a widespread

belief or realization that students having a good grasp of their first language was critical in the subsequent successful acquisition of English (and, of course, any other language) (244).

The authors and the people they interviewed (most of whom were school teachers) acknowledge that first language maintenance 'presents a considerable challenge for New Zealand schools' (247). They all seem completely unaware of the existence of community organised language maintenance schools and hence, of course, they are unaware of the fact that in many cases they would not have to bear the language maintenance burden on their own.

In Chapter 4, the origins of attitudes to societal multilingualism and language policy in New Zealand were examined and it was pointed out that most explicit policy-making about language in New Zealand has concerned te reo Mãori and the relationship of Maori and English.

The work of Jeffrey Waite was also examined and the policy recommendations embodied in Aoteareo were discussed. This work does not significantly depart from Waite's findings as expressed in Aoteareo. The research reported here has not dealt at all with Maori language revitalisation, second chance adult literacy or international languages and I cannot comment on these except to say that I find Waite's arguments for including them in the policy framework persuasive.

This research has however, provided in-depth inquiry into first language maintenance and also some inquiry into ESL requirements and provision of services in languages other than English. In all these areas, the research reported on here strongly supports Waite's conclusion that these are important subjects for a National Language Policy. 
In Chapter 4 it was stated that a National Language Policy will

a. set goals

b. describe how these goals will be attained

c. (allocate funding)

d. describe a system for evaluating how well the goals are being attained

e. describe a system for allowing evaluation to feed back into performance and, possibly into definition of goals

This work cannot comment on all the possible goals of a worthwhile languages policy. However, following Waite and Lo Bianco, I accept the arguments for the desirability of a coordinated, national language policy. This research enables well-founded recommendations to be made as to desirable national languages policy goals in the area of minority immigrant language populations. Here, the goals are outlined and methods for achieving those goals are briefly touched upon.

Based on this research, the policy implications for minority immigrant languages in New Zealand are fall into two categories. In the first category are the policies that make participation in New Zealand society more possible for those with limited English skills. These policies are important both because they guarantee that basic human rights are met and also because they help to give everyone living in New Zealand access to the wider society thus increasing social cohesion within the country as a whole. Two simple and very basic policies that would help achieve these aims are:-

- Adequate provision of interpreting services for in all state organisation but with particular emphasis on health, justice and immigration processes

- Provision of basic written information in the MT on administrative and citizenship issues

There are existing private, government owned but commercial and community based interpreting and translation services. There are also some training programmes already operating in New Zealand. This provides a base from which to expand. New Zealand interpreting and translation provision has always been heavily reliant upon Australia as a model and it seems likely that this would be a fruitful connection to continue.

\subsubsection{ESL for new settlers}

As outlined in section 4.6.1 this area is desperately in need of a coherent policy. It is, at present, an extremely complex area but at the most basic level, an allocation $\mathrm{X}$ many hours 
stage four (the draft Samoan syllabus). None of the languages is at stage three. Samoan is the only one at stage two 'lower governmental services' (Fishman 1990:25) provided in the language, although not local mass media. Samoan is at stage one inasmuch as it is offered as a university subject at universities in New Zealand and Dutch is also offered at one university in New Zealand and so may be considered as having some stage one qualities. Gujarati does not register at all at stages $4-1$.

Both Samoan and Gujarati are affected by the stage five 'timidity' that Fishman describes, but Gujarati is affected to a greater degree. Samoan respondents were very clear that government funds should be spent on Samoan community language education and that Samoan language should be offered in the state school system. Indian respondents were by no means as certain that Gujarati should move out into the wider community's scrutiny in this way. The different attitudes reflect amongst other things the differing immigration histories of the two communities; the Indian community has faced a much higher degree of discrimination which acted efficiently to keep the community low profile in self protection. They also reflect the differing demographic profiles of the two communities: the Samoan community is larger and has a higher degree of residential concentration both of which make the delivery of educational services easier.

It can be seen that the scale is a useful device for comparing and analysing minority linguistic/ethnic communities. It does provide a useful heuristic framework. The situations of Samoan and Dutch however, show that the scale is not fully implicational. Both Dutch and Samoan respondents have some presence at stage one but Samoan has no presence at stage three and Dutch does not register at stages two, three or four and even at five, its presence is weak. Fishman claims that the scale is only quasi-implicational and it may be that it operates better as an implicational scale for indigenous minority groups than it does for immigrant groups.

Some of the differences between the position of the different languages on the scale can be seen as historical. The colonial relationship of New Zealand and Samoan, the large numbers of Samoan immigrants and the fact that New Zealand has a natural interest in the Pacific region have led to the establishment of Samoan language university courses. Thus the historical and geographical facts that caused the Samoan immigration to New Zealand, plus the sheer numbers of immigrants have, in their turn, led to the establishment of Samoan language courses. Gujarati however, does not have history, geography or numbers on its side in New Zealand and thus remains firmly at stages 5 and 6. 
community language maintenance school has been shown to be an effective tool for achieving some degree of MT literacy. The varied immigration histories of the three communities under discussion have been highlighted as important factors in language maintenance and shift outcomes. The integrated model, based on Fishman's theories, which has been used as a framework for this research predicts that these histories will be important in language maintenance and shift outcomes. This research has found that prediction to have useful explanatory power.

The GIDS scale has been shown to be a useful heuristic device although not strongly implicational for the communities under discussion here. Policy suggestions have been considered and strong support for language maintenance and for ESOL and LOTEM services has been recommended. 


\section{CONCLUSION}

This thesis started with an investigation into the historical background of modern concepts of the role of language in society. The development of European ideas about the relationships between language, group identity, personal identity and even national identity were outlined and it was shown that these ideas have been influential in many immigrant communities. Minority immigrant groups around the world have accepted the links between language and group and personal identity and predicated the importance of language maintenance upon the existence of those links.

A brief examination of the history of immigration history as it has affected minority immigrant groups in New Zealand showed that minority immigrant groups have always been seen as exceedingly marginal. There has been extreme pressure on the members of such groups to assimilate. If assimilation has been perceived as an unlikely outcome for a particular immigrant group (because of race, religion, ethnicity etc) then New Zealand policy makers have tried, very efficiently, to make immigration to New Zealand difficult for that particular group. Of the groups under consideration here, the Gujarati were most strongly affected by this attitude. New Zealand immigration policy has only begun to move away from this set of attitudes in the last 20 years and is still in a state of flux.

An examination of the immigration and settlement histories of the three groups showed how very different their backgrounds were. It also showed however, that they all came from societies with quite strong orientations towards the English language and towards bi- or multilingualism. English was the colonial language and a language of education in Samoa as it was in India. Multilingualism is not uncommon in India and many of the Gujarati immigrants were trilingual in Hindi, Gujarati and English. The Dutch language is closely related to English and Dutch society has a strong positive orientation to multilingualism in general and English acquisition in particular.

Each of the communities had had different patterns of arrival and community development in New Zealand and had been differently received by the New Zealand government and society. The Gujaratis had undoubtedly faced the most negative attitudes from the host country.

A general examination of language policy showed that this was a large and complex field with deep historical roots. New Zealand attitudes to language in society and policy about language 
has been shaped by the traditional 'Anglo-Saxon' approach, favouring societal monolingualism and very little explicit policy about language.

An examination of U.S.A., U.K, and Australian policy showed some of the similarities of approach taken by three 'Anglo-Saxon' polities. However, Australia has broken from this traditional approach and has formulated a clear and explicit language policy. This has been influential in New Zealand and led to the Aoteareo report on national language policy which was widely admired but not adopted. At the time of writing, New Zealand has no formal, explicit national language policy.

When implicit policy in New Zealand is considered, it can be seen that language policy in education and broadcasting has been quite extensive and has tended to focus on Mäori language and the relation of Mäori and English. Provision for minority immigrant groups has been woefully inadequate.

Language maintenance is, for most communities, a major undertaking at individual, family and community level. Language maintenance is not undertaken lightly and the reasons for many communities deciding to embark on the language maintenance project were considered. The major sites of language maintenance within the community were also discussed. These issues, the issue of the historical context of minority communities and their languages and the issue of specific ethnic group orientations towards language maintenance and shift have all been much canvassed by Fishman. Fishman's writings in this area were used as the basis for an integrated model for the study of minority group language maintenance and shift processes. This model emphasised the importance of gathering habitual language use data, good demographic data to enable useful interpretations to be made, information about the social contexts in which language change was occurring, and information about attitudes to and behaviours towards language. The model also emphasised the importance of gathering information about change over time and about the sociohistorical forces of dislocation to which the minority group under study had been subjected.

In the chapter on methodology it was shown how the integrated model was used as a guide for the development of the questionnaire instrument. The development of the research methodology and the necessary changes in approach for each of the communities was also discussed. 
The next three chapters gave a straightforward description of the language maintenance and shift processes in each of the three communities as revealed by self-report questionnaires and interviews. Language shift has occurred in all the communities but at very different rates. Language maintenance has been important to the Gujarati and Samoan communities and comparatively less important to the Dutch.

When the three groups were compared, a complex picture of varied processes of language maintenance and shift emerges. When only one minority group is studied, it may be tempting to conclude that the pattern of language maintenance and shift displayed in that community is typical in some way. By examining three groups, it can be seen that there is no 'typical' pattern of language maintenance and shift, or rather, perhaps, that the 'typical' elements such as the fact that shift almost always occurs, are at a very general level. The complicated patterns of habitual language use described discussed in section 10.8 show how varied the patterns can be.

Following Fishman, the family, as the 'bulwark' of language maintenance has figured prominently in this research. The family has been shown to be the prime site of language maintenance (10.4.6) and the dynamics of language use within the families of the three groups were explored in Chapter 11. It was seen that the New Zealand-born Dutch had almost completely ceased to hand the MT on to their children but language maintenance amongst New Zealand-born families was continuing amongst the Gujarati and Samoan respondents. A wide range of MT environments, including the language maintenance school, was identified as being related to successful language maintenance acquisition. Essentially, as much exposure to the language, in as many domains as possible, will help children growing up in New Zealand to become MT speakers. The amount of MT exposure and the range of domains in which it is encountered is linked to the attitudes of the individual, family and community to the importance of language maintenance. It seems likely that the two factors are mutually reinforcing, forming a virtuous circle: positive attitudes to language maintenance lead to wide ranging language use which leads to positive attitudes to language maintenance (because the language is serving a socially useful function).

Attitude to language maintenance in general and to language maintenance education was explored in Chapter 12. Attitude and behaviour toward language are important components of the language maintenance and shift processes. They are often held to be related to ethnic group values, as in the theory of 'core value', which suggests an 'organic' or 'natural' link 
between ethnic group and language values. This research does not dispute that an ethnic group may hold a particular set of values about a particular area of life but suggests that ethnicity is not the only shaping factor in this area. For minority immigrant communities, the immigration and settlement experience itself (including host country attitudes) can be of prime importance.

A framework that has been used by Fishman to measure degree of dislocation within a language and a language community is the GIDS scale. The GIDS scale was investigated in this research and shown to be useful heuristic device that provided a formula for ranking languages and placing them on a scale. The GIDS scale itself contains a prescription for what the next step on the scale might be for a language trying to reverse the process of language shift. In the case of immigrant minority communities, there is a caveat in that the scale, designed as an implicational scale, is not in fact fully implicational. This raises some questions about the logical progression of the eight stages on the scale as far as minority immigrant communities are concerned. The suggestion is that a community should seek to move from one stage to the next in a fairly orderly manner, but, given the fact that the scale does not, in fact, appear to be implicational for at least some minority communities, it is unclear whether such an orderly progression is necessarily most appropriate.

Finally, the question of a national language policy for New Zealand was reconsidered and some policy suggestions made. Minority immigrant MTs have been neglected for far too long in New Zealand; it is time they received support from the wider society. 


\section{APPENDIX 1}

Below are the questionnaires that were used in surveying the Gujarati respondents. The first questionnaire was either posted to respondents in full, or a shorter version that omitted a range of questions was sent. Interviewees who were never sent a questionnaire or who only received a short version, were asked questions by the interviewer reading from the questionnaire.

The short version of the questionnaire omitted questions 6, 7, 8, 14, 17-20, 27, 28, 31-36, 4042, 44-49 


\section{QUESTIONNAIRE}

Please put a tick beside your answers

To start with here are some questions about the languages you speak

1. WHAT LANGUAGE/S DO YOU SPEAK

(please tick $A L L$ that apply)

Gujarati

English

Other (please specify)

2. WHICH LANGUAGE DID YOU SPEAK FIRST

Gujarati

English

Other (please specify)

3. WHICH LANGUAGE DO YOU USE MOST

Gujarati

English

Other (please specify)

4. APART FROM THE LANGUAGE THAT YOU USE MOST, HAVE YOU USED ANY OTHER LANGUAGE/S IN THE LAST MONTH

No

Yes (please write down the language/s in the space below)

5. WHAT LANGUAGE/S DO YOU SPEAK AT HOME

(please tick $A L L$ that apply)

Gujarati

English

Other (please specify)

6. WHO ARE THE OTHER MEMBERS OF YOUR HOUSEHOLD

(please tick $A L L$ that apply)

Father

Mother

Spouse/Partner

Children

Older relatives (not father or mother)

Younger relatives

Flatmates

Other (please specify)

No other members of my household

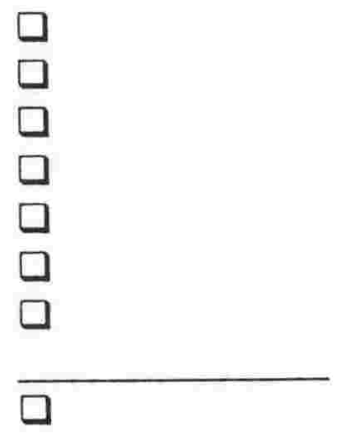


7. WHAT LANGUAGE DO YOU SPEAK WITH YOUR FATHER $\underline{M O S T}$ OF THE TIME

Gujarati

English

50/50 Gujarati/English

Other (please specify)

Not applicable

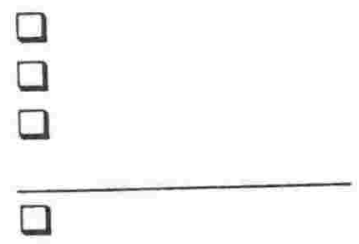

8. WHAT LANGUAGE DO YOU SPEAK WITH YOUR MOTHER MOST OF THE

TIME

Gujarati

English

50/50 Gujarati/English

Other (please specify)

Not applicable

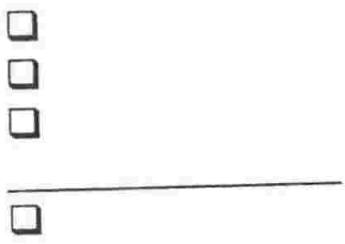

9. WHAT LANGUAGE DO YOU SPEAK WITH YOUR SPOUSE/PARTNER MOST OF THE TIME

Gujarati

English

50/50 Gujarati/English

Other (please specify)

Not applicable

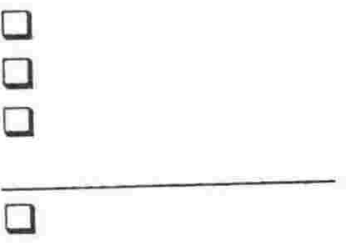

10. WHAT LANGUAGE DO YOU SPEAK WITH YOUR CHILDREN MOST OF THE TIME

Gujarati

English

50/50 Gujarati/English

Other (please specify)

Not applicable

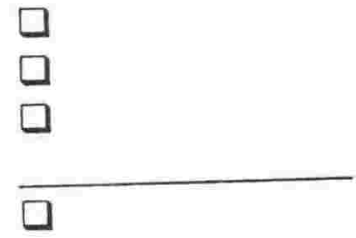

11. DO YOU SPEAK GUJARATI OUTSIDE THE HOME?

No

$\square$ (please go to question 14)

Yes

12. WHO DO YOU SPEAK GUJARATI TO OUTSIDE THE HOME?

(please tick $A L L$ that apply)

Friends my own age

Older friends

Older relatives

Younger relatives

Younger children (other than your own children) $\square$

The priest

New immigrants

Other (please specify) 
13. WHERE DO YOU SPEAK GUJARATI OUTSIDE THE HOME? (please tick $A L L$ that apply)

At social gatherings

At work

At Gita class

Other (please specify)

If you were born in New Zealand. please answer questions 14 to 20. If you were not born in New Zealand please go to question 21 .

14. DID ANYBODY TEACH YOU TO READ AND WRITE GUJARATI?

No

Yes

Grandfather

Grandmother

Father

Mother

Older brothers

Older sister

Other (please specify)

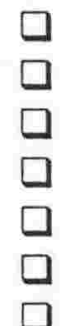

口

15. IN NEW ZEALAND HAVE YOU ATTENDED ANY KIND OF INDIAN LANGUAGE SCHOOL OR CLASS

$\begin{array}{ll}\text { No } & \square \text { (please go to question 22) } \\ \text { Yes } & \square\end{array}$

16. WHAT KIND OF SCHOOL WAS IT?

Organised by the community

Other (please specify)

17. HOW MANY HOURS A WEEK DID YOU GO TO THE SCHOOL?

Under three hours

Three hours

More than three hours

18. DID YOU GO REGULARLY?

Yes

No

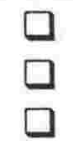

19. ABOUT HOW OLD WERE YOU WHEN YOU STARTED TO GO TO THE SCHOOL? (please write your answer in the space below) years old

20. FOR ABOUT HOW LONG DID YOU GO TO THE SCHOOL?

(please fill in the relevant space below)

About months

About years 
IN THE NEXT SECTION YOU ARE ASKED ABOUT BOTH GUJARATI AND ENGLISH

21. PLEASE TICK THE BOX THAT BEST DESCRIBES YOUR SPEAKING SKILLS FOR EACH LANGUAGE

Fluent

Fairly fluent

Not very fluent

I can't speak it but I can understand it

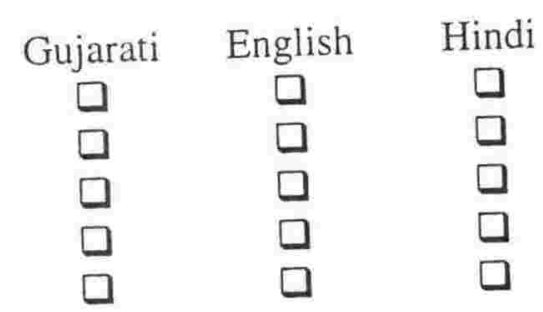

I can't speak or understand it

22. PLEASE TICK THE BOX THAT BEST DESCRIBES YOUR WRITING AND READING SKILLS FOR EACH LANGUAGE

I can write easily

I can write fairly easily

I can write with difficulty

I can't write but I can read

I can't read or write it

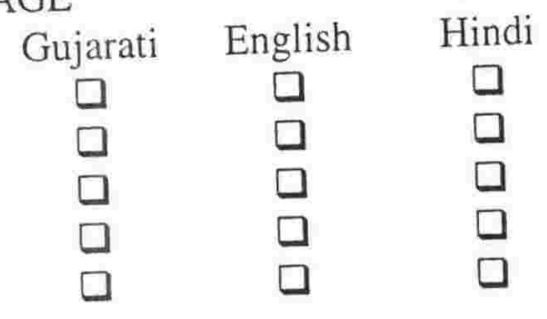

23. WHAT DO YOU THINK ABOUT THE INDIAN LANGUAGE SCHOOL FOR CHILDREN?

It is a good idea

It is not a good idea

Not sure

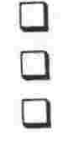

CHILDREN (please go to question 31 if you do not have any children)

24. HOW MANY CHILDREN DO YOU HAVE? (Please write in the space below) child OR children

(If you have only got one child please answer question 25 then go to question 28)

25. HOW OLD IS YOUR OLDEST CHILD? (please write in the space below) years old

26. HOW OLD IS YOUR YOUNGEST CHILD? (please write in the space below) years old 
27. WHAT LANGUAGES DOES YOUR OLDEST CHILD USE (please tick $A L L$ that apply)

My oldest child is too young to speak

S/he speaks Gujarati

S/he can understand Gujarati but can't speak it

S/he speaks English

S/he can understand English but she can't speak it

S/he speaks Hindi

S/he can understand Hindi but she can't speak it

28. WHAT LANGUAGES DOES YOUR YOUNGEST CHILD USE

(please tick $A L L$ that apply)

My youngest child is too young to speak

S/he speaks Gujarati

S/he can understand Gujarati but can't speak it

S/he speaks English

S/he can understand English but she can't speak it

S/he speaks Hindi

S/he can understand Hindi but she can't speak it

29. DO YOUR CHILDREN GO TO THE INDIAN SCHOOL?

No, they have never attended $\square$ (please go to question 31)

They are too young to attend but will go when they are old enough

They used to go but don't go now

Yes

30. WHY DECIDE TO SEND YOUR CHILDREN TO THE INDIAN SCHOOL?

Mainly so they could learn Gujarati

Mainly so they could come into contact with Indian culture

Both are equally important

Some other reason (please specify)

31. DO YOU THINK CHILDREN OUGHT TO BE ABLE TO STUDY GUJARATI AT ORDINARY STATE SCHOOL?

Yes

No

Not sure 
32. DO YOU THINK CHILDREN OUGHT TO BE ABLE TO STUDY HINDI AT ORDINARY STATE SCHOOL?

Yes

No

Not sure

33. DO YOU THINK THAT THE COMMUNITY RUN SCHOOLS LIKE THE WELLINGTON INDIAN ASSOCIATION SCHOOL SHOULD RECEIVE SOME FORM OF GOVERNMENT FUNDING?
Yes
No
Not sure

34. DO YOU THINK IT IS IMPORTANT TO KEEP GUJARATI AS A LIVING LANGUAGE IN NEW ZEALAND Yes

No

Not sure

35. DO YOU THINK THAT IT IS IMPORTANT FOR THE INDIAN PEOPLE OF NEW ZEALAND TO SEE THEMSELVES AS PART OF INDIAN/NEW ZEALAND COMMUNITY

Yes

No

Not sure

36. DO YOU THINK INDIAN PEOPLE IN NEW ZEALAND SHOULD FORGET ABOUT BEING INDIAN AND SEE THEMSELVES SIMPLY AS NEW ZEALANDERS

Yes

No

Not sure

Finally some questions about you. These answers are needed only to enable us to process the data effectively. Like the rest of the questionnaire, the answers are completely confidential

37. SEX

Male

Female

38. AGE

21-25

26-30

36-40

31-35

$\square$
$\square$
$\square$

41-45

46-50

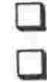

39. WHERE WERE YOU BORN?

In New Zealand

$\square$ (please go to question 41) 
In India in the state of Gujarat

In India outside the state of Gujarat

Other (please specify)

40. HOW OLD WERE YOU WHEN YOU CAME TO NEW ZEALAND?

Under 10 years old

10 to 20 years old

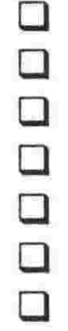

21 to 30 years old

31 to 40 years old

42 to 50 years old

51 to 60 years old

Over 60 years old

41. WHERE WAS YOUR FATHER BORN

In New Zealand

In India in the state of Gujarat

In India outside the state of Gujarat

Other (please specify)

42. WHERE WAS YOUR MOTHER BORN

In New Zealand

In India in the state of Gujarat

In India outside the state of Gujarat

Other (please specify)

43. WHAT IS YOUR OCCUPATION? (please write in the space below)

44. ARE YOU MARRIED OR LIVING WITH A PARTNER?

No

Yes

$\square$ (please go to question 47)

Other (please specify)

45. WHAT IS YOUR SPOUSE/ PARTNER'S OCCUPATION? (please write in the space below)

46. WHAT LANGUAGE/S DOES YOUR SPOUSE PARTNER SPEAK?

(Tick more than one choice if necessary)

Gujarati

English

Hindi 
Other (please specify)

48. WHERE WERE YOU EDUCATED?

Only in New Zealand

Only outside New Zealand

(please speacify what country)

In New Zealand after a certain age

What age years

49. WHAT LEVEL OF SCHOOLING DID YOU COMPLETE?

IN NZ

Primary School

Secondary School

University

Polytechnic

Apprenticeship

Teacher Training

Other - please specify

What kind of schooling
OUTSIDE NZ

(please name the country)

In which country

Please feel free to write any comments you may have in the space below. 


\section{Thank you for taking the time to do this questionnaire.}

In addition to this postal questionnaire, I intend to do some interviews with people about the issues that have been raised in this questionnaire.

The interview will take from half an hour to two hours depending on how much the interviewee has to say. In my experience, the average time is about 45 minutes.

If you could spare the time for an interview that would be a very great help.

If you are willing to be interviewed please write your name, address and telephone number in the space below. If there are other members of your household, or if you have Gujarati friends who would agree to be interviewed, please write their names as well.

Name

Name

Address

Address

Phone number

Phone number 
The following questionnaire was used by the interviewer as an interview schedule. Most respondents did not see the questionnaire although one or two asked to look at it for specific questions. The questions were usually asked in the order in which they are given here although occasionally this order was varied.

\section{CHILDHOOD}

The next group of questions are about your childhood. They are intended to give me some idea of your own language background.

1. Birthplace

Country

Locality

2. Mother's Birthplace

Country

Locality

3. Father's Birthplace:

Country

Locality

4. What language/s were spoken in your home when you were a child?

Gujarati

Hindi

English

Other

5. Was Gujarati spoken in your home?

Sometimes

Other language/s = English,

Mostly

Always

Never

Other language/s = English,

6. Did your parents speak Gujarati to each other?

Sometimes

Other language/s = English,

Mostly

Always

Never

Other language/s = English,

7. Did your parents speak Gujarati to you?

Sometimes Other language/s = English

Mostly

Always

Never

Other language $/ \mathrm{s}=$ English,

8. Did you parents speak any other Indian language to you?

Yes - Hindi

Yes - Other

No 
9. Did you speak Gujarati at home as a child?

Sometimes

Mostly

Other language/s = English,

Always

Never

Other language $/ \mathrm{s}=$ English,

10. With whom

Grandfather

Grandmother

Father

Mother

Older brothers and sisters

Younger brothers and sisters

Others

11. Did you speak Gujarati outside the home as a child?

Yes

No

In what situations and to whom

a. PEOPLE

Friends

Relations in general

Older relations

Older people

Younger people

People the same age

Immigrants

Everyone

b. SITUATIONS

At other people's home

Anywhere

At the Indian School

At the Indian Association

At Gita Class

At Indian social functions

Everywhere 
12. Did you speak any other Indian language outside the home as a child

Yes - Hindi

Yes - other

No

13. In what situations and to whom

a. PEOPLE

Friends

Relations in general

Older relations

Older people

Younger people

People the same age

Immigrants

b. SITUATIONS

At other people's home

Anywhere

At the Indian School

At the Indian Association

At Gita Class

At Indian social functions

\section{NON-NEW ZEALAND BORN}

13. How old were you when you came to New Zealand

14. What country did you come to New Zealand from

India - Gujarat

India - Other

Fiji

Kenya

Other

15. How well did you speak English when you arrived in New Zealand?

1. Very well, I had no problems

2. Quite well but I had some problems

3. Not very well, I had a lot of problems

4. I couldn' speak English at all

16. What did you do to improve your English in New Zealand?

a. Formal schooling in regular educational institutes

b. Night school classes of some kind 
c. Informal self-initiated attempts (watching lots of TV, reading English books etc)

d. No particular steps - it just got better over time

e. No particular steps - my English skills haven't altered much

17. How long did it take before your English reached its present standard

\section{SUPPLEMENTARY QUESTIONNAIRE FOR INTERVIEWS}

18. Do any radio stations have programmes in Gujarati / Hindi

YES

NO

If YES, please specify,

Which radio station:

What day(s) and times(s)

19. How important do you think it is to have radio programmes in Gujarati / Hindi

Not at all important

Quite important

Very important

20. In general, do you think that the Government should provide services in Gujarati / Hindi

Yes If yes, please answer questions $21 \& 22$

No If no, please go to question 23

21. Which services do you think should be available in Gujarati / Hindi ?

Court interpreters

Hospital interpreters

Community interpreters (for Social Welfare, Housing Corp ...)

Information about social services (in pamphlets)

Major forms (eg. taxation forms, election forms)

Other (please specify):

22. Should these services be available

for anyone who speaks Gujarati / Hindi ?

OR only for those who do not speak English well enough?

23. What is your caste

24. What is your religion

25. What is your partner's caste

ethnicity , religion 


\section{CHILDREN}

26. With whom does the child speak Gujarati?

Grandmother

Grandfather

Mother

Father

Older siblings

Younger siblings

Other family members

Friends of the family

Their own contemporaries from within the community

Other community members

27. Where does the child speak Gujarati

At home

Outside the home

At the Indian School

28. Are you happy with the child's level of competence in each language skill area

\begin{tabular}{|c|c|c|c|c|c|c|c|}
\hline & & $\mathrm{AKI}$ & & & & $\mathrm{HEN}$ & \\
\hline child 1 & $\mathrm{Y}$ & $\mathrm{N}$ & NS & child 1 & $\mathrm{Y}$ & $\mathrm{N}$ & NS \\
\hline child 2 & $\mathrm{Y}$ & $\mathrm{N}$ & NS & child 2 & Y & $\mathrm{N}$ & NS \\
\hline child 3 & $\mathrm{Y}$ & $\mathrm{N}$ & NS & child 3 & $\mathrm{Y}$ & $\mathrm{N}$ & NS \\
\hline child 4 & $\mathrm{Y}$ & $\mathrm{N}$ & NS & child 4 & $Y$ & $\mathrm{~N}$ & N S \\
\hline child 5 & $\mathrm{Y}$ & $\mathrm{N}$ & N S & child 5 & Y & $\mathrm{N}$ & N S \\
\hline & & DIN & & & & & \\
\hline child 1 & $\mathrm{Y}$ & $\mathrm{N}$ & NS & child 1 & $\mathrm{Y}$ & $\mathrm{N}$ & N S \\
\hline child 2 & Y & $\mathrm{N}$ & NS & child 2 & $\mathrm{Y}$ & $\mathrm{N}$ & N S \\
\hline child 3 & $\mathrm{Y}$ & $\mathrm{N}$ & NS & child 3 & $\mathrm{Y}$ & $\mathrm{N}$ & S \\
\hline child 4 & $\mathrm{Y}$ & $\mathrm{N}$ & NS & child 4 & Y & $\mathrm{N}$ & N S \\
\hline child 5 & $\mathrm{Y}$ & $\mathrm{N}$ & NS & child 5 & $\mathrm{Y}$ & $\mathrm{N}$ & N S \\
\hline
\end{tabular}

29. Why do you want your child to be able to speak/understand/read/write Gujarati

Cultural Heritage Reasons

Return to India

Speak to Grandparents / Older family members

30. If your child speaks Gujarati will it affect their English in any way? Will it affect their school study in any way

Yes - it will be good for it

Yes - it will be bad for it

No it won't have an effect

Not Sure 
31. Is it important to you that your child has a good command of English

Yes

No

Not Sure

32. Would you like your child to be able to master languages other than Gujarati and English?

Yes

No

Not Sure

Up to Child

33. Do you want your children to be able to speak an Indian language when they grow up

Yes

No

Not Sure

34. What kind(s)

Gujarati

Hindi

Sanskrit

Other

35. If the respondent replied positively to questions about State provision of Language schooling:-
a. at primary level
b. at secondary level
c. at tertiary level
d. as medium of instruction
e. as subject
f. do you think the emphasis should be on learning to speak and understand or on learning to read and write
g. how many hours a week

36. Do you think you can teach your children in the home

Yes

No

Not Sure

37. Do you think it is important that your children should be literate in an Indian language Yes

No

Not Sure 
These questions were asked about every one of the interviewees' children

No. of Questionnaire

Sex of child

Age of child

Educational level of child

How would you rate your child's ability to speak Gujarati

a. Very good - as well as an Indian born child of his or her age

b. Good

c. Fair

d. Limited - just a few words and phrases

e. Not at all

How would you rate your child's ability to understand Gujarati

a. Very good - as well as an Indian born child of his or her age

b. Good

c. Fair

d. Limited - he/she can only understand simple words and phrases

e. Not at all

How would you rate your child's ability to read Gujarati

a. Very good - as well as an Indian born child of his or her age

b. Good

c. Fair

d. Limited - he/she can only understand simple words and phrases (NB this might well be appropriate for certain age groups)

e. Not at all

How would you rate your child's ability to write Gujarati

a. Very good - as well as an Indian born child of his or her age

b. Good

c. Fair

d. Limited - he/she can only write simple characters and phrases (NB this might well be appropriate for certain age groups)

e. Not at all 
The following two letters are specimens of the letters that were sent to prospective respondents or interviewees. The first letter was used as a covering letter for the printed questionnaire. The second letter was used towards the end of the data gathering period when $I$ was attempting to target New Zealand-born respondents, and being handed on from one interviewee to another in friend of friend style interviewing.

Blank Tce

Suburb

Wellington

$\operatorname{MrX}$

Blank St

Suburb

\section{Dear Mr X}

I am a student at Victoria University doing research for my $\mathrm{PhD}$. on immigrant languages in New Zealand. I am studying three different immigrant languages, including your community, the Pacific Island community and the Dutch community. As part of the study I am collecting answers to the enclosed questionnaire.

The Wellington Indian Association has been informed of my research and has raised no objections. Your name has been chosen at random from the Indian Association telephone book which has been supplied to me by the immediate past chairman of the school committee. If you have any questions about how your name was chosen or about the nature of my research please contact me (ph. XXX XXX).

Your answers to my questions will be kept completely confidential. There is no need to write your name on the questionnaire unless you want to or unless you feel that you can give me even more help by agreeing to an interview.

In either case, your name will not be mentioned to anyone else.

I hope that my research will eventually prove useful both to your community and to policy makers. The results of my research will be made available to the Wellington Indian Association.

At the moment the Government is in the process of developing a National Languages Policy, to make sure New Zealand's language resources are put to the best use. The policy will look at community heritage languages and my research will also be useful to the people who are working on the development of this policy.

\section{Yours Sincerely}

Mary Roberts 
Blank Tce

Suburb

Dear Mr and Mrs X

I am a student at Victoria University doing a $\mathrm{PhD}$ in the Linguistics Department. I am studying minority immigrant languages in New Zealand and I am interested in how people from a Gujarati background use Gujarati and English in their day to day lives. Amongst other people, I have spoken with Name and Name Surname and they suggested that you might be willing to talk to me.

I will give you a ring in a day or two, and, if it suits you, perhaps we could arrange a time to meet. If you would like to ring me, my home number is XXX XXX.

Yours sincerely

Mary Roberts 


\section{APPENDIX 2}

\section{QUESTIONNAIRE}

To start with here are some questions about the languages you speak

1. WHAT LANGUAGE/S DO YOU SPEAK

(please tick $A L L$ that apply)

Dutch

English

Other (please specify)

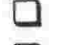

$\square$

WHICH LANGUAGE DID YOU SPEAK FIRST

Dutch

English

Other (please specify)

3. a. HAVE YOU SPOKEN ENGLISH IN THE LAST MONTH

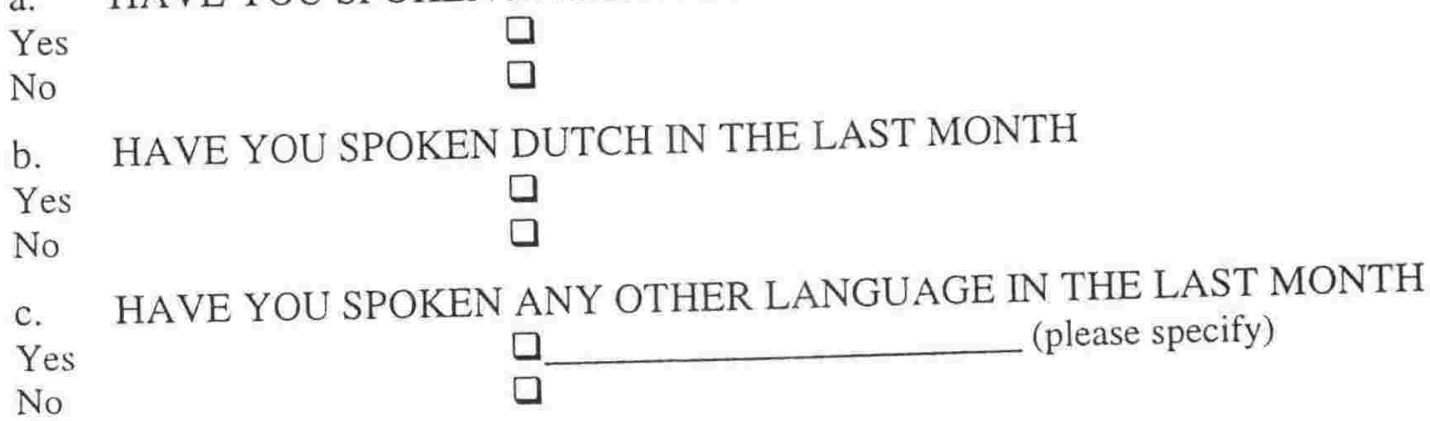

4. WHICH LANGUAGE DO YOU USE MOST

Dutch

English

$\square$

50/50 Dutch/English

Other (please specify)

5. WHAT LANGUAGE/S DO YOU SPEAK AT HOME

(please tick $A L L$ that apply)

Dutch

English

Other (please specify)

6. WHO ARE THE OTHER MEMBERS OF YOUR HOUSEHOLD

(please tick $A L L$ that apply)

Your Father

Your Mother

Spouse/Partner

Your Children

Older relatives

Younger relatives

Flatmates

Not applicable

Other (please specify)

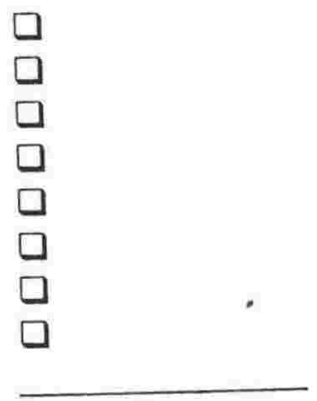


7. WHAT LANGUAGE DO YOU SPEAK WITH YOUR FATHER $\underline{M} \boldsymbol{M S T}$ OF THE TIME

Dutch

English

50/50 Dutch/English

Not applicable

Other (please specify)

8 WHAT LANGUAGE DO YOU SPEAK WITH YOUR MOTHER MOST OF THE TIME

Dutch

English

50/50 Dutch/English

Not applicable

Other (please specify)

9. WHAT LANGUAGE DO YOU SPEAK WITH YOUR SPOUSE/PARTNER $\underline{M O S T}$ OF THE TIME

Dutch

English

50/50 Dutch/English

Not applicable

Other (please specify)

10. WHAT LANGUAGE DO YOU SPEAK WITH YOUR CHILDREN MOST OF THE TIME

Dutch

English

50/50 Dutch/English

Not applicable

Other (please specify)

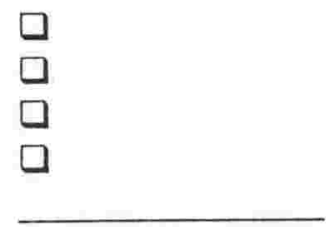

11. IF YOU SPEAK MAINLY ENGLISH TO YOUR CHILDREN, DO YOU TRY TO SPEAK SOME DUTCH WITH THEM AS WELL

$\begin{array}{ll}\text { Yes } & \square \\ \text { No } & \square \\ \text { Not applicable } & \square\end{array}$

12. DO YOU SPEAK DUTCH OUTSIDE THE HOME

Yes

No

13. WHOM DO YOU SPEAK DUTCH TO OUTSIDE THE HOME (please tick $A L L$ that apply)

Friends my own age

Older friends

Younger friends

Older relatives

Younger relatives 
Young children

The priest or minister

New immigrants

Not applicable

Other/s (please specify)

14. WHERE DO YOU SPEAK DUTCH OUTSIDE THE HOME

(please tick $A L L$ that apply)

At social gatherings

At work

At Church

Not applicable

Other (please specify)

15. HAVE YOU BEEN FROM NZ TO THE NETHERLANDS FOR A VISIT Yes

No

Not yet but $I$ intend to go

16. HAVE YOUR CHILDREN BEEN TO VISIT THE NETHERLANDS

(please tick $A L L$ that apply)

Yes - I have taken my children to the Netherlands

Yes - Some or all of my children have chosen to visit the Netherlands by themselves

No - None of my children have ever been

No - They have not been yet but I intend to take them

No - They have not been yet but they intend to go

Not applicable

If you were born in, or raised for part of your childhood in New Zealand. please answer the following questions. If you did not live in New Zealand until you were past childhood please go to question 34 on page 5 .

17. WAS DUTCH SPOKEN IN YOUR HOME IN NEW ZEALAND

Always

Mostly

Sometimes

Never

18. DID YOUR PARENTS SPEAK DUTCH TO EACH OTHER IN YOUR HOME IN

NZ

Always

Mostly

Sometimes

Never

19. DID YOUR PARENTS SPEAK DUTCH TO YOU IN YOUR HOME IN NEW

ZEALAND

Always

Mostly

Sometimes

Never 
20. DID YOU SPEAK DUTCH AT HOME AS A CHILD IN NEW ZEALAND

Always

Mostly

Sometimes

Never

21. IF YOU ANSWERED YES TO QUESTION 20 PLEASE TICK THE APPROPRIATE BOX OR BOXES

(please tick $A L L$ that apply)

I spoke Dutch to:-

Grandfather

Grandmother

Father

Mother

Older brothers and sisters

Younger brothers and sisters

Other/s (please specify)

22. DID YOU SPEAK DUTCH OUTSIDE THE HOME AS A CHILD IN NEW

ZEALAND

No

Yes

23. AS A CHILD, IN WHAT SITUATIONS DID YOU SPEAK DUTCH OUTSIDE THE HOME IN NEW ZEALAND (please tick $A L L$ that apply)

Visiting Dutch friends

Visiting relatives

Dutch social gatherings

Dutch clubs or organisations

Dutch school or classes

Other (please specify)

Not applicable

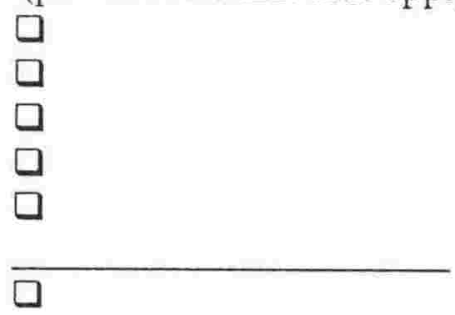

24. AS A CHILD, TO WHOM DID YOU SPEAK DUTCH OUTSIDE THE HOME IN NEW ZEALAND (please tick $A L L$ that apply)

Older people

Older relatives

New immigrants

Other children

Not applicable

25. WHEN YOU WERE A CHILD DID YOU GO TO ANY KIND OF DUTCH SCHOOL OR CLASS IN NEW ZEALAND

No $\quad \square$ (please go to question 32 on page 5)

Yes

26. WHO ORGANISED THE SCHOOL

Dutch community group

Church group

Other (please specify)

Not applicable 
27. HOW MANY HOURS A WEEK DID YOU GO TO THE SCHOOL

Less than three hours

Three hours

More than three hours

Not applicable

28. HOW OLD WERE YOU WHEN YOU BEGAN TO GO TO THE SCHOOL

Not applicable years old

29. HOW OLD WERE YOUR WHEN YOU STOPPED GOING TO THE SCHOOL years old

Not applicable

30. DID YOU GO TO THE SCHOOL REGULARLY

Yes

No

Not applicable

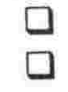

$\square$

31. DID YOUR BROTHERS AND/OR SISTERS GO TO THE SCHOOL AS WELL Yes

No

Not applicable

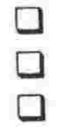

32. IN NEW ZEALAND, DID YOU RECEIVE ANY FORMAL INSTRUCTION IN SPOKEN DUTCH OTHER THAN IN A DUTCH SCHOOL OR CLASSES

Yes (please specify who taught you) No

33. AND/OR IN WRITTEN DUTCH

Yes (please specify who taught you)

No

In the next section you are asked about your Dutch and English language skills.

34. PLEASE TICK THE BOX THAT BEST DESCRIBES YOUR SPEAKING SKILLS FOR EACH LANGUAGE

FLUENT

FAIRLY FLUENT

NOT VERY FLUENT

I CANT SPEAK IT BUT I CAN UNDERSTAND IT

I CANT SPEAK OR UNDERSTAND IT

$\begin{array}{cc}\text { Dutch } & \text { English } \\ \square & \square \\ \square & \square \\ \square & \square \\ \square & \square \\ \square & \square\end{array}$


35. PLEASE TICK THE BOX THAT BEST DESCRIBES YOUR WRITING AND READING SKILLS FOR EACH LANGUAGE
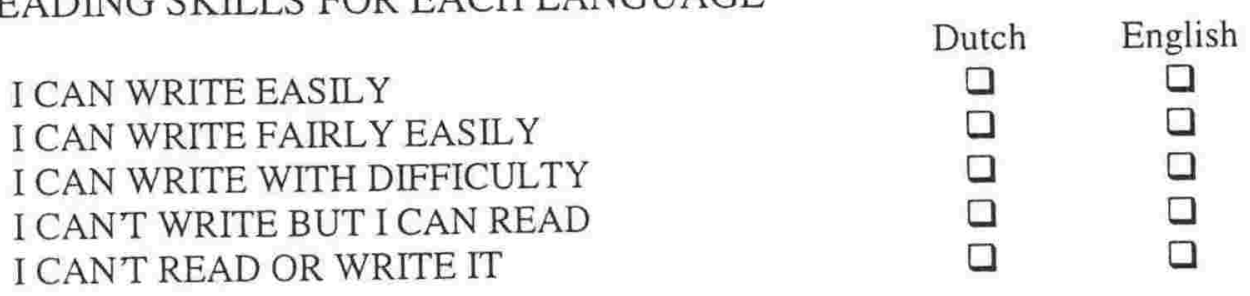

The nest section asks about your children and their language use. If you do not have any children please go to question 43 on page 6 .

36. HOW MANY CHILDREN DO YOU HAVE child OR children

37. HOW OLD IS YOUR OLDEST CHILD years old

38. HOW OLD IS YOUR YOUNGEST CHILD years old

39. WHAT LANGUAGES DOES YOUR OLDEST CHILD USE (please tick $A L L$ that apply)

S/he speaks Dutch

S/he can understand Dutch but can't speak it

S/he speaks English

S/he can understand English but she can't speak it

S/he is too young to speak

40. WHAT LANGUAGES DOES YOUR YOUNGEST CHILD USE (please tick $A L L$ that apply)

S/he speaks Dutch

S/he can understand Dutch but can't speak it

S/he speaks English

S/he can understand English but she can't speak it

S/he is too young to speak

41. DO YOUR CHILDREN GO TO DUTCH LANGUAGE SCHOOL/CLASSES

No, they have never attended

They are too young to attend but will go when they are old enough

They used to go but don't go now

Yes 
42. WHY DECIDE TO SEND YOUR CHILDREN TO DUTCH LANGUAGE SCHOOL/CLASSES

Mainly so they could learn Dutch

Mainly so they could come into contact with Dutch culture

Both are equally important

Some other reason (please specify)

The following section asks your opinions about some aspects of Dutch language and culture in New Zealand

43. WHAT DO YOU THINK ABOUT THE IDEA OF A DUTCH SCHOOL FOR CHILDREN OPERATING AFTER SCHOOL HOURS OR ON SATURDAY

It is a good idea

It is not a good idea

Not sure

44. WHAT DO YOU THINK ABOUT THE IDEA OF CLASSES AIMED AT NZ BORN DUTCH ADULTS WHO WANTED TO LEARN SOME DUTCH OR IMPROVE THEIR PRESENT LEVEL OF DUTCH

It is a good idea

It is not a good idea

Not sure

45. DO YOU THINK CHILDREN OUGHT TO BE ABLE TO STUDY DUTCH AT ORDINARY STATE SCHOOLS

Yes

No

Not sure

46. DO YOU THINK THAT THE COMMUNITY RUN LANGUAGES SCHOOLS THAT SUPPORT IMMIGRANT LANGUAGES IN NEW ZEALAND SHOULD GET SOME FORM OF GOVERNMENT FUNDING

Yes

No

Not sure

47. DO YOU THINK IT IS IMPORTANT TO KEEP DUTCH AS A LIVING

LANGUAGE IN NEW ZEALAND

Yes

No

Not sure 
48. DO YOU THINK THAT IT IS IMPORTANT FOR THE DUTCH PEOPLE OF NEW ZEALAND TO SEE THEMSELVES AS PART OF DUTCH/NEW ZEALAND COMMUNITY

Yes

No

Not sure

49. DO YOU THINK DUTCH PEOPLE IN NEW ZEALAND SHOULD FORGET ABOUT BEING DUTCH AND SEE THEMSELVES SIMPLY AS NEW ZEALANDERS

$\begin{array}{ll}\text { Yes } & \square \\ \text { No } & \square \\ \text { Not sure } & \square\end{array}$

\section{DEMOGRAPHIC INFORMATION}

Finally some questions about you. These answers are needed only to enable us to process the data effectively. Like the rest of the questionnaire, the answers are completely confidential

50. SEX

Male

Female

51. AGE

$\begin{array}{llllll}21-25 & \square & 36-40 & \square & 51-55 & \square \\ 26-30 & \square & 41-45 & \square & 56-60 & \square \\ 31-35 & \square & 46-50 & \square & 60+ & \square\end{array}$

52. WHERE WERE YOU BORN

In New Zealand

Area

In The Netherlands

Area

In Indonesia

Area

Other (please specify)

53. HOW OLD WERE YOU WHEN YOU CAME TO NEW ZEALAND

Under 10 years old

10 to 20 years old

21 to 30 years old

31 to 40 years old

42 to 50 years old

51 to 60 years old

Over 60 years old

Not applicable

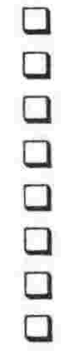


54. WHERE WAS YOUR FATHER BORN

In New Zealand

Area

In The Netherlands

Area

In Indonesia

Area

Other (please specify)

55. WHERE WAS YOUR MOTHER BORN In New Zealand

Area

In The Netherlands

Area

In Indonesia

Area

Other (please specify)

56. WHAT WAS THE RELIGION OF THE HOUSEHOLD IN WHICH YOU GREW UP

No religion

Christian Catholic

Christian Protestant

Other

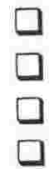

57. WHAT IS YOUR OCCUPATION

58. WHAT IS YOUR MARITAL STATUS

Married

Living with partner

Formerly married

Never married

Other (please specify)

59. WHAT IS YOUR SPOUSE/ PARTNER'S OCCUPATION

60. WHERE WAS YOUR SPOUSE/PARTNER BORN

In New Zealand of Dutch descent

Area

In New Zealand of non-Dutch descent

In The Netherlands

Area 
In Indonesia of Dutch descent

Area

In Indonesia of non-Dutch descent

Area

Other

61. WHAT LANGUAGE/S DOES YOUR SPOUSE PARTNER SPEAK (please tick $A L L$ that apply)

English

Dutch

Other

62. WHERE WERE YOU EDUCATED

Only in New Zealand

Only outside New Zealand

Partly in NZ and partly in the Netherlands

Other (please specify)

\section{PLEASE TICK THE BOXES THAT APPLY TO YOU}

\section{WAS EDUCATED AT}

IN NZ

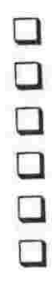

IN THE

NETHERLANDS

Primary School

Secondary School

University

Polytechnic

Apprenticeship

Teacher Training

Other - please specify

In which country

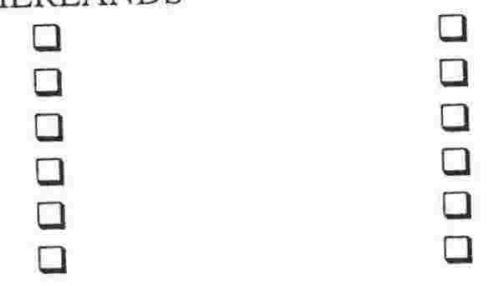

\section{OTHER}

Some of the people who answer this questionnaire do help them fill it out. Could you please tell me

You answered the questionnaire by yourself

Someone helped you answer the questionnaire

In order to interpret the data from this questionnaire as accurately as possible it would be helpful for me to know if you are related to the person who suggested your name to me.

Could you please tell me

You are not related to the person who suggested your name

You are the child of the person who suggested your name

You are the parent of the person who suggested your name

You are the spouse of the person who suggested your name

You are the brother or sister of the person who suggested your name

You are related by marriage to the person who suggested your name

(please specify)

Other family relationship (please specify) 


\section{8}

Yes, I would be interested in attending a seminar about the results of this research

Name:

Address:

And/or Phone

\section{8}

Thank you very much for taking the time to complete this questionnaire. If you have any comments you would like to make, please feel free to use the blank paper at the end of the questionnaire.

In addition to filling out the questionnaire I would be grateful if you could give me some further help.

I hope to get more people to answer this questionnaire and I wonder if you can think of any people who might be willing to fill out the questionnaire for me.

I am looking for people who fall into the following categories:

- Born in the Netherlands and now resident in the Wellington region

- Born in Indonesia of Dutch speaking parents and now resident in the Wellington region

- Born in New Zealand with a Dutch speaking parent or parents and now resident in the Wellington region

If you know any such people whom you think might be prepared to answer the questionnaire could you please write their names in the spaces provided below.

I will write to the person or people you suggest and send them a copy of the questionnaire with the same covering letter that I sent to you and in addition I will tell them that you suggested their names to me as possible respondents to the questionnaire. Because I want to be able to tell people who suggested their name, I will need to know your name also. Could you please give me your name in the space below.

Your name (please print)

Names and addresses of possible respondents (please print)

Name:

Address:

Name:

Address: 
APPENDIX 2

Name:

Address:

Name:

Address:

A later version of this questionnaire asked only for names and addresses of people, now living in the Wellington region, who were born in New Zealand with a Dutch speaking parent or parents 
Linguistics Department

Victoria University of Wellington

Box 600

Wellington

\section{Dear Mr X}

I am a PhD student in the Linguistics Department at Victoria University. My area of research is sociolinguistics which is the study of language use in society. I am doing research into minority immigrant languages in New Zealand. I have collected information from the Cantonese Chinese, Gujarati Indian and Samoan communities and I am now collecting information on language use in the Dutch community in New Zealand.

I am writing to you because Name Surname suggested that you might be able to help me in carrying out this research. Enclosed is a questionnaire that I hope you will fill out for me. Most of the questions are about Dutch and English language use in New Zealand. Also enclosed is a stamped, addressed envelope for you to return the questionnaire in.

If there is sufficient interest I would be more than happy to give a seminar on the results of the research for people who had answered the questionnaire and for any others who were interested. If you would like to attend such a seminar please indicate your interest at the end of the questionnaire and provide a name and contact address or phone number. The seminar would not be held for some months as I would first of all have to collect and process the data.

Complete confidentiality is guaranteed. There is no need for me to know who filled out each questionnaire and you do not need to put your name on the questionnaire unless you wish to attend the seminar. If you do give your name it will not appear in any way in my research.

The results of this research will appear in my $\mathrm{PhD}$ thesis and may appear in journal articles that I may write about this research. I will also discuss the results of this research at academic conferences and in some tutorials and lectures. A copy of the thesis will be lodged with the Victoria University library and thus the results of the research will be available to anyone who wishes to have access to them.

If you have any questions about the research or the questionnaire please feel free to contact me. My home phone number is XXX XXXX.

Yours sincerely

Mary Roberts 


\section{APPENDIX 3}

\section{LISI O FESILI}

Fa'amolemole, fa'asa'o tali e talafeagai.

O fesili nei e fa'atatau i gagana e te tautala ai.

O A NI GAGANA E TE TAUTALA AI? ( $f a$ 'amolemole fa 'asa 'o tali uma e talafeagai)

Samoa

Fa' aperetania

O nisi gagana (fa'amolemole ta'u mai)

2

O LE A LE GAGANA SA E TAUTALA AI MUAMUA?

Samoa

$\mathrm{Fa}^{\prime}$ aperetania

Nisi gagana (fa'amolemole ta'u mai)

O LE A LE GAGANA E TE FA'AAOGAINA I LE TELE O TAIMI?

Samoa

Fa'aperetania

Nisi gagana (fa'amolemole ta'u mai)

O A NISI GAGANA SA E FA'AOGAINA I LE MASINA UA TUANAI?

Leai

Ioe (fa'amolemole tusi mai gagana i le avanoa oi lalo)

O A GAGANA O LO'O E FA'AOGAINA I LE MEA O LO'O E NOFO AI (household)? (fa'amolemole fa'asa'o uma mai gagana e talafeagai)

Samoa

Fa'aperetania

Nisi gagana ( $f a^{\prime}$ amolemole ta'u mai) 
6 O AI ISI TAGATA O OUTOU NONOFO I LE MEA O LO'O E NOFO AI? ( $\mathrm{fa}$ 'amolemole fa 'asa 'o tali uma e talafeagai)

O lou tama

O lou tina

Ava/Tane

O lau fanau

Tagata matutua o lou aiga (e le a'afia ai le tama ma le tina)

Tupulaga talavou (e le a'afia ai lau fanau)

Tagata o loo mautotogi

$\mathrm{O}$ isi (fa'amolemole ta'u mai)

E leai nisi, na'o a'u

7 O LE A LE GAGANA E TE LUA TALANOA AI MA LOU TAMA I LE TELE O TAIMI?

Samoa

Fa'aperetania

$\mathrm{O}$ isi (fa'amolemole ta'u mai)

E le talafeagai pe fetaui

8 O LE A LE GAGANA E TE LUA TALANOA AI MA LOU TINA I LE TELE O TAIMI?

Samoa

Fa'aperetania

$\mathrm{O}$ isi (fa'amolemole ta'u mai)

E le talafeagai pe fetaui

9 O LE A LE GAGANA E TE LUA TALANOA AI MA LOU TO'ALUA/ PO'O LAU PAGA I LE TELE O TAIMI?

Samoa

Fa'aperetania

$\mathrm{O}$ isi (fa'amolemole ta'u mai)

E le talafeagai pe fetaui

10 O LE A LE GAGANA E TE TALANOA AI I LAU FANAU I LE TELE O TAIMI?

Samoa

Fa'aperetania

$\mathrm{O}$ isi (fa'amolemole ta'u mai)

E le talafeagai pe fetaui

11 E TE TAUTALA I LE GAGANA SAMOA I FAFO ATU O LOU AIGA?

Leai

Ioe

(fa'amolemole tali le fesili 14) 
Uo matou te tupulaga

Uo matutua

Tagata matutua o lou aiga

Tamaiti (e le o la'u fanau)

O le faife'au

Oi latou fa'ato'a taunu'u mai i le atunuu (new immigrants)

$\mathrm{O}$ isi (fa'amolemole ta'u mai)

13 O FEA E TE TALANOA AI I LE GAGANA SAMOA I FAFO ATU O

LOU AIGA? (fa 'amolemole fa 'asa 'o uma tali e talafeagai)

I so'o se fa'atasiga/fa'afiafiaga/mafutaga

I le galuega

I le lotu

$\mathrm{O}$ isi (fa'amolemole ta'u mai)

Afai na e fanau mai i Niusila, fa'amolemole tali fesili amata mai i le 14 e o'o atu i le 20. Afai e te l'ei soifua mai i totonu o Niusila, tali mai i le fesili e 21.

\section{PE SA I AI SE ISI NA A'OA'O INA OE I LE FAITAU MA LE TUSITUSI I LE GAGANA SAMOA?}

Leai

Ioe

Tama o ou matua

Tina o ou matua

O lo'u tama

O lo'u tina

O le uso o lo'u tama po'o le tuagane o lo'u tina

O le uso o lo'u tina po'o le tuafafine o lo'u tama

O lo'u uso tama matua

O lo'u uso teine matua

$\mathrm{O}$ isi (fa'amolemole ta'u mai)

15 PE SA E A'OGA I SE A'OGA O LE GAGANA SAMOA PO'O SE VASEGA SAMOA I NIU SILA?

Leai $\quad \square \quad$ (tali mai le fesili 21)

Ioe

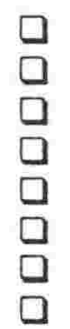

O LE A LE ITUAIGA A'OGA?

A'oga sa faia i se pito nu'u (community)

A'oga sa faia e se Ekalesia

A'oga sa faia e nisi 
Lalo ifo o le tolu itula

Tolu itula

Sili atu i le tolu itula

18 SA E ALU FAALAUSOSO'O I LE A'OGA?

Ioe

Leai

19 E TUSA O LE A LOU MATUA NA AMATA AI ONA E ALU I LEA

A'OGA? (fa'amolemole tusi mai lou matua, i le avanoa o lo'o i lalo) tausaga lou matua

20 O LE A LE UMI NA E ALU AI I LEA A'OGA? (fa'amolemole fa'atumu mai le avanoa o lo'o i lalo ifo)

Po'o le masina

Po'o le tausaga

I LE VAEGA O FESILI O LO'O SOSO'O AI, O LO'O FESILIGIA AI LOU FA'AAOGAINA O LE GAGANA SAMOA MA LE GAGANA

FA'APERETANIA.

21 FA'AMOLEMOLE FA'ASA'O MAI LE AVANOA E FA'AMATALA LELEI MAI AI LOU ILOA I LE FA'AAOGAINA O NEI GAGANA

$\begin{array}{lll}\text { Gagana Samoa } & \text { Fa'aperetania } & \text { Gagana Samoa } \\ \text { fa'aaoga i aso uma } & & \text { fa'aaloalo }\end{array}$

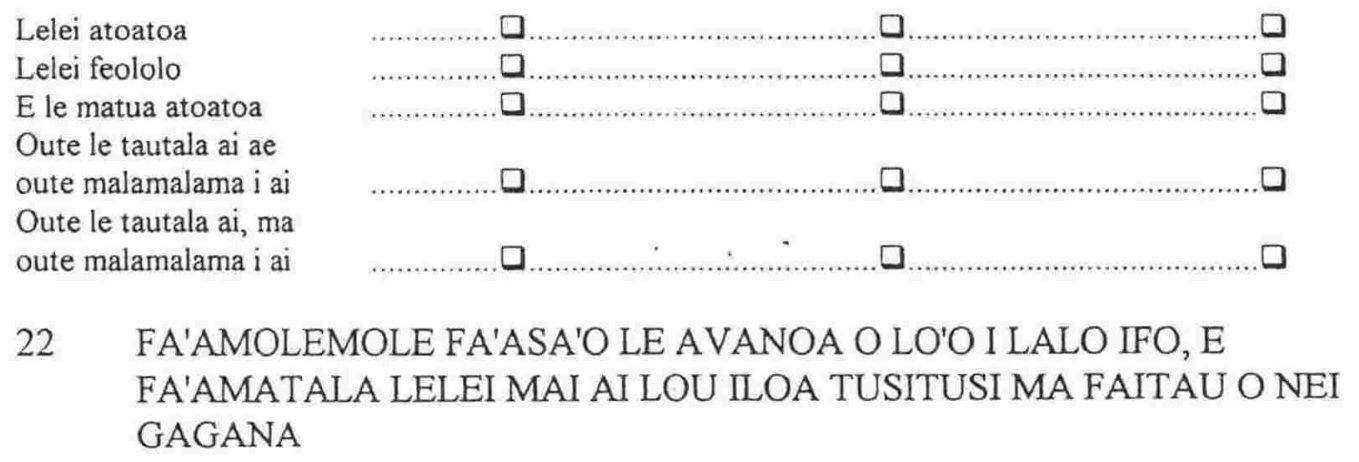

E faigofie ona ou tusitusi

E le faigofie tele ia te au

E mafai, ae le faigofie tele

E mafai ona faitau, ae le mafai ona 'ou tusitusi.

E le mafai ona ou faitau, fa'apena foi ma la'u tusitusi.

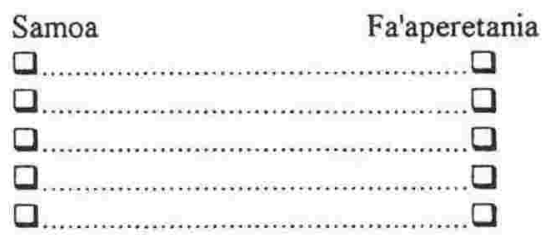




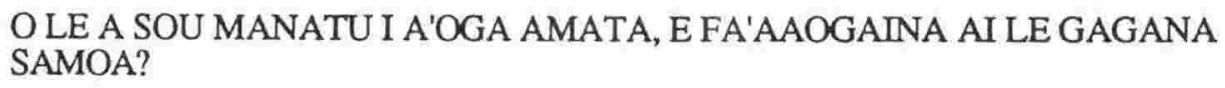

O se mea lelei

E le o se mea lelei

Oute le mautinoa

FESILI E UIGA I LAU FANAU (fa'amolemole, va'ai i le fesili numera 31 pe afai e le'i i ai sau fanau)

24 E TO'A FIA LAU FANAU?(fa'amolemole tusi mai i le avanoa oi lalo ifo) tamaititi teineiti

(Afai e to'atasi lau tama, fa'amolemole tali le fesili 25 ona si'i lea i le fesili 28.)

25 O LE A LE MATUA O LAU TAMA MATUA ( $f a$ 'amolemole tusi mai $i$ le a avanoa $o$ lo'o i lalo ifo)

tausaga le matua

26 O LE A LE MATUA O LAU TAMA LATTTTI? (fa'amolemole tusi mai i le avanoa o lo'o i lalo ifo) tausaga le matua

O A GAGANA E TAUTALA AI LAU TAMA LA'TTTTI? (fa'amolemole fa'asa'o uma pusa e talafeagai)

O lau tama:

E la'ititi tele, e lei mafai ona tautala

E tautala i le gagana Samoa

E malamalama i le gagana Samoa, ae le tautala ai

E tautala i le gagana fa'aperetania

E malamalama i le gagana fa'aperetania, ae le mafai ona tautala ai

28 O A GAGANA E TAUTALA AI LAU TAMA MATUA?

O lau tama:

( $f a$ 'amolemole fa'asa'o uma mai tali e talafeagai)

E laititi tele, e lei mafai ona tautala

E tautala i le gagana Samoa

E malamalama i le gagana Samoa, ae le mafai ona tautala ai

E tautala i le gagana fa'aperetania

E malamalama i le gagana fa'aperetania, ae le mafai ona tautala ai 
Leai, e l'ei o'o lava i ai

(fa'amolemole tali le

O lo'o l'aiti tele, s'ei matutua ona auina lea i le a'oga Samoa

Sa masani ai, ae ua le toe o

Ioe

30 O LE A LE MAFU'AGA NA AUINA AI LAU TAMA I LE A'OGA O LO'O A'OA'OINA AI LE GAGANA SAMOA?

Ina ia mafai ona a'oa'o le gagana Samoa

Ina ia mafai ona iloa tu ma aganu'u fa'asamoa

E tutusa uma le taua o tali e lua muamua

O nisi mafu'aga (fa'amolemole fa'amatala mai)

31 E TE MANATU E TATAU ONA A'OA'OINA LE GAGANA SAMOA I A'OGA FA'ALEMALO?

Ioe

Leai

Le mautinoa

32 PE TATAU I A'OGA I P'TTONUU (community) MOLE GAGANA SAMOA E PEI O A'OGA AMATA, ONA MAUA MAI SINA FESOASOANI TAU TUPE MAI ALAGATUPE A LE MALO?

loe

Leai

Le mautinoa

33 E TE MANATU E TAUA LE FA'AOLAOLAINA O LE GAGANA SAMOA I TOTONU O NIU SILA ?

$\begin{array}{ll}\text { Ioe } & \square \\ \text { Leai } & \square \\ \text { Le mautinoa } & \square\end{array}$ 
34 E TE MANATU E TAUA I TAGATA SAMOA O LO'O NONOFO I NIU SILA, ONA IAI SE LAGONA O I LATOU O TAGATA "SAMOA NIU SLA"? (Samoan New Zealand Community)

Ioe

Leai

Le mautinoa

35 E TE MANATU E TATAU I TAGATA SAMOA O LOO NONOFO I NIU SILA, ONA FA'AGALO O I LATOU O SAMOA, AE MANATU O I LATOU O TAGATA NIU SILA?

Ioe

Leai

Le mautinoa

O fesili nei e fa'atatau ia 'oe lava. O tali o nei fesili e mana'omia aua le

fa'alautele ina ma le fa'amanino ina lelei o sue'su'ega pe a tu'u fa'atasi. Pei o fesili uma ua tu'uina atu, ua na'o 'oe ma le ua fesiligia 'oe o le a la iloa.

36 ITU'AIGA

Tane

Fafine

TAUSAGA O LOU OLAGA
$21-25$
$\begin{array}{ll}\square & 36-40 \\ \text { ㅁ } & 41-45\end{array}$
$\begin{array}{ll}\square & 36-40 \\ \square & 41-45\end{array}$
$26-30$
$51-55$
$56-60$
$31-35$

$\begin{array}{ll}\square & 51-55 \\ \square & 56-60 \\ \square & 60 \text { mona tupu }\end{array}$

口 $46-50$

38 OFEA NA E FANAU AI?

I totonu o Niu Sila

I totonu o Samoa

$\mathrm{O}$ se isi atunuu (fa'amolemole ta'u mai)

39 O LE FLA O OU TAUSAGA NA E MALAGA MAI AI I NIU SILA?

Lalo ifo o le 10 tausaga le matua

10 i le 20 tausaga lou matua

21 i le 30 tausaga lou matua

31 i le 40 tausaga lou matua

41 i le 50 tausaga lou matua

51 i le 60 tausaga lou matua

Luga atu o le 60 tausaga lou matua

(fa'amolemole fa'aauau i le fesili 41) 
O totonu o Niu Sila

O totonu o Samoa

O seisi atunu'u (fa'amolemole ta'u mai)

41 O FEA LE ATUNU'U NA FANAU AI LOU TINA?

O totonu o Niu Sila

O totonu o Samoa

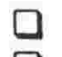

O seisi atunu'u (fa'amolemole ta'u mai)

42 O LE A LAU GALUEGA? (fa'amolemole tusi mai i le avanoa oi lalo)

43

UA FAI SOU TO'ALUA FA'AIPOIPO, PO'O E NOFO FA'APOULIULI?

Leai $\quad$ (fa'amolemole fa'aauaua i le fesili 47)

Ioe

O nisi itu (fa'amolemole ta'u mai)

O LE A LE GALUEGA A LOU TO'ALUA? (fa'amolemole tusi mai i le avanoa oi lalo )

45 O A GAGANA E TAUTALA AI LOU TO'ALUA? (fa'amolemole fa'asao' uma mai tali e talafeagai)

Samoa

$\mathrm{Fa}^{\prime}$ apereteania

O nisi (fa'amolemole ta'u mai)

46 OFEA SA E A'OGA AI?

O totonu lava o Niu Sila

O atunu'u i fafo atu o Niu Sila

(fa'amolemole ta'u mai)

Sa ou a'oga i totonu o Niu Sila ina ua ou matua

$\mathrm{O}$ le a lou matua? tausaga lou' matua 


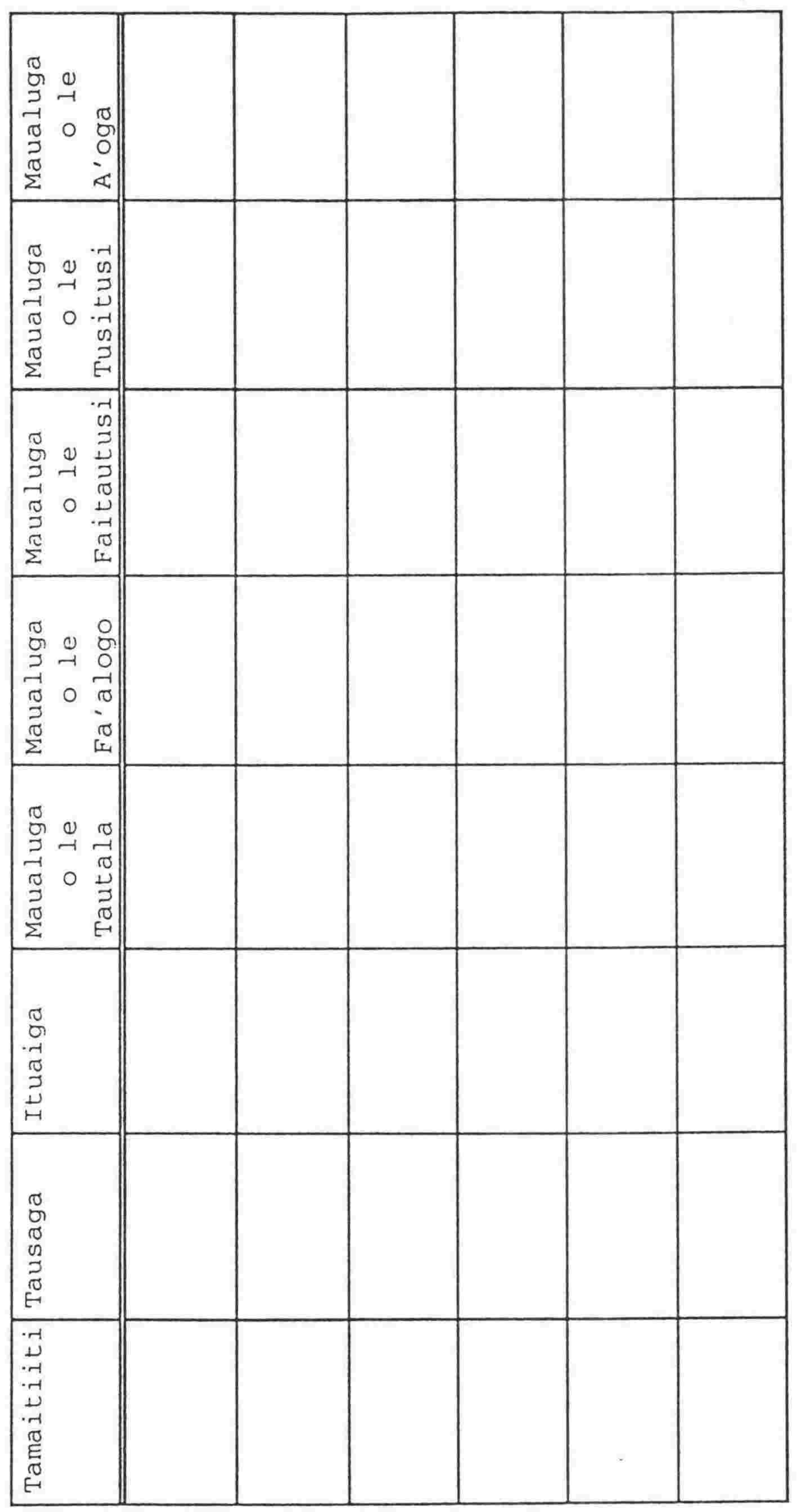


47 O LE A LE MAUALUGA O LE AO'AOGA SA O'O I AI LOU A'OA'OINA?

Totonu o Niu Sila

Fafo atu o Niu Sila

(fa'amolemole tusi mai le atunu'u)

IGOA O LE ATUNU'U

A'oga tulaga lua

A'oga maualuga / Kolisi

Iunivesete

Politekeniki/Polytechnic

Apprentice

A'oga Fa'afai'a'oga

O nisi a'oga a'amolemole ta'u mai)

O le a le ituaiga

O fea le atunu'u 


\section{QUESTIONNAIRE}

Please put a tick beside your answers

To start with here are some questions about the languages you speak

1 WHAT LANGUAGE/S DO YOU SPEAK? (Please tick $A L L$ that apply)

Samoan

English

Other (please specify)

2 WHICH LANGUAGE DID YOU SPEAK FIRST WHEN YOU WERE LEARNING TO TALK?

Samoan

English

Other (please specify)

3 WHICH LANGUAGE DO YOU USE MOST ?

Samoan

English

Other (please specify)

4 WHAT OTHER LANGUAGES HAVE YOU USED

IN THE LAST MONTH ?

No

Yes (please write down the language/s in the space below)

5 WHAT LANGUAGE/S DO YOU SPEAK AT HOME? (Please tick ALL that apply)

Samoan

English

Other (please specify)

6 WHO ARE THE OTHER MEMBERS OF YOUR HOUSEHOLD? (Please tick $A L L$ that apply)

Your Father

Your Mother

Spouse / Partner

Children

Older relatives (not father or mother)

Younger relatives (not children)

Flatmates

Other (please specify)

No other members of my household

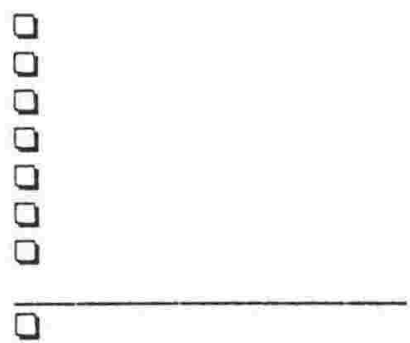


WHAT LANGUAGE DO YOU SPEAK WITH YOUR FATHER MOST OF THE TIME ?

Samoan

English

Other (please specify)

Not applicable

$\square$

a

8 WHAT LANGUAGE DO YOU SPEAK WITH YOUR MOTHER MOST OF THE TIME?

Samoan

English

Other (please specify)

Not applicable

$\square$

$\square$

可

9 WHAT LANGUAGE DO YOU SPEAK WITH YOUR SPOUSE / PARTNER MOST OF THE TIME ?

Samoan

English

Other (please specify)

Not applicable

$\square$

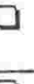

10 WHAT LANGUAGE DO YOU SPEAK WITH YOUR CHILDREN MOST OF THE TIME ?

Samoan

English

Other (please specify)

Not applicable

$\square$

口

a

11 DO YOU SPEAK SAMOAN OUTSIDE THE HOME ?

No

Yes

$\square$ (please go to question 14 )

12 WHO DO YOU SPEAK SAMOAN TO OUTSIDE THE

HOME ? (Please tick ALL that apply)

Friends my own age

Older friends

Older relatives

Younger children (other than your own-children)

The priest

New immigrants

Other (please specify)

13 WHERE DO YOU SPEAK SAMOAN OUTSIDE THE HOME ?

(Please tick $A L L$ that apply)

At social gatherings

At work

At Church

Other (please specify)

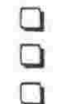


If you were born in New Zealand please answer questions 14 to 20 . If you were not born in New Zealand please go to question 20.

44 DID ANYBODY TEACH YOU TO READ AND WRITE SAMOAN?

No

$\begin{array}{ll}\text { Yes } & \text { Grandfather } \\ \text { Grandmother } & \\ \text { Father } & \\ \text { Mother } & \\ \text { Uncle } & \\ \text { Aunt } & \\ \text { Older Brother } \\ \text { Older Sister } \\ \text { Other (please specify) }\end{array}$

15 IN NZ, HAVE YOU ATTENDED ANY KIND OF SAMOAN LANGUAGE SCHOOL OR CLASS?
No
$\square$ (please go to question 21)
Yes

16 WHAT KIND OF SCHOOL WAS IT ?

Organised by the community

Organised by the Church

Other (please specify)

17 HOW MANY HOURS A WEEK DID YOU GO TO THE SCHOOL OR CLASSES?

Under three hours

Three hours

More than three hours

$\square$

18 DID YOU GO REGULARLY?

Yes

No

$\square$

$\square$

19 ABOUT HOW OLD WERE YOU WHEN YOU STARTED TO GO TO THE SCHOOL? (please write your answer in the space below)

years old

20 FOR ABOUT HOW LONG DID YOU GO TO THE SCHOOL? (please fill in the relevant space below)

About

months

About

years 
IN THE NEXT SECTION YOU ARE ASKED ABOUT SAMOAN AND ENGLISH

21 PLEASE TICK THE BOX THAT BEST DESCRIBES YOUR SPEAKING SKILLS FOR EACH LANGUAGE

Everyday Samoan English Formal Samoan

Fluent

Fairly fluent

Not very fluent

I can't speak it but I can understand it

I can't speak or understand it

22 PLEASE TICK THE BOX THAT BEST DESCRIBES YOUR WRITING AND READING SKILLS FOR EACH LANGUAGE

Samoan English

Can write easily

Can write fairly easily

Can write but only with difficulty

Can't write but I can read

I can't read or write it

23 WHAT DO YOU THINK ABOUT SAMOAN LANGUAGE NESTS FOR CHILDREN ?

They are a good idea

They are not a good idea

Not sure

CHILDREN (please go to question 31 if you do not have any children)

24 HOW MANY CHILDREN DO YOU HAVE ? (please write in the space below) child

$\mathrm{OR}$ children

(If you have only got one child please answer question 25 then go to question 28).

25 HOW OLD IS YOUR OLDEST CHILD? (please write in the space below)

years old 
(Please tick $A L L$ that apply)

My youngest child is too young to speak

S/he speaks Samoan

S/he can understand Samoan but can't speak it

S/he speaks English

S/he can understand English but can't speak it

2 (8) WHAT LANGUAGES DOES YOUR OLDEST CHILD USE ?

(Please tick $A L L$ that apply)

My oldest child is too young to speak

S/he speaks Samoan

S/he can understand Samoan but can't speak it

S/he speaks English

S/he can understand English but can't speak it

29 DO YOUR CHILDREN GO TO A SAMOAN SCHOOL?

(For example; Language Nest/ Pre-school, Pastor's Class, Sunday School, Primary School, College, University)

No they have never attended (please go to question 31)

They are too young now but will go when they are old enough They used to go but don't now Yes

30 WHY DECIDE TO SEND YOUR CHILDREN TO THE SAMAON SCHOOL? Mainly so they could learn Samoan

Mainly so they could come into contact with Samoan culture

Both are equally important

Some other reason (please specify)

34 DO YOU THINK CHILDREN OUGHT TO BE ABLE TO STUDY SAMOAN AT AN ORDINARY STATE SCHOOL?

Yes

No

Not sure 
32 DO YOU THINK THAT COMMUNITY RUN SCHOOLS LIKE THE AOGA AMATA SHOULD RECEIVE SOME FORM OF GOVERNMENT FUNDING ? Yes

No

Not sure

33 DO YOU THINK IT IS IMPORTANT TO KEEP SAMOAN AS A LIVING LANGUAGE IN NEW ZEALAND Yes

No

Not sure

34 DO YOU THINK IT IS IMPORTANT FOR THE SAMOAN PEOPLE OF NEW ZEALAND TO SEE THEMSELVES AS PART OF AN SAMOAN / NEW ZEALAND COMMUNITY Yes

No

Not sure

35 DO YOU THINK THE SAMOAN PEOPLE IN NEW ZEALAND SHOULD FORGET ABOUT BEING SAMOAN AND SEE THEMSELVES SIMPLY AS NEW ZEALANDERS

Yes

No

Not sure

Finally some questions about you. These answers are needed only to enable us to process the data effectively. Like the rest of the questionnaire, the answers are completely confidential.

36 SEX

Male

Female

$37 \quad$ AGE

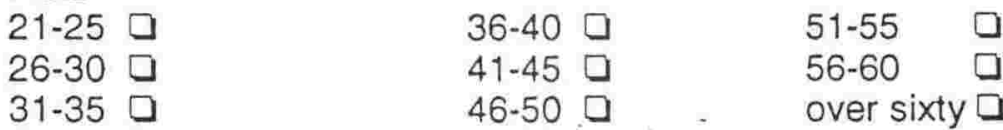

38 WHERE WERE YOU BORN ?

In New Zealand $\square$ (please go to question 40)

In Samoa

Other (please specify)

39 HOW OLD WERE YOU WHEN YOU CAME TO NZ ?

Under 10 years old

10 to 20 years old

21 to 30 years old

31 to 40 years old

41 to 50 years old

51 to 60 years old

Over 60 years old 
40 WHERE WAS YOUR FATHER BORN ?

In New Zealand

In Samoa

Other (please specify)

41 WHERE WAS YOUR MOTHER BORN ?

In New Zealand

In Samoa

Other (please specify)

42 WHAT IS YOUR OCCUPATION ? (please write in the space below)

43 ARE YOU MARRIED OR LIVING WITH A PARTNER ?

No

$\square$ (please go to question 46$)$

Yes

Other (please specify)

44 WHAT IS YOUR SPOUSE/PARTNER'S OCCUPATION? (please write in the space below)

45 WHAT LANGUAGE/S DOES YOUR SPOUSE / PARTNER

SPEAK? (Tick more than one choice if necessary)

Samoan

English

Other (please specify)

46 WHERE WERE YOU EDUCATED ?

Only in New Zealand

Only outside New Zealand

(please specify what country)

In New Zealand after a certain age

What age?

years 
47 WHAT LEVEL OF SCHOOLING DID YOU COMPLETE?

IN NZ

$$
\text { (please name the country) }
$$

COUNTRY NAME

Primary school

Secondary school

University

Polytechnic

Apprenticeship

Teacher Training

Other (please specify)

What kind of schooling

In which country

Thank you for taking the time to do this questionnaire.

Please feel free to write any comments you may have in the space below. 


\section{BIBLIOGRAPHY}

The first section of the bibliography contains books, theses and articles from books. The second section of the bibliography contains journal articles.

ACTON, JOHN EMERICH DALBERG-ACTON, FIRST BARON ACTON, FIGGIS J.N. and R.V. LAURENCE (eds)

The History of Freedom and Other Essays. London: Macmillan and Co, Ltd.

'AIPOLO, ANAHINA

Profile of language maintenance and shift within the Tongan speech community in Wellington. Unpublished M.A. Thesis. Victoria University of Wellington.

ADAMS, KAREN L. and DANIEL T. BRINK

"Joshua A. Fishman on Language Planning" in David F. Marshall (ed.) Language Planning: Focusschrift in honor of Joshua A. Fishman. Amsterdam/Philadelphia :John Benjamins Publishing Company.

AIREY, WILLIS

A Learner in China. Christchurch: The Caxton Press and the Monthly Review Society.

AKENSON, DONALD HARMAN

"Immigration and Ethnicity in New Zealand and the U.S.A. - The Irish Example" in Jock Phillips (ed) New Worlds? The Comparative History of New Zealand and the United States. Wellington: NZ-US Education Foundation Stout Research Centre.

ALLADINA, SAFDER and VIV EDWARDS (eds)

Multilingualism in the British Isles: Africa, The Middle East \& Asia. London and New York: Longman.

ALTINKAYA, JUDY

1998

"False Hopes: English for effective resettlement" in Rolf E Panny (ed) People People People. Christchurch: New Zealand Federation of Ethnic Councils (Inc.).

ANNAMALAI

"India: Language Situation" in R.E. Asher and J. M. Y. Simpson (eds) The Encyclopedia of Language and Linguistics. Oxford: Pergamon Press.

Blessed With Bilingual Brains: Education of Immigrant Children with English as a Second Language. Pacific Educational Press, Faculty of Education, UBC. 
The Encyclopedia of Language and Linguistics. Oxford: Pergamon Press.

BALDAUF, Jr RICHARD

"Language Planning and Education" in Richard Baldauf, Jr and Allan Like (eds) Language planning and education in Australasia and the South Pacific. Clevedon: Multilingual Matters Ltd.

BALDAUF, Jr RICHARD

"Education and Language Planning in the Samoas" in Richard Baldauf, Jr and Allan Like (eds) Language planning and education in Australasia and the South Pacific. Clevedon : Multilingual Matters Ltd.

BALDAUF, Jr RICHARD and ALLAN LUKE

Language planning and education in Australasia and the South Pacific. Clevedon : Multilingual Matters Ltd.

BANKS, JAMES A.

Multiethnic education: theory and practice, Boston: Allyn and Bacon.

BANDURA, ALBERT

"Conclusion: Reflections on Nonability Determinants of Competence" in Robert J. Sternberg and John Kolligan, Jr (eds) Competence Considered. New Haven and London: Yale University Press.

BARRINGTON, JOHN MICHAEL

Education and National Development in Western Samoa, unpublished paper held in V.U.W. library

BARNARD, F.M.

Herder's Social and Political Thought. Oxford: Clarendon Press.

BARNARD, F.M.

J.G. Herder on Social and Political Culture. Cambridge at the University Press.

BARNARD, F.M.

Self Direction and Political Legitimacy: Rousseau and Herder. Oxford: Clarendon Press. 
A Small Price to Pay: Refugees from Hitler in New Zealand, 1936-46. Wellington: Allen \& Unwin Historical Branch.

Facing the Past: looking back at refugee childhood in New Zealand 1940s - 1960s. Wellington: Allen \& Unwin New Zealand Limited in association with the Port Nicholson Press.

BEAGLEHOLE, T. H.

"The Missionary Schools, 1816-1840" in John Ewing and Jack Shallcrass (eds) Introduction to Maori Education. Wellington: New Zealand University Press.

BEEBY, C.E.

The Biography of an Idea. Wellington: New Zealand Council for Educational Research.

BELL, DANIEL

"Ethnicity and Social Change" in N. Glazer and D. Moynihan (eds) Ethnicity: Theory and Experience. Cambridge: Harvard University Press.

BENTON, RICHARD A.

The Flight of the Amokura: Oceanic Languages and Formal Education in the South Pacific. Wellington: New Zealand Council for Educational Research.

BENTON, RICHARD A.

"Language Policy in New Zealand: defining the ineffable" in Michael Herriman and Barbara Burnaby (eds) Language Policies in English-Dominant Countries. Clevedon: Multilingual Matters.

BERLIN, I.

Vico and Herder. London: The Hogarth Press.

"Multiculturalism and Education of Immigrants in Canada" in J. Bhatnagar (ed) Educating Immigrants. London: Croom Helm.

Educating Immigrants. London: Croom Helm.

The assimilation of immigrants in Australian and New Zealand: an annotated bibliography. Canberra: Department of Demography, Research School of Social Studies. ANU. 
BORRIE, W.D. Immigration to New Zealand 1854 - 1938, Canberra: Demography program, Research School of Social Sciences Australian National University.

BOURHIS, RICHARD YVON

1979

"Language in Ethnic Interaction: A Social Psychological Approach" in Howard Giles and

Bernard saint-Jacques (eds) Language and Ethnic Relations. Oxford : Pergamon Press.

BRADFORD, HON. MAX

"Keynote Address" in Rolf E Panny (ed), People People People. Christchurch: New Zealand Federation of Ethnic Councils (Inc.).

BRASS ,PAUL R.

The New Cambridge History of India. Cambridge: Cambridge University Press.

BRENNAN, M.C.

"A Comparison of Two Survey Methods: Face-to-Face interview versus Self-Completion Questionnaire" in Research Report 49. Palmerston North: Market Research Centre. Massey

University.

BRENNAN, M.C.

"The Effectiveness of Some Procedures for Improving Mail Survey Returns" in Research Report 51. Palmerston North: Market Research Centre. Massey University.

BROOKING, TOM and ROBERTO RABEL

"Neither British nor Polynesian: A Brief History of New Zealand's Other Immigrants" in Stuart Greif (ed) Immigration and National Identity in New Zealand, Palmerston North: The Dunmore Press.

BURNLEY, IAN, SOL ENCEL and GRANT McCALL (eds)

Immigration and ethnicity in the 1980s. Melbourne: Longman Cheshire.

CAMPBELL, A.E.

Educating New Zealand. Wellington: Department of Internal Affairs.

CARTER, IAN

Gadfly: The Life and Times of James Shelley. Auckland: Auckland University Press in association with the Broadcasting History Trust.

CHENG, ROBERT L.

"Teaching Chinese Outside China" in Bernard Spolsky and Robert L. Cooper (eds) Case Studies in Bilingual Education. Rowley (Mass): Newbury House. 
Multilingual Australia. Melbourne: River Seine Publications.

CLYNE, MICHAEL

"Language Maintenance and Language Shift: Some Data from Australia" in Nessa Wolfson and Joan Manes (eds) Language of Inequality. Berlin: Walter de Gruyter \& Co..

CLYNE, MICHAEL (ed)

An Early Start: Second Language at Primary School. Melbourne: River Seine Publications.

CLYNE, MICHAEL

Community Languages: The Australian Experience, Cambridge, England; Melbourne:

Cambridge University Press.

CLYNE, MICHAEL

"Linguistics and Sociolinguistics Aspects of Language Contact, Maintenance and Loss: Towards a Multifacet Theory" in Maintenance and Loss of Minority Languages, Willem Fase et al (eds). Amsterdam: John Benjamins Publishing Company.

In J.A. Fishman and J. Cobarrubias (eds) Progress in Language Planning: International

Perspectives. Berlin: Mouton Publishers.

COGLE VAN SCHIE

"The Dutch in New Zealand" in Hirsch W. Living Languages: Bilingualism and community languages in New Zealand. Auckland: Heinemann in association with the Office of the Race Relations Conciliator:

COHEN, A.D.

A Sociological Approach to Bilingual Education. Rowley, Mass: Newbury House Publishers.

CORSON, DAVID

Language, Minority Education and Gender: Linking Social Justice and Power. Clevedon: Multilingual Matters. Toronto: Ontario Institute for Studies in Education.

CROWLEY, TONY

Language and History: theories and texts. London: Routledge.

CUMMING, IAN and ALAN CUMMING

History of State Education in New Zealand 1840 - 1975. Wellington: Pitman Pacific Books. 
Samoa mo Samoa; The Emergence of an Independent State of Western Samoa. Melbourne: Oxford University Press.

DAY, PATRICK

The Radio Years: A History of Broadcasting in New Zealand. Volume One. Auckland. Auckland University Press in association with the Broadcasting History Trust.

de LEPERVANCHE, MARIE M

"Women, Nation and the State in Australia" in Nira Yuval-Davis and Floya Anthias (eds),

Women - Nation - State. Houndmills: Macmillan Press Ltd.

DILLMAN, DON A.

Mail and Telephone Surveys: the total design method. New York: Wiley.

DURANTI, ALESSANDRO

From Grammar to Politics: Linguistic Anthropology in a Western Samoan Village. Berkeley: University of California Press.

EAGLESON, ROBERT D., R. WHITE and C. BENTLEY

Language and Literature in the Formation of National and Cultural Communities. Australian Universities Language and Literature Association.

FAIRBURN, MILES

The Ideal Society and its Enemies. Auckland: Auckland University Press.

FASE, WILLEM, KOEN JASPAERT and SJAAK KROON

Maintenance and Loss of Minority Languages. Amsterdam : John Benjamins Publishing Company.

FASOLD, RALPH W.

The Sociolinguistics of Language. Oxford. Blackwell.

FAWCETT, JAMES T. and BENJAMIN V. CARINO (eds)

Pacific Bridges; The New Immigration from Asia and the Pacific Islands. Staten Island: Center for Migration Studies.

Language in the U.S.A.. Cambridge: Cambridge University Press. 
"A Koorie view" in David Goodman et al Multicultural Australia: The Challenges of Change. Newham, Vic.: Scribe in Association with Australian Centre, University of Melbourne.

FISHMAN, J.A.

Language Loyalty in the United States. The Hague: Mouton.

FISHMAN, J.A.

"Language maintenance and language shift as a field of inquiry" in Language Loyalty in the United States. The Hague: Mouton.

FISHMAN, J.A. (ed)

Advances in the Sociology of Language. The Hague: Mouton.

FISHMAN, J.A.

Languctge in Sociocultural Change; Essays by Joshua A. Fishman, Anwar S. Dil (ed).

California: Sanford University Press.

FISHMAN, J.A. (ed.)

Readings in the Sociology of Language. Mouton: Paris.

FISHMAN, J.A. (ed.)

Advances in Language Planning. The Hague: Mouton.

FISHMAN, J.A.

"Language Planning and Language Planning Research: the State of the Art" in J.A. Fishman (ed) Advances in Language Planning. The Hague: Mouton.

FISHMAN, J.A.

"Language Modernization and Planning in Comparison with other Types of National Modernization and Planning" in J.A. Fishman (ed) Advances in Language Planning. The Hague: Mouton.

FISHMAN, JOSHUA A. and JUAN COBARRUBIAS (eds)

Progress in Language Planning: International Perspectives. Berlin: Mouton Publishers.

FISHMAN, J.A. et al

The Rise and Fall of the Ethnic Revival: Perspectives on Language and Ethnicity. Berlin: Mouton. 
FISHMAN, J.A.

Language and Ethnicity in Minority Sociolinguistic Perspective. Clevedon Philadelphia:

Multilingual Matters Ltd.

FISHMAN, J.A.

Reversing Language Shift. Clevedon: Multilingual Matters.

FISHMAN, J.A. and V.C. NAHIRNY "The Ethnic Group School and Mother Tongue

maintenance" in J.A. Fishman (ed) Language Loyalty in the United States. The Hague: Mouton.

FREEMAN, DEREK

Margaret Mead and Samoa: The Making and Unmaking of an Anthropological Myth. Canberra:

Australian National University Press.

GELLNER, ERNEST

1983

Nations and Nationalism. Oxford : Basil Blackwell.

GELLNER, ERNEST

Plough, Sword and Book: the Structure of Human History. London: Paladin.

GILES, HOWARD

"Ethnicity markers in speech" in Klaus R. Scherer and Howard Giles (eds) Social Markers in Speech. Cambridge: Cambridge University Press. Paris: Editions de la Maison des Sciences de l'Homme.

GILES, HOWARD and N. COUPLAND

Language: Contexts and Consequences. Pacific Grove, CA: Brooks/Cole Publishing Company.

GILITON, R.L.O.

Fiji's Indian Migrants. Melbourne: Oxford University Press.

GLAZER NATHAN

"The Process and Problems of Language-Maintenance: an integrative review" in J.A. Fishman (ed) Language Loyalty in the United States. The Hague: Mouton.

GLAZER NATHAN

Ethnic Dilemmas 1964 - 1982. Cambridge, Massachusetts: Harvard University Press.

GLAZER NATHAN and DANIEL P. MOYNIHAN

Ethnicity: Theory and Experience. Cambridge: Harvard University Press. 
Multicultural Australia: The Challenges of Change. Newham, Vic.: Scribe in Association with Australian Centre, University of Melbourne.

GORDON, MILTON M.

"Toward a General Theory of Racial and Ethnic Group Relations" in N. Glazer and D. Moynihan (eds) Ethnicity: Theory and Experience. Cambridge: Harvard University Press.

GRAFF, GERALD

Professing Literature: An Institutional History. Chicago and London: The. University of Chicago Press.

"The Transmission of Cultural heritages: The Case of the Irish and the Italians" in N. Glazer and D. Moynihan (eds) Ethnicity: Theory and Experience. Cambridge: Harvard University Press.

GRILLO, R.D.

Dominant languages: Language and Hierarchy in Britain and France. Cambridge: Cambridge University Press.

GUDYKUNST, WILLIAM B. and STELLA TING-TOOMEY

"Ethnic Identity, Language and Communication Breakdowns" in Howard Giles and W. Peter Robinson (eds) Handbook of Language and Social Psychology. Chichester: John Wiley and Sons.

GUMPERZ, JOHN J.

"Types of Linguistic Communities" in J.A. Fishman (ed) in Readings in the Sociology of Language. Paris: Mouton.

GUSTAFSON, BARRY

From the Cradle to the Grave: A biography of Michael Joseph Savage. Auckland: Reed Methuen.

HARRIS, ROY AND TALBOT J. TAYLOR

Landmarks in Linguistic Thought. London: Routledge.

HARRISON, BARBARA

Rakaumanga School: A Study of Issues in Bilingual Education. Centre for Maaori Studies and Research, University of Waikato.

HAYDEN, ROBERT G.

"Some community dynamics of language maintenance" in Joshua Fishman (ed) Language Loyalty in the United States. The Hague: Mouton 
"Bilingual Education and a National Language Policy" in James E. Alatis (ed) International Dimensions of Bilingual Education. Washington: Georgetown University Press.

HEATH, SHIRLEY BRICE

"English in our language heritage" in Charles A. Ferguson and Shirley Brice Heath Language in the U.S.A. Cambridge: Cambridge University Press.

HEATH, SHIRLEY BRICE and CHARLES FERGUSON

"Introduction" in Charles A. Ferguson and Shirley Brice Heath Language in the U.S.A.. Cambridge: Cambridge University Press.

HEATH, SHIRLEY BRICE and FREDERICK MANDABACH

"Language Status Decisions and the Law in the United States in J.A. Fishman and J. Cobarrubias (eds) Progress in Language Planning: International Perspectives. Berlin: Mouton Publishers.

HENDERSON, ANN

1998

"Politics and Policies: New Zealand immigration" in Rolf E Panny (ed) People People People. Christchurch: New Zealand Federation of Ethnic Councils (Inc.).

HERDER, J

"Essay On The Origin Of Language" in Herder on Social and Political Culture translated and edited by F.M. Barnard. Cambridge: Cambridge University Press.

HERRIMAN, MICHAEL

"Language Policy in Australia" in Michael Herriman and Barbara Burnaby (eds) Language Policies in English-Dominant Countries. Clevedon: Multilingual Matters.

HILL, PETER

"Lexical Revolutions as an Expression of Nationalism in the Balkans" in Robert D. Eagleson and R. White and C. Bentley 1976 Language and Literature in the Formation of National and Cultural Communities, Australian Universities Language and Literature Association.

HIPPLER, HANS -J. and NORBERT SCHWARZ

"Response Effects in Surveys" in Hans-J. Hippler, Norbert Schwarz, Seymour Sudman (eds Social Information Processing and Survey Methodology,), New York, Springer-Verlag.

Living Languages: Bilingualism and Community Languages in New Zealand. Auckland: Heinemann in association with the Office of the Race Relations Conciliator. 
Lost in Translation, London. Minerva.

HOFFMAN, ALISON and STEVEN CHRISP

1998

Government Language: Policies and Practices in Rolf E Panny (ed) People People People.

Christchurch: New Zealand Federation of Ethnic Councils (Inc.).

HOLM, AGNES and WAYNE HOLM

1981

Bilingual Education in New Zealand. Wellington, New Zealand: Department of Education.

HOLMES, JANET and 'ANAHINA 'AIPOLO

In Janet Holmes and Ray Harlow (eds) Threads in the New Zealand Tapestry of Language. Auckland: Linguistics Society of New Zealand.

HOLROYD, MICHAEL

Bernard Shaw. Volume III 1918-1950. The Lure of Fantasy. London. Chatto \& Windus.

HOROWITZ, DONALD L.

"Ethnic Identity" in N. Glazer and D. Moynihan (eds) Ethnicity: Theory and Experience. Cambridge: Harvard University Press.

HORVATH, BARBARA M. and PAUL VAUGHAN

Community Languages: A handbook. Clevedon: Multilingual Matters.

HUTCHISON, JOHN

The Dynamics of Cultural Nationalism: The Gaelic Revival and the Creation of the Irish National State. London Allen \& Unwin in association with The London School of Economics and Political Science.

HYMES, DELL H.

"Foreword" in Charles A. Ferguson and Shirley Brice Heath Language in the U.S.A. Cambridge: Cambridge University Press.

IMBERGER, BARBARA

"Children from German Speaking Families" in Michael Clyne (ed) An Early Start: Second Language at Primary School. Melbourne: River Seine Publications.

IP, MANYING 1990 Home Away from Home: life stories of Chinese women in New Zealand. Auckland: New Women's Press. 
"Basic Group Identity: The Idols of the Tribe" in N. Glazer and D. Moynihan (eds) Ethnicity: Theory and Experience. Cambridge: Harvard University Press.

JAKICH, MIRANDA

"The Yugoslav Language in New Zealand" in W. Hirsch Living Languages: Bilingualism and community languages in New Zealand. Auckland: Heinemann in association with the Office of the Race Relations Conciliator.

JANSEN, ADRIENNE

I have in my arms both ways: Stories by ten immigrant women. Wellington: Allen \& Unwin.

JOHNS, BRIAN

"SBS: coping with a strange idea" in David Goodman et al Multicultural Australia: The Challenges of Change. Newham, Vic.: Scribe in Association with Australian Centre, University of Melbourne.

JOHRI, ROOPALI

Stuck in the middle or clued up on both? Language and identity among Korean, Dutch and Samoan immigrants in Dunedin. Unpublished M.A. thesis. University of Otago.

JONES, GRETA

Social Darwinism and English Thought. Sussex: The Harvester Press. New Jersey: Humanities Press.

JUPP, JAMES

"One among many" in David Goodman et al Multicultural Australia: The Challenges of Change. Newham, Vic.: Scribe in Association with Australian Centre, University of Melbourne.

JURGENSEN, MANFRED

"The politics of imagination" in David Goodman et al Multicultural Australia: The Challenges of Change. Newham, Vic.: Scribe in Association with Australian Centre, University of Melbourne.

KALTON, GRAHAM

1983

Introduction to Survey Sampling. Sage University Paper series on Quantitative Applications in the Social Sciences, 07-035. Beverly Hills and London: Sage Pubns.

KAMENKA, EUGENE (ed)

Nationalism: The nature and evolution of an idea. London: Edward Arnold. 
"Language Planning in Theory and Practice" in Richard Baldauf, Jr and Allan Like (eds) Language planning and education in Australasia and the South Pacific. Clevedon: Multilingual Matters Ltd.

KARAM, FRANCIS X.

"Toward a Definition of Language Planning" in J.A. Fishman (ed) Advances in Language Planning. The Hague: Mouton.

KASANJI, L.V.

The Gujaratis in Wellington, unpublished M.A. thesis, V.U.W.

KASANJI, LALITA

Let's Talk: Guidelines for government agencies hiring interpreters. Wellington: Ethnic Affairs Service, Department of Internal Affairs Te Tari Taiwhenua.

KENNEDY, SHELLEY AND SHARON DEWAR

1997

Non-English-Speaking Background Students: A Study of Programmes and Support in New Zealand Schools. Wellington, New Zealand: Research and International Section, Ministry of Education.

KERSLAKE, M.T. and D. KERSLAKE 1987

"Fa'asamoa" in W. Hirsch Living Languages: Bilingualism and community languages in New Zealand. Auckland: Heinemann in association with the Office of the Race Relations Conciliator.

KEYNES, JOHN MAYNARD

1920

The Economic Consequences of the Peace. London: Macmillan and Co., Limited.

KING, M.

Being Pakeha. Auckland: Hodder and Stoughton.

KIPP, SANDRA, MICHAEL CLYNE and ANNE PAUWELS

Immigration and Australia's Language Resources. Canberra: Australian Government Publishing Service.

KLOSS, HEINZ 1966 "German-American Language Maintenance Efforts" in Joshua Fishman (ed) Language Loyalty in the United States. The Hague: Mouton.

KOEPKE, WULF in cooperation with S.B. Knoll 1982 Johann Gottfried_Herder: Innovator Through The Ages. Bonn: Bouvier Verlag Grundmann. 
The Age of Nationalism: the first era of global history. Westport, Conn: Greenwood Press.

KRISHNAN, VASANTHA, PENELOPE SCHOEFFEL and JULIE WARREN

The Challenge of Change: Pacific Island Communities in New Zealand 1986 - 1993.

Wellington: NZ Institute for Social Research and Development Ltd.

LAKOFF, ROBIN TOLMACH

Talking Power. New York: Basic Books, A Division of HarperCollinsPublishers.

LASKI, HAROLD J.

The State in Theory and Practice. London: George Allen \& Unwin Ltd.

LEE, JOHN A.

Socialism in New Zealand. London: T. Werner Laurie Ltd.

LEMAIRE, HERVE-B.

"The French Language in New England" in Joshua Fishman (ed) Language Loyalty in the United States. The Hague: Mouton.

LEONG, CHOO YOON

"A Study of Non-Response bias in Mail Surveys", in Research Report 31, Department of Marketing, Massey University.

LIU, DAVID MICHAEL

A Politics of Identity in Western Samoa. Unpublished PhD Thesis, University of Hawaii. UMI Dissertation Services.

LMP

The Other Languages of England. Michael Stubbs (ed). London: Routledge and Keegan Paul.

LO BIANCO, JOSEPH

National Policy on Languages. Canberra: Australian Government Publishing Services.

LO BIANCO, JOSEPH

"Making Language Policy: Australia's Experience" in Richard Baldauf, Jr and Allan Like (eds) Language planning and education in Australasia and the South Pacific. Clevedon: Multilingual Matters Ltd.

LOCHORE, R.A.

From Europe to New Zealand. Wellington: A.H.\&A.W. Reed. 
Problems in Paradise; The view from Government House. New York: Pageant Press.

LUKE, ALLAN and RICHARD B. BALDAUF, Jr

"Language Planning and Education: A Critical Rereading" in Richard Baldauf, Jr and Allan Like (eds) Language planning and education in Australasia and the South Pacific. Clevedon: Multilingual Matters Ltd.

LUKE, ALLAN, ALEC W. McHOUL and JACOB L. MAY

"On the Limits of Language Planning: Class, State and Power" in Richard Baldauf, Jr and Allan Like (eds) Language planning and education in Australasia and the South Pacific. Clevedon: Multilingual Matters Ltd.

MACKEY, HUGH

Reinventing Australia. Sydney: Angus\&Robertson, HarperCollinsPublishers.

"On the Future of Samoan Ethnicity in New Zealand " in P. Spoonley, C. Macpherson, D. Pearson, and C. Sedgewick (eds) Tauiwi. Palmerston North, The Dunmore Press.

McENTEGART and R.B. LE PAGE

"An appraisal of the statistical techniques used in the Sociolinguistic Survey of Multilingual Communities" in Suzanne Romaine (ed) Sociolinguistic Variation in Speech Communities. London: Edward Arnold.

McGILL, DAVID

The Lion and the Wolfhound. Wellington: Grantham House.

McKINNON, MALCOLM

Immigrants and Citizens: New Zealanders and Asian Immigration in Historical Context. Wellington: Institute of Policy Studies.

McPHERSON, JAN and D. CORSON

Language Policy Across the Curriculum: Eight case Studies of school based policy development. Palmerston North: Department of Education, Massey University.

MARCHAND, J.W.

"Herder: Precursor of Humboldt, Whorf, and Modern Language Philosophy" in W. Koepke (ed) in cooperation with S.B. Knoll Johann Gottfried Herder: Innovator Through The Ages. Bonn: Bouvier Verlag Grundmann. 
The Emergence of Samoan Language in New Zealand Education. Unpublished M.A. thesis. Victoria University of Wellington.

MELEISEA, MALAMA

The Making of Modern Samoa. Suva: Institute of Pacific Studies of the University of the South Pacific.

MELEISEA, MALAMA and PENELOPE SCHOFFEL MELEISEA

Lagaga: A Short History of Western Samoa. Apia: University of the South Pacific.

MFODWO, KWAME

"Can New Zealand's Media Rise to the Challenge?" in Rolf E Panny (ed) People People People.

Christchurch: New Zealand Federation of Ethnic Councils (Inc.).

MILL, JOHN STUART

Mill on Bentham and Coleridge. London: Chatto \& Windus.

MILROY, LESLEY

Language and Social Networks. Oxford: Basil Blackwell.

MOSEL, ULRICH and EVEN HOVDHAUGEN

Samoan Reference Grammar. Oslo: Scandinavian University Press.

MOSER, C.A. and G. KALTON

Survey Methods in Social Investigation. New York: Basic Books Inc., Publishers.

MURDOCH, J.H.

Education in Transition: a short study of educational trends in New Zealand. Auckland (?): Institute of International Affairs.

NEW ZEALAND IMMIGRATION SERVICE TE RATONGA MANENE

New Zealand's Targeted Immigration Policies: Summary of October 1995 Policy Changes.

Wellington: New Zealand Immigration Service Te Ratonga Manene.

NEW ZEALAND IMMIGRATION SERVICE TE RATONGA MANENE (no date, received 1996) New Zealand the right choice: Self Assessment Guide for Residence in New Zealand.

Wellington: New Zealand Immigration Service Te Ratonga Manene.

NGAN-WOO, FELETIE. (no date)

FaaSamoa: The World of Samoans. Office of the Race Relations Conciliator. 
Free and Equal: A Philosophical Examination of Political Values. Oxford University Press.

OHANNESSIAN, SIRARPI

"The Language Problems of American Indian Children" in Bernard Spolsky (ed) The Language

Education of Minority Children. Rowley Mass: Newbury House Publishers Inc.

O'MEARA, TIM

1990

Samoan Planters. Fort Worth: Holt, Reinhart and Winston, Inc.

OPENHEIM, ROGER, GREG LEE and HOWARD LEE

Challenging the Myths: rethinking New Zealand's educational history. Palmerston North:

Dunmore Press.

OPPENHEIM, A.N.

Questionnaire Design, Interviewing and Attitude Measurement. London and New York: Pinter Publishers.

ORANGE, CLAUDIA

The Treaty of Waitangi. Wellington: Allen and Unwin Port Nicholson Press with assistance from the Historical Publications Branch Department of Internal Affairs.

OZOG, CONRAD K.

1990

"The English Language in Malaysia and its Relationship with the National Language" in Richard Baldauf, Jr and Allan Like (eds) Language planning and education in Australasia and the South Pacific: Clevedon: Multilingual Matters Ltd.

OZOLINS, ULDIS

The Politics of Language in Australia. Cambridge: Cambridge University Press.

PANDHARIPANDE, RAJESHWARI

"Language Shift in India: Issues and Implications" in Willem Fase et al. (eds) Maintenance and Loss of Minority Languages. Amsterdam: John Benjamins Publishing Company.

PARSONS, TALCOTT

"Some Theoretical Considerations on the Nature and Trends of Change of Ethnicity" in N. Glazer and D. Moynihan (eds) Ethnicity: Theory and Experience. Cambridge: Harvard University Press.

\section{PATEL, SHANTI}

"Gujarati and Hindi in New Zealand" in Walter Hirsh (ed) Living Languages: bilingualism and community languages in New Zealand. Auckland: Heinemann in association with the Office of the Race Relations Conciliator. 
"Context and Choice in Ethnic Allegiance: A Theoretical Framework and Caribbean Case Study" in N. Glazer and D. Moynihan (eds) Ethnicity: Theory and Experience. Cambridge: Harvard University Press.

Immigrants Dialects and Language Maintenance in Australia: The Cases of the Limburg and Swabian Dialects. Dordrecht: Foris Publications.

PEARSON, DAVID

A Dream Deferred: the origins of ethnic conflict in New Zealand. Wellington: Allen \& Unwin Port Nicholson Press.

PHILIPS, D.,G. LEALAND, G. MCDONALD (eds)

The Impact of American ideas on New Zealand's Educational Policy, Practice and Thinking. Wellington: NZ: NZ-US Educational Foundation, New Zealand Council for Educational Research.

PHILLIPS JOCK (ed)

New Worlds? The Comparative History of New Zealand and the United States. Wellington: NZUS Education Foundation Stout Research Centre.

PIHAMA, LEONIE no date, post 1988 "He Taonga": He Whakamaramatanga Mo Nga Akoranga Wahine Maori. Women's Advisory Committee on Education.

PIPES, RICHARD

"Reflections on Nationality Problems in the Soviet Union" in N. Glazer and D. Moynihan (eds) Ethnicity: Theory and Experience. Cambridge: Harvard University Press.

POLYNESIAN ADVISORY COMMITTEE

Understanding Samoans. Wellington: Vocational Training Council.

PORTER, JOHN

"Ethnic Pluralism in Canadian Perspective" in N. Glazer and D. Moynihan (eds) Ethnicity: Theory and Experience. Cambridge: Harvard University Press.

PRICE, CHARLES A.

"The Ethnic Composition of the Australian Population" in Ian Burnley, Sol Encel and Grant McCall (eds) Immigration and Ethnicity in the 1980s. Melbourne: Longman Cheshire. 
RAESIDE, I.

"Gujarati" in R.E. Asher and J.M.Y. Simpson (eds) The Encyclopedia of Language and

Linguistics. Oxford: Pergamon Press.

RENWICK, WILLIAM

"Fraser on Education" in Margaret Clark (ed), Peter Fraser: Master Politician. Palmerston

North: The Dunmore Press Limited.

RICENTO, T

Language Policy in the United States in in Michael Herriman and Barbara Burnaby (eds)

Language Policies in English-Dominant Countries. Clevedon: Multilingual Matters.

ROBERTS, MARY

Language Maintenance and shift and issues of language maintenance education in a section of the Chinese Community in Wellington, New Zealand. Unpublished M.A. thesis. Victoria University of Wellington.

ROBERTS, MARY

"Immigrants and Language in New Zealand" in Andrew D. Trlin and Paul Spoonley (eds) New Zealand and International Migration: A Digest and Bibliography Number 3. Palmerston North: Department of Sociology, Massey University.

ROMAINE, SUZANNE

1995

Bilingualism, Oxford: Blackwell.

ROSS, JEFFREY A.

"Language and the Mobilization of Ethnic Identity" in Howard Giles and Bernard Saint-Jacques (eds) Language and Ethnic Relations. Oxford: Pergamon Press.

RUBIN, JOAN

"Evaluating Status Planning: what has the past decade accomplished?" in J.A. Fishman and J.

Cobarrubias (eds) Progress in Language Planning: International Perspectives. Berlin: Mouton

Publishers.

SCHIAVONI, FRANCO

"The case for linguistic pluralism" in David Goodman et al Multicultural Australia: The

Challenges of Change. Newham, Vic.: Scribe in Association with Australian Centre, University of Melbourne.

Linguistic Culture and Language Policy. London and New York: Routledge. 
Tasman's Legacy: The New Zealand - Dutch Connection. Wellington, New Zealand: The New Zealand - Netherlands Foundation (Inc.).

SHACKLEFORD, NICK

Languages Policy and international languages of trade and tourism: rhetoric and reality.

Unpublished MEd thesis. University of Auckland.

SHAMEEM, NIKHAT

Hamai Log Ke Boli: Our Language: Language Shift in an Immigrant Community: The

Wellington Indo-Fijians, Unpublished PhD Thesis, Victoria University of Wellington.

SHARP, ALAN

The Versailles Settlement: Peacemaking in Paris. Houndmills: Macmillan.

SHERGOLD, PETER R.

"Discrimination against Australian migrants: an historical methodology" in Ian Burnley, Sol Encel and Grant McCall (eds) Immigration and ethnicity in the 1980s. Melbourne: Longman Cheshire.

SIBAYAN, BONIFACIO

"Language Policy, Language Engineering and Literacy in the Philippines" in J.A. Fishman (ed.) Advances in language Planning. The Hague: Mouton.

SIMPSON, J.M.Y.

"Dutch" in R.E. Asher and J.M.Y. Simpson (eds) The Encyclopedia of Language and Linguistics. Oxford: Pergamon Press.

SINCLAIR ,KEITH

A Destiny Apart. Wellington: Unwin Paperbacks in association with Port Nicholson Press.

SMITH, A.D.

The Ethnic Revival. Cambridge: Cambridge University Press.

SMITH, A. D.

The Ethnic Origin of Nations. Oxford: Blackwell.

SMITH, HILARY

English Language Acquisition in the Lao Refugee Community of Wellington New Zealand. Unpublished M.A. Thesis, Victoria University of Wellington. 
SMOLICZ, J.J.

Culture and Education in a Plural Society. Canberra: Curriculum Development Centre.

SORRENSON, M.P.K.

Maori Origins and Migrations, Auckland University Press, Oxford University Press.

SPOLSKY, BERNARD

Report on the Samoan language in the New Zealand educational context. Wellington:

Department of Education.

SPOONLEY, PAUL

1988

Racism and Ethnicity. Auckland: Oxford University Press.

SPOONLEY P., C. MACPHERSON, D. PEARSON and C. SEDGEWICK

Tauiwi. Palmerston North: The Dunmore Press.

STATISTICS NEW ZEALAND TE TARI TATAU

Samoan People in New Zealand. Wellington: Statistics New Zealand.

SRIDHAR, KAMAL K.

"Aspects of language and culture of Asian Indians in New York" to appear in Ofelia Garcia and Joshua Fishman (eds) Language in New York City. The Hague: Mouton.

STERNBERG, ROBERT J. and JOHN KOLLIGAN, JR (eds)

Competence Considered. New Haven and London: Yale University Press.

STOCKWELL, WENDY

Maori and Pacific Island Language Demand for Educational Services: Overview. Unpublished Report produced by MRL Research Group for the Ministry of Education.

STOFFEL, HANS PETER

"Language Maintenance and Shift of the Serbo-Croatian Language in a New Zealand Dalmatian Community" in Roland Sussex (ed) The Slavic Languages in Émigré Communities. Carbondale USA, Edmonton Canada: Linguistic Research Inc.

SUDMAN, S. and N.M. BRADBURN

Response effects in surveys; a review and synthesis. Chicago: Aldine Pub. Co.

SUTTER, FREDERIC KOEHLER

The Samoans; a global family. Honolulu: University of Hawaii Press. 
TAFT, R, and CAHILL D.

"Education of Immigrants in Australia" in J. Bhatnagar (ed) Educating Immigrants. London:

Croom Helm.

TAULI, VALTER

1974

"The Theory of Language Planning" in Joshua A. Fishman (ed) Advances in Language Planning. The Hague: Mouton.

TAYLOR, DONALD M. and HOWARD GILES

"At the Crossroads of Research into Language and Ethnic Relations" in Howard Giles and Bernard Saint-Jacques (eds) Language and Ethnic Relations. Oxford: Pergamon Press.

THUNDYIL, ZACHARIAS

"National Unity Despite Linguistic Diversity: The Indian Experience" in Robert D. Eagleson and R. White and C. Bentley 1976 Language and Literature in the Formation of National and

Cultural Communities. Australian Universities Language and Literature Association.

TIWARI, KAPIL N (ed)

Indians in New Zealand: Studies in a sub culture. Wellington: Price Milburn for the New

Zealand Indian Central Association Inc.

TIWARI, KAPIL N

"The Indian community in New Zealand" in Kapil Tiwari (ed) Indians in New Zealand: Studies in a sub culture. Wellington: Price Milburn for the New Zealand Indian Central Association Inc.

TOLLEFSON, JAMES W

Planning Language, Planning Inequality. London and New York: Longman.

TOMIC, OLGA MIŠESKA

"Minority Language Maintenance and Learning as Instruments for Improving the Status of the Minority Group" in Willem Fase et al. (eds), Maintenance and Loss of Minority Languages. Amsterdam: John Benjamins Publishing Company.

TOSI, ARTURO

Immigration and Bilingual Education. Oxford: Pergamon Press.

TREGEAR, EDWARD

The Maori Race. Wanganui: A.D. Willis.

TRLIN, ANDREW

Now Respected Once Despised: Yugoslavs in New Zealand. Palmerston North: Dunmore Press 
TRLIN ANDREW D.

"New Zealand's Immigration Policy in the Early 1980s" in Andrew D. Trlin and Paul Spoonley (eds), New Zealand and International Migration: A Digest and Bibliography, Number 1. Palmerston North: Department of Sociology, Massey University.

TRLIN, ANDREW D. and PAUL SPOONLEY (eds)

1986

New Zealand and International Migration: A Digest and Bibliography, Number 1. Palmerston North: Department of Sociology, Massey University.

TU'INUKUAFE, EDGAR

1987

"The Tongan Language in New Zealand" in Walter Hirsh (ed) Living Languages: bilingualism and community languages in New Zealand. Auckland: Heinemann in association with the Office of the Race Relations Conciliator.

TURNER, JOHN C. and HOWARD GILES (eds)

Intergroup Behaviour. Oxford: Basil Blackwood.

VELTMAN, CALVIN

Language Shift in the United States. Berlin: Mouton Publishers.

VERHOEVEN, J.W.M.

"Netherlands: Language Situation" in R.E. Asher and J.M.Y. Simpson (eds) The Encyclopedia of Language and Linguistics. Oxford: Pergamon Press.

VERIVAKI, MARIA

1990

Language Maintenance and shift in the Greek Community of Wellington, New Zealand. Unpublished M.A. thesis. Victoria University of Wellington

VERIVAKI, MARIA

"Greek language maintenance and shift in the Greek community in Wellington" in Threads in the New Zealand Tapestry of Language, Janet Homes and Ray Harlow (eds). Auckland: Linguistic Society of New Zealand.

VERVOORT, V.J.

1983

From the Netherlands to New Zealand: An Essay in Migration, unpublished M.A. thesis V.U.W.

WAITE, JEFFREY

Aoteareo: speaking for ourselves. Parts A \& B. Wellington: Learning Media, Ministry of Education.

Report of the Waitangi Tribunal on the Te Reo Maori Claim (WAI 11). Wellington: GP Publications. 
"Manawatu - A place to feel at home?" in People People People, Rolf E Panny (ed). Christchurch: New Zealand Federation of Ethnic Councils (Inc.).

WALL, ARNOLD

New Zealand English: a guide to correct pronunciation of English with special reference to New Zealand conditions and problems. Auckland: Whitcomb and Tombs.

WALLACH, LUITPOLD

MCMLIX

Liberty and Letters: The Thoughts of Leopold Zunz. London: Published for the Leo Baeck Institute of Jews From Germany by the East and West Library.

WARDHAUGH, RONALD

Language and Nationhood; The Canadian Experience. Vancouver: New Star Books.

WARDHAUGH, RONALD

Languages in Competition, B. Blackwell in association with Andre Deutch.

WEBB, LEICESTER

The Control of Education in New Zealand. New Zealand Council for Educational Research.

WHITELEY, WILFRED H.

"Language Policies of Independent African States" in J.A. Fishman (ed.) Advances in Language Planning. The Hague: Mouton.

WILLIAMS, GLYN

Sociolinguistics: a sociological critique. London, New York: Routledge.

WOLFSON, NESSA and JOAN MANES (eds)

Language of Inequality. Berlin Walter de Gruyter \& Co.

WONG FILLMORE, L.

"Bridges or Barriers? The Role of Schools in Culturally Diverse Societies" in The Impact of American Ideas on New Zealand's Educational Policy, Practice and Thinking, David Philips, Geoff Lealand and Geraldine McDonald (eds), NZ-US Educational Foundation for Educational Research

WOOD F.L.W.

This New Zealand. London: Hammond, Hammond and Co..

Statistics in Language Studies. Cambridge: Cambridge University Press. 
WRIGHT, S.J.

"Mail Survey Response Rates: A Test of Four Techniques Designed to Increase Response Rates to Mail Survey" in Research Report 47. Palmerston North: Market Research Centre, Massey University.

WURM, STEPHEN A.

"Language Policy, Language Engineering and literacy in New Guinea and Australia" in J.A. Fishman (ed.) Advances in language Planning. The Hague: Mouton.

YEABSLEY J., IAN DUNCAN and DOUG JAMES

Broadcasting in New Zealand: waves of change. Report to Communication Division, Ministry of Commerce. Wellington: New Zealand Institute of Economic Research.

YUVAL-DAVIS, NIRA and FLOYA ANTHIAS (eds)

Woman - Nation - State. Houndsmills: Macmillan Press Ltd. 


\section{PERIODICALS}

'AIPOLO, 'ANAHINA and J. HOLMES

"The Use of Tongan in New Zealand: Prospects for Language Maintenance" in Journal of Multilingual and Multicultural Development Vol. 11, No.6, pp 501-521.

ALLADINA, SAFDER

"South Asian Languages in Britain: Criteria for Description and Definition in Journal of Multilingual and Multicultural Development Vol. 6, No. 6 pp 449-466.

ANNAMALAI, E.

"Comment" in International Journal of the Sociology of Language, 60, pp 145-151.

BACHMAN, LYLE F. and ADRLAN S. PALMER

"The construct validation of self-ratings of communicative language ability" in Language Testing, Volume 6, Number1, pp 14-25.

BAETENS BEARDSMORE, HUGO and ROLAND WILLMYNS

"Comment" in International Journal of the Sociology of Language, 60, pp 117-128.

BARRINGTON J. M.

Maori Scholastic Acheivement: A Historical Review of Policies and Provisions" in New Zealand Journal of Educational Studies, Vol. 1, No. 1, pp 1-14.

BENNETT, JANE E

"Language maintenance in the second generation: the Dutch in Australia" in Australian Review of Applied Linguistics, 15,1, pp 53-70.

BOURHIS, RICHARD YVON, HOWARD GILES and DOREEN ROSENTHAL

Notes on the Construction of a 'Subjective Vitality Questionnaire' for Ethnolinguistic Groups in Journal of Multilingual and Multicultural Development, Vol. 2. No. 2, pp 145-155.

BOWRON, JANE

"Mune makes mark as two patriarchs" in The Dominion, Tuesday, October 14, p.53

BUCHHEIT, ROBERT H

"Language shift in the concentrated Mennonite district of Kansas" in International Journal of the Sociology of Language, 69, pp 5-18. 
"Language Policy in Peru: a historical overview" in International Journal of the Sociology of Language, 77 , pp 11-33.

CHUMAK-HORBATSCH, ROMA

"Language Use in the Ukrainian home: a Toronto sample" in International Journal of the Sociology of Language, 63, pp 99-117.

"Language, Politics and American Identity" in Dialogue, No. 1, pp 60-65.

CLYNE, MICHAEL

"Comment" in International Journal of the Sociology of Language, 60, pp 139-143.

\section{CLYNE, MICHAEL G}

"The German-Australian speech community: ethnic core values and language maintenance" in International Journal of the Sociology of Language, 72, pp 67-83.

CLYNE, MICHAEL

"Australia's Language Policies: Are We Going Backwards?" in Australian Review of Applied Linguistics, Series S No. 8, pp 3-22.

CLYNE, MICHAEL and STEPHANIE JAEHRLING

"Trends and Factors in Language Shift in Australia" in VOX No. 3, pp 63-71.

CLYNE, MICHAEL and SANDRA KIPP

"Language Maintenance and Language Shift in Australian, 1991" in Australian Review of Applied Linguistics 19,1, pp 1-19.

CLYNE, MICHAEL and SANDRA KIPP

"Trends and Changes in Home Language Use and Shift in Australian, 1986-1996 in Journal of Multilingual and Multicultural Development, Vol. 18, No. 6, 451-473.

COOPER, ROBERT L.

"Sociolinguistic Surveys: The State of the Art" in Applied Linguistics, Vol. 1, No. 2, pp 113-128.

de LEPERVANCHE, MARIE

1980

"From Race to Ethnicity" in Australian and New Zealand Journal of Sociology Vol. 16, No. 1, March 1980, pp 24-37. 
"A 16-year longitudinal study of language attrition in Dutch immigrants in Australia" in Journal of Multilingual and Multicultural Development, Vol. 15, No. 1, pp 17-28.

DEMOS, VASILIKIE

"Ethnic mother-tongue maintenance among Greek Orthodox Americans" in International Journal of the Sociology of Language, 69, pp 59-71.

DEVETAK, S,

"Are Contacts with the 'Mother Nation' Prerequisite for the Free Linguistic Cultural Development of Ethnic Minorities? A Special View of the Yugoslav Situation" in Journal of Multilingual and Multicultural Development, Vol. 8, No. 5, pp 433-442.

DORIAN, NANCY C.

"The value of language maintenance efforts which are unlikely to succeed" in International Journal of the Sociology of Language, 68, 57-67.

DOW, JAMES R

"Towards an understanding of some subtle stresses on language maintenance among the Old Order Amish of Iowa" in International Journal of the Sociology of Language, 69, pp 19-31.

EDWARDS, J. and J. CHISHOLM

"Language, Multiculturalism and Identity: A Canadian Study" in Journal of Multilingual and Multicultural Development, Vol. 8, No. 5. pp 391-408.

FAIRBURN-DUNLOP, P.

"Factors associated with language maintenance: the Samoans in New Zealand" in New Zealand Journal of Educational Studies. Vol. 19, No. 2, pp 99-113.

FISHMAN, JOSHUA A

"What is Reversing Language Shift (RLS) and How Can it Succeed?" in Journal of Multilingual and Multicultural Development, Vol. 11 , Nos. 1 \& 2, pp 5-34.

"Dutch immigrants in New Zealand: a case study of language shift and language loss" in Australian review of Applied Linguistics 15, 2 pp 1-18.

"Ethnic languages in two small communities: Swedish and Russian in Melbourne" in International Journal of the Sociology of Language, 72, pp 37-50. 
"An Intergroup Approach to Second Language Acquisition" in Journal of Multilingual and Multicultural Development Vol. 3, No. 1, pp 17-40.

GILES, HOWARD and PATRICIA JOHNSON

"Ethnolinguistic identity theory: a social psychological approach to language maintenance" in International Journal of the Sociology of Language, No. 68, pp 69-99.

GILES, H., D. ROSENTHAL and L. YOUNG

"Perceived Ethnolinguistic Vitality: The Anglo-and Greek-Australian Setting" in Journal of Multilingual and Multicultural Development Vol. 6, Nos. 3\&4, pp 253-269.

GORTER, DURK

1987

"Surveys of the Friesian language situation: some considerations of research methods on language maintenance and language shift" in International Journal of the Sociology of Language No. 68, pp 41-56.

GRACE, K.W.D.

"Maori - Rising Again" in VOX No. 2, pp 27-30.

HAKUTA, KENJI and DANIEL D'ANDREA

"Some Properties of Bilingual Maintenance and Loss in Mexican Background High-School Students" in Applied Linguistics, Vol. 13, No. 1, pp 72-99.

HOFMAN, JOHN E. and JEHUDITH CAIS

"Children's attitudes to language maintenance and shift" in International Journal of the Sociology of Language No. 50, pp 147-153.

HOLMES, JANET

"Women's Role in Promoting Bilingualism" in Many Voices: A Journal of New Settlers and Multicultural Education Issues No. 4, February 1993.

HUFFINES, MARION LOIS

"Pennsylvania German: Maintenance and Shift" in International Journal of the Sociology of Language No. 25, pp 43-57.

HUSBAND, C. and V. SAIFULLAH KAHN

"The Viability of Ethnolinguistic Vitality, Some Creative Doubts" in Journal of Multilingual and Multicultural Development Vol. 3, No3 pp 193-205

"Language and Culture in Australian Public Policy" in VOX, No. 2. 
"The Pattern of Urban Language Loss" in Australian and New Zealand Journal of Sociology 16:2 July 1980. pp 102-109.

JAHANBEGLOO, RAMIN

"Philosophy and Life: An Interview" in New York Review of Books, Vol. XXXIX, No. 10, May 28, 1992.

JANIK, JANUSZ

"Polish Language Maintenance of the Polish students at Princes Hill Saturday School in Melbourne" In Journal of Multilingual and Multicultural Development, Vol. 17, No. 1, pp 3-15.

JANSSEN-van DIETEN, ANNE-MIEKE

"The development of a test of Dutch as a second language: the validity of self-assessment by inexperienced subjects" in Language Testing, Volume 6, Number 1, pp 30-46.

JOHNSON, PAT, H. GILES and R.Y. BOURHIS

"The Viability of Ethnolinguistic Vitality: A Reply" in Journal of Multilingual and Multicultural Development Vol. 4, No. 4, pp 255-269.

"The Japanese Immigrant Community in Brazil: Language Contact and Shift" in Journal of Multilingual and Multicultural Development, Vol. 9, No. 5, pp 423-435.

"Comment" in International Journal of the Sociology of Language, No. 60, pp 183-189.

KASANJI, L. V.

"Community language schools and their future". Unpublished paper delivered at the Fourth National Conference on Community Languages and English for Speakers of Other Languages. 14 September 1994, Christchurch.

KLOSS, HEINZ

"Comment" in International Journal of the Sociology of Language, No. 60, pp 169-176.

KOMENAKA, APRIL R

"Autobiography as a sociolinguistic resource: Maxine Hong Kingston's The Woman Warrior" in International Journal of the Sociology of Language, No. 69, pp 105-118.

"Language use and language maintenance in two Russian communities in Australia" in International Journal of the Sociology of Language, No. 72, pp 51-65. 
LALLEMAN, J.

"The Relation Between Acculturation and Second-Language Acquisition in the Classroom: A Study of Turkish Immigrant Children Born in the Netherlands" in Journal of Multilingual and Multicultural Development Vol. 8, No. 5 pp 409-431.

LANDRY, WALTER J.

"Comment" in International Journal of the Sociology of Language No. 60, pp 129 - 138.

LeBLANC, RAYMOND and GISELE PAINCHAUD

1985

"Self-Assessment as a Second Language Placement Instrument" in TESOL Quarterly, Vol.19, No. 4, pp 673-687.

LE PAGE, R. and A. TABOURET-KELLER

1982

"Models and Stereotypes of Ethnicity and Language" in Journal of Multilingual and Multicultural Development Vol. 3, No. 3 pp 161-192.

LIBERSON, S.

1980

"Procedures for Improving Sociolinguistic Surveys of Language Maintenance and Language Shift" in International Journal of the Sociology of Language No. 25, pp 11-27.

LIEBERSON, S.J. and EDWARD J. McCABE

1982

Domains of language usage and mother-tongue shift in Nairobi in International Journal of the Sociology of Language No. 34, pp 83-94.

LO BIANCO, JOSEPH

1990

"A Hard-nosed Multiculturalism: Revitalising Multicultural Education?" in VOX No. 4, pp 8094.

LYON, JEAN

Patterns of Parental Language Use in Wales, in Journal of Multilingual and Multicultural Development Vol. 12, No. 3 pp 165-181.

McMAMARA, Tim

"Language in Social Identity: Israelis Abroad" in Journal of Language and Social Psychology 6, pp 215-228.

MAKIN, LAURIE

"Supporting children's home languages in mainstream education programs" in Australian Review of Applied Linguistics, 15,1. pp 71-84.

"Comment" in International Journal of the Sociology of Language No. 60, pp 105-114. 
"The Question of an official language: language rights and the English language Amendment" in International Journal of the Sociology of Language No. 60, pp 7-75.

MARTIN-JONES, MARILYN

"Sociolinguistic surveys as a source of evidence in the study of bilingualism: A critical assessment of survey work conducted among linguistic minorities in three British cities" in International Journal of the Sociology of Language No. 90, pp 37-55.

"Comment" in International Journal of the Sociology of Language No. 60, pp 153-156.

MILROY, L.

"Language and Group Identity" in Journal of Multilingual and Multicultural Development, Vol.3 No. 3, 207-216.

NAUGHTON, JOHN

"A Detached Life" in The Observer (Review Section) 14 November 1993.

OZOLINS, U

"Government language policy initiatives and the future of ethnic languages in Australia" in International Journal of the Sociology of Language: The Future of Ethnic Languages in Australia, No. 72, pp 113-129.

PAULSTON, CHRISTINA BRATT

"Catalan and Occitan: comparative test cases for a theory of language maintenance and shift" in International Journal of the Sociology of Language, No. 63, pp 31-62.

PAUWELS, ANNE

International Journal of the Sociology of Language: The Future of Ethnic Languages in Australia, No. 72 .

PEIRCE, BONNY N., MERRILL SWAIN and DOUG HART

"Self-Assessment, French Immersion, and Locus of Control" in Applied Linguistics, Vol. 14, No. I, pp $25-42$.

PIERSON, H.D., H. GILES and L. YOUNG

"Intergroup Vitality Perceptions During a Period of Political Uncertainty: The Case of Hong Kong" in Journal of Multilingual and Multicultural Development, Vol.8 No. 5, pp 451-460.

PUNETHA, D. Giles H. and Young L

"Ethnicity and Immigrant Values: Religion and Language choice" in Journal of Language and Social Psychology, Vol. 6, No.s 3 and 4, pp 240-258. 
"Defending the Faith" in The New York Review of Books, Vol. XXXIX, Number 9, pp 44-51.

RENZ, BYRON B.

"Portuguese broadcasting in linguistic and cultural maintenance in northern California" in International Journal of the Sociology of Language, No. 68, pp 23-40.

RESNICK, MELVYN C.

"Beyond the ethnic community: Spanish-language roles and maintenance in Miami" in International Journal of the Sociology of Language, No. 69, pp 89-104.

ROBERTS, A.

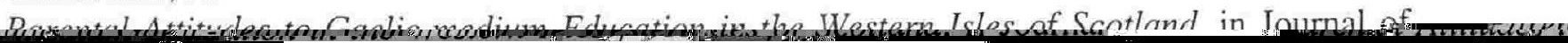

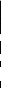

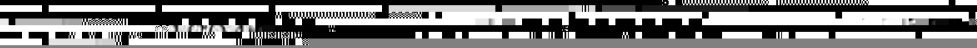


"The Effects of the Ethnicity of the Interviewer on Conversation: A Study of Chicana Women" in International Journal of the Sociology of Language, No. 17, pp 91-102.

TRUDGILL, PETER

"Language maintenance and language shift: preservation versus extinction" in International Journal of Applied Linguistics, Vol. 1, No. 1 pp 61-69.

VELTMAN, CALVIN

"Comment" in International Journal of the Sociology of Language, $60 \mathrm{pp}$ 177-181.

WILLIAMSON, R.C. and J.A. VAN EERDE

"Subcultural Factors in the Survival of Secondary Languages: A Cross-National Sample" in International Journal of Sociolinguistics, $25 \mathrm{pp}$ 59-83.

WOOD, RICHARD E

"Language Maintenance and External Support: The Case of the French Flemings" in International Journal of Sociolinguistics, 25 pp 107-119.

WOOLARD, KATHRYN A.

"Comment" in International Journal of the Sociology of Language, 60 pp 191-195.

"Ethnic identity and language: a look at language use among Chinese in Sydney" in Australian Review of Applied Linguistics 4 (2), pp 64-76. 